\title{
Re-Kindling Community Education in Neoliberal times
}

Camilla Fitzsimons

Submitted in part fulfilment of the requirements of a $\mathrm{PhD}$ in Adult and Community Education

Department of Adult and Community Education, Maynooth University. Co. Kildare

Supervisor: Bríd Connolly

Head of Department: Josephine Finn 


\section{Contents}

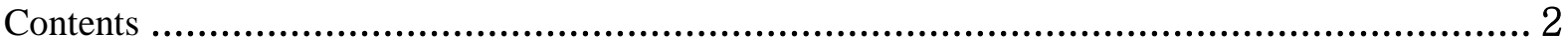

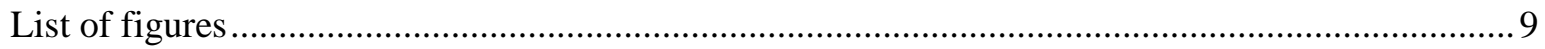

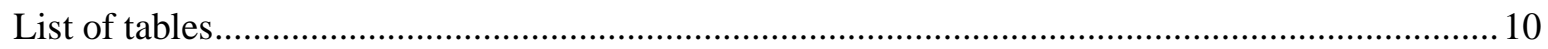

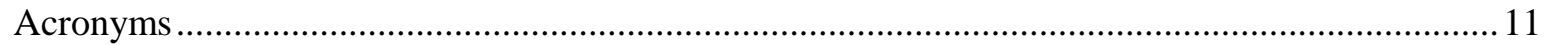

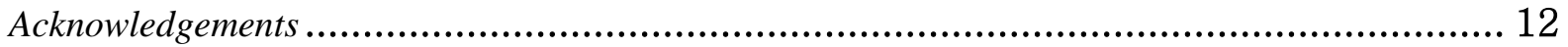

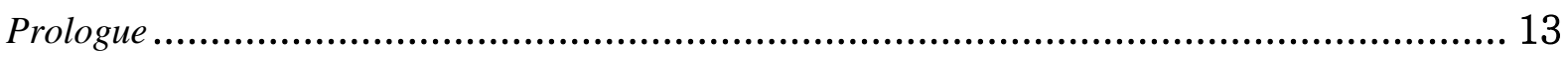

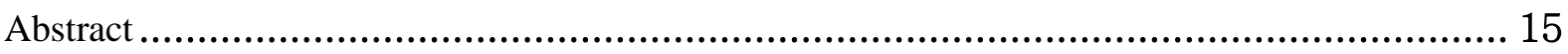

Chapter one: Introduction: Community Education in Neoliberal times..................... 17

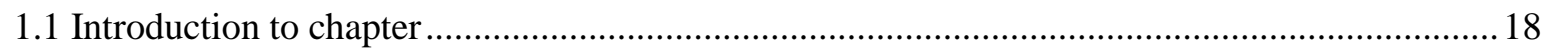

1.1.1 Setting the scene: personal beginnings in politicised practice ............................... 19

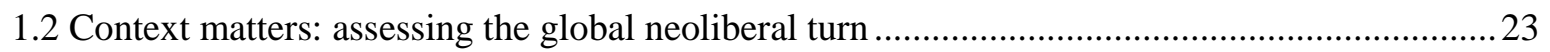

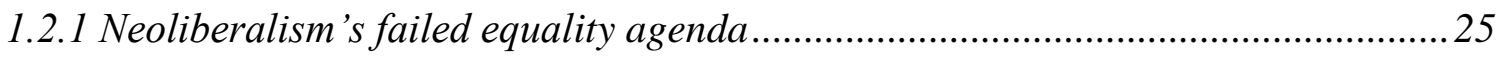

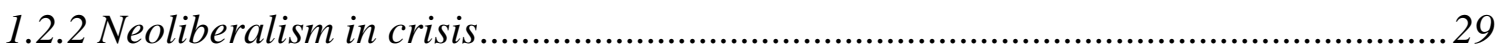

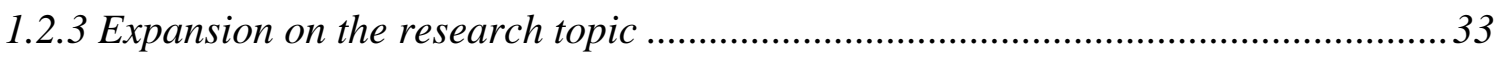

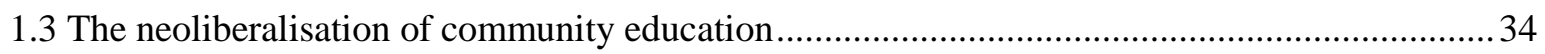

1.3.1 New Public Management and the prevailing logic of the market ...........................35

1.3.2 Neoliberalism by subterfuge: community education and social partnership .......... 39

1.4 Interrupting the narrative: pockets of difference and resistance to change ................................. 43

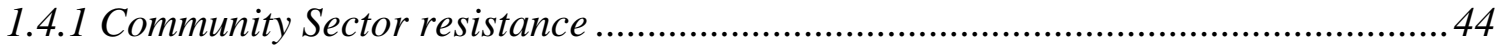

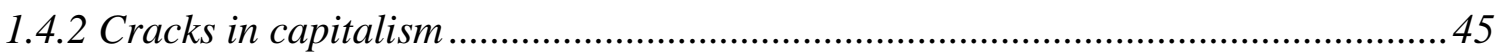

1.5 Exploring the purpose and practice of community education.................................................. 46

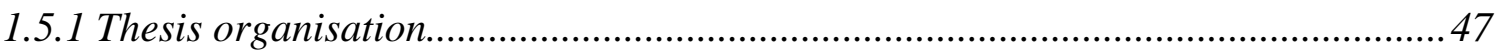

1.5.2 Consistency of language amidst community education restructuring ..................... 49

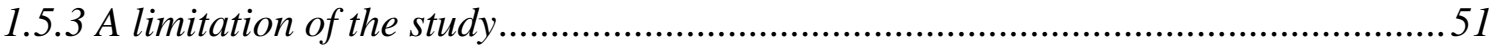

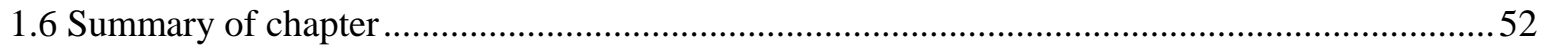

Chapter Two: Critical Realism, Feminism and the shaping of the study ................... 53

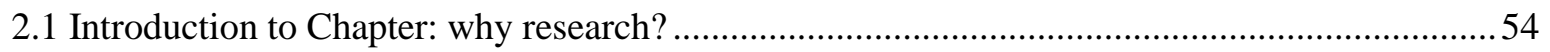

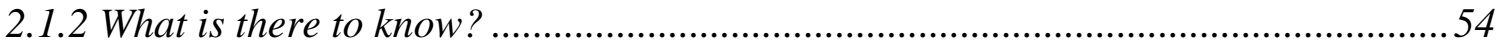

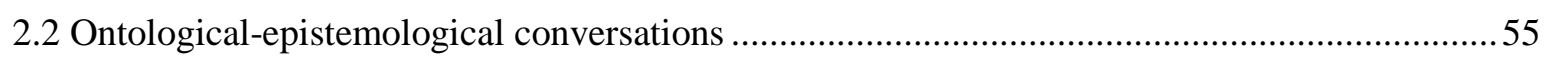

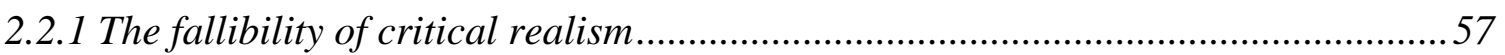

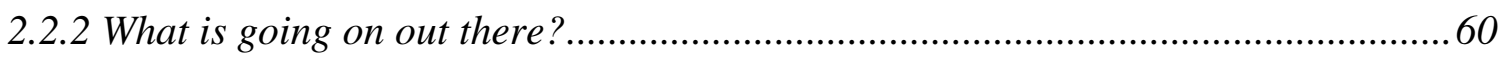

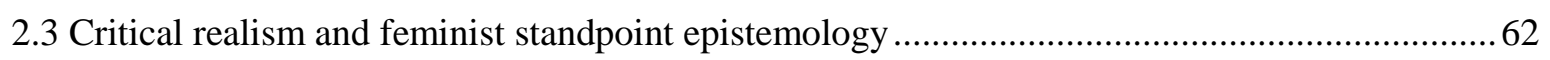

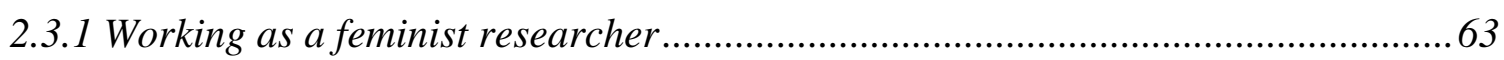


2.4 Summary of chapter

Chapter three: Community Education in Ireland - conceptual frameworks, historical

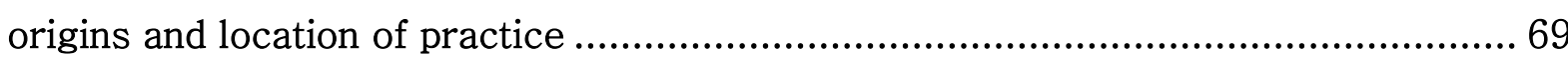

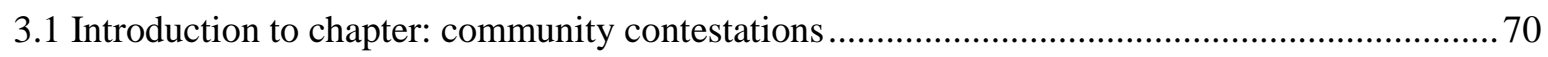

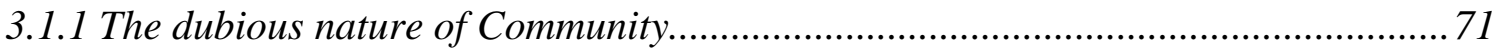

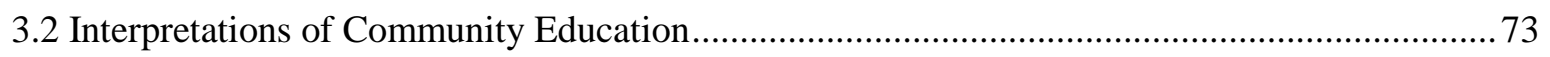

3.2.1 Universal approaches to Community Education..................................................... 76

3.2.2 Community Education as a second-chance .......................................................... 78

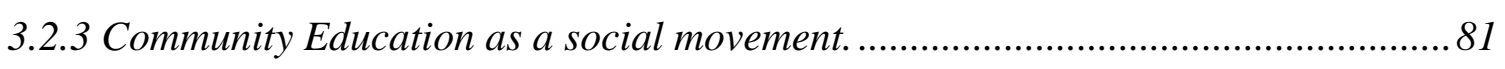

3.2.4 Adapting Martin's (1987) theory to Irish contexts ................................................ 84

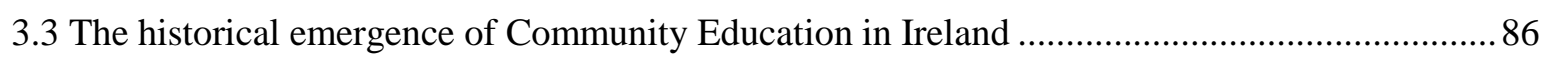

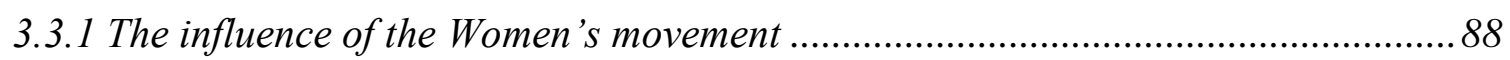

3.3.2 Locally based adult education programmes and the literacy movement ................ 91

3.3.3 The spread of ideas through Liberation Theology ................................................. 95

3.3.4 The wider community development/anti-poverty movement ................................. 97

3.3.5 Capturing connections between Community Sector and public provision............. 102

3.4 Insiders/outsiders and the restricting potential of professionalisation ......................................... 104

3.4.1 Sociological interpretations of professionalisation............................................... 105

3.4.2 Professionalisation of community development and community education ........... 107

3.4.3 Professionalisation gathers pace: potential involvement of The Teaching Council

3.4.4 Maintaining standards whilst questioning professionalism .............................. 110

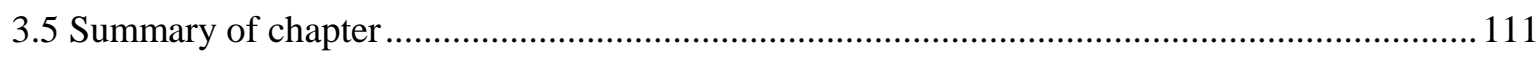

Chapter four: The Neoliberalisation of Community Education, policy influences in

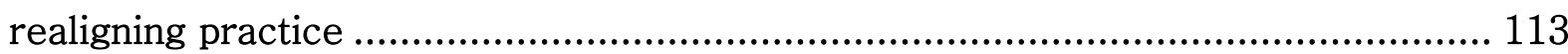

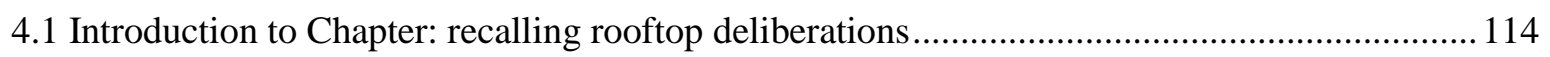

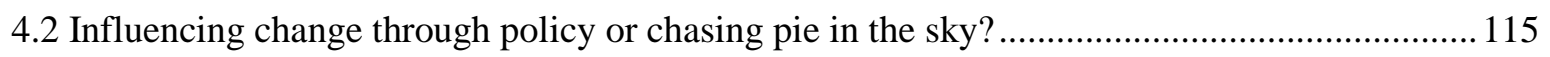

4.2.1 Sectoral engagement as stratagem for a marketised approach .......................... 118

4.3 A Europe-wide agenda: laying foundations for co-option ........................................................ 119

4.3.1 Lifelong learning and human capital: creating an army of workers .................... 120

4.4 Ireland's policy reaction: the implications for community education........................................ 125

4.4.1 Change through New Public Management: community education in the 2000s .. 127

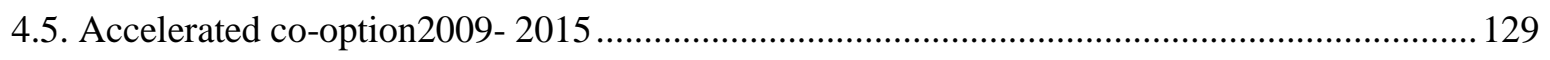

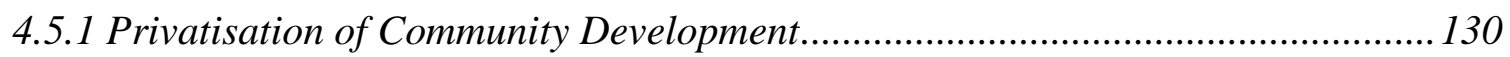


4.5.2 State service realignment: from community need to employer need

4.5.3 Community Education and conditional labour market re-activation.................... 132

4.6 Community-educators counter-hegemonic responsibility ................................................... 135

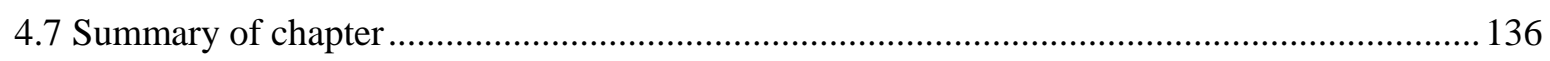

Chapter five: Accreditation and Community Education ...................................... 138

5.1 Introduction to Chapter: critical practice meets external accreditation.................................... 139

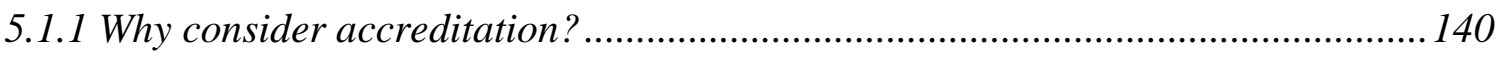

5.2 Demands from below for recognition of learning .............................................................. 141

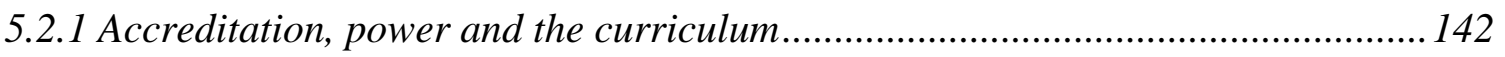

5.3 State-led growth of interest in the accreditation of learning .................................................... 143

5.3.1 The development of Irish Accreditation mechanisms .......................................... 144

5.3.2 Interrogating mainstays: challenging apolitical accounts .................................. 149

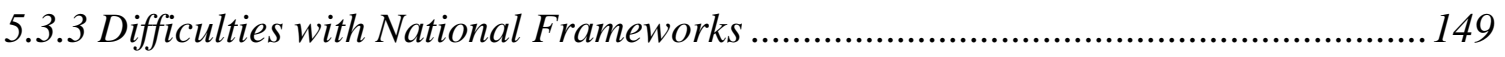

5.3.4 Interrogating learning outcomes approaches in community contexts................... 151

5.3.5 Questioning quality assurance frameworks ..................................................... 153

5.4 How is it going? Sharing experiences from practice ............................................................. 154

5.4.1 Community educators struggle with accreditation............................................... 154

5.4.2 Regulators/accreditors as a panoptical illusion?.............................................. 157

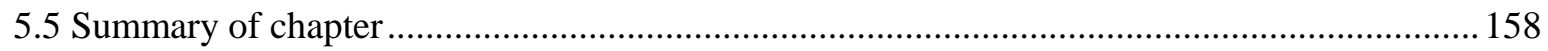

Chapter six: Critical education's person-centered approach .............................. 160

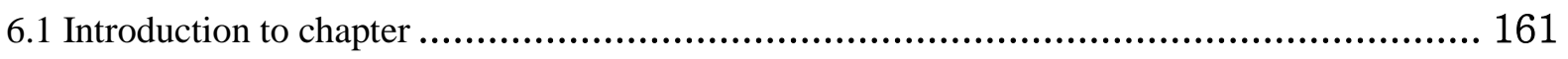

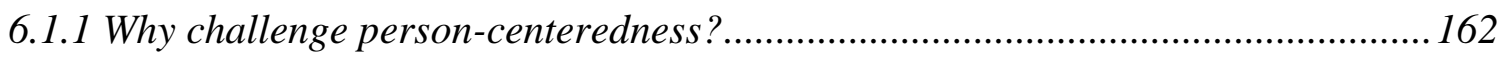

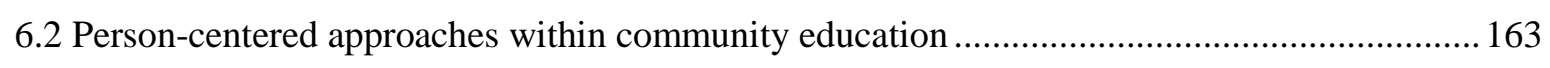

6.2.1 The benefits of humanistic, person-centered approaches ..................................... 165

6.3 Critical pedagogy and equality based community education ................................... 166

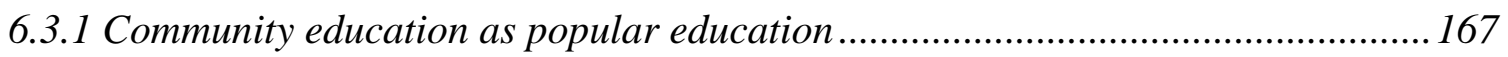

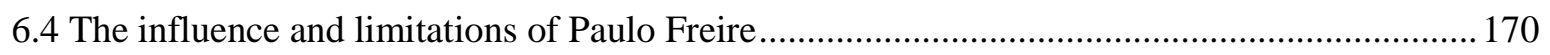

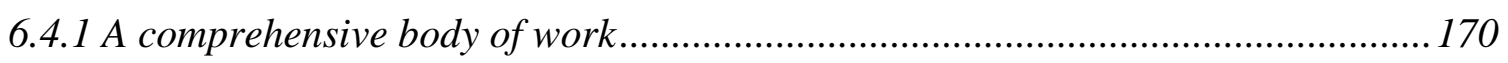

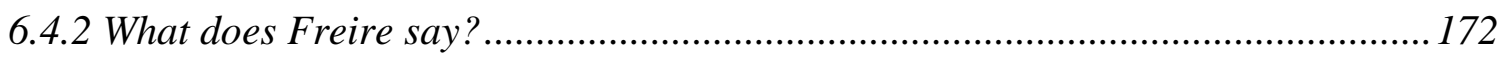

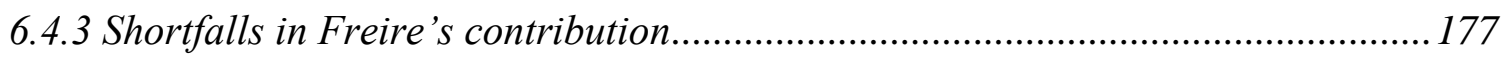

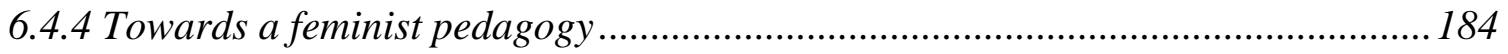

6.5 Doing critical community education: what it looks like in practice ............................. 186

6.5.1 The fallibility of practitioners - skills, contexts and philosophical beliefs ........... 188

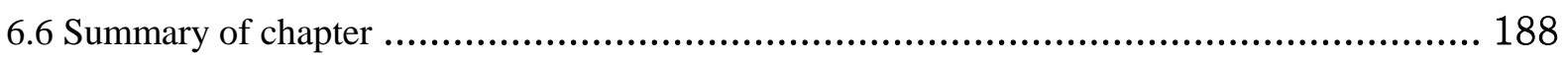


Chapter seven: Mixing methods, research design and participant engagement 190

7.1 Introduction to chapter. 191

7.1.1 Reminder of the research topic. 192

7.1.2 Reasons for choosing a Mixed-methods framework ........................................... 192

7.1.3 Challenging quantitative-qualitative dichotomies.............................................. 193

7.1.4 Questioning some mainstays of qualitative and quantitative research ................. 194

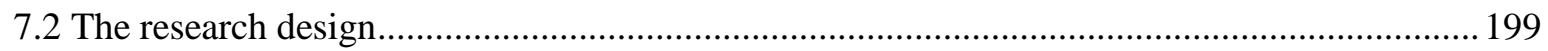

7.2.1 Phase one: selection, recruitment and interview techniques ...............................2200

7.2.2 Phase two: survey design and dissemination .......................................................202

7.2.3 Phase Three: extending dialogue through focus-groups....................................207

7.3 Ethical considerations in design, implementation and dissemination ......................................210

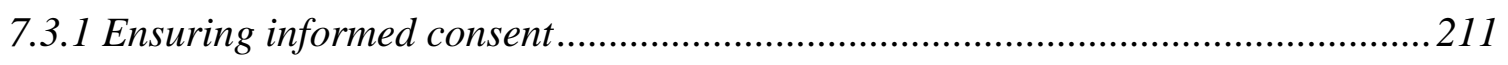

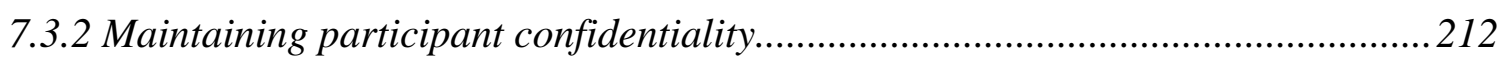

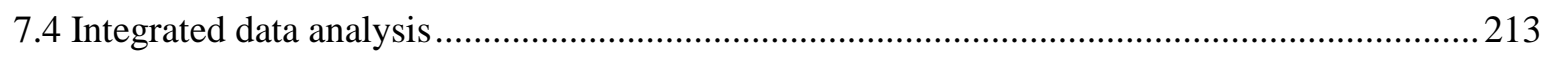

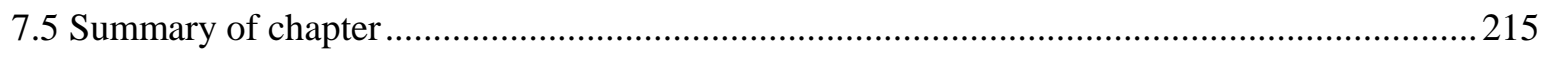

Chapter eight: Narratives from popular educationalists ................................... 217

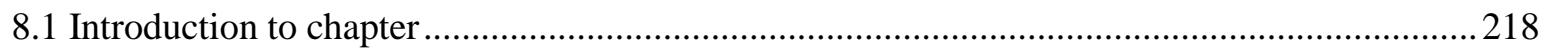

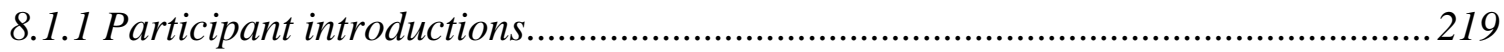

8.2 What we do - describing radically based community education ................................... 231

8.2.1 Experiences of being a critical community-based educator ..................................2234

8.2.2 Philosophical influences: ideas that inform their work.......................................2. 236

8.3 Criticisms of the Community Sector............................................................ 238

8.4 Community Sector relationships with the State ................................................... 241

8.4.1 The burdening effect of administration and accountability to funders .................2244

8.5 Radical practitioner experiences of working with accreditation bodies ........................... 245

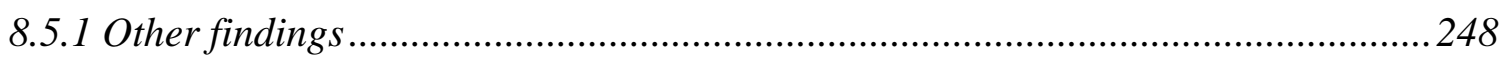

8.6 Imagining possibilities: what the future could hold ........................................... 248

8.7 Summing up findings from one-to-one interviews ............................................... 250

Chapter nine: Community Education - Views from Practitioners: chronicling survey

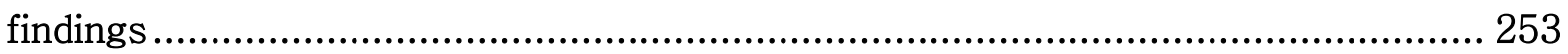

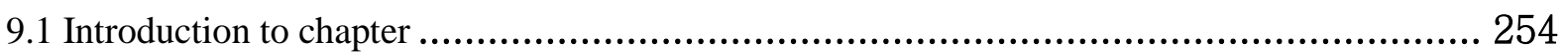

9.1.1 Community education - views from practitioners, some limitations.....................255

Section 9.2 Contexts and Characteristics ............................................................. 257

9.2.1 Identifying 'insider' and 'outsider' community educators ...................................2.258 
9.2.2 Locating practice - where do Community Educators work?.................................2260

9.2.3 Shared spaces: network membership and other links ......................................263

9.2.4 Hours of work, remuneration and other comments on working conditions ...........265

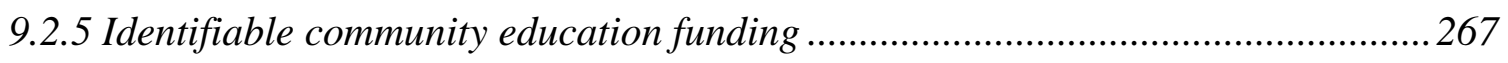

9.2.6 Quantification of accredited programmes..........................................................269

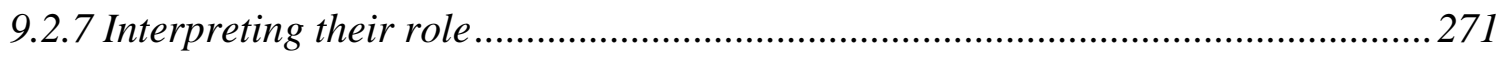

SECTION 9.3 - Descriptions and Philosophies of Practice........................................... 274

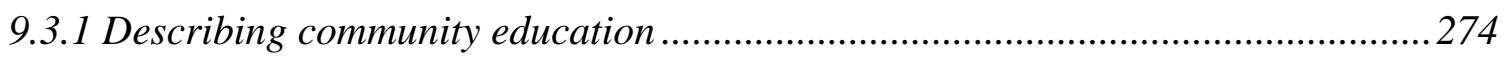

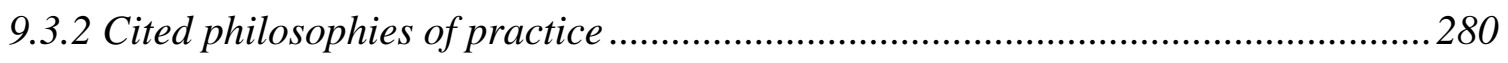

9.3.3 Further quantification of stated philosophies .................................................... 282

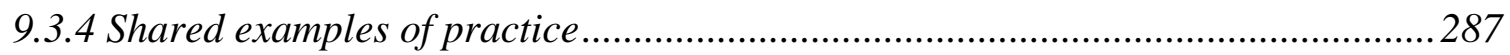

SECTION 9.4 Attitudes to equality, accreditation, and relationships with the State.................. 298

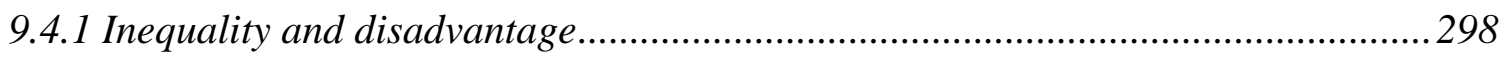

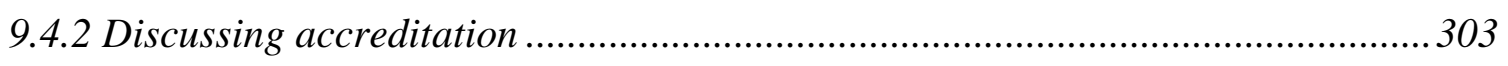

9.4.3 Thoughts on the potential involvement of the Teaching Council ...........................308

9.4.4 Thoughts on relationships with the State .............................................................. 310

9.4.5 Strengthening Community Education.................................................................. 316

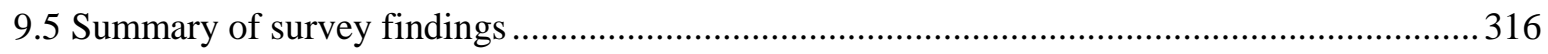

Chapter ten: Delving deeper, findings from focus-group encounters..................... 320

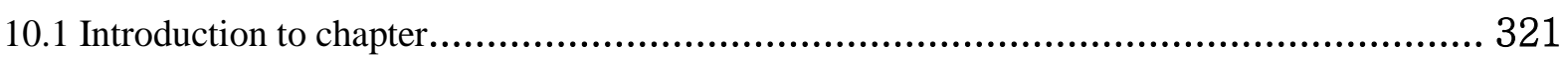

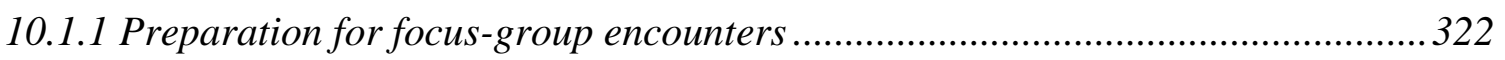

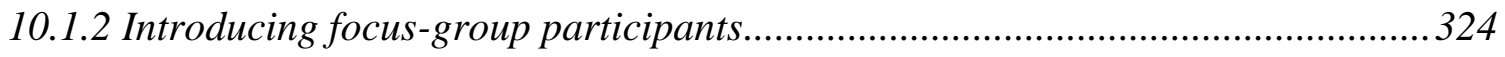

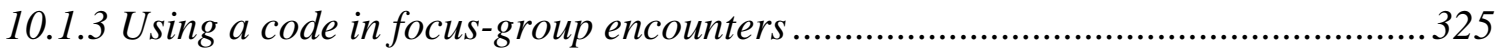

10.2 Uncomfortable bedfellows: relationships with the State ….....................................................3 330

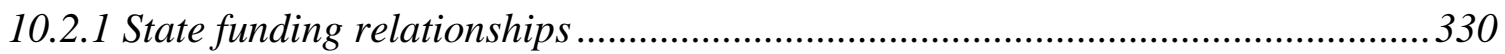

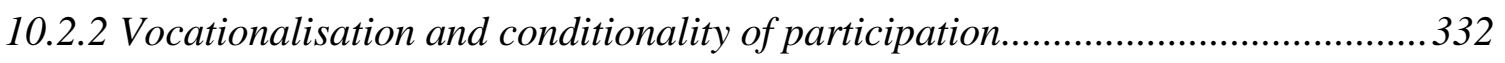

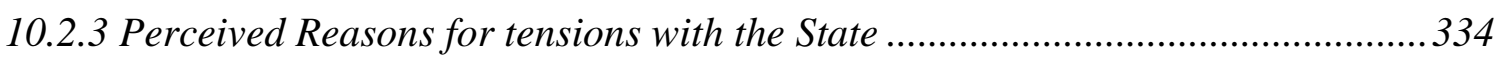

10.2.4 Managing imposed changes implemented through policy ..................................335

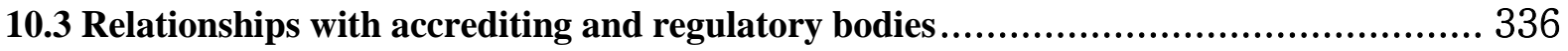

10.3.1 Involvement of the Teaching Council and Community Sector professionalisation

10.4 Criticism of community education providers from within................................................... 340

10.4.1 'Insider' community educators and relating to experiences ................................341

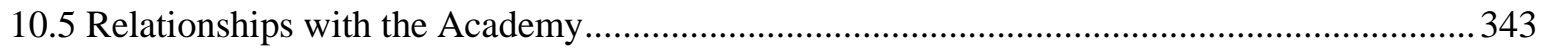




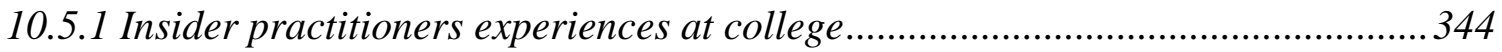

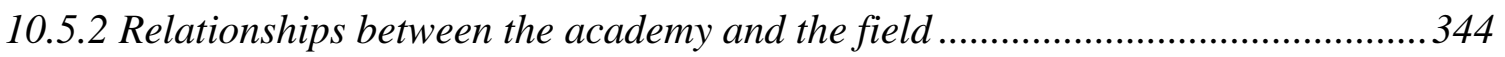

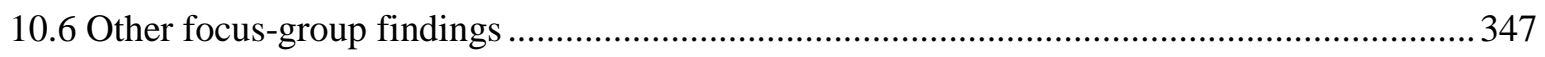

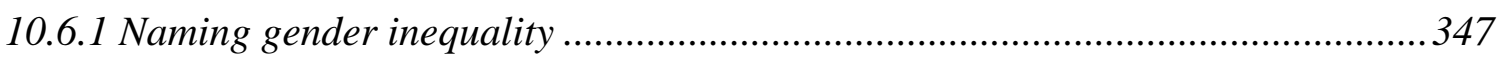

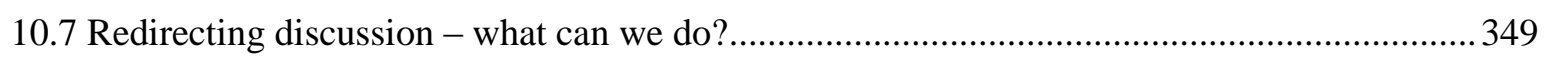

10.7.1 Community education and the need to showcase our work.................................351

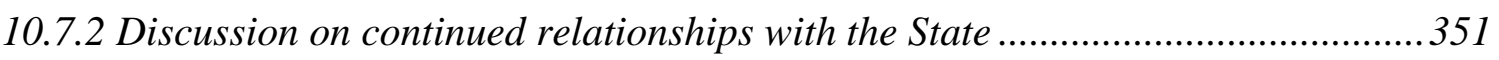

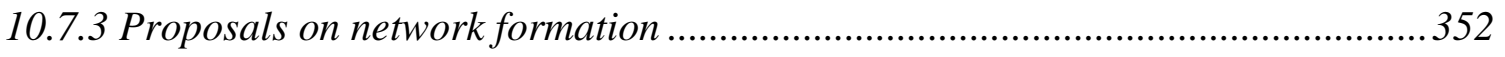

10.7.4 Direct action? Discussions on greater involvement ..............................................353

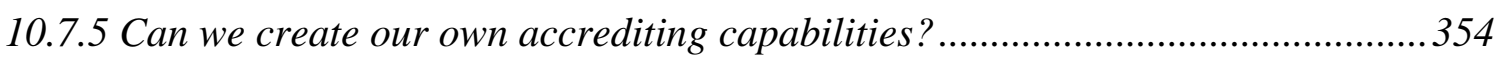

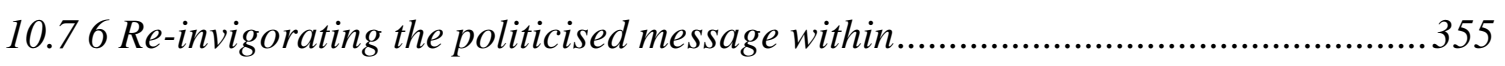

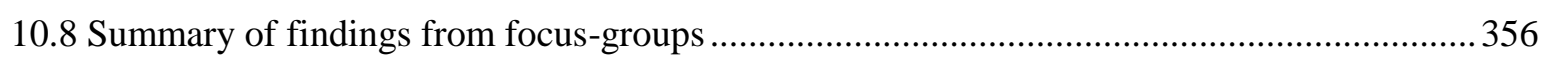

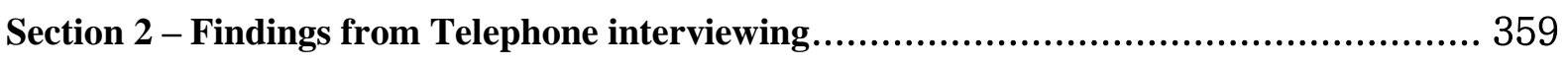

10.9 Introductions, motivating factors, and thoughts on community education as a whole ............359

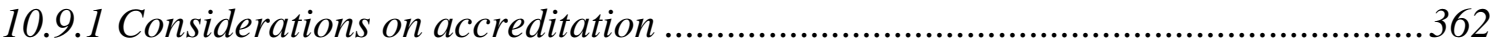

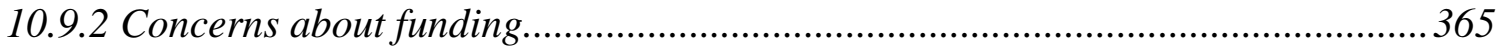

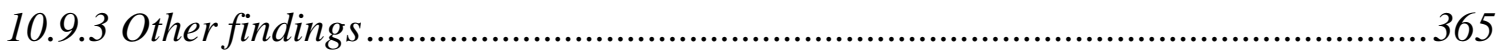

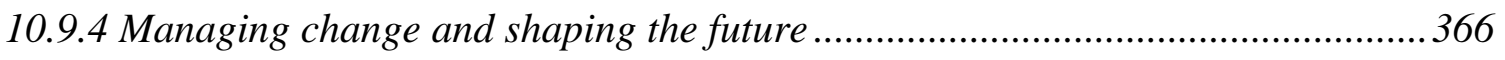

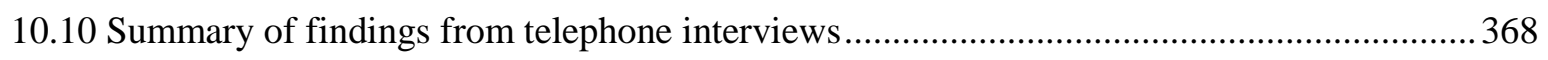

Chapter eleven: Mapping a landscape of Practice ......................................... 371

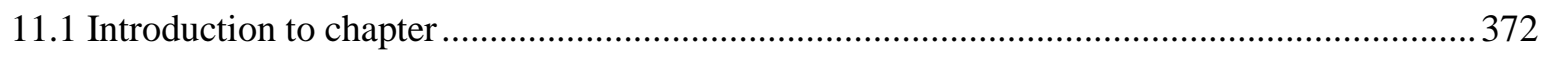

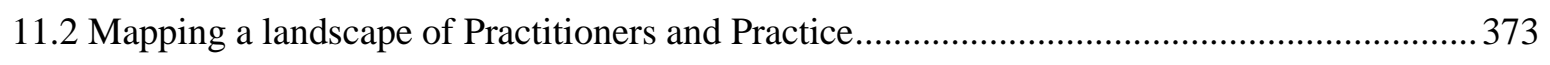

11.2.1 The precarious and demanding nature of community education ..........................375

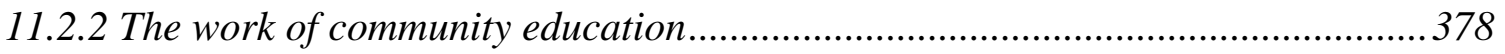

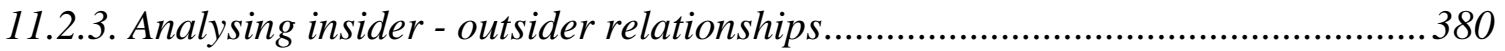

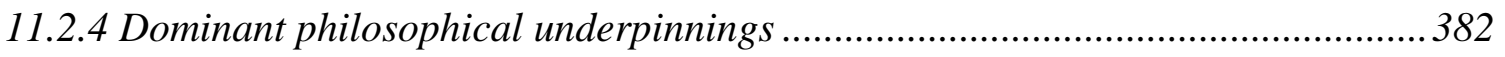

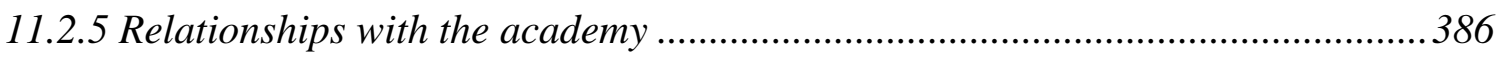

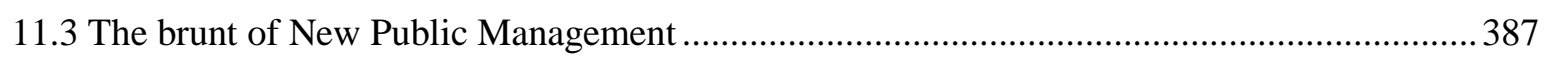

11.3.1 Negotiating neoliberalism: the malleable nature of relationships ......................391

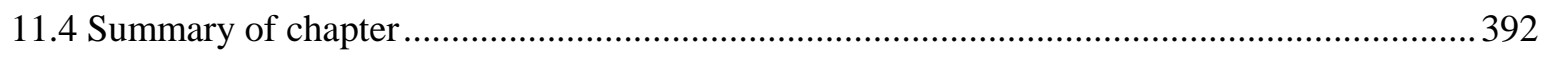

Chapter twelve: Re-kindling Community Education ............................................ 393

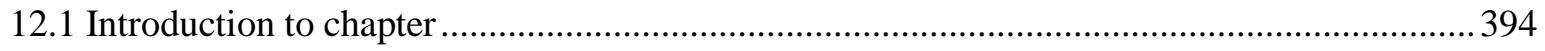

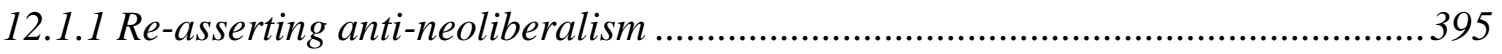

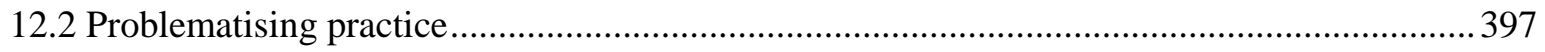


12.2.1 The appropriateness of Further Education Awards in Community Education ...399

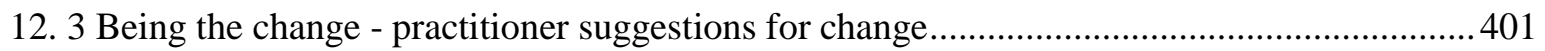

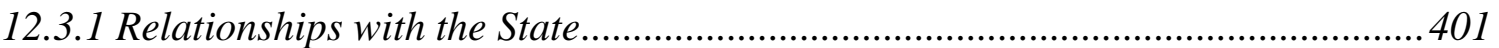

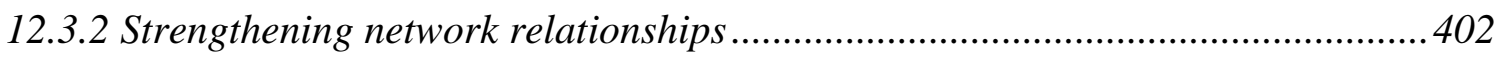

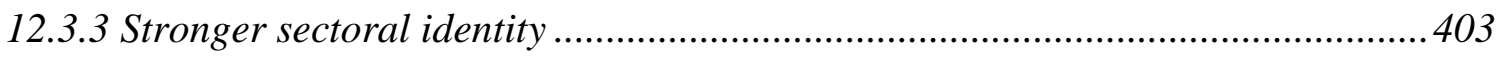

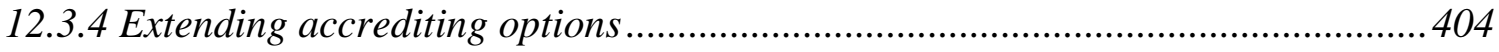

12.3.5 Greater engagement with social movements ................................................... 405

12.4 Oil and Water? Person-centered approaches and relationships with radicalism.....................405

12.5 Light many fires: encouraging anti-neoliberalism within and beyond .................................407

12.5.1 Extending practice beyond traditional walls .....................................................410

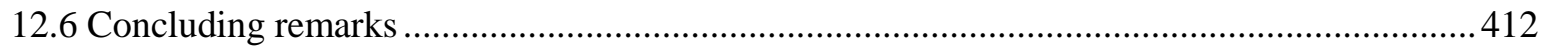

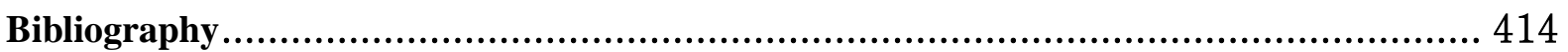

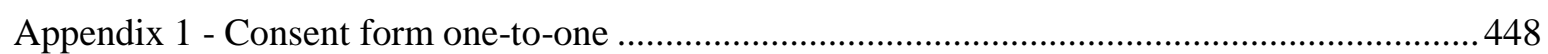

Appendix 2 - Survey - Community Education, Views from Practitioners ........................................ 449

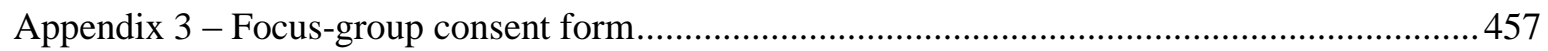

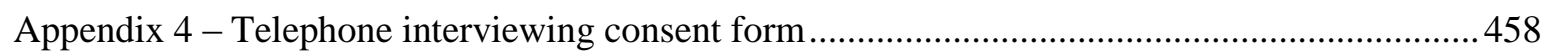

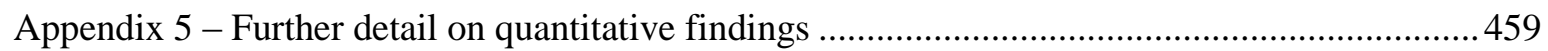

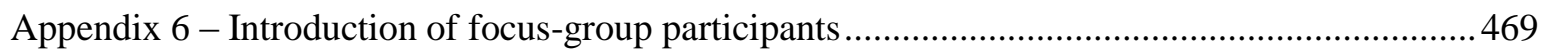

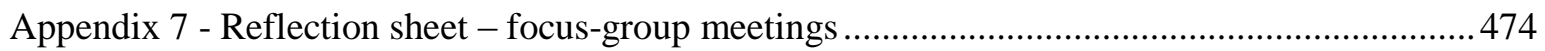

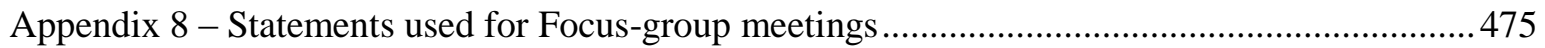




\section{List of figures}

Figure 1 - Universal, Second-Chance and Radical approaches (adapted from Martin, 1987)..............85

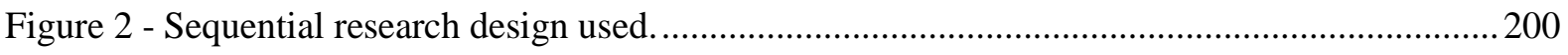

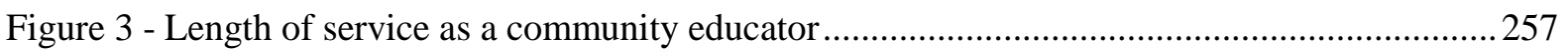

Figure 4 - Highest qualification held by community educators surveyed..........................................257

Figure 5 - Location of research participants initial qualification. ..................................................258

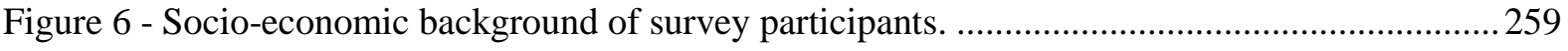

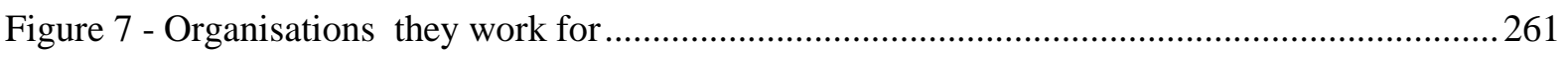

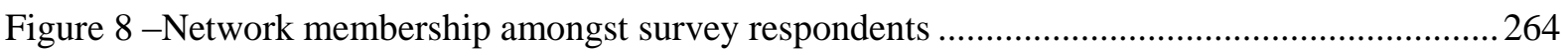

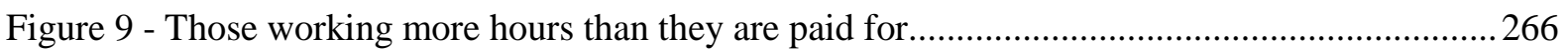

Figure 10 - Identifiable funding streams amongst survey participants ...........................................268

Figure 11 - Percentage of programmes that involve accreditation...............................................270

Figure 12 - Breakdown of accrediting bodies awarding within community education. .....................270

Figure 13 - Quantification of descriptions of community education ..............................................22

Figure 14 - Dominant philosophical leanings of survey participants...............................................283

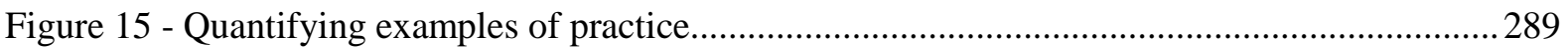

Figure 16 - Sub-catagorised quantification of examples of practice...............................................289

Figure 17 - Breakdown of person-centered examples of practice.....................................................290

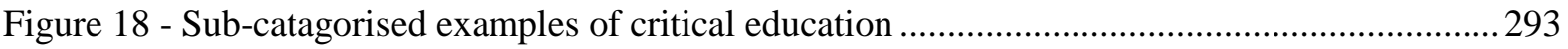

Figure 19 - Survey respondents attitudinal scales relating to inequality and disadvantage...............299

Figure 20 - Survey findings of attitudes to accreditation within community education .....................304

Figure 21 - Attitudinal scaling on need for community educators to hold a primary degree..............309

Figure 22 - Attitudes to relationships between the Community Sector and the State .........................312

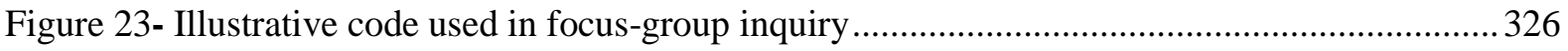

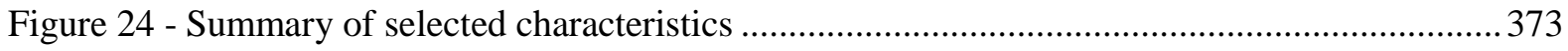

Figure 25 - Quantification of philosophies and examples of practice …..........................................383 


\section{List of tables}

Table 1- Summary of Project outputs in relation to participation in, and content of Training and Education and Social Awareness programmes (1996-1999) ........................................ 100

Table 2 - Some connections between Community Sector and State Provision ..................... 103

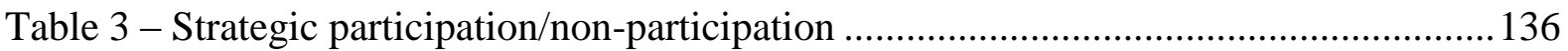

Table 4 - 'Community Education views from practitioners - Survey circulation...................206

Table 5 - Location of Community Education amongst survey participants .........................262

Table 6 - How community educators interpret their role...............................................272

Table 7 - Approaches to practice; universal, compensatory or radical ..............................281

Table 8 - Cross tabulation of socio-economic background and community education work. 


\section{Acronyms}

AEO

BTEI

CEF

CEN

CDP

CPA

CSO

CVS

CWC

DCRGA

DECLG

DOES

DSP

ETB

EU

FE

FET

FETAC

FRC

HEI

HETAC

ICTU

IMF

IT

LAP

LCDP

MMR

NCCWN

NDP

NFQ

NSMs

NWCI

OECD

PESP

QQI

SICAP

TfT

UNESCO

VEC

VTOS
Adult Education Officers

Back to Education Initiative

Community Education Facilitator

Community Education Network

Community Development Project

Combat Poverty Agency

Central Statistics Office

Community and Voluntary Sector

Community Workers Cooperative

Department of Community, Rural and Gealteacht Affairs

Department of Environment, Community and Local Government

Department of Education and Skills

Department of Social Protection

Education and Training Board

European Union

Further Education

Further Education and Training

Further Education and Training Awards Committee

Family Resource Centre

Higher Education Institute

Higher Education and Training Awards Committee

Irish Congress of Trade Unions

International Monetary Fund

Institute of Technology

Local Area Partnership

Local Community Development Programme

Mixed-methods Research

National Collective of Community based Women's Networks

National Development Plan

National Framework of Qualifications

New Social Movements

National Women's Council of Ireland

Organisation for Economic Cooperation and Development

Programme for Economic and Social Progress

Quality and Qualifications Ireland

Social Inclusion and Community Activation Programme

Training for Transformation

United Nations Educational Scientific and Cultural Organisation

Vocational Education Committee

Vocational Training Opportunity Scheme 


\section{Acknowledgements}

A sincere thanks to all those who participated in this research, thank you for your time, forthrightness, insight and ongoing dedication as community educators.

Thanks to Bríd, a fantastic supervisor who gave me a long leash gentling tugging at various junctures when I needed to be kept on track. Her imaginative, constructive and analytical insights along the way have been invaluable.

To others undertaking PhDs, you were a constant source of support as were the wider team within the Department of Adult and Community Education. Special thanks to Brian, Bernie, Sarah and Jerry for some proof reading, any typos are your fault!

Again special thanks to Peter Dorman who did such a fantastic job drawing the illustrations littered throughout, and to Nicky Merriman for drawing the original code used with focusgroups.

To Brian, Anna, Dylan and Isobel, so sorry I've been distracted, thanks for all your support.

To my Dad, thanks for encouraging a strong sense of equality and justice from an early age. 


\section{Prologue}

$14^{\text {th }}$ January, 2015.

It was a bitterly cold day. Roughly 15 of us were gathered in an upstairs room of a city centre college. Technically, I don't think we were supposed to be there. One of our steering committee members was a student and had asked if some community activists could use the space for a couple of hours. We were all involved with The Spectacle of Defiance and Hope, an oppositional collective that was formed in response to what we believed were really harsh cuts to Community Sector budgets.

There were less of us there than usual. The low temperatures were probably a factor but another kind of low was the sense of foreboding and strain amongst us as we found it increasingly hard to take time away from our projects since the cuts began in 2008 . There were six apologies that day alone.

There were just three items on the agenda. To share progress on design and delivery of experiential workshops called The Irish Debt Crisis What Happened?, to review recent involvement at a national anti-water charge demonstration and to share concerns about the privatisation of government funded community development work in the hope we might be able to do something to stop it.

At the anti-water charges demonstration we had taken to the stage to sing some songs composed through local workshops we organised with the help of some musicians. One I especially remember is called everybody doesn't live like this. Its title and lyrics were gathered from life experiences shared by a group on a Community Development and Leadership certificate programme.

The discussion around the Irish Debt Crisis What Happened? was vibrant and invigorating. Together, we had created a workable educational resource where, through role-play, participants could act out events surrounding the State introduced Bank Guarantee of 2008 (see page 29). I had been centrally involved in designing the work, so I was particularly excited by its progress. By now we had delivered the workshop in four communities where it was enthusiastically received. We had future workshops planned also. People were becoming stimulated, informed and empowered to interrogate this enormous issue, an issue that directly affects their lives. They were also becoming politicised and many participants were keen to do something more than just talk about it.

"It's a great exercise" one voice shared "when people watch the news and don't understand what is being said it makes them feel stupid...this exercise breaks it down so they can understand". Another adds "people are getting upset about it and I think that is a good thing, they are angry to do something about it". Plans were set for future workshops across the city, 
and we talked about organising a large gathering for all participating groups so we could collectively plan next steps.

When our conversations moved on to the current open-tender process for community development work, the air seemed thick with conflicting emotions that might best be summed up as, defiance, defeatism and dismay. Staff of previously independent Community Development Projects told us they were on protective notice with 50\% expected to lose their jobs. They shared feelings of upset and powerlessness. They were worried about the future of bottom-up community development work, work supported by an infrastructure built up over 25 years. Some of those in the room had been involved since the beginning.

Large geographical communities with rich histories and cultures but also those to experience the harsh end of structural inequality had now been assigned lot numbers. Both domestic and international Consortiums were secretly tendering for government contracts to deliver services, the nature of which was determined through rigid criteria. "Have you seen the tender?" one person asks "it is all about courses for employment, none of the ground-up work that we do, they've reduced slow, process based empowering work to service provision". "This is pure neoliberalism" adds another.

"What'll we do....." 


\begin{abstract}
This is a study about community education in Ireland. It begins by problematising our current globalised neoliberal epoch interpreting this socio-political environment as built on a return to laissez-faire economics and a hegemonic imbuement of inequality as the norm. The research draws from literature to demonstrate how neoliberalism has greatly exacerbated income inequality demonstrating how this has been despite those responsible for implementing the neoliberal project as often asserting an equality-based agenda. This mixedmethods study sets out to determine the impact of neoliberalism on community education. It enhances our knowledge of community education by mapping a landscape of domestic practice. This is undertaken by drawing from the experience and insights of circa 226 practitioners who are working in a range of local settings. The study uncovers community educator characteristics, identifies where community educators work and details what their day-to-day practice often entails.
\end{abstract}

Examples of community education that are uncovered locate practice within both Community Sector organisations and State (public) provision alike. This locational dispersal is congruent with a domestic history of community education most notably that which emerged since the 1970s and 1980s with much practice built from collective organisation through social movements most notably the women's movement, the literacy movement and the wider community development/anti-poverty movement. The history of community education presented also reveals a growth in public provision which was often a response to community demands. The study upholds the view that much community education is inspired by a vision of an egalitarian society, something that is determined both through literature, and through the many practitioner insights that are shared. This research also demonstrates varying interpretations of how inequality should be addressed including, for example, a secondchance approach to dealing with educational disadvantage and a minority approach that directly links community education to community development and collective action.

Across each philosophical perspective, the study reveals a harsh neoliberalisation of community education practice. This has been advanced through an EU-led policy approach that interprets all education as largely instrumentalist. In the main, neoliberalism views community education as an exercise in up-skilling a flexible workforce, a perspective which underpins a system of New Public Management. This type of managerialism focuses on the measurement of outputs and brings the logic of business into spaces where 'education' once 
related to issues of personal development and recovery or to consciousness-raising praxis is now instrumentally reduced to the vocational demands of the market.

Based on the politics of free market neoliberalism, New Public Management has had a profound effect on community education with much Community Sector activism either coopted into State structures or simply shut down. Other findings from this research demonstrate deterioration in working conditions for community educators. These include pay cuts, unstable contracts of employment and an erosion of occupational autonomy on a day-today basis. These problems are caused by the increased demand to accredit all (community) learning through an overly prescriptive, over-assessed model of certification that has been principally designed for Further Education (FE) settings.

Given its ambition to re-kindle community education this research is undertaken as an attempt to support practitioners in upholding the equality agenda many hold firm. The study calls on community educators to expand anti-neoliberal spaces where possible and draws from the suggestions of those participating in this research to imagine how this might be done. Specifically, these suggestions are the need (a) to be more strategic in relationships with the State (b) to strengthen network relationships amongst themselves (c) to assert a stronger sectoral identity (d) to explore alternative accreditation mechanisms and (e) to expand ways in which stronger links with oppositional movements can be created.

Along with drawing from practitioners suggestions, the research is underpinned by a critical realist-feminist perspective, a paradigm that brings with it an interrogation of contemporary community education practice. It particularly challenges a majority person-centered philosophy held by practitioners critiquing the potential for this philosophy to realise egalitarian change when utilised within neoliberal contexts. Person-centeredness is important for its holistic attention to participants of community education, but it is a limiting perspective in achieving egalitarianism given its lack of attention to the structural causes of inequality. It also discourages dichotomisation of radical and non-radical practice and encourages community educators to infuse a problem-posing approach within all of their interactions. Rekindling Community Education encourages community educators to reflect on their practice and to consider how best to advance the principles of equality and social justice though their work. This reflection should include consideration of practitioner relationships with the communities they purport to support encouraging authenticity in their interactions. 
Chapter one: Introduction: Community Education in Neoliberal times

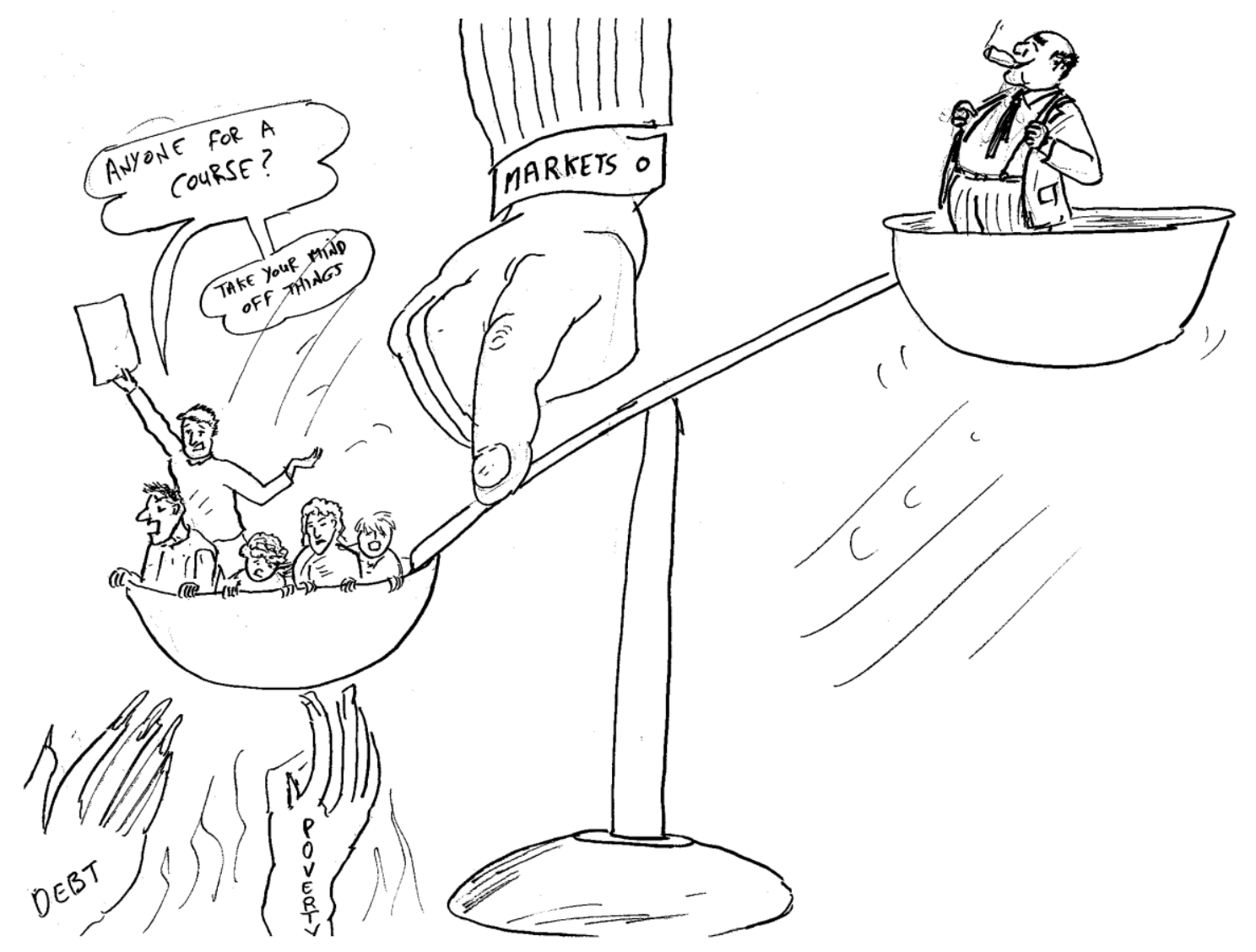




\subsection{Introduction to chapter}

On the face of it, community education has come a long way. From fledgling beginnings often characterised by temporary premises, sparse materials and a reliance on significant voluntary effort, contemporary practice is now typically State-funded and is often located in purpose-built community centres. Much of its growth has been through the Community Sector, a national network of bottom-up community-based organisations and a concept that will be explored more fully throughout this study. There has also been growth in public provision. This is mostly through work co-ordinated by a national network of Community Education Facilitators (CEFs) as well as through locally based Vocational and Training Opportunities Schemes (VTOS). Since the 1970s and 1980s there have been some notable developments for those availing of community education. These include State subsidy for attendance, greater opportunities to gain recognisable certification and a more identifiable progression pathway. Specialist practitioner based adult education programmes have also forged a more distinct occupational identity for community educators. Another example of change is through a recent government led realignment of practice, something SOLAS, the National Further Education and Training Authority, alleges has streamlined provision and addressed a previous 'absence of co-ordinated delivery' (SOLAS, 2014a: 36).

In contemplating these changes, it is important to contextualise them within the neoliberal circumstances from which they have emerged and with consideration for their impact on those involved. This study adopts an anti-neoliberal positioning (which will be explained in due course) and sets out to explore the implications of this socio-political doctrine through the insights, experiences and opinions of community educators. The research uncovers a depoliticisation of practice shepherded in through broad acceptance of the logic of neoliberalism and implemented through systems of New Public Management (NPM). The study also proposes a responsive and complex 'anti-logic of humanity' (Holloway, 2010: 72). 
This is demonstrated by revealing how community educators often act in ways that are anathema to neoliberal aspirations and against government policy leanings. Before providing a more concrete explanation of neoliberalism, and in advance of more detail on the research topic, I will begin by sharing my own entry into community education. This is a funnel through which a broader understanding of community education is offered.

\subsubsection{Setting the scene: personal beginnings in politicised practice}

In the late 1990s I left behind a career as a nurse to work as a community educator. This was within a State funded Community Sector organisation located in a relatively poor urban neighbourhood often described as socio-economically disadvantaged. Some reasons for this distinction most likely included its concentration of people living on low incomes, its high levels of unemployment, and a greater than average number of lone-parents. To some extent this consolidated demographic was as a result of poor government planning and allocation in social housing provision (Fahey, 1999; Drudy and Punch, 2005; Norris and Redmond, 2005). One such example from the 1980s was when financial incentives were offered to families who were prepared to vacate social housing and enter the private housing market. Those who took up this offer had high levels of employment and much leadership capacity, but were replaced by those 'at high risk of poverty' and in urgent need of housing (Norris and Redmond, 2005: 175).

I worked for a community project that operated from three vacant social housing units located in high-rise flat complexes. Most of the work was educational and was particularly informed by the philosophies of Brazilian educationalist Paulo Freire as well as influences from an Irish influx of the Training for Transformation (TfT) movement. The organisation was funded through the Community Development Project (CDP). As was typical of this State grant scheme, the majority of voluntary positions on the Board of Management were held by 
local people. These were complemented by people from outside of the community, including one from a religious congregation, as well as paid community workers from more advantaged social backgrounds (like me) who were working in other organisations. There were also some experts for example an accountant based within a local college, who was invited into the fold because of certain capabilities. Interpreting the socio-political realm as unjust, staff and management worked in a way that was politicising, highly participatory, experiential, and deeply respectful towards the people we encountered.

My role was as Project Leader with an adult education initiative for women with a history of problematic drug use, a label that greatly undersold their many abilities and insights. These women were directly involved in determining the mission and ethos of the project, in designing the curriculum and, where possible, in engaging in consultation processes on local and national policy. I didn't work alone but was paired with a local unqualified woman who had crafted her trade on the job. She brought an authenticity to the work, continually compensating for my unfamiliarity with many cultures and experiences strong within the group. Together we traversed such topics as local history, women's health, politics, social analysis, computers, and creative writing as well as organising work experience, something resisted by some employers but supported by others. We smoked cigarettes, drank tea, laughed, cried, discussed, debated and, where we could, collectively extended our energies towards tangible community outcomes. These included the establishment of a service-users forum, participation in demonstrations against the closure of a local swimming pool, and linking with other activist organisations in addressing ongoing community needs.

This work formed part of an expanding Community Sector of the 1990s and 2000s. The bulk of these organisations engaged in educational work in such areas as housing management, local democracy, community development, literacy, health, and social care (Nexus, 2002: 35). As stated within the opening paragraph, Community Sector work operated alongside 
State initiated (public) community education which was organised as part of the work of Vocation and Education Committees (VECs) as well as involving FÁS (the since disbanded Irish National Training and Employment Authority). Public provision and locally established Community Sector organisations coalesced within certain neighbourhoods forming a localised milieu that is often interpreted as not only extending educational opportunity beyond traditional settings, but as fulfilling important civic functions.

One commonly associated civic objective is community education's potential to actualise a range of citizen rights. Supporters of this interpretation often claim this is through collective, praxis-oriented approaches that are undertaken to encourage systemic change. The fulfilment of this political aspiration is through an ideological interpretation of community education described within the government policy document Learning for Life: White Paper on Adult Education as 'a process of communal education towards empowerment, both at an individual and a collective level' and something that is intrinsically linked to community development (DOES, 2000: 112). Whilst understandings of community development can vary, most domestic versions connect it to broader international concepts of locally based, bottom-up processes of collective action, underpinned by principles of empowerment, social justice, participation and equality (Lee, 2006; Motherway, 2006; CWC, 2008; Crickley and McArdle, 2009; Lloyd, 2010; Fitzsimons and Dorman, 2013). By its own admission, the white paper's inclusion of this 'second view' (DOES, 2000: 112) came about as a result of successful consultation with community organisations (including the project I describe) following a review of the proceeding Green Paper: Adult Education in an Era of Learning (Government of Ireland, 1998).

As this research will demonstrate, not all community education works from politicising ambitions. Where it is political, it is often connected to the community development described above and therefore as a socially transformative process. This understanding most 
notably emerged in Irish and UK settings in the 1970s and 1980s (Lovett, 1975; Fordham, 1979; Kirkwood and Kirkwood, 1989; Kelleher and Whelan 1992; Connolly, 1996) and was built around historical events at the time. Its underlying philosophies are often linked to critical education, influenced by grassroots popular education movements in Latin America (Kane, 2001; 2010) and liberation theology as sometimes practiced by missionaries in certain African countries (Naughton, 2002). Irish contributions to its development, implementation and documentation have emanated from the academy (Connolly, 1996; 1999; 2001; 2003; 2007; 2010; 2014; Keily et al, 1999; Feeley, 2007; Fitzsimons, 2012), from AONTAS: The Irish National Adult Learning Organisation (Basset et al, 1989; Inglis et al, 1993; AONTAS 2004; 2008; Bailey et al, 2010; 2011) and from practitioners (Cullinane, 2003; Dorman, 2006; McCallion, 2009; Slevin, 2009). There are also Irish produced how-to handbooks containing politicising, collective, dialogic and experiential exercises for practical application in community settings (e.g. Sheehy, 2001; McNeill, 2005; Sheehy et al, 2007). A common trend across these publications, by academics, advocates and practitioners alike, is a starting point that views present day capitalism as causative in both creating and sustaining the inequality encountered by many who access community education. To demonstrate this perspective within practice, the AONTAS Community Education Network $(\mathrm{CEN})^{1}$, a practitioner network with over 200 members describes community education as 'a process of personal and community transformation, empowerment, challenge, social change and collective responsiveness...grounded in principles of justice, equality and inclusiveness' and different from 'general adult education provision due to its political and radical methodologies' (AONTAS CEN, 2008: 1). Similar meaning is shared by the Community Education Facilitators Network (CEFA), an association of State employed Community Education Facilitators (CEFs). Research by CEFA claims that community educators 'assert

\footnotetext{
${ }^{1}$ It is important to distinguish the AONTAS CEN from the AONTAS umbrella organisation. CEN members do not have to be AONTAS members; there are no membership fees and no reporting structure to AONTAS.
} 
the social purpose, origins and meaning of adult and community education which is about empowerment of marginalized individuals and communities for collective social and economic transformation' and continues, 'it is political and asserts democratic participation and focuses on social justice outcomes' (McGlynn, 2014: 6). These commitments to egalitarianism not only confirm discontent with current social arrangements but reserve a critical and oppositional role for community education in working towards collective solutions.

\subsection{Context matters: assessing the global neoliberal turn}

Any suggestion that community education can act as panacea for the woes of capitalism should be treated with considerable caution. This is because during the same period when there was a mushrooming of equality-based community education, there has also been a marked growth in income inequality both globally (OECD, 2011; United Nations, 2014: 2), and domestically (O'Connor and Staunton, 2015). This has been presaged by a profound global shift to the political right as Keynesianism, paralysed by stagflation in the 1950s and 1960s, was strategically replaced with neoliberalism (Harvey, 2005). Spurred on by Reaganomics and Thatcherism but born out of the ideas of Chicago School economists (Birch and Mykhnenko, 2010: 3-5), neoliberalism encouraged a return to elements of classical liberalism's laissez-faire economics. Its stated intention was to re-invigorate the accumulation of capital through specific political and economic actions. Bhagwati (2004: 53) explains how 'poverty is licked' by free market economics, proposing a 'two-step argument; that trade enhances growth, and that growth reduces poverty'. Deregulated entrepreneurialism at the top of society would create economic growth below which would benefit all of society through widespread job creation. This would concurrently drive consumer spending, the fulcrum of all capitalism. Simultaneously, individual freedom would be protected through market freedom as prices independently adjust (including wages) in 
response to supply and demand (Duménil and Lévy, 2004: 11). Whilst government is called upon to implement the neoliberal project, the relationship between the State and the socioeconomic realm is also revolutionised as the former is refashioned as preserver of the free market economy 'at all costs' (Harvey, 2005: 64). Harvey (2005: 64) describes how this is to allow businesses and corporations to operate without restrictions and boundaries. Expensive and cumbersome State mechanisms would also be disbanded. These are to be replaced with streamlined, privatised services enabling a more efficient, rationalist operation with marketisation shaping social services such as transport, health, housing and education. This is largely through an infusion of business-like, performance-related models, or New Public Management (NPM), which reforms the public sector by measuring effectiveness within the confines of national economic strategies (Clarke and Newman, 1997; Walsh, 2006; Lynch et $a l, 2012)$. As will be demonstrated, NPM's encouragement of a standardised, measurable, commodified approach has been extended through the Community Sector and within public community education provision. In its defence, NPM claims to improve efficiency, raise standards through competition, and enhance customer choice. Milton Friedman, an economist often considered a key architect in the design of neoliberalism, claims these principles can tackle educational disadvantage by enabling 'the exceptional few... who are the hope of the future - to rise above the poverty of their initial state' (Friedman, 1962/2002: 93). Friedman (1962/2002: 191) also advocates the privatisation of other forms of social responsibility with philanthropic endeavour relieving nation States of liability to protect those most vulnerable.

One of the ways in which neoliberal ideology has been put into practice is through The Washington Consensus (1989), a policy convergence measure between the World Bank, the International Monetary Fund, and the US Treasury. These organisations agreed to a set of policy directives described by Birch and Mykhnenko as, 
tight fiscal discipline (with virtually no public budget deficit allowed); an end to subsidies and re-direction of public expenditure on basic health, education and infrastructure; tax cuts; financial liberalization; free-floating exchange rates; trade liberalisation and a unified low tariff; openness to foreign direct investment (FDI); privatization; deregulation; and secure private property rights'. (Birch and Mykhnenko, 2010: 9)

The Washington consensus was later expanded to include other organisations (such as the World Trade Organisation) as a compliant global economy became characterised by capital mobility fed by a presumption of continued growth and implemented through domestic attention to short-term market demands (Saad-Filho, 2004). Saad-Filho (2004: 113) explains how previous presumptions that some countries were poorer because they lacked resources where overturned. Instead the causes of poverty were reframed as 'misconceived state intervention, corruption, inefficiency and misguided economic incentives' (Saad-Filho, 2004: 114). Saad-Filho (2004: 114) continues, 'neoliberals also claim that international trade and finance - rather than domestic consumption - should become the engines of development'.

\subsubsection{Neoliberalism's failed equality agenda}

These claims of expanded employment, educational opportunities, and greater life choices made by neoliberals often concur with many of the aspirations of community education, and with needs commonly expressed within communities. However, the equality objectives asserted by this political doctrine have not transpired and Harvey (2005: 21) notes, 'enough contradictions in the neoliberal position to render evolving neoliberal practices (vis-à-vis issues such as monopoly power and market failures) unrecognisable in relation to the seeming purity of neoliberal doctrine' (brackets in original). Instead neoliberalism has overhauled national and international policies and politics towards the protection of corporate interests at the expense of the public good. Financial prosperity has failed to trickle down

rather a system has been instituted that is designed to 'hoover wealth up to the top' (Klein, 2007: 86). The focus of redistributive policies has been to allow capital accrual by the minority whilst economically squeezing the majority, something frequently cited as a 
persistent and dominating feature of neoliberalism (Birch and Mykhnenko, 2010; Chomsky, 1999; Duménil and Lévy, 2004; Harvey, 2005; Allen and O’Boyle, 2013; Giroux, 2013).

To demonstrate the extremes of inequality, the 2014 Forbes rich list cites the global topearner Bill Gates, as having a personal net worth of some $€ 77.1$ billion $^{2}$. Gates is one of the 1\% that owns almost half the world's riches, an estimated $\$ 100$ trillion (Oxfam, 2014: 2). Oxfam (2014: 2) further catalogue increasing wealth for the $1 \%$ since $1980^{3}$ with the US $1 \%$ capturing $95 \%$ of post-financial crisis growth whilst the bottom $90 \%$ became poorer. Concurrently, a United Kingdom (UK) based charity is highlighting the preventable deaths of one million babies per year on their first day of life (Save the Children, 2014). Two and a half billion people worldwide live without sanitation, and $22 \%$ live on less than US $\$ 1.25$ per day (United Nations, 2013). Whilst historical images of inequity tended towards perceptions of country to country poverty, with the global North interpreted as rich and the global South as poor, this has been somewhat discredited. This is through measureable differences captured across social class in life-expectancy and infant mortality, physical and mental health, educational performance, and imprisonment rates within so called Western societies (Wilkinson and Pickett, 2009).

In spite of these shortfalls there has been rapid expansion of neoliberalism. An important feature in understanding its near unimpeded growth was a global illusion of shared economic prosperity through the 1990 s and early 2000 s. Certainly there was some prosperity, however, the 1990s began a trend of steep increases in income inequality (OECD, 2011) largely enabled through a reinvention of capitalist relations of production outside of the accrual of surplus value created by workers, over and above actual labour cost. This created a mirage of growth through a culture of high risk financial transactions, an inflated property bubble, and an amassment of loans against which shares (asset-backed securities) were generated

\footnotetext{
${ }^{2}$ In 2013, Forbes listed Bill Gates, Co-chair of Bill and Melinda Gates, and famed as the creator of Microsoft, as the richest person in the world. The full rich list is accessible at www.forbes.com

${ }^{3}$ This is reported as between 1980-2012 and in 24 out of 26 countries where data was available.
} 
(Duménil and Lévy, 2011: 106). Another accelerant in capitalist reinvention and a sustained veneer of middle-class comfort was the expansion of privatised debt as a mechanism for fuelling consumer spending. This plugged capitalism's chasm of inadequate basic income, as debt-money funded both subsistent needs and life events such as divorce, illness and/or unemployment (Soederberg, 2013: 494). Rather than question the unsustainable nature of the credit-led accumulation of wealth and the folly of citizens kicking the can of day-to-day expenditure down an uncertain road, the response from governments was to transform themselves into what Soederberg (2013) describes as debtfare States. This was by validating and even lauding unsecure debt creation, including sub-prime mortgage lending, all facilitated through a paralleling deregulation of financial systems.

A second, fundamentally important, and interrelated feature in the spread of neoliberalism is the internalisation of a neoliberal logic. This hegemony, or consent by the majority to the general direction of society imposed by a minority (Gramsci, 1971: 12), ensures sufficient agreement to enable such policies to be advanced. Increasingly, neoliberal discourse is hegemonically imbued though a homogenised popular culture, and control of public pedagogic spaces (Herman and Chomsky, 1994; Giroux, 2013). These are powerful mechanisms in determining whose voices are heard, what counts as representation, what behaviours are considered normal, and, conversely, what is thought of as subversive. Along with a globalised media largely controlled by a small number of individuals or entities (Bagdikian, 2004), education systems themselves have been a significant domain for consensual adoption of capitalist logic as common sense (Giroux, 1983).

The influence of neoliberalism has been so powerful; its architecture has included an imperialist style spread of its principles to nations often presented as ostensibly nondemocratised and therefore problematic to western capitalist value systems. This enables the adoption of a protectionist, global policing role for dominant nations framed as necessary for 
domestic defence, something Chomsky (2006: 3) describes as 'a doctrine of "anticipatory self-defence" with unstated bounds'. At times the spread of neoliberalism requires co-option of local elites, commonly achieved through International Monitory Fund (IMF) and World Bank structural adjustment programmes, entered into as part of often much needed loan deals (Manfred and Roy, 2010: 119).

Though carrying many similarities with broader global events, Ireland's transformation to a 'neoliberal State' (Allen, 2007: 62) is worth considering in isolation. Its neoliberalisation was largely influenced by a Celtic Tiger economic growth period of the 1990s, a time during which there was rapid expansion of the Community Sector. During this period Ireland boasted an impressive national spread-sheet bolstered by an inflated and, ultimately unsustainable, property boom that was reliant on the American sub-prime market (Allen, 2003). A domestic financial sector also expanded. This was again reinforced by foreign investment which was attracted to our shores by a substantively unregulated banking system whose primary intention was to encourage market growth (Kirby, 2010: 9; Tobin, 2010; Allen and Boyle, 2013). Public endorsement was packaged as one of mutual benefit offset by the employment opportunities created by multinational visitors who availed of an educated, efficient workforce. As with other global nations, the Irish State adopted a debtfare approach, again supported by financial deregulation. At the height of the boom, Irish banks had lent out the equivalent of over twice the worth of the Irish economy, and an amount almost €200 billion greater than what they held in deposits (Allen and O’Boyle, 2013: 3). Personal debt rocketed during the Celtic Tiger period with the Central Bank revealing how by 2004, outstanding personal debt stood at €85 billion, well above $100 \%$ of estimated disposable income at the time (Kelly and Reilly, 2005: 85). 


\subsubsection{Neoliberalism in crisis}

According to Žižek (2009: 9), the only surprising thing about the global economic crash of 2008, was acceptance by so many that it was a surprise. By the late 1990 s and early 2000 s re-engineered capitalism experienced a near disintegration of stock market values, bankruptcy of leading financial institutions, and a global collapse of property values. Birch and Mykhnenko (2010: 256) link the global downturn to 'the shrinkage of money credit that began in 2007 ' further claiming,

The global financial and economic crises have painfully revealed that the long boom in the heartland of global financial capitalism was propelled by consumer led indebtedness. We can now see that global financial capitalism was the ultimate neoliberal innovation enabled by the proceeding waves of deregulation and liberalization. (Birch and Mykhnenko, 2010: 256)

Rather than let neoliberalism crash, the response by governments has been to socialise much of the banking system, a contradictory, but predictable move given neoliberalism's ongoing business-friendly financial assistance programmes amidst rhetoric of laissez-faire economics (Lapavistas, 2004: 34-35). Despite various stimulus packages and often crippling austerity measures, the anticipated recovery associated with the boom-bust nature of capitalism has been slow to emerge. In 2010, the US congressional research service described capitalism as 'locked in a descending spiral' with conventional federal interventions failing to get the crisis under control (Jickling, 2010: 4).

Domestically, many financial institutions became dependent on the State, most notably through a controversial bank guarantee of 2008 that was part-funded through an International Monetary Fund (IMF) loan. The IMF partnered with the European Central Bank (ECB) and the European Union (EU) bringing Ireland into the midst of structural adjustment more commonly associated with industrialising nations. This Troika (the term commonly used to describe the joint work of the IMF, ECB and EU) enforced repayment of loans through harsh 
austerity measures targeted, in the main, at those who had little or no involvement in causing the crisis in the first place.

The impacts of austerity have been profound. For those in employment, a series of payfreezes, income tax hikes and unpopular indirect taxes have considerably reduced consumer wealth. By 2012 unemployment had reached $19 \%$ and particularly affected certain sectors of society. These are named as lone-parents, young people and those living in 'unemployment black-spots' (CSO, 2012: 15-17). The Central Statistics Office (CSO) provide a list of these 'black-spots' (CSO, 2012: 162) and in doing so reveal urban neighbourhoods and rural locations with poor infrastructural connections, the same communities commonly engaging with community education ${ }^{4}$.

For those dependent on social welfare, the burden of austerity is captured by in-depth research on income adequacy across household types with just $22 \%$ of welfare dependent households 'with an income sufficient to meet minimum expenditure costs' (Collins et al, 2012: 154). Youth unemployment has trebled affecting 75,000 of those under 25 years, a figure distorted by its failure to capture those compelled to emigrate and those re-entering or remaining in education (ICTU, 2012: 6). Other stark impacts include claims by Social Justice Ireland that over 1.2 million people are forced to go without some basic necessities, with 750,000 living in poverty, an increase of 120,000 since the recession began (Social Justice Ireland, 2014). The same report notes $16 \%$ of those with an income below the poverty line are working, whilst $58 \%$ are either older people, have disabilities that render them unable to work, are in caring roles, or, are students. Twenty-five percent are children (Social Justice Ireland, 2014: 11). Eighty-two percent of households report reduction in expenditure, most frequently on socialising, but also on clothing and footwear, cited by $65 \%$, and groceries, cited by $51 \%$ (CSO, 2013a). This typifies the contradiction at the core of austerity given its

\footnotetext{
${ }^{4}$ The highest unemployment rate named is within the electoral district 'Johns A' in Limerick City, recorded at $56 \%$. Ballymun in Dublin is listed as having an unemployment rate of $44 \%$ whilst in Kilanarden in Tallaght, South Dublin, unemployment is measured at 42\%. The complete list is appendix 14 (CSO, 2012: 162).
} 
undermining of capitalism's dependence on consumer spending. A connection between increased rates of suicide and deteriorating personal economic circumstances has also been demonstrated (Arensman et al, 2012).

Responses to Ireland's economic downturn, and indeed the bulk of conversation in the public domain, are about managing this crisis and similar ideologies are usually espoused from both sides of the mainstream political spectrum. Rather than abandon the political-economic model that perpetuated these circumstances, the current financial crisis provides fertile ground for the deepening of neoliberalism (Klein, 2007). The rationale offered is that we must safeguard our financial institutions, further reduce expenditure by streamlining the public sector, and promote entrepreneurial endeavour as the only reasonable route to revival. As talk now turns to recovery, this is an important misconception to engage with as the emerging Ireland is fundamentally different to pre-neoliberal situations, not least given the absence of an independent Community Sector. Neoliberalism continues to siphon capital to the top as average wages have decreased (Central Bank, 2014: 21) whilst household debt in 2014 (although slightly improved on the previous year) runs at $€ 168.6$ billion or $€ 36,717$ per capita. The TASC report Cherishing All Equally: Economic Inequality in Ireland (2015) demonstrates post-recessionary growth disparity by measuring gross-market income inequality as highest in the OECD with the top $10 \%$ receiving $34 \%$ of all taxable income, an increase from 27\% in 1970 (O'Connor and Staunton, 2015: 8). A recent conference paper presented by the independent Economic and Social Research Institute (ESPR) also illustrates the stark impacts of neoliberalism by reporting a growing gap in life expectancy to income inequality (ESRI, 2015).

For many, there has been a cultural hegemonic acceptance of such hardship as an inevitable and necessary consequence of the modern world. This can be understood through the way in which neoliberal logic is continually strengthened. An important component within this logic 
is a continual centralising of individualism. This perpetuates the ongoing location of power within the person, holding each of us singularly responsible for our wellbeing and life circumstances. An increasingly relevant feature of this imbuement is a greater than before militarisation of the fabric of our society which encourages further permeation of a Darwinian individualised mind-set (Giroux, 2013: 80). Whilst Giroux's analysis predominantly focused on US events, American cultural hegemony also influences European behaviour (Stephen, 2006; Storey, 2010) with Irish society increasingly shaped by a ubiquitous global militarisation. To demonstrate, the 2014 Christmas day movie aired by the national broadcaster (RTÉ) was the animated film Arthur Christmas. This depicts the militarisation of the story of Santa Clause with Santa and his elves dressed in full army fatigues and associated paraphernalia. More recent again, the Irish Foreign Minister evoked military language in describing Ireland as 'on alert' following Parisian terrorist attacks despite admitting no imminent risk (http://www.thejournal.ie /ireland-terrorist-risk-1877632Jan2015/). Giroux claims this militarisation is having a profound effect on how we organise society and is ultimately leading to a cultural acceptance of brutality on those most vulnerable (Giroux, 2013: 80). Domestic examples of such brutality are all too easy to evoke. Those seeking asylum, displaced as a result of complex social and economic factors, are left for years in direct provision centres, there are increased levels of poverty for older people (CSO, 2013b), and Ireland's minority Muslim population experience rising levels of racism and discrimination (Carr, 2011). These, and many other vulnerable communities, be they geographically determined or identity based, are often those most affected by disproportionate funding cuts to the Community Sector (Harvey, 2012) as will be further determined in due course.

Whilst this depiction of the broad impacts of neoliberalism is an important contextualising feature, insufficiently countenanced to this point are its specific implications for Irish 
community education. This will be undertaken following further expansion of the research topic detailed below.

\subsubsection{Expansion on the research topic}

This study has three primary objectives. These are to expand knowledge on community education practitioners and practice across Ireland, to explore the impacts of neoliberalism, and to investigate ways in which a critical approach can further inform community education's egalitarian ambition. It takes on these core objectives whilst up-holding an understanding of community education as equality-based, albeit influenced by varying interpretations as to how this translates in practice. The research adopts a mixed-methods approach gathering and assessing insight into practice during a specific historical period (2011-2013) when there was much non-negotiated governmental change imposed (Murtagh, 2014a; CWC, 2014b). The knowledge generated is through contact with circa 226 educators ${ }^{5}$ working in community settings across a range of organisations and groups, something not previously undertaken in an Irish context. Participation is across three distinct phases: oneto-one conversations with purposefully selected radical educators, a broad based survey questionnaire with defined criteria for participation ${ }^{6}$, and regional focus-groups incorporating many of the participatory strategies commonly associated with community education.

The research's last objective, to investigate ways in which a critical approach can further inform community education's egalitarian ambition, is worth emphasising in light of my own positioning as a critical educator. Radical approaches are not only utilised across each phase of the study, they are offered as a theoretical framework from which we can both interpret current circumstances, and encourage counter-hegemonic responses.

\footnotetext{
${ }^{5}$ There is uncertainty about exact numerical participation due to an anonymous element of the study where phase one participants may or may not have participated within phase two (see chapter seven).

${ }^{6}$ Participation was invited from those working directly with groups in local educational settings outside of Higher education and Further Education institutions.
} 


\subsection{The neoliberalisation of community education}

As well as establish the research topic, this introductory chapter sets out to serve a specific purpose namely to present the socio-political optic through which the study is interpreted. To some extent this has been covered but with insufficient attention to community education. Market superiority has had a profound effect on how we construe all education. This is largely through a functionalist perspective that commonly reduces the purpose of education to the achievement of skills required for the neoliberal workplace. At the same time, there is often a belief that education as just another service to be consumed and is therefore commodifiable. Education's potential to nurture personal capacity and build social agency is commonly relegated to the side-lines, as is regard for its potential to foster critical awareness in a way that supports transformative action.

To understand the implications this has for community education, a brief historical overview (drawn out more fully in chapter three) will help. Though locally-based education initiatives can be dated back to at least the 1900s, of particular interest in this study is a wave of bottomup emergence, most often linked to the 1970s and 1980s. This was during a domestic period of social and economic unrest and increased trade union militancy (Coakley, 2012). It also coincided with global turbulence and a growth in identity based politics which are commonly linked to the new social movements (NSMs) of the time. Archetypical uprisings included the US civil rights movement, the women's movement, peace movements, green movements, and gay and lesbian movements (Stammers, 2009). In Ireland, a politicised approach to community development emerged (Lee, 2003; Lloyd and Lloyd-Hughes, 2009). This was partly in response to perceived failures of more traditional efforts in tacking poverty, including efforts extended through the Trade Union Movement (Motherway, 2006: 11). Another active component was an influential second wave of feminism that was strong within the emerging community development movement (Connolly, 2001; 2014). Women's 
consciousness-raising groups contributed to, and also helped shape, a wide range of selfmanaged critically oriented groups who were dissatisfied with the status quo and were interested in bringing about systemic change (Crickley and Devlin, 1989; Kelleher and Whelan, 1992; Cullen, 1994). These groups were commonly banded together through shared funding streams, such as the Community Development Support Programme and EU initiatives like the New Opportunities for Women (NOW) measure. Community Sector organisations often worked closely with a second historical strand of local educational provision through State organised Vocational and Educational Committees (VECs). As will be detailed within chapter three, much public provision was instigated as a response to emergent community based movements for change. These included a justice based grassroots literacy movement (Brady, 2006) and demands for adult education programmes from below (Feehan, 1979).

Despite varying degrees of autonomy, the logic of neoliberalism has increasingly shaped community education, pushing it towards a more marketised agenda. Two mechanisms have eased this transition the first being the aforementioned public sector reform through New Public Management. A second influence is through Ireland's now stalled model of corporatism through social partnership, an important feature to consider given the involvement of the Community Sector within this process. Though interconnected in practice, each will now be considered in isolation.

\subsubsection{New Public Management and the prevailing logic of the market}

Although the introduction of New Public Management (NPM) in Irish contexts has been located within the 1990s (Lynch et al, 2012: 3), its origins pre-date this with Clarke and Newman (1997) tracking its emergence to UK based Thatcherite policies of the 1980s. Clarke and Newman (1997) describe NPM as the marketisation of the public sector. This is through devolved budgeting in a way that reframes funding arrangements through 
accountancy discourse. The implications of this are explained as a situation where, instead of being led by perceived inputs required to address public need, measurable outputs become the key determinant. These are deciphered through concepts of accountability and transparency in spending (Clarke and Newman, 1997). A consequence of this process is a redefinition of relationships between provider and user, with the latter now considered a consumer of business-led service provision. This metamorphosis claims to tame previously unwieldy bureaucratic organisations, making them more efficient and user-friendly. New Public Management is commonly implemented by addressing perceived duplication through rationalisation, increasing staff productivity through performance indicators, and improving standards by introducing competition across providers (Lynch et al, 2012). Following an initial period that cultivates supremacy of business approaches, Clarke and Newman (1997: 22) detail a more deliberate second phase. This is one of marketisation through privatisation involving outsourcing and increased charges for services. This undermines the concept of State subsidy for public services greatly altering public sector culture, both internally and externally. Rather than being led by social responsibility and public need, all spending becomes justifiable through economic prudence, ring-fenced within specific fiscal allocation.

Though Community Sector organisations are not part of the public sector, their heavy reliance on State funding have meant they have not been immune to the penetrable influence of NPM. Although recent reform is sometimes considered intrinsic to the effects of the recession of 2008, a more relevant starting point is 2002 and the shift of responsibility for the Community Development Support Programme (an amalgam of Community Development Projects and Family Resource Centres) into the newly founded Department of Community, Rural and Gealteacht Affairs ${ }^{7}$ (DCRGA). One year later, DCRGA announced a review of

\footnotetext{
${ }^{7}$ To this point the Community Development programme and the Family Resource Centre programme were managed within the Department of Social, Community and Family Affairs. The dismantling of this department
} 
departmental programmes and structures with a view to measuring effectiveness of services and supports as they impact local communities (Combat Poverty Agency, 2003: 2). Core tenets of NPM were included within its terms of reference namely examination of perceived duplication, increased transparency in expenditure and rationalisation of administrative overloads (Combat Poverty Agency, 2003: 7). The 2003 review period also instigated a parallel monitoring of work as previous three year funding cycles were replaced by annual reviews with corresponding work-plans now requiring endorsement by local government structures. Funder-funded relationships became characterised by a need to justify work in terms of value for money, quantified through service delivery, and not previously accepted objectives of building capacity, empowerment and social change (Bassett, 2007).

The influence of NPM can also be uncovered when considering public provision of community education, though relevant research has only become available more recently. Research by McGlynn (2012) which began in 2009 details the work of Community Education Facilitators (CEFs) as increasingly measured through outcomes approaches, most notably certified learning. This is despite the way in which State funded community education has traditionally accommodated both accredited and non-accredited work enabling practitioners to address a range of community needs. McGlynn (2012: 143-4) also details increasing demands for financial accountability deliberately set against performativity models.

Since the election of an openly right wing government in 2011, Lynch et al (2012) effectively demonstrate the way in which NPM practices within the education sector have significantly increased. This has affected both Community Sector and State providers alike. There has been a redesign of State provision through the 2013 non-negotiated merger of VECs and FÁS into 16 Education and Training Boards (ETBs). These now hold responsibility for public community education, managed within a new national authority called SOLAS (An tSeirbhís

split Community Development work from Family Resource work previously co-supported under the Community Development Support Programme. 
Oideachais Leanúnaigh agus Scileanna). In line with NPM sentiment, the creation of SOLAS was packaged as crucial in tidying up an unnecessarily disparate sector, and within 'the need for efficiency, effectiveness and value in the deployment of public funding' (SOLAS, 2014b: 6). SOLAS also parcels community education and its multiplicity of approaches within the umbrella concept of Further Education and Training (FET), the limiting implications of which will be discussed within chapter four.

Community Sector co-option through NPM has rapidly accelerated since the forced closure of the Community Development Programme in 2013. This previously independent programme was merged into Local Area Partnership companies (see section 4.5) and together these formed the since disbanded Local Community Development Programme (LCDP). Once again, the justification for this was presented within the language of NPM, with reform considered necessary in order to ease administrative burdens, streamline funding and reporting relationships, reduce duplication, and to create better access for service users (DECLG, 2012a: 3-8).

A move towards commodification has also been advanced as the work of the LCDP was put out to competitive tender through the Social Inclusion and Community Activation Programme (SICAP) introduced in 2014. In preparation for SICAP there was a trimming at the edges with potentially un-profitable avenues such as addiction supports, Traveller education, and other services for Travellers disproportionally affected by cuts (Harvey, 2013). The Community Workers Cooperative (CWC) objected to changes to the previously independent Community Development Programme claiming 'this opens up the possibility of the biggest social inclusion programme (the Local and Community Development Programme) being implemented on a commercial/for-profit basis' (CWC, 2014b: 4). Other Community Sector organisations such as Family Resource Centres (FRCs) and addiction supports have also been streamlined into State structures with the former instructed to take on 
a monitoring role as a condition of funding. For addiction supports, many of which were established by Community Sector organisations (see section 3.3.4), these have been consumed into the structures of the Health Service Executive (HSE). Following the usual touchstones of NPM, The National Drugs Strategy 2009-2016 (DCRGA, 2009) framed approaches to problem drug use through 'value for money' over a needs-based perspective, setting out key measurable performance indicators within which projects must comply.

\subsubsection{Neoliberalism by subterfuge: community education and social partnership}

When considering the role of the Community Sector in shaping Irish politics, Kirby and Murphy (2011: 35) assert that 'while their commitment to developing a more just society and a more participative society held much promise in the mid to late 1980s, this faded away as from the mid 1990s onwards they were drawn into a tight embrace by the state through the institutions of social partnership'. Again global contextualisation helps us understand events. Social partnership as an approach to liberal democracy was not an isolated model of decisionmaking but emerged as part of a world-wide trend in third way politics. Largely attributed to prominent sociologist Anthony Giddens, the third way claims a fusion of left and right wing political ideologies that harnesses the more extreme consequences of capitalism. Liberal democracy is reinvented as a 'movement of double democratization' (Giddens, 1998: 72) where civil society and government meet half way to agree the terms of social management. Ireland's domestic model of social partnership principally involved an initial ensemble of State, employer, and farmer representative organisations. The first partnership agreement $A$ Programme for National Recovery was signed in 1987 and was broadly welcomed. The initial partnership period was more sedate than the turbulent times preceding it as Trade Union endorsed strike action dissipated, and a seemingly more humane approach to capitalism gathered momentum. After a period of considerable lobbying (Larraghy, 2006) the original 'pillars' of State, employers and farmers were joined by a Community Pillar in 
1997. This was an amalgam of self-appointed Community Sector leaders, along with other chosen Non-governmental organisations (NGOs). Supporters claim the Community Pillar (along with the Trade Union movement) ensured a re-negotiation of power thereby ensuring justice and equality were key components of National Partnership agreements (Nye, 2001: 192; Hardiman, 2002: 11; Fahey et al, 2007: 5; Larraghy, 2014).

The consensus model embedded within partnership became a key feature of Ireland's social, political and cultural landscape for over 20 years and also profoundly shaped the Community Sector at local level. This was through an EU led re-negotiation of State-civil society relationships as European grant aid enabled the creation of locally based partnership structures (Harvey, 1994). As will be further explored within chapter four, these partnership structures were to become important players in the subsequent realignment process some years later. Harvey (1994) details how local partnership arrangements were again broadly welcomed for their interpretation of poverty that included rights, benefits and opportunities, and for their insistence on partnership between public and civil society organisations. An initial 12 Local Area Partnership companies (LAPs) were established as part of a pilot programme and were tasked with addressing stubbornly high unemployment in targeted areas, promoting entrepreneurialism and business start-ups, and supporting existing community development work (Walsh et al, 1998; Teague and Murphy, 2004: 5). This was expanded to 38 LAPs in 1994 and, by 1998, over 150 partnership structures were up and running. Funding was provided along two tracks, the rural LEADER programme linked to the EU Rural Development Programme, and a domestic urban based programme set out to replicate national partnership at local level ${ }^{8}$. Many partnership companies became involved in provision of education and training by forging close working relationships with both FÁS and existing Community Sector organisations.

\footnotetext{
${ }^{8}$ For further information on the Leader programme as part of the EU Rural Development programme see http://www.environ.ie/en/Community/RuralDevelopment/EURuralDevelopment/ [accessed December, 2014].
} 
In 2002, a State commissioned national review of the Community Development Programme described social partnership structures as the space where Community Sector presence was 'most evident widespread and sustained' (Nexus, 2002: 46). The difficulty with this involvement and with social partnership more broadly, is that it didn't tame capitalism. Instead social partnership offered an illusion of compromise and shared decision making that concealed a transfer of wealth from the lower tiers of society to the top (O'Hearn, 1998; Douthwaite, 1999, 292-4; Allen, 2000; 2003; 2007; Kirby, 2002; Coulter, 2003). Allen (2000: 14) demonstrates how it was our first social partnership agreement that introduced three key features of neoliberalism namely cuts in public spending, tax breaks for private enterprise, and the curbing of trade union activity and power. In reality there was only a surface embracement of civil society with those directly involved at national level describing negotiations as unproductive and as delivering only tokenistic gains (Murphy, 2002; Meade, 2005; Stafford, 2011). Stafford (2011:78) reveals how those inside both the Community Pillar and the Trade Union Movement experienced involvement as 'merely a box-ticking exercise' and not the space for meaningful grassroots engagement they had hoped it would be. There was also an incremental weakening of any limited influence the Community Pillar might have at first held. Where refusal to sign off on certain policies forced minimal concessions during early negotiations, this changed in 2002 when rejection of aspects of the national agreement Sustaining Progress resulted in the expulsion of objectors from the process (Larraghy, 2006: 395-6). Those outside of direct involvement also raised concerns about the un-mandated nature of representation (Broaderick, 2002: 13) and its detraction from grass-roots activism (Lee, 2003: 55). There was also ongoing commentary within community development academic literature that argued partnership represented the infusion of neoliberal ideology, protecting the interests of the rich, whilst simultaneously muzzling resistance from the Community Sector (Ó’ Cinnéide, 1998/9; Collins, 2002; Meade and 
O’Donovan, 2002; Powell and Geoghegan, 2004: 241). Other Community Sector tensions also emerged through reports of division between those inside and those outside the partnership process with some on the outside believing those involved were compromised (Crowley, 2013: 152).

Whilst Lloyd (2010: 50) interprets Local Area Partnerships as having an interest in seeking representation as part of their attempts to 'engage with and collectivise those experiencing social exclusion', their formation and ongoing relationships with communities have raised many questions about their democratic legitimacy (Sabel, 1996; Crowley, 1998; Walsh, 1996a; 1996b; Walsh et al, 1998; Zappone, 1998). In a review carried out on behalf of the Combat Poverty Agency, Walsh et al (1998: xv) cite concerns about how decisions made by Local Partnership Companies were commonly dictated by central government. They also express apprehension about poor, if any, structures of public accountability and of a lack of uniformity in coordinating relationships between LAPs and the communities in question. The review also emphasises haphazard relationships with local and national policy makers and hugely varying management practices across different community settings (Walsh et al, 1998).

Despite the way in which involvement in social partnership commonly demonstrated power over rather than power with (Somers and Bradford, 2006) the community organisations involved, many of those inside the Community Sector continued to support ongoing involvement within its structures. One explanation that has been put forward links Community Sector behaviour to what Stafford (2011) describes as the political establishment's 'way of doing business' at the time. This refers to how consensus was reached by offering enough monetary incentive to guarantee partners toe the line with the alternative being financial penalties should they disengage (Stafford, 2011). 
Coinciding with Troika involvement in domestic financial management, social partnership effectively collapsed in 2009. The Community Sector which has emerged is profoundly different than that which entered with a review of government expenditure measuring funding cuts to the Community Sector as significantly disproportionate to other publicly funding entities (Harvey, 2012). The impact of these cuts is demonstrated by O'Byrne (2012: 22) when she quotes one Community Development Project (CDP) coordinator describing 'the heavy boot of the state on their neck through the use of economic violence'. Realignment has also removed many local management structures centralising control within NPM influenced State structures. In contemplating the de-politicisation of practice, O'Byrne (2012: 14) describes community development as 'in crisis' believing it has been de-radicalised and that its social change ethos has been compromised. Although not apportioning all blame to governmental actions, she concludes,

It [the State] has removed local management groups of CDPs; it has removed their support agencies; it has introduced managerial practices; and it has failed to understand the nature of community development. What seems certain, however, is that government has detected the growing power of CDPs, and that the demise of community development in Ireland may be due to, more than anything, a perverse response by the state to a growing political influence in the process. (O'Byrne, 2012: 34)

\subsection{Interrupting the narrative: pockets of difference and resistance to change}

Any suggestion of a neoliberal turn should also incorporate documentation of its opposition. Alongside perpetual militarisation and war, increasing income inequality, public sector shrinkage, and co-option of much civil society infrastructure, perpetual protest has also arisen. The 1999 Battle in Seattle remains a noteworthy international example given its convergence of anti-globalisation movements including many community-based organisations worldwide. During the 2000s, the World Bank and IMF were regularly accompanied by anti-globalisation protesters dissatisfied with international trade and tariff arrangements, but also with the banking system itself (Žižek, 2009: 9; Birch and Mykhnenko, 
2010: 256). In 2011, the Occupy Movement popularised discussion on $99 \%$ versus $1 \%$ income distribution rates raising awareness about the starkness of disparity. The Irish based Occupy movement partnered with the oppositional Community Sector movement The Spectacle of Defiance and Hope, linking cuts being imposed on community organisations with wider social disparity (Fitzsimons, 2012: 38). In the current decade there have been mass mobilisations against austerity in Greece, Spain and many Latin American countries, accounts of which are sporadic in the mainstream corporatised media but readily available across on-line journalistic sites. In 2014 there was a domestic outpouring of dissatisfaction when up to 100,000 people marched against the introduction of domestic water charges (The Irish Times, October $\left.11^{\text {th }}, 2014\right)$, linking the water charge to a wider concern with austerity.

Reactions to adversarial movements from second-wave neoliberal politicians have been swift and decisive as political leaders turn to the coercive wing of the State and their relationship with the conventional journalistic press to keep such forces in check (Steger and Roy, 2010: 121). Although occasional victories are enjoyed, the impact of mass mobilisation has been diminished with key historical turning points including the disregard of globally synchronised opposition to the invasion of Iraq in 2003. This undoubtedly gave confidence to neoliberal governments enabling them to push through further unpopular measures. A further quashing of opposition has been the continuous attrition of trade unionism. As well as co-option through corporatism (Allen, 2003; Coakley, 2012) this has been advanced through hard-line political tactics and media portrayals of strikers as deviant and often largely to blame for national problems (Philo et al, 1995). This is alongside little reporting of the erosion of working conditions that commonly lead to industrial action in the first place.

\subsubsection{Community Sector resistance}

There has also been some Community Sector opposition. The aforementioned Spectacle of Defiance and Hope, a broad based alliance of community organisations, artists and trade 
unionists, is committed to creative resistance to Community Sector cuts and wider economic injustice. Its actions to date have not only culminated in the mobilisation of 2,000-3,000 community members and workers, in colourful street protests, but in a Freirean influenced process of conscientisation, initiated through a programme of community education to raise political awareness (Fitzsimons 2012: 38). They have also produced photographic exhibitions of community members sharing grievances and hopes, and a stage performance 'Songs of Grievance and Hope' performed by community workers and local unpaid activists outlining the impact of cuts to the sector ${ }^{9}$. A second collaboration between the Community Sector and trade unionism, the Communities against Cuts Campaign has also mobilised support, most significantly through a rally of 12,000 people opposing cuts to the Community Sector in 2009. In February 2015, a rally in opposition to SICAP saw Communities against Cuts and The Spectacle of Defiance and Hope joined forces with their demonstration attracting national media attention (The Irish Times, February $28^{\text {th }}, 2015$ ). Additionally the Irish Congress of Trade Unions has convened assemblies for workers, spaces where community workers can share information, validate experiences, and organise responses to the challenges faced by the Sector ${ }^{10}$.

\subsubsection{Cracks in capitalism}

As has been already argued, the growth of neoliberalism has been accompanied by perpetual protest. There has also been many acts of individualised and collective rebellion as well as the emergence of alternative forms of social relations, some born out of survival in negotiating the conditions of neoliberalism (Holloway, 2010). Within his contribution Crack Capitalism, Holloway (2010: 72) suggests there is 'not only a logic of capitalism but an antilogic of humanity, of refusal, of movement in-against-and-beyond capital' and he cites

\footnotetext{
${ }^{9}$ Further information about the Spectacle of Defiance and Hope can be found at www.aspectacleofdefianceandhope.ie

${ }^{10}$ Further information on this initiative is available at http://siptucommunity.blogspot.ie/2013/11/communitysector-assembly.html [accessed, July, 2014]
} 
increasing examples of miss-fitting elements. Holloway (2010) sees limitations to protest claiming it is a reactionary activity that allows neoliberals to continue determining the agenda. Saad- Filho (2013) also notes difficulties with mass mobilisations though he does draw out some benefits. He names these as collective expressions of frustrations, vocalisation of political dissatisfaction, and the way in which spontaneous protest can highlight atrophy within both media outlets and trade unionism. Saad-Filho (2013: 664) also warns that protest can be 'destabilising without being constructive' and can sometimes result in an extension of power by the political right.

\subsection{Exploring the purpose and practice of community education}

In determining what we can do, Holloway (2010) repeatedly suggests an expansion and linking of alternatives, or what he suggests are cracks that exist within capitalist society. This notion of working within the cracks, or the crevices, has been previously explored within writings on community education (Thompson, 2007). Additionally, much influential theorising has been born out of significant struggle, for example Freire (1972) and hooks (1994). In negotiating current social relations, adult and community educators have also been encouraged to reflect on the neoliberal circumstances within which they work and to consider how these shape power relationships (Finnegan, 2008; Brookfield and Holst, 2011). At the heart of such assertions are ongoing interpretations of community education as counterhegemonic, not only capable of challenging the premise that there is no alternative to neoliberal global capitalism, but of advancing alternative notions of society through praxis.

It is hoped that as this study maps a landscape of practice and practitioners including detail on key philosophical influences, we can better explore the purpose of community education from a more complete foundational understanding. In explaining how this will be undertaken, an overview of the structure of the thesis will now be provided. 


\subsubsection{Thesis organisation}

Following this introductory chapter, chapter two details the methodological blueprint that shapes the inquiry. This locates the research as influenced by critical realism as well as feminist standpoint epistemology. It discusses ontological-epistemological relationships further exploring assumptions about the social world and human interactions within this. It offers a continuum from positivism to anti/post positivism and supports less dichotomised interpretations of research methodology.

Chapter three presents an account of community education in Ireland. It offers a framework for interpreting community education through universal, compensatory and radical lines of inquiry (Martin, 1987), each of which is located within Community Sector and State provider alike. A historical account draws out the influence of the intersecting women's movement, liberation theology, and community development movement, each presented amidst wider international contexts. Concerned by rose-tinted interpretations of an ostensibly positive and united Community Sector, this façade is challenged through examination of heterogeneous, often competing influences within. Chapter three also addresses relationships between insider and outsider community educators; the former being those living and working within the communities in question, the latter those whose relationships with communities are largely occupational.

Chapter four focuses on relevant education policy and considers its significance through bottom-up attempts at influencing government direction. It also considers top-down implementation of European Union (EU) labour market activation measures. New Public Management is again evoked as an optic through which we can better understand changes to community education that include vocationalisation and co-option of practice. The expressions 'lifelong learning' and 'human capital' are especially scrutinised in the context of their infiltration into educational discourse. 
Chapter five locates debate within the realm of the accreditation of learning, a core theme to emerge within the research findings. It begins with interpretations of accreditation and details early demands for its introduction from practitioners. It then explores how Irish accreditation systems have evolved. It problematises core concepts of national frameworks, outcomes approaches and quality assurance before detailing existing research relating to the accreditation of learning in community contexts. It cautiously expresses the possibility that community educators themselves unnecessarily limit possibilities associated with the formal validation of learning.

Given the centrality of critical education within the research topic, chapter six discusses this theoretical framework. It offers a critique of the contributions of Paulo Freire, welcoming aspects of his work whilst challenging other features most notably the patriarchal nature of his writings, a patriarchy that can at times more broadly extend to the field of critical pedagogy. It provides a more complete account of what community education ought to look like if perceived through a Freirean lens. This includes discussion on group-work as an approach to community education.

Before presenting the core feature of this research - the voices of practitioners involved, chapter seven provides further explanation of the decisions to adopt a mixed-methods approach and presents a research design. It details participant selection and recruitment, data generation, and data analysis techniques employed. It also relays ethical considerations, sharing how those participating were protected throughout.

Chapters eight, nine and ten are reserved for the reporting of findings, each relevant to a different stage of the research process. Chapter seven shares insights from a first phase of one-to-one interviewing, chapter eight reports on an embedded survey questionnaire whilst 
chapter nine thematically reports on a final phase of focus-groups and telephone interviews. Each chapter is concluded with a summary of the core themes to emerge.

Chapter eleven offers an integrated analysis drawn from the three phases of data collection. These are considered amidst theoretical insights and literature reviewed. A key purpose of this penultimate chapter is to address the first two research ambitions as detailed within section 1.2.3. These are a mapping of practitioners and practice, and consideration for neoliberal incursion within. This includes reporting on relationships with the academy, an unanticipated finding to emerge, as well as a summary of the brunt of NPM. It also emphasises how practitioners have negotiated State-civil society relationships from within community education.

Chapter twelve, re-kindling community education, draws the threads of inquiry together. It begins by problematising contemporary practice including emphasis on the limitations of person-centered approaches, and the pitfalls of the uncritical adoption of Further Education certification within practice. Through expansion of research participant proposals on future direction, it discusses specific suggestions that might assist community educators when considering their work.

\subsubsection{Consistency of language amidst community education restructuring}

Notwithstanding the political significance of language in appropriating philosophical stances (Murray, 2014), deciphering the quagmire of terminology within community education is an additional challenge when presenting work in this area. Not only are we swimming in a sea of acronyms (typified by the list provided on page 11), it is not uncommon for seemingly different terms to be used interchangeably by some, and rejected by others. The expressions 'community' and 'education' will be deconstructed within the text to enable the reader to grasp my meaning of these. Other terms I have used interchangeably, applying sameness to 
'State provision' and 'public provision'. 'Critical education' and 'critical pedagogy' are also used interchangeably and I most commonly use the former given its greater accessibility for readers. Broadly speaking these latter terms are used to describe an approach to education that interprets the social realm as distorted by unequal power-relationships. In essence, critical education challenges compliance with capitalist norms and argues unquestioned conformity augments oppression. Popular education, a concept within critical education and that which is often aligned with radical community education will also appear. Its meaning and relevance are unpicked within chapter six. My decision not to wholly adopt the expression 'popular education' when discussing radical practice is influenced by its more common adoption in other locations (notably Scotland and Latin America) with some participants in this study more readily associating it within these jurisdictions. Another expression to repeatedly appear is 'co-option'. I interpret co-option as the suggestion that the neoliberal State has appropriated a particular phenomenon for its own use.

It is also important to draw the reader's attention to the use of 'Community Sector' and 'Community and Voluntary Sector (CVS)', terms I propose refer to the same entity, an amalgam of organisations that incorporate paid and unpaid community workers and activists. Whilst State policy encourages adoption of 'Community and Voluntary Sector', describing this as an entity where many organisations combine features of volunteerism and paid work (Government of Ireland, 2000: 16), I prefer 'Community Sector' largely due to the forced disbandment of voluntary management structures as part of State led realignment (further discussed in chapter four). At times the reader will see CVS used where this expression is preferred by a research participant or adopted within secondary sources.

Given the extent of change for community education during the lifetime of this study, further clarification is also required. This is because previously established organisations, namely 
Vocational Educational Committees (VECs), FÁS, Local Area Partnerships (LAPs), and Community Development Projects (CDPs) all ceased to exist in the lifetime of this research. As a result of these changes, VECs in particular are frequently referred to by research participants, with reference to their successor, Education and Training Boards (ETBs) elsewhere in the text. This can also be said for FÁS, now too consumed into ETB structures. Because of these changes, readers will at times come across the expression VEC, at other times encountering ETB, depending on the different stages of the research project. These changes represent more than simply a name-change as they incorporate significant structural realignment that has occurred. Similar difficulty arises with the newly formed, and now disbanded, Local and Community Development Programme (LCDP). This again does not just signify a name-change from previous LAPs but represents an immense re-shaping of a core component at the heart of the Community Sector. When reporting on findings, voices are represented as emanating from LCDP staff, with the origins of their organisational roots (potentially through independent Community Development Projects or State established LAPs) not always evident. These differing historical roots are discussed within chapter three. The language of accreditation has also changed with FETAC and HETAC ${ }^{11}$ merging into Quality and Qualifications Ireland (QQI) during the lifetime of the research. When participants were contributing they tended to refer to FETAC which has now been disbanded, an explanation of which is contained within the study.

\subsubsection{A limitation of the study}

A significant limitation of the study is the absence of voices of those engaging in community education. This means assumptions are made on the shape of practice without consultation with the communities it purports to support, and, at times, represent. To further demonstrate this limitation, few involved in critical education would disagree that diverging accounts of

\footnotetext{
${ }^{11}$ The Further Education and Training Council (FETAC), and Higher Education and Training Council (HETAC) respectively
} 
school education seem likely whether one relays events through the lens of teacher experience, or student experience. There are, of course, other limitations to the study which will be drawn out throughout the text.

\subsection{Summary of chapter}

This introductory chapter has positioned the research within an epoch of reshuffling capitalism towards laissez-faire economics that is propped up by concepts of individualism and personal responsibility. This process encourages a disregard for collective conscience and accountability. The chapter introduced common interpretations of community education offering a brief contextualising history of its emergence and an account of change through New Public Management and models of Social Partnership. Alongside the suggestion that there is a neoliberal logic carried as common sense, an 'anti-logic of humanity' (Holloway, 2010: 72) is also proposed where on many occasions people act against neoliberalism. The purpose of this study is to contextualise community educator experiences and insights within these socio-economic circumstances and I have summarised this purpose into three primary objectives. These are to expand knowledge on practitioners and practice, to explore the impacts of neoliberalism, and to investigate ways in which a critical approach can further inform egalitarian ambition. I will now turn my attention towards further uncovering methodological intent. 


\section{Chapter Two: Critical Realism, Feminism and the shaping of the study}

"Ally. I'll add it to the list of words I use to try to figure you out. The problem is, I can't tell what's real anymore, and what's made up."

Peeta Mellark - Mockingjay (book three of The Hunger Games series of books by Suzanne Collins, 2010). 


\subsection{Introduction to Chapter: why research?}

My first formal introduction to $\mathrm{PhD}$ studies was at an induction day for new entrants undertaking doctoral studies at Maynooth University back in 2011. On arrival, the 80 or so of us were asked to complete a 'graduate entry survey'. This probed into previous studies, obstacles and challenges we anticipated (such as financial and time constraints), and other questions the researchers hoped would provide insight to the thoughts of this disparate bunch. Heightened by our own future intentions to reel in research participants, I imagine that return rates were high. What interested me about this process was a question concerning 'primary motivation' for undertaking research in the first place. As I scanned the suggested answers I was intrigued by the individualist options, five of which directly referred to career advancement, with outliers citing 'for love of the subject' and, 'as a result of unemployment'. Certainly I love teaching and exploring adult and community education, it would also be disingenuous to suggest academic advancement wouldn't be a welcome by-product. However I found myself ticking the 'other' box perplexed for a moment by the absence of my desired option; a hope that in some way my research might enhance understanding of community education and potentially influence change. Ignoring a nagging "who do you think you are' internal narrative, I scribbled down my answer before submitting the completed form on my way out the door.

\subsubsection{What is there to know?}

I have pondered this experience since, as I reflect on the purpose of both education and research. What specifically intrigues me is the way in which personal progression, usually involving vocational mobility aspirations, is predominantly presented as the only legitimate reason for all educational encounters. I have also thought about other dominant influences in our understanding of reality. One such assumption many of us take for granted is that something is true, if an 'expert' has seen it, measured it and written it up for us to consume. 
This sense of how things are comes from a variety of sources such as scientific dalliances at school, perpetual media presentations of social research as fact, and vocational exposures to commonly unchallenged paradigms, in my experience the medical model through a previous career as a nurse. In more recent years, my own assumptions have fundamentally shifted as I formulate ways of knowing, testing schematic shifts through my practice as a community educator, as temporary staff member within a university, and in other areas in my life.

This chapter tries to capture how I currently construe reality, my ontology, or interpretation of the social world, my epistemology, or understanding of how knowledge is generated, and my axiology, or value judgments, as I perceive them to influence this research. These terms are not mutually exclusive, rather the opposite is the case and at times I struggle to prize them apart. Here I will attempt to do this, laying bare assumptions in order to demonstrate their influence at all levels of inquiry namely choice of research topic, approach to documentary analysis, decisions on theoretical framework, ethical considerations, methods of data generation and analytic procedures.

\subsection{Ontological-epistemological conversations}

Drawing out my research identity has been more challenging than I originally anticipated, perhaps an indication of my own paradigmic shifts throughout the work. Research can be transformative in nature and a useful way to conceive of its relationships with community education is through the premise of really useful research. To me this means approaching studies such as this as a way in which we can advance the equality principles that underpin much community education. The methodological influences I most prominently carry into the study are both critical realism and feminist research, both of which will be explained within this chapter. I agree with Linda Connolly (2002: xiv) when she identifies how 'feminism is both a theoretical paradigm that has a valid place in any general academic 
interpretation of Irish society and a tangible and real form of politics with an observable history and trajectory in the social construction of contemporary societies' (italics in original).

There are sometimes anomalies in the way in which research terms are depicted within the social sciences. This is somewhat unsurprising given the depth of discussion on concepts of research paradigms in and of themselves (Oakley, 1999; Guba and Lincoln, 2005; Green and Hall, 2010; Hug, 2010; Mertens, 2012). At their broadest, research paradigms are often presented as opposites of each other, a situation historically demonstrated through presentations of positivism and post and/or anti-positivism. Generally thought to have originated with the ideas of Auguste Comte, the essence of positivism is that a 'real world' exists independent of how each of us experiences it. Understanding this reality is through scientific research on bite size pieces that, when put together, enable a better understanding of its totality. To do this requires certain research standards, most importantly 'objectivity', but also the application of such scientific conditions as controls, standardisation and preestablished hypotheses to test. Post-positivist, anti-positivist or non-positivist perspectives that emerged in the 1960s challenged the legitimacy of such propositions, offering an axiology that dismisses value-free social research, believing it to be value-laden instead. Much discussion at the time poured scorn over positivism as debates in academic journals were (and often still are) characterised by each identity's opposition to the other (Oakley, 1999; Valsiner, 2000). Some contributors further differentiate an interpretive, poststructuralist paradigm. This is set aside from positivist and post-positivist tendencies, both of which are posited as relying on a determination of some form of truth (Denzin and Lincoln, 2005: 11-12). Broadly speaking, and acknowledging simplicity in my assertion, interpretivism proposes that all truth is subjective, and all knowledge constructed. 
The difficulty across much literature is that the methods commonly associated with a particular paradigm can be interpreted as evidence of the philosophical and paradigmic undercurrents being applied. This means positivism is viewed as quantitative research, and post-positivism as qualitative research. One case in point can be drawn out when Denzin and Lincoln state,

Qualitative researchers stress the socially constructed nature of reality, the intimate relationships between the researcher and what is studied, and the situational constraints that shape inquiry. Such researchers emphasize the value-laden nature of inquiry....In contrast, quantitative studies emphasize the measurement and analysis of causal relationships between variables, not processes. Proponents of such studies claim that their work is done from within a value-free framework. (Denzin and Lincoln, 2005: 10)

There is some truth in what they say. Quantitative research, by and large, relies on certain laws of probability to draw generalities from representative samples, often proposing hypotheses from which generalities are drawn. These are then presented to an audience as the way things are. There are also discrepancies in Denzin and Lincoln's explanation. De Vaus (2002: 5), for example, is unhappy with such 'sterile and unimaginative' presentations of quantitative research, a method that doesn't preclude a researcher from either revealing their values, or carrying constructivist characteristics. Such dichotomising also negates the way in which the use of qualitative methods in the same study as quantitative methods can enable subjectivism to be centralized without completely forgoing objectivity. However, suggestions of a complete ontological-epistemological collapse, as is sometimes proposed (Guba and Lincoln, 2005: 203), are important to counter, the reasons for which will be detailed below.

\subsubsection{The fallibility of critical realism}

Though sometimes considered identical, critical realism differs from traditional descriptions of realism where empirical accounts are committed to 'the existence of some disputed kind of being (e.g. material objects, universals, causal laws; propositions, numbers, probabilities; 
efficacious reasons, social structures, moral facts)' (Bhaskar cited in May, 2001:12, brackets in original). Critical realism offers a dualistic approach where systems, whilst culturally embedded in the life-world, can also be differentiated from an individual's experience of them (Archer, 1995; Sayer, 2000a; 2000b; Zachariadis et al, 2013). This does not completely dismiss interpretivism as reality is viewed through each person's outlook. Critical realism is a belief we can retain ontological realism, in other words the belief that a real world exists, outside of our perceptions and constructions of it. It also accepts epistemological relativism therefore that our understanding is socially constructed through our own perspective and standpoint (Maxwell, 2012: 5). Resonance with constructivism is therefore located through recognition of relativity of meaning; knowledge is both scaffolded and interpreted relative to circumstances and experiences. This clearly doesn't dismiss subjectivism, but interprets it as reflective of the systems within which experiences are formed; subjectivism therefore uncovers the apparatuses, or structural mechanisms, that give rise to these events in the first place.

Critical realism is committed to ontological and epistemological fallibility. Sayer (2000a: 2) explains this when he details how we must be "wary of simple correspondences concepts of truth', acknowledging instead that 'the world can only be known under particular descriptions in terms of available discourses, though it does not follow from this that no description or explanation is better than the other'. Critical realism thus offers a mid-point between positivism and interpretivism and one that sets out to validate social arrangements whilst centralising experiences, a balancing act that 'claims to be able to combine and reconcile ontological realism, epistemological relativism and judgemental rationality' (Bhaskar, 1998: xi, italics in original). Critical realism differs from instrumentalism through its infusion of theoretical deliberation that enables an interpretation of data as more than observational, but as properties of a real world (Maxwell, 2012: 8). Maxwell (2012: 8) 
further explains how meanings and intentions, though not observable, are considered part of the real world, conceptualised through different concepts and frameworks. This is something often denied by both positivists and constructivists.

The challenge for researchers adopting such a position, is to move beyond the study of everyday social conversations and interactions so they can examine the underlying mechanisms that create social circumstances in the first place (May, 2001: 12; Parr, 2015). This methodological position carries a strong commitment to social justice as well as acknowledging the transformative nature of research. Critical realism exposes the structural nature of oppression that determines which communities are disadvantaged and encourages us to take action to address this situation.

There has been criticism of critical realism. Drawing particularly on the writings of Bhaskar, Cruikshank (2004) describes critical realists as 'engaged in a hegemonic project which seeks conceptually to re-tool the natural and social science' and is sceptical about its dual ontology, a fallible interpretation of reality and a conclusive belief in reality beyond knowledge claims. Cruikshank's claim could surely be applied to all paradigmic assumptions as social researchers make explicit their inner assumptions, claiming superiority in their own version of how things are. Denzin and Lincoln (2005), who identify themselves as critical theorists, are also critical. They rather dismissively 'reject much of what the critical realists advocate', perceiving it as another 'ism' that will not 'keep the social science afloat' accusing it of a distraction from existing social justice ambitions already embedded in qualitative research (Denzin and Lincoln, 2005: 13). Denzin and Lincoln (2005: 9) are equally dismissive of mixed-methods research claiming they presume a methodological hierarchy of quantitative over qualitative, and take qualitative methods 'out of their natural home' within an interpretivist framework. Moreover, Roberts (1999) objects to critical realism's dualistic approach and epistemological vagueness believing these characteristics 
undermine the monistic nature of Marxism, a concept he believes requires little modification.

\subsubsection{What is going on out there?}

In claiming that there is a non-Marxist overture within critical realism, Roberts (1999) touches an ideological nerve given my own commitment to much Marxist theory. This is through my belief that there is disproportionate ownership of the means of production, a situation that manifests itself in a stratified, antagonistic class system. I also interpret the State as a partisan entity perpetually taking sides with capitalist interests thereby facilitating economic injustice and not a transcendental reflection of civil society (Marx, 1932/1996: 12). I don't agree that modernity heralded an expanded middle-class characterised by white-collar employment, home ownership, and the adoption of certain social cultures or values leaving a minority working-class; protected from abject poverty by welfare provision and entrepreneurial job creation elsewhere. As demonstrated within chapter one, our current epoch of neoliberalism has deepened capitalism and perpetuated by class divisions by worsening living standards for those once considered middle-class (Giroux and Giroux, 2006: 22-23) and proportionately increasing inequality.

I am also somewhat uneasy about such power-laden presentations of reality that are absolute about class divisions the 'resolution of which must be objectively verifiable' (Freire, 1972: 32, italics in original). However, drawing from my own life, a liminal position between classes which has been brought about through family relationships, and my experiences as a community educator, I am in regular contact with the lives of those considered oppressor and of those allegedly oppressed. As I intersect with both, I am continually jolted by the exploitative depth of social divisions, both through capital, and the consumerist driven hegemonic logic that supports social separations. 
Notwithstanding my realist predispositions, I have difficulty accepting some tenets of Marxism, most notably the absoluteness of its grand narrative, a more accurate description being grand analyses as proposed by Sayer (2000a: 5). Marx helps us conceive of the centrality of social structures in maintaining injustice, but positions all social relationships as a reflection of circumstances within our economic laboured conditions (Marx, 1977: 164). Blind support of this would suggest the only way in which community education can be socially transformative is by encouraging work-place politicisation and organisation. Instead we should be critical of such oversimplifications of the social realm that fail to account for oppression along gendered, racial and other oppressive forces as well as consideration for the complexities through which identities are formed. Sayer's words are useful in conceiving of the limitations of Marx's position when he shares,

Realism, as a philosophy, does not provide any warrant for putting class and production at the center of social explanation, for that is a substantive, not a philosophical question. But it does support the view that some structures (mechanisms, objects or whatever we care to call them) are more important than others in shaping particular outcomes. This doesn't justify assuming a single centre: rather it simply supports the unexceptional idea that what is central or most important depends on what objects we are dealing with and what we are trying to explain. (Sayer, 2000a: 74)

Gramsci's (1971) more complex development of relationships between economics and the social realm into a tangible concept of hegemony is a more palatable theoretical explanation. His proposal of a concurrent politicisation, and action, on civil society through simultaneous wars of position and maneuver (Gramsci, 1971: 238) hold currency with many critical educators. Though more comprehensive in exploring the social realm, Gramsci (1994: 249254) shared Marx's commitment to a united approach between Trade Unions and revolutionary politicians as the singular locus for change.

A related problem within Marxism is an ultimate location of power with the economic base as the determining attribute in social characteristics, with the superstructure retaining only relative autonomy (Olssen, 2004; 555-556). One way in which this limitation can be 
reconciled is through a more complex interpretation of power as evoked by drawing aspects of Foucauldian thinking. Foucault, though conceiving of power as manifold, helps us comprehend the power of discourse in upholding what is considered truth (Foucault, 1980). In using this aspect of Foucault's comprehensive contribution I am not abandoning critical realism, rather acknowledgement that some elements of post-modernism, in this instance the nature of power through discourse, may be valid (Sayer, 2000a: 30). Power through discourse acknowledges the changing technological nature of our social systems, where there is a countenancing of our economic base, without interpreting it as the totalising factor (Olssen, 2004). Power at the extremities of society, at 'those points where it becomes capillary' becomes invested within institutions, embodied within techniques, and an instrument through which material intervention can be led (Foucault, 1980: 96).

The incorporation of Foucauldian logic alongside contributions from Marx and Gramsci offer a critical realist approach that better incorporates the intersectional nature of oppression, and that acknowledges the non-absoluteness of any one theory given the fallibility of each. However there remains a fundamental difficulty with reliance on these theories, given their ethnocentric nature, and inherent sexism within. This difficulty will now be discussed through the incorporation of feminism.

\subsection{Critical realism and feminist standpoint epistemology}

Although I am too young to remember the resurgent feminist movement in the 1960s, I can clearly recall the impact of reading Betty Freidan's The Feminine Mystique some years later, a book I accidentally happened upon in a second-hand charity shop. This insight into the depth of thinking behind liberal second-wave feminism ignited my interest in the movement. It helped me challenge the alleged passivity of women as their histories and positions were determined within a patriarchal system with women cast as 'other'. Second-wave feminism 
made the personal political expanding the meaning of injustice to incorporate discrimination within the family, cultural traditions, civil society, and everyday life (Fraser, 2009).

It interests me now that even on studying this movement in depth the impacts of patriarchy didn't fully resonate until more recently. I believed in the oppression of women but interpreted it as something that happened to other women 'out there'. I now reflect on my gender identity having experienced maternity, the alleged choices I made to prioritise handson parenting, and the challenges of forging a career. This leads me to a more conscious consideration of my childhood gendering at home and at school, both of which shaped by occupational identity through an early career as a nurse. Being a mother also impacted my identity as an adult and community educator as I became invisible for long periods of time, playing catch-up on return, whilst others progressed without interruption. I have also become more aware of the continual, often unspoken, difficulties of womanhood in a patriarchal, capitalist society. These include conformity to an idealised body-shape, segregation in top flight sports and the continued dominance of masculine ways of knowing as the norm.

\subsubsection{Working as a feminist researcher}

Feminism, whilst synonymous with much community education because of its focus on group based consciousness-raising, is not a homogenous movement. Such theoretical distinctions as radical, separatist, lesbian, Marxist, liberal, cultural and ecofeminism are well documented and have been influential in their own right within community education. It seems likely that many women, including myself, draw elements from across theoretical catagorisations encouraging unity through sisterhood rather than divisions within. However, there are important distinctions that influence the way in which I approach this research. One such consideration is the notion arising from some feminist quarters that, allowing for variances within, most gender traits are fixed. This essentialist approach is a particular 
feature of third-wave feminism's promotion of individualistic choice agendas that often include a celebration of sexual commodification (Heilmann, 2011). The idea that women carry free choice is preserved through a post-modern constructivist hypothesis that allows a disassociation between alleged Western sexual liberty, and such global phenomena as rising sexual exploitation of women and girls (UN-GIFT, 2009), physical and/or sexual violence by an intimate partner as high as $71 \%$ in some global regions (Garcia-Moreno et al, 2006), and the commodification of 'female sexual dysfunction' to the benefit of the global pharmaceutical industry (Fishman, 2004). Third-wave feminism can be interpreted as a regression of some of the epistemological gains of feminism, enabled through an oppositional masculine re-assertion of more fundamentalist views (Klinger, 1998; Thompson, 2001). As Thompson explains,

There is no third-wave feminism - feminism at present is a classification and holding onto the insights and gains of the Women's Liberation Movement in the face of the male supremacist backlash and of those co-optations and repercussions which penetrate (pun intended) the very body of feminism itself. (Thompson, 2001: 2)

By challenging essentialism, I am proposing many gendered life-choices, such as adopting a caring role and wearing makeup for women, and competition, risk taking and working long hours (outside of the home) for men, have emerged from familial social structures. It is true more women are participating within paid employment however these are concentrated in particular occupational realms notably within caring and educational professions (Ridell and Tett, 2010). Community education is also a profession with high numbers of female practitioners. The resulting feminisation of certain professions (O'Sullivan, 2012) represents an extension of essentialism outside of gendered divisions at home and into the workforce. This enables essentialism to often go unchallenged and in doing so neglects the way in which gender difference is a process of socialisation from different vantage points and not biological destiny. 
Within this research I challenge feminist empiricism, an approach that doesn't challenge scientific research norms but calls for their utilisation across essentialist notions of the sexes. I also challenge feminist deconstruction thought, a post-modern paradigm that rejects truth claims in favour of stories and texts within living cultures shaping the meanings admixed into everyday life (Olesen, 2005: 246). Instead I support feminist standpoint epistemology that questions that which previously passed for science, viewing this as a masculine perspective where objectivity is cloaked in systemic sexism that excludes women's voices and experiences (Harding, 1991; Thompson, 2001: 17-18; Letherby, 2003; Olesen, 2005; Brooks, 2006). Given the social collectivism of women's history and camaraderie of conditions, women's epistemology offers a legitimate standpoint from which a shared knowledge of social relations can be drawn (Lengermann and Niebrugge, 2003: 468). Feminist standpoint epistemology therefore suggests not only that women's life experiences need to be placed centre stage to achieve authentic knowledge, but that dominant histories, including those presented by such theorists as Marx, Gramsci and Freire, need to be repaired in a way that corrects traditional failures to do so. When working as a feminist researcher, it is therefore of central importance that participants, in this case community educators, are given the power to define and explain a particular phenomenon for themselves (Letherby, 2003).

\subsubsection{Feminist epistemology and critical realism}

This centralisation of epistemology within a particular historical context allows better understanding of the intersectional nature of oppression, and demonstrates relativity within critical realist interpretations. It also reveals the fallibility of dominant ideas, and how an uncovering of new knowledge can overturn this. The fusing of feminist standpoint epistemology with critical realism might also help to address the paradoxical nature of second-wave feminism which, whilst to some extent was successful in promoting a reversal of oppressive attitudes towards women, has failed to bring about the institutional change 
required to address structural patriarchy. Fraser (2009) further advances a co-opted notion of second-wave feminism proposing it has actually legitimised many oppressive structures within neoliberalism as it has benefitted from female participation in an exploitative labour market. Additionally neoliberalism has increased commodification pressures on women, through a co-optation of feminism in order to further satisfy capitalism's perpetual invention and re-invention of new markets (Azmanova, 2012: 154).

Some feminists have merged concepts of critical realism with feminist research. Satsangi (2013) proposes feminist realism, a research paradigm built on certain core characteristics. These are named as a belief that reality exists beyond our minds, that seeing knowledge is transitive and that it is possible for alternative arguments to be endorsed should analytical evidence be presented. She also proposes their fusion through a belief that knowledge is power-laden and therefore exists within a context of inequality, that the un-faltering relativism of pure constructivism should be rejected, and finally, that we undermine perceptions of a distance between the researcher and those to be passive researched. Satsangi (2013) argues that feminist realism brings epistemological advantages over positivism and intepretivism whilst also enabling us to accept the moral and political value of standpoint feminism. Whilst accepting many tenets of Satsangi's argument, Parr (2015) draws from her own experiences as a feminist researcher to draw out specific tensions between feminist epistemology and critical realism which I believe are helpful to acknowledge. This is the way in which feminist research undertakes to amplify the experiences of those often unheard, correcting previous epistemological assumptions. Critical realism, on the other hand, asserts some accounts of reality are superior to others. Parr (2015: 204) does not offer resolution to this tension but leans towards a reconstitution of experiences as told, through 'sociological conceptualisation and theorising'. This is applied in this study where the desire to support community educators in naming and describing their own experiences and beliefs on practice, 
is both honoured and problematised when considered amidst researcher theoretical insights I bring to bear.

Before concluding discussion on relationships between feminism and critical realism, it is on my mind to challenge the way in which much institutionally based critical pedagogy (a theoretical concept that incorporates radical community education) can also insufficiently acknowledge feminist epistemology (Luke and Gore, 1992; hooks, 1993; Thompson, 2000: 90-91). Luke and Gore (1992: 2) discuss female anthologies within the wider school of university based critical pedagogic practice, a space they describe as 'hip-deep in cultures saturated with phallocentric knowledges in institutional structures, ruled epistemologically and procedurally by men and masculinist signifiers...[and in] the theoretical and administrative custody of men'. Luke and Gore's observations are now 20 years old yet there is little to suggest things have dramatically changed. This is because of the way in which much women's community education, despite encapsulating many of the transformative ambitions of critical pedagogy, is still often accounted for as separate to critical education's historical trajectory rather than an essential force within.

Prominent contributions on critical realism also reveal difficulties in fully embracing feminist epistemology. When drawing on critical realism's structural dependence, Sayer (2000b) suggests an associational rather than contingent relationship between patriarchy and capitalism arguing it is the pervasiveness of patriarchy within capitalist societies that commonly connect the two. From this he proposes capitalism could potentially outlive patriarchy (the assumption being he also believes patriarchy could outlive capitalism). Though acknowledging feminist arguments of capitalism's need for 'unpaid domestic workers to reproduce its employees' (Sayer, 2000b: 710) he simultaneously dismisses these, proposing gendered roles could be quite easily reversed. Not only does Sayer (2000b) underestimate the levels of adjustment required when one takes into account capitalism's 
reliance on female labour as carers across the life-cycle, he over-simplifies the intersectional relations of patriarchal power, and the fallibility of foundations concepts of systems and lifeworld, both largely conceived of through masculine lenses.

\subsection{Summary of chapter}

Many pages have been covered within academic and philosophical literature discussing the nature of reality. Varying paradigms continue to compete for supremacy, as social researchers jostle for position on whose version is truest. This chapter set out to expose my logic through the ontological and epistemological assumptions I bring to the research. This is aligned most recognisably with a form of feminist critical realism, in a way that embraces ontological fallibility and centralises subjectivity, viewing reflections on experiences as the route to uncover the social structures under investigation. By incorporating feminism within critical realism I argue for commonality across experiences of patriarchy, but divergence in the epistemological significance of feminist ways of knowing in correcting real world interpretations proposed. Discussion on methodology also notes an unresolved tension between critical realism and feminism when balancing the latter's commitment to amplifying previously unheard voices, and the former's assertion that some truths are more valid than others. Further methodological discussion emerges within chapter seven when a research design is proposed. Before this, discussion will now turn to a more comprehensive account of community education as interpreted through available literature. 
Chapter three: Community Education in Ireland

- conceptual frameworks, historical origins and location of practice

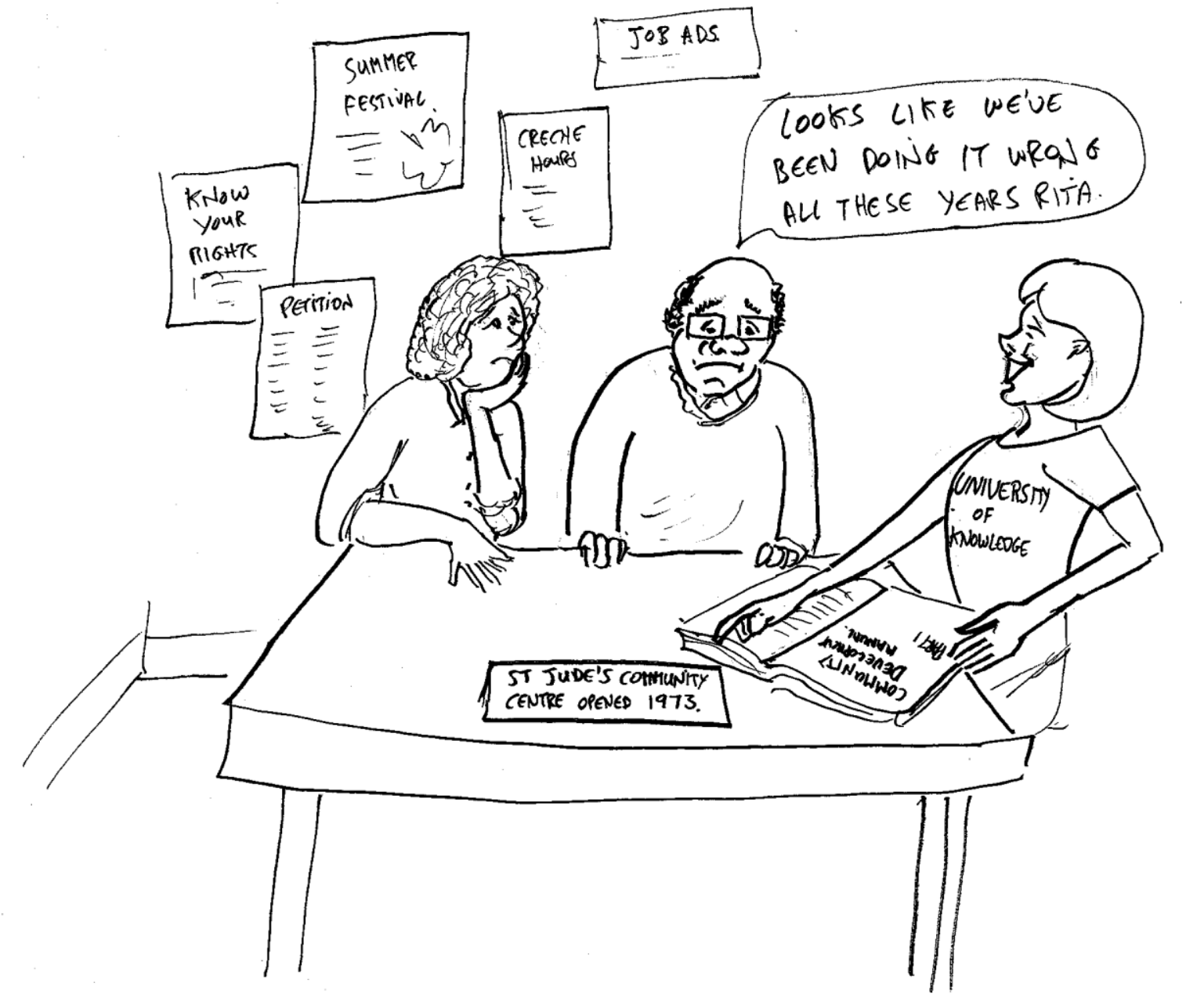




\subsection{Introduction to chapter: community contestations}

Navigating the terrain of community education is a complex undertaking. This is partly due to the multifaceted nature of many concepts at play, its locational dispersal, and the variety of meanings attributed to practice. It is also important to be cautious when we are describing any aspect of the social realm as there is the potential to fall victim to reductionist tendencies. This is where complex historical and relational factors are gathered into one overriding version of events that is then presented as truth.

Amidst these trepidations, this chapter attempts to better understand community education in Ireland. Contested concepts are explored, common interpretations are presented, and dominant aspirations are determined. A framing of practice is undertaken through apportioning of universal, compensatory, or radical approaches, as proposed by Ian Martin in 1987. Asserting a theoretical taxonomy is relatively straightforward on paper, with community education in practice often more interdependent and influenced by contextualising factors. These include the socio-political climate at the time, its geographical location and the reasons why a group comes together in the first place. However it is important to comprehend varying ideological influences and different anticipated outcomes so we can consider ways in which these shape diversity within community education.

This section undertakes to do this. It considers past situations, including drawing from significant social movements that helped shape community education in Ireland. It also locates contemporary practice. This latter undertaking is informed by social and historical circumstances that include Community and Voluntary Sector involvement and also State (public) provision. Differing locational and historical trajectories along Community Sector and public provision are easy to draft on the pages of a study such as this, but these differences sometimes more difficult to prize apart in practice, particularly for participants of community education. 
A final segment offers consideration of the relationships between insider community educators, those who are from the communities in question, and outsiders, community educators whose core relationship with a community is as their place of work.

\subsubsection{The dubious nature of Community.}

A good starting point in discussing the nature of community education is to examine the expression community. Usually signifying positivity, wellbeing and social cohesion, literal translations can be applied universally covering all elements of a particular geographical area regardless of the make-up of its population. Other types of communities often presented are communities of interest, for example the Gaelic Athletics Association (GAA), issue based, such as rights and environmental awareness communities, and those linked by identity, for example the gay or Muslim community. Discussions are often related to the ideas of German sociologist Tönnies (1887/2002) who is noted for contrasting gemeinshaft (community) and gesellshaft (society) whilst considering them in tandem. According to Tönnies (1887/2002: 33), gemeinshaft relates to personal contacts that are private and intimate yet linked by spaces that share such characteristics as language, religion, cultures and beliefs. Gesellshaft 'is public life - it is the world itself' (Tönnies 1887/2002: 33), a space characterised by urbanism, heterogeneity and impersonality. Tönnies (1887/2002) suggests the track from former to latter is born out of prudence as societies modernise.

In managing this transition, Clark (1996) offers a useful model of community as a social system that does not necessarily negate differentiations between community and society, but encourages a negotiation of relationships between the two. By considering the importance of people, place, relationships, beliefs and values, Clark contends it is the presence of feelings of significance (I matter), solidarity (I belong) and safety (both physical and psychological), that are the hallmarks of a good community. Along with these three components, Clark proposes 
a communal dilemma as 'the problem of how social systems can become more open to one another without weakening their own sense of community or destroying that of others' (Clark, 1996: 48). It is by engaging with this communal dilemma that communitarianism can be developed thus ensuring authentic connections with others that respect, nurture, and strengthen diversity.

Whilst holding some value to Clark's contentions, it is important that we also challenge assumptions implicit in use of the word community, most obviously the broad presumption of homogeneity that disregards micro-economic, political, cultural, and other differences. The historical visioning that is often evoked is also problematic, especially when we consider how rose-tinted memories of contented, cohesive neighbourhoods usually revolve around a domestic role for women. A bedrock of abuse within State institutions has also been exposed, again mostly affecting women and also children. Although carried in the experience of individuals, often with devastating consequences, the impacts of institutional abuse was in many ways silenced from the collective conscience of communities at the time. Additionally, the existence of some societal groupings in the first place, for example the aforementioned gay and Muslim communities, surely indicate exclusion from mainstream community? This again reveals an underbelly of discrimination and even banishment. We must also consider the way in which the word 'community' is called on more readily to describe geographical areas occupied by the working and lower-middle classes where disproportionate numbers on welfare benefit reside, 'sometimes with complex social difficulties' (Drudy and Punch, 2005: 157). These are set against neighbourhoods where populations are predominantly middle-class and wealthy. Thompson (2000: 68) raises a related point concerning the promotion of a 'sense of community', a characterisation particularly associated with working-class neighbourhoods. She argues this implies a reverse 'loss of community spirit' when apportioning blame for the symptoms of structural 
disadvantage (Thompson, 2000: 68). It is this logic that supports Robert Putnam's notion of 'social capital', where broad disengagement from civil society spaces is held responsible for the social decline he observes (Putnam, 2000). The alternative suggestion proposed is that by building social capital, we can somehow remedy the structural causes of inequality. Under current neoliberal conditions, the manifestations encouraged by the State are towards a siding with Putnam style self-help suggestions. This implies that communities can themselves overcome a milieu of economic and social disadvantage with little regard for the social policies that create these conditions in the first place (Berner and Philips, 2005). This bootstraps mentality absolves policy makers of any redistributive responsibility and allows us to blame the poor for the circumstances within which they find themselves.

As is the case with all contested concepts, the most important consideration is the inclination of the user and Shaw (2008) alerts us to a range of adoptions across the political continuum from revolutionary socialist movements to deeply conservative traditions alike. Mayo (1994: 48) notes 'not just that the term has been used ambiguously, it has been contested, fought over and appropriated for different uses and interests to justify different politics, policies and practices'.

\subsection{Interpretations of Community Education}

Defining any type of education is also an arduous task and attempts to do so elicit much debate. Aspin and Chapman (2000: 4) steer us away from agreeing parametered definitions by proposing that ontologies underpinning such quests rest on essentialist approaches. This means a belief that certain ideas and skills are indispensable and can therefore be methodically transferred to others. A more useful way to consider definitions is to demonstrate openness to the contested nature of many concepts at the core of educational thought. There is logic in being cautious. A possible consequence of agreeing ring-fenced definitions is the potential to limit what is considered appropriate thereby excluding 
innovation. Another pitfall is the way in which setting parameters can result in strenuous efforts by supporters to shoehorn real world events within these. Further cause for concern is how multi-disciplinary fields of study that evolve around social phenomenon, as is the case with community education and community development, can serve the expansion of academic discourse rather than influence the events they purport to understand. This situation is compounded by the absent voices of those living the experiences under discussion (Lynch, 1999). In defence of proposing parameters, failure to do so can contribute to the cooption of oppositional practices undermining their epistemological and methodological approaches. It can also mean those in powerful positions are more likely to have their interpretation culturally embedded within hegemonic logic. The current consequence of this means acceptance of market-oriented perspectives and instrumentalist approaches that satisfy labour-market demands.

At its broadest, community education can be understood as any localised, structured learning that happens outside of traditional institutions. These can be within specialist adult learning centres such as those managed by Education and Training Boards (ETBs), community buildings, literacy support centres, independent Community Sector organisations, Family Resource Centres (FRCs), training centres, health centres, within schools, churches, unoccupied social housing, people's homes, and whatever other premises are available to providers and groups. Community education is often incorporated within the wider discipline of adult education. Adult education traditionally captures a range of ideas and approaches alongside a common critique of functionalist perspectives that perceive education as a process of socialisation towards a shared vision of society (Grummell, 2008: 2). This breadth of philosophical encompassment enables community education to fit in well amidst the wider fabric of adult educational discourse. 
It is common for academic contributions on community education to consider it not only as locally based education, but as an approach that is underpinned by egalitarian principles. Tett (2006: 2), a prominent contributor, proposes that 'community education sees a community as a group of people who perceive common needs and problems, have a sense of identity and a common sense of objectives'. Connolly (2008: 24), a prolific domestic theorist, interprets community education as something that can harness the potential of gemeinshaft in a way that can shape gesellshaft bringing about social transformation. These views differentiate community education from outreach models, a distinction captured eloquently by Connolly (2008: 6) when she describes it as not just for the people, but of the people. Connolly centralises its role as a tangible form of politics, something also captured by Johnston (2000: 14) when he states that 'community education provides a localised focus for a social purpose education whose key values are a commitment to social justice, greater social and economic equality, and a more participatory democracy'. Community education prides itself on process as much as content with a commonly evoked mantra being the idea of starting where the person is at. This doesn't just mean accommodating many practical challenges facing adults as they return to education such as flexibility, affordability and childcare, it also means a cognisance of the knowledge, skills and values a person brings to a learning experience. These are then drawn from in determining subjects and modes of delivery.

There is political significance in the way terminology is used and one of the strengths of neoliberalism is its appropriation of previously oppositional language for the benefit of extending market control (Murray, 2014). As counteraction, further distillation of theories of community education is required that more distinctly unearths its purpose. One model that both captures expansive possibilities, and identifies important differences, is offered by Ian Martin (1987). Acknowledging 'considerable dilution and cross-fertilization in practice' (Martin, 1987: 23), he considers community education across three broad approaches: 
consensus, which he associates with concepts of lifelong learning, pluralist, evoking compensatory, or second-chance models, or conflict banners, when considering a radical stance in opposition to the macro-environmental status quo. It is important to understand these at times contradictory approaches. Does community education set out to comply with existing conditions, to rebalance circumstances through opportunities for those often excluded, or to challenge the structures that encapsulate and perpetuate inequality in the first place regardless of whether someone engages in a period of set learning? Each of these categorisations will now be detailed including adaptations to contemporary and domestic circumstances.

\subsubsection{Universal approaches to Community Education.}

The first of Martin's (1987) differentiations is described as a consensus, universal (or conservative) approach. Martin (1987) determines this as epitomised by lifelong learning, integrated provision, rationalisation, volunteerism and neutrality. Writing from a UK base, he details its emergence through the Community-College movement and presents it as a practice that is premised on homogeneity and harmony of interests. In Irish contexts it can be linked to the functions of FÁS ${ }^{12}$, some extra-mural university programmes, some services delivered by Education and Training Boards (ETBs), and that offered by other educators including Macra na Feirme ${ }^{13}$. Some community groups in both rural and urban settings can also be included depending on their mission and purpose.

What is interesting to observe about Martin's model, now almost 30 years old, is its construal of lifelong learning as a seemingly non-contentious expression and one which can be mostly detached from other approaches to adult and community education. Much has changed in the intervening years. Lifelong learning, once largely adopted in respect of recreational

\footnotetext{
${ }^{12}$ FÁS is the State managed Irish National Training and Employment Authority. FAS was disbanded in 2013.

13 A large voluntary organisation established in 1944 and involved in the organisation of sports, travel, agricultural and community events across rural Ireland.
} 
endeavours (Rogers, 2002: 9; Jarvis, 2004: 44), has altered in meaning and is now commonly used interchangeably with adult education as a whole (for examples see Field and Leister, 2000; Boshier, 2006; Maunsell et al, 2008; Duckworth and Timmons, 2010). This has extended its meaning to incorporate social, democratic, and economic wellbeing. In an attempt to understand why this change has occurred, Murtagh (2014a: 13) links the expansion of the term lifelong learning to State policy interest in the expression from the 1950s onwards. Whilst lifelong learning was initially, though perhaps somewhat cautiously adopted by many adult educators, there has been increased recognition of its use as Trojan Horse for the implementation of a neoliberal vocationalisation of educational endeavour (Johnston, 2000; Borg and Mayo, 2005; Brine, 2006; Grummell, 2008; 2014; Óhidy, 2008). This colonisation (discussed in more detail within chapter four) is essential to acknowledge when refashioning Martin's concept of a universal approach.

It is important to advocate for the resourcing of spaces for recreational, vocational and personal learning and on the surface universal approaches can appear uncontroversial. What is problematic is when these endeavours fail to challenge dominant cultural ideology within set learning spaces thereby perpetuating fixed notions of what is normal and natural. Upskilling for employment may appear to be neutral and to do no harm. However, unless it exposes the centrality of social class in determining employment options (Smyth and McCoy, 2011), it reinforces hegemonic ideas that hard work alone ensures occupational mobility (the reverse of which is that those unemployed are lazy) and that anyone can rise to the top of a particular profession. Universal approaches can also act as an instrument of power in enforcing gender stereotypes. This has been demonstrated through focus on much early community education targeted at women that promoted a homemaker role without exposing the dominance of patriarchy (Slowey, 1979; Ingles et al, 1993). More recently there has been compliance with traditional views of Irishness that are blind to our contemporary ethnic, 
cultural and linguistic diversity (O’Connor, 2010). Even where topics such as politics are studied, a universal approach supports seemingly impartial delivery. The Quality and Qualifications Ireland (QQI) level 5 award in politics ${ }^{14}$ offers one such example where its emphasis is on political structures; European, national and local, with a largely descriptive approach encouraged. Less countenanced is space for exposure of democratic deficiencies within contemporary models (Jerzack, 2014), or the local impacts of central decision making on local communities.

\subsubsection{Community Education as a second-chance}

Martin's second reformist model differs from a universal approach given its premise on a pluralist interpretation of society thereby recognising heterogeneity and diversity within. The school system is largely viewed as disproportionately benefitting some citizens over others with reformist models compensating for this by levelling the playing field through a secondchance at education. This is deliberately targeted within specific communities considered educationally disadvantaged. The essence of second-chance, or compensatory, approaches is of personal advancement and a widening of equality of opportunity with Martin (1987: 24) linking its origins to the targeting of certain UK based geographical areas for priority funding. From an Irish perspective its roots can most readily be linked to VEC supports beyond secondary school. These include accredited and non-accredited personal development and vocational courses, some extra-mural university accredited certificates, and, again, activities within some community groups in both rural and urban settings depending on their mission and purpose.

There is little doubt that there is demand for compensatory approaches with many accounts of disparity in educational output repeatedly linked to socio-economic status (Boldt et al, 1998; Eivers et al, 2004; 2005; 2010; Williams et al, 2009; McCoy et al, 2014). Even before

\footnotetext{
${ }^{14}$ The full award is available to view at http://docs.qqi.ie/AwardsLibraryPdf/5N1837_AwardSpecifications_ English.pdf [accessed March, 2015].
} 
school has begun, Fallon (2005: 289) estimates up to 51,000 Irish based children are 'at risk' from educational disadvantage.

Ensuring equality of access and participation for adults is an important equality objective and a range of both vocational and non-pecuniary benefits have been measured within other studies (Denny et al, 2003, Preston and Hammond, 2003; Bailey et al, 2010; 2011; Field, 2011). For a community there can be increased income through falling unemployment and, in cases where individuals progress to Higher Education Institutions (HEIs), a normalising of this pathway which might have been previously considered unattainable.

There are also limitations to compensatory approaches. One constraint is its positioning of deficiency within the individual and their community, often decontextualised from a wider systemic analysis of educational structures and purposes. Claims are made that some communities have little experience of tertiary education and are therefore not inclined to encourage attendance (Share et al, 2007: 235). A 'Rational Action Theory' has also been put forward (Goldthorpe, 1996). This hypothesis relies on the 'self-maintaining character of class inequalities' (Goldthorpe, 1996: 494) and proposes it is through personalised costbenefit analyses that logical choices are made on whether or not a person engages in higher education. This logic is thought to alter across class positioning and the availability of resources and is influenced by the likely return anticipated from any spend, financial or otherwise.

These arguments may carry some weight. However they continue to largely present the education system itself as ostensibly neutral, with meritocracy perceived as the most effective way to ensure equality across experiences. What is missing from this analysis is acknowledgement of a hidden curriculum where schools themselves are interpreted as sites for the reproduction of a capitalist system, maintaining and exacerbating social discrimination and purposefully directing recipients towards certain social and economic goals (Bowles and 
Gintis, 1976; Giroux, 1983; Lynch, 1989; 1999; Radner et al, 2007; Connolly, 2008: 108109). This is achieved through the alienating nature of school work, hierarchical relationships reflecting the social order beyond its walls, a normalisation of inequalities, and a re-enforcement of attributes of civil obedience and respect for authority. Meritocracy's conjecture of a standardised experience for all where the brightest will rise to the top can be challenged. One way is through Bourdieuan interpretations of habitus, the variant cultural inculcations of customs, tastes and attitude determined by the lifestyle spaces a person occupies (Bourdieu, 1984: 170). There is often non-recognition of cultural incongruities beyond a dominant middle-class experience within schools with success reduced to a person's ability to internalise the dominant culture. This hegemony is not only internalised through the education system. Lawlor (2005) draws from journalism, popular writing and academic texts to demonstrate 'a fictive we' (p342, italics have been added). This we not only symbolically excludes anyone not considered middle-class, it openly expresses disdain for class based cultural differences. The societal derision of non-dominant culture is compounded by a dearth of working-class teachers, and an advantage paradigm that includes the subjective expectations of teachers (Smyth and Hannon, 2007; Radnor et al, 2007). Moreover, economic resources enable a wider choice of schools for some (Lynch and Lodge, 2002: 40; O’Brien, 2003), and benefits from a 'shadow grinds system' have also been drawn out (Smyth, 2009).

There are incidences that suggest continuation of a hidden curriculum within community education. One example is within an AONTAS commissioned review of compensatory models of community education (Bailey et al, 2011). The authors propose use of a 'social recognition model' that measures learning outcomes through individualised developmental goals, all of which are mapped to conventional societal behaviours and dominantly enforced norms most of which are passive and conformist in nature (Bailey et al, 2011). This 
disregards more dissident roots of much community education where the yardstick for measuring learning could include incidences of civil disobedience and protesting, and where a more open and tolerant educational environment is paramount.

\subsubsection{Community Education as a social movement.}

Martin's third conflict model sits comfortably within radical approaches to community education and can be linked to activist interpretations of community development. This approach is primarily interested in trying to bring about egalitarian social change. It is premised on 'equality of condition' described by Baker et al (2004: 33) as 'to eliminate major inequalities altogether or at least massively to reduce the current scale of inequality'. Radical community education (sometimes described as popular education) is overtly political in its approach with Crowther et al (2005: 1-2) describing a process that 'unambiguously takes the side of those social interests and movements which are progressive in the sense that they are concerned to challenge inequality, exclusion and discrimination and to be part of the broader struggle for democracy and social justice'. Radical community education believes that education can never be neutral and challenges traditional approaches by interpreting them as a component part in societal injustice. Centrally, education alone is not considered the route to a more equal society, what is required is praxis, a cyclical process of collective action and reflection undertaken to effect societal transformation.

The way in which these ideas are transformed into action is through social movements. Popular education (or radical community education) is commonly considered part of wider global upheavals in the latter half of the twentieth century with archetypical uprisings including peace movements, green movements, gay and lesbian movements, the civil rights movement in the USA, as well as 'Western' based indigenous movements (Stammers, 2009: 132). Eschle (2001: 2) describes these New Social Movements (NSMs) that exist across a range of issues and stratifications as collective action-in-process, and as under continuous 
reconstruction. Egalitarian led NSMs share similarities which have been named as demands for political reform, often conflictual relationships with the State, and shared cynicism at the singular notion of economic growth without due regard for its negative elements (Connolly and Hourigan, 2006: 1; Della Porta and Diani, 2006: 20).

For radical community education in Ireland, the social movement it is commonly connected with is a community development movement that emerged most tangibly from the 1980s onwards. This included women's movements, tenants' rights and housing action movements, anti-drugs activism and anti-unemployment initiatives (Cullen, 1994: 31-37), all of which formed part of a 'new wave of citizen involvement and community activism...[which] recognised that the causes of poverty were rooted in economic and social structures' (Kelleher and Whelan, 1992: 4). As a whole, community development is described as resting on values of equality, empowerment, participation and collective action. When enacted these are thought to bring a more diffuse distribution of power enabling representatives to negotiate the amelioration of community concerns (Popple, 1995; Craig et al, 2008; Twelvetrees, 2008; Gilchrist, 2009).

Not all community development carry the tenets associated with popular educational and, in truth, governmental interpretations have always been towards a self-help individualised approach (see Government of Ireland, 2000). The yardstick for popular education is where community development is interpreted as a bottom-up, collective process with critical education as its spine (Ledwith, 2007; Beck and Purcell, 2010; Fitzsimons and Dorman, 2013). Praxis can take many forms including the creation of alternative spaces, dialogue and negotiation with power-holders, rights based campaigning and lobbying work, and the establishment of supports that simultaneously address and highlight shortfalls in public provision. 
There are some examples of popular education across Ireland. Connolly (2005) has demonstrated this through examination of elements of the woman's movement of the 1980s, whilst a more recent example is the Rialto Rights in Action group; a human rights housing related project facilitated by the Community Action Network (CAN). The key principles this particular example ascribes to is a structural analysis of inequality, a belief struggles for justice require creativity, commitment to support those experiencing inequality to selfdetermine, and an ongoing emphasis on the importance of shared leadership and praxis (CAN, 2010: 4).

Connecting community education to NSMs potentially offers the most tangible opposition to neoliberalism and is the model that underpins this research project. However there are difficulties in adopting this approach. One such challenge relates to its incorporation into community education structures which are largely funded by the State. Although some commentators argue a useful tension to this in and against the State positioning (Paterson, 1999; Chanan, 2009; Crickley and McArdle, 2009; Lloyd, 2012), the contradictory nature of this relationship raises considerable difficulties for practitioners. This inconsistency was graphically illuminated in 2010 through the sudden cessation of funding to certain Community Development Projects who adopted a more overtly radical approach (O’Byrne, 2012: 33). Steyn (2012) draws our attention to a number of international examples where social movement potential is stymied because of financial and bureaucratic interdependence on the State with autonomy only ever partially achieved. Regulations adopted for the certification of learning are also restrictive, the parameters of which make it questionable as to whether the radical intentions of practitioners can be fully realised (Torres, 1993; Fitzsimons, 2014).

Kane (2010) notes further difficulties with generalisations when describing popular education. He details how its mantra of 'starting where the person is at' can inherently result 
in a failure to explicitly address political questions, noting the way in which social context has an important impact on the nature of practice. The ideological diversity of practitioners is also emphasised as central in determining both the extent, and direction of dialogic probing. Another difficulty Kane (2010) draws our attention to is the way in which it can be hard for practice to live up to theory, especially where ideas are often passed from one person to another in the field.

\subsubsection{Adapting Martin's (1987) theory to Irish contexts}

Whilst it is relatively straightforward to propose differing approaches across universal, compensatory and radical modes of practice, the reality is often less clearly defined. Additionally, this study will demonstrate how the emergence of community education in Ireland differs from UK experiences. This results in a divergence from Martin's original proposal namely the way in which he suggests ideological departure can usually be traced along historical lines of inquiry. Were this to be applied to an Irish context, the implication would be that radical approaches would most likely be found within independent, locally emergent Community Sector organisations. Conversely, you would expect to find compensatory models within specialist State provision, and universal approaches most likely within university outreach and private provision. This is not the case as practices influenced by radical, social justice models can be drawn out amongst State delivered VEC/ETB models (for example Fleming, 1989; Ingles et al, 1993; Cullinane, 2003). Much radical practice also emerged from university organised extra-mural programmes (Connolly, 2014) with secondchance, individualist models prevalent within the Community Sector (for example Bailey et $a l$, 2011). Adapting elements of Martin's approach, figure 1 offers a landscape of community education, locating practice within theoretical undertows of universal, compensatory (secondchance) and radical approaches to community education. 


\section{UNIVERSAL}

Implicit model of society: Consensus.

Underlying principles: Homogeneity, nonselective across ages and social groups.

Origins: Part-time university programmes, Macra-Na-Feirme, VECs, FAS, some community based groups.

Dominant themes: Lifelong learning, labour market re-activation, personal development, neutrality.

\section{SECOND-CHANCE}

Implicit model of society: Pluralism. Underlying principles: Heterogenity, individualism, equality of opportunity, social mobility for the disadvantaged.

Origins: VECs, liberal extra-mural university courses, some community based groups.

Dominent themes: Learning that is relevant to people's lives, supportive and cognisant of challenges such as child-care, partnership as a route to change.

\section{RADICAL}

Implicit model of society: Conflict, oppression on class but also other factors such as gender, race, \{dis\}ability.

Underlying Principles: Issue based approach to education, equality of condition.

Origins: Community development, the women's movement, liberation theology, radical community educators within VECs, radical academics, some community based groups.

Dominent themes: Local control of decision making, political education, structural analysis, praxis.

Figure 1 - Universal, Second-Chance and Radical approaches (adapted from Martin, 1987) 


\subsection{The historical emergence of Community Education in Ireland}

There are challenges when chronicling a history of social, political and cultural events. Documentation from the past is composed amidst ideological tensions of a particular era, and its social and cultural norms. Those with resources are often the ones with power to record events through their lens and it seems likely many histories carried within folklore have been lost. Another difficulty is the way in which women's histories are largely absent from accepted canonical knowledge (Clover et al, 2013: 15).

In considering a history of adult education in Ireland, Murtagh (2014b: 194-200) provides a comprehensive linear account over five distinct phases: before the Act of Union, during which Maynooth College was established and a growth in hedge schools was recorded; 18001922, during which time there was a growth in agricultural movements involved in education; and 1922-1965, when relevant events included the growth of university outreach programmes. The final two phases, 1993-2006 and 2007-2014, are noted as periods of significant reform, the former including expansion of State community based initiatives, and the latter a period of momentous legislative and structural alteration. Earlier examples of practice can be captured. One example is the work of Dublin based Sir Robert Kane at the Museum of Irish Industry in the mid-1800s. Kane was a supporter of non-denominational education and deliberately targeted 'ordinary people', facilitating access to 'scientific education' (Cullen, 2009). Before this again, P. J. Connolly's historical account Divided Kingdom makes reference to local organised gatherings in coffee houses as early as the $1600 \mathrm{~s}$ though little is shared about these interactions (in Forrest, 2009: 379).

More recent points of reference include the Irish Country Women's Association (est. 1912) which carried a specific objective 'to improve the standard of life in Ireland through Educational and Cooperative effort' (http://www.ica.ie/Breif-History.2534.1.aspx, sourced 2015). The Irish Housewives Association (IHA) was also influential. The IHA was formed 
in 1942 as an organisation primarily concerned with the rights of women in the economic sphere and delivered education and employment workshops concerning the status of women in Ireland (National Archives, 98/17, ND: 76). Another organisation to be aware of is The Dublin Institute of Adult Education (originally the Dublin Institute of Catholic Sociology) which was founded in 1940. Also of note is The People's College (est. 1948) who provided 'workers education' and was founded with the support of the Irish Congress of Trade Unions and encouragement from the UK Workers Education Association (http://www.peoplescollege.ie/history/, sourced February, 2015). The University College Cork (UCC) outreach programme (est. 1946) is cited as the first such outreach to attract nontypical college attendees (Ó Fathaigh, 1998; Murtagh, 2014: 198). Though Murtagh (2014a: 198) draws this out as a model for other university outreach provision, little is recorded about the teaching methodologies employed.

In scoping a history of contemporary community education, a common starting point is to begin with events in the 1960s and 1970s, a period cited as an important juncture in the modernisation of Ireland (Tovey and Share, 2000: 72-3). Rather than chronicle events since this time, another way to consider community education is along four distinct trajectories. These are through an upsurge of women's consciousness-raising groups commonly linked to the wider women's movement of the time, locally based adult education initiatives including the literacy movement, liberation theology including the influence of Training for Transformation and the aforementioned community development/anti-poverty movement. There are intersecting and overlapping features of these somewhat forged divisions and examples of universal, second-chance and radical perspectives within each. There are also differences that help us understand complexities in the location, delivery, and ideology of contemporary practice. Each will now be considered separately. 


\subsubsection{The influence of the Women's movement}

In the period leading up to the 1970 s and 1980 s, women were those most likely to access community education across Ireland (Bassett et al, 1989: 58). One reason was because, prior to the 1960s, many girls were excluded from post-primary education with what school opportunities there were, described as largely instructional and domestically focused (Cullen, 1987; Harford, 2005). It was because of demand from women, as well as from the workingclass, those unable to read, early retirees, and employers eager to improve skills in the workplace that Vocational Education Committees (VEC) began organising part-time educational programmes (Feehan, 1979). Some VEC Community Schools and Colleges were opened in the 1970s to accommodate locally based evening courses (Bassett et al, 1989: 37) and these programmes have been described as the 'backbone' in the advent of community education in Ireland (AONTAS, 2004: 9). However, most educational initiatives targeted at women were domesticating in emphasis, and largely in the control of men (Slowey, 1979). Bassett et al (1989: 78) share documentation from within Adult Education Boards at the time that describes the perceived needs for women as in 'subjects such as child-management and home making'. This was to change as part of a global upsurge in second-wave feminism from the 1960s/1970s onwards as I will now detail.

When introducing the book The Irish Women's movement, from Revolution to Devolution, Linda Connolly (2002) reminds us how the story of the Irish Women's movement can be told through a range of histories and experiences. The Irish Country Women's Association (est. 1910) is considered important for some given its involvement in setting up the National Women's Council of Ireland (NWCI) which was established in 1973. This was the same year that the marriage bar was lifted, a stipulation that required women working in the civil service to resign on marriage. In 1974 the first report from the Commission on the Status of Women offered another historical perspective, brought about as a result of pressure from a female 
working group within Fianna Fail ${ }^{15}$ (Connolly, L. 2002: 112). The Women's Liberation Movement (est. 1970) is considered central for some as is the role of female politicians most notably the election of Ireland's first female president, Mary Robinson, in $1990^{16}$.

Another historical starting point is through women's community education in the 1970s and 1980s. Rooted in Freirean practices of praxis and consciousness-raising, women's community education confronted domesticating approaches by enabling economic and patriarchal analysis in safe, supportive, self-managed environments (Tobin, 1989; Connolly, 2001; 2003; 2005; 2014; Crean, 2008). This wasn't unique to Ireland with the global secondwave of feminism taking gender equality in a new direction through its epistemological challenge to mainstream knowledge (Ramazonoglu, 1989; Connolly, 2003).

Radical community education enabled women experiencing such circumstances as gender discrimination, poor housing, poverty, unemployment, the effects of emigration and lack of facilities for their children to come together and collectively analyse their circumstances. These courses acted as a bridge between the perceived middle-class nature of the women's movement to that point, and the experiences of working-class women, something encapsulated by one research participant in this study (see section 8.1.1). Funding and other supports for women's community education were ad hoc coming from a range of sources. This included delivery of extra-mural certificates from St Patrick's College at NUI Maynooth (Connolly, 2014), and assistance from some Adult Education Organisers (AEOs) (Bassett et al, 1989). Not all women's community-education carried such overtly radical agendas however those that did, were influential in curbing the overwhelming domesticating emphasis up to that point. As women's community education grew, it is likely to have encapsulated radical, compensatory and universal approaches within it.

\footnotetext{
${ }_{15}$ An Irish political party who have dominated domestic government in post-colonial times

${ }^{16}$ Robinson was an active feminist long connected with campaigns for the realisation of a range of women's rights including reproductive rights
} 
By the late 1980s, the wider Women's movement in Ireland was in crisis. This was largely due to failed campaigns to legalise divorce and publicise information on abortion, and a strongly negative portrayal of feminism within popular culture (Mullins, 1991: 29). However women's community education continued to grow, in part resourced by the New Opportunities for Women (NOW) programme (1989), an EU initiative promoting educational and employment equality. In 1992, AONTAS began accessing NOW funding and offered training and support for women's groups funded through this initiative, as well as lobbying on their behalf. Indicative of the cultural backlash to feminism, Brady (2003: 69) reports how 'in the process [AONTAS] encountered a great deal of resistance to women's education from policy and decision makers as well as many of its own statutory members'. This, she details, included attempts by some members to block access to AONTAS membership for women's community groups, something that 'almost split the organisation in two' (Brady, 2003: 69). Brady (2003: 69) shares how this was overcome by a combination of 'dynamic women, and the notion of organising one's own learning opportunities'.

Other important revenue streams were the National Women's Education Initiative (WEI) (1998), and the Equality for Women measure 2010-2014 (a gender equality initiative part funded by the EU social fund $)^{17}$ It remains difficult to estimate the number of womenspecific community education groups as no single administrative or networked organisation exists. The National Collective of Community Based Women's Networks (NCCWN) list 23 member networks each with their own membership of between six to 70 local women's groups (Pillinger, 2011: 9-10). These potentially include groups coming together within other Community Sector organisations such as Family Resource Centres (FRCs) and addiction services, those organised through the activities of Community Education

\footnotetext{
${ }^{17}$ Twenty-three recipient organisations include organisations within the Local and Community Development Programme, network organisations, legal advice centres and other independent Community Sector organisations. Further details are available at https://www.pobal.ie/FundingProgrammes/EqualityForWomenMeasure /Pages/default. aspx, [accessed February, 2015].
} 
Facilitators (CEFs), and those coming together through book-clubs, parent and toddler groups, breast-feeding support groups and other gatherings.

\subsubsection{Locally based adult education programmes and the literacy movement}

Women's community education was to become a central force in supporting other community-based anti-poverty and anti-drugs movements at the time (Connolly, 2003). This included a class-based literacy movement that emerged in the 1960s and 1970s which deliberately linked ability to substandard and sometimes brutal conditions within Irish schools (Brady, 2006: 41; Dorgan, 2009: 13). The National Adult Literacy Agency (NALA) locate the origins of this movement within the activist backdrop of the 1960s and name Cherish, the Association for Deserted and Alone Women, and the Simon Community as just three of many groups involved (NALA, 2010: 14). These activities were also influenced by a UK 'Right to Read' initiative accessed by default through British TV channels (Bailey, 2006). Whilst some approaches were charitable in orientation, a Freirean philosophy has also been identified with both philosophical approaches dependent on much voluntary effort (Bassett et al, 1989: 26-28; NALA, 2010: 14). A common subvention model within VECs was one where fee-paying programmes subsidised literacy work (Bassett et al, 1989: 38). Given the unreliable nature of funding, and the substantial reliance on voluntary effort this meant delivery was uncertain from year-to-year.

It was also voluntary effort that led to the formation of AONTAS, the National Association of Adult Education (est. 1969). Addressing its launch event, the Minister for Education announced the setting up of a committee to examine and make recommendations on the future of adult education in Ireland (http://www.aontas.com/about/whoweare/history.html, sourced Jan, 2015). The fruits of this committee's work appeared three years later as the government commissioned Adult Education in Ireland (1973), or Murphy Report; the first demonstration of interest in adult education by the State (Murtagh, 2014a: 27). Adult 
Education in Ireland/The Murphy Report (Committee on Adult Education, 1973) offers an interesting vantage point through which we can consider the evolving adult education sector, especially when considered amidst the mushrooming of consciousness-raising women's groups detailed thus far. Review of The Murphy Report (1973) reveals a commission that was largely male controlled, something that can be clearly gleaned through its absence of female representation and its partisan language throughout. The report is noteworthy for its recognition of inadequate literacy levels. This was the first State acknowledgement of adult literacy concerns however attention to this was inadequate and it was cited as mostly affecting rural populations. The Murphy Report (1973) recommended further research in literacy levels with no real change in terms of funding or policy development emerging (NALA, 2010: 14). The report does name adult education's purpose as to ensure 'adults who are no longer participants in the full time school system may learn whatever they need to learn at any period in their lives' (Committee on Adult Education, 1973: 1) and makes recommendations that resulted in the creation of an adult education section within the Department of Education, from which Adult Education Organisers (AEOs) were appointed in 1979. Many though not all AEOs worked alongside volunteers at the time, with some actively involved in the establishment of independent community-based organisations (Fleming, 1989).

Overall, the Murphy Report strongly supported an equality of access perspective positioning Higher Education Institutions (HEIs) as key providers. It also recommended a non-statutory response through State funding for AONTAS which would be managed independently. AONTAS undertook research in adult education including research on women's education (by Slowey, 1979) and research on adult literacy, as the Murphy Report had recommended (NALA, 2010: 15). This second undertaking led to the establishment of the National Adult 
Literacy Association (NALA) in the late 1970s which became an independent organisation in 1980 (http://www.aontas.com/about/whoweare/history.html, sourced February, 2015).

Entitled Lifelong Learning and known as the Kenny Report (Commission on Adult Education, 1984), this second governmental report marked further expansion and resourcing for community education. The Kenny Report (1984) initiated Adult Education Boards in each VEC and ensured ring-fenced budgets for adult literacy and community education.

State provision for adult education through the VECs also grew through the Vocational Training and Opportunities Scheme (VTOS) introduced in 1988. Another important juncture was expansion following publication of the International Adult Literacy Survey Report (Department of Education and Science, 1997). Twenty-five years after inequality in literacy was first muted in The Murphy Report (1973), this research revealed the extent of the problem with one in four Irish adults estimated as having difficulty with simple literacy tasks. NALA pinpoint this international study as a tipping point in evoking the political response that they had long been advocating for. They comment,

This could not be ignored. Here was a major study from a respected international body, of adult literacy levels in sixteen countries, in which Ireland was in fifteenth place, second last to Poland. The findings were met with understandable shock on the part of Ireland's political establishment and, embarrassing as they were, also garnered a great deal of media attention. The OECD findings were later credited with prompting a dramatic increase in the new government's commitment to tackling adult literacy, reflected in both increased levels of funding and in policy developments. (NALA: 2010: 56-57)

Further consolidation of VEC provision of community education emerged as a result of Learning for Life: White Paper on Adult Education (DOES, 2000). This will be discussed in more detail within chapter four. Most notable was the appointment of dedicated Community Education Facilitators (CEFs) in the early 2000s, and the Back to Education Initiative (BTEI) introduced in 2002.

It is important to understand that much VEC provision was in response to unpaid grass-roots effort on the ground, efforts that also involved some religious congregations (Carey, 1979). 
Independent community education organisations to emerge, and subsequently receive funding from a variety of sources, included the Cork based Social and Health Education Project (SHEP) in 1974 (http://www.socialandhealth.com, sourced January 2015), The Kilbarrack Local Education for Adult Renewal (KLEAR) in 1980 (http://kleared.ie /about/our-story/, sourced January 2015), The Shanty, in 1985, (http://www.ancosan.com/, sourced January, 2015), and The Community and Family Training Agency which opened its doors in 1987 (http://www.cafta.ie/about-us/, sourced February, 2015). Some of these organisations received funding through VEC allocated hours and Department of Education grants whilst others entered into specific grant-aid programmes such as the Community Development Programme (discussed in more detail within section 3.3.4).

Government documentation of adult and community education within the Murphy (1973) and Kenny (1984) reports and amidst Adult Education in an Era of Lifelong Learning: Green Paper on Adult Education (Government of Ireland, 1998) and Learning for Life: White Paper on Adult Education (DOES, 2000) was largely through an equality of opportunity perspective. This fits most comfortably within previously detailed second-chance, or compensatory approaches. However, it is not the united position of practitioners. Philosophical differences have been identified within the VEC funded adult literacy programme where tensions were captured between a radically influenced 'literacy movement' strand and a more compensatory service provision approach (NALA, 2010: 67). Other examples of radical influence can also be drawn out. The Community Education Facilitators Association (CEFA) details community education as 'rooted in the Freirean process of dialogue, reflection and action' hoping to 'empower participants with the skills, knowledge and collective analysis to challenge oppression and to engage in action to bring about change' (CEFA, 2011: 2). Where this radicalism is translated into practice, McGlynn (2012: 122127) notes how CEFs can feel hamstrung by an ontological mismatch with their host VECs, 
who uphold an individualist framework, and their own interpretation of their role as custodians of social justice models of practice.

\subsubsection{The spread of ideas through Liberation Theology}

Another influencing movement, and one not disconnected from both women's community education and the voluntary emergence of local education programmes, was the influence of liberation theology. This was largely initiated by returning members of religious congregations who were involved in overseas development work, many of whom subsequently resigned from religious service. The influence of liberation theology was not confined to Ireland. The Paris-based Ecumenical Institute for the Development of Peoples (INODEP) which was founded by Paulo Freire and had connections with the Kenyan Delta programme influenced a team of Church groups, community workers and NGOs to bring the ideas to Britain. This was through the establishment of the UK based Freire Institute and followed this team's participation in Parisian based workshops (http://www.freire.org /about/history/, sourced September, 2014). The Irish story starts with the activities of The Irish Missionary Union and personal connections between its members and critically influenced development workers in Kenya, particularly Anne Hope and Sally Timmel. As a result of discussions with missionaries on her own Irish heritage, Hope circumvented the confiscation of her South African passport by successfully applying for Irish citizenry and visited Ireland in 1978, 1981 and $2000^{18}$. Hope co-authored the Training for Transformation set of workbooks with American activist Sally Timmel. These books, originally published in 1985, described the work of the Delta Training Programme in Kenya which began in 1973. The Delta Project identified five influencing prongs in educational development work. These are Freire's approach to consciousness-raising and praxis, human relations training in group-

\footnotetext{
${ }^{18}$ This information was provided through a conversation with a founding member of Partners, Training for Transformation who worked alongside Anne Hope and Sally Timmel within the Kenyan based Delta Project and was involved in organising these Irish visits.
} 
work, organisational development, social analysis and spiritual influences most notably the Christian concept of transformation (Hope and Timmel, 1995: 14).

Although linking his own introduction to Training for Transformation (TfT) to use of Delta Project materials in Pakistan, Naughton (2002: 10) details the first complete TfT workshop in Ireland led by Ann Hope in 1981. Half of the 36 participants were working in Irish settings within education, health care, pastoral work and community development with the remainder involved in development work overseas. Naughton describes how this course had a profound effect on participants on a personal level, introducing them to 'a whole new way of working with people' (Naughton, 2002: 230) that was highly participative and a translation of the theories and ideas of Freire into a working methodology. From this initial process a core group Partners in Mission was formed, its name indicative of connections with Church members (Naughton, 2002: 231). Naughton details a spread of participation over the next 10 years with over 400 practitioners completing TfT programmes in Ireland, the bulk of who were working in local community settings and connected to community development work. These graduates were to extend the influence of Hope and Timmel's approach across Ireland. Whilst acknowledging its religious roots, Partners Training for Transformation as an organisation is now non-denominational (Naughton, 2002: 235) reflecting a more secular Ireland both inside and outside the organisation. Partners continue to deliver TfT workshops and the influence of this approach has been acknowledged across the sector (Powell and Geoghegan, 2004: 178).

Liberation theologians were influential elsewhere also. The Community Action Network (est. 1986) was set up with the help of funding from the Jesuit Solidarity Fund (JSF). The JSF outlined its strategic objectives as influenced by direct experience of liberation theology in Latin America claiming it 'eschewed the traditional 'charity' model of community development and instead stressed the need for an integrated approach based on the 
development of individual and interpersonal relationships and transformation of the structures with which people have to engage' (Jesuits in Ireland, 2012: 1).

\subsubsection{The wider community development/anti-poverty movement}

Women's community education, locally emergent VEC funded work, and the community based actions of those influenced by liberation theology intersected with a wider foray of bottom-up community development movements to emerge at the time. Local upsurges included housing related concerns, anti-drugs initiatives, and an active movement against unemployment (Cullen, 1994: 31-37). Again context matters and early writings within the community development movement make reference to a wider European movement, with the adoption of a definition of community development by the UN in the 1950 s presented as significant (Crickley and Devlin, 1989: 54). Community development in Ireland is also likely to have been influenced by the growth of a UK movement that set out to offer alternatives to addressing poverty through the bureaucracy and impersonality of the Welfare State (Craig et al, 2008: 178). This movement is likely to have influenced domestic events because of our close geographical location, shared history, and the Irish community development movement's early adoption of an all-Ireland perspective that incorporated Northern Ireland (Clarke, 1989).

The Republic of Ireland's story is also somewhat different given our lack of a clearly identifiable Welfare State. This is principally due to the absence of a strong left-wing tradition post-independence, with such inclinations largely subdued by the Catholic Church (Lynch et al, 2012: 5). Domestic histories are more commonly linked to the 1940s and 1950s through Muintir Na Tíre, a rural based enterprise initiative with strong links to the Catholic Church (Lee, 2003: 49; Lloyd and Lloyd-Hughes, 2009: 29). It was some years later, and in the shadow of global discontent previously detailed that the intersection of women's groups and other self-managed groups emerged, dissatisfied with the status quo and interested in 
bringing about systemic change (Crickley and Devlin, 1989; Kelleher and Whelan, 1992; Cullen, 1994).

It is difficult to pin-point the exact origins of the Community (and Voluntary) Sector, with some questioning whether a range of civil society groups can indeed constitute a sector in itself (Ó Cinnéide, 1998/99: 49; Collins, 2002: 96-7; Powell and Geoghegan, 2004: 119). One recognisable influence was the funding certain urban groups received through EU poverty 1 and poverty 2 programmes in the 1980s. These programmes largely promoted change through a self-help philosophy (Curley, 2007: 10). Another important juncture was the State establishment of the Combat Poverty Agency (CPA) in 1986. The CPA was set up to provide the State with information and analysis on the alleviation of poverty (Combat Poverty Act, 1986). It was also originally instructed to oversee the Community Development Fund (est. 1991). This was introduced to ensure continuity of funding for groups involved with the earlier EU poverty 1 and poverty 2 programmes (Lloyd, 2010: 46) and the Community Development Fund supported an original 15 Community Development Projects (CDPs). Although State funded, there was an important difference when CDPs were compared to public provision as the first step in project evolution was the coming together of a local group to analyse local issues and demands. It was only on submission of a work-plan to address these concerns that grant-aid was provided. Crucially the money provided was entrusted with the projects themselves to be administered by locally based voluntary boards of management. This gave significant autonomy and ownership to representatives of the communities in question.

Despite this freedom, the Community Development Programme was not uncritically welcomed as the Combat Poverty Agency claimed governmental support lacked a sufficient analysis of the issues it sought to address, and was unclear about anticipated outcomes for community development (Cullen, 1994: 4). This didn't stop an expansion of the Community 
Development programme and between 1990 and 2009 the number of CDPs grew to around 185 projects. These operated alongside other independently managed State funded organisations including a network of Family Resource Centres (FRCs) who also ascribed to the principles of community development.

Though not strictly conforming with the objectives of the Community Development Programme, Brady (2003: 69) shares how some women's groups entered the programme attracted by the opportunity to avail of three-years funding cycles, and of money for premises and staff. Other groups also entered into the programme again not strictly led by the collectivised social change aspirations of community development, but who were involved in a range of community supports. This meant that, in some respects, The Community Development Programme became a catch all for a range of community initiatives and philosophical tendencies, a situation that continually played itself out through the lifetime of the programme. Mid-way through the now discontinued Community Development Programme, extensive research by Powell and Geoghegan (2004) identified a range of personal influences that motivated community workers involved. These included a desire to care for others, a personal involvement in politics, and religious undertows. Powell and Geoghegan (2004: 157) identify a minority as being 'radically motivated' concluding 'community development appears then to be firmly rooted in liberal, humanistic values, with an emphasis on the value, capacity and worth of individuals, rather than the explicitly radical collective ones'. Ideological tensions were not only as a result of potential mismatch between community development funding allocations and the philosophies and purpose of recipient groups. When reporting on a conference of community workers held in the late 1980s, therefore before the influx of significant State funding, Clarke (1989) alerts us to a range of internal debates around gender equality, religion, and relationships with the State. 
Such philosophical departures are not unique to Irish contexts. When discussing the Community Sector in the UK, Shaw (2008: 26) describes an entity also characterised by 'functional ambiguity' as opposing rationalities are contained within one seemingly homogenous sector. The resultant 'curious hybrid of practice' (Shaw, 2008: 26) resonates with Irish experiences.

Central to this research is the extent to which these organisations engaged in community education. This is captured during a 2002 evaluation of the Community Support Programme carried out by the Department of Social Community and Family Affairs, its core funder at the time. The evaluation reported 'all projects are involved, to a greater or lesser extent, in delivering training, educational or social awareness programmes within their own communities' (Nexus, 2002: 33). A summary of type and participation on these programmes is provided within the evaluation report as below.

\begin{tabular}{|l|l|l|l|l|}
\hline Nature of Output & $\begin{array}{l}\text { Total Nos. } \\
\text { Participating }\end{array}$ & $\begin{array}{l}\text { Average Nos. } \\
\text { participating per } \\
\text { year }\end{array}$ & $\begin{array}{l}\text { Main Target } \\
\text { Groups }\end{array}$ & $\begin{array}{l}\text { Most Common } \\
\text { Content }\end{array}$ \\
\hline $\begin{array}{l}\text { Training Courses } \\
\text { and Programmes }\end{array}$ & 4,321 & 33 & $\begin{array}{l}\text { Women, } \\
\text { Travellers, Men, } \\
\text { Tenants }\end{array}$ & $\begin{array}{l}\text { Estate Management, } \\
\text { Health, Community } \\
\text { Development }\end{array}$ \\
\hline $\begin{array}{l}\text { Social Awareness } \\
\text { Programmes }\end{array}$ & 2,112 & 23 & Women, Tenants & $\begin{array}{l}\text { Community Arts, } \\
\text { Communication, } \\
\text { Local Democracy }\end{array}$ \\
\hline $\begin{array}{l}\text { Educational } \\
\text { Courses or } \\
\text { Programmes }\end{array}$ & 1,206 & 15 & $\begin{array}{l}\text { Women, Lone } \\
\text { Parents, } \\
\text { Travellers }\end{array}$ & $\begin{array}{l}\text { Literacy, Health and } \\
\text { Social Care }\end{array}$ \\
\hline
\end{tabular}

Table 1- Summary of Project outputs in relation to participation in, and content of Training and Education and Social Awareness programmes (1996-1999) (Nexus, 2002: 35).

In fulfilling these and other community based functions, another feature of the Community Development Programme and one which again emphasises its heterogeneity, was the way in which CDPs in particular were able to leverage much additional EU and domestic funding. Crowley (2013: 151) reports how during the boom times of the 2000s many CDPs were administering funding that was substantially larger than their original government grant. This 
included money from FÁS through the Community Employment (CE) Scheme and a number of grants and initiatives for childcare specifically available for the development of facilities in areas considered disadvantaged (Horgan, 2001: 6). Some CDPs were also recipients of funding through the New Opportunities for Women (NOW) programme.

Another strand of activism and subsequent funding not captured in the story so far is through grass-roots responses to problematic drug use, particularly within many Dublin communities. In 1981, The Youth Action Project (YAP) in Ballymun established itself as an organisation that placed community education as a core part of its activities explicitly linking their work to the philosophies of Paulo Freire (McCann, 1991). Freirean approaches have also been drawn out in other settings, including within my own place of work at the time. These projects nurtured resistance to the medicalisation of addiction and rehabilitation and emphasised how the medical model removed problem drug-use from its socio-economic contexts $\left(\mathrm{O}^{\prime}\right.$ Brien, 2007; McGlynn, 2012: 123). Following a Dublin based mass meeting of community activists and local representatives held in 1995, Citywide was formed as a network organisation committed to community development principles (Rourke, 2005: 7). One year later, a substantial influx of State funding came through the First Report of the Ministerial Task Force on the Measures to Reduce the Demand for Drugs (1996), undoubtedly influenced by the growing HIV/AIDS epidemic and a desire to control associated behaviours in the interest of public health. The thirteen geographical areas or 'black spots' where the problem was considered most acute were, unsurprisingly, the same areas where CDPs were operating and much of the funding channelled through newly established Local Drugs Task Forces went to existing CDPs. In 1997 Citywide entered into the Community Development Support Programme and, over the next 10 years, worked with over 70 community groups supporting the adoption of community development responses to drugs issues (Rourke, 2005). 


\subsubsection{Capturing connections between Community Sector and public provision}

What has emerged over the years is a landscape of community education provision that straddles both State and Community Sector provision alike. In practice, this has meant the emergence of a range of independent community education organisations, some of which were at one stage funded through Community Development Programme funding streams, others which have historically survived by mixing a range of funding avenues into one operational entity. A myriad of funders have therefore emerged (Conroy and O'Leary, 2007: 13, AONTAS CEN, 2011). In research carried out in 2011, the AONTAS CEN measured 78 different funding streams across 40 member organisations. Primary streams are named as the Department of Community Rural and Gaelteacht Affairs, the Department of Environment, Heritage and Local Government, and the Department of Education and Science. These are three of 10 separate government departments providing funding with other sources listed as charitable trusts, businesses, EU funding and 'other sources' (AONTAS CEN, 2011: 3). Strong working relationships have often emerged across public provision and Community Sector providers. Table 2 overleaf attempts to capture these connections. 


\begin{tabular}{|c|c|c|c|}
\hline Timeline & Community Sector & State Providers & Overlap/relationships \\
\hline $\begin{array}{l}\text { Early to } \\
\text { mid } \\
1900 \text { s }\end{array}$ & $\begin{array}{l}\text { Rural based voluntary } \\
\text { organisations inc. Macra Na } \\
\text { Feirme, The Irish } \\
\text { Housewives Association } \\
\text { and The Irish Country } \\
\text { Woman's association }\end{array}$ & $\begin{array}{l}\text { Extra-mural college courses } \\
\text { esp. from within UCC }\end{array}$ & \\
\hline $\begin{array}{l}1960 s- \\
1980 s\end{array}$ & $\begin{array}{l}\text { Literacy education } \\
\text { initiatives influenced by the } \\
\text { UK right to read campaign, } \\
\text { ongoing emergence of local } \\
\text { groups especially women's } \\
\text { community groups }\end{array}$ & $\begin{array}{l}\text { Locally based VEC centres } \\
\text { and community schools } \\
\text { providing programmes. Some } \\
\text { local literacy services } \\
\text { introduced }\end{array}$ & $\begin{array}{l}\text { Literacy movement dependent on } \\
\text { collaboration between voluntary } \\
\text { organisations and VEC paid } \\
\text { tutor hours }\end{array}$ \\
\hline 1975 & & $\begin{array}{l}\text { Department of Adult and } \\
\text { Community Education } \\
\text { founded within St Patrick's } \\
\text { College, Maynooth }\end{array}$ & $\begin{array}{l}\text { Support and guidance from some } \\
\text { academics }\end{array}$ \\
\hline & $\begin{array}{l}\text { Ongoing emergence of } \\
\text { locally based independent } \\
\text { community organisations }\end{array}$ & 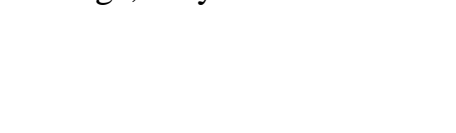 & \\
\hline 1979 & & $\begin{array}{l}\text { Adult Education Officers } \\
\text { appointed (AEOs) }\end{array}$ & \\
\hline 1988 & & $\begin{array}{l}\text { Vocational Training and } \\
\text { Opportunities Scheme } \\
\text { (VTOS) }\end{array}$ & \\
\hline 1989 & $\begin{array}{l}\text { Women's groups funded } \\
\text { through the EU New } \\
\text { Opportunities for Women } \\
\text { (NOW) measure and } \\
\text { supported by AONTAS }\end{array}$ & & $\begin{array}{l}\text { Support from individual AEOs in } \\
\text { historically establishing some } \\
\text { Community Sector organisations }\end{array}$ \\
\hline $\begin{array}{l}1990- \\
2013\end{array}$ & $\begin{array}{l}\text { Community Development } \\
\text { Projects }\end{array}$ & & $\begin{array}{l}\text { Support and guidance from some } \\
\text { academics including } \\
\text { representation on } \\
\text { management structures, strong } \\
\text { relationships with past students } \\
\text { and providing accreditation for } \\
\text { Community Sector organisations }\end{array}$ \\
\hline $\begin{array}{l}1992- \\
2015\end{array}$ & Local Area Partnerships & & \\
\hline $\begin{array}{l}1994- \\
\text { present }\end{array}$ & Family Resource Centres & & $\begin{array}{l}\text { Funding of tutors within CDPs } \\
\text { and FRCs paid for by ETB/VECs } \\
\text { Independent practitioners } \\
\text { operating across both provider } \\
\text { groups }\end{array}$ \\
\hline $\begin{array}{l}1996- \\
\text { present }\end{array}$ & $\begin{array}{l}\text { Addiction projects through } \\
\text { Ministerial Taskforce on } \\
\text { measures to reduce demand } \\
\text { for Drugs }\end{array}$ & $\begin{array}{l}\text { Adult literacy scheme } \\
\text { extended }\end{array}$ & \\
\hline $\begin{array}{l}2002- \\
\text { present }\end{array}$ & & $\begin{array}{l}\text { Community Education } \\
\text { Facilitators }\end{array}$ & $\begin{array}{l}\text { Strong relationships between } \\
\text { some CEFs, AOEs, ETB tutors } \\
\text { and the Community Sector }\end{array}$ \\
\hline
\end{tabular}

Table 2 - some connections between Community Sector and State Provision 


\subsection{Insiders/outsiders and the restricting potential of professionalisation}

Another important feature of community education and one I alluded to at the beginning of this thesis, is the way in which its more lateral approach has blurred boundaries between professional, in other words qualified, and lay practitioners. This latter cohort is commonly made up of past recipients of community education and members of the communities in question. These insider practitioners' ability to more genuinely empathise with learners is thought by many to add a richness to community education which is absent from more elitist models of practice.

The involvement of insider practitioners is not simply to provide a more convincing voice, or to empathise more holistically with experiences, there are also important theoretical considerations. Evoking Gramscian theories on intellectualism help us to understand the importance of insider practitioners, most notably his interpretation of the organic intellectual within each class-based strata of society. Organic intellectuals refer to those primarily distinguishable not by their profession, but by their role in directing the ideas and objectives of the class they are organically bound to (Gramsci, 1971: 3). They do this, Gramsci maintains, by carrying an organising function across all spheres of society that promotes an understanding of their cultural norms. The function of organic intellectuals within workingclass communities fits well with philosophies of radical community education that endeavour to create space for the cultivation of counter-hegemony. It is through problem-posing education we can draw out and validate knowledge produced through lived experiences. This enables a theorising of life circumstances, and a self-determined praxis within practice.

Insider practitioners commonly work alongside outsider practitioners, people often strongly motivated by a desire to address inequality despite not being as directly affected as many within the groups they work with. When such allies, many of whom carry existing qualifications (Whelan, 1989; Sayer, 2008; Grummell, 2014: 126), become embedded within 
community contexts, a consequence can be the assumption of representative and advocacy roles. This is often without sufficient feed-back mechanisms to ensure decisions that are made on behalf of communities, adequately represent the difficulties these communities experience (Ikeotunoye, 2002; Meade and O'Donovan, 2002). The potential is for a marginalisation of local voices representing what Freire (1972) termed a cultural invasion, where members of the oppressor class, often inadvertently, embed their dominant cultural norms into the logic of communities where they work. Perhaps unwittingly, they can act as vanguard for the deepening of neoliberalism by legitimising unsavoury policy decisions and suppressing potential dissent (Shaw, 2009; Powell and Geoghegan, 2009; Meade, 2012).

When professionalisation of community based practice was first muted, oppositional voices tended towards support of these arguments. In 1988, a working group from within the Community Workers Cooperative (CWC) described the professionalisation of community work as 'anathema' to practice, largely about 'gaining status' for outsider community workers, and potentially a mechanism for restricting entry to those from communities affected themselves (in Whelan, 1989: 154). CWC's position was expressed elsewhere also with Crickley and Devlin (1989: 62) fearing 'the creation of a closed profession is we feel contradictory to principles of community work'. These concerns have largely dissipated in recent years and a professionalisation process has emerged within the Community Sector and wider community education provision.

\subsubsection{Sociological interpretations of professionalisation}

In order to understand professionalisation and 'professionalism', an expression that describes what is required of expected members of a profession (Evans, 2008: 25), it is helpful to consider sociological interrogations of this phenomenon. Professionalism was once considered a distinction only some specialist vocations could possess (Flexnor, 1915/2001). It was contributions such as that by Houle (1980) which proposed any vocation could achieve 
professional status once certain touchstones were achieved. Broadly speaking these touchstones include a determination of prerequisite attributes, a proposed set of standards, endorsement of specialist education programmes (including Continuous Professional Development) and often, a regulatory body overseeing professional membership (Houle, 1980; Cevero, 1988; MacDonald, 1995; Evans, 2008). Importantly, professionalisation and ongoing professional status is dependent on the construction, sustainment and validation of specialist knowledge through university recognition (Flexner, 1915/2001; Larson, 1977; Houle, 1980; Cevero, 1988; MacDonald, 1995).

Much like community, the notion of the professional is largely seen positive and as beneficial for all involved. It is good for the skilled expert who gets recognition, better pay and conditions, and greater occupational support. It is also presented as good for their clients, in this case a community. This is through increased standards of practice, improved services, and the aforementioned regulation of practitioners protecting them from unsafe practice. Challenges to this seemingly progressive pathway question the often associated altruistic sentiment. Larson $(1977$; 2014) adopts a Marxist interpretation of professionalisation, framing it as an exclusionary exercise in the commodification of expertise, available only to a few and to be traded across a neoliberal vocational market. Another important challenge points to the role of the State, a key influencer in determining the parameters of professional activity (MacDonald, 1995; Goodson, 2003). Elites within a particular profession are also central in constructing agreed professional attributes. MacDonald (1995: 134) helps us comprehend the role of these elites when he describes their functions as to develop professional ideology, to agree characteristics that forms the basis of membership and, crucially, to negotiate the realms of practice and levels of autonomy from the State. 


\subsubsection{Professionalisation of community development and community education}

Previous research I have undertaken (Fitzsimons, 2010) identified the CWC publication Towards Standards for Quality Community Work (CWC, 2008) as the most significant driver in professionalising community development work in Ireland. Towards Standards emerged from a process initiated by self-appointed leaders including university based academics, and follows the usual criterion for professionalisation. This is through the way it details appropriate professional attributes, suggests acceptable standards, and proposes that certain educational programmes be undertaken to qualify as a community worker. Crucially, it commits community work to pluralist interpretations when it pins its future to "networking, solidarity and engagement with all of the stakeholders, including central government and local authorities' (CWC, 2008: 13). This promotion of harmony with the State as funders, demonstrates the potential power of the elite, few of whom are resident in the communities under discussion.

Simultaneously, discussion has emerged from within adult education in favour of professionalising community education (Government of Ireland, 1998; DOES, 2000; Fleming, 2004; Ryan, 2014). The core rationale put forward is to support the key skills of community educators, and to recognise certain qualifications of practice specific to the field. Of note, both the Green Paper, Adult Education in an Era of Lifelong Learning (Government of Ireland, 1998: 110) and Learning for Life; White Paper on Adult Education (DOES, 2000: 152) suggested professionalisation take place in a way that recognises a range of backgrounds and expertise, and supports those with no previous qualification to attain whatever benchmarks for professionalism are proposed. Additionally the white paper makes reference to the potential for adult educators to steer the course towards professionalisation through the establishment of practitioner forums. 
These proposals for agreed qualifications, and indeed the wider professionalisation debate, have created tensions. Whelan (1989) cites unequal class-based power as present at the point of creation of community work as a profession where those with existing qualifications automatically assumed more senior positions despite often weaker connections with the communities in question. Studies elsewhere also help us comprehend relationships between insider and outsider practitioners. Within the UK, Henderson and Glen (2006) evidence capacities built up by insiders within communities as a result of unpaid activism. They also note the skills, expertise, perspectives and beneficial distance outsiders can bring, including a less entrenched position from which to analyse events. However, Henderson and Glen (2006) identify a belief within insider practitioners that the attributes held by outsiders were often held in higher esteem, and that some paid-workers simply didn't register the role and importance of insider volunteers. Similarly, domestic difficulties have been captured relating to a potential side-lining of volunteers. NALA (2010: 46) alert us to debates within the literacy movement of the potential marginalisation of volunteers in favour of paid workers with existing qualifications. Elsewhere, within other research I undertook with a practitioner colleague, I have explored this relationship through notions of 'credibility' and 'credentials' ${ }^{19}$. We frame this within a model of three sources of authority explaining these as,
Authority from above - conferred by a role we occupy or designation from a higher authority, -authority from below or around- conferred from those we work with in the respect or recognition they have for us, and authority from within - that which we give ourselves through self-confidence in the validity of our position. (Fitzsimons and Dorman, 2013: 53)

Those involved in the study named credibility sources as having lived with oppression, through occupying the role of ally, from grass-roots experience as a community educator, from having made mistakes and from having certain qualifications. As with Henderson and

\footnotetext{
${ }^{19}$ This was built from ideas originally conceived of within work of the Community Action Network and Partners Training for Transformation.
} 
Glen (2006) a finding was again, that greater esteem is given to 'authority from above' over 'authority from within' and 'around'. This hierarchy of credibility measurement was also thought to be incrementally increasing under the weight of professionalisation processes. The exclusionary nature of professionalisation is further compounded by difficulties many from communities experiencing disadvantage have in accessing professionally endorsed programmes within Higher Education (HE). Reasons for inequality in HE attendance that have been put forward include poor guidance at school, the financial cost of university attendance, and cultural barriers (O’Connell et al, 2006; McCoy et al, 2014).

Further concern relates to how the power to determine what a profession is, also implies determination of what one might consider unprofessional. This has been argued elsewhere as potentially devaluing local activism and excluding grass-roots social movements (Collins, 1993; Wilson, 1995: 167; McVeigh, 2002; Henderson and Glen, 2006: 282).

\subsubsection{Professionalisation gathers pace: potential involvement of The Teaching Council}

The professionalisation of the Community Sector appears to have stalled. Devastating cuts and co-option of its independence into the newly aligned Social Inclusion and Community Activation Programme (SICAP) makes it unlikely a recognisable professional body will emerge in the coming years as the sector struggles to regain lost ground. For community educators involved in the delivery of accreditation there has been a potential, though as yet unconfirmed, acceleration through professionalisation of Further Education and Training (FET). This is through expanded interpretation of regulation five of The Teaching Council [registration] regulations $2009^{20}$. This legislation gave the State funded professional standards body for teachers, The Teaching Council (the council) the power to review

\footnotetext{
${ }^{20}$ A directive introduced on foot of section 38 of the legislative Teaching Council Act 2001. Section 38 'review of standards required for entry into teaching profession a) review and accredit the programmes of teacher education and training provided by institutions of higher education and training in the State b) (b) review the standards of education and training appropriate to a person entering a programme of teacher education and training, and c) review the standards of knowledge, skill and competence required for the practice of teaching, and shall advise the Minister and, as it considers appropriate, the institutions concerned.
} 
standards and competencies of Further Education accredited programmes and to make recommendations to the Minister for Education and Skills. Should this be extended to community education providers offering FE accredited awards, this would position The Teaching Council of Ireland in the role of elite, despite no representation at council level from adult education, community education or Further Education for that matter. (Ryan, 2014: 172).

In response to the publication of Teaching Council regulations, AONTAS (2010) requested a broadening of consultation towards those within adult and community education including those responsible for already established practitioner programmes. This was during a wider period of consultation by the council though it is not clear how this process was organised as no report on its outcomes has been published. In 2011, The Teaching Council did publish Further Education: General and Programme Requirements for the Accreditation of Teacher Education Qualifications enabling HEIs to apply for approval for existing and newly devised post-graduate programmes. Ten programmes were approved ${ }^{21}$ including those identified by AONTAS as most fit for purpose. However these programmes were required to adapt their approach towards the acquisition of technical skills and acceptable knowledge that is more commonly associated with secondary school environments. As Grummell (2014: 131-2) explains, 'providers had to defend the relevance of an adult and further education pedagogy that emphasizes the participatory learning and critical thinking methods that address the inequalities which constitute the lived realities for many of our learners'.

\subsubsection{Maintaining standards whilst questioning professionalism}

Whilst potentially beneficial for their insistence on completion of educational programmes relevant to a particular field, the demands of professionalisation have been detailed thus far as

\footnotetext{
${ }^{21}$ Recognised programmes are offered at NUI Galway, Mary Immaculate College, Limerick (two programmes), National College of Ireland, Dublin, Waterford Institute of Technology (two programmes) NUI Maynooth, Co. Kildare, Marino Institute of Education, Dublin, Dublin City University, and the National College of Art and Design, Dublin.
} 
also problematic. Where specific programmes may indicate the competencies of a candidate for a particular role, they can say little in terms of commitment and can undermine credibility from peers within a community context, attributes argued elsewhere as also relevant for community leadership (Fitzsimons and Dorman, 2013: 54). Another difficulty is how some practices within accredited practitioner programmes can also be challenged for example the esteem sometimes awarded to banking approaches to education (Shor and Freire, 1987: 30) or the way in which theorising through the norms of academia can hold more cultural currency than that which emerges from struggle (hooks, 1994).

Misinterpretations of an anti-professional stance as also meaning an anti-standards stance can also arise. This is not the case, with many who are sceptical about the implications of professionalisation also emphasising the need to maintain certain standards of practice (for example Collins, 1995: 47-48; Freire, 2001: 85; Holst, 2009a: 324). Challenges to professionalisation do not diminish the importance of what Connolly and Hussey (2013) describe as really useful practice, ways of working that are reflexive, dialogic and transferable across a spectrum of circumstances. It is also disingenuous not to acknowledge how Connolly and Hussey (2013) and participants in the cooperative inquiry detailed above (Fitzsimons and Dorman, 2013) acknowledge the benefits of credentialised university based education in developing their own capacities, a situation drawn out in this study also. This poses difficulties for anti-professionalisation arguments because it demonstrates the way in which set learning periods on specialist educational programmes can support the development and nurturing of critical community educators.

\subsection{Summary of chapter}

Amidst contestation over key concepts most notably community, this chapter interprets community education as universal, compensatory or radical and locates its origins amidst socio-economic circumstances that influenced the emergence of key social movements. 
These include the women's movement, literacy movements, liberation theology and the community development/anti-poverty movement. It draws out a Community Sector demonstrating how much of its work has always been educational. It also shows a close working relationship between public provision through VECs/ETBs and the Community Sector. Many of these relationships are dependent on the ideological aspirations of practitioners, a determining feature in their interpretation of community education regardless of their employer type or whether they are a paid or voluntary worker. Ideological tensions emerge across providers dependent on philosophical orientations with an additional encumbrance being relationships between insider practitioners and those whose organic connections are more privileged. The most recent historical period is absent from this chapter meaning the momentous change introduced within chapter one is missing from this chronology. This will be rectified within the next chapter through a more deliberate focus on community education and its relationship with policy. 
Chapter four: The Neoliberalisation of Community Education, policy influences in realigning practice

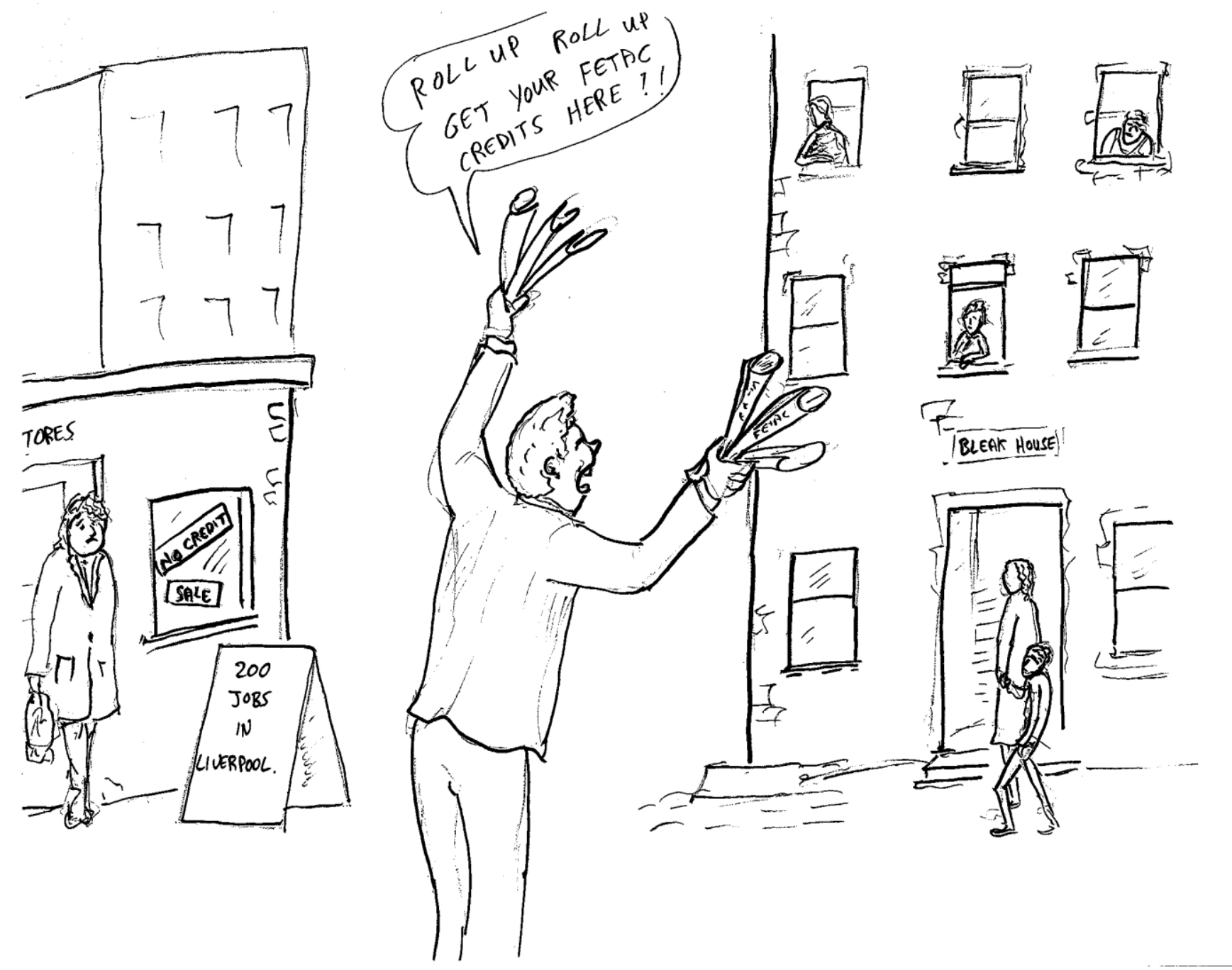




\subsection{Introduction to Chapter: recalling rooftop deliberations}

So there we were. Members of the AONTAS Community Education Network (CEN) gathered together enjoying the relatively rare summer sunshine. Rarer still was the city centre rooftop garden where we congregated, a hidden bonus unknown to us when the room was rented for our network gathering.

Perhaps more predictable was the sense of resignation I felt about what we were doing. It was close to the deadline date for submissions to Quality and Qualifications Ireland (QQI), Ireland's newly formed State agency responsible for approving and awarding all qualifications. During its start-up phase, there was a window where providers could respond to a series of green papers on such concerns as access to accreditation, recognition of prior learning, fees for providers, and access, transfer and progression. I remember people noting the timing for submissions wasn't great. Some people were on holidays, others weren't paid over the summer months and therefore weren't around. Nonetheless I seem to remember about 30 of us present, organised into groups of six to eight with each group working collaboratively on a particular theme.

I had been in similar situations before throughout my years as a community educator. I remember feeling very excited when Learning for Life: White Paper on Adult Education (DOES, 2000) was published, with a whole chapter dedicated to community education. Despite much ambiguity on its eventual philosophical positioning, it was great to leaf through its pages with women I had worked with in preparing our submission. I was sure I could draw out our words. Maybe rose-tinted glasses influence such nostalgic reminiscence but I remember some sense of validation, of solidarity, and of worth. 'Perhaps we could influence change and help advance a better world' I thought, 'maybe it could become a reality in some small way because of the work I was involved with'. 
I don't have memories of participation in many of the initiatives promised within the white paper as most were never realised. This, and my ongoing experiences of Community Sector co-option in the decade that followed, were factors in the heavy heart I carried into participation on the rooftop garden. I was unconvinced of the merits of what we were doing, though yet not ready to give up trying.

This chapter sets out to understand the relationship between community education and government policy, specifically the way in which the latter influences the former. It doesn't present an exhaustive overview of policy, rather it theorises particular interventions locating them within neoliberal socio-economic and cultural conditions. It looks at the degree to which much policy, implemented through systems of New Public Management (NPM), has impacted the day-to-day micro-circumstances within which community educators' work and argues the resultant neoliberalisation compromises equality based agendas. The importance of a European led schedule will be drawn out that particularly advanced an agenda of lifelong learning and human capital accumulation.

Before mapping a terrain of relevant EU interventions and domestic responses, the chapter begins with an examination of the way in which community educators have, by choice, embedded themselves within a culture of practice that includes ongoing attempts to influence social policy.

\subsection{Influencing change through policy or chasing pie in the sky?}

Broadly speaking, social policy relates to the way in which relationships between the State and its citizenry are determined (Coffey, 2004). The most usual contemporary arrangements are municipal policies that relate to public wellbeing, some of which are legislatively protected. Commonly, these focus on such fields as social welfare, health, housing, transport, and education with foundations often broadly interpreted as equality-led (Coffey, 2004: 60). 
Where community education carries an egalitarian emphasis, this has been advanced in part through efforts to mainstream equality into public policy. This approach is not uncommon within social movements, particularly the women's movement (Chaney, 2012; Speeden, 2012) as representative organisations work to ensure many voices, not just those traditionally heard, contribute to the design of policy. The incorporation of an equality focus into public policy also carries a more pragmatic consideration for development work. The amalgamation of principles and values congruent with equality should, in theory, lead to the provision of financial resources to achieve these. This is important in securing funding streams for equality-focused organisations such as their need to pay wages.

With these reasons in mind, community educators, the wider Community Sector, and representative groups such as AONTAS, have been at the forefront of pre-budget submissions, inputs into the National Anti-Poverty Strategy (NAPS) and contributions to the National Economic and Social Forum (NESF). Practitioner influence is also palpable within the Adult Education in an Era of Lifelong Learning: Green Paper on Adult Education (1998), and Learning for Life, White Paper on Adult Education (2000), with the former premised as a consultative backdrop to the latter (Government of Ireland, 1998: 6). Practitioner commitment has been strong when considering proposals for educational change through submissions to the SOLAS consultation process in January, 2012 22 , Quality and Qualifications Ireland (QQI) consultative processes of $2013^{23}$, and an AONTAS coordinated dialogic and written response to the Further Education and Training Bill (2012). This latter event led to the inclusion of a consultative voice for Community Education providers in

\footnotetext{
${ }^{22}$ AONTAS invited considerable dialogue with its members before submitting its submission 'the voice of the adult learner' to the SOLAS consultative process. It can be viewed at http://www.aontas.com/download/pdf/aontas_submission_on_solas_consultation_process.pdf [accessed, July, 2014].

${ }^{23}$ All submissions made to QQI during their consultation process can be viewed at http://www.qqi.ie/ Consultation/Pages/default.aspx [accessed, July, 2014]. Furthermore, at an AONTAS CEN meeting in March, 2015, the CEN reported making over 20 written submissions to QQI since its establishment.
} 
future National Further Education and Training Plans (Further Education and Training Act, 2013, section 5C).

In coordinating these actions, networks and affiliate organisations have been established. Some community educators have connected themselves with AONTAS since its creation in 1969, whilst more recently, the AONTAS CEN (est. 2007) has emerged. This carries an overtly political agenda, committed to securing a distinct funding stream for community education. It is also dedicated to raising the profile of community education, and commits to ongoing and critical evaluation of community education work (AONTAS CEN, 2008: 2). Other network organisations include the Community Education Facilitators Network (CEFA) and, within the Community Sector, the Community Workers Cooperative (CWC) and Citywide. Historically, there was also an active regional web of community development networks at the peak of the now discontinued Community Development Programme.

These networks often organise opportunities for practitioners to engage in policy formation (such as in the example used to open this chapter) including encouraging members to independently participate beyond what is co-ordinated by the networks themselves. Guidebooks have been designed and disseminated perhaps most notably Brian Harvey's guide to influencing policy entitled Working for Change and published by The Combat Poverty Agency in 1998, 2002 and 2008. These provide explanations of the political system and offer assistance in setting objectives on how to influence policy. AONTAS also commonly produce advocacy toolkits, templates for campaign letters, and other guides to influencing specific policy and working towards legislative reforms ${ }^{24}$.

Alongside creating the conditions for policy engagement, networks have also been proposed as essential in strengthening civil society by generating social capital and fostering democratic pluralism (Gilchrist, 2009). Broad benefits to practitioner networks include

\footnotetext{
${ }^{24}$ These advocacy packs and specifically targeted policy work including submissions can be viewed at www.aontas.com [accessed, July, 2014].
} 
interaction between newer and more established educators, and educational opportunities for those often working in precarious environments (Bowl, 2011). Conversely, difficulties can also be drawn out not least the way in which practitioners often struggle to find the time to attend network meetings. Larger organisations can dominate membership, and those in coordinating positions are often those in attendance, potentially marginalising those working at the coal face. Another challenge is the way in which, whilst often espousing support for self-determination for those experiencing structural inequality, network formation and support for representative organisations can create a centralised recognisable leadership. These are often people in paid positions within network or advocacy organisations, or those who assume leadership positions due to associations with particular organisations including certain universities. It is not uncommon for these leaders, at times self-appointed, to be outsider community educators/workers rather than those with organic connections to communities through grass-roots efforts. Whilst these leaders can carry esteem and credibility with policy makers, this may not be extended from the communities they purport to represent, who might not even be aware of their existence. This situation is further compounded when one considers a more concealed function of networks, namely the way in which they can act as a vehicle for sectoral compliance with government policy accelerating co-option of potentially oppositional forces (Giacinto Garchi, 2001; Bowl, 2011).

\subsubsection{Sectoral engagement as stratagem for a marketised approach}

To understand the rationale for any such concealment, it is important to contextualise the design and dissemination of equality based policies within their socio-economic contexts namely a global retreat from Keynesianism to market-oriented neoliberal ideology (Harvey, 2005). Part of this transformation has been to question State legitimacy in claiming responsibility to address equality (Coffey, 2004: 49). What neoliberalism does instead is recast the State as promoter of liberty and freedom, with the market claiming responsibility for 
the redistribution of wealth through job creation. Equally, individuals are liberated to take responsibility for their own social wellbeing, again something which is consistently linked to employment (see chapter one for further related discussion).

One feature of neoliberalisation has been a Janus-face approach to social policy. During the same period when philosophies of individualised freedom and liberty through market servitude were embedded, there has been a near inundation of policy interventions relating to poverty and social exclusion. Between 1996 and 1997 alone, Duggan (1999: 6-7) lists 25 such initiatives in Ireland centered on three core themes, partnership and integration, clientcentered approaches and the need to improve the effectiveness of existing services. This contradictory approach can be understood when we interpret policy as a tool in bringing about the micro-dynamic everyday changes that are required to advance the macro-dynamics of neoliberalism (Whitehead and Cranshaw, 2012: 2). This means that although there may have been an emphasis on addressing inequality through policy, this has been coupled with a shifting logic in how this is to be achieved, reframed through a philosophy of business with its augmentation through systems of New Public Management (NPM).

The vocationalisation of education has been an especially dominant policy direction with the driving forcing being to match recipients of education with industry led job-creation. This ideological shift has had a direct impact on community education in Ireland (Hurley, 2014) with a common starting point in its evolution being relationships between domestic and EU policy. This will now be explored, first through EU pathways, and then with an emphasis on domestic responses.

\subsection{A Europe-wide agenda: laying foundations for co-option}

A country's connectedness with the EU is complex, described as neither top-down nor bottom-up, but a complex, discursive process (Rees et al, 2010: 17). Rees et al (2010: 1718) offer this as an explanation as to why much research, including cross-country and cross- 
sectoral, is inconclusive in demonstrating consistent domestic policy change across memberStates. What is significant is the way in which Europeanisation, the extent to which EU membership becomes embedded within national politics, is most influential 'when the logic of domestic political actors change' (Radaelli, in Rees et al, 2010: 17, italics in original).

Even where this logic is embraced, EU led direction on education policy can evoke tensions. Field (1998: 5) suggests this is because of interrelationships between education and a country's inculcation of its culture and nationalism. He argues this can create an opposing wrench when it comes face-to-face with globalised homogeny in meeting the needs of multinational employers (Field, 1998: 5-6). In Ireland, any opposing wrench involves negotiating a post-colonial identity. The cultural legacies of this include the power and esteem afforded the Catholic Church (Inglis, 1998), and a strong nationalist base of racial and territorial identity (Boyce, 1995). These can sit uneasily alongside previously discussed openness to, and dependency on, direct foreign investment for our economic integrity. Ireland is largely thought to have positively benefitted from its relationship with the EU, through European legislation, the European Social Fund, the Common Agricultural Policy, and the European Structural Funds (Murtagh, 2014a: 37). This has somewhat eased potential concerns about policy direction from the EU, their incorporation also assisted by the way in which politicians have tended to play on nationalist sentiment, rather than 'fresh concepts inspired by the EU' when implementing European led reform' (Hayward, 2009: 2).

\subsubsection{Lifelong learning and human capital: creating an army of workers}

The way in which domestically introduced policy is connected to EU policy, helps us to understand the neoliberalisation of community education. This association is particularly strong when we consider the European led reframing of adult education towards concepts of lifelong learning. A Memorandum on Lifelong Learning (European Commission, 2000) is commonly presented as the most recognisable landmark in EU concentration on adult 
education policy, and the end result of a decade-long intensification of interest in lifelong learning. The concept of lifelong learning that dominated during the 1990s was a broad Church, influenced by humanistic approaches but also accommodating radical collective potential within (Hake, 1999; Borg and Mayo, 2005). Hake (1999) tracks its upsurge in popularity as it featured within G7 communications, in OECD development programmes, within UNESCO promoted Adult Education work, at European Round table of Industrialists (ERTI) discussions, and within the workings of the European Commission. Lifelong learning is presented as so important, Óhidy (2008: 13) announces how 'since the proclamation of the European Year of Lifelong Learning in 1996, the programme has been considered the only possible answer to the political and economic changes in modern times in Europe'.

At surface level, the language of A Memorandum on Lifelong Learning (2000) leant itself towards broad interpretations, potentially incorporating a range of meaning. It proposes members engage in domestic consultation 'as close as possible to citizens themselves' (European Commission, 2000: 3) and suggests 'lifelong learning is no longer just one aspect of education and training; it must become the guiding principle for provision and participation across the full continuum of learning contexts'. However, adult and community education discourse operates within a terrain where there is continual competition for meaning (Murray, 2014). Whilst a Memorandum on Lifelong Learning claims equal billing for employability and active-citizenship; the latter is interpreted through a more limited understanding than those likely to be evoked in conversation with many community educators. The reason for this is its compliance with paid employment as the primary route to wellbeing and social participation.

Another EU led initiative introduced in 2002 A programme for Education and Training, should also be considered. This formed part of the Lisbon goals during the period leading up the signing of the Lisbon Treaty in 2008. It urged attention to three priority areas, namely 
human resource development, lifelong learning, and the creation of a Europe of education and training, including the advancement of accreditation frameworks (Keogh, 2004: 20). These processes were exclusionary at their core, disadvantaging those not seeking employment, such as older people, people with disabilities that render them unable to work, or people in a caring role. They also undermine ideological interpretations of education beyond vocational meaning.

The difficulty with EU led interpretations of lifelong learning is its rootedness in the notion of human capital, a resource thought essential in developing and sustaining the knowledgeeconomy. The origins of the concept of human capital are commonly associated with the work of Chicago school economist T.W. Shultz and his thesis Investment in Human Capital $(1961)^{25}$. The premise of his argument is that 'human capital' is an untapped resource where investment in up-skilling people can create monetary return for an economy. Hurley (2014: 80) notes how, in the intervening years, 'economists and management gurus have fastened onto human capital as a convenient semantic category to cover all the dynamics affecting the capacity of a workforce', enabling it to have 'largely gained uncritical currency'. Though it has become a normative expression in conceptualising the purpose of education within EU policy, Shultz shares insight into the radical nature of his ideas when they were first proposed stating,

The mere thought of investment in human beings is offensive to some among us. Our values and beliefs inhibit us from looking upon human beings as capital goods, except in slavery and this we abhor. ... hence to treat human beings as wealth that can be augmented by investment runs counter to deeply held values. It seems to reduce man [sic] again to a mere material component, to something akin to property. (Shultz, 1961: 2)

As envisioned within Shultz's original concept, human capital development within EU policy has been squarely placed within the economic domain. This has meant an emphasis on measurable up-skilling, a problematic concept given its unexamined notion that a person who

\footnotetext{
${ }^{25}$ Within Shultz's thesis he notes indebtedness to Milton Freidman, another prominent Chicago School economist and someone commonly cited as influential in conceptualising neoliberalism.
} 
acquires skills in IT, linguistics, entrepreneurial and social skills can automatically counter social exclusion (Hurley, 2014: 85).

This pro-business turn spurred on by A Memorandum on Lifelong Learning (2000) has been enforced within subsequent EU policy. The 2001 communication Making a European Area of Lifelong Learning a Reality relays consultation with member States as a mandate that 'confirms lifelong learning as a key element of the strategy...to make Europe the most competitive and dynamic knowledge-based society in the world' (European Commission, 2001: 3). The communication calls for a transformation of traditional approaches to education and training, again centralising the self-directed individual engaging with flexible, transferable knowledge. Whilst it repeats education's potential to encourage active citizenship and appears to encompass concern for civic wellbeing, this is again narrowly interpreted through the expansion of opportunity within standardised systems of meritocracy viewed as opportunities designed to promote employment.

The most recent significant communication from the EU is the Resolution on a Renewed European Agenda for Adult Learning (Council of the European Union, 2011). This circular explicitly links adult education to another important influence, the European Strategic Framework on Education and Training $\left(\right.$ ET2020) ${ }^{26}$. Adult learning is presented as having a 'major role...by enabling adults - in particular the low skilled and older workers - to improve their ability to adapt to changes in the labour market and society'. It repeats the priority objectives set out in ET2020 (see footnote on page 124) and explicitly links lifelong learning to policy developments concerned with standardising and measuring learning across constituent members. Again this communication re-enforces education, particularly Further Education (FE) as an instrument for servicing the demands of the neoliberal global economy

\footnotetext{
${ }^{26}$ ET2020 sets out four strategic objectives as 1) making lifelong learning and mobility a reality, 2) improving the quality and efficiency of education and training, 3) promoting equity, 4) social cohesion and active citizenship.
} 
and dualistically stratifies learners towards binary visions of Higher Education and Further Education (vocational) pathways (Council of the European Union, 2011).

Some might argue there is little wrong with offering up-skilling such as computer training to a citizenry. The notion of a well trained, mobile workforce is surely beneficial, strengthening people's employment opportunities. Along with improving technological knowhow, increasing the value of human capital has been posited as essential in promoting individual wellbeing and ensuring equality of opportunity (OECD, 2001). In reality, human capital expansion through lifelong learning has exacerbated inequality through its binary approach as it divides society into those who are high-knowledge skilled, and those who are lowknowledge skilled (Brine, 2006). This has resulted in what Lauder (2011: 241) describes as a 'global auction for high-skilled work but a Dutch or reverse auction where jobs go to the lowest priced' a situation the author believes has been exacerbated by the global commodification of education beyond the EU and US. Maltone et al (2012) share how numerous studies have demonstrated that benefits from a more mobile workforce divide unequally, both country to country, and across social stratums. The researchers demonstrate increased numbers of working poor existing within an environment of low-pay, precarious contracts and increased levels of outsourcing (Maltone et al, 2012). Citizens within newer EU member States are especially at risk, over-run with piecemeal employment contracts, low-pay, and difficulties in maintaining work-life balances as EU rhetoric focuses on employment creation, or job quantity, and not job quality (Davoine et al, 2008). To borrow from Borg and Mayo (2005: 214-5), initiatives undertaken to increase the pliability of workers to the changing demands of the global economy is a strategy that ensures the availability of an 'army of workers' that is consistently updating itself', continuing, 'the process of the privatization of the learner, financed mostly by public funds and close to market needs, is well underway'. 


\subsection{Ireland's policy reaction: the implications for community education}

Ireland's response to A Memorandum on Lifelong Learning (2000) was to establish a steering committee of government representatives from the Department of Education and Science (DES), and the Department of Enterprise, Trade and Employment (DETE) (DES, 2001). This committee 'considered the Memorandum in the context of national policies and strategies for Lifelong Learning' with particular regard for 'the development of common strategies for employment and the co-ordination of national policy' (DES, 2001: 3). The committee described how it operated following an 'unprecedented level of dialogue on the theme of lifelong learning' (DES, 2001: 4). Included within this were the Green Paper, Adult Education in an Era of Lifelong Learning (Government of Ireland, 1998) and Learning for Life: White Paper on Adult Education (DES, 2000). Another policy worth emphasising is the White Paper on a Framework for Supporting Voluntary Activity and for Developing the Relationship between the State and the Community and Voluntary sector (Government of Ireland, 2000). Long awaited by those within the Community Sector, and again introduced following a consultation process with civil society organisations, it promised formal recognition for organisations, open and regular communication with the State, representation in policy making, and increased and more regularised funding. In its foreword the Minister for State, Community and Family Affairs shares, "my own personal view, is the most significant impact the White Paper will have over the long term is that it is based on a strong philosophy of support for the Community and Voluntary sector as an essential requirement to the health of our society and our democracy' (Government of Ireland, 2000: iii). The White Paper on a Framework for Supporting Voluntary Activity also acknowledged funding for community based organisations as a 'major issue' (p132) and promised to rectify this through multi-annual funding for 'agreed priority services and community development activities' committing to 'a major move away from the present unsatisfactory and ad hoc funding 
schemes experienced by many Community and Voluntary groups (Government of Ireland, 2000: 3, italics in original).

For those directly involved in community education, the White Paper Learning for Life (2000) was also momentous for its dedication of a chapter on what it described as 'the Community Education movement', a process-led innovative egalitarian approach (DES, 2000: 109). Its inclusion of two perspectives, outreach provision of educational institutions, or an ideologically led collective process linked to community development, is often cited as significant in preserving politicised approaches to community education. Yet despite recognising the work of an independent Community Sector and the way in which it was inadequately financed, the supports committed within the white paper did not directly address this. Instead Community Education Facilitators (CEFs) were appointed within State apparatuses of VECs. Their remit included encouraging close working relationships with independent groups and, in many respects, their role can be interpreted as a bridge between the work of community organisations and those within VECs (such as some AEOs), linking the two as best they could.

Some resources were put in place as a result of recommendations within the white paper. However, the equality-based language within this document should not detract from a broader much more powerful paralleling policy trajectory interested in harmonising domestic policy with EU sentiment. Such was the commitment of the time, the National Development Plan (NDP) 2000-2006 included a comprehensive statement on adult education and lifelong learning couched within its programme for employment and human resources development (Murtagh, 2009: 163-4). Murtagh (2009: 164) thinks this is particularly significant given the NDP's worth in determining budgetary allocation and policy priority. The implication is that the White Paper: Human Resource Development (1997), and its subsequent creation of an 
Expert Group on Future Skills Needs (EGFSN) ${ }^{27}$ was a more influential policy trajectory for adult and community education. Policy makers of Learning for Life (2000) were acutely aware of the emphasis on human resource development within the NDP and it was proposals also contained within the NDP that were ultimately implemented (Murtagh, 2009: 164-5). Murtagh (2009: 165) cautions of the need to pay close attention to Human Resource Development policy, the significance of which he believes adult educators fail to grasp.

\subsubsection{Change through New Public Management: community education in the 2000s}

The success of EU policy in infusing change was, in part, influenced by a period of uncertainty for community education at the beginning of the new millennium as it struggled to assert its identify. Clear landmarks could be evoked to demonstrate recognition and expansion, namely the Murphy (1973) and Kenny (1984) reports, as well as the green paper Adult Education in an Era of Lifelong Learning (1998) and white paper Learning for Life (2000) as previously outlined. The latter especially provided a framework for local practitioners, preserving an equality focus, and confirming an emphasis within communities of disadvantage. There was also the ongoing presence of AONTAS, The National Adult Literacy Agency (NALA), and growing involvement with other educators across the EU such as through the European Association for the Education of Adults ${ }^{28}$. Ó Muircheartaigh, (2004: 42) also details a growth in practitioner-led education strategies at the time as attempts were made to shape and define work on the ground. However, broader policy decisions away from the field were starting to be felt as practitioners reported increases in bureaucratic, vocational led demands from government funders (Fleming, 2004; Keogh, 2004: 10; Ó Muircheartaigh, 2004). There was no obvious policy or legislative intervention at this time to explain changes in relationships. What had changed was the way in which the logic of

\footnotetext{
${ }^{27}$ The EGFSN describes its central role as ensuring 'labour market needs for skilled workers are anticipated and met' (http://www.skillsireland.ie/aboutus/, accessed February, 2015).

${ }^{28}$ This was formally called the European Bureau of Adult Education.
} 
neoliberal marketisation was permeating socio-economic contexts, including the acceptance of its core tenets by the State (Finnegan, 2008). Fleming captures the implications of this shift by drawing our attention to a speech by the Minister for Education and Science at a community education conference held by AONTAS in the early 2000s where she stated,

There needs to be accountability for that money and an end result, not just a process. It is becoming increasingly obvious that, if education sectors and initiatives within them are to continue to attract and grow their funding, outcomes must be documented in terms of the objectives achieved and the concrete gains for the participants. That means that high quality and detailed participant data have to be produced at the start of the programme, ... and at the finish. Funding of a project cannot be solely justified on the worthiness of the client group. (De Valere, quoted in Fleming, 2004: 12).

This language of accountability and measurement marked a new direction in approaches to equality based community education; something previously framed in terms of community requirements and within an understanding of the process-oriented nature of the work.

For the Community Sector there was a distinct change of relationships with the State in 2002. This was through the dismantling of the Department of Community and Family Affairs, a department that swam against the tide of other departmental objectives by committing to an interpretation of community development as a way to support participation, empowerment and social justice (Connolly, 2014: 64). This change led to a review period under the newly established Department of Community Rural and Gealteacht Affairs (DCRGA) as is detailed within chapter one. Much change was implemented. Three-year funding streams were discontinued, work-plans became dependent on local government endorsement and a value for money paradigm was introduced that shifted emphasis away from previously accepted principles of capacity building and empowerment (Bassett, 2007). Again these were implemented through core tenets of New Public Management (NPM) with emphasis on reducing duplication (regardless of the different needs of communities and groups), more transparency in financial accounting, and administrative rationalisation (Combat Poverty Agency, 2003: 7). 


\subsection{Accelerated co-option2009- 2015}

On November $29^{\text {th }} 2009$ everything changed for the Community Sector in Ireland. This was due to the sudden announcement that the Community Development Programme, (established in 1990) and funding for Local Area Partnership Companies through the Local Development and Social Inclusion Programme (established in 1996), were to be terminated in 2010. This meant the disbandment of all locally based voluntary boards of management, with the majority of Community Development Projects (CDPs) merging within Local Area Partnership structures, now collectively entitled The Local and Community Development Programme (LCDP).

Some CDPs were not given this option with an immediate decision to cease funding communicated via e-mail ${ }^{29}$. The news was met with objection and organised protest from some of those working within the Community Sector. A range of oppositional tactics was employed, including picketing the offices of relevant politicians, open objection at information sessions, and collective gatherings to voice concerns and propose alternatives. These actions are reported within editorial and news accounts within Spring/Summer editions of the Community Sector magazine Changing Ireland ${ }^{30}$. However objections were sporadic and not united and an important consideration when advancing a neoliberal argument is reminder of neoliberal logic that accompanies economic structural change. The perceived common sense of NPM was, at times, internalised by practitioners within the sector. This included a welcoming by some of attempts to tidy up perceived messiness and heterogeneity. Additionally, many in the field were often unaware of the changes, including those within organisations likely to be most affected (CWC, 2012: 8).

\footnotetext{
${ }^{29}$ This information came from a CDP coordinator directly affected by this decision and action.

${ }^{30}$ www.changingireland.ie
} 
This wasn't the first attack on the Community Sector. Earlier in 2009, the State appointed Special Group on Public Service Numbers and Expenditure Programmes (or McCarthy Report) marked the implementation of a programme of rationalisation and funding cuts across the Community Sector that was disproportionate to other publically funded entities (Harvey, 2012). In adjusting to these cuts, Crowley (2013) details a 'survival agenda' as projects downsized, implemented redundancies, and competed with each other for increasingly limited funding including from philanthropic sources. Crowley (2013: 152) also notes a culture of self-censorship as some organisations toned down political opposition anxious to maintain whatever State funding they were left with.

\subsubsection{Privatisation of Community Development}

Further change came through increased State local authority control over the perceived functions of community development (DECLG, 2012a; DECLG, 2012b). This was again introduced through the optic of NPM namely administrative accountability, streamlined funding and prevention of duplication. On seeking legal advice on the implications of an EU directive $^{31}$, the DECLG opened the awarding of contracts for Local and Community Development Projects (LCDPs) to competitive tendering in 2014 through The Social and Community Activation Programme (SICAP). This is an important ideological shift in community provision, now potentially implemented on a commercial basis. Moreover, this realignment of community development, initially into State structures through local authorities, and then potentially privatised through an open competitive tender process, represents a direct transfer of resources built up by local communities through the Community Sector into private ownership. Objections to the launch of SICAP were

\footnotetext{
${ }^{31}$ Directive 2014/24/EU in public procurement calls for the awarding of public contracts by or on behalf of members States to comply with certain principles, most specifically non-discrimination, proportionality and transparency in the awarding of contracts (European Parliament, 2014).
} 
documented at information seminars held by its State funder Pobail including claims by some LDCP staff that the process was one of neoliberalism in action (Meagher, 2014). There has also been journalistic reporting of the impacts of Community Sector cuts (for example The Irish Independent, 30 ${ }^{\text {th }}$ September, 2009; Hearne, 2014; The Irish Examiner, $12^{\text {th }}$ March 2014; The Irish Times, February $\left.28^{\text {th }} 2015\right)$. However these are sparse when one considers the impacts of cuts at local level. The CWC also draw our attention to a lack of awareness amongst practitioners throughout the alignment process at one point noting how,

The lack of information on the ground is startling, even in the frontrunner areas where it might be expected that there would be some level of awareness. This is primarily due to the lack of information (a) from the Department of Environment, Community and Local Government who have so far not undertaken any communication strategy to ensure that communities are informed of the proposed changes, and (b) from the local authorities, who, apart from some exceptions, have been very selective in their communication. Real consultation is all but absent. (CWC, 2013: 2)

\subsubsection{State service realignment: from community need to employer need}

It is worth noting the way in which SICAP, for the first time, openly aligns community development and community education practice. This is something historically encouraged by those adopting radical/popular educational approaches, but in this instance is interpreted in a fundamentally different way. The essence of SICAP is of labour market activation implemented through measurable delivery on three predetermined goals. These goals are support for communities in engaging with local and national stakeholders in addressing social inclusion and equality issues, support for individuals and marginalised target groups experiencing educational disadvantage to engage with lifelong learning opportunities, and to move those unemployed closer to the labour market by improving work readiness, and promoting entrepreneurialism (www.pobail.ie, accessed, December, 2014).

The period leading up to SICAP also heralded a separate strand of change for community education provision this time as organised through the workings of Vocational Education Committees (VECs). This included the dismantling of FÁS (The Irish National Training 
Authority), and creation of Seirbhísí Oideachais Leanunaigh Agus Scileanna (SOLAS) in 2013. SOLAS was legislatively charged with overseeing a revised Further Education and Training (FET) landscape as VECs were merged into 16 Education and Training Boards (ETBs) with FÁS, integrated within this. Through SOLAS, Further Education was rebranded as Further Education and Training (FET). Demonstrating a strong pro-market logic, the SOLAS Corporate Plan 2014-16 (SOLAS, 2014b: 7) describes FET as a mechanism that will 'play its part by ensuring that individuals are equipped with the skills to compete for work...' further detailing 'employers play a key role in identifying the FET skills needed for business to thrive'. It continues 'SOLAS will collaborate more-intensely with employers at a national level...It will also support ETBs at local level to get closer to employers and build capacity to innovate and respond more rapidly to local employer needs and the changing contours of the labour market' (SOLAS, 2014b: 7-8). This reveals the centrality of employer demands over learner and community need, a sentiment continued throughout. Whilst the strategy fails to mention community education per say, its reference to 'many actors in addition to former VECs and FÁS', and to community development programmes and other Pobail funded schemes (SOLAS, 2014b: 20) indicates an interpretation that includes Community Sector organisations carrying FETAC accrediting rights.

\subsubsection{Community Education and conditional labour market re-activation}

Both SICAP and SOLAS (through the FET strategy, 2014-2019) are open to the influence of an ideological and policy shift towards implementing conditionality over welfare payments. This is where failure to attend particular education programmes can result in reduction of social welfare assistance for some people. A particular accelerant in advancing Ireland's conditionality agenda involves attention to policy approaches through a third governmental strand; the Department of Social Protection (DSP). The DSP transformed Ireland's approach to conditionality of welfare, something sluggishly implemented to that point (Murphy, 2012). 
Murphy (2012) explains the reasons for previous approaches as relative freedom for State employees responsible for implementation, a department (the DSP) considered down the governmental pecking order in terms of priority, and a lack of policy ambition within FÁS, content instead to provide piece-meal services in local communities. The DSP established the National Employment and Entitlements Service (NEES) (DSP, 2011), which strengthened this arm of welfare provision introducing compulsory individualised progression plans where failure to comply would lead to reduction or cessation of benefit payments (DSP, 2011: 4).

Ireland's newfound conformance with conditionality of welfare was not domestically conceived outside of external forces. Ladi and Tsarouhas (2014) describe the influence of the EU Stability and Growth Pact in demanding such policy reform as part of Ireland's Troika imposed structural adjustment programme (see chapter one). More broadly, the turbulence of EU economic downturns, including in Ireland, enabled austerity imposed fiscal discipline to be opportunistically exploited to align Nation States with neoliberal anti-welfare policies (Ladi and Tsarouhas, 2014; Windebank and Whitworth, 2014).

Community education particularly enters the fray through the NEES Labour Market Activation Policy as detailed within the Pathways to Work programme (Government of Ireland, 2012) with subsequent Pathways to Work publications for 2013 and 2014. This labour market activation policy is endorsed by the Department of Education and Skills and the Department of Social Protection, and promoted within the SOLAS FET Strategy 20142019 and can be described in terms of five strands. These are named as regular and ongoing engagement with the unemployed, greater targeting of activation places and opportunities, incentives for taking up employment, incentives for employers to provide employment (a strand linked to internship programmes Jobspath and Jobsbridge), and reform of institutions to improve services to the unemployed (Government of Ireland, 2012). 
This moved labour market activation away from seemingly passive approaches of processing claims and payments, to a more punitive case management approach organised through Intreo a one-stop-shop for unemployment related welfare supports. Here, jobseekers (policy terminology) are referred to education and training programmes thought to meet their needs as determined through an in-depth registration process. The meeting of DSP policy and community education (including VECs and ETBs) particularly emerges as a result of some providers tendering to the Labour Market Activation Fund. This was launched by the Department of Enterprise and employment in 2010 and has since moved to the Department of Education and Skills. Its seems likely any concerns held by community educators over mismatching of objectives were overlooked given the way in which historically community education has cobbled funding together from a range of sources and across a multitude of government departments.

In a review of labour market activation by the Department of Education and Skills, the involvement of the Community Sector has been applauded through an assertion,

The inclusion of providers outside the mainstream delivery agencies (e.g. from the private or community and voluntary sectors) was found to be a key attribute of the LMAF, despite concern among some stakeholders at involving providers who may not necessarily have delivered publicly funded programmes in the past. However, there were certainly notable successes arising from the inclusion of such providers as they often brought a new approach and way of thinking to the table. There is, therefore, a rationale for continuing to allow such open competition for activation funding on the basis of outcomes. (DOES, 2011: iv)

At yet, domestic research on impacts of educational attendance as a conditionality of welfare appears largely unavailable. One comprehensive UK study, Choosing to learn or chosen to learn (O'Grady, 2008), focused on UK conditionality of attendance relating to language, literacy and numeracy. The research demonstrates attendance as not only unlikely to improve capacities, but as a situation that creates conditions where participants actively reject engagement often amplifying negative associations with education. 


\subsection{Community-educators counter-hegemonic responsibility}

As demonstrated when determining the focus of this inquiry and as touched on within chapter one, a feature of this research is to ponder the reaction most relevant for community educators when faced with the at times pervasive affects of the neoliberal turn. Some commentators (including myself within Fitzsimons, 2012) have suggested that community education has somewhat lost its way and is often disconnected from original aspirations to nurture critical thinking and build a more authentic democracy. Demonstrating the global nature of neoliberal influenced NPM, similar concerns are expressed within other jurisdictions (e.g. Brookfield and Holst, 2011; Tett, 2014; Crowther and Shaw, 2014; Wildemeersch, 2014). Brookfield and Holst (2011: 2) share their sense of contemporary discourse where they claim that when compared to discussion on up-skilling and employability, talk of adult education 'in the same breath as democracy or socialism can seem either hopelessly out of date $[\ldots]$ or completely utopian'.

Whilst a number of Irish commentators have drawn our attention to neoliberal policy incursion (such as Finnegan, 2008; Grummell, 2014; Hurley, 2014; Murray, 2014), less considered are tangible examples of what practitioners might do to countenance this. Some suggestions are forthcoming. Neville et al (2014) propose a re-emphasis on individualised benefits of community education, whilst Connolly and Hussey (2013) propose attention to the personal is extended towards an analysis of the political and structural.

Suggesting that practitioners re-visit the purpose of their work in the face of policy interventions and the hegemonic weight of neoliberalism can at times feel like an overwhelming task and something it is hard to know how to address. Noting a demoralising impact, Crowther and Shaw (2014) offer us a framework for making sense of where we might begin. This is through a combination of 'strategic participation', and 'strategic nonparticipation' in our dealings with policy makers and the State more broadly. The former is 
proposed where involvement in governance structures can enhance democratic efficacy, hold these to account, and expand the pool of involvement beyond the same few. Strategic nonparticipation relates to ongoing work in opening democratic spaces for learning outside of traditional governance spaces, and supporting ground-up activism. Their more fleshed-out interpretation of these approaches is contained within table 3 below.

\begin{tabular}{|c|c|}
\hline Strategic participation & Strategic non-participation \\
\hline $\begin{array}{l}\text { - where intervention can make structures more } \\
\text { democratic and effective }\end{array}$ & $\begin{array}{l}\text {-the creation of convivial, democratic educational } \\
\text { spaces }\end{array}$ \\
\hline $\begin{array}{l}\text {-Where politicians and institutions can be held to } \\
\text { account }\end{array}$ & $\begin{array}{l}\text {-strengthened democratic spaces outside of } \\
\text { traditional governance arrangements }\end{array}$ \\
\hline $\begin{array}{l}\text {-Where democratic processes have grassroots } \\
\text { support and not just a ' 'consultative elite' }\end{array}$ & $\begin{array}{l}\text {-support the autonomous development of local } \\
\text { groups by emphasising distinctions between } \\
\text { policy priorities and group ambitions }\end{array}$ \\
\hline $\begin{array}{l}\text {-Where there can be challenges brought to } \\
\text { tokenism and manipulation } \\
\text {-Where the limits of democracy can be tested } \\
\text { through democratic engagement }\end{array}$ & $\begin{array}{l}\text {-challenging the framing of democracy through } \\
\text { policy instead of practice; making demands on } \\
\text { government that reinforce its democratic } \\
\text { capacities }\end{array}$ \\
\hline & $\begin{array}{l}\text {-emphasising the destructive implications of } \\
\text { neoliberalism }\end{array}$ \\
\hline
\end{tabular}

Table 3 - Strategic participation/non-participation (taken from Crowther and Shaw, 2014: 402-404)

Crowther and Shaw's framework would appear to hold resonance within Irish contexts also.

\subsection{Summary of chapter}

This chapter began by outlining the way in which interest in policy engagement has been a consistent feature of much equality-led community education practice. It outlines a process of neoliberalisation instigated through an EU led policy landscape that is informed by principles of marketisation. The objective of policy advancement, both EU and domestic, is towards a re-invention of lifelong learning, instrumentally applied and amidst attempts to exclude alternative approaches to education, be they in support of human development and wellbeing, or more critical social movement construal. Concepts underpinning this approach 
are towards human capital expansion interpreting this as a way to support the knowledge economy, once a marginal positioning but now adopted within the everyday discourse of adult education policy. Whilst an initial refashioning of community education has been through New Public Management and hegemonic cultural compliance, more recent changes have been more coercively imposed and with little or no consultation with practitioners on the ground. These events can be demoralising for practitioners and a model of strategic participation and strategic non-participation (Crowther and Shaw, 2014) is offered as a possible way of conceiving responses.

This chapter has been designed to complement the more historical and conceptual contextualisation offered within chapter three. Absent from both of these chapters is attention to the involvement of accreditation throughout the lifetime of contemporary community education. This will now be undertaken. 


\section{Chapter five: Accreditation and Community Education}

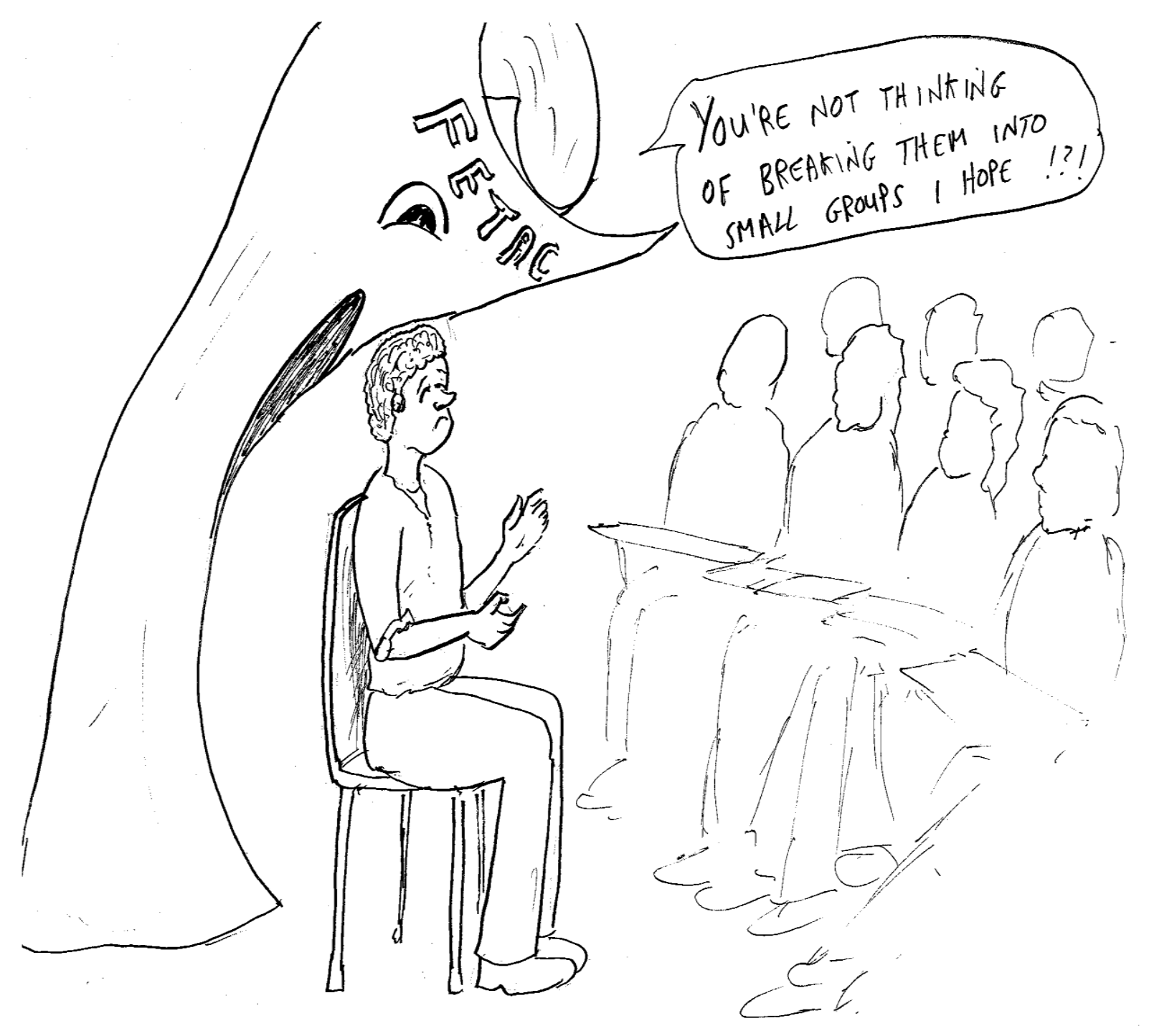




\subsection{Introduction to Chapter: critical practice meets external accreditation.}

A strange thing happened to me a few years ago when working on a community education initiative in Dublin. Through local recruitment efforts, 12 adults were enrolled for a short accredited course in housing studies. Among this group were people working in Community Sector and social care organisations, both paid and unpaid, as well as tenants of social housing. Led by generative themes emerging from the group and with one eye on the prescribed programme descriptor, I facilitated a process where we traversed such topics as State provision of housing, tenant's rights, rent arrears, culture and interculturalism, problem behaviour on estates, and community development responses. In designing the assessment, I incorporated direction from the group, encouraged by energetic discussions and keen to promote assessment for as an alternative to more rudimentary assessment of learning. People were allowed select any housing related issue they had encountered and, through dialogue and personal research, they were asked to consider an analysis of the personal, community, economic and political factors. The resulting social analysis spiral ${ }^{32}$ enabled an identification of key areas where a community could strategically intervene should they wish to influence change. The submissions I received were insightful, at times profound, and always informative. They were also presented within the literacy and linguistic standard I believed appropriate for the certification level in question.

What was strange was what happened when this submitted work encountered external authentication processes. This was as part of certification criteria by the accrediting organisation, in this instance a UK based housing institute. Rather than marvel at the work the participants had produced, as I had done, the outside adjudicator admonished my supervision informing me that at this level (UK level 2, equivalent to Eire level 4), these adults were not allowed to analyse. She suggested I replace the social analysis assignment

\footnotetext{
32 This exercise was designed by Banulacht, an independent development education organisation disbanded in 2009 in part due to the severance of State funding.
} 
with a descriptive exercise that would produce a more uniform response, one she considered more in sync with the course descriptor. This external authenticator was technically correct given the National Framework of Qualifications (NFQ) level in question as she interpreted its approach to measuring learning verbatim. That way, I was told, learning could be benchmarked against the prescribed marking criteria in a way that ensured their future vertical progression could be more easily calculated. This incident has stayed with me and I often reflect on it as an event that encapsulated limitations within some approaches to accreditation.

\subsubsection{Why consider accreditation?}

Much of the policy introduced as part of neoliberalisation has contributed to the circumstances detailed above and a key function of this chapter is to lay these bare. The development of systems of accreditation is relayed amidst reference to their relationship with vocationalisation, and their implementation under the influence of New Public Management (NPM). This is not the only purpose of this chapter. It also considers demands for accreditation from the ground up and dwells on the importance of epistemological power when the right to validate learning meets the instrumentalist standardisation relayed within the example shared. This chapter also reviews existing domestic research that shares experiences of accreditation within community education contexts. It draws from Foucauldian logic relating to the power of discourse (as introduced within chapter two) and contemplates practitioner responses to accreditation and the manifestations of power that stem from this.

Though the accreditation of learning is a research area of particular interest to me, I had reservations about reserving a chapter on the topic rather than a more summarised offering integrated elsewhere. What convinced me to persist was the weight of concerns about accreditation shared by participants in this study. I also wonder if, at times, its political 
significance is underestimated, a particular consideration given the sparseness of research into the impact of accreditation in domestic community education contexts.

\subsection{Demands from below for recognition of learning}

Increasingly, accreditation is the word used to describe systems of quality assessment that approve an institution, a programme, or both (Kohler, 2003; Harvey, 2004; Saarinen and AlaVa"ha"la", 2007). What is assessed includes the learning environment and learner supports, adequate resources including appropriate teaching staff, curriculum design and course contents, fair and consistent assessment of learning, programme accessibility and progression, and management and governance. It is only when the relevant accrediting body determines that these conditions are met, that recognised certification for programmes can be awarded. These are commonly benchmarked against national qualification frameworks.

The most comprehensive understanding of the historical demand for accreditation from within community education comes through research entitled Can you Credit it? Undertaken by Mary Kelly, this mixed-methods research was commissioned by both The Combat Poverty Agency and AONTAS and was published in 1994. It consulted with participants and organisers nationwide investigating 'the issues, if any in relation to accreditation needs' (Kelly, 1994: xiii). Kelly (1994) details how most community education at that point was non-accredited with her research measuring demand for accreditation at $79 \%$ of learners and $74 \%$ of providers. The reasons for such high demand are cited as threefold.

1. The right of adults in disadvantaged communities to have options for securing credit for competency, developed at local level, on the basis of merit.

2. The need for accreditation options, to improve access of disadvantaged groups and individuals to paid work, and to strengthen argument for more paid jobs in the Community Sector itself.

3. The need for accreditation to improve the current inequitable access, of those with no or low levels of qualification, to places on continuing education and advanced training courses. (Kelly, 1994: xix) 
Some opportunities to accredit learning were available at this time. These were through links with adult educators in certain universities, most notably within St Patrick's College, Maynooth (see Connolly, 2014 for an example). Other opportunities were through the National Council for Vocational Awards (NCVA) (est. 1991 and precursor to FETAC), the private UK based City and Guilds, and the Department of Education through Intermediate and Leaving certification (Kelly, 1994: xxi-xxiv). However early accreditation opportunities were sporadic and usually dependant on the impetus of the provider. Can you Credit it? was undertaken as part of attempts to advance a case for accreditation, something demanded of the sector elsewhere within literature (Kelleher and Whelan, 1992).

\subsubsection{Accreditation, power and the curriculum}

These demands for accreditation were not uncritically expressed. Kelly (1994) voices concern about individualisation and liberalisation of practice that conceives education as a way out of a community, rather than a challenge to the structural inequality it experiences. When examining EU policy, she expressed concern about a lack of clarity on the relationship between accreditation and non-vocational community courses. Kelly (1994) suggests the only way it can fully support community development processes is through equal partnership of practitioners, accreditors and the State. Less countenanced within Can you Credit it? is consideration for the relationship between accreditation and the curriculum, the determining factor in deciding whose version of knowledge or events form the axis of our understanding of a particular topic (Giroux, in Freire and Macedo, 1987: 18-19). This is to some extent taken up by Quilty (2003) who, when discussing women's community education, identifies a latent conflict between alienating theoretical knowledge as packaged by institutions and the knowledge built from life experiences. Curricular control is particularly relevant when we are reminded of the power of the hidden curriculum in conveying capitalist values of deference to authority, class expectations, and societal values (see pages 79-80). In 
determining how community education can avoid a hidden curriculum, Connolly (2008, within chapter eight) proposes that this can be achieved through curricular negotiations with groups, including shared decision making on aims, outcomes, and the knowledge that underpins learning. She also draws out the need to interpret assessment as a continuation of learning rather than a testing of pre-determined knowledge, and encourages incorporation of teaching methods in support of this. Additionally, Connolly (2008) suggests authentic and ongoing evaluation in order to direct ongoing and future events. Many community educators try to incorporate these tenets into practice on an ongoing basis. As outlined in the opening vignette, the difficulty is in considering the ways in which contemporary approaches to accreditation can compromise this. A helpful way to consider this is to expand our perspective on accreditation, positioning it within the wider educational realm, and the New Public Management led vocationalisation that has been discussed at length within the preceding chapter.

\subsection{State-led growth of interest in the accreditation of learning}

A common starting point when considering State interest in accreditation is Ireland's commitment to the Bologna Declaration (1999) and lesser known Declaration of the European Ministers of Vocational Education and Training, and the European Commission, or Copenhagen Declaration (2002). The Bologna Declaration (1999) committed members to adopting systems of easily transferable degrees at undergraduate and graduate levels, at appropriate levels of qualification. Endorsers also agreed on freedom of access for teachers and researchers, cooperation through comparable quality assurance mechanisms, promotion of required measurements regarding curricular development, inter-institutional cooperation, including staff and student mobility, and integrated study, and shared training and research programmes (European Higher Education Area, 1999). 
Given that accreditation, along with Quality Assurance (QA) have been described as 'inseparably linked and basic to the Bologna process' (Kohler, 2003: 317), one might be forgiven for perceiving its origins within State policy mechanisms. More accurately there is a long history that pre-dates Bologna as the origins of institutional and programmatic accreditation lies within universities, introduced as peer review structures to monitor standards (Harvey, 2004; Brittingham, 2009).

A core feature in implementing EU policies on lifelong learning that were advanced during the 1990s was finding a way to connect organically-conceived accreditation mechanisms across co-operating States. The Bologna Declaration (1999) helped to do this, significantly altering the educational landscape across 29 European countries, many of whom had previously resisted convergence measures (Van Der Wende, 2000: 305; Saarinen and AlaVa“ha“la, 2007:33; Croché, 2009). Both Bologna (1999) and Copenhagen (2002) declarations committed to the creation of transferable, credit-weighted measurements of learning. This was mainly through the creation of a European Credit Transfer System (ECTS) with our own 10 tiered National Framework of Qualifications (NFQ) fitting neatly within this. The impact of these changes in accreditation were not only confined to associating nations they also had a more global effect with many neighbouring countries adopting recommendations within these agreements voluntarily (Harvey, 2004: 200; Young, 2007).

\subsubsection{The development of Irish Accreditation mechanisms}

Leading up to Bologna, some advances had been made to streamline domestic accreditation outside of schools and universities through the establishment of the National Council for Vocational Awards (NCVA) in 1991. Prior to this, Further Education (FE) relationships with accreditation were 'ad hoc' (Clancy, 1999: 95), something relevant to community education given its growing reliance on FE qualifications. The government policy contribution Adult 
Education in an Era of Lifelong Learning: Green Paper (Government of Ireland, 1998: 66-

67) did consider accreditation for community education. However, this was predominantly framed through a vocationalised perspective, with the proposed introduction of foundational awards in literacy particularly encouraged for their potential to enhance employability.

Significant change mostly took shape through introduction of the Qualifications (education and training) Act (1999). This led to the creation of the Higher Education and Training Committee (HETAC) $)^{33}$ and, of significance for community education, the Further Education and Training Committee (FETAC) which was to become the primary accreditor. The Qualifications (education and training) Act (1999) also established the previously cited National Framework of Qualifications (NFQ) which was introduced in 2003. The NFQ was agreed following consultation with providers (NFQ, 2003c: 5) and expressed its vision to be,

The single, nationally and internationally accepted entity, through which all learning achievements may be measured and related to each other in a coherent way and which defines the relationship between all education and training awards. (NFQ, 2003c: 7)

The NFQ was introduced during a time when Lynch et al (2012) identify significant New Public Management (NPM) reform within public educational decision making. The NFQ helped anchor State interpretations on the purpose of education and named the NFQ's key principles as transparency, simplicity, relevance, quality, comprehensiveness and coherence and equality and accessibility (NFQ, 2003a: 11). Significantly there was a binate division of benefits, either for the learner, or for the employer, both of which are encapsulated within vocationalised ambition. Learner benefits are described as to enable career progression, to compare and contrast qualifications, to make more informed choices and to offer progression routes 'thereby avoiding education and training cul-de-sacs' (NFQ, 2003b: 6). For employers, there is promise of an easier way of measuring the standards of potential employees, and, in so doing, enabling identification of 'the most appropriate fit' for a

\footnotetext{
${ }^{33}$ HETAC replaced the National Council for educational Awards (NCEA) which had conferred Institute of Technology (IT) based qualifications to that point. The IT sector was particularly responsible for applied studies, vocational awards and technical advancement.
} 
particular position (NFQ, 2003b: 7). As with other such international frameworks, the NFQ measures learning through a 10-level grid of indicators with each level purporting to measure learning across categories of knowledge, skills, and competencies (sometimes referred to through the acronym KSC) with increasing complexity anticipated at each stage. To give an example, when considering how to measure competence insight, a person studying at level 4 is expected to 'assume partial responsibility for consistency of self-understanding and behaviour'. At level 7, the competence insight anticipated is to 'express an internalised, personal world view, manifesting solidarity with others' (NFQ, ND: 3).

Despite the instrumentalist perspective of the NFQ, the implementation of domestic change was initially less vocationally focused than the Bologna and Copenhagen declarations had intended. This was because of Ireland's established culture of consensus and partnership, and much responsibility for programme development and mapping was delegated to existing providers (Killeavy, 2005). This devolved approach was advantageous for community education as it opened up exciting possibilities for independent local organisations to apply to FETAC in order to become Quality Assured. Community education providers who were successfully awarded Quality Assurance (QA) were then able to interpret existing programmes to suit communities they were working with, and to devise their own modules, many of which were approved within FETAC mechanisms during the 2000s. These included FETAC awards in community development, interculturalism, social studies, social analysis, and group-work. They sat alongside other vocational awards commonly delivered in community contexts such as childcare and healthcare as community organisations up-skilled local people to take up employment opportunities both within the Community Sector itself, and further afield. Indicative of the accessibility of this system at the time, 203 Community and Voluntary Sector organisations were listed as FETAC registered centres by 2012. This 
figure represented $24 \%$ of all providers ${ }^{34}$ and demonstrated Community Sector organisations commitment to validation for learning.

This freedom was however curtailed by further domestic change, instigated through the Quality Assurance and Qualifications (Education and Training) Act (2012). The subsequent establishment of Qualifications and Quality Ireland Authority (QQI) through the merger of HETAC, FETAC and aspects of the Irish Universities Quality Board (IUQB) was particularly important with QQI now responsible for overseeing all qualifications and for managing the NFQ. It also issues certification within Further Education and private Higher Education providers, with universities and the Institute of Technology sector entrusted with the freedom to give their own awards. Quality and Qualifications Ireland monitors quality assurance, and, in the future, will authorise use of an International Education Mark (IEM) for providers that attract international students (http://www.qqi.ie/Pages/Mission,-Values-and-Goals.aspx, sourced March, 2015).

One of QQI's early undertakings was an internal re-structuring of FE awards into a Common Awards System (CAS) introduced in 2010. CAS wound up all public certification at levels 16 merging them under one standardised structure, an amalgamation that was completed in 2014. The migration process through which CAS was implemented decisively strengthened QQI's power over programme providers, introducing a validation system for all awards prior to delivery. Community education providers were now requested to submit a detailed programme outline for each award including rationale for its delivery. They were also tasked with providing detail on anticipated vocational outcomes, overall aims and objectives, and such details as contact hours, self-directed study recommendations, and progression pathways. Lengthy detail on indicative contents were also required, all of which were to be mapped to learning outcomes as pre-determined by QQI. These learning outcomes, often

\footnotetext{
${ }^{34}$ A full list of registered centres can be viewed at (http://www.fetac.ie/fetac/listProviders. do., accessed April, 2014).
} 
numbering up to 100 for a major award, are each to be summatively assessed. The migration process caused difficulty and discontent for many community educators, including some awards being withdrawn without negotiation (Fitzsimons, 2014: 159). For those that survived, organisations had to embark on a labour intensive and often unpaid process to secure their future capacity to deliver them; even where the original award had been organisationally conceived. This represented a shift in curricular power away from community educators and communities, into the hands of administrators and bureaucrats. It also decontextualised knowledge, weakening the integrity of community education that is dependent on circumstances to fulfil philosophical ambitions.

Another early action of the Quality and Qualifications Ireland (QQI) was publication of a set of green papers for consultation on a range of areas including access, progression, protection for learners, recognition of prior learning, and fees. The opening paper Green Paper on the Comprehensive Implementation of the Functions of Quality and Qualifications Ireland (QQI, 2013a), reveal the limitations of consultation and of the ideological shaping of relationships between QQI and providers sharing,

As a result of public sector cutbacks staff numbers have fallen by approximately $25 \%$ since the amalgamation was announced in 2008 and no new staff members have been recruited. Our operational budget has been reduced and we have also incurred costs in relocating and restructuring. The close and supportive nature of the relationships between the predecessor bodies and providers will be difficult to sustain in these circumstances. Moreover the nature of these relationships will need to be examined in the context of emergent QQI strategy. (QQ1, 2013a: 3-4)

This severance of a historically perceived 'close and supportive' relationship between QQI (formally FETAC) and registered providers marked a new era in dealings between accrediting awarders and the deliverers of these education programmes with the former adopting a more authoritarian, directional and monitoring role. Furthermore, disclosure of QQI's own limited financial resources further demonstrates the impact of neoliberalism's 
NPM within the public sector. It would appear that education is now considered something that must fund itself and not a social intervention that warrants State support.

\subsubsection{Interrogating mainstays: challenging apolitical accounts}

Alongside concern over curricular ownership and sufficient State subsidy, there are other interrogations of accreditation structures important to highlight, most of which rely on international literature. Accreditation is, at times, presented as an ostensibly neutral development within educational systems designed to lift standards, improve accountability and ensure the learner is at the heart of the educational experience. However, there have been important challenges to the often unquestioned proliferation of accreditation and its relationship with broader neoliberal agendas. The accreditation of learning has shepherded much standardisation and individualization into education systems, both of which are important components in advancing lifelong learning strategies neoliberal style (Harvey, 2004). Mainstays of NPM include the previously stated shift in power away from educators into the hands of managerial bureaucrats who, increasingly, also carry a monitoring role and whose interest in education is advancing labour market flexibility (Van de Wende, 2000; Harvey, 2004; Lock and Lorenzo, 2007). Additionally, there are concerns about the connections between the strengthening of external accrediting bodies and the commodification of education through a growth in private education providers (Scheele, 2004). Alongside broad-based criticism, there is documented disquiet about core components of accreditation mechanisms namely national frameworks, learning outcomes approaches, and quality assurance. Each of these will now be discussed.

\subsubsection{Difficulties with National Frameworks}

National Frameworks (such as the NFQ) form an important part of the advancement of accreditation. Despite their often unchallenged implementation across EU and non-EU States alike, there are conceptual problems to consider. Many of these are captured by Young 
(2007) who questions standard benchmarking independent from delivering institutions expressing concern about a rarely recognised gap between the written model, and practitioner attempts to make the model work. National frameworks offer a matrix that demand sometimes illogical amounts of qualifications are boxed into standard units, regardless of whether it is appropriate for every field to have representation at every level (Young, 2007; Allias, 2007; 2011). This can limit the emergence of organic awards with Young (2007) noting how many mainstays of national framework approaches namely concepts of transparency, progression and portability, fail to take the contexts of learning into account. Other criticisms include an overreliance on qualifications when determining suitability for employment (Young, 2007; Lauder, 2011), and the way in which the pursuit of qualifications is of most benefit to benefactors of marketisation, rather than recipients of certification (Allias, 2007). The standard application of frameworks across a range of disciplines is also argued as illogical given its assumption that similar benchmarks can be used to measure learning across disparate disciplines (Entwistle, 2005). Can certification in activism really be benchmarked against the same criteria as certification for arithmetic?

When considering domestic implementation of our NFQ a particular difficulty arises. This is because of the way in which the NFQ applies absolutes to such subjective concepts as insight and self-understanding. When one considers the application of the NFQ across either Further Education (FE) for levels 1-6, or Higher Education (HE) for levels 7-10 this brings a hierarchy of esteem, directly linking professionally recognised qualifications to specific levels. In practice there has sometimes been a resuscitation of Bloom's taxonomy (Fitzsimons and Dorman, 2013: 53-54), a proposition first muted in the 1950s and built on the notion that there is logical progression in skills and knowledge acquisition, as learners continue to learn. Bloom et al (1984) categorise learning as cognitive, affective and psychomotor, proposing a six-tiered hierarchy ranging from knowledge or the ability to recall 
at its lowest level, to synthesis and evaluation at its peak where new knowledge is constructed and judgments are made on the validity of certain claims. When applied to a laddered framework of qualifications such as the NFQ, this classification encourages behaviourist practices at the lower rungs, a carrot-and-stick approach concerned with the transference of certain unchallenged skills and predetermined knowledge, measured through repetition and reinforcement. Whilst arguably affective in encouraging recall, behaviourism can be criticised for its lack of creativity and critical thinking, and its failure to acknowledge constructivist beliefs where knowledge can be created through the lens of our experiences. Behaviourism also encourages previously named assessment of, rather than assessment for learning.

The epistemological power at the heart of curricular control can again be emphasised as national frameworks determine the weight of meaning attributed to certain knowledge. It does this by positioning Higher Education (HE) as generator of new knowledge, a privilege not only enforced by national frameworks, but additionally protected by academic freedom (West, 2006). For Further Education (FE), the role becomes reproducer of knowledge created and validated by those within $\mathrm{HE}$, therefore usually people whose socio-economic and cultural contexts greatly differ from many FE and community education attendees. This relegation of FE awards to lower rungs serves to entrench perceptions that it is only those at the upper echelons that are capable of high level thinking. This is problematic for community education that is built on notions of conscientisation and underpinned by concepts of critical thinking revealing a potential incompatibility with frameworks approaches.

\subsubsection{Interrogating learning outcomes approaches in community contexts}

The NFQs relatedness (not sameness) with outcomes approaches measured through the assessment of learning is also central to fully understanding its implications. Measuring the effectiveness of an educational encounter against the meeting of certain pre-determined 
learning outcomes has become a widespread and pervasive feature of contemporary educational discourse. Programmes are now routinely shaped around learning outcomes from which curricula are commonly developed, then benchmarked against national frameworks. As with wider concepts of accreditation, learning outcomes approaches emerged from universities themselves (Hadril, 1995). Outcomes approaches were largely welcomed by educators for their student-centeredness over teacher-centeredness which was the prevailing model before implementation (Hadril, 1995; Beno, 2004).

This reduction of the prime objective of education to a pre-determined end product can be challenged, not least because of the way in which it is blind to outcomes that could be delayed or unanticipated. Of importance to community education, especially that which connects itself to concepts of community development, there is also blindness to the way in which outcomes can be self-determined. Another difficulty is their limited recognition for the knowledge and experience a person brings to a learning environment. Allias (2007: 69) believes the emphasis on the end-product is again of particular benefit to the neoliberal market, dismissing contexts and processes thereby enabling funding to be awarded to whoever can achieve a set of prescribed outcomes at the lowest cost. She claims this creates a more competitive market for both the provision and purchase of education.

Practical difficulties that arise in implementation are not disconnected from conceptual concerns. Learning outcomes approaches provide a string in the bow of NPM as they enhance opportunity to monitor practitioners and promote the marketisation of education, becoming, in practice, little more than an administrative chore for course designers (Hussey and Smith, 2002; 2008). The excessive number of learning outcomes and their imposing system of summative assessment that accompanies QQI awards has led to discontent amongst community educators (Fitzsimons and Dorman, 2013; Fitzsimons, 2014). The sheer volume of outcomes to be summatively assessed also particularly suits banking approaches to 
education given its suitability to assessment of learning over assessment for learning. Both approaches to assessment are a power-laden activity and an educator's familiarity with assessment can sometimes lead to casualness in its introduction. This can underplay the weight of emotion for those being assessed, something Boud pays attention to when he claims,

Learning is an act which necessarily leaves us vulnerable: we open ourselves to changes in the ways we see the world, not knowing where we shall end up. We might find a secure spot or be exposed. Rarely are we confident about what we know during the early stages (which include most of the time we are being taught) - the very stages at which we are mostly likely to receive the comments from teacher. We know how little we know and we fear the depths of our ignorance. To have someone come along and tell us that, for example, what we are doing is all wrong or that we will never do it well or that we haven't read the book when we thought we had is a direct attack on us when we are least able to cope with it. (Boud, 1995: 43)

As the accreditation of community education can strengthen negative associations with education that began in schools (Quilty, 2003; Cullinane, 2003: 82), it is imperative this emotional dimension of assessment is not overlooked as bureaucratic demands to measure pre-determined outcomes can become the priority.

\subsubsection{Questioning quality assurance frameworks}

A third aspect of understanding is consideration for quality assurance (QA) mechanisms, the procedural rules in verifying quality systems, as approved by the accrediting body. In the past, it was not uncommon for a range of local models to exist, drawn up by education providers and contextualised within their participant group and circumstances. More recently, QA documentation has become more standardised, with a central feature being the introduction of internal and external monitoring processes. Notwithstanding the benefits that outside perspectives can bring, there are difficulties with this system not least the way in which little training and support is available to those occupying these roles. Diversity across student's work can also be portrayed as a negative feature with external authentication procedures sometimes appearing to favour a more uniform approach (see for example 
FETAC, 2010; Universities UK, 2011). This negates the opportunity for problem-posing assessment in favour of banking approaches to education where the regurgitation of set knowledge is preferred over the co-construction of new knowledge by learners.

\subsection{How is it going? Sharing experiences from practice}

As has been demonstrated, the accreditation of learning was conceived of by educationalists as a collaborative process in shared learning and improvement of standards. For community education, its introduction was largely welcomed, given strong demand for recognition (Kelleher and Whelan, 1992; Kelly, 1994; Quilty, 2003: 58). This demand has also been reasserted more recently (Neville et al, 2014: 47). Thus far, a number of concerns have been drawn out for community education, a central issue being epistemological control over curricula, and the way in which mainstays of accreditation are more suited to marketised and vocationalised approaches. This alienates those working from alternative philosophical perspectives, and disenfranchises those either not in a position to take up employment, or engaging in education with another purpose in mind.

\subsubsection{Community educators struggle with accreditation}

On contemplating the momentous changes accreditation has brought and the strength of emotion surrounding it (Fitzsimons and Dorman, 2013: 52), there is surprising little domestic research available on community educator experiences. Since the creation of FETAC in 2001, just two papers relating to accreditation and its impact have appeared in The Adult Learner, the Irish Journal of Adult and Community Education. The most recent of these is detail of a cooperative inquiry I co-facilitated in 2011-2012 (Fitzsimons and Dorman, 2013). This was carried out with a purposefully selected group of facilitators, all involved with accredited and non-accredited programmes. A paradoxical relationship with accreditation was uncovered within this study with positives named as the way in which accreditation builds confidence, gives credibility to community research, develops critical capacities, documents 
practice, and enhances the status of community education. However there was an overwhelming sense of dissatisfaction with current accreditation systems perceived of as being dominated by FETAC awards. Negatives were named as the overtly prescribed nature of curricula, its potential to stifle self-determination, and, shared by one participant, 'a potential tyranny of writing with set academic methods encroaching on more spontaneous, unstructured narratives' (Fitzsimons and Dorman, 2013: 53). There was acknowledgement of the financial value in holding accredited awards, something most of these research participants had directly benefitted from, and a concern that by not offering accreditation, there is complicity in reinforcing inequality. Underpinned by a critical theory framework, the inquiry emphasised three specific advantages. These are the way in which accreditation on a subject relevant to life struggle can lay a foundation in personal confidence, the way it enhances the rigor of learning through the need to often formulate analysis in writing, thereby sharpening thinking and the way in which it can provide some guide in standards for competency. Similarly, there are tensions including encouragement of standardisation, congruence with meritocracy, positioning of the facilitator as expert, and acknowledgement of the economic capital certain awards carry over others (Fitzsimons and Dorman, 2013).

The second publication within The Adult Learner details the experience of a group of VEC employed community based literacy tutors. Keyes (2004) draws out difficulties as a perceived tutor inadequacy around subject specialisms, as well as concerns for learner autonomy. She also notes an increased tendency towards behaviourist, banking approaches to education. Tutors shared how standardised curricula and prescribed outcomes were reinforcing traditional teacher-student relationships, and encouraging standardised approaches. She relays, 
The primary tension that existed for our tutors was that of a perceived conflict between a student/learner led curriculum and a subject led one; they perceived accreditation as taking the major focus away from the student to the subject, something which they saw as in direct conflict with their ideological position on adult education. Whereas they would have worked from a 'curriculum' previously, it was one that was negotiable and very much driven by the learner's needs. (Keyes, 2004: 71)

The recent NPM conceived re-structuring of education provision through the creation of Quality and Qualifications Ireland (QQI), has resulted in further measurable discontent from practitioners, this time the potential for their capacity to accredit to be withdrawn. This is through QQI's introduction of a new fee structure for 'legacy providers'. ${ }^{35}$ Some community educators have objected to this, raising concerns about the socio-economic profile of those they seek to support and the limited funding available to Community Sector organisations (QQI, 2013b: 5). Reflecting discontent, the AONTAS CEN launched a campaign against these fees in 2014. Their campaign launch document states,
AONTAS and the CEN are particularly concerned about the impact of the proposed fees on the community education sector. Community education providers are already under resourced and overstretched. The introduction of this fee would have a detrimental effect on the community education sector as many providers would have to withdraw from engaging with QQI and thus not be able to provide accredited community education courses to learners. (AONTAS CEN, 2014: 2)

Challenges such as these create an opportunity for community educators to consider developing their own models of accreditation built upon the principles of community education. This suggestion has been advanced previously (Kelly, 1994: 123) and alternative models for measuring the effectiveness of community education have been advanced (AONTAS, 2012b; Neville et al, 2014). The difficulty with alternative models of accreditation is the lack of social and economic capital they carry, a key driving force in early demands for accreditation (Kelly, 1994: xix). A further factor that will be demonstrated in

\footnotetext{
${ }^{35}$ The term used by QQI to describe existing providers who are required to re-apply for accrediting rights every five years
} 
this study is the increasing difficulty practitioners are experiencing in securing funding for non-accredited programmes.

\subsubsection{Regulators/accreditors as a panoptical illusion?}

As has been detailed, Qualification and Quality Ireland (QQI) have been positioned as the organisation responsible for establishing and maintaining these systems of accreditation, agreeing standards by which awards can be distributed. The premise this supports is that, guided by regulations of the awarding body, the community educator should create the conditions conducive to successful measurement of pre-determined learning outcomes. There is however a further as yet under-investigated consideration relating to the interpretation of accreditation by practitioners, as it would often appear too much power is afforded accrediting organisations over and above the restrictions they set out (as depicted in the illustration on page 138). Keyes (2004: 70) alludes to this through her observation that many concerns shared by tutors are often misguided. It is also important to share examples where accreditation is adopted within experiential, participatory, praxis oriented approaches (Fitzsimons and Dorman, 2013: 45).

A helpful way in conceiving of why community educators may attribute excessive power to accrediting bodies is to again look to Foucauldian insights on relationships of power at the extremities (Foucault, 1977; 1980). There is particular worth in the conception of selfregulation, originally conceived of through a genealogy of prison architecture and the introduction of panoptical observation (Foucault, 1977, within chapter three). Foucault contends the potential of surveillance alone is sufficient in creating a culture where the expectations of the observer (or in this case regulator as QQI) can result in the internalisation of perceived regulatory demands. This can lead to an adaptation of practice over and above what is actually required. The possibility of this disciplinary power operating within education structures and related to the measurement of learning has been proposed elsewhere 
with respect to school systems (Lynch, 2010: 15). Lynch notes the way in which the potential for observation and monitoring over and above the actuality of regulator demands directly impacts behaviours within individualised encounters between teachers and students.

This suggestion doesn't negate the power of the accreditor or the changes that have been imposed through QQI rather it suggests attention be paid to additional power in discourse. This is the way in which discourse may not only re-enforce the demands of the accrediting body, but result in a metamorphosis that is more controlling than the accrediting body originally intended its regulations to be. The end result is an exercising of power over community education's teaching methodologies that is not strictly demanded by QQI. A contributing factor in such self-regulation is the absence of research relating to accreditation in community education settings. Such Foucauldian assertions are offered amidst acknowledgment of the complexities they throw up when considering theories of power, and the complicatedness of their broad application. Further exploration, beyond the scope of this inquiry, would enable a more comprehensive review of literature and experiences in this regard.

\subsection{Summary of chapter}

This chapter began with an account of bottom-up demands for accreditation by community education providers, largely conceived of through a rights-based perspective. It then set out to demonstrate the significance of neoliberal led policy, both EU and domestic, in shaping the work of community educators. Momentous change has occurred since the late 1990s, overshadowing all previous policy interventions to that point. Whilst the impetus for the formal validation of learning emerged from educationalists themselves, this chapter details the propagation of these mechanisms for the implementation of a vocationally-led neoliberal agenda. There seems little doubt but that there has been a neoliberal colonisation of mechanisms of accreditation, appropriated as a way to measure outputs, eases transparency 
through standardisation, and monitoring practitioner performance. This chapter proposes that accreditation in a way that curtails curricular control is detrimental to the epistemological esteem of much community education given its disregard for the generation of knowledge through experience, and the importance of localised knowledge. Drawing from limited literature on experiences in practice, this chapter also raises the potential for power at the extremities to be exercised in a way that limits practitioner's abilities to manipulate accreditation mechanisms in a way that might bring greater unity with philosophical stances and community need. This assertion is extended cautiously and in contradiction with the vignette that opened the chapter. 


\section{Chapter six: Critical education's person- centered approach}

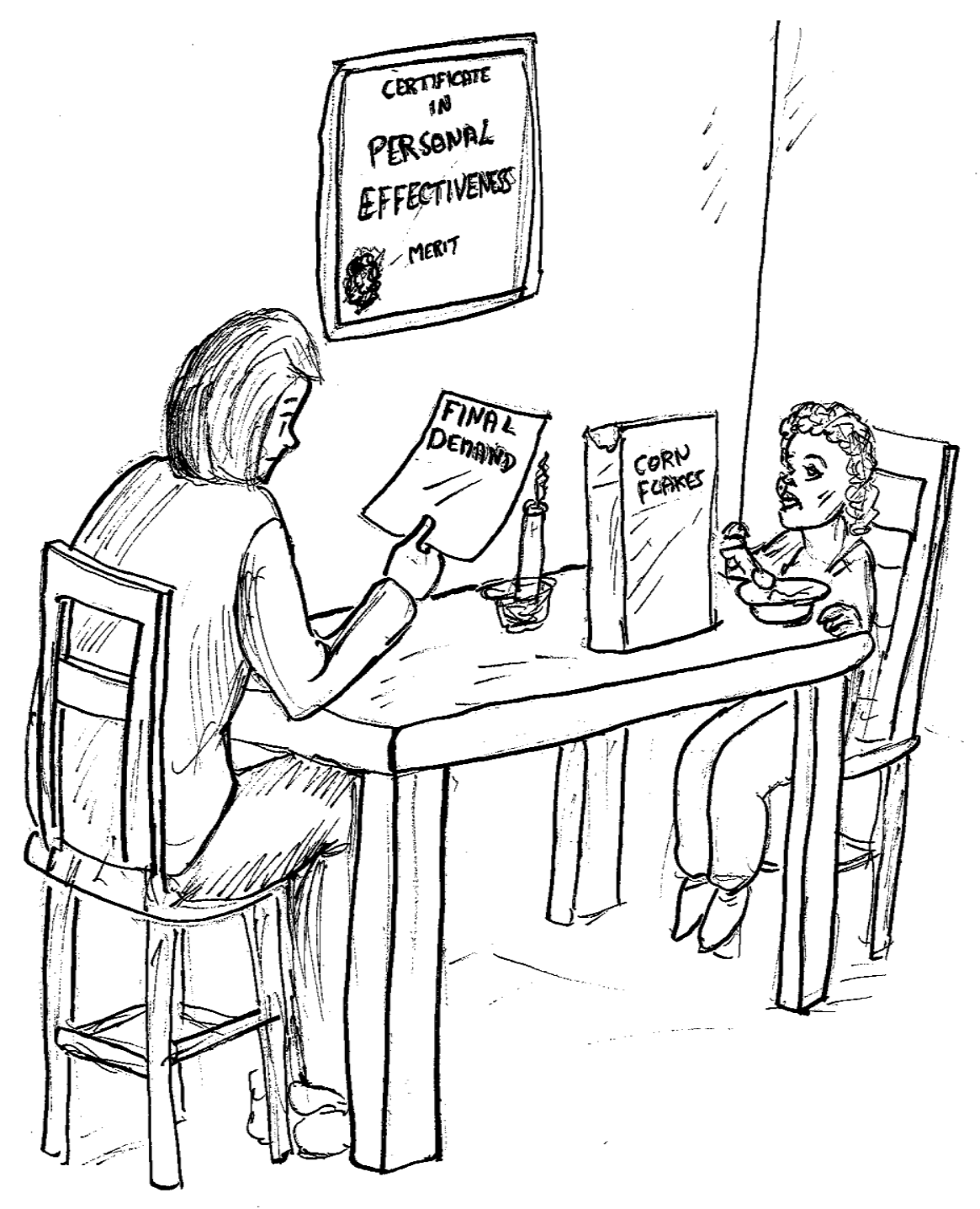




\subsection{Introduction to chapter}

In the classrooms of Charles Dickens Hard Times (2012/1854), Cissy Dupe's intimate equestrian knowledge is ridiculed by the authoritarian Mister Gradgrind. What is favoured is a scientific, depository approach where objectified knowledge is poured into to the minds of near apathetic recipients. Cissy, or girl number 20 as Gradgrind prefers, is admonished for supposing her personal encounters can illicit understanding, and ridiculed for quizzing authoritative sources. Facts, facts and more facts are the order of the day as listless learners are prepared for unquestioning adulthood where the societal status quo will be harmoniously maintained. Cissy's free-spirited disposition would, in time, be eradicated.

I have sometimes used this literary passage in totality with community based groups I have worked with. It encourages contemplation of Cissy's circumstances, and on the way Gradgrind embodies a particular approach to education, the transfer of indisputable knowledge from elder to youth to be absorbed and reproduced in a manner that maintains a functioning, non-questioning society. Deliberation on the situation as Dickens imagined it enables contemplation of our own experiences within school and colleges, and encourages a sharing and validation of personal biographies.

Although fictitious, Cissy's experience holds currency for those of us who seek other ways than such impersonal, depository approaches to education. Adult (and community) education offers such alternatives and in doing so, has developed into a distinct field of practice with a supporting academic tradition. Adult education is informed by beliefs that have been developed along philosophical lines of inquiry that include classical and rational humanism, rationalist, empirical and scientific though, concepts of materialism, and anarchist and Marxist traditions (Elias and Merriam, 1995). These are commonly organised into distinct philosophies of education introduced to students along categories of liberal, behaviourist, progressive, radical, and humanistic approaches, with some variation across 
contributors (see for examples Elias and Merrian, 1995; Merriam and Brockett, 1997; Tisdell and Taylor, 2001). Whilst there are important differentiations across these categories, there can also be commonalities; most notably a person-centered, self-directed approach which Knowles claims can be applied across traditions (Knowles et al, 2011: 2).

\subsubsection{Why challenge person-centeredness?}

Considering this research's ambition to inquire into ways in which critical education can rekindle community education, this chapter is about determining what critical education is. It doesn't do this in isolation but attempts to draw out similarities and differences with humanistic/person-centered philosophies. Part of the need to do this is in recognition of the considerable influence humanistic concepts of person-centeredness have extended over adult education since the mid-1900s (Elias and Merriam, 1995: 121; Merriam and Brockett, 1997: 39; Pearson and Podescki, 1999: 42; Cornelius-White, 2007: 113; Rogers and Horricks, 2010: 109). This study presents person-centeredness as important (a concept also strong within progressive traditions), but fundamentally challenges its limitations when contained within humanistic approaches alone.

Acutely aware of my earlier reluctance in strictly adhering to definitions when discussing contested concepts, this claim is made amidst a certain interpretation of humanism. I have drawn from Elisa and Merrian (1995: 116-121) who broadly characterise humanism as a belief that people are essentially good, that our behaviour is influenced by our freedom to choose, that each of us has the potential to succeed, that the self is at the core of our being, a self that can be nurtured and can grow, that we each have our own perceptions of things, and that we each carry personal responsibility. The notion that self-developed individuals can influence social progress is also common amidst explanations of humanism. This chapter challenges these assumptions and presents humanism as insufficient in advancing egalitarian 
change within current neoliberal conditions. This is because of an insufficient structural analysis of inequality and power, and the way in which communities availing of locally based education are particularly impacted by this.

Before detailing critical theoretical concepts, a critique of humanism will be offered drawing out its limitations. This is followed by a comprehensive account of the ideas of Paulo Freire drawing from his contributions to offer an approach to community education that addresses its egalitarian demands.

\subsection{Person-centered approaches within community education}

Person-centered approaches have been a mainstay within contemporary community education since its inception in the mid 1900s. It is revolutionary as an approach to learning when compared to the Church led classrooms that preceded it. Stories not dissimilar to that detailed by Dickens were common during Ireland's post-independence period as classrooms were characterised by nationalist inculcation and embedding of fixed Christian notions of human nature and destiny (Coolahan, 1981: 38; Inglis, 1998; O'Sullivan, 2005; Walsh, 2005). By putting the person at the centre of learning, community education brought a radical alternative that honoured subjective experiences, and took cues on what was to be learnt from participants themselves. This greatly differs from many people's previous experience of education, and it is not uncommon for adults within community education spaces to share stories of unhappiness from school. Community education can offer a safe, respectful haven for the development of intellectual capacities.

Humanistic concepts of person-centeredness are influenced by client-centered approaches to therapy, most notably as conceived of by Carl Rogers $(1969 ; 1989)$. As a school of thought person-centeredness holds empathy, unconditional positive regard, authenticity; and reflexivity as fundamental. Rogers describes the central hypotheses as, 
That the individual has within himself or herself vast resources for self-understanding, for altering his or her self-concept, attitudes, and self-directed behaviour - and that these resources can be tapped if only a definable climate of facilitative psychological attitudes can be provided. (Rogers, 1989: 135)

Maslow's suppositions of the self through a hierarchy of human need, proposed in 1943, have also been afforded considerable space across literature on person-centeredness. This is where individuals are thought to carry responsibility for their own growth and, through this, are capable of influencing social progress (Pearson and Podescki, 1999: 44). Similarly, Knowles' concept of andragogy is commonly linked to humanistic approaches, the idea that learning can be differentiated from that in childhood with motivated adults drawing from their experiences to self-direct in a goal-oriented fashion (Knowles, 1980; 1984; Knowles et al, 2011). Knowles conceptions have not gone unchallenged with confrontations of the idea of adulthood in and of itself presenting it as socially constructed and open to cultural variance (Rogers, 2002: 40; Jarvis, 2004: 45; Fenwick and Tennant, 2004: 55; Boshier, 2006: 59). Additionally, Merriam (2001: 5) believes children can also learn in a selfdirected way that draws from personal experience.

Humanism as a philosophy has been traced to renaissance ideals of the well-rounded citizen based on essential principles that, where there are positive human relationships between teacher and learner, a person's full potential can be achieved through education (Elias and Merrian, 1995: 112-3). When applied to community contexts, the facilitator/tutor assists learning towards enhancing a fully-functioning person; better equipped to take up meaningful citizenship, better at initiating informed actions, and more effective at taking positive action in their lives. In offering their approach to adult education, AONTAS, the Irish National Adult Learning Organisation appears to align itself with this approach, one which encourages personal transformation as a means of strengthening democracy (Rogers, 1989: 325). They propose, 
For the individual, adult learning provides a means of achieving ones full potential through developing confidence and skills essential for employability, nurturing creativity and imagination, enhancing family relationships and enabling civic participation. For society at large adult learning is essential to building a sustainable economy, promoting social change, highlighting structural inequalities and building a healthy democracy. (AONTAS, 2011: 2)

Individualism is centre stage; a mechanism for social participation over transformation, whilst structural inequalities are to be highlighted rather than directly challenged.

\subsubsection{The benefits of humanistic, person-centered approaches}

This humanistic approach has changed the lives of many people accessing community education. Its person-centered philosophy underpins many compensatory, or second-chance, approaches addressing short-falls in the education system through opportunities to make up lost ground. At a glance, it is difficult to see downsides to person-centeredness. After all, why would a community educator work in any other way? Some compelling arguments within humanistic approaches have been put forward that centralise education in advancing a more equal society. This is by presenting individuals as agents for change. Weber makes the case as follows,

Humanistic psychology's contextualism leads to participation as an intricate and delicate dance of learner, teacher, and global context, contributing to transformational kinds of learning promoting change. Such a change considers globalization's demands, people's inter connectivity, quality participation, and learning environments committed to a concern for humanity. (Weber, 2014: 66)

Not only does this ascribe to the needs of the learner as paramount, it casts a different role for the teacher requiring them to take on a facilitative over directional role sharing tutelage with the self-directed learner.

However there are fundamental problems at the core of humanistic tendencies, not least the way in which individualism is a largely Western notion therefore not culturally applicable universally (Merriam, 2001: 5). Its promise of increased democracy through greater participation can be challenging by questioning the concept of the autonomous self, a self that can exercise 'inner freedom' in realising her or his full potential (Rogers, 1989: 28). Critical 
pedagogy rejects this notion, its essence well summarised by McLaren as belief that rather than being free, we are 'unfree and inhibit a world rife with contradictions and asymmetries of power and privilege' (McLaren, 2009: 61, italics in original). By suggesting a dialectical relationship between humans and their social and cultural environments, critical pedagogy proposes attempts to remove the individual from contexts that are stratified by class, gender, ethnicity, religious belief and physical ability are futile. Where humanism is concerned with how we, as individuals can be different in the world we inhabit, critical pedagogy is concerned with how the world itself can be different.

\subsection{Critical pedagogy and equality based community education}

Critical pedagogy is a school of thought that has been described as evolving 'out of a yearning to give some shape and coherence to the theoretical landscape of beliefs and practices that contributed to an emancipatory ideal of democratic schooling' (Darner et al, 2009: 3). Giroux $(1983$; 2009) draws out historical connections to neo-Marxism within the Frankfort School notably Adorno, Horkheimer, Marcuse and also Habermas. What he sees as important in these contributions is their attempts to re-claim elements of Classical Marxism from orthodox readings that were deliberated on as reductionist and defensive in their protection of European communist parties of the time. Giroux (2009: 29) summarises collective discontent as difficulty with the notion of historical inevitability, the centrality of history being shaped through the mode of production and the primacy of the labour process as the site of struggle. Often critical of classical Marxism's positivistic tendency towards economic determinism and lack of attention to the social realm, many critical theorists encourage us to focus on human activity as contributory in forming its economic base as much as being determined by it.

For critical pedagogy the notion of individualism as freedom (Freidman, 1962/2002) is challenged. Instead, individualism is viewed as enshrined within marketisation and as 
detraction from the systemic causes of our circumstances. Critical pedagogy problematises social relations such as class and gender with its essence being to create a counter-hegemony that gives voice to subordinate culture and provides courage to question our compliant participation in maintaining oppression (Darner et al, 2009). A central feature of critical pedagogy is belief that another world is possible.

Rejecting individualism can sit uncomfortably for some as its opposition can be mired by confusion of sameness over collectivity thereby inhibiting self-expression. Pearson and Podeschi (1999) offer a contribution that makes a useful distinction between individualism and individuality. They draw out three defining characteristics that hold current concepts together. These are an ontological belief that the individual exists outside of social arrangements, a conviction that the rights and attitudes of this individual takes precedence over collectives, and a sense that society is best understood by studying individuals rather than social structures. Pearson and Podeschi (1999: 49-50) view this perspective on individualism as the opposite of socialism and differentiate it from individuality, the opposite of conformity and a word that describes the uniqueness of each of us within the social conditions within which we exist.

\subsubsection{Community education as popular education}

There is heterogeneity within critical pedagogy, not least given its theoretical assertion of the need to continually critique itself. One substantial approach commonly considered when discussing community education is popular education. Popular education carries the core tenets of critical pedagogy and is also capable of incorporating many canons of humanism within. This is through the way in which self-directedness and belief in human potential are considered important in developing critical consciousness, whilst nurturing personal experience in order to reveal the structural and cultural nature of inequality, also requires

mutual respect between teacher and learner. Popular education emphasises dialogic methods 
undertaken not only to promote individuality, wellbeing and capacity, but to also reveal structural inequalities of power and knowledge and to encourage people to join forces in intervening (Crowther et al, 1999; Kane, 2001; Beck and Purcell, 2010). Its differentiation from critical pedagogy lies in its particular rootedness in the hopes and struggles of ordinary people located outside of public educational spaces (such as universities) and in community contexts (Horton and Freire, 1990; Kane, 2001; Choules, 2007; Connolly, 2008: 54; Beck and Purcell, 2010; Wiggins, 2011). Choules (2007) explains how crucial pedagogy arose from the 'Western academy' as a well developed social justice vision with a strong sociological critique of the education systems detailing how,

Popular education, on the other hand, arose from the lived experience of working with groups denied access to resources and power. It has a stronger focus on its methodological aspects - on the "how to" or the instructional form that it takes. Critical pedagogy's greater focus on sociological critique rather than instructional practice has facilitated the adoption in the West of the instructional form developed by popular education in Latin America. (Choules, 2007: 160)

Where critical pedagogy is principally concerned with theorising a coherent vision to transform public educational structures, popular education holds greater concern for specific contexts and struggles by developing experiential, dialogic, problem posing practices to begin to address these (Gore, 1993: 17; Choules, 2007; Wiggins, 2011).

The historical origins of popular education have been identified through the work of Danish Folk High schools and the Highlander school in Tennessee (Westerman, 2009), through community-based education in working-class neighbourhoods in Scotland (Kirkwood and Kirkwood, 1989), within the women's movement in Irish settings (Connolly, 2005), through 'an Asian Pacific wing of the movement' that developed in the 1980s (Boughton, 2013: 240), and perhaps most notably, through work with peasants and land movements within Brazil (Freire, 1994; Kane, 2001).

Popular education's commitment to the language of ordinary people is also emphasised as a way in which it can be distinguished from critical pedagogy (Wiggins, 2011). Wiggins 
(2011), who is critical of US based critical pedagogy's refusal to acknowledge the considerable contribution of popular education outside of the academy, also notes methodological differences. Popular education is detailed as relying on experiential socially contextualising exercises, provocative role-play, social skits and problem-posing education. One way of enabling this is through the use of codes, enactments of the ordinary circumstances of people's lives, re-presented in a problem-posing manner so participants can critically analyse the circumstances within which they find themselves. These codes should be conceived of following time spent listening for commonalities or, 'generative themes', within a particular community. Decoding is facilitated in learning groups, or culture circles, where a thematic programme is constructed across disciplines that address personal, local, national and international realities (Kirkwood and Kirkwood, 1989: 13).

There are Irish examples of radical Freirean approaches to community education construed through community development, and infused within social movements. These include the aforementioned Irish women's movement and its emphasis on consciousness-raising groupwork (Connolly, 2007; 2014), tenant participation and housing action (Bissett, 2008; Dorman, 2006; CAN, 2010), and politicisation and campaign building in response to Community Sector cuts (Fitzsimons, 2012). Some difficulties in incorporating popular educational approaches within the confines of Irish neoliberalisation have also been highlighted. With reference to the literacy movement, Feeley, (2007: 16-17) relays how 'evidence on the ground suggests that valiant and often voluntary efforts in adult literacy have produced little more than a 'trickle-up' effect from literacy to higher levels of education or economic advantage' and not the broader egalitarian ambitions of a Freirean led philosophy.

Popular education is not a universally agreed expression and whether it is adopted or not may say more about culturally prevalent linguistic discourse than of ideological tendencies. There 
are also differences of opinion on what the expression means an example of which can be gleaned through the pages of the influential Popular Education and Social Movements in Scotland Today, an observation shared within its own introduction (Martin, 1999: 5). Inside there are oppositional analyses of power and the State. Paterson (1999) proposes the most effective route to change as through respectful relationships with a liberal democratic State, whilst Martin and McCormick (1999) offer an account of the systematic denial of basic housing rights by what they perceive as a partisan government, rights that were eventually realised through persistent struggle with largely uncooperative State mechanisms that tried to blame those affected for their predicament. Similarly, Freirean (popular education) approaches are drawn from within Irish accounts that appear more aligned to compensatory models of community education (for examples see Slevin, 2009; McCallion, 2009). These set out to incorporate a fostering of critical capacities in strengthening human agency, the objective being to change the person and not the wider system.

\subsection{The influence and limitations of Paulo Freire}

Shared across interpretations of critical pedagogy and popular education, and often evoked when considering community education and community development, is the towering influence of the Brazilian educationalist Paulo Freire. A summary and critique of his related ideas will now be presented.

\subsubsection{A comprehensive body of work}

Although much emphasis is placed on Freire's early writing Pedagogy of the Oppressed (first published in English in 1970) Freire completed around 25 books. Some of these were in conversation with colleagues, offered alongside additional papers and contributions to the efforts of others. Predominantly writing in Portuguese many, though not all have been translated to English and a range of other languages particularly Spanish. Describing Pedagogy of the Oppressed as 'one of the most widely read books by an educationist this 
century', Roberts (2000) suggests an appraisal of Freire across three distinct periods: early works (1965-75); quieter years (1976-86) which included Pedagogy in Process: The Letters to Guinea-Bassau, a book criticised by some followers as anti-dialogic; and a final period (1987-present), which Roberts presents as 'crucial in assessing Freire's views on, and contribution to, education, literacy, and politics' (Roberts, 2000: 23). Noteworthy from a practitioner perspective, this final period includes three influential talking books A Pedagogy for Liberation: Dialogues on Transforming Education (1987) with Ira Shor, Literacy, Reading the Word and the World (1987) with Donaldo Macedo (which includes a lengthy introduction by Henry Giroux), and We Make the Road by Walking: Conversations on Education and Social Change (1990) with Myles Horton. These provide practical discussion on the challenges when implementing the ideology of Pedagogy of the Oppressed and demonstrate a key strength in Freire's approach; a continual encouragement that his offerings be interrogated to expose flaws and encourage reflexivity.

Alongside Freire's own contributions are a range of critical texts that enhance readings of Freire's body of work. Influential amongst these are Paulo Freire: A Critical Encounter (1993) edited by McLaren and Leonard and containing contributions from Stanley Aronowitz, Carlos Alberto Torres, bell hooks and Henry Giroux, and Teaching to Transgress (1994) by bell hooks. Other contributors include a synthesis of Freirean ideology with Gramscian thought such as that offered by Peter Mayo in Gramsci, Freire and Adult Education (1999), and a reading of Freire in unison with the political life and times of Che Guevara put forward by Peter McLaren (McLaren, 2000). Striking about this catalogue is its American emphasis and influential European interpretations include prominent British contributors such as in Popular Education, and Social Change in Latin America (2001) by Liam Kane, and Kirkwood and Kirkwood's Living Adult Education: Freire in Scotland (1989). These exist alongside accounts of his impact within community development 
discourse including Margaret Ledwith's $(2011)^{36}$ Community Development; a critical approach, and discussion within Keith Popple's much cited Analysing Community Development, its theory and Practice (1995). More recent again is Beck and Purcell's contribution Popular Education Work for Youth and Community Development Practice (2010). Domestic attention to Freire is also to be found. Early champions of Freirean approaches include Radical Approaches to Adult Education: A Reader (1988) by Tom Lovett and For Adults Only; A case for Adult Education in Ireland by Bassett et al (1989). This latter contribution set out to infuse Freirean ideology into growing community education practice of the time, and offered an important documentation of practice. More recently, Connolly (2008) draws from the ideas of Freire, expanded into a feminist pedagogy of practice. A noteworthy shift in recent years is the emergence of Irish accounts from broader educational spaces within Higher Education Institutions (HEIs), a change from specialised Adult Education and Social Studies influences. Irwin Jones's Paulo Freire's philosophy of education (2012) is a contribution which considers Freire through a post-modern lens. Pedagogy, Oppression and Transformation in a Post Critical Climate- The Return of Paulo Freire (O'Shea and O'Brien, 2011) also offers contributions from university based academics across social justice, education and adult education in collaboration with teachers and community based practitioners.

\subsubsection{What does Freire say?}

While there are limitations to Freire's propositions (which will be discussed in due course), it is the overriding sentiment of Freire's philosophies that bring about such consideration. With much of his own practice focused on literacy work carried out as a deliberate politicising action (Freire and Macedo, 1987), it is Freire's concepts of 'conscientisation' and 'praxis' that garnish particular attention. Freire offers an emotional domain to politicised education

\footnotetext{
${ }^{36}$ Ledwith published a first edition of this book in 2005.
} 
through its recognition that is it only by honouring the subjective that an objective reality can be viewed. Disclosing his own subjective/objective narrative within Pedagogy of Liberation written with Ira Shor (Shor and Freire, 1987: 28-32), Freire details core influencing factors as the experience of poverty as a child allowing him a view of both working and middle classes, the impact of material poverty, particularly hunger, impeding his ability to learn at school and his introduction to teaching with workers offering him a second chance 'to reknow' what he had known before but had become removed from due to improved financial and social status. He also includes the Brazilian coup in 1964 which resulted in his exile and solidified his belief in the limits of education alone in bringing about transformative change (Shor and Freire, 1987: 28-32).

It was whilst in exile Freire principally developed his theory, an education for those at the receiving end of systemic injustice. This is built on a belief that each person's human existence can only be truly understood when historically positioned within its economic, political and cultural contexts (Freire, 1972: 30). Penning the first three chapters in a matter of weeks with chapter four following some time later (Roberts, 2000: 28), Pedagogy of the Oppressed is consistent with Karl Marx's theory of historical materialism in understanding the organisation of society. This is of a divided world, the principal divisor being that of oppressor and oppressed. Presenting an oppressor led reality where 'to have is to be' (Freire, 1972: 35, italics in original), Freire (1972: 21) proposes the continuation of this unjust separation is bad for everyone as it 'engenders violence in the oppressors, which in turn dehumanizes the oppressed'. In chapter four of Pedagogy of the Oppressed Freire lays bare his theories of 'antidialogical' and 'dialogical action', suppositions pertinent to the perpetuation of capitalist injustice (in the case of the former) and possibilities for its defeat (for the latter). Conformity through antidialogue is through acts of conquest where the image of the oppressor becomes internalised by the oppressed bringing about an adoption of their 
norms. Resonating with Gramscian conjectures of hegemony, Freire believes this is achieved by the oppressor class preserving certain myths that the status quo is a free society. Quoting Freire at length, these include,
the myth that this order respects human rights and is therefore worthy of esteem; the myth that anyone who is industrious can become an entrepreneur, worst yet, the myth that the street vendor is as much an entrepreneur as the owner of a large factory; the myth of the universal right of education;...the myth of the equality of all men [sic]; the myth of the heroism of the oppressor classes as defenders of 'Western Christian Civilization against 'material barbarism'; the myth of charity and generosity of the elites, when what they really do as a class is to foster selective 'good deeds'; ...the myth of private property as fundamental to personal human development (so long as oppressors are the only true human beings); the myth of the industriousness of the oppressors and the laziness and dishonesty of the oppressed, as well as the myth of the natural inferiority of the latter and the superiority of the former. (Freire, 1970: 109-10, brackets in original)

He also describes the deliberate promotion of individualism as a divide and rule tactic that discourages unity and maintains 'a focalized view of problems rather than on seeing them as dimensions of a totality' (Freire 1972: 111, italics in original). The possibility of social mobility as a route to betterment is a further act of manipulation maintained through an illusion of dialogue, or partnership, whilst the real ambition is for the oppressor class to achieve its own ends (Freire, 1972: 116). Along with interlacing features of, 'conquest', 'divide and rule' and 'manipulation' Freire's theory of oppression is completed by a connecting cultural invasion, the penetration of one culture in a way that imposes the invader's world view, whilst dismissing alternative expressions and forms of creativity convincing the oppressed of their own inferiority (Freire, 1972: 121-2). The culture of silence which prevails means that, although those oppressed are not completely blind to their circumstances, there is reverence to minority oppressors primarily through a desire to mirror their image.

In conversation with Ira Shor, Freire, returns to discussion on culture of silence addressing critiques as to whether this assertion holds true beyond so called Third World circumstances from which earlier writings emerged. Shor and Freire (1987) propose its manifestation as the 
passive internalisation of socially determined roles and submissiveness to uninspiring, dispassionate educational experiences. Given the unnaturalness of passivity or the 'symbolic violence' (Shor and Freire, 1987: 123) this represents, the authors extend the culture of silence to incorporate a 'culture of sabotage', particularly prevalent in Western cultures. One contemporary interpretation could be towards an analysis of the London riots of 2011, not as amoral unrest by hooded arsonists and looters as they are commonly portrayed, but as an expression of deep-seated discontent within a class-divided modern Britain reflected through a deep pessimism, with many involved in rioting citing political circumstances as causative (Thornburgh et al, 2011). Similar meaning can be evoked when considering dissident behaviour within a current anti-water charges movement in Ireland where protesters often extend this campaign to a wider anti-austerity agenda and express their anger through sabotage ${ }^{37}$

By way of challenging this status quo, Freire suggests each of us hold an ontological vocation to become more fully human. Lankshear (1993: 108) links ontological vocation to Aristotle's argument that the ultimate good for humanity is for us to perform at our highest human function. 'Hope' is an ontological need (Freire, 1994: 2) and the realisation of a collective true humanity is through critical intervention in reality. For Freire, 'only power that springs from the weakness of the oppressed will be sufficiently strong to free both' (Freire, 1972: 21), a revolutionary conjecture again in harmony with Classical Marxism, yet different in its presentation of the complexities of objective-subjective relationships seeing these as in a constant dialectic with each other (Freire, 1972: 26). It is only when those oppressed discover themselves as 'hosts' of the oppressor, they can 'contribute to the midwifery of their liberating pedagogy'. Freire continues,

\footnotetext{
${ }^{37}$ The example easiest to evoke is of a protest outside a community education graduation ceremony in West Dublin during which the Tánaiste was barricaded in her car for a number of hours with protests drawing out wider concerns than objection to water charges alone but linking it to wider anti-austerity measures. http://www.thejournal.ie/joan-burton-car-protest-1782480-Nov2014/
} 
The Pedagogy of the oppressed is an instrument for their critical discovery that both they and their oppressors are manifestations of dehumanization. Liberation is thus a childbirth, and a painful one. The man [sic] who emerges is a new man, viable only as the oppressor-oppressed contradiction is superseded by the humanization of all men [sic]. (Freire, 1972: 25)

For members of the oppressor class who feel compassion towards the oppressed, the ambition set out for them by Freire is to find communion across classes. To do this they must share analyses of structural causes as foundational, and must trust people's ability to selfdetermine. This is an important part of Freire's theorising for outsider community educators (discussed in chapters three and four) who, through the lens of Freire's philosophy, should interpret themselves as allies. Freire is at times ruthless in his criticism of some originating within the oppressor class who voraciously seek change. He accuses them of carrying such 'absolute conviction of their certainties' they become sectarian and authoritarian (Freire, 2005: 26). This concept of ally, or collaborator, is not dissimilar to Gramsci's discussion on traditional intellectuals 'whose position in the interstices of society has a certain inter-class aura about it but derives ultimately from past and present class relations' (Gramsci, 1971: 3). This presents them as those whose organic ties to the ruling class have been lost.

When people consider the contribution of Freire what is perhaps most commonly drawn out is his critique of traditional approaches to education. Freire challenges banking approach to education, described by hooks (1994: 5) as a system 'based on the assumption that memorizing information and regurgitating it represented gaining knowledge that could be deposited, stored and used at a later date'. This approach brings with it division into expert teachers and largely passive learners a division that appropriates 'great hermeneutical power to the master' (McLaren and Giroux, 1994: 9) and diminishes the intellect, capacities and worth of the supposed apprentice. Its epistemological worth is questioned and the teacherstudent relationship, itself a contradiction of capitalism based on each other's social relations, is replaced with a more lateral, problem-posing approach. This ascribes value to all 
knowledge viewing academic theory, not as unimportant, but as an optic through which we can better understand our lived experiences. The purpose of this way of working is to foster conscientisation (politicisation), and praxis (a cyclical process of action and reflection), components in dialogical actions of cooperation, unity, organisation and cultural synthesis (Freire, 1972).

An aspect of Freire's approach that particularly links it to radical community education/community development is its connectedness with action. For Freire, 'hope needs practice in order to become historical concreteness' (1994: 2) and the practice he aspires to is a dialogic one. Dialogue is an interpretation of 'the word' not just as a tool but as a two dimensional instrument, a complex of action and reflection 'in such radical interaction that if one is sacrificed-even in part-the other immediately suffers' (Freire, 1972: 60). Praxis therefore requires the exposure of one's authentic voice and it is through this, a naming of the world can be facilitated that enables it to be changed.

Saying that word is not the privilege of some few persons, but the right of everyone. Consequently, no one can say a true word alone-nor can he [sic] say it for another, in a prescriptive act which robs others of their words. (Freire, 1972: 61)

Encouragement is towards self-determined action, dialectically embroiled with reflection.

\subsubsection{Shortfalls in Freire's contribution}

Alongside support for the tenets of Freirean thinking (and action), there are limitations to his philosophies. The dichotomous nature of Freire's analysis of power is sometimes challenged for its rigid either/or approach to oppression. The risk is of a doctrinaire attitude that reduces the intricacies of our social and economic world to uncomplicated interplays between various parts. There is also an absence of significant attention to previously drawn out intersectionality, multiple forms of oppressions which interact with each other in complex ways (Crenshaw, 1995). In discussing popular education in practice, Kane (2001: 50) draws on his own experience to demonstrate this noting the way in which a range of different 
oppressions; racial, gendered, age related and because of institutional power, can often be experienced within the same group.

Freire's presentation of any group in society as powerless and stuck in a culture of silence is also challenged. Blackburn (2000: 8-9) claims there are continual expressions of power by those considered oppressed which include non-cooperation with dominant norms and the observance of distinct cultural identities. This holds currency with the previous assertion of an 'anti-logic of humanity' (Holloway, 2010: 72) where many of us act in ways that are contradictory to capitalism's expectations. Presentations of education as either banking or problem-posing are equally dichotomous with the latter often presented as the only true form of emancipatory education. Torres (1993) is amongst those to express concern about the level of change that would be required within current systems to allow for the radically alternative approaches proposed by Freire. Part of Torres (1993) disquiet relates to the way in which curricular demands can at times supersede space for spontaneous conversation thereby resulting in anti-dialogic practice. This, and other critiques levied at Freire's philosophy are addressed by Freire in his talking book with Ira Shor A Pedagogy for Liberation, Dialogues on transformative education (1987). They challenge the legitimacy of formulaic curricula interpreting their inflexible adoption as the infusion of business interests into a school system in situ to maintain corporate interests. This enables control over the transfer of knowledge that is most appropriate in supporting elitist authority. This not only ensures powerlessness for students, it removes considerable decision making from teachers (Freire and Shor, 1987: 75-6). Elsewhere Freire also addressed criticisms of the relevance of his writings outside of developing world contexts. This is through his interpretation of neoliberal incursion as a process of 'Thirdworldization' with mass poverty in the global North, particularly in inner cities, set against opulent oligarchy present in proposed Third World nations (Freire, 2005: viii). The growth in the development education movement in 
Ireland and its connectedness with community education, (a strong feature for some research participants in this study) has also brought relevance to Freirean ideology outside of Latin American settings where concepts of local-to-global are not simply theoretical, but are often expressed through personal experiences within community education contexts.

\section{Post-modern critiques}

For critics influenced by post-modernism and post-structuralism, Freire's reliance on an allencompassing world view is confronted. Such grand narratives are called into account as resting on little more than assumption, with knowledge and the world made up of numerous ways in which it is discussed and experienced (Lyotard, 1984; Rosenau, 1991; Malpas, 2005). This critique is where Freirean conceived notions most obviously contrast with Foucauldian beliefs of power as manifold, 'exercised through a net-like organisation' (Foucault, 1980: 98). Post-structuralism interrogates a theory of dialogue through deconstruction of language thereby challenging the way in which Freire interprets subjectivism. It questions the weight of meaning attributed to the spoken word, presenting language as something unsystematic, contextually based and fundamentally unstable. Particularly critiqued is logocentrism, or the 'logic of presence', an expression developed by Derrida to describe systems of thought that purport to reveal what is wholly true (Dooley and Kavanagh, 2006: 2). Derrida's critical deconstruction of society sets out to free it 'of the ideas of all the intellectual authorities who have created the dominant discourse' (Ritzer and Goodman, 2003: 584) with language seen as constantly creating and recreating the world. Such critiques often don't formulate alternative assumptions; rather they catalogue the implausibility of establishing such underpinnings for knowledge (Rosenau, 1991: 6). Tensions between post-structuralism and Freirean inspired notions of critical pedagogy ultimately boil down to ontology. Different conceptions of reality bring a different sense of what it means to be critical; each of which are often conceived of within notions of social 
justice (Biesta and Stams, 2001). In reconciling the potential ontological gulf between the two schools, Jones (2012: 191) suggests many practitioners work 'with and against certain aspects of Freire's thinking'.

\section{Freire - Reformist or revolutionary?}

A further metaphysical consideration, both philosophical and practical, revolves around whether interpreters of Freire's writings consider its adoption as reformist or revolutionary. Is the pedagogic ambition to foster revolutionary struggle within the classroom as part of attempts to overthrow global capitalism? Does it seek a more reformist pathway more suited to pluralist interpretations of power? Can it accommodate both?

Praxis is at the heart of Freire's writings and he draws influence from Latin American revolutionary activists Che Guevara, Castro, and Cabral, documenting their achievements alongside the oppositional actions of ordinary people (Freire, 1972). Despite evoking such alliances, Freire's ambiguity on how praxis can bring about the level of change required to defeat capitalism has led to continual discussion on whether an adoption of these ways of working lead to an intellectual praxis without the requisite activism component that might more readily link it to revolutionary theories of Marxism. There have also been assertions of a failure to maintain the revolutionary vigour of Pedagogy of the Oppressed. Some critics have also suggested there is an absent acknowledgement of the role of revolutionary political parties inside and around popular education movements (Holst, 2009b; Boughton, 2013). Boughton maintains,

It seems to me that this failure continues a much longer tradition within university based accounts of radical adult education, of avoiding such questions because of the difficulties which revolutionary socialist organisations pose for liberal intellectual views about dissent, freedom of debate, the autonomy of individuals and university-based intellectual activity itself. (Boughton, 2013: 240)

Freire's own participation in parliamentary politics as member of the Workers Party in São Paulo is also sometimes criticised. Aronowitz (1993: 19) defends Freire's parliamentarian 
involvement arguing this was not an unconditional nod to parliamentary reformism as the only route to change, but as indicative of the historical circumstances of the time and the unpopularity of revolutionary movements. Comparisons can be drawn with current trends in Irish politics where large numbers of independent $\mathrm{TDs}^{38}$ and those with socialist affiliations participate in government whilst concurrently expressing distain for these structures.

Freire became involved in party politics at a late stage, a situation that differs greatly when compared to theorists more readily claimed by Traditional Marxism, most notably Antonio Gramsci. Gramsci built his theories on the back of extensive involvement in revolutionary politics (Davidson, 1977) and is steadfast in his convictions that the route to radical social change is through syndicalism (Gramsci, 1994: 249-254). For Holst (2009b) consideration of Gramscian notions outside of the centrality he places with the political party would have been unthinkable for Gramsci. Holst (2009b) criticises the way in which much university conceived critical pedagogy seem to find it unthinkable to consider Gramsci within the political and revolutionary framework he designed his ideas to be incorporated within.

Freire himself does not discount a role for a revolutionary party, though as pointed out earlier, his own writings appear to infer considerable dissatisfaction with the way these entities can negotiate and interpret self-determination. In Teachers as Cultural Workers (2005: 20), he is vague in concretising the shape praxis can take describing it as critical awareness of social and political responsibility so as 'not to take over the state's role, letting it sleep undisturbed, but to learn to mobilize and organize so that we can better supervise the state as it fulfills or fails to fulfill its constitutional duty'. Further differences between Freire and Gramsci can also be identified. Gramsci holds firm to a universal interpretation of the working-class within which organic intellectualism can be nurtured (Gramsci, 1971: 3-7) with the workplace considered the locus of change. Acknowledging the significance of class,

\footnotetext{
${ }^{38}$ Teachta Dála, a member of the Irish house of Parliament - Dáil Éireann.
} 
Mayo (1999: 97) more readily aligns Freire to a 'polyphony of voices' particularly in his talking books. Mayo (1999: 97) claims this offers a non-essentialist perspective, opening the door to New Social Movements (NSMs) reflecting a range of struggles with a variety of power-holders.

This point, whether Freire can be considered a reformist or a revolutionary, is particularly discussed through the writings of Peter McLaren. In his contribution Che Guevara, Paulo Freire, and the Pedagogy of Revolution (2000) he differentiates critical pedagogy and critical revolutionary pedagogy, a term he claims to have borrowed from Paula Allman (Moraes, 2003: 118). Critical pedagogy is understood as a process of dialecticism and dialogism, teacher-student reciprocity, and a problem-posing, reframing process that calls to account the structural and relational dimensions of power and knowledge. Revolutionary pedagogy is considered that which through its analysis of power and knowledge, puts each in collision with their own internal contradictions giving birth to more than an epistemological clarity, but a vision for an alternative society. In discussion with Moraes (2003: 118) McLaren challenges the domesticating nature of much contemporary critical pedagogy asserting 'critical revolutionary pedagogy brings some desperately needed theoretical ballast to the teetering critical education tradition'. He proposes full consideration of social relations and concepts of labour rejecting neoliberal commodification suggesting,

The larger goal that revolutionary pedagogy stipulates for radical educationalists involves direct participation with the masses in the discovery and charting of a socialist reconstruction and alternative to capitalism. However, without a critical lexicon and interpretative framework that can unpack the labor/capital relationship in all of its capillary detail, critical pedagogy is doomed to remain trapped in domesticated currents and vulgarised formations. (McLaren in Moraes, 2003: 118)

This reclamation of Freire's writing is a consistent feature of McLaren's work. In his preface to Freire's Teachers as Cultural Workers (2005), he calls for repossession of Freire's ideas releasing them from domesticating interpretations that lean heavily on the 
psychology of individualism leaving aside consideration for the self within its socio-political context. Community educators who ascribe to Freirean ideology should too reflect on the potential dilution of Freire's original assertions amidst neoliberal circumstances.

Another way of conceiving of reform versus revolution arguments is to question their helpfulness in the first place. As a dichotomisation it can create false tension between potential allies and loses sight of the need to create, support, and unite pockets of difference across society (Holloway, 2010). Holloway (2010: 89) challenges tendencies on the left to wait for a future revolutionary event suggesting we create as many alternative ways of doing and being through an expansion of 'consciousness life activity' when set against the alienated labour associated with capitalism. Moreover, the notion of future class revolution again doesn't address intersectionality further emphasising the gender-blindness inherent in the andocentric nature of much canonical knowledge.

\section{A patriarchal pedagogy?}

This comment leads us to a particular difficulty with any incorporation of Freirean influence, namely its gender blindness. Jackson (1997) draws from Freire's own emphasis on the oppressive nature of language to demonstrate the influence of patriarchy. She discusses Freire's challenge to the way in which Portuguese (the language of the oppressor) is given greater esteem than Creole. By suggesting a supplanting of Portuguese with 'men's language' and Creole with 'women's language' Jackson (1997) demonstrates how, in utilising men's language throughout, Freire draws solely from a male interpretation of the world that stereotypes women and subjugates their societal position. As language is constructed by both dominant class and dominant gender, female becomes other in the shadow of male as the norm.

Freire himself addresses the many feminist critiques of Pedagogy of the Oppressed in Pedagogy of Hope (1994). He owns up to an initially challenged and somewhat defensive 
reaction before announcing indebtedness to North American Women in particular, for illuminating his shortfall. In revision he proposes less use of sexist 'and therefore discriminatory language, in which women have no place' (Freire, 1994: 54). Freire (1994: 55) details how 'this sexist discourse...enfleshed in concrete practices', is a colonial endeavour and one that is incompatible with progressive positions. Despite this acknowledgment of patriarchy, Freire still falls short as missing from conversation about the importance of the word in naming the world, is sufficient repairing of past contributions that exclude women's epistemological perspectives. How different might the structural inequalities identified within Pedagogy of the Oppressed be if an analysis of patriarchy had also been explored? Roberts (2000) challenges feminist discomfort with Freire claiming it lies in a narrow reading with particular attention being paid to Pedagogy of the Oppressed. The trouble with Roberts' protestations is that he also somewhat misses the point as, although later works amend sexist language and acknowledge important insights by feminist writers, Freire fails to fully engage with the intricacies of women's oppression. These include the way in which patriarchy is largely maintained in the private realm through the relationships of sexual production and the division of labour, and how the subjugation of women differs from other oppressions due to the social interconnectedness of the sexes.

\subsubsection{Towards a feminist pedagogy}

Perhaps most influential in drawing out a feminist pedagogy from the writings of Freire is bell hooks. Her engaged pedagogy claims to have 'taken the threads of Paulo's work' (hooks, 1994: 52) and woven it into a pedagogy that acknowledges the specific gendered realities of oppression and exploitation of women's right to subjectively define their own realities. hooks not only draws from the writings of Freire but also from her own subjective experiences of racial oppression, of emancipatory teaching approaches from women within the segregated school system, and of incidents in non-segregated educational spaces where 
black students were there to prove rather than experience equality with whites, the expectation of conformity weighting heavily on their shoulders. She draws from her 'mutually illuminating interplay of anticolonial, critical and feminist pedagogies' (hooks, 1994: 10) enabling her to enact a pedagogy that encourages a critique of our own historical circumstance and power differentials within this. hooks encourages an interrogation of curricular bias based on race and gender and challenges the reduction of teaching to the transfer of skills. Another important contributor is Ledwith (2010) who challenges Gramscian led gendered epistemological inadequacy. She offers a three-dimensional model in exploring intersectionality. These are across difference, including age, race, gender, sexual orientation and ability as well as contexts, including economic, cultural, intellectual, environmental and emotional. The third dimension proposed is of levels, including local, national, regional and global. Ledwith (2010: 110) suggests these 'form a complex set of interrelationships which not only interweave between axes, but which also intertwine on any one axis'. Critical education, she argues, must entail knowing who we are and what shapes our realities across each of these dimensions in order for us to collectively act for change.

Ledwith and hooks are amongst those to argue for a feminist pedagogy as a distinct approach to education that should be applied across all educational contexts regardless of the gender of participants or the issues under discussion. This can be differentiated from feminist pedagogies, an approach to education that are predominantly linked to Women's Studies therefore differing depending on the situation and targeted group (Gore, 1993: 18-19). Adopting a feminist pedagogy does not negate the need to contextualise and be led by generative themes as previously drawn out. Rather it encourages practitioners to name and problematise gender discrimination both micro and macro. This includes inviting male practitioners to become more conscious of their power and privilege reflecting on the implications this has. In accordance with the demands of feminist pedagogy, classrooms 
must value the individuality of students continually exploring subjectivity as a resource for learning, and continually re-evaluating dominant masculinity based world-views (Weiler, 1991; Luke and Gore, 1992; hooks, 1994; Jackson, 1997). Again acknowledging intersectionality, white supremacy, deficit approaches to disability, ageism, and hegemonic middle-class incursion are also traits adult educators must engage with reflexively.

\subsection{Doing critical community education: what it looks like in practice}

As determined earlier in this chapter, enacting a vision of community education underpinned by feminist pedagogy involves a critique of isolated personal development or skills based learning. Dialogic approaches do not mean lassie-faire discussion on daily events without analysis rather it acts as a historical function of humanity. This is described by Shor and Freire (1987: 98) as 'a moment where humans meet to reflect on their reality as they make and remake it' suggesting 'reflecting together on what we know and don't know, we can act critically to transform reality'. Those adopting these approaches must endeavour to work 'with people to enable them to think critically or dialectically in their reality' something Allman (2001: 94) believes is Freire's most important contribution. Enabling this is through 'a full recognition of the fact that there could never be an absolute set agenda governing teaching practices' with agendas always being flexible enough to allow 'spontaneous shifts in direction' (hooks, 1994: 70).

Working to Freirean principles also requires facilitative teaching methods that involve certain skills and a repertoire of experiential and participatory exercises along with the know-how to design and de-code codes. It is also helpful to be able to reframe ubiquitous popular culture in a way that develops a critical media literacy which can transform sites of conformity to sites of critical resistance (Tisdell, 2007). One difficulty with much writing on critical pedagogy, and to a lesser extent popular education, is failure to sufficiently acknowledge how to embody this approach, consistently telling the reader what to do but not how to do it. 
Some do provide insights into power-laden interactions between teacher-student interactions. Shor (1996) discusses these relationships in detail in reflections within When Students Have Power: Negotiating Authority in a Critical Pedagogy, offering reflections on this approach to education within the confines of a college setting. He includes discussion on the power-laden organisation of chairs and the importance of trying not to position oneself as teacher at the front of the room. He also reflects on some challenges he experiences in creating conditions where there is co-creation of critical knowledge. These include the challenges of negotiating curricula, difficulties with self-assessment, and the need to check one's own prejudicial assumptions based on gender, socio-economic backgrounds and political opinion. Connolly (1999: 113) also reminds us of the importance of non-therapeutic group-work as central, an approach that differs from humanistic environments given its concern with sociological contexts. The facilitative, but also politicised, approach at the centre of achieving this is presented by Connolly as follows,

Facilitation aims to empower people. This necessarily entails interfering with the relationship between unquestioned authority and unquestioned subordination. The main point is to facilitate people to become autonomous and independent...It is vital to recognize that facilitation is not an absence of direction and expertise or a chaotic melee, leaving people to their own devices. Rather, it is a highly organized, critically reflective, skill-based process that depends on the approach and expertise of the facilitators, and underpinning principles of respect, tolerance, trust and transparency. (Connolly, 2008: 91)

Connolly, and Shor, are not alone in detailing the importance of such supports for learners with Aronowitz (1993) also revealing the importance of humanistic principles within Freirean approaches that ensure respect, trust, and a lateralising of power differentials within a learning environment. Working in highly participatory, experiential learning environments does not negate the incorporation of some lecturing; something that can be introduced as a spoken codification within emancipatory approaches (Shor and Freire, 1987: 39-40). What is important is how this methodological approach is managed with lectures used as stimuli for conversation rather than as presentation of indisputable fact as the only viable theory. 


\subsubsection{The fallibility of practitioners - skills, contexts and philosophical beliefs}

Eyebrows might be raised when one considers the momentous and complex task this sets for community educators with Kane, revealing concerns by Archer and Collingham (1996) shared as how,

..the magic of 'codification' rarely works, that teachers are just ordinary (not the ideal envisioned by Freire) who often struggle to promote dialogue in groups and that Freirean efforts usually end up either concentrating on literacy skills or conscientisation but seldom achieve a balance of the two (in Kane, 2001: 49, brackets in original).

Kane (2001: 48-49) also draws out cases where incremental actions are encouraged instead of direct action against oppressors given the psychological impact defeat might have. He also points to examples where codifications are interpreted as manipulative and more reflective of the politics of the facilitator rather than the sentiments and experiences of a community/group. Elsewhere, Kane (2010: 282) further cautions again abstract interpretations of 'a Freirean philosophy' given the many connotations espoused from revolutionaries to business-led entrepreneurialism alike. As with all contested concepts, the ideology of the user would seem the most trustworthy interpretation of meaning.

\subsection{Summary of chapter}

This chapter began by placing the reader within a Dickensian classroom. Whilst disingenuous to suggest nothing has changed in the intervening years, much adult education to replace this is humanistic in nature. This approach centralises self-development in a way that can be criticised for removing the self from its socio-political contexts. There are principles within humanism that are important to retain. However, its limitations in achieving egalitarian change outside of a more radical approach are questioned. Bold in its assertion of Freirean influenced feminist pedagogy as superior, this chapter argues that politicising practices are required should community education live up to its repeated aspiration, to work towards a more equal society. In doing this the importance of group- 
work, respect and genuineness is encouraged. This is considered amidst the demands this can place on practitioners thereby acknowledging individual fallibility.

An ambition of this study is to determine a role for critical education in aligning community education with its commonly stated commitment to equality. It is therefore timely to move towards introduction of the research design, and a sharing of participant findings. 


\section{Chapter seven: Mixing methods, research design and participant engagement}

We believe that mixed-methods research blurs the dichotomy between "researchers" and "human problem solvers." We believe that the mixed approach closely parallels everyday human problem solving in a way that neither qualitative nor quantitative methods alone can do.

Tashakkori A. and Teddlie, C. (Editorial for Journal of Mixedmethods Research, 2013) 


\subsection{Introduction to chapter}

To this point, you have been introduced to methodological influences, most notably within chapter two, and have encountered a secondary reporting of literature, policy and theory, all of which have been simultaneously analysed. I have discussed the at times unhelpful dichotomisation of positivism/post-positivism and its associated quantitative/qualitative research methods. I have also shared influences from critical realism and from feminist standpoint epistemology and have acknowledged a tension between feminist research's ambition to illuminate voices that are often unheard and critical realism's proposal that some truths are more valid than others (section 2.3.2). What is absent thus far is further elaboration on my decision to adopt a mixed-methods research (MMR) model such as the technicalities of organising and executing data collection and the approach taken to analysis. The methods I have used are nonrandom one-to-one interviewing, a broad based survey to purposefully selected community educators, self-selecting focus-group participation, and one-to-one telephone interviewing for people unable to attend focus-groups but who wanted to be involved.

Before discussing these in more detail, this chapter begins with further explanation on the choice of MMR as pertinent to the research undertaken. This includes further deconstruction of the dichotomisation of research methods as well as discussion on the limitations of each technique in isolation. I then present the sequential design the research adopted and explain a nesting relationship between phases (Collins et al, 2007: 277) where some people selected for components of the study were subsets of those participating in other phases. This section explains how each method was employed by introducing the practicalities involved in getting each phase off the ground. This is through information on selection, recruitment and operationalisation of the research. 
This chapter also explains the ethical principles employed over three broad areas of respect, wellbeing and fairness (Citro et al, 2003) leading us to discussion on participant confidentiality and consent. Finally the approach to analysis across modalities is presented.

\subsubsection{Reminder of the research topic}

The study has three primary objectives. These are to expand our knowledge on practitioners and practice, to explore the impacts of neoliberalism and to investigate ways in which a critical approach can further inform egalitarian ambition. The research is presented amidst opposition to neoliberalism as well as a commitment to equality. It has been conducted during a period when there has been momentous shifts in the State affirmed purpose of community education which has been detailed across chapters one, three and four. By mapping a landscape of practice and practitioners and measuring dominant trends, the study assesses the impacts of neoliberalism and considers how critical education can re-kindle it ambition towards equality.

\subsubsection{Reasons for choosing a Mixed-methods framework}

Mixing qualitative and quantitative methods or mixed-methods research (MMR) has been growing in popularity over the last 10 to 15 years and much discussion on its proposed merits and flaws has emerged. The crux of deliberations relate to the nature of the mix. Is MMR the use of quantitative and qualitative methods as complementary, correcting each other's potential blind-spots whilst not disturbing paradigmic consideration, or, is there a mixedmethods way of thinking that represents a research paradigm in its own right? Definitions of MMR have tended to remain broad enough to accommodate both possibilities, describing it as a way to address an inquiry through quantitative and qualitative approaches whilst integrating data collection and analysis to varying extents (e.g. Tashakkori and Creswell, 2007: 4; Hesse-Biber, 2010: 3). Sceptics problematise un-critical adoptions of MMR claiming supporters only emphasise the technical differences between qualitative and 
quantitative methods, something Sale et al (2002) consider within the positivism/postpositivism philosophical debate. This criticism feeds into tensions within academic research. Creswell and Clarke (2011) refer to its development as evidence of a 'third methodological approach', a stance supported by Freshwater and Cahill $(2012 ; 2013)$, who claim the use of mixed-methods bring unique ontological, epistemological, and axiological assumptions in and of itself. Others discount this, arguing the mixing of methods doesn't necessarily interfere with paradigmic frameworks depending on methodological inclination of the researcher. Rather it encourages philosophical, theoretical and socio-political issues are embraced in a way that allows researchers to eclectically approach an inquiry by selecting methods most appropriate to the way in which their study unfolds (Biesta, 2010; Green and Hall, 2010; Tashakkori and Teddlie, 2010: 8; Mertens, 2012). This latter position is the one I adopt conscious that, prior to taking on this particular research, I too carried considerable anti-quantitative bias believing it to be less authentic than its qualitative counterpart. Yet I began to notice how much I leant on the quantitative findings by others to support my world view on poverty, educational opportunity and gender inequality, something I have done throughout this research.

\subsubsection{Challenging quantitative-qualitative dichotomies}

It also helps to question some of the assumptions commonly presumed when identifying differences between qualitative and quantitative research. This is artfully done by Bryman (2004: 444-446) who, whilst acknowledging important variances, deconstructs a quartet of weaknesses in qualitative/quantitative contrasts. Firstly he challenges rigid delineation between behaviour (quantitative) and meaning (qualitative) demonstrating the use of attitudinal scales (such as those employed in this research) as also uncovering meaning. A second focal point is the way in which quantitative work is commonly seen as hypothesis driven, a presentation Bryman views as a caricature that both fails to appreciate the way 
findings often reveal new departures, and is blind to how much qualitative work also sets out to test particular theories. Unbending presentations of numbers versus words are also disregarded by highlighting a quasi-quantification often present in qualitative research through the use of terms such as 'most' and 'many'. Finally, Bryman (2004: 446) challenges claims sometimes made by qualitative researchers, particularly ethnographers, that they can create a more authentic environment than quantitative studies can achieve. This assertion is supported by examples where interviewees from individual and focusgroup semi-structured research conversations claim reports of naturalistic settings are often exaggerated.

\subsubsection{Questioning some mainstays of qualitative and quantitative research}

Qualitative research brings richness to this project. It is adopted within each phase of the study and provides a detailed account of community education ensuring an important contextualising layer. It allows for conditions where knowledge can be co-created amongst participants and, arguably, provides a more fulfilling experience for those who engage. It also enables the purposeful selection of 'experienced and knowledgeable experts' (Maykut and Morehouse, 1994: 54) enabling findings from secondary research to be explored. Purposeful selection for qualitative conversations enabled in-depth engagement with seven radical practitioners, engagement that informed other phases of the research. This was important given the axial positioning of critical education within the research topic.

In isolation, qualitative methods are inadequate in fully addressing the topic under consideration as it offers a limiting perspective. This is due to its failure to reach a large number of participants in order to capture as broad an opinion as possible. Quantitative research compensates for this shortfall by enabling me to test broad theoretical perspectives brought to bear in this research. From this we can get a sense of community education in 
action, quantifying dominant trends of practice and measuring the extent to which neoliberal incursions are changing the landscape of provision.

Qualitative research in isolation also carries a possible comfort that can be interrogated. As a research method is relies heavily on personal interpretations of histories, and an 'intersubjective exchange' where the researcher is epistemological co-creator (Granek, 2013). Researcher ontology and influencing discourses are therefore considerable factors in shaping the way in which stories are heard, potentially creating a chasm between participant interpretation and researcher interpretation of opinions and events. Additionally, could the purposeful selection of a small number of research participants shield me from engaging with the sentiments of a much wider pool of community educators, many of whom might interpret their work through competing lenses? Again quantitative research can compensate, minimising the influence of researcher interpretation when measuring attitudes.

There are also limitations to quantitative research and those relevant to this study revolve around two particular concerns. Firstly, there are the limitations to human participant surveying in gathering data, testing ideas and proposing the nature of a particular phenomena. A useful starting point to help us comprehend these limitations is a reminder of what survey questionnaires are, namely data collection tools that commonly question a sample of people drawn from a wider identifiable research population. Where the size of a research population can be determined, monitored sampling procedures enable a sample to be viewed as representative of a wider research population. Quantitative research measures variables i.e. something that respondents can differ on be that a characteristic, an experience or an opinion. The logic of analysis is that not only can variation across variables be measured; these can be compared with variation in other variables with conclusions drawn as to whether one affects the other. As quantitative research is being used within a critically influenced mixed- 
methods study, inferential statistics (correlation between variables) as indisputable proof of a particular phenomenon have been rejected within this study.

To ensure standardisation, certain procedures are commonly followed. This is thought to increase the likelihood that another researcher with the same sampling technique and questionnaire would get the same results, that results could be anticipated at another time, and that the survey is valid in measuring what it set out to measure. The notion of standardisation can also be critiqued and we should evaluate the weight of meaning often given to human participant surveying. Commentators have noted how people don't always tell the truth, sometimes don't understand the question, forget when relaying past events, and have been found to answer questions in the way they anticipate a researcher wants them to (Dockery and Bedeian, 1989; Lohr, 2009: 10).

It is also important to identify researcher power with quantitative research specifically when introducing directional hypotheses and when undertaking quantification. Discussing the former, Valsiner (2000: 14) notes how when generating meaning from weighting predetermined hypotheses, there is often limited acknowledgement of the influence of the researcher in choosing what hypotheses to introduce in the first place. This point is encapsulated by one contributor in this research who questions the weight of emphasis on accreditation she extrapolated from survey participation (section 9.4.2). Quantitising, or the conversion of qualitative data into numeric form, is also wrought with difficulty. This is because it is the subjective researcher who determines what gets counted thereby increasing the potential for misinterpretation and misclassification of responses (De Vaus, 2002: 100; Sandelowski et al, 2009; Selzer-Kelly et al, 2012). Quantification places significant power with the researcher whose ontological and epistemological lens determines, and ultimately categorises, meaning from textual contributions. The separation of component yet interconnected features can also bring falsity of differentiation (Seltzer-Kelly et al, 2012). 
This makes quantification reductionist in its delineation of complex concepts and philosophical approaches. It oversimplifies relationships between theory and practice, and is blinkered to how practitioners are likely to pragmatically draw from a range of interpretations depending on contexts.

Another difficulty with electronic survey questionnaires, such as that which was used in this study, is how there is little control over the conditions under which participants engage. Simultaneousness of quantitative and qualitative data collection also generates complications. What weighting is given to each method? What if there are discrepancies between quantitative and qualitative findings? What are the implications where sample size drops for qualitative questions?

Notwithstanding these trepidations, the dominant position I take is that there are advantages to survey research. This is through an already named uncovering of the composition, traits and attitudes of a much wider number of those working in community education than qualitative questioning alone would allow with quantification enabling the generation of statistics from textual contributions. It also enables a testing of assumptions commonly made about the nature of community education. Electronic surveys also offer anonymity to those not keen to participate face-to-face. Quantitative research can also be defended amidst trepidations relating to researcher power by considering the need for community educators committed to social justice to engage with the full range of possibilities to illuminate our practice. Oakley (1999) contends the fight for social justice needs quantitative research if we are to differentiate between personal experiences and collective oppression. She draws from C. Wright Mills' problematising of the 'twin evils' of grand theory and conceptual empiricism and proposes research methods should be used in a way that best serve the social problem under examination, and not the other way around. Positioning her contribution (now 15 years old) within an era that embraced concepts of multiple meanings, Oakley's words 
still resonate when she notes how unfashionable it can be to suggest social research is about approximating a sense of what is really going on despite this being the notion that drives our everyday lives (Oakley, 1999: 252).

By gathering understanding on the nature, contexts and concerns of community education work as perceived by practitioners, this research offers a tangible entity from which to defend our work. This is needed given the social problem I see, a conceptual and structural neoliberal siege. As community education predominantly exists within the confines of the Community Sector as well as allocated public provision, there is a need to take stock of the policy incursion of Further Education and Training (FET) and of continued funding cuts to what remains of the Community Sector. This study offers a broad-based overview enabling us to concretely illustrate the way in which community education differs from FET and other more traditional approaches to education, philosophically, methodologically and practically.

Whilst I concur with Oakley (1999) when she encourages a reclamation of the political possibilities of statistical analysis and comparative study, I remain convinced the focus of this inquiry would be incomplete in rectifying the quagmires of quantification and hypotheses posing should this method be utilised in isolation. This is where mixed-methods alleviate concerns as qualitative contributions at every phase ensured scope to qualify reactions to hypotheses, to challenge researcher weight of meaning, and to introduce topics not thought of by me. Mixed-methods research commonly evokes symmetry in utilisation and critique of quantitative methods (Seltzer-Kelly et al, 2012). This allows us to effectively address blindspots within each with the combination of statistics and stories enabling a better understanding than each might uncover in isolation. Key shortfalls to quantitative research alone can be addressed through qualitative/quantitative embedding as research participants are given the opportunity to provide context thereby helping combat potential disempowerment. 


\subsection{The research design}

Between 219 and $226^{39}$ community educators participated in this research. These people were working in both paid and voluntary capacities across a range of organisations and structures. With MMR, participation is commonly accommodated by use of a sequential research design with each phase relating to another to varying degrees. In this instance, three distinct phases sit within a transformative framework. Phase one involved purposeful selection of community educators known to work within radical modes of practice, each of whom participated in lengthy one-to-one semi-structured interviews. Findings from this phase shaped thoughts and actions brought to bear in phase two, the design, dissemination, data gathering and analysis of a broadly distributed, embedded on-line survey questionnaire. The final phase three also demonstrated significant relationships between its preceding phases both practically and philosophically. It engaged self-selecting participants from phase two in either focus-groups or one-to-one telephone interviews. Design and implementation of this phase was shaped by preceding findings and their initial analysis. Figure 2 overleaf pictorially demonstrates this description.

\footnotetext{
${ }^{39}$ The exact number is not determinable as given the anonymous nature of phase two I have no way of knowing if participants in phase one also participated in phase two.
} 


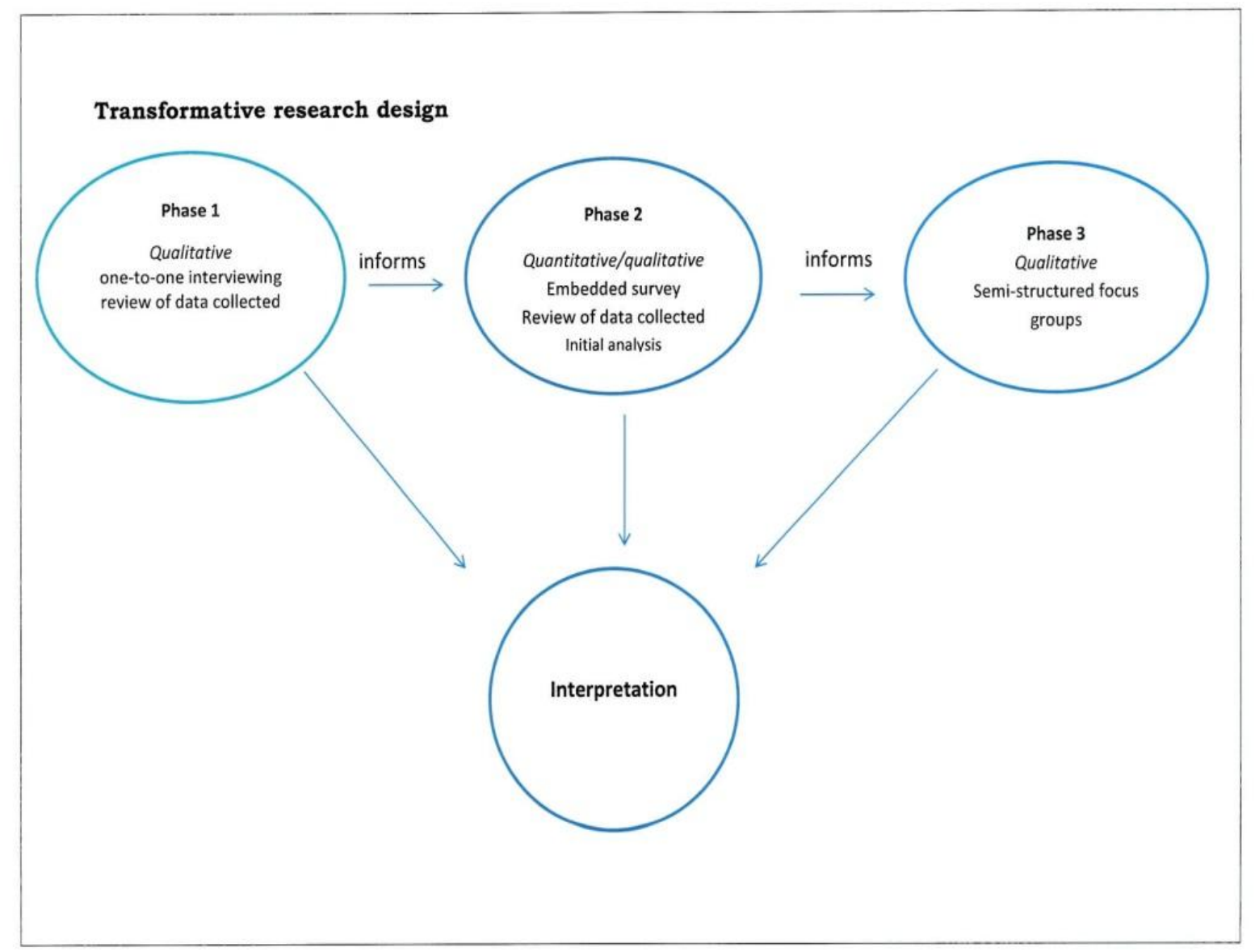

Figure 2 - sequential research design used.

\subsubsection{Phase one: selection, recruitment and interview techniques}

Seven critical educators were invited to participate in lengthy, one-to-one semi-structured interviews. Three of these were facilitators I had worked with in the past and two were community educators I knew, but I hadn't worked directly with them. I had not previously met the remaining two research participants, but I had heard about their work.

When discussing the challenge of working with participants that are known to the researcher, Paul (2010: 27) suggests there is 'no absolute correct procedure' but recommends a path similar to that which I took. My initial invitation to participate was through an e-mail where I explained I was doing research on community education as part of a $\mathrm{PhD}$ and sought permission to send through more detailed information with a view to participation. This was sent to an initial ten people, three of whom declined to reply. For 
the seven who expressed an interest, a second correspondence was sent. This time I detailed my own ontological position identifying myself as a community activist working from a radical/popular educational perspective. I explained that, to me, this meant working in a way that was deliberately political and politicising, that whilst individual learning and the individual experience of those I worked with was important to me, equally important was my desire as educator to encourage wider community engagement and collective activism, beyond the classroom walls and towards a more equal society. I explained that at this stage of my research, I was looking to interview others who could relate to, and share this perspective. I attached an outline of areas for discussion and included an explanation of semi-structured interviewing indicating we might not stick to initially proposed questions. I also suggested a time frame of one hour. Information on confidentiality and consent were introduced at this early stage and are discussed in more detail later in this chapter.

Interviews took place over a four month period in 2012 in a range of settings, in workplaces, homes, and a coffee shop. The semi-structured approach I used enabled fluidity within discussions giving me the opportunity to test my perspective on community education and to bounce thoughts and ideas on a range of relevant areas. Within these conversations people explicitly discussed their thoughts on equality and inequality and the social and political organisation of our world. All seven interviews were transcribed in full with completed transcripts e-mailed to participants for review and refinement if they chose to do so.

I found these interviews very enriching, enhancing my interpretation of the literature I was reading and encouraging a continual reframing of my thoughts on community education in practice. My early appraisals of one-to-one interviews also considerably shaped the direction of the inquiry confirming my inkling that a broad-based survey would be beneficial in ascertaining the shape of community education in Ireland. It also directly 
influenced questions posed within the questionnaire as detailed within the discussion below. Findings from one-to-one interviews are presented as chapter eight.

\subsubsection{Phase two: survey design and dissemination}

It was November, 2012 when I first put pen to paper in designing a questionnaire that was eventually launched on the $13^{\text {th }}$ of March, 2013. Composing it occupied a considerable amount of my time as I laboured over questions, formatting, circulation and criteria. Piloting was an active part of design and almost immediately I began asking people close to me what they thought of particular questions. An early mistake was to overly rely on academic terminology, a consequence of time spent buried in literature on the topic at hand. There was also over-use of qualitative questioning in initial versions, a comfort-zone from previous research work and influenced by the way I was, even at this stage, not fully convinced of the merits of hypothesis led approaches to quantitative research. In the weeks coming up to its launch, a more formalised piloting phase was entered into. Two small working groups were brought together where participants completed the survey then gave verbal feed-back on the experience of completing it. Had any questions not made sense? Made them feel uncomfortable? Felt too repetitive? Both instances led to changes, such as the abandonment of questions and the insertion of new ones, and the decision to use a 7-point attitudinal scale instead of the more commonly used 5-point scale. A third and final phase of piloting was of an on-line version, the intended dominant mode of circulation. Here I identified three 'critical friends', one of whom had little familiarity with community education but who was experienced in the use of survey questionnaires. Again what was asked for was a critique of the experience of completing it and further changes were made of foot of these.

When complete, the questionnaire (appendix 2) facilitated a quantitative strand containing 12 closed questions (q1-9, q11-13) that build a profile of research participants, nine directional hypotheses questions (q14-17, q22-26) that employed likert scales to gauge attitudes, and two 
null hypothesis questions (q10, q21) which ask participant to rank statements from a set of possible answers. Some questioning is recursive in nature with 'a test-re-test method' (May, 2001: 100) strengthening the reliability of findings. Textual data was enabled through four open-ended research questions amidst 27 in total. Using open-ended questions not only allowed participants to answer questions in a way that best suits their interpretation, they also offered space to challenge aspects of the questionnaire that don't sit comfortably, and to introduce themes and topics I had not thought to include. For me, this strand had two primary functions. Firstly it allowed me to contextualise statistics also sharing related qualitative findings, and secondly, it enabled quantification of texts supplied. A final openended question explicitly invited further comment both on issues introduced by me the researcher, and any other thoughts participants wanted to share. Despite proving significant detail introducing the survey, I did not include details on my own philosophical orientations as I had done when recruiting participants for phase one.

\subsubsection{The survey research sample}

Decisions on selection, scheme and size of samples are pivotal moments in the lifecycle of research the ramifications of which determine representation and influence research goals (Fowler, 2002: 7; Collins et al, 2007: 269). It is therefore important to both explain, and critique, approaches to sampling and representativeness when detailing use of a survey. A common approach within quantitative work is random sampling from a definable finite research population. I chose not to adopt random sampling given the absence of a clearly parametered research population. This therefore categorises my work within depictions of non-probability (non-random) sampling. Non-probability sampling is often treated with scepticism for its absence of probability procedures; the incorporation of calculations thought to ensure as neutral a sample as possible. The argument presented is that only probability sampling can ensure un-bias research and therefore be truly representative. 
There are important ideological challenges to rigid catagorisation of probability and nonprobability sampling and some proponents of MMR have questioned the dichotomisation of the two proposing a continuum approach instead (Teddie and Yu, 2007: 84). This should sit alongside a demystification of some of the theory surrounding probability sampling most notably claims of un-biasness. I wonder about the notion of data as something static, waiting to be collected and analysed by unassuming researchers. Instead data is better understood as produced under the influence of the transient and constructed veracities of researchers (Schwartz, 1999; Valsiner, 2000; Sandelowski et al, 2009). Probability sampling can also unwittingly produce bias. There can be accidental selection of people sharing similar experiences. For example, had the AONTAS CEN alone been surveyed, this might contain a disproportionate number of Dublin based participants given the location of its meetings, or a top-heavy sample of coordinators with many tutors only paid for contact hours therefore not able to attend network meetings.

Opt-in mechanisms for survey involvement are also sometimes challenged with critics arguing self-selection is detrimental to representation (Blaikie, 2010: 177). Opponents again claim bias citing disproportionate responses from those with strong opinion or negative experiences, over-coverage and un-quantifiable numbers of non-responses (Lohr, 2009: 6-10; Bethlehem, 2010). Aside from an inability to measure non-responses which is a limitation in this study, these generalities are also present with random-sampling, a method that can only guarantee randomness in selection, carrying no sway over whether that person then chooses to participate. De Vaus (2002: 59-60) demonstrates how, within any sample, those with postlevel qualifications are more likely to participate whilst those for whom the language of the researcher is different from their own first language, are less inclined to get involved. Beyond the research itself, Ball and Drury (2012) effectively demonstrate the way in which 
the political inclination of the interpreter can also conflate statistics to satisfy their own ideological leanings.

Non-probability sampling can also fall victim to uniform dismissal with little consideration for variation within. These variations include differentials between such approaches as convenience sampling, a particularly unreliable sampling technique, and purposive ‘judgmental sampling' (Sarantakos, 2005: 164), a process where choice of potential respondents is led by the judgment of the investigator. Snowballing is also more reliable, as is the safeguard of setting eligibility criteria. In this case, participation was ring-fenced by asking participants if they met the criteria below.

Those working as a facilitator/tutor role with adult groups in community settings (or who have done so in the last 2 years). This means working with groups outside of Higher Education and Further Education institutions and local to participants.

Given the absence of a finite list of community educators, and my reluctance to hazard a guess, this research is limited through its failure to numerically capture statistics on participation. However I maintain merit in suggesting representativeness with a purposefully selected cohort attributing worth to self-selection, the most common sampling technique utilised across mixed-methods research (Collins et al, 2007). In addition, multi-indicator questions further enhance representativeness (Bryman, 2004: 68) as does the establishment of specific criteria for eligibility as illustrated above.

\subsubsection{Survey circulation}

Survey dissemination was through the use of identifiable gatekeepers, the first of whom was the AONTAS CEN. At the time of survey launch, this network held a data-base of 223 selfidentifying community educators from circa 115 organisations. I also targeted other 
community educators who were connected to $\mathrm{VECs}^{40}$. This included Community Education Facilitators (CEFs) who are not typically AONTAS CEN members, in part given the existence of the Community Education Facilitators Association (CEFA). Other gatekeepers were Adult Education Officers (AEOs) and Adult Literacy Organisers (ALOs). Similarly Community Sector organisations could be targeted through Local and Community Development Programmes (LCDPs), Family Resource Centres (FRCs), addiction projects and Community Development Projects (CDPs) not integrated within the LCDP. It was also important to approach certain Higher Education Institutions (HEIs) that carry community education functions in local contexts. Considering these elements, purposeful selection with set eligibility and chosen gatekeepers enabled circulation to the following study population.

\begin{tabular}{|lc|}
\hline Circulation of survey questionnaire & 1 \\
\hline AONTAS CEN members via AONTAS & 52 \\
\hline Local and Community Development Projects & 107 \\
\hline Family Resource Centres, as listed by the Family Support Agency & 37 \\
\hline Community Education Facilitators (CEFs)* & 39 \\
\hline Adult Education Organisers* & 78 \\
\hline Adult Literacy Organisers and Centre contacts* & 97 \\
\hline Citywide Member Organisations & 3 \\
\hline Targeted HEIs & 5 \\
\hline $\begin{array}{l}\text { Targeted Independent Community Education Projects, networks and Practitioners } \\
\text { known to be outside of the ACEN network. }\end{array}$ & 17 \\
\hline $\begin{array}{l}\text { Through the network of the National Collective of Women's Community Based } \\
\text { Networks }\end{array}$ & 17 \\
\hline
\end{tabular}

* as listed in the AONTAS 'What Next' publication, January, 2013 discounting delivery failure rates.

Table 4 - 'Community Education; views from practitioners - Survey circulation

Given the dominance of snowballing techniques, counting of circulation is unreliable. There is also overlap across contacts. For example $22 \%$ of those citing AONTAS CEN membership would also have received the questionnaire through an e-mail to their employer Community Sector organisation. Also, all Citywide organisations were contacted even

\footnotetext{
${ }^{40}$ At the time of survey circulation, VECs were still operating. When focus-groups were carried out, ETBs had been established merging FAS within.
} 
though the bulk are unlikely to house people fitting the criteria laid down as many engage in counselling and other supports and not structured educational programmes. This is reflected in lower participation rates from these organisations.

Distribution was via e-mail using the Bristol On-Line Survey (BOS) software package ${ }^{41}$. An initial e-mail invitation was sent followed by a reminder e-mail some time later. The survey was entitled Community Education - Views from Practitioners and was open between $12^{\text {th }}$ of March, $2013-12^{\text {th }}$ of July, 2013 with valid completion by 219 participants. Further detail on uptake can be found within chapter nine when findings are reported.

\subsubsection{Phase Three: extending dialogue through focus-groups}

Focus-groups can raise difficulties when incorporated into social research. People can tend towards consensus even where they might not agree a point and might say what they think they should say rather than what they would ideally like to say. Researchers can also make incorrect often simplistic assumptions that assume agreement and/or mask gradient of emotion (Barbour, 2007: 130). Group settings can also impede those not comfortable with such surroundings not least by revealing their identity to others in the room. In addition, cultural dimensions of power, such as those relating to gender, nationality/ethnicity, and voluntary versus paid worker, can permeate a group-setting leading to inequality in participation and unequal weight of meaning attributed to some contributions. Focus-groups also bring significant benefits through their creation of conditions where participants can engage with each other towards a co-creation of knowledge captured by the researcher.

All of those who participated in phase three were also involved in phase two of the research project. Opting into group participation was enabled through response to the statement below which appeared at the foot of each survey questionnaire circulated,

\footnotetext{
${ }^{41} 12$ people completed the survey in hard copy circulated through the ACEN and these were manually inputted into BOS by the researcher
} 
I will be holding group discussions around the country where I hope we can discuss issues raised and other thoughts people have about community education. Would you like further information on these with a view to participation? Remember that by doing this you are wavering anonymity relating to your survey answers. You are only revealing your identity to me and at no time will the answers you provided in this survey be revealed to others. Your identity will at no time be revealed in the writing up of this research.

Eighty-six people answered yes, all of whom were sent further information via e-mail or text message (depending on the type of contact details they left). This invited them to participate in a group setting with agreement sought before moving to discuss the intricacies of involvement. Geographical locations were chosen in line with emergent clusters with meetings held in Limerick City, Cork City, Waterford City, Athlone Co. Westmeath, Naas Co. Kildare, Dublin-South, Dublin-North and Dublin-Central. This second opt-in opportunity and subsequent negotiations on dates and venue translated into 35 participants. Attempts were made to gather participants for two further groups, in Galway and DublinCentral, but these did not materialise as participant numbers were only two people. One-toone telephone interviews were offered instead which were availed of by seven people, four of whom reside in areas where there were insufficient numbers for a focus-group, and three who had intended participating in an arranged session but could not make it on the day. All focusgroups took place between late July and September, 2013. Meetings were held in community centres (x4), the offices of an ETB (x1), an Independent Community Education Organisation (x1), a Local and Community Development Project (x1) and the training room of a Nongovernmental organisation (x1). People were asked to give two hours of their time to the process with some groups running over this allotted time. All focus-group participants were sent a written consent form in advance of their involvement that included a request not to reveal the identities of others they encountered. Each focus-group encounter was transcribed in full with completed transcripts e-mailed to participants for review and refinement if they chose to do so. Permission was given to withdraw or amend their own voice only. 
Perusing research literature on focus-groups, dominant instruction is towards a minimum of 4-5 and maximum of 10-12 participants (Bryman, 2004: 351; Sarantakos, 2005: 196; Cohen et al, 2011: 437). I took my lead from the number of participants opting in, their geographical dispersion, and my objectives to create problem-posing interactive environments with a maximum of nine and minimum of four invited to each session. Group numbers varied from three participants in Waterford and Cork, four participants in DublinCentral, Dublin-North, Limerick, and Kildare, five in Athlone and eight in Dublin-South. In all but Dublin-South and Athlone, higher numbers were expected with people not making it on the day. Whilst it could be suggested groups with three participants fall short of recommended norms, much literature on focus-groups interpret these as the chief data gatherer rather than as complementary as is the case in a multi-method undertaking such as this. No criteria was set for participation outside of that which had been previously determined i.e. 'if you are currently working in a group in a community setting or have done so in the last 2 years this means working with groups outside of higher education and further education settings'. Findings from focus-group encounters can be found within chapter ten.

\subsubsection{Research design for telephone interviewing}

Telephone interviewing as part of qualitative research is sometimes considered the poor relation to face-to-face encounters. In a review of literature on telephone interviewing Novik (2008) reveals this bias through its omission in core qualitative research texts and the relatively small body of knowledge created on this method. It is important to challenge this perception and present telephonic communications as a legitimate and often enhancing mechanism in conducting qualitative research. Notwithstanding the potential for distraction the researcher might not be aware of, and the absence of non-verbal cues, positives include increasing opportunities for participation, enhanced confidentiality, an enablement of freer 
speech, and a decrease in social pressures which focus-groups can carry (Burke and Miller, 2001; Novik, 2008; Mealer and Jones, 2014).

Participation in one-to-one telephone interviews was the final way people could become involved in the research process. The rationale for including this option was as a way to ensure equality of participation for all community educators who were keen to speak to me. Interviews were held between September and November, 2013. Each was carried out using the loudspeaker option on a mobile phone, and each phone-call was placed and conducted in an empty room. At the beginning of each interview, participants were told of the exact point at which the digital recorder was turned on, and again when it was turned off at the end of the interview. In total, seven one-to-one telephone interviews were carried out varying in length from 15-40 minutes. All were transcribed in full with completed transcripts e-mailed to participants for review and refinement if they chose to do so. One transcript was withdrawn in full following review by the participant, and the recording was deleted. Only six interviews are therefore reported on within chapter ten.

\subsection{Ethical considerations in design, implementation and dissemination}

As researchers we sometimes carry a sense of intrusion and burden when inviting participation. However many people want to be involved in social research, borne out in this study both by the volume of people opting in to further involvement, and through personal emails I received from people commending the initiative. It is nonetheless important that we carry ethical responsibilities to protect such participants when they do volunteer. The integrities of these relationships can be considered across three broad areas. These are respect including the securing of full and informed consent, wellbeing, physical, psychological social, economic, legal or dignitary and fairness in equitability in selection (Citro et al, 2003). Some categorisations might seem less relevant for a research project such as this when compared to medical research for example. However, the same guiding 
principles must be adhered to as assumptions cannot be made on the risks being taken by participants. Say for example an independent community educator was to express a value that affronts the organisation from which they get the bulk of their work and this was relayed to those with control over hiring and firing? Equally, might a community education organisation based in a remote area have the right to feel aggrieved if no effort was made to include them in the study? Responsibilities towards a wider audience are also important. De Vaus (2002: 64-65) names this audience as other social researchers, sponsors and the general public, suggesting potential harm includes fraudulent reporting of findings, insufficient divulgence of methodology and non-disclosure of funders. De Vaus (2002: 59-60) also alerts us to the fact that whilst participation is in the hands of those that opt into research, this is not the case with third parties. A case in point in this instance is deliberate questioning about Quality and Qualifications Ireland (QQI) when discussing Further Education awards in particular. This makes the accrediting organisation involuntary participants in this research with no right to reply afforded.

This section details the ethical considerations adhered under the guidance of the Social Research Ethics Sub-Committee at Maynooth University. Particular attention is paid to the areas of consent and confidentiality.

\subsubsection{Ensuring informed consent}

In considering voluntary participation, the principle of consent I carried into the inquiry was that I wanted everyone involved to give full and informed permission at a variety of stages. Given the adoption of mixed-methods, the nature of this consent would vary. For one-to-one, focus-group and telephone interviewees this involved ensuring both verbal and written consent was elicited and that people felt they had some control over the process and the right to change their mind about involvement. All participants signed a written consent form which included agreement on audio-recording and transcribing, details on safe storage of 
recordings, and contact details of supervising staff and the university ethics committee (appendices 1, 3 and 4). Other considerations included assurances that people knew I intended to quote directly from transcripts in this thesis submission, in presentations, and in academic journals.

As mentioned already, all one-to-one interviews and focus-group meetings were audiorecorded and transcribed as was explained at the point of first consent. A copy was given to each person after their interview to allow amendments, deletions or withdrawal of the complete transcript. This enhanced the quality of consent and also benefited the interview process itself as people seemed more at ease knowing they had control over the final data available. Where notes were taken within focus-groups, these were also circulated to participants for them to review and agree on as an account of events.

For those completing the survey, the concept of voluntary participation was observed as the self-selecting nature of the questionnaire allowed for opt in rather than opt out. This was enhanced by an information sheet as the first page of the survey giving contact details, university links, guidance that no questions were compulsory and a reminder of the anonymous nature of the survey (appendix 2).

\subsubsection{Maintaining participant confidentiality}

As social researchers it is equally important that we maintain participant confidentiality, a concept often closely linked to consent. Again there are unique considerations at play at each stage of this inquiry. For one-to-one interview participants, identities were not disclosed to others and habitual speech patterns likely to reveal who they are were removed from transcripts as were names of third parties and organisations. Safe storage also ensured audiorecordings and typed transcripts were not accessible by others.

Whilst these principles were adhered to for focus-groups, confidentiality in group settings was not guaranteed as, though I would not reveal anyone's identity, I could not extend that 
guarantee for others they encountered in group settings. A separate consent form was prepared explaining this. In order to enhance the likelihood of confidentiality being maintained, participants were verbally asked to enter into a confidentiality agreement at the beginning of each group asking that they don't reveal either the identity of others.

Twelve people who were not comfortable with the use of on-line surveys were facilitated to participate in phase two in writing. This was via hard-copies circulated at the survey launch, or on postal request. To facilitate confidential return, a manual drop-box was made available at an AONTAS CEN meeting and pre-stamped addressed letters were provided where hardcopy surveys were posted. For those completing online, BOS software maintained anonymity by not gathering IP addresses of responses. This ensured that whilst gatekeepers, those who control access to potential participants (Paul, 2010: 39), were relied on to circulate the survey, they had no knowledge on who chose to complete it.

Where survey respondents opted into further participation, they are reminded of how this removes confidentiality through the following statement,

\section{Remember that by doing this [leaving your name and contact details] you are wavering anonymity relating to your survey answers. You are only revealing your identity to me and at no time will the answers you provided in this survey be revealed to others. Your identity will at no time be disclosed in the writing up of this research}

\subsection{Integrated data analysis}

Whilst there is growing literature extolling the virtues of MMR, limited amongst this is consideration for the integration of analyses from each modality (Bryman, 2007; Castro et al, 2010). Where discussion is evident, the crux of this relates to the extent to which textual and numerical findings should be integrated and, if in doing so, the sum of such integration results in a more superior research model than each method would produce in isolation. 
Bryman (2007) is interested in addressing this discrepancy within MMR literature setting out reasons for its absence as uncertainty amongst researchers on how to reveal their analytical tendencies. He notes concerns about the intricacies of writing for different audiences, a personal preference towards one method over another, rigid research structures, competing time-lines and publication limitations, and the potential challenges of bridging ontological divides (Bryman, 2007). This final concern, the marrying of objectivism generated through quantitative research and constructivism uncovered through qualitative research, can be viewed by some as erroneous, and contradictory in nature. It is through revisiting previously asserted proposals of a positivist-post positivist continuum over dichotomisation held within a fallible critical realist perspective (chapter two) a complementary approach is asserted that suggests weight of meaning from both sources.

In reporting findings, there has been an initial separation across stages presented in separate chapters. This is followed by an integrative analysis (chapter 11) that incorporates findings from each phase. This requires cognisance of strengths and weakness within each method and endeavours to afford equal worth to both, the textual narrative of qualitative findings, and the value of measurement and hypothesis testing with quantitative findings. This integration requires parallelism with Castro et al (2010) believing the greater the qualitative-quantitative coordination, the easier it is to convert and interpret textual and numeric data across techniques. This was assisted in this study through the sequential, correlational nature of the study with qualitative and quantitative questioning not dissimilar in nature.

The initial analysis of qualitative data within phases one and three was through thematic open coding. Data was organised through a constant comparative method where, following the coding of data into categories, each unit of meaning was compared to other units with new units evolving where necessary (Maykut and Morehouse, 1994: 134). To give an example, strong to emerge across each phase was both relationships with the State as funder, and 
relationships with accreditation mechanisms. These were catagorised separately and, for the latter, further catagorisation was employed relating to the nature of concerns be they philosophical, or technical. Codes were summarised into a coherent synopsis of findings which could be carried forward for inferential analysis. This was done manually without employing computerised qualitative software. Further integration across phases one to three that incorporate qualitative and quantitative findings are again thematically merged within the analysis offered as chapter 11.

Phase two differed where textual accounts were themed along corresponding variable measurement. Quantitative variables were organised through initial creation of a detailed code-book that assigned numeric valued to each response given. These were then entered into IBM SPSS version 20 for analysis. The hypothesis testing I undertook was predominantly frequency measurements and cross-tabulation.

\subsection{Summary of chapter}

This chapter serves a specific function namely to provide the reader with information on underlying processes that I employed in carrying out the field based research that forms a central part of this overall study. Procedural detail is situated within methodological considerations most notably the decision to work from a MMR perspective, the virtues and limitations of which have been discussed. As well as detailing technical considerations, it offers a critique of both qualitative and quantitative methods when utilised in isolation. It argues a mixed-methods approach as relevant to the research topic. This is particularly through quantitative research's ability to reach a larger number of people in order to better map the landscape of provision. It is also through a social justice lens, arguing a need to ensure research is generated that encapsulates community education is a way that can generate currency with policy makers and funders. Under guiding influences of respect, wellbeing and fairness, an ethical framework is also detailed with particular attention paid to 
the areas of consent and confidentiality. This chapter acts as prequel to reporting on primary research findings which is undertaken within chapters eight, nine and ten. 


\section{Chapter eight: Narratives from popular educationalists}

So that is what I do, I encourage people to pool their experiences, you know, share their experiences; whatever issue we might be talking about. 'What's your view of that?' or 'what's your experience of that?', to learn from that sharing - 'oh right that happens to you' and then to begin to unravel some of the patterns that you begin to see and use. That is a way of putting the issues that people experience, that society has, up for question.

Research participant, phase one. 


\subsection{Introduction to chapter}

A clear ambition of this research is to draw attention to critical practice within the broader tapestry of community education; to shine a light on education in line with my own pedagogic philosophy and ways of working. This helps us understand the potential it might offer in shaping community education, especially when contextualised within neoliberal conditions. To sufficiently address this, and to authentically serve my own ontological and epistemological beliefs, the influence and participation of other radical educators needed to be more than a voice amongst other philosophical leanings. Instead their insights would assist in informing the direction of the process. This was enabled through a first phase of primary research where seven one-to-one interviews were carried out with purposefully selected contributors, all of whom were working in community education settings. These were carried out in advance of survey design generating a reflexive relationship between data uncovered, on-going secondary research, and my own experience of practice. It was only when these were completed, and transcripts were reviewed in depth, that survey and concurrent focus-groups were designed. Information on selection, recruitment and operationalisation of one-to-one interviewing are presented within section 7.3.1 of chapter seven. This chapter presents findings from this first phase drawing out core themes that emerged.

Five of those I spoke to work in Community Sector organisations, with one also working some hours within a Higher Education Institution. One works within a large nongovernmental organisation (NGO) with a national profile. Another is with an NGO whose work is principally within Northern Ireland though I became aware of this person through their involvement with development work south of the boarder. All are predominantly based in large urban settings. Four interviewees were female, the others male and they have been working in community education for between 4-30 years. Where possible, further 
introductions will be through their own accounts as shared during interviews. This will be followed by a thematic reporting of other findings that focus on descriptions of practice, philosophical influences, relationships with the State, criticisms of the Community Sector, experiences of working with accreditation and hopes for the future. These were gathered through a constant comparative method as detailed within section 7.5. These educators offer confidence in the concept of community as a potential site for egalitarian change and, the narrative structure utilised, offers a sense of the complexity within community education in Ireland.

\subsubsection{Participant introductions}

\section{Community Educator 1}

Referring to her work as 'popular education', the first interviewee describes herself as someone who became interested in radical adult education through critical analysis of her upbringing on a local authority estate in a Dublin suburb. She describes 'seeing poverty in my house and around me, seeing all the crap that comes with that' and expressing sorrow at the way her father in particular felt responsible for symptoms of the economic inequality they experienced. Her prelude to practice was to see local education in action whilst living in this neighbourhood in the 1990s. She describes what she witnessed as from a 'domesticating approach', a model she is now critical of. Acknowledging some role for community education in personal development, and as a route to employment, she explains how her current commitment to radical practice began when she encountered critical theories as a university attendee on a programme categorised within the social sciences. Her university enrolment was made possible through individualised government grant-aid during the 2000 s. This enabled her to undertake undergraduate studies within social science with post-graduate emphasis on equality studies. 
She is unhappy with policy makers perceived prioritisation of equality of opportunity over equality of condition and shares paradoxical opinion about being first in her family to experience third level explaining,

It is really depressing for me, on the one hand your family are really proud, so they want to play you up as 'the one that got it' and 'you can get out of here', it is really individualised. For them it also proves that they reared you well, they cared for you. That whole family thing, you can't play it down. And then there is the whole thing, I wouldn't be here now if it wasn't for it, you know, they are not wrong either. There has to be a balance, one the one hand you want to advance and, you are this token you know, 'this is what actually works if you try hard'.

(Community Educator $1-$ CE1)

It was her involvement at post-graduate rather than under-graduate studies that was to have the most powerful effect, transforming the way in which she interprets the world. She names particular influences as feminism and radical education theories, ideas she encountered through a mingling with others. She elaborates, 'I wouldn't have been as feminist as I am now only through a process of meeting other women in a forum where there were feminists' and continuing 'it doesn't just happen naturally; you don't just wake up and read Paulo Freire's Pedagogy of the Oppressed'. When asked about the changes she would like to see in the world (a question posed to all interviewees) she describes capitalism as 'a rotten system' and expresses a desire for 'real fundamental change, massive systemic, structural change' the purpose of which would be to bring about 'a society based on care'. She claims her workingclass origins have influenced her sense of reality and decisions to work towards change but cautions against automatically equating the experience of structural inequality with the carrying of radical intent. She points out how 'it doesn't mean you have a problem with capitalism, you might actually embrace it'. For her such inferences are problematic in fuelling assumptions that the Community Sector, by virtue of its existence, is by and large, a left-wing influenced force for change. With notable and named exceptions, this has not been 
her experience particularly in recent years. Her own efforts are through alliance with others who share her convictions so they can collectivise actions hoping to advance social justice.

She explains,

We were disillusioned with community education, but we were also conscious that we need to have the foundation. We weren't saying we were there to replace what is there, we were just saying let's start to do what was did happen in the original days as well; politicised education. (CE1)

In collaboration with others, they approach existing community groups often established in response to personal development motivators, and offer educational programmes designed to politicise. She describes recent work with a women's group brought together through a shared history of problematic drug use. Through a problem-posing approach to education the women are encouraged towards 'not seeing it [the world] the way we have learnt to see it'. Rather than proselytize the virtues of her political beliefs through instructive teaching methods, she relates inquiries to lived experiences asking the women 'why your lives are where you are, stuck in a one bed-roomed council flat?' elaborating as follows,

\begin{abstract}
Some of them would only have just stepped into their lives and looking into areas of poverty and looking at these issues for the first time and we create the conditions that this is very, very safe and like kind of a fun experiential way of learning. They do feel they are learning but they don't feel the same education system [as school] because they would feel quite comfortable in the way we go through stuff and we learn stuff... We would be doing it because we would be hoping that some of them would get more involved locally, and see the value of getting involved locally with some of the things that are effecting their lives locally. (CE1)
\end{abstract}

\title{
Community Educator 2
}

Another voice you will hear is of a woman whose first formal introduction to the theories of adult education was again through post-graduate studies. Her first encounter is different to CE1 as she describes a trajectory from practice-to-theory beginning when she was living in a working-class Dublin suburb and was primary carer for her children. She remembers vividly the experience of 'being a woman and being quite unhappy with my situation and not knowing why'. This was despite this same period being transitional for many women as 
she recalls the actions of The Council for the Status of Women and of being "very much in favour of what they were talking about'. She was uncomfortable with some of the changes she observed sharing 'there wasn't anyone like me with a voice there' and she continues,

Ok there was the civil rights movement going on in America, assertiveness was all coming out, so you had all this stuff coming at you but it was a bit like, what about the ordinary woman in the home... what do we do?

(Community Educator 2 - CE2)

She recalls the fledgling women's community education movement of the 1980s sharing her involvement in setting up a morning adult education group where 'we had our crèche, and we could decide what to learn, who we wanted to have in, and it's funny because it became very political very quickly'. These sessions were 'really about learning the language and the analysis' stating 'it was only when you start to talk to other women and analyse it you could see that it was the way society and patriarchy and [how] the system was working that you were unhappy with'. When asked to give examples of discussions at the time she replies,

It was really about how women were managed in society, and men as well because there was a lot of unemployment, so it was how society valued you and where was the voice, your voice being heard. I would have been very critical of the Council for the Status of Women at the time because most of them spoke, ok people's pay and conditions, whatever the issues were, but I suppose they were good, but the way they were speaking it didn't relate to my life [...] so we started to look at social studies, we started to look at health, why was women's health being ignored? (CE2)

She remembers supports for this group from volunteers within Trocaire ${ }^{42}$ who brought a 'Freirean method' influenced by the Training for Transformation (TfT) approach as outlined by Hope and Timmel (1984). She also recounts involvement from both AONTAS and an Adult Education Officer (AOE) employed through the local Vocational Education Committee (VEC). She remembers the AOE as being someone who was 'very open to groups', an attribute she considers not present in all AEOs at the time. She welcomed the collective approach these supporters brought explaining how before this, much community education she encountered was individualistic and domesticating.

42 An Irish based charity with a history of overseas development work. 
She has now completed university hosted periods of set learning in Adult and Community Education, and has many years as a paid community worker/educator. Continually, she closely links processes she employs to collectivised approaches to community development. Questioned on what sort of change she would like to see, her hope is for 'a more equal society' reporting,

the longer I have been working in community development, I just find that the gap is getting wider and wider...nearly everything is unequal, if you are looking at quality of life you are looking at where you live, your housing, the health system, the services, education, I can go on and on. (CE2)

She names on-going influences in her practice as critical feminism, Freire, 'dialogics' and human rights approaches as she works with locally based community groups usually in urban settings. This is sometimes as part of accredited set learning periods and other times as nonaccredited processes of community development. Her work is 'about having the system accountable but the system being made up of everyone, it is not that the community get off either, for real change to happen they have to hear each other and work through the system'. She continues,

I suppose we have to strategise on ways of intervening, it's about using social analysis and [seeing] where can we make interventions? It takes time again, but any community development process takes time so it's not so much of us being a radical voice out there, it's working with who we are working with to be the radical voice and that is so powerful when it happens. (CE2)

\section{Community Educator 3}

A third interviewee also shares a history of being first in his family to go to college. His studies within the social sciences were only made possible through free fees and government grants available in the 2000s that were awarded on the grounds of socio-economic circumstances. The experience of college as a mature student was to have a lasting impact and he talks about meeting others who shared similar histories also availing of opportunities that were denied to his older siblings and parents. He laments the current loss of many of these supports through increasing registration fees and of a reality where there are families 
that, the social environment that they are born into in comparison to other groups in society shapes what they can expect and the opportunities they can expect'. He would like to see radical reform of capitalism particularly a deep-seated redistribution of wealth through taxation, greater expenditure on public services named as health, housing and education and more access to meaningful employment for those currently denied this. He challenges negative connotations sometimes associated with such ideas suggesting that many people he encounters seem keen to distance themselves from radicalism despite the fact that 'the options that they put forward would be considered part of left wing ideology'.

His introduction to community education was after college and through practice within a nongovernmental organisation (NGO). Here he met others who carried a radical vision for change introducing him to theories and practices associated with popular education. On paper, this organisation espoused social justice ambitions but he reports a gulf between rhetoric and practice and an absence of 'pull from the top' in challenging structural inequalities. Instead he paints a picture where individuals are attracted into the organisation based on a veneer of social justice and a declared commitment to the philosophies of Paulo Freire. Once inside, they become disillusioned by disparities between what is said and what is done but, rather than forgo radical tendencies, manage to mediate covert spaces within. $\mathrm{He}$ explains,

\begin{abstract}
you work on the margins basically of the organisation and the sense is that it is not only that you are working in the margins, I think of the margins in terms of a copy-book, it's in the margins that you put down notes that you really have to pay attention to. If you work in the margins where you are almost hidden, you are under the radar.
\end{abstract}

(Community Educator 3 - CE3)

His role includes delivering a university accredited fully subsidised community development programme delivered as part of a wider organisational strategy to build the capacities of local leadership and local leaders. Whilst he is doubtful about the organisation's concept of leadership, one which appears more attuned to notions of compliant rather than critical 
citizenship (Berner and Philips, 2005), his account of practice resonates with others shared in this chapter. He explains, 'if you are looking at a particular issue, a lot of the time the initial focus is on the individual and what is happening to them in relation to that and their local community'. His work is,

about opening that up, making connections to the wider world in terms of well, 'what are the other influences on us', and 'what are the other options that are out there for us, to try and address this issue' so it's not all 'well if its anti-social behaviour it's about the kids', you know, it's about what is going on in the wider world that has connections to this and we look at power, culture and economics and again it's about just opening people's eyes to structures in societies and the institutions that play a role in people's lives at different levels, at local level and at nation level. (CE3)

\section{Community Educator 4}

Describing herself as from a rural upbringing, this fourth person details her relationship with critical education through its comparison with her own experiences of traditional schooling. This was an experience she describes as 'dominated very much by higher and middle-class values'. She also details the personal impact of ability streaming explaining,

I was a victim of that actually... being graded in a particular way that positions you all the way through, and I remember the labelling, there was so much labelling that went into that...I would have had really highfalutin ideas about what I wanted to do, but when I got graded in second level and the consequences of that all the way through because there was different expectations in our class than there was for others classes. We were given the less skilled teachers and there was loads of messing.

(Community Educator 4 - CE4)

She first came across community education when working as a volunteer within a 'social justice group' Family Resource Centre (FRC). Her exposure to radical theories and practices began when this FRC invited educators from Partners Training for Transformation (TfT) to facilitate a TfT summer school where she was a participant. She remembers being 'really excited' and 'completely won over by the approach' motivated by a desire to 'try and learn, get people in, get women in, see what it was like'. Many years later, and now employed 
elsewhere, she continues to cite this event as having significant and lasting impacts, both personally and politically,

That is where I realised myself that you have a role, each of us have a role and each of us has something to offer when you have gone through it. We did loads of exercises, the experiential stuff, the Freirean stuff, and I thought that, because I wouldn't have thought of myself as a part of that, I would have thought differently about the world, I wouldn't have thought I had a role to play in it particularly, so that really opened it out for me. (CE4)

Now educated to masters level in equality studies, she maintains it was this earlier experience that particularly shaped her belief system, beliefs she wouldn't have developed from secondary school. When questioned on the changes she would like to see in the world, she aligns herself with socialist ideology and hopes for 'a more equal society' blaming current socio-economic systems for structural and gender inequality believing 'that the capitalist model, or the neoliberal model, hasn't benefitted people, it has only benefitted people at the top'. She articulates 'I want a different economic and political system...a system where men and women are treated equally and where there isn't this division between rich and poor which there is in Irish society'. Her current work is with urban based women's groups where inequality is openly explored in a non-accredited learning environment. She provides a safe, comfortable, supported learning space where women can 'begin to question more and begin to make demands about society and begin to ask more hard questions and not take everything that they hear'. At the heart of her work is a commitment to peer-exchanges, peer-listening and peer-dialoguing that, with the support of facilitation, enables discussion to evolve to include,

stuff around gender, the economic system, women's role in society... when people become aware of that stuff and begin to unpick it, they become a lot more critical and they realise that because they are not that well off, it's not because of their own fault, and they begin to understand the world and they begin to want to change it. (CE4)

Within the organisation where she works, a no class without crèche policy is conditional on groups coming together. 


\section{Community Educator 5}

My fifth interviewee also works within the Community Sector as well as working within a Higher Education Institution (HEI). He too draws from his scholastic narrative describing a 'chequered' educational and vocational past. Despite early drop-out from school, he relays third level involvement, again made possible through State-granted funding. He describes his background as working-class and remembering the way his exposure to others considered more affluent, enabled him to 'recognise how limited my life experience had been, I met with...you know people who were different from the world that I was brought up in'. It was during further post-graduate university studies that he came to fall in love with adult learning environments, a passion he has carried for many years. 'I liked the buzz of people learning together, it's the buzz of people learning together that I find really interesting'. Detailing how he 'would respect a lot of traditions' he claims to 'probably stand more in a popular education tradition, which in my mind puts a lot of emphasis on people's experiences and on validating them and recognising them'. His introduction to popular education is described through overseas development work as he shares stories of practices that centralised subjectivity whilst not abandoning a sense of realism. Now working within the Community Sector for many years, he also demonstrates a constructivist, equality led leaning continually linking the need for attention to the personal as well as the systemic. He elaborates,

I think it is important that people recognise, you know that they are multidimensional and multifaceted. That is very important, that people come to know what they know but also, maybe know how they come to know it in the sense of being able to see the way in which they see the world, that they can take off their spectacles and look at them every now and then and see 'that's why I see that' and 'I can change my spectacles' you know. 'If I was given these spectacles then I can change them'.

(Community Educator 5 - CE5)

Much of his current work involves non-accredited bespoke group-work led out by local demands along with the delivery of accredited programmes within a HEI where his methodology is to be led by the group rather than the course descriptor. When questioned on 
his hopes for the future he wishes for an eradication of inequality lamenting, 'at the end of the day it's a decent sort of world you know', the creation of which would have implications at both personal and systemic level as he continues to raise subjective-objective balances claiming 'there must be some sort of a congruency between them you know what I mean...that's what motivates me, that the world be a bit kinder for us'.

\section{Community Educator 6}

Again an employee of an urban based Community Sector organisation with an educational focus, the penultimate interviewee was also first generation in her family to attend university. Although initially working in another field following under-graduate studies, she describes a period in her life when she deliberately sought out employment that would better respond to her 'instinct that society needed to change'. Through community employment in the 1990s, she began working in a support agency for people who were unemployed and whilst here, applied for a university based post-graduate programme in Adult and Community Education. This was to have an intense and lasting impact on her as she explains,

That course really radicalised me I would say, and then I kept on radicalising if you like, but that course really radicalised me. That course introduced me to critical theory, Adorno and Marcuse, people like that and Freire and so on and I kind of went from critical theory to Marxism and at the same time, very much at the same time, maybe a year after, half way through that course I got politically active.

(Community Educator 6 - CE6)

The political activism described is towards the achievement of socialism and she offers an analysis where class is the determining factor in the way in which history unfolds. She believes the world is 'full of contradictions' explaining,

A fundamental contradiction is between those who exploit people and those who are exploited...people have interests on that basis. So the capitalist class, it seems to me, the wealthy and powerful in the world have an interest in maintaining the system the way it is, and the majority of the rest of us have an interest in changing it. (CE6) 
Her work as a critical educator is interpreted as 'to challenge the dominant ideology by encouraging people to question' so they can become social actors in creating a more democratic world with more accountable State structures. She continues,

So that is what I do, I encourage people to pool their experiences, you know, share their experiences whatever issue we might be talking about, 'what's your view of that?' or 'what's your experience of that?'. To learn from that sharing; 'oh right that happens to you' and then to begin to unravel some of the patterns that you begin to see and use that as a way of putting the issues that people experience, that society has, up for question. (CE6)

Working within a Community Development Project and in both accredited and nonaccredited environments, she describes much of her practice as about encouraging local people to make connections between their life circumstances and the lives of others overseas. It is about,

Looking at the kind of issues that people think are important in a community, in their own community and then linking those to have a look at, well what is the situation on a global scale? Or what are other communities doing? How have they addressed that, what is their situation like? And using that I suppose as a way of analysing our own situation and how the wider world works. (CE6)

\section{Community educator 7}

Detailing a vocational past of many years within the development education sector across Ireland, the final interviewee talks less about his own story. This was not deliberate but rather is reflective of the absence of specific questioning to all on personal backgrounds with discussions mentioned thus far organically emerging. He aligns himself with Keynesianism and is strongly critical of current economic policies and practice stating 'I think the way we manage our economy is completely wrong, the economy is being run by markets and driven by people who are supporting the markets and I think the economy should be driven by human needs and the needs of the wider community'. He suggests, 
people are still talking about 'we have got to keep the multinational corporations coming in. The economic model was fundamentally sound but the problem was the bankers, or the problem was the developers'. I think the whole approach to the economy that we had in Ireland was wrong, I personally believe that. And I don't think the way to sustainable economic management is to continually be beholding on foreign companies coming in and letting them pay $12.5 \%$ corporation tax you know. So I think it is about really big fundamental changes to the economy.

(Community Educator 7 - CE7)

He also comments on the way in which we have 'really lost sight of what education is for, of the values and the ethos, it is not just about getting kids over the line in terms of exams it is about making them into citizens who have a stake in society and the right values and approaches to life'. He is particularly influenced by the ideas of Paulo Freire and wonders if some aspects of 'popular education' have been lost explaining 'it is almost like Freire has been put through a strainer, and what has been left is that the radicalism and the whole concept of society and the connection between education and society is gone'. He interprets his role as about challenging these notions and about playing some part in bringing about egalitarian change through a re-invigoration of Freirean ideology. Much of his current work is supporting other development workers to enhance their leadership skills and analytic capacities, many of whom are from ethnic minorities. This is in both accredited and nonaccredited learning environments and the issues raised in doing this include,

globalisation, neoliberalism, we look at gender, at economic injustice... as well as some of the other things that are related to minority groups; racism, cultural diversity, tolerance and, migration, issues that are more focused on those sort of communities but we also try to look at a broader menu of development issues. (CE7)

His facilitation style is described as 'about participative learning, working in groups and pairs; it's about discussion, it's about focussing on social justice issues'. Alongside supporting local groups and local leadership, he also emphasises the importance of wider networking and campaigning. This is to offer counter-hegemonic challenges to current State practices that perpetuate inequality and social injustice believing 'I don't think there is any credibility with local communities if you are not taking them [the State] on'. 
His current work is within a large NGO, largely based in Northern Ireland whose emphasis is locally based educational work. He is also involved in cross-border work as well as being actively involved within a Dublin based campaign group.

\subsection{What we do - describing radically based community education}

During our interview, CE5 shares an example of practice that fittingly captures methodological undertows across all conversations. He explains how, when working with a new group, he often enters the room armed with the prop of a suitcase filled with newspaper cuttings, trinkets, books and other such stuff before emptying these onto the floor. He then invites people in the group to consider the way in which each of them, as participants, are entering into the same space with their own suitcase full of knowledge, experiences and values. Rather than him stuffing more knowledge on top of what each person has, his hope is to carefully unpack each person's suitcase within conditions where learners, of which he is one, can re-pack their bag in a way that is coherent, meaningful and affirming.

This approach is revealed across each interview as people talk of drawing content from rather than presenting content to with one noting how 'you facilitate the ideas out of people'. Another spoke of putting 'a lot of emphasis on people's experiences and on validating them and recognising them', another of remaining, 'rooted in what people are living at the moment' with others outlining situations characterised by genuine listening and dialoguing.

One voice elaborates,

it's just to do with valuing people, valuing people's own understanding already and valuing that they might have a belief or a certain mind-set in relation to an issue and you take that on board and you give them space to get it out there, and you don't have to be able to argue for and against it you can just put the point across and then you open up the whole spectrum to it, in the hope that, well in the hope that they are paying attention and they are listening and they are taking on board the whole, you know, 'I've been listening', 'I've been heard', 'let's listen to all sides of the story'. (CE3) 
The rationale for working in this way is, by-and-large, described as more than about humanistic tendencies towards care, concern and support. These concepts are not absent from the work, rather co-exist alongside listening and dialoguing as an essential feature of politicising processes. As one contribution explains,

you are putting everybody's point of view out there, you know if in the class, people are hearing all different perspectives and then...I suppose that the inequalities in society will speak for itself and any rational person is able to recognise that...It is hard to argue that it is just one person's fault or that it is just that particular incident that needs to be changed. (CE4)

Connecting the micro-experience to the macro-environment is discussed elsewhere also. One talks about a programme involving people who have migrated to Ireland from other countries, all of whom are now 'local people and they work in local communities so bring their local experiences into that'. He continues,

They deal with experiences such as racism and migration and then have a local and global focus to them. So they are experiencing racism on the ground here but some of that racism is informed by global issues and you certainly couldn't talk about an issue like migration without talking about the factors which force people from the Global South to come and live in Ireland, I mean it's just impossible, you couldn't address and issue like migration fully without talking about the local factors. (CE7)

Some examples of methods that enable such exchanges are shared. Research participants cite the use of exercises that encourage active reflection on personal circumstances before these are shared in small groups, and of world café methodology as a way of hosting large dialogic discussions in a safe, supportive space enabling greater involvement from all. Some contributors spoke of using codes. These include the use of simulated exercises that re-create political and economic systems. Another talks of introducing a 'community exchange' slot to sessions within an accredited programme ensuring permeability between classroom and community and enabling praxis-oriented work to address issues directly affecting the community. Another reveals how the assessment of work for university accreditation is deliberately linked to perceived problems in a particular neighbourhood with participants 
instructed not only to analyse circumstances, but to collectively act in some way on whatever the issue might be.

The types of courses named include local leadership programmes, cited within each interview, with the inference being to promote leadership within others and not maintain this position for the community worker/facilitator. Other programmes named were accredited community development courses, women's groups, development education work, reflective practice, up-skilling in facilitation and a workshop for Dublin based members of the Roma community described as follows,
A couple of weeks ago we ran a workshop in Dublin on the Roma community. We used development education methodologies to explore some of the issues that are confronting the Roma, using development education and participative learning, working in groups and in pairs and the world café methodology. The two trainers were people who have completed our course, they are both Romanian, very familiar with development education. (CE7)

Along with accounts of critical spaces within learning environments, measurable action outcomes reported include participant involvement in local environmental campaigning, people voting for the first time, the establishment of a regeneration group which then linked to a wider tenants' rights organisation, involvement with a successful campaign against the closure of a local crèche, the setting up of a women's support group for dealing with suicide, first time attendance at public meetings, and improved relationships between youths and Gardaí as a result of specific dialogic work. There were also reports of participants joining demonstration movements against the closure of community projects and welfare cuts, and of participation in a dialogic day with other community groups. This balance between creating conditions for critical thinking and tangible outcomes that authenticate activist notions implicit within the work is discussed with some interviewees. One shares how participants 'may never get to do anything politically active but I suppose we would be hoping that they find a way...that you are actually giving them tools, to think critically, from now on'. 
Someone else expresses optimism when describing the importance of the work, coupling this

with the challenge of often not seeing instant gain explaining,

An important seed within community work is to see people going on and being radicalised and wanting to take on the world and getting out there because of what they know...I mean it is slow work, community development work and you don't get victories, it can take a long time for someone to get that confidence to take that sort of initiative you know. (CE4)

The pursuit of such noticeable upshots is not always thought of as the most appropriate outcome. Several voices balance this with desires to respond authentically to where a group is at, and to take pride in lifting hegemonic veils that encourage reframed ways of knowing.

This sentiment is well captured by one interviewee, whom I will quote at length,

The one thing you can't measure is that this might help that woman to not close that door, her being in a better mood with her kids, her better self really. I am concerned with how fluffy that sounds but it is real energy stuff, in a strange way, if, that is if that is linked into political activism...you are really making that personal power that the feminist movement talks about, that I think has got side-tracked. I think it is kind of about personal empowerment as an outcome, it is more than just that when you think about the fact that, that woman, even if she never got experience in being politically active, she would have a critique that will always allow her to have some sense of empowerment...that she will realise and be able to critically look at what is going on around her. And maybe you know, in 20 years time, an older woman, when kids are reared... the output maybe can't be measured today because she has young kids, still going through whatever is going on, but in 20 years, if you went back to that same person, you don't know where they use that critical analysis, what ways they use it. (CE1)

\subsubsection{Experiences of being a critical community-based educator}

Some of the demands of working as a critical educator in local settings are raised. One participant refers to work within a particular Dublin community noting how she is often, 'so touched and so moved by their lives and how they are still fighting', a sentiment shared within two other interviews also. She also identifies challenges brought about through a lack of finance for the work. A particular concern is how funding can be leveraged for direct involvement with groups for delivery of programmes such as a certificate in leadership, or certificate in community development. Her frustration relates to a lack of money for 
preparatory work in advance of a group coming together, or ongoing community development work following completion of a specific programme. Because of this she carries a sense of letting communities down as her organisation moves on to the next piece of funded work. She explains,

It's like you can see the jigsaw and the bigger picture but you are only one part so it's, like you have to come away and let go of the potential and the opportunity and I know they have to as well now ok, I think it's harder for them, and maybe it isn't [for us] because we then go onto our other piece of work. (CE2)

Another voice takes time to reflect on other demands of being popular education sharing the following except,

I also remember when I was training in this kind of work, training in radical education or whatever, you know we talked about all these qualities that you need to have as a facilitator, being open, being genuine, genuineness and congruence and all these sorts of things and I remember going, Jesus that's an awful lot to live up to [laughing] you know and I kind of sort of put my hand up and said 'wow' that's a kind of tall order to get there. (CE6)

Another challenge 'you constantly face' is related to process, as community educator 3 shares frustration at the way others can reduce many of the methods used to non-philosophical, less meaningful practices. He explains,

I hear 'soft' or 'those games, you are doing, all those games' or 'all the fun kind of things' and it is not that. It's, I suppose that it's people who don't really have experience of it are trying to find an appropriate language but yet in not finding the right words to describe the work we do, they are undermining it to an extent in calling it all these things, games and you know 'she's just having a bit of crack in there, it's all just chairs around in a circle and things like that' and even gags about flip-charts and stuff. (CE3)

Managing a tension between the desire to politicise and participant's desire to achieve formal validation of learning is also relayed. Certification is interpreted as a justifiable equality objective for people who are disadvantaged by their previous educational attainment. One interviewee notes how she struggles with this balance explaining, 
It is easy for me to sit here and say, 'all they are doing is a cert in this [pause], we want radical'. A lot of them, you know, they were just doing what people got in their own area, people wanted a job, because they wanted to go back to work, you can't say 'no you have to go off and become more political in the world' you are talking to people who don't have that luxury. The last thing on their mind is going out to change the world... It is like the baby with the bathwater, until you get to that more radical space you are always going to have to be balancing, because people do have rights, within the current system you know. (CE1)

\subsubsection{Philosophical influences: ideas that inform their work}

When specifying theoretical influences, all but one cites commitment to the philosophies of Paulo Freire with his name being mentioned first by each interviewee. The writings of Ann Hope and Sally Timmel are mentioned by two, feminism features prominently, and other theorists named included Karl Marx, Antonio Gramsci, David Kanter, Mary Belenkey (and colleagues), Ivan Illich, Kathleen Lynch, Mohammed Eunice, Jane Thompson, and Myles Horton and the Highlander model of popular education.

What is much admired about Freire's philosophy is its critique of traditional education, with the current school system presented across interviews as pro-market, conservative, lacking in scope to develop dialogue, limited by the curriculum and structurally perpetuating inequality. Radical alternatives encouraged by Freire are praised for the explicitly non-neutral nature of teachings, the centrality of politicisation and, prevalent across the majority of interviews, the encouragement of self-determination by those experiencing socio-economic disadvantage. For one interviewee, Freirean ideology enables you,

you recognise that people in the room have a particular knowledge and have a knowledge of life and have, they may not understand the economic system and all that but in terms of living their lives that you can survive in difficult circumstances rearing children, budgeting, managing, micro-managing their own economic system in their own family and even understand how their own community runs, that they have a huge knowledge base, that you try and tap into that, and it's more active learning in a way, it's shared learning, we facilitate it that way. (CE4)

There are cautionary notes shared about the adoption of Freire as forefather to the work they do. These criticisms relate to Freire's shortfalls in understanding patriarchy (discussed in section 6.4.3) and a failure to present a road-map for the future as the participant believes 
Classical Marxism more effectively does. There is also a critique of Freire in action that wonders about its de-politicisation within Irish community education/development education work. Community educator 7 (CE7) shares,

We watered it down to a large extent and we have maybe kept some aspects of the methodology. You know 'the methodology is ok', you know the active learning, the group-work, the discussion, the notion of teacher as the learner as well, all of that stuff, but what we have gotten rid of I think is the radicalism and the notion of education as a form of social transformation.

Another expresses a contrary concern about a sometimes rigid adoption of Freire's approach sharing a story of practice in a literacy-based setting. He describes another tutor utilising associated tools namely codes and learning circles and certainly producing a group that were 'much more aware, much more politically conscious'. However, when he compared them to another literacy programme that was less politically charged and more technically oriented, he expresses concern that whilst participants on the latter might have left the process less politically aware, they were better equipped with the tools of reading and writing. This, he feels, better enables them to discover their own reading of the world beyond the set learning episode. He explains,

Something got lost, do you know what I mean? It was almost like the motivation of the people running it, it was like in the same way that they were accusing the government of being completely ideological driven, but the alternative was just another form of domestication because ultimately people didn't learn. (CE5)

He continues 'it can be reductionist from all sides, that popular education has certain things to offer but it is a strand in the midst of other ones, so it is not all consuming' adding,

I'm a bit weary of ideology, I mean we all have our ideology, and I have ideology but I am a bit weary of them because I just think people are too complex do you know...they have become, both on the left and the right, unreflective orthodoxies and people are inviting people to swap one orthodoxy for another. (CE5)

He further elaborates on how 'sometimes I think development education is just propaganda by subterfuge because you know what you want them to think, so exercises that are apparently experiential, they are actually dynamic didacticism; you are just getting the people 
to the same place'. This balance between potential dogmatism and truly listening and responding is continued elsewhere with others appearing aware of this tension as they go about their work. Whilst expressing strong commitment to radical theories, CE1 emphasises how for participants of a group 'the answer is not necessarily what feminists, or Marxists [say], it can be what people say, it can be what they decide...I don't believe in having a doctrine given to people'. Another also discusses this tension internalising it towards reflection on challenges she experiences as a facilitator, a position she believes is powerful within a group. She reconciles this with her strong opinions and sense that her own analysis on issues such as equality and social justice are correct. She shares 'it is not very radical if you are telling people what to think, if you are trying to enforce either consciously or unconsciously a particular view of the world'. The challenge as she sees it is to be 'real and genuine in your practice' and in doing this accepting that,

In encouraging people to question, they may not come up with the answers that you want them to...Allowing people to dissent, well allowing is the wrong word, creating the space for people to dissent, and to know that it's ok to dissent, to know that they don't all have to agree, that they don't have to agree with me as a practitioner. (CE6)

\subsection{Criticisms of the Community Sector}

Considering the Community Sector in totality, there was praise for the establishment of the Traveller movement, and the women's movement and subsequent creation of The National Women's Council and the Rape Crisis Centre. The Community Sector is also praised for its significant and successful involvement in housing rights campaigning, its role in establishing much needed front-line services, and for its functioning as a mechanism that amplified ordinary voices that had previously been silenced. Recent anti-austerity initiatives that have emerged from the Community Sector were also acclaimed. These are named as S.P.A.R.K.S (Single Parents Acting for the Rights of Our Kids) and The Spectacle of Defiance and 
Hope $^{43}$. However, there were criticisms of a reshaping of the Community Sector that included a challenge to the expressions 'Community Sector' and 'Community and Voluntary Sector' with more than one identifying a recent re-defining of boundaries as to what actually constitutes a community organisation. Where previous interpretation of what constituted a Community Sector organisation was dependent on bottom-up emergence, State independence and adherence to certain principles of practice, 'community groups' and 'community and voluntary groups' are now used as catch all for a much wider and less politicised assemblage. For one, there is surprise at a lack of capacity within newer groups on starting up new initiatives in response to local needs, something she thought of as the kernel of community development/community education work describing a history where, 'that whole way of working was through the principles of local people participating and empowering, being empowered, taking on decisions that affect their own lives and bringing about the changes that they want to see'. Contemporarily, she remarks on a locally based community development group she is working with where,

Whilst everyone was associated with an organisation I was struck by the lack of knowledge around staring up a group, staring up an initiative, getting involved in that way and having that 'just go and get at it' and I think I was quite surprised. (CE2)

There are also claims of a 'poverty industry', accentuated by the professionalisation of community education and community development work, a process that was also linked by more than one voice to the neutering of radical voices. Professionalisation was not unanimously presented as a negative feature with one participant in favour of the professionalisation of her work interpreting this as something that would raise standards, and value and validate the work done. Another challenge is of a sector that at times presides over poor employment practices and employee supports. This voice also expresses difficulties with what she describes as a 'volunteerist streak' explaining,

\footnotetext{
${ }^{43}$ Further information is available in section 1.4.1
} 
I'm not against volunteering or anything, many people give their time, but a notion that somehow you should be doing that and that people aren't worth paying for, that their skills and dedication and commitment aren't worth paying for and then it is sort of used against them that 'they are taking the food out of the starving child's mouth' sort of thing, which I think is an abusive sort of thing you know'. (CE6)

Another concern raised is how much radical ideology and practice is not carried by organisations, but by individuals within these. This was not always the experience shared. Most of those I spoke to could align personal philosophies with those of their employers. Where this was not the case, there were reports of a sense of isolation, a lack of organisational support for some initiatives, disappointment at refusals to support political demonstrations, and a lack of understanding of the purpose of radically-oriented practice. Within one interview the relationship between individuals and organisations is discussed at length as CE1 argues against critical practitioners enabling isolation though a contentedness to work within cracks. This is thought to result in a concealment of radical tendencies to all but those he or she comes into contact with in group settings. She argues instead for the collectivisation of radicalism and the strength to speak out adding,

It can't just be hope do you know what I mean? If the [political] right can manage to make what they do how society operates, then the [political] left can make what we do, do you know what I mean? We have to start institutionalising it. (CE1)

This same voice, also expresses concern and a sense of weariness at common evaluations of the Community Sector, that it is apolitical, an extension of State services, and a co-opted sector. She argues much of these writings and vocalised sentiment emanates from outsider community workers, those working within the academy, trade unionists and left-wing political parties. Whilst she doesn't dispute such claims she is apprehensive at the ease as which others voice it asserting,

it is easy to critique it if you haven't lived in it - 'Community Sector groups weren't radical', 'they fell apart too quickly', and 'they were an easy sector', 'they were mainly women', that is kind of what is said on the left if you talk to say, trade unionists or political activists, that is their critique of the Community Sector. (CE1) 
She extends this to criticisms of involvement in Local Area Partnerships from within the sector claiming many groups became involved 'because no one else was $\mathrm{f}^{* *}$ king coming and handing out help do you know what I mean' continuing,

\begin{abstract}
if anyone else had been serious about engaging in communities that were really living in poverty from a socialist critique, and said 'you are getting money now and we will involve you in a process of education and we will start linking with you around your experience and your life because we know it is wrong, and we will engage in a process and we will share that experience with you and learn together'. They could have, well that's my sense of it anyway, and certainly the women who got active in our area, they would have thought 'great, someone is going to bring in money for drugs workers, community workers'. Why would you say no? (CE1)
\end{abstract}

\title{
8.4 Community Sector relationships with the State
}

Funding for the work under discussion was mostly provided by the State with named revenue streams being Irish Aid, The Equality for Women Measure, The Community Development Programme, the Health Service Executive (HSE) through projects supported by Local Drugs Task Forces, The Department of the Environment. Three participants also work within organisations that generate some income by charging fees to other Community Sector organisations such as Local Area Partnerships. This matches the myriad of funders identified within chapter three, with the orientation of the funder influential in determining the work carried out by practitioners.

Each of the seven educators I interviewed considered relationships with the State as problematic. Accusations levied include descriptions of a neoliberal structure guided by an agenda to outsource public services through the cheaper, less unionised Community Sector thereby relinquishing responsibility for sufficient provision of services themselves. It is admonished for being led by utilitarianism, blind to all but a narrowly interpreted vocationalisation of education for low-paid employment. Much criticism is of specific behaviours by government departments and officials where goalposts for funding have been shifted with initiatives sometimes ruthlessly halted. Discussing the closure of Community 
Development Support Agencies as a result of cessation in funding, one respondent describes how,

It was the flick of a pen. He [the Minister of the Department of Community, Rural and Gealteacht Affairs] could just decide that the whole programme was down by two million you know, or that it just wasn't value for money. That is soul destroying. (CE2).

Another uses similar terminology describing how, 'the government has almost wiped out the sector. It has put a pen through it and said it's not of value...I am thinking my God this is such an insult to my profession it is such an insult to the work that people do'. When asked why this is the case, she expands,

Well there could be a number of reasons, number one they don't understand it, two they don't like the fact that people are able to think for themselves and they don't like the fact that people are getting together. They are getting an awareness through coming into groups and they feel threatened by that, maybe...I think that it is extremely worrying the way the Community Sector is going, and I think a lot of it is being dictated by government and by the fact that McCarthy and his 'wisdom' [said sarcastically] just put a pen through community projects and it is shocking and it is unjust you know. (CE4)

Further commenting on the recent closure of the Community Development Programme she talks of a shift in relationships as whilst funding was historically from the State, guidance on how it was to be spent was 'very indirect'. Now, 'more and more as you get sucked into the centre you find less and less freedom to challenge the State and what it doesn't do and the shotgun is with the State so they have you under a barrel really'.

Associations between radicalism, or lack thereof, and funding arrangements are a strongly recurring theme with one comment on how this has 'really diluted radical voices'. People talk of the way in which certain funders would simply not be approached for particular initiatives, and of potential unease by financiers to support less-radical work if they were aware of radical actions funded by others within that same organisation. Someone specifically refers to the closure of The Combat Poverty Agency (CPA), interpreted as the silencing of an oppositional voice, an organisation he is also critical of for being relatively tame in its actions. He explains, 
It [CPA] was critical of government policy but it was in no way, I suppose, what you would call radical or it was in no way, you know, it wasn't whipping up storms, or trying to mobilise groups in terms of protest or anything like that, or strike action or anything like that. It was just, you know, shining a light on discrepancies in what policies were saying and what was being implemented on the ground. And that is disheartening. (CE3)

Alongside the direct closure of certain projects and certain areas of work, another impact of these changes named by some are the way in which some organisations and practitioners censure their own practice as they try to navigate funding streams and match certain work to certain funders. The result of this is either a concealing or abandonment of some of the more radical projects previously undertaken. There were also criticisms of the culture of partnership dominant within relationships with the State. Reflecting on the period when some people got the opportunity to participate in localised governance structures, some individualised benefits to partnership engagement were identified. This was where there was a sense of people,

Being respected and not disrespected because they came from certain communities...influencing policy, influencing the White Paper on Adult Education .... and going, oh wow, a radical notion of community education got into that. (CE6)

However this contribution is tempered with the sense of a more sinister underbelly as CE6 continues, 'but when you look at what has happened over the last 10 years and the way that slowly, even before the crisis, community development and community education was being co-opted and blunted'. When asked how this was being done the respondent believes State policy has prioritised the commodification of community work over other considerations. Her sense is this has 'pushed it down this route of outcomes and accreditation and of being pushed in a direction of servicing the market'. She continues, 
I think that that sort of crept up on people in a way, and when crisis hit in 2008 and since then, it has become really obvious how quickly that could be withdrawn, even the good parts and the genuine gains that people had made, they could just be withdrawn and be undermined in four years how much stuff has been simply undermined so quickly. And I think what that suggests is, you know, that we didn't have the power that we thought we had. (CE6)

Not all of the criticisms shared were directed at the State and one voice was supportive of some level of State led streamlining of what he considers a bloated Community Sector especially, he feels, because many groups are not motivated by a sufficient desire to address inequality. Another somewhat blames the sector itself for enabling cuts alluding to internal disagreements between individuals within. She states,

It was so fragmented and it is nearly like the tensions, I suppose from my experiences of it, it had the tension and it had the resources, I just can't say it was egos, I suppose I haven't analysed it enough but there was too much infighting and power struggles. I don't know. (CE2)

\subsubsection{The burdening effect of administration and accountability to funders}

A common concern raised within interviews was increasing levels of administrative demands from funders. One image shared was of an inverted triangle with more and more bureaucratic practices in situ to support less and less work being done on the ground. One was unhappy with the IRIS evaluation system employed within Local Area Partnership Companies ${ }^{44}$, and with extensive written criteria to draw down funding from government departments. One describes a sector caught up in a game of survival where there is imbalance between the work that is done and the paper-trail requirements, claiming 'it doesn't matter about the outcomes at all...it's about covering your arse, being able to say that you did the thing'. He shares 'as long as you can show on paper that you did it, that you did what you were supposed to do, that's all that matters'. The analogy continues as follows,

\footnotetext{
${ }^{44}$ This is reference to the Integrated Reporting and Information System (IRIS) an online evaluative online database developed by Pobal and introduced to all LCDPs in 2011.
} 
It's all about scaffolding not about the building we are putting up. So you can have the health and safety, you can have this statement you can have that, people check have you got the right gear going up but the actual building doesn't matter, so all that stuff, a huge amount, you can see this all over the place now, so the energy is going into rules and policies and documentation and all of that, which are all supportive of the real endeavour but which have actually replaced the real endeavour I think. (CE5)

Another describes the increase in bureaucracy as 'another feature of neoliberalism' expressing concern about the New Public Management practice of outsourcing public sector systems. Because of this, community development is being 'put into boxes that don't actually fit' continuing,

So it is all these boxes, we have to fit into, these particular box systems and then there is loads of recording, now I don't mind recording and detailing but it's all, it's taking a huge amount of time and it is taking you further and further from the people on the ground. (CE4)

She continues by describing a situation where community educators find themselves becoming 'fixated on numbers' in a way that can usurp the vision of the work explaining 'it isn't about having twenty in the room, I mean I can run a session, we can get fifty people in a room, do you know what I mean but what is the value in that work?'

Concerns about employment conditions were also raised. Two interviewees shared working without pay for aspects of their work, whilst another spoke of a recent significant pay-cut amounting to one third of her salary.

\subsection{Radical practitioner experiences of working with accreditation bodies}

Another theme to emerge centred on the accreditation of learning though this was not raised by everyone with some working in non-accredited environments. People spoke about increased administrative demands associated with FETAC (now QQI) with concern about a burden of over-assessment led out by what were perceived as over-zealous policy enforcers. The weight of this system is thought to be carried by students as well as impacting detrimentally on classroom based pedagogic actions. One interviewee, who has experience 
working with both Higher Education (HE) and Further Education (FE) awards in community contexts offers a comparison as follows,

My experience with FETAC, just with the workload and what is expected, the time frame that it is expected in as well. It just doesn't work at all. There is no sense that, I mean so much of the emphasis is on the assignment and getting an assignment completed.

Whereas with [names university], so much of it was about reflecting on the experiences in the room and being, having time to take it in and not having a constant burden of assignments over their heads, so it wasn't preoccupying people at all. So people could be in the space when you are doing group activities and group exercises, groups are breaking up and they are staying focused where, I think, with FETAC after a certain time you would walk around and people are talking about their assignments. (CE3)

There were also ideologically driven criticisms with one deliberately working in nonaccredited environments expressing concern that 'FETAC are corroding the system'. Another shares a reluctance to explore accreditation within his place of work and reflects on conversations with his colleagues where they question whether to accredit learning might compromise some foundations upon which principles of community education rest. For another, the accreditation of learning is conceptually described as ' a major issue' continuing 'I think it is extremely divisive, I think it really re-enforces that whole thing, that whole idea of you are measured in life and someone has the power to tick that box'. This voice continues,
what you are actually doing is reinforcing that system of rewarding measured ability, so there is no recognition of prior learning, you can't get 'well there is your accreditation for living, for actually having reared two kids and fighting poverty and dealing with an alcoholic husband, there is your accreditation'...It is like the whole thing of symbolic violence, who defines it? These are my issues with it. I wouldn't have a problem even in the morning if we started to institutionalise popular education and had our own Highlander schools around, I think even in Highlander what they do in the States, they do have forms of accreditation right, but they have politicised accreditation. (CE1)

This paradoxical reaction, a denigration of accreditation alongside its approval in certain guises, is not isolated as another reveals an on-going grappling with use of accreditation in her current practice. Addressing this, CE2 describes how she is keeping a journal for the duration of a particular programme hoping to probe into whether it has been 'an obstacle, or 
an actual opportunity for people?' Now that the course is over, she has arranged a focusgroup with some course participants so collectively they can deepen discussion on this question.

Other concerns were the social and economic capital attributed to FE awards when compared to HE awards, and a situation where some people are gathering many FETAC awards but remain excluded from university settings as they simply cannot afford to go. Another prohibitive feature for both individuals and organisations is the cost of accreditation. One story is shared of how a group, whilst confident they could meet the Quality Assurance (QA) criteria of a particular university, were prevented from doing so as the registration fees the community group would have to pay amounted to more than the total programme cost when delivered un-accredited.

There was also praise for the availability of accreditation. Benefits identified include vocational and personal progression, recognition of achievements, a process that adds rigor to local learning environments, and as an important equality of opportunity endeavour. When I suggested the accreditation of work previously delivered in non-accredited settings could be compromised in any way, one voice disagrees elaborating on work with a colleague explaining,

Interviewee: I think all of the learners who have gone through the course have found it really enjoyable and haven't found the accreditation side of it to be a constraint. Interviewer: That is good to hear. Interviewee: It is delivered by a very interactive, experienced practitioner and she wrote the course and she delivered the course as well and I think her methodology, her approach to it, which is all completely rooted in development education, I think made people feel very relaxed about the process. (CE7)

This was not the only positive example. Another is complementary of university accreditation on a community development programme tempering this with sadness about the impact a written assignment can have on some who struggle to communicate through writing. 
They [the university] trusted us in a large degree, they weren't looking over our shoulder at the content, they weren't intrusive, it was great... I suppose the accreditation element of it, I don't think it was a hindrance bar with some of the assignments there is that massive fear around assignments and no doubt we lost a couple of students based on the assignments and even with supports and stuff just you know, just fallen out of the course because of it and that is disheartening to an extent. (CE3)

\subsubsection{Other findings}

Alongside personalised and thematic findings presented thus far, other subjects were discussed. There was concern about the value attributed to academically supported research that did little more than repeat what some communities have been vocalising for some time. The disappointment was how communities are often not heard unless they have the weight of an institution behind them. There was some criticism of AONTAS, presented as a co-opted entity that is re-enforcing domesticating approaches. One participant is concerned about the disintegration of many voluntary boards of management brought about by State enforced closure of Community Development Programmes, and apprehension is expressed at an 'aging population' of radical practitioners within some community groups. There was an example of domesticating community education shared and a call to others to be more creative in their work. There was positive reference to overseas social movements active at the time namely anti-government protests in Greece and the Arab Spring movement, particularly in Egypt. Some discussion emerged on the burden of personal debt and its impact on many people in Ireland.

\subsection{Imagining possibilities: what the future could hold}

Different perceptions were shared on the future for community education. Some expressed pessimism for the Community Sector with one expressing concern about long term impacts of current de-politicisation processes sharing, 
Interviewee: I don't think we are in a political space for radical change, I mean they [community groups] will re-group and they will get the pickings, keep maintaining the services at the front line and that will be it.

Interviewer: which is important?

Interviewee: Yes, but it is not going to deliver on the social change agenda. (CE1)

Another expresses much concern that 'smaller groups are suffering the most at the minute' because of the cuts in funding, groups he considers are originators of 'a lot of the best practice'. His reaction to current circumstances is hope of a shoring up of losses as he continues,

The kind of context that we are operating in...you have the wider, gloomy economic picture so, it's very tricky right now and I think at the moment it is about trying to get through this period, this period of austerity and policy change and funding reductions and hope that we emerge from it strong enough as a sector whereby we can rebuild. (CE7)

This sense of re-grouping is shared by the majority, as people present current ideological and practical arrangements as an opportunity to re-group and re-emerge as a more radicalised sector. This would be dependent on much voluntary effort, but is conceptualised as something that could challenge neoliberalism and re-assert collectivism, something seen as central to community based practice. One voice explains,

for the Sector I suppose, my hope would be that more people would get conscientised [politicised]...I think the more fires that you can light around the place, or even in people's heads and then my hope is that, even in the financial crisis in some ways, my hope is that people will begin to question more. (CE4)

Another interviewee concretely conceptualises a call to community educators to look outwards towards allies and become involved in a mass movement powerful enough to challenge neoliberal forces (named as the Troika and the IMF). When I ask how this can be done she draws out how the Community Sector 'has the potential to play a much bigger role than it does'. She notes how at the moment 'we are weak and isolated in one way with deep roots in certain communities but, from the rest of society in a sense, can be isolated' she continues, 
On its own I think the Community Sector will struggle but the notion of community, and I know it can mean different things to different people, but I think that can be a potentially unifying force in, you know, particularly in the context of all the division we have faced in the last few years. Sort of divide and conquer, public versus private, you know, the deserving poor versus the undeserving poor, the working-class and people who are allegedly middle class and all that. I think community has, is a very powerful notion, and could lead and unite people if it was willing to take a much bigger role and to say that we all live in communities. When I say 'we all' I am not talking about the upper echelons of society, but I am talking about the bulk of society. (CE6)

\subsection{Summing up findings from one-to-one interviews}

The opinions, experiences and interpretations of practice reported in this chapter have come from people who express a shared vision of society, built on ontological and epistemological frameworks similar to that which I hold. This incorporates a radical interpretation of community education believing it has the potential to influence systemic social change. All findings have been reported on, organised through a constant comparative method (Maykut and Morehouse, 1994: 134) and each theme will be carried into an integrated analysis within chapter 11. As these narratives are included within a wider study, the analysis offered is admixed with findings from phases two and three. In some respects this is unfortunate given the richness of findings uncovered as it limits the depth of analysis made possible amidst the broad scope of the study. This final segment offers an initial summary of these key findings.

There are a lot of similarities in the backgrounds of these community educators worth bringing to the fore. Most identify a working-class upbringing with all but one sharing the experience of being first in their family to attend university. Many have completed radically influenced university based programmes with courses in Adult and Community Education, Equality Studies and Social Studies specifically named. It is worth noting how for three people, attendance at university was only possible as a result of State grant aid that is now more difficult to access. The Training for Transformation movement is also cited as influential. 
When describing their work, popular education was the dominant expression with all but one referring to the ideas of Paulo Freire. For some there was a sense these ideas were not always translated into practice as Freire would have intended. There are examples of a de-politicised reading of Freire's works and of a perception where a literal application of ideas can lose sight of the needs of a particular group. A linking of local and global issues through the practice of development education also featured as a way of working for three of those I spoke to.

The importance of carrying expertise in facilitation was is also evident with certain skills required to create hands-on, supportive, respectful environments. A recurrent theme was for people to interpret their role a one in which they create conditions for learning facilitating dialogue between participants and probing through a problem-posing approach. There were references to participatory mechanisms, the use of codes, and the use of experiential exercises. There was also a strong emphasis on developing leadership capacities. This demonstrates a commitment to self-determination and the desire to support collective local development. Sometimes, a tension between one's own political positioning, and the political intentions of a group was named This can manifest in concern for the way practitioners can potentially direct participants towards the educator's intended outcome and not those that are self-directed by the group. The need to support literacy capacities was also named.

Difficulties with the work were shared. These included dissatisfaction with working conditions, pay-cuts, expectations of voluntary commitment, the emotional burden of working with people experiencing oppression on a regular basis, and, for some, isolation within their employer organisations. There was emotion and dissatisfaction expressed when discussing relationships with the State. These incorporated micro and macro concerns with reports of coercion through financing arrangements, self-censorship to comply with funder 
expectations, and excessive bureaucracy. Mixed criticism of the Community Sector emerged. For some it was considered fragmented, de-politicised and by one, bloated and in need of some rationalisation.

Almost all of research participants welcomed opportunities to accredit learning but there was dissatisfaction with the way in which this is currently done. The difficulties named were the domesticating nature of current accreditation models, over-assessment within Further Education (FE) qualifications, and potential interference from accrediting bodies in determining the direction taken by a community/group. One person compares accreditation mechanisms across FE and Higher Education (HE) settings sharing a more autonomous, less assessment heavy approach with HE qualifications.

There is mixed sentiment on the future of community education; both pessimism given the co-option of Community Sector work, and optimism through an opportunity for more politicised ways of working to emerge. The notion of working within the cracks is raised, with one voicing limitations to this notion as it can offer a hiding place of sorts for radical practitioners. This can enable them to operate in relative comfort without offering any real challenge to systemic circumstances.

The language used when describing relationships with the State are worth emphasising with comments such as 'the flick of a pen', 'in a barrel', and 'totally constrained' summing up much sentiment and the powerlessness people experience.

An important final consideration is a reminder to the reader that findings from this phase were influential in shaping the questions and hypotheses posed within the research project's second phase of a broad based survey questionnaire. This was cast wide in the hope of catching the interests of a range of educators working with groups in local settings. Findings from phase two will be reported on in the next chapter. 


\section{Chapter nine: Community Education - Views from Practitioners: chronicling survey findings}

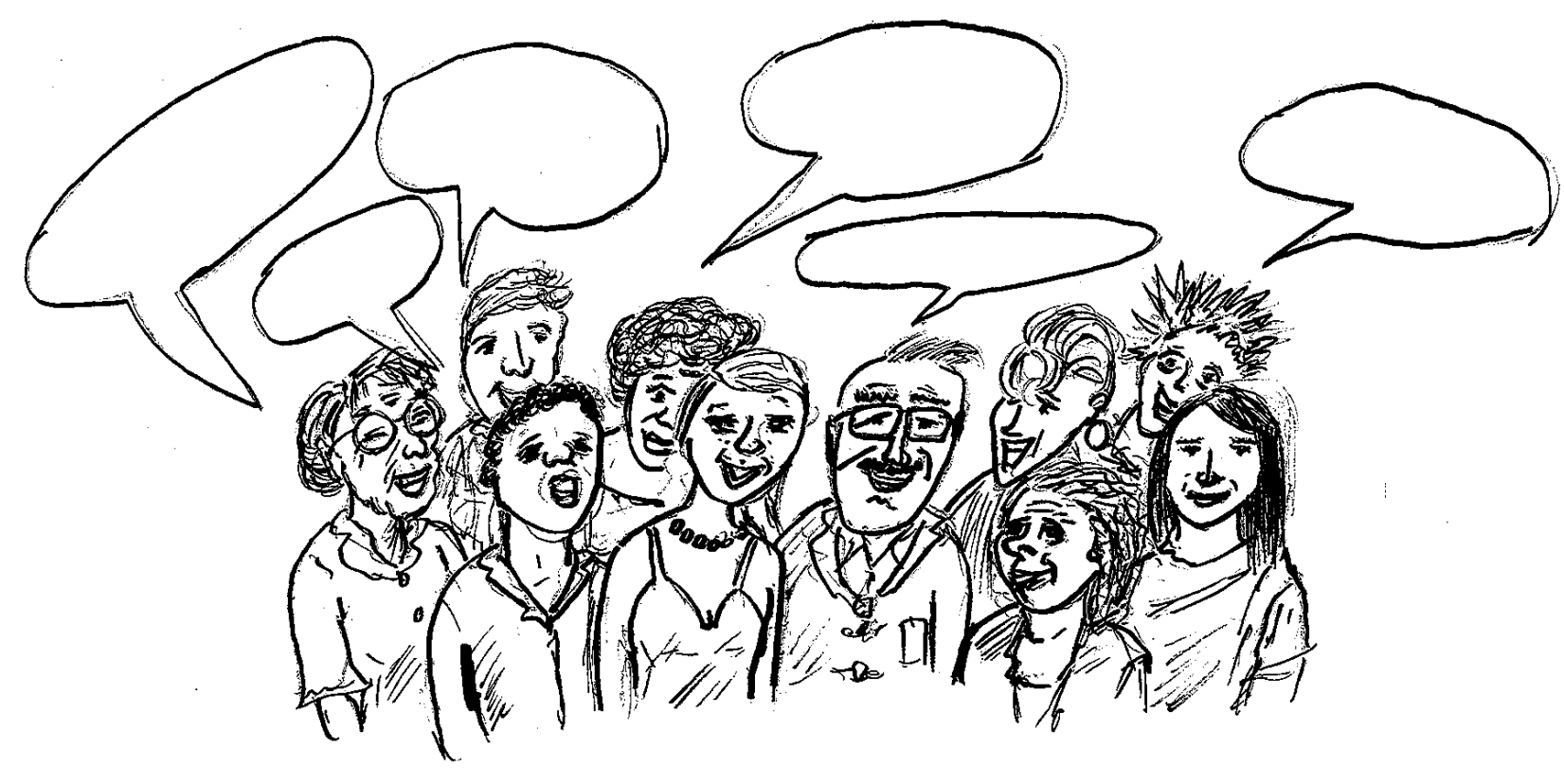




\subsection{Introduction to chapter}

The purpose of this chapter is to detail findings gathered through an embedded on-line survey questionnaire entitled Community Education - Views from Practitioners. The at times unwieldy nature of the survey, and volume of data generated have made it a difficult chapter to put together, and one which took considerable time and effort. This was a symptom of my novice status as a quantitative researcher, plying my trade on the hoof as I simultaneously discovered, and conducted, quantitative research. Whilst each question posed is reported on, and each theme raised by respondents is represented, considerable data in the form of lengthy textual contributions cannot be fully incorporated given the confines of this written element of $\mathrm{PhD}$ studies. Honouring the ethical announcements within chapter seven, these may serve as useful to the sector in other formats and future settings.

In this study, community educators are interpreted as those located outside of Higher Education and Further Education contexts working in local areas with practice presented within chapter three as straddled across Community Sector and community based public provision. Dissemination of this survey was through identifiable gatekeepers as detailed within section 7.3.2. A limitation worth noting at this early stage in the chapter is to remind the reader there is no finite list of community educators meaning I was unable to accurately gauge percentage representation. A more comprehensive account of sampling, representation and dissemination can also be found within section 7.3.2.

The survey Community Education - Views from Practitioners (appendix 2) was opened 314 times. Fifty-seven questionnaires were left blank and it is possible some returned subsequently to complete the survey in totality. Thirty-six respondents completed sections one and two only and did not complete any part of section three or four exiting the survey on encountering the first qualitative question. As these respondents are recorded by Bristol Online Survey (BOS) software as incomplete, they have been eliminated from findings 
representing a drop-out rate of $11.5 \%$. A further two questionnaires were eliminated, in one instance where the respondent completed the survey twice (discernible through leaving contact details on both occasions). A second elimination was where within an open-ended question a respondent identified that they did not believe they were eligible to participate. This left a total of 219 questionnaires from which findings and analysis are drawn. Before statistical analysis was undertaken, each questionnaire was manually inputted into the IBM SPSS software package, version 20 with data re-checked for errors following initial input. As all questions were optional, there were varying levels of participation across answers.

\subsubsection{Community education - views from practitioners, some limitations}

Alongside ideological and practical considerations voiced through conception and dissemination of the survey (see chapter seven), other limitations emerge when reporting on findings. There is a drop in participation between quantitative and qualitative questioning limiting the reliability of comparisons across variants when used to surmise (not prove) trends. Another limitation is that, unlike the on-going refinement possible in qualitative research, launching a survey means mistakes emerge retrospectively. Whilst I asked participants whether or not their work offered accreditation, I didn't as at what level. I also didn't think to ask if qualifications held fall within the realms of related disciplines of community education and/or community development.

\section{Detailing reporting of survey findings}

Throughout the chapter, the dominant mechanism for reporting quantitatively is as percentage values with each equation supported with detailed numerical frequency tables within appendix 5. Missing values (where a question has not been answered) are specifically named when there is a greater than 5\% (n11) non-response rate. Where missing values are less than 
$5 \%$, valid percentage ${ }^{45}$ is reported with accompanying tables (again within appendix 5) demonstrating precise missing value amounts.

The chapter is presented across four distinct sections the first of which is this short introduction. Section 9.2 provides contexts and characteristics of those participating and section 9.3 details descriptions of the work and philosophies that underpin it. Section 9.4 predominantly deals with attitudinal measurement contextualised within textual contributions. The chapter concludes with a summary of findings with a more comprehensive integrated analysis provided within chapter 11.

Throughout the chapter you will encounter both qualitative and quantitative findings with the former enabling contextualisation of the latter. Often, these are drawn from an open-ended opt-in question 'have you any other thoughts or views about community education that you would like to share (including any thoughts on matters already raised such as accreditation, co-option, disadvantage, working conditions etc.), a question that carried a response rate of $57 \%(\mathrm{n} 124)$.

\footnotetext{
${ }^{45}$ Valid percentage refers to the percentage amount of 219 less those who did not answer the question. For example when I ask how long you have worked as a community educator? Seven people failed to answer. The percentages reported on are therefore percentage values of 219 less 7, i.e. 212.
} 


\section{Section 9.2 Contexts and Characteristics}

Of those surveyed, $80 \%$ were female and $20 \%$ male. Fifty percent have been working in community education for over 10 years whilst $17 \%$ have been involved for less than 5 years.

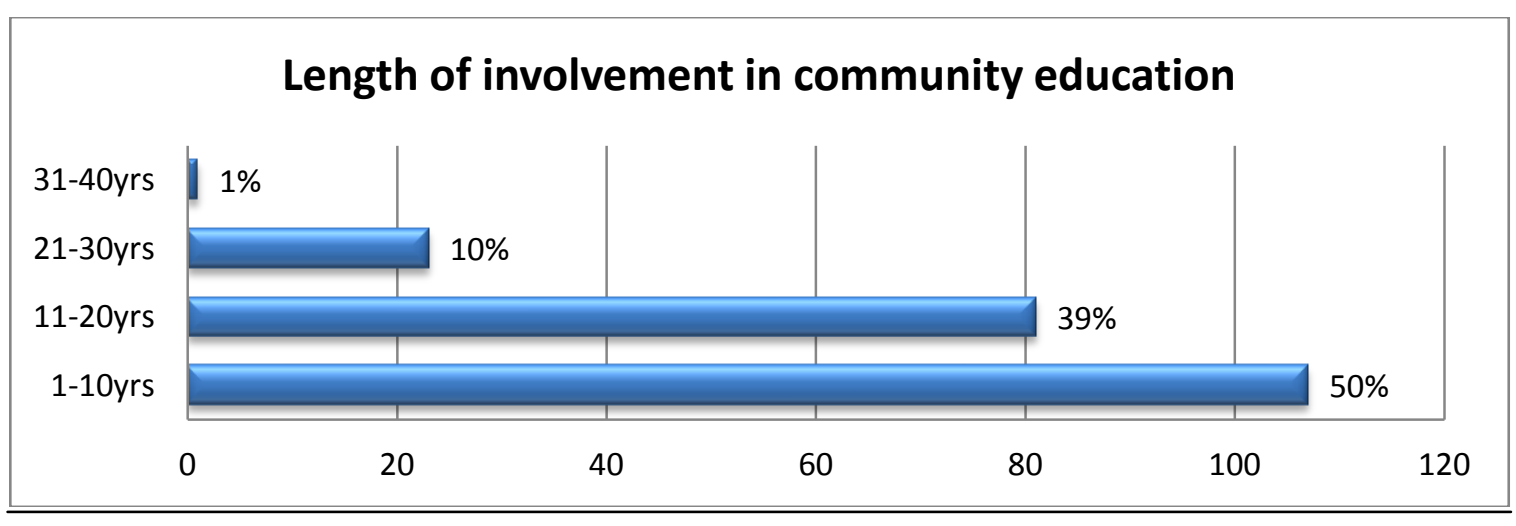

Figure 3 - length of service as a community educator

Fifty-eight percent hold post-graduate qualifications with a further $18 \%$ qualified to degree level. Five $(<3 \%)$ report no formal qualifications. Figure 4 gives percentage breakdown of highest qualification held.

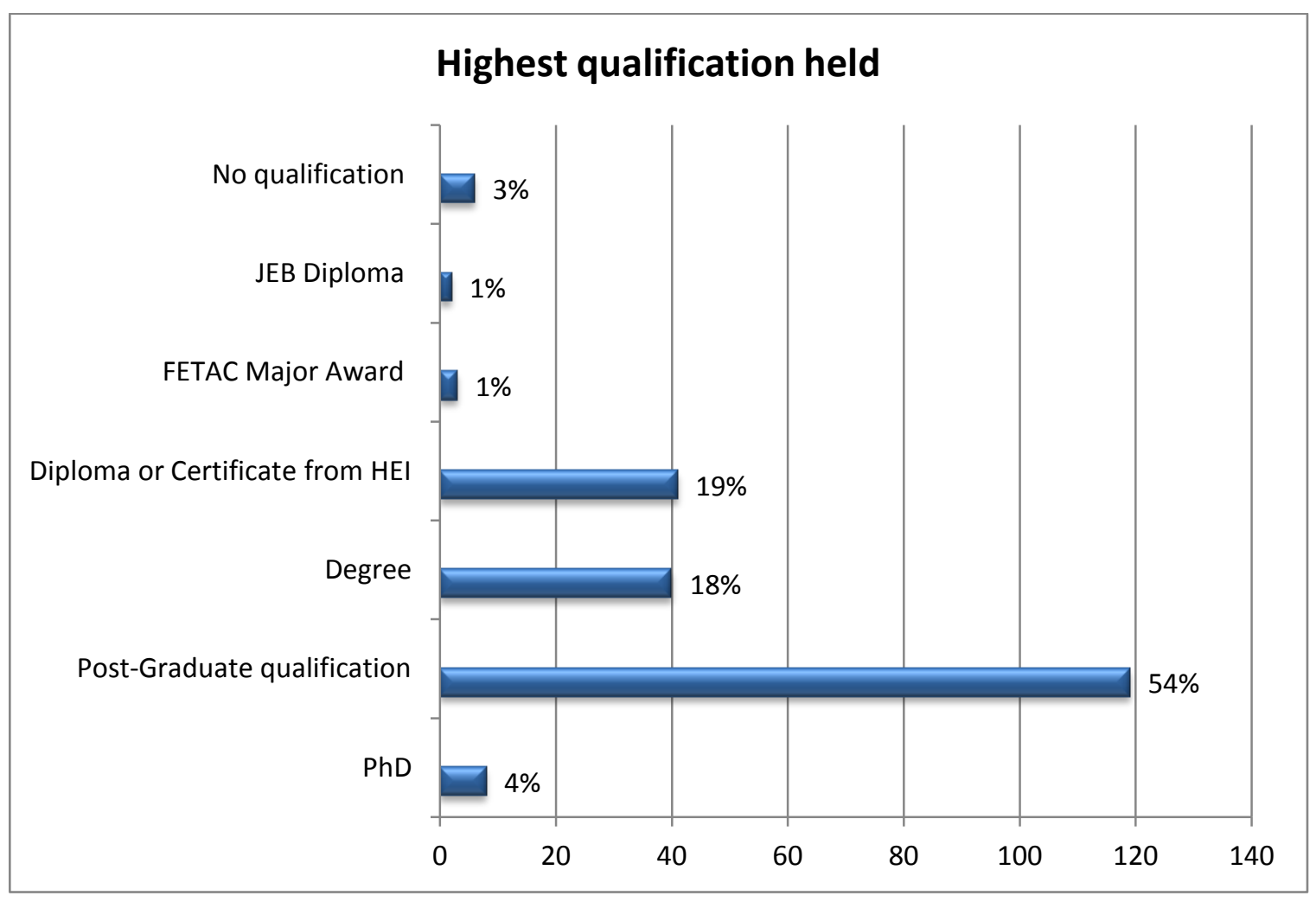

Figure 4 - Highest qualification held by community educators surveyed 
Whilst figure 4 identifies 1\% (n3) as holding a FETAC (now QQI) major award as their highest qualification, 7\% (n15) hold this award in total with most progressing from FETAC certification to Higher Education Institution (HEI) qualifications at certificate, diploma and degree level.

When asked where they undertook their initial studies, the largest cohort is those who progressed from school directly to tertiary education. Those to attend Higher Education (HE) as part-time mature students are also strongly represented as revealed below.

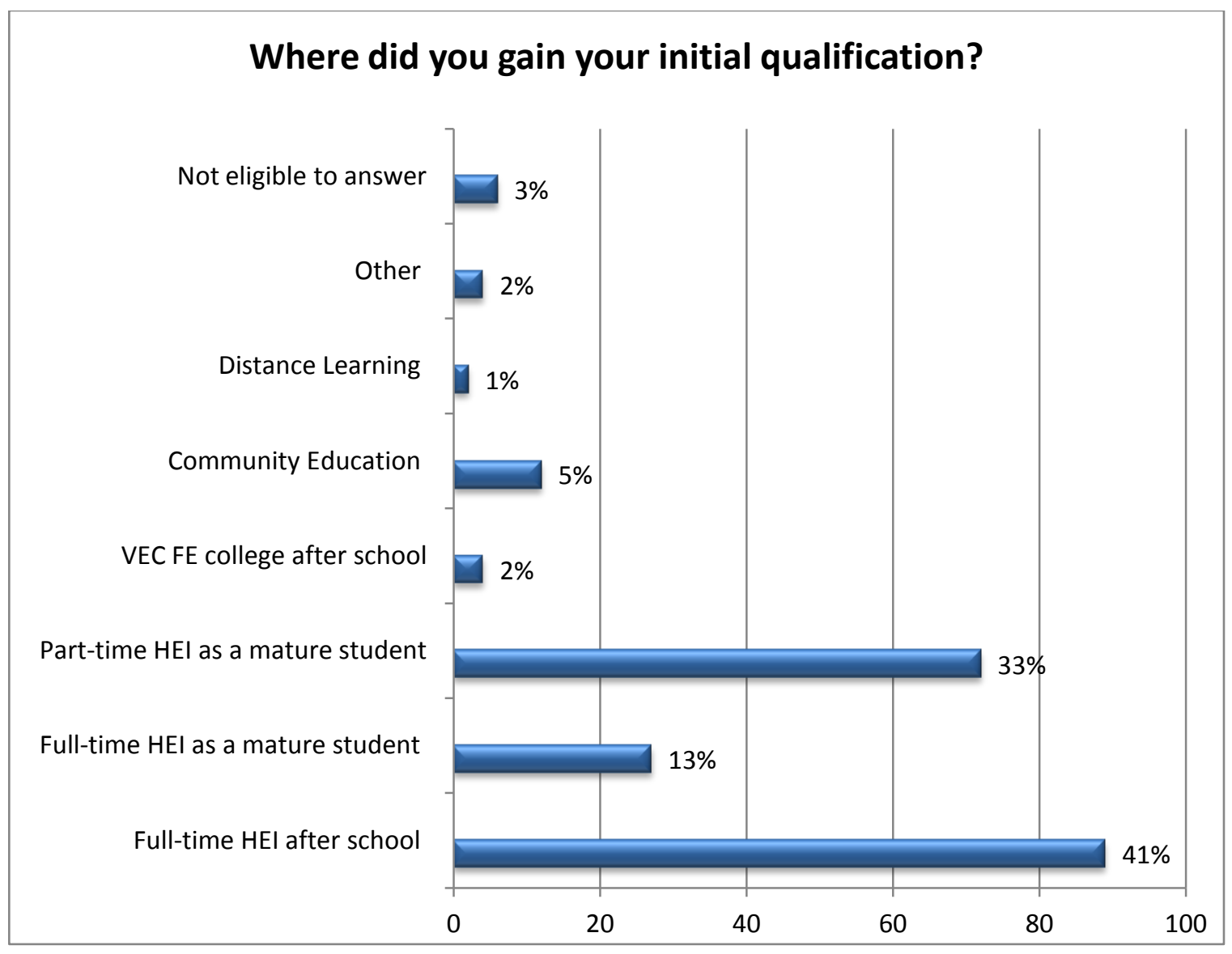

Figure 5 - Location of community educator's initial qualification.

\subsubsection{Identifying 'insider' and 'outsider' community educators}

As well as asking about educational background, one closed-question related to socioeconomic background. This differs from preceding trait questions as meanings can vary depending on such factors as age, cultural grouping and geographical location (De Vaus, 
2002: 98). The contested nature of the expressions disadvantage and community is also a feature and answers can differ based on people's subjective comparatives. To demonstrate disadvantaged when compared to whom? I asked this question to determine percentage ratings of 'insider' and 'outsider' practitioners. Section 3.4 provides comprehensive discussion on these catagorisations.

Sometimes research participants can be reluctant to answer questions relating to socioeconomic status. Carroll and Patterson (2010) report a drop in participation rates when mature students across universities were asked about socio-economic backgrounds, dropping from $84 \%$ to $33 \%$. In this instance contribution rates remain high with just $n 1$ non-response along with 6\% (n13) answering 'don't know'. For the rest, when greeted with the question "The Combat Poverty Agency describe 'educational disadvantage' as something that especially impacts 'individuals from poorer socio-economic backgrounds and communities' is your own background typically described in this way?" 33\% answered 'yes' and 61\% answered no as indicated below,

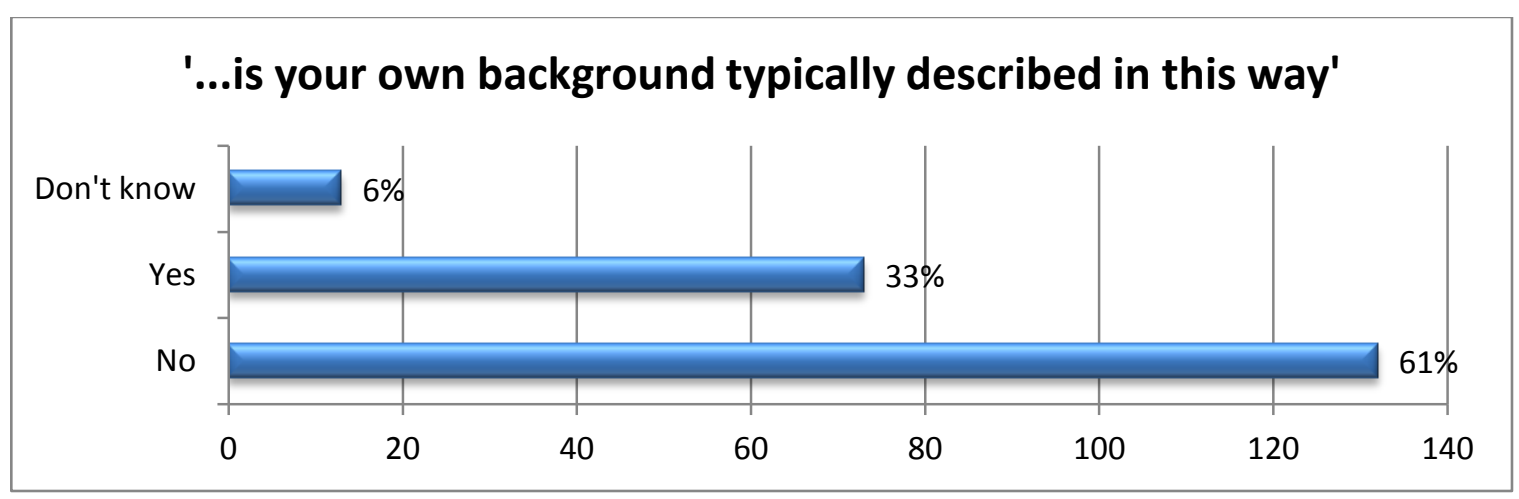

Figure 6 - Socio-economic background of survey participants.

When qualification level is set against socio-economic background, there is no discernible difference. Where discrepancy does arise is that those describing themselves as from 'poorer socio-economic backgrounds and communities' are more likely to have returned to education as a mature student, measured as $71 \%$ (n52) of this subset. By comparison, those not considering their backgrounds as 'poorer' socio-economically, reveal $44 \%$ (n55) returning as 
mature students with most (53\%) attending Higher Education Institutions (HEIs) directly after school $^{46}$. A higher proportion of insider community educators whose highest qualification is certificate or diploma level are also revealed. This is measured at $25 \%$ of this cohort and compares to $15 \%$ of those who do not align their background in this way.

\subsubsection{Locating practice - where do Community Educators work?}

Fifty-seven percent identify their work as urban based with $33 \%$ based in both urban and rural settings. Ten per cent work exclusively within rural settings. When people share the type of organisation they work for the following breakdown emerges,

\footnotetext{
${ }^{46} \mathrm{Six}$ of those who returned to education as mature students answered 'don't know' when quizzed on socioeconomic background.
} 


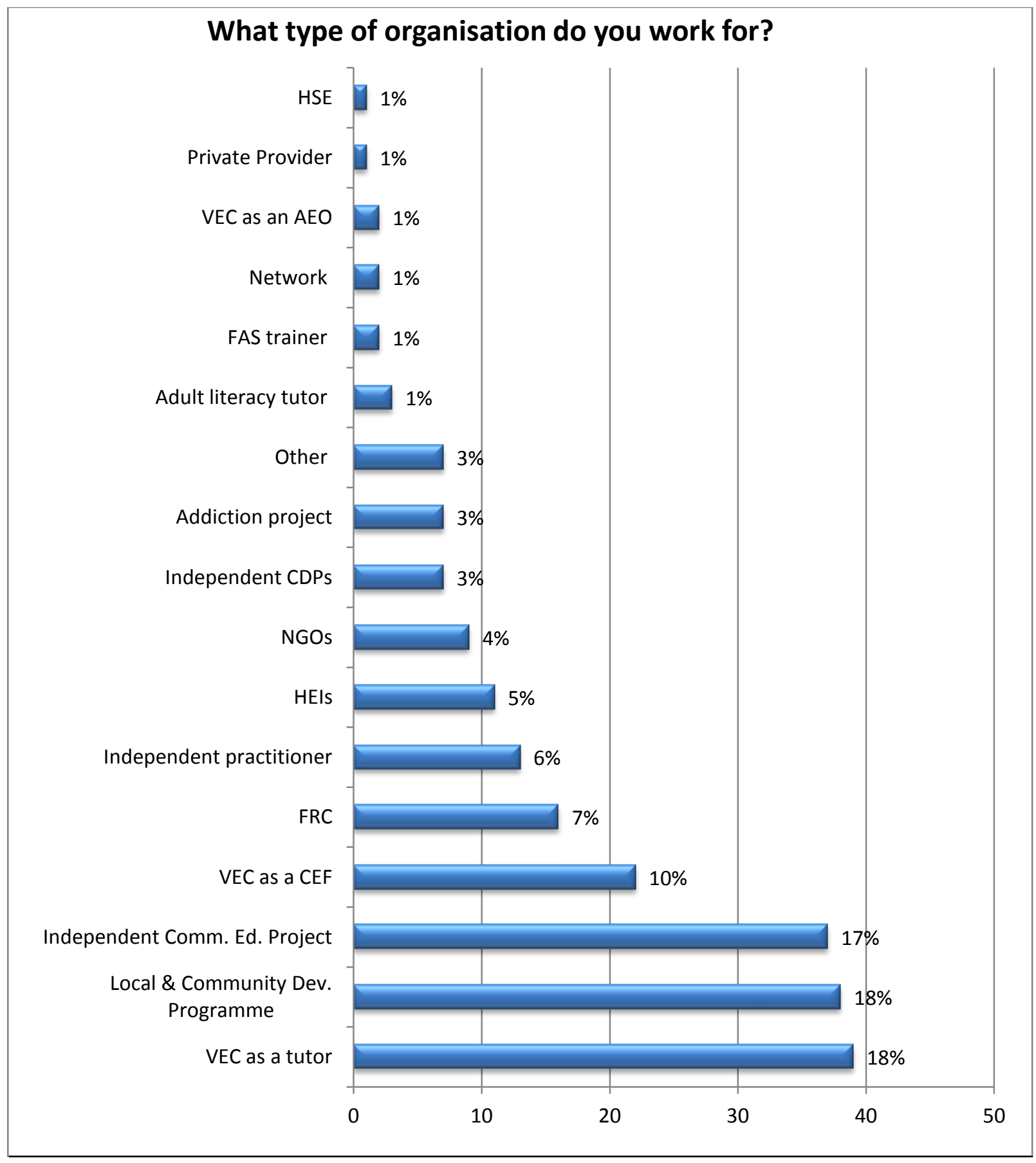

Figure 7 - Organisations survey participants work for ${ }^{47}$

Table 5 overleaf further groups these categorisations revealing most practice (49\%) reported in this study as located within the Community Sector, with $30 \%$ emanating from VEC (now ETB) structures.

\footnotetext{
${ }^{47}$ Others are made up of a community based hospital, an organisation supporting Asylum Seekers, community radio and local parent support organisations, a theatre company, and one employed within a secondary school
} 


\begin{tabular}{|l|l|}
\hline Organisational type & \multicolumn{2}{|c|}{} \\
\hline Community Sector Organisations & $49 \%(\mathrm{n} 107)$ \\
\hline VECs & $30 \%(\mathrm{n} 65)$ \\
\hline Higher Education Institutions & $5 \% \quad(\mathrm{n} 11)$ \\
\hline NGOs & $4 \% \quad(\mathrm{n} 9)$ \\
\hline Other State Providers (HSE and FAS) & $2 \% \quad(\mathrm{n} 4)$ \\
\hline Others (inc. private provider) & $4 \% \quad(\mathrm{n} 8)$ \\
\hline Independent practitioners & $6 \% \quad(\mathrm{n} 13)$ \\
\hline Total & $100 \%(\mathrm{n} 217)$ \\
\hline
\end{tabular}

Table 5 - Location of Community Education amongst survey participants

In addition, $41 \%$ (n16) of tutors who identify themselves as paid by VECs locate this work within Community Sector organisations namely Local and Community Development Programmes (LCDPs), independent Community Development Projects (CDPs) and Family Resource Centres (FRCs). Similarly, over half of independent practitioners who participate also locate their efforts within the Community Sector.

Sixty percent (n22) of those working within LCDPs selected 'Community Development Project (CDP) now managed through a Local Area Partnership' as best describing their place of work. This signifies a transfer of organisational management (including determination of ethos) from bottom-up local community structures to State introduced top-down arrangements for these community educators.

One Community Education Facilitator $(\mathrm{CEF})$ wonders about the recent rationalisation and cohesion of the Community Sector including the use of LCDPs as receptacle to much VEC funded work remarking,

What seemed to be a reasonable decision has become a very damaging experience for community groups as there were no clear guidelines issued to VECs and Local Area Partnerships to ring-fence the money for community providers. In light of the fact that VECs and Local Area Partnerships are all struggling due to budget cuts and staff cutbacks, the reaction to this streaming of funding has been damaging.

A second contributor, identifying herself as working within a VEC as well as working independently within 'community organisations' refers to 'a disconnect between local VECs and other education providers' continuing, 
I would like to make the point that the structure of the VEC is not conducive to a flexible and responsive community education provision. Also, that the new 'outcomesbased' approach being pushed by all funders at the moment is unrealistic and may, unfortunately, lead to the devaluing of learning which is not readily measured.

Another participant working within the LCDP also challenges the appropriateness of VEC structures suggesting 'State agencies are not always the natural choice of those most removed from education within their local communities'. She compares VECs to the Community Sector she considers herself a part of describing it as a network of organisations she believes carry more authentic community connections that are strengthened by outreach work, a practice she perceives as absent from VEC provider's actions.

\subsubsection{Shared spaces: network membership and other links}

When participants were asked about network membership, there was a $23 \%$ (n50) drop in participation rates. As can be determined by viewing the survey (appendix 2) participants were offered a list of common networks to choose from with an additional 'other' category where respondents were asked to specifically name other networks. Seventy-four percent identify themselves as network members as detailed overleaf. 


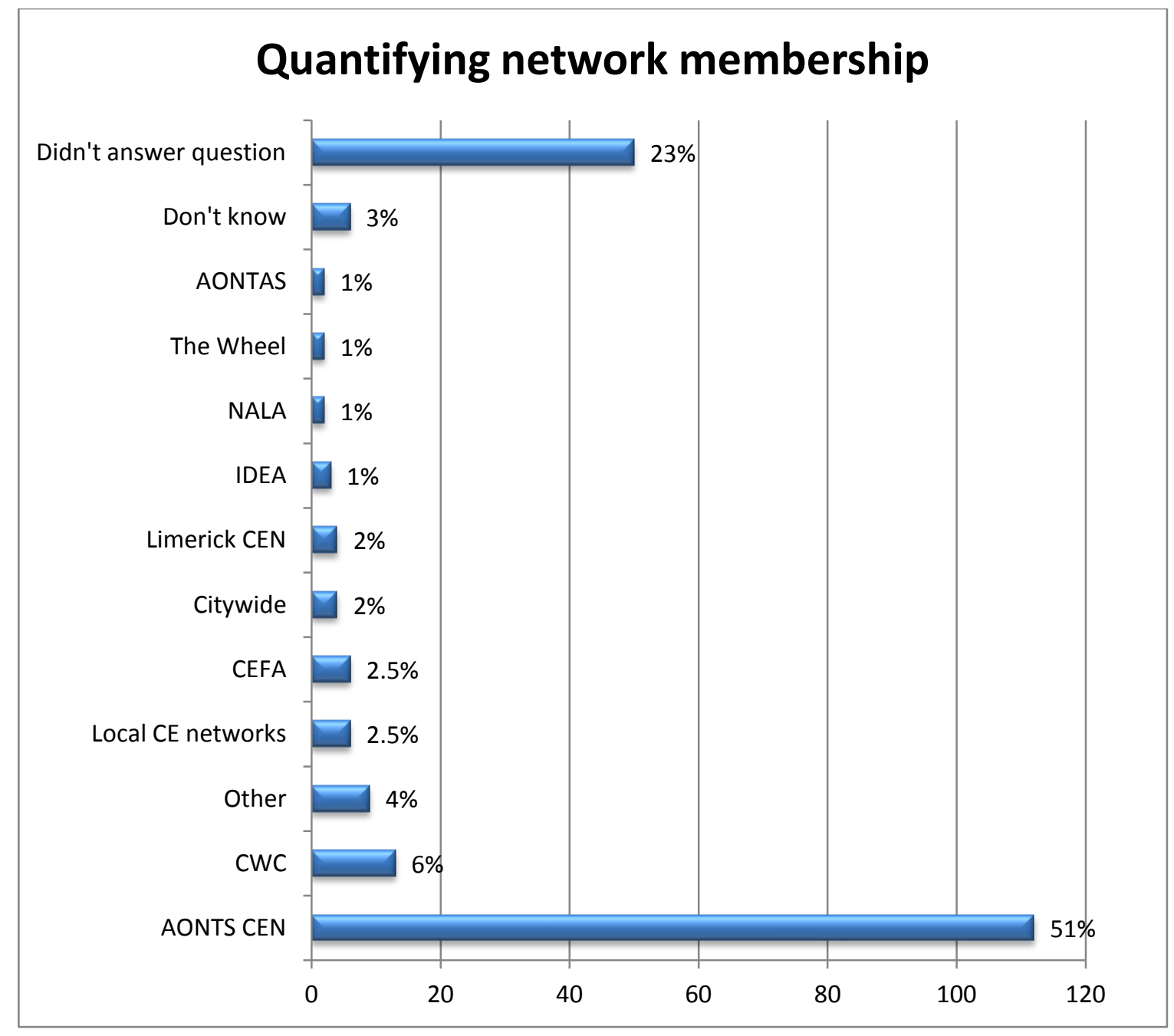

Figure 8 -Network membership amongst survey respondents

Twenty-six of those who cite AONTAS CEN membership also name other networks but have only been counted within the AONTAS CEN. Most usual amongst these was CWC membership with $23 \%$ of CEN members also citing CWC involvement. In total, $24 \%$ of those who cite network membership identify themselves as members of the CWC. The Community Education Facilitators Association (CEFA) was named by some with local networks in both Limerick and Cork also cited. 'Others' represent Cross-care, Partners Training for Transformation, The Irish Men's Shed Movement, Trade Unions, The Spectacle of Defiance and Hope, and The National Collective of Women's Community Based Organisations (NCCWN). 
Those working in Independent Community Education Organisations are most likely to be members of the AONTAS CEN, 70\% (n26) of who cite membership. Tutors within VECs are also well represented, measured at $46 \%$ of this cohort.

When discussing how they relate to each other more informally, different themes emerge. One CEF expresses concern that FÁS, VECs and Local Partnership companies are 'nearly pitched against each other' as they work to secure funding. Others suggest there should be more cross-organisational co-operation and more links with international policy and practice in adult and community education. One complains of groups engaging in independent lobbying for funding without due regard for the need to come together and collectively campaign. There is also a belief that FRCs should be more central to the development of community education and community development with particular dissatisfaction about their reliance on VECs for the delivery of education programmes, something one person believes 'makes then subject to the criteria of another organisation'.

\subsubsection{Hours of work, remuneration and other comments on working conditions}

Seventy-nine per cent of those to participate are paid employees, $11 \%$ are volunteers whilst $10 \%$ identify working in both paid and voluntary capacities. The highest identifiable location for voluntary effort alone is within Independent Community Education Organisations with $27 \%$ of those to identify this as their place of work, working in a voluntary capacity only.

Forty-eight per cent indicate full-time employment (n3 of who are volunteers) with 52\% working part-time ${ }^{48}$. Within appendix 5 (table $\mathrm{J}$ ) readers will find a detailed breakdown of patterns of part-time and full-time work which are set against organisational type. This reveals the highest numbers working part-time are tutors paid by a VEC. Within qualitative inputs, some VEC tutors note they are only paid for a few hours per week taking on additional paid work from time to time as independent practitioners.

\footnotetext{
${ }^{48}$ There is a $19 \%(\mathrm{n} 42)$ non-response rate for this element of $\mathrm{q} 7$.
} 
One closed question inquired into how much work effort is falling outside of paid hours with the following emerging.

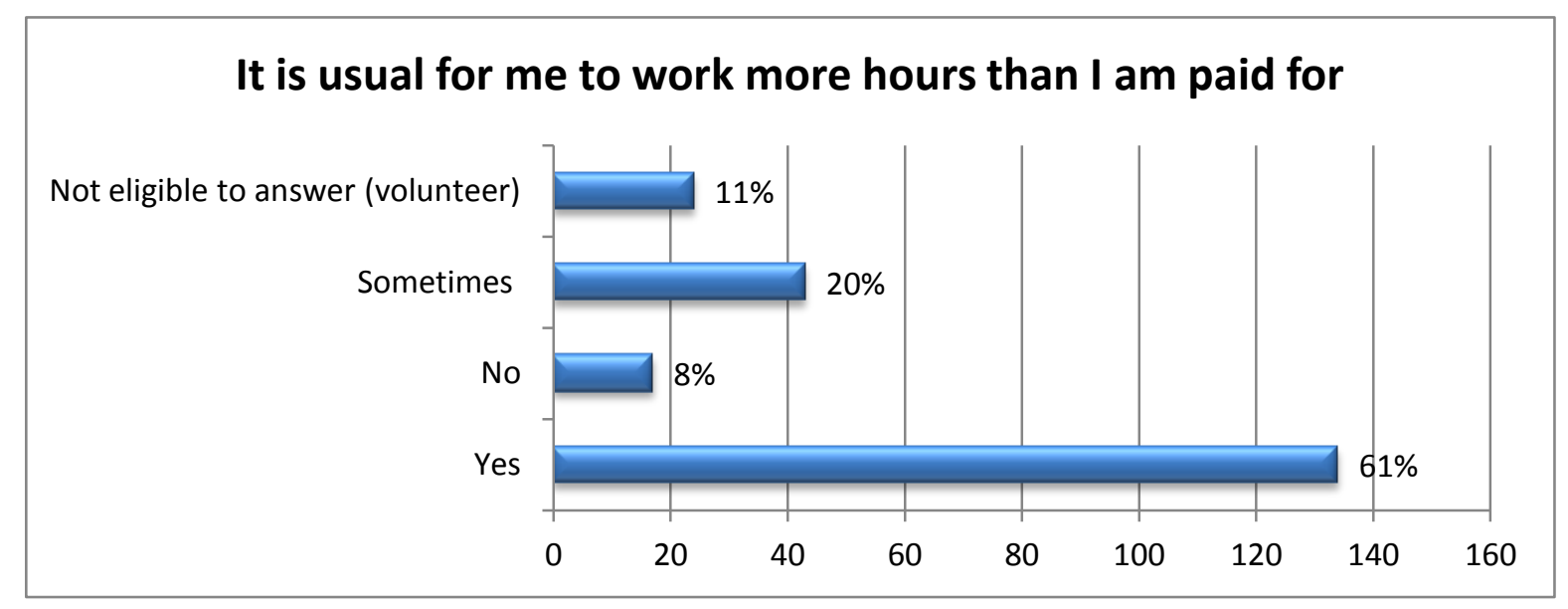

Figure 9 - those working more hours than they are paid for.

As can be seen above, $81 \%$ answer either 'yes' or 'sometimes' to this question. Most likely to answer in this way are tutors paid by the VEC where $76 \%$ answer yes and a further $13 \%$ answer sometimes. Community Education Facilitators (CEFs) also featured strongly, 68\% of who answer 'yes', with $27 \%$ answering 'sometimes'. Those most likely to answer no to this question are $16 \%$ of those who work within the LCDP (16\%). One part-time employee of an Independent Community Education Organisation elaborates further on this point sharing,

In my experience, I feel the people who work in community education do so because they believe that everyone deserves a chance to better their own situation through education. People who work in community education often put in many more hours than is per their job description. Filling out forms can be a real barrier for people, if $50 \%$ of your day is spent filling forms and ticking boxes then that only leaves $50 \%$ for the actual work. The form filling is just a joke.

Difficulties with pay and conditions are revealed. One person is reluctant to participate for fear her identify would be exposed thereby jeopardising her employment status. She shares 'the Community Sector is in a lot of flux at the moment. Funding is almost non-existent. There is no job security. There is a fear of becoming yellow pack HSE workers...' Others share dissatisfaction with VEC pay rates and with lack of resources for planning and 
preparation. The absence of scope for practitioner led research and a lack of continuous professional development are also raised.

\subsubsection{Identifiable community education funding}

As was outlined within chapter three, multiple funding streams are a consistent feature for community education. Participants in this research were not explicitly asked to name their funding stream unless they identified their employers as either 'Independent Community Education Organisations' or 'other' (a category that captured NGOs, some State providers and networks). Allocations have been made on information available from other sources. For example the work of CEFs and VEC tutors is financed by the Department of Education and Skills; the LCDP is financed by Pobail, whilst the Department of Children and Youth Affairs is known to fund the Family Resource Programme. Given these caveats, funding streams can be cautiously identified as follows, 


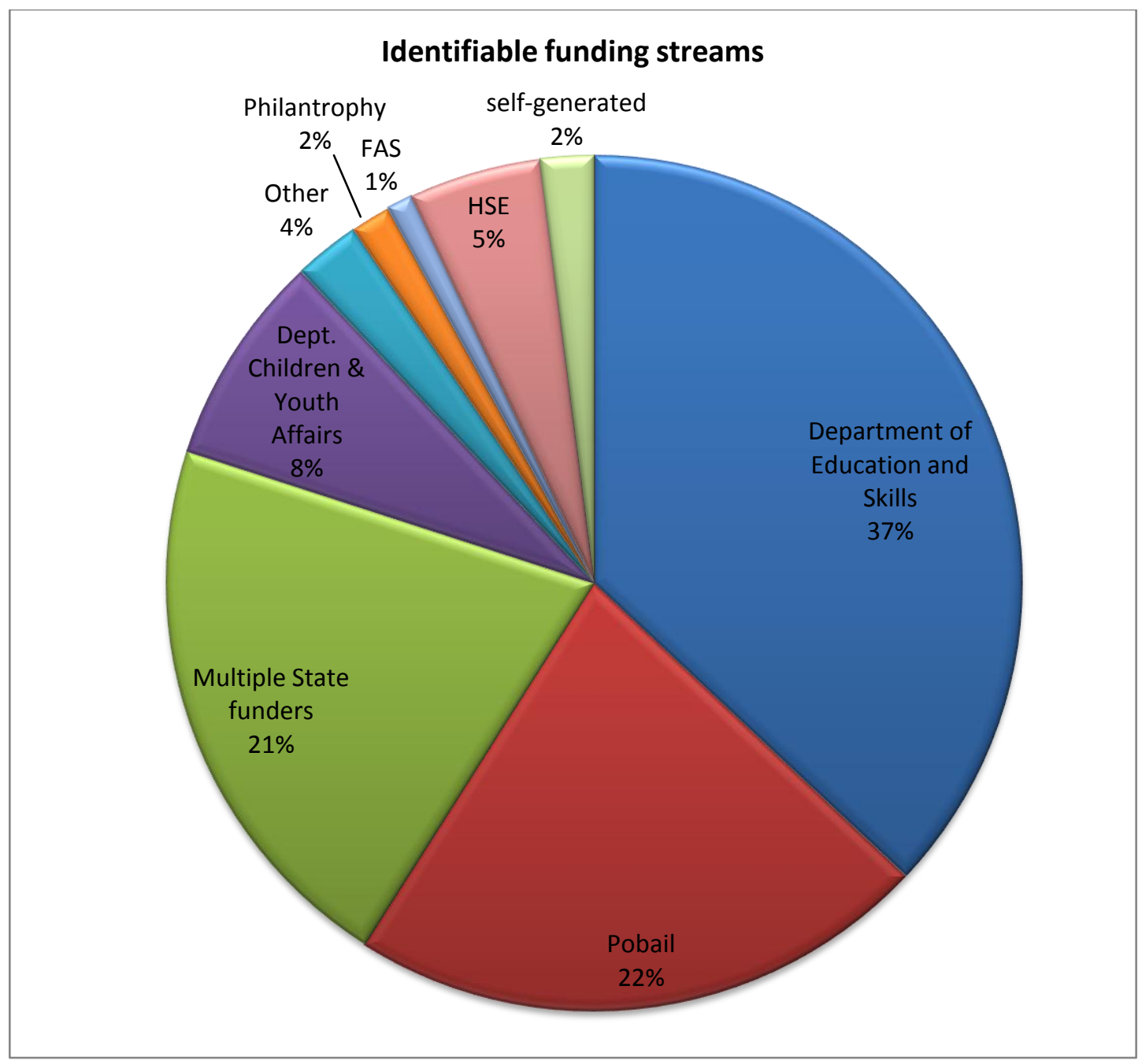

Figure 10 - identifiable funding streams amongst survey participants

This replicates named funders within research elsewhere (AONTAS CEN, 2011). Amongst those to indicate more than one funder, three respondents from Independent Community Education Organisations respectively cite 15 funding streams, 13 funders, and 11 public funding streams as well as corporate, philanthropic and self-financing routes. Government departments named within multiple funding arrangements are the Department of Education and Skills, the Department of Social Protection, FÁS, the HSE, and Irish Aid. Philanthropic sources are The Ireland Fund, and Community Foundation Ireland. Some also refer to selfgenerated income.

Funding arrangements with the State, or lack thereof, is raised by $19 \%$ of those who commented further when invited to do so with concerns spread across those within VEC 
structures and Community Sector organisations alike. There are calls for increased funding across the board with some wishing community education could be better recognised and resourced within the broader scope of educational provision. One CEF links budget cuts to a shift in State understanding of the purpose of community education (a theme returned to later in this chapter) sharing 'there is a danger that the only courses that will be delivered are those that fit funding requirements and ensure high enrolment numbers'. Others recommend more funding for specific population groups named as women dependent on spousal income therefore ineligible for some Department of Social Protection funded programmes, men's groups, migrants where English is an additional language, and rural communities where group sizes are likely to be smaller.

The impacts of funding cuts to date are also reported. These are the removal of student supports on accredited programmes, and the limiting of interventions that traditionally promote choice and inclusion. There is specific mention of dramatic funding cuts to one women's group, implemented in 2011. This is described as having a 'huge effect' as the respondent relays a $21 \%$ pay cut for staff despite working increased hours. Additionally, an independent practitioner personalises funding cuts as causative in his own difficulty in securing paid work.

\subsubsection{Quantification of accredited programmes}

People were asked about the number of programmes they offer which carry recognisable qualifications across the National Framework of Qualifications (NFQ) with the following revealed, 


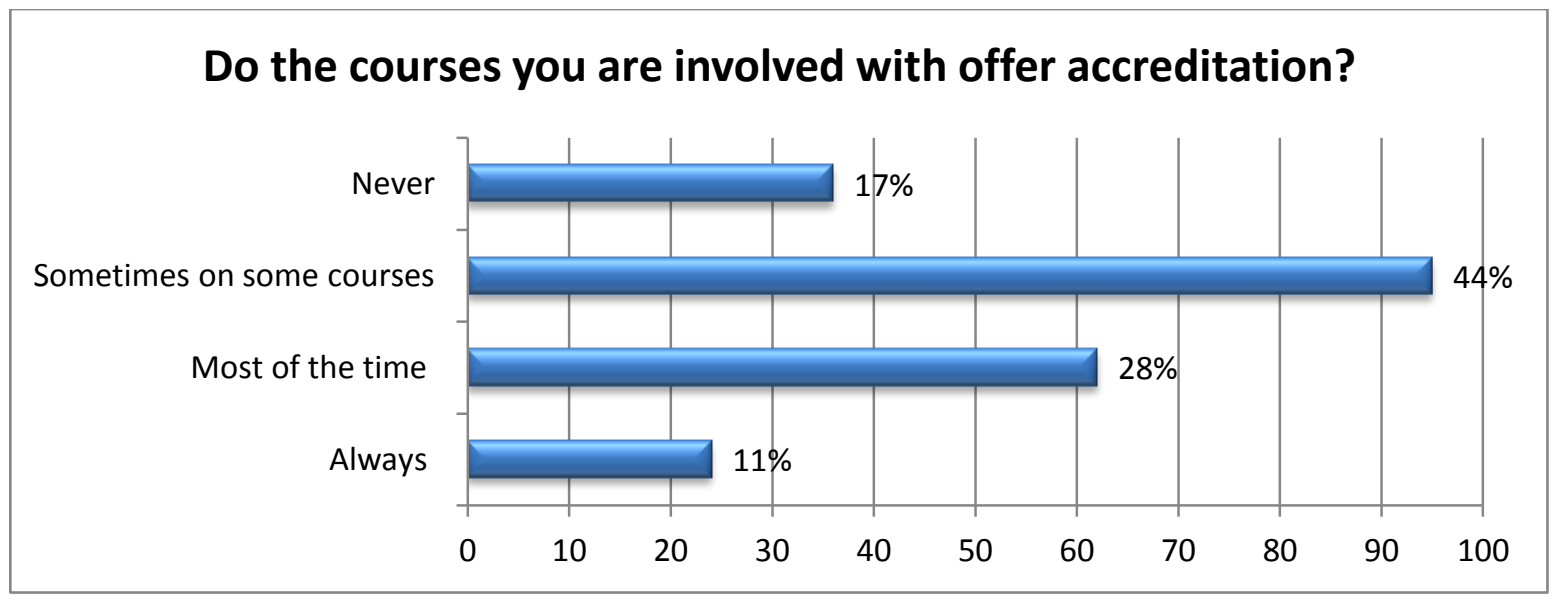

Figure 11 - Percentage of programmes that involve accreditation

This question shows how $83 \%$ (n181) of those participating work within accreditation frameworks in the delivery of at least some of their programmes. Working across both accredited and non-accredited environments is most frequently reported. A further breakdown determines the identity of awarding bodies' involved revealed dominance of Further Education and Training (FETAC, now QQI) awards which are cited by $84 \%$ of these community educators.

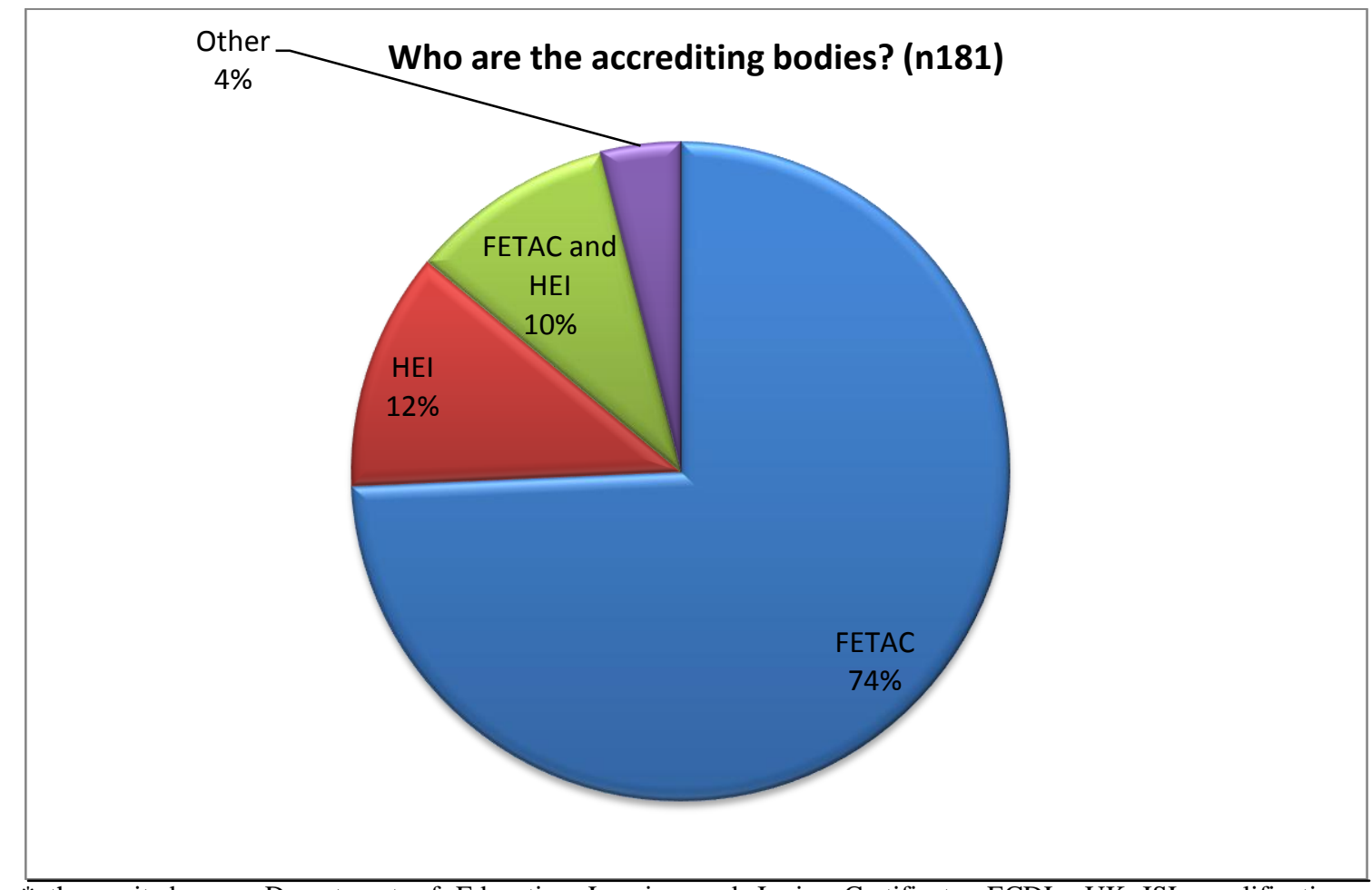

*others cited were Department of Education Leaving and Junior Certificate, ECDL, UK ISL qualification, fitness qualifications, and locally devised certification.

Figure 12 - breakdown of accrediting bodies awarding within community education. 
It is also possible to draw out those most likely to use accreditation. Ninety-five percent of participating CEFs utilise accreditation frameworks all of whom cite FETAC as the awarding body (with $\mathrm{n} 2$ citing FETAC and HEI accreditation). Also featuring strongly, $87 \%$ of tutors paid by the VEC again cite FETAC involvement falling to $79 \%$ of those working within the LCDP. Non-accredited work is spread across VEC structures and the wider Community Sector alike. Certification (accreditation) is the topic most mentioned in textual contributions as it is raised by $33 \%$ of those to comment beyond the questions I specifically asked. These contributions will be shared when reporting on related attitudinal measurements to directional hypotheses (section 9.4.2).

\subsubsection{Interpreting their role}

To get a sense of how community educators view their role, question 10 presented participants with 5 statements asking them to 'please rank the following statements describing how you 'mostly' interpret your role when tutoring/facilitating'.

Statement A - 'To respond to the issues and needs of the group regardless of the demands of the course descriptor/programme'.

Statement B - 'To introduce groups to knowledge and theories that I am familiar with thereby sharing my expertise.'

Statement C - 'To build the self-confidence and knowledge base of individuals enabling them to avail of a range of opportunities'.

Statement D - 'To encourage the groups that I work with to collaborate with each other and to together, take action to address issues that affects their community'.

Statement E - 'To up-skill individuals so they are better equipped to compete against others in getting a job'.

There was some confusion with this question. Six percent (n13) choose not to rank answers instead applying equal weighting to all statements. A further $22 \%$ gave equal weighting to either three or four statements. Across all responses, 30\% ranked statement E 'To up-skill individuals so they are better equipped to compete against others in getting a job' as the 
lowest ranked statement with $17 \%$ ranking this as a how they mostly interpret their role. Both of these percentage weightings include those to afford equal priority to all statements.

Discounting those to give equal priority to each answer, $10 \%$ rank statement $\mathrm{E}$ as mostly how they interpret their work, a figure that significantly drops where just one statement is prioritised. Where this is the case, just $\mathrm{n} 7$ respondents, or $3 \%$, prioritise up-skilling for employment as how they interpret their job.

The most likely statement for people to prioritise is Statement C 'To build the self-confidence and knowledge base of individuals enabling them to avail of a range of opportunities', cited by $68 \%$ of all responses, and prioritised by $57 \%$ where no more than two statements are ranked highest.

Seventy-one percent of respondents prioritised, or ranked lowest no more than two statements and these have been quantified below.

\begin{tabular}{|l|l|l|}
\hline $\begin{array}{l}\text { Please rank the following statements describing how you 'mostly" interpret } \\
\text { your role when tutoring/facilitating'. Where respondents choose no more } \\
\text { than } 2 \text { statements. }\end{array}$ & $\begin{array}{l}\text { Mostly } \\
\text { accurate }\end{array}$ & $\begin{array}{l}\text { Least } \\
\text { accurate }\end{array}$ \\
\hline $\begin{array}{l}\text { To respond to the issues and needs of the group regardless of the demands } \\
\text { of the course descriptor/programme'. }\end{array}$ & $30 \%$ & $36 \%$ \\
\hline $\begin{array}{l}\text { To introduce groups to knowledge and theories that I am familiar with } \\
\text { thereby sharing my expertise.' }\end{array}$ & $11 \%$ & $22 \%$ \\
\hline $\begin{array}{l}\text { To build the self-confidence and knowledge base of individuals enabling } \\
\text { them to avail of a range of opportunities'. }\end{array}$ & $57 \%$ & $6 \%$ \\
\hline $\begin{array}{l}\text { 'To encourage the groups that I work with to collaborate with each other and } \\
\text { to together, take action to address issues that affects their community'. }\end{array}$ & $17 \%$ & $21 \%$ \\
\hline $\begin{array}{l}\text { To up-skill individuals so they are better equipped to compete against others } \\
\text { in getting a job' }\end{array}$ & $8 \%$ & $45 \%$ \\
\hline
\end{tabular}

Table 6 - How community educators interpret their role.

Also emerging from table 6 above, is reticence in occupying the role of expert. As people discuss their role further, particular expressions emerge with the use of 'facilitator' not uncommon alongside a distancing from the word 'teacher'. One shares, 'most of the learners I work with have had negative educational experiences and would not attend courses if they were ran by a Teacher'. Others also distance themselves from their sense of what encapsulates a secondary school teacher, usually interpreting their own role as one that brings 
more individualised attention and support to learners, of creating environments that deliberately differ from traditional models of education and of developing a space for people to realise their potential at their own pace.

Section 9.3 (overleaf) will continue an account of survey findings, shifting the focus to descriptions of community education and underlying philosophies of practice. 


\section{SECTION 9.3 - Descriptions and Philosophies of Practice}

\subsubsection{Describing community education}

In order to gather descriptions of what participants understand community education to be, an open-ended question was posed as follows. 'When you see community education in action, what is happening that causes you to say "now that is community education",. This question allowed statistical generation of those elements most emphasised through quantification, complemented by textual accounts that allow respondents to answer as best suits their interpretation. As previously signalled quantification is problematic as the separation of concepts suggests set ingredients can be independently identified, the inclusion of which automatically result in a phenomenon's existence. There are many factors outside of a checklist of constituents not least the ontological and epistemological perspectives of practitioners, the context within which a group comes together, and the external socioeconomic circumstances. In defence of quantification, parting ingredients does allow for a capturing of regularities thereby revealing dominant trends. These can then be considered alongside stated philosophies and examples of practice.

In the shadow of such benefits and limitations, not least the influence of the subjective researcher discussed within chapter seven, quantification was generated on whether a particular characteristic was 'mentioned' or 'not mentioned' by each respondent. Again I used a constant comparative method meaning all components raised by participants are represented. Quantifying involved organising unstructured material into categories before assigning a numeric tag to each category generated (Bryman, 2004: 146). Figure 13 shows the categories that emerged across n188 responses (representing a drop-out rate of $14 \%$ for this question). 


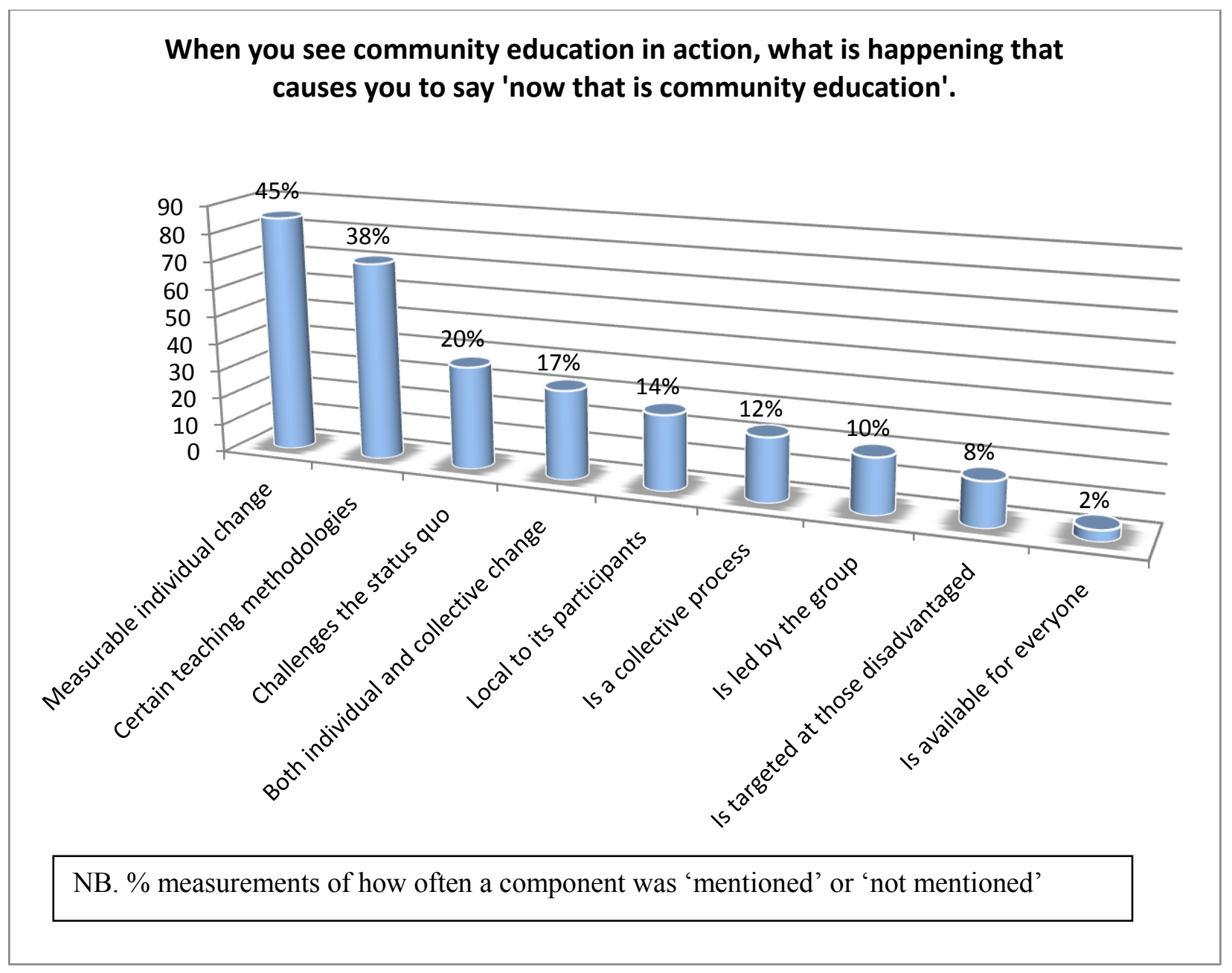

Figure 13 - Quantification of descriptions of community education

In total, n315 elements are named as many participants cite more than one feature. For example, $\mathrm{n} 3$ to propose that community education is specifically for those experiencing disadvantage also cite the presence of both individual and collective change as a requisite feature. Furthermore, n21 who cite community education as evidenced by measurable individual change also refer to the presence of certain teaching methodologies. These are not the only contributions that capture an array of interconnected features. One participant, an independent practitioner working on FETAC accredited programmes and describing her practice as 'in line with critical theory particularly Marxism' describes community education as having 'a number of components' explaining, 
It is; genuinely participative and delivered in engaging learning environments in which the traditional teacher/student dichotomy doesn't exist; responsive to the needs of learners and their communities, underpinned by critical pedagogy; concerned with social justice, change and equality, not about equipping people with specific technical skills to enable them to respond to the demands of the economy.

A further contribution provided by a tutor within a self-funding Independent Community

Education Organisation who links practice to feminism refers to four levels as follows,

Personal, community, political and wider society, it is individual and collective transformation. That it captures participant's interests and passion on posing issues and problem solving solutions collectively. Participants learn to analysis, cause and effect and to develop their own critical analysis and theories.

Others also draw out multi-layered meanings as an overlapping myriad of personal, vocational and political. Emphasising the importance of context, one CEF who has been working as a community educator for over 25 years, describes what can happen when a local group comes together. She describes how people are often 'listening to each other, supporting each other, identifying what they would like to do together' such as arts or cookery classes. She continues,

Then as the class progresses, the conversations that happen and are facilitated, can lead to stronger bonds being created and further support for each other. The group may then decide to work together to create something for the community or to resolve some issue in the community. Sometimes, where a group have formed as part of a CDP or women's group, there is a more explicit community education/ development agenda and the group may work to develop their capacity to collectively address issues that affect their community.

\section{Where individual change is measurable}

The most commonly mentioned element to emerge was belief that community education can be evidenced through measurable individual change. This can be further divided in three ways,

1. Progression into education and/or employment.

2. Personal development such as increased self-esteem and self-worth.

3. Individualised change that engenders confidence to engage more productively with social structures and services. 
Just n5 respondents, therefore $<3 \%$ of answers, evidence progression as towards employment most of whom (n3) contextualise this within broader supports and other possible progressions including additional education. One working within adult literacy services speaks of 'developing personal ability, confidence to participate more fully in their community, family and work'. Another, who works within an urban based independent community education organisation, links it to entrepreneurial opportunities and the development of future small business opportunities. This strengthens findings when interpreting their role where just $\mathrm{n} 7$ people singularly ranking up-skilling for employment, as that which most described their role.

Nine cite formal educational progression as a requisite feature providing pathways into both FE and HE whilst some speak of progression from non-accredited to accredited programmes. One participant working for an independent organisation with multiple funding streams and involved in FETAC delivery speaks of progression to 'the next level of education' continuing 'they have gained confidence and now they don't want the learning to stop; they don't fear education anymore'.

Overwhelmingly most refer to individual change outside of progression pathways towards personal development ambitions. Submissions include mention of 'empowerment', of promoting 'more independence', of people 'gaining confidence', 'improvement in social and soft skills', 'taking on a challenge which they would previously not have done'. Dimensions of greater community involvement are also revealed, sometimes to combat isolation, but more commonly as summed up below,

Individuals are becoming more confidence in their individual ability, more aware of the opportunities that are available to them. This builds capacity in the community to positively progress, it is a slow process but achievable with the right commitment, resources and community engagement.

This contributor works within an independent CDP but cites previous experience in both FÁS and a VEC. 


\section{Individual and collective change}

On n32 occasions (17\% of all answers), change is presented as both individual and collective enabling people to initially gain in confidence then wield this towards collective response. For some this was through collective engagement with State structures, for others to improve conditions within communities or increase community engagement. One contributor, working within an Independent Community Education Organisation and influenced by liberation theology, speaks of it as being 'about power, empowerment, participation and social change' continuing,

People are seeing their own gifts and resources and those of others and believing that change is possible. The process of learning individually and communally begins to replace the notion that learning is about acquiring lots of knowledge. People see themselves as knowledgeable and capable of generating knowledge.

\section{Where there are certain teaching methodologies}

The importance of teaching methodologies, as named by $38 \%$, was shared across all provider types. As previously indicated, this is often by comparing the approach used to traditional education which is viewed as hierarchical and non-critical. Many detailed a more diffuse sharing of power described through participants having significant input into course design with actions agreed on, rather than prescribed by the tutor/facilitator. This specific example was shared by a FRC coordinator, some HEI tutors, some LCDP staff and some CEFs.

Broader participatory approaches are also cited. One respondent with almost 30 years experience and currently involved voluntarily explains, 'its emphasis is process (including group-work, check-ins, consultation, supports, childcare etc.), and never letting a pre-written syllabus dictate how it should be done' (brackets in original). An employee of the LCDP, who gained her own qualifications through community education, describes the way in which every time a programme is delivered cognisance is given to each group. This means acknowledging different dynamics and educational standards described as 'a fresh approach 
and openness to changing the direction of learning accordingly'. Others share dialogic methods that includes debate on voting, and peer exchange on 'community based issues/problems' reported on within an addiction based project.

\section{When it challenges the Status Quo}

There are also incidences where community education is evidenced through its challenge to the status quo, raised by $20 \%$ of all responses. These contributions were more likely to be towards politicised interpretations of the work. Sometimes this was towards individualised awakenings, what one describes as 'fostering awareness of structural injustice', other times they lean in the direction of collective responses. This is described by another as when participants 'take ownership of issues and reach a point of analysis that allows them to take action on their circumstances'. Again contributions of this nature emerge across all provider types. One employee of an addiction project interprets community education as about people beginning 'to understand the nature and patterns of inequality and developing collective strategies to change these inequalities', working with allies to advance 'community and social change'. Another example is shared by a woman working with a FRC who interprets community education as,

when people begin to take responsibility for changing their situation; when they take on statutory bodies; when they develop critical social analysis; when they are able to delay a process when they see it is to their advantage; when they trust their own cultural insights.

For others, change is through the formation of local action groups or the establishment of services. Over half (n26) who cite challenges to the status quo as fundamental are from community educators who indicate the use of accreditation in their work.

\section{When it is a collective process}

A commitment to collective interpretations of community education also features strongly, proposed as a requisite feature for $12 \%$ (n23) of responses. One HEI employee located in local communities describes the process as a 'social movement' linking it to campaign 
movements in her local area. A rural based CEF also refers to collective campaigns around welfare rights, housing conditions and a campaign against hospital closures. Others link it to community development and to groups identifying issues and collectively working towards influencing change. For half of those who evidence community education through collectivism, this is presented as shared processes of learning within classroom settings, rather than collective activism beyond their walls.

\section{Locational factors}

Local availability is required for $14 \%$. There are practical reasons put forward for this such as the availability of childcare and lower transport costs. There are also ideological dimensions for localised delivery where sentiments of collectively and activism emerge in response to local issues. This latter point is made by those working within the Community Sector and those situated within VECs alike.

\section{When it is for those considered disadvantaged}

Eight percent believe a requisite feature is that the work is targeted towards those considered 'disadvantaged'. Specific reference is made to initiatives for new communities, disadvantaged women, people with intellectual disabilities, and those parenting alone.

\subsubsection{Cited philosophies of practice}

Figure 1 (page 85) presents a framework for considering community education, adapted from original work by Martin (1987). This considers practice under consensus, pluralist or conflict banners named as universal, for all regardless of socio-economic circumstance, compensatory, deliberately targeted at certain population groups to correct earlier educational deficit and radical, instigated as a collective process that sets out to influence systemic change. Notwithstanding previous hesitation on the falsity of prizing complex theories apart, respondents were asked a question designed to indicate a dominant position by siding with 
one of three statements as detailed in table 7. I first asked, "which one of these approaches would you most align your own practice with', and then 'which of these approaches would you most align your main employer with'. The following results emerged.

\begin{tabular}{|c|l|l|l|}
\hline 1. & $\begin{array}{l}\text { Where the emphasis is on offering a wide range of } \\
\text { courses (vocational, personal, political) that are open to } \\
\text { anyone who is interested regardless of where they live } \\
\text { and what their background is. } \\
\text { [UNIVERSAL] }\end{array}$ & Practitioners & Organisations \\
\hline 2. & $\begin{array}{l}\text { Where the emphasis is on offering a wide range of } \\
\text { courses (vocational, personal, political) specifically } \\
\text { targeted at those who are considered 'educationally } \\
\text { disadvantaged' thereby providing opportunities } \\
\text { otherwise not readily available. } \\
\text { [COMPENSATORY] }\end{array}$ & $36 \%$ \\
\hline 3. & $\begin{array}{l}\text { Where the emphasis is as a political and politicising act } \\
\text { taking its lead from issues affecting people in } \\
\text { communities considered disadvantaged. Its approach is } \\
\text { collective over individual and its hope is to influence } \\
\text { wider social change' } \\
\text { [RADICAL] }\end{array}$ & $28 \%$ & $58 \%$ \\
\hline
\end{tabular}

Table 7 - approaches to practice; universal, compensatory or radical ${ }^{49}$

One respondent connected to a HEI and aligning herself with the third statement, also comments on the limitation of such separations. She chooses not to categorise her organisation's approach sharing,

Q21 assumes that there is one approach over another. I find that individuals come to the organisation with the second set of goals, and the very act of the organisation being in existence and being involved in campaigns reflects the third set of goals. It did not allow me to select both 2 and 3 for both parts of the question.

This question reveals how over one third of those researched favour approaches that do not weight practice in favour of those traditionally considered disadvantaged despite identifying how most organisations do positively discriminate in this way. In total, $43 \%$ of those who answered both elements of this question (q21) are at odds with their organisation's approach. The most notable discrepancy occurs for $41 \%$ of those who align themselves with universal

\footnotetext{
${ }^{49}$ Discounted missing value of $10 \%$ (n23) when naming personal leaning and $14 \%$ (n30) when identifying organisational leaning.
} 
approaches who are employed within organisations promoting second-chance methodologies. We can also see how $55 \%$ of those aligning themselves with radical approaches work within organisations ascribing to second-chance/compensatory models. Cross-tabulation verifying these findings can be viewed in appendix 5 (as table Q).

\subsubsection{Further quantification of stated philosophies}

An open-ended question was posed as follows: 'If there is a particular way of working that informs your approach (a certain belief system, theory, philosophy, etc.), can you explain or describe it?' Response rates were $81 \%$, varying from one or two lines to contributions of two to three paragraphs. As with previous examples of quantification, I used a constant comparative method with all components raised by participants represented as unstructured material was organised into categories then assigned a numeric tag for entry into SPSS (see section 7.4). Categories identified are humanistic (person-centered), radical/critical education, and those who stated no philosophy. The following breakdown emerges across philosophies shared. 


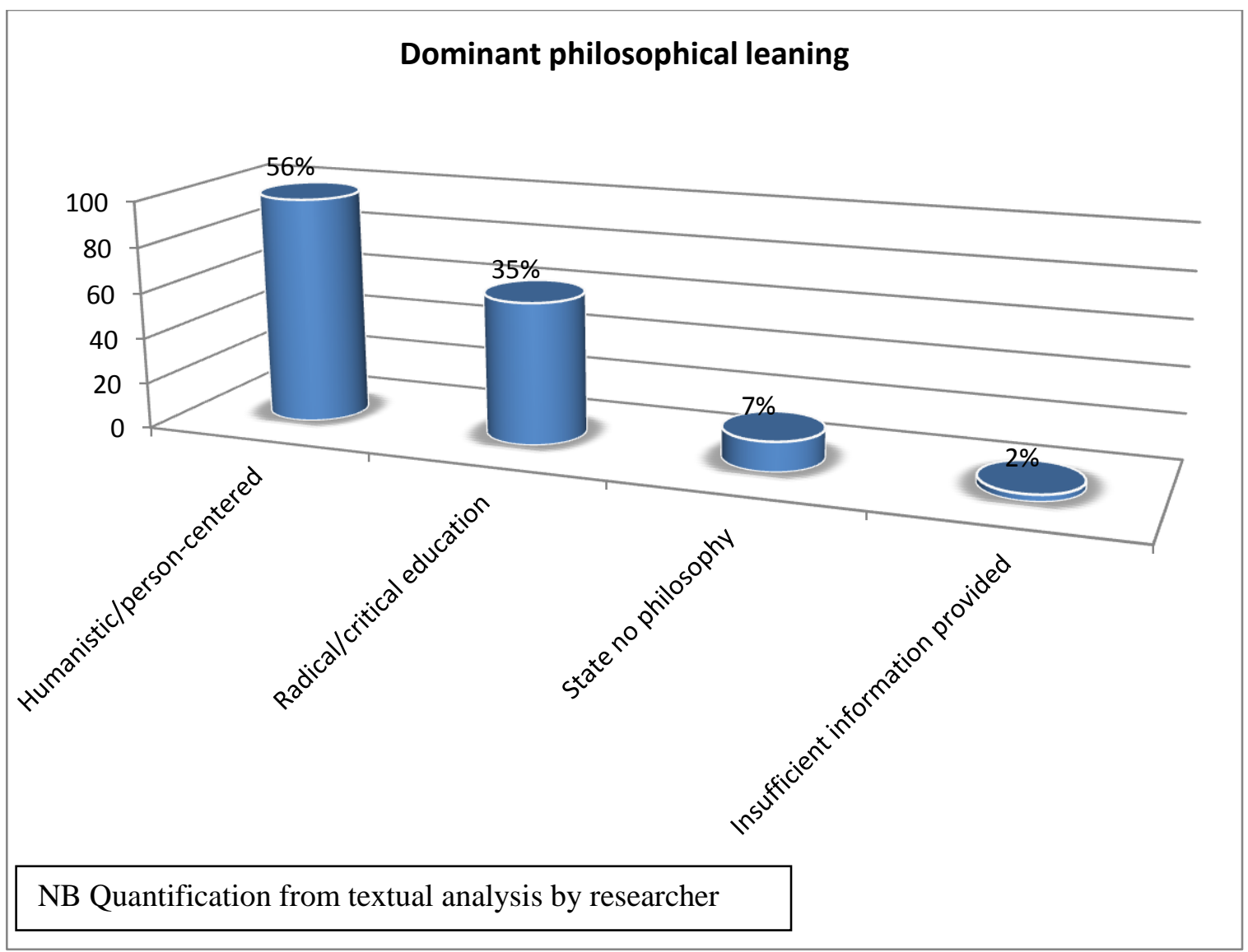

Figure 14 - Dominant philosophical leanings of survey participants

Within appendix 5 (table $S$ ) provides a complete breakdown of specific influences named within answers to this question. Eleven percent specifically link community education to 'community development' including within the contributions below,

A community development and human rights based approach.

Bottom up Community Development, i.e. the demand comes from the ground.

Community Development underpins my practice as a volunteer or as a paid worker, which means I believe in equality (to achieve equality there must be equity) active participation, social justice, empowerment (dodgy word if used without understanding its true meaning) collective approach. I believe we all can.

Others link community development to humanism such as the quote below, 
A humanistic belief in the inherent capacities of communities and groups to make wise and positive choices about how they wish to live - the ideas and principles of community development

'Humanism' is specifically named within $4 \%$ of answers whilst a further $4 \%$ specifically name either 'person-centered' or 'learner-centered' approaches. The job of a researcher adopting quantification is to infer meaning from contributions where recognisable philosophical catagorisations are not explicitly named, in some instances this included where multiple influences were cited ${ }^{50}$. Some examples of how interpretations were made are as follows,

The individual and their need is the priority and where possible that need should be fulfilled in the locality if at all possible.

All students, regardless of their abilities or socio-economic background, deserve to be treated with respect and to receive training which is delivered to the highest professional standard regardless of content.

Both catagorised as humanistic/person-centered and,

A belief that power needs to be decentralised to the greatest possible extent, that everyone has a right to take part in making decisions that affect them, and that they should be supported and facilitated in acting on that right - that collective action makes it much easier to indicate these rights

The poverty trap is created for others by those who can afford it equalling inequality... who is creating the poverty trap? What needs to happen to change it? How can I contribute to that change?

Both of which were catagorised as a critical approach to education.

As determined in figure 14, the largest influencing trend is towards a humanistic/personcentered approach. Emphases shared are of respect, belief in intellectual capabilities of all, and of people being experts in their own lives. Recurring descriptions were of the community educator as active listener, instiller of confidence and promoter of self-directed learning. Many again draw out person-centeredness in opposition to school experiences.

\footnotetext{
${ }^{50}$ For example, one woman, quantified as working from a humanistic/person-centred approach cites influences across a psychotherapeutic spectrum - 'Rogers, Skinner, Mazlow and Kolb'. Another, catagorised as radical, cites influences as Freire, feminism, group work, community development, Kantor, Kotter, and quotes 'Warren and Bennis' and their concept of leadership.
} 
The mutuality of learning was raised by others and the concept of 'expert' was again challenged on more than one occasion. Describing people as 'experts in their own lives', one employee of the LCDP illuminates sentiment well when she states,

I believe we learn together through sharing and communicating, and I see my group facilitation as a partnership. Where it is relevant, there may be occasions where I have more knowledge on a topic or an issue that I can share with the group, but it is their analysis of that knowledge that of ultimate importance in the group. I do not believe myself to be an expert in any field, or to have more expertise than any person attending a group.

Others spoke of a way of working that is led by the needs of the group.

Where contributions have been aligned with political-radical philosophies, some participants include quotes from Freire, from poetry and from popular fiction. Others disclose political affiliation. One describes herself as 'socialist', another of 'not believing in capitalism' and for a few, of being 'feminist'. Others align their analysis of society to Marx with many describing their work as about addressing systemic inequality an injustice and of a powerladen system. One contributor working within a CDP not merged into the LCDP describes this philosophy as led by a belief that community education as about 'struggling for social change and human rights'. His work is with men's groups and he is vocal about the depoliticisation of the sector when elaborating further stating,

We have a huge challenge to defend the value and effectiveness of what we do in the face of a concerted and intentional deconstruction of the primary function of community work and community education as an engine for progressive social change and human rights

Somewhat similar sentiments are expressed by one working within an addiction project extending this towards a vision for the future commenting, 'we need to develop a much more radically political community education and to build on the strengths that already exist in the field and in communities around the country'. He continues, 
Activism should be much more to the forefront of the work. The levels of exploitation, corruption and inequality are simply unacceptable and the levels of suffering that people are experiencing are also unacceptable. We need to change this and community education is one of the key tools that we have for doing this. Let's continue this journey!

\section{The stated influence of Paulo Freire}

The philosophies of Paulo Freire are identified by $17 \%$ of respondents, the highest single influence named. As indicated in table $\mathrm{S}$ (appendix 5), alliance with Freire is not always catagorised as indicative of critical approaches to community education. One CEF to cite Freire names her influence as a 'humanistic philosophy' further sharing,

Education for me is student centred, meeting the needs of the student that reflect what is essential in their lives. My role is to facilitate self-actualisation, potential, develop selfconfidence, self-esteem, and to support and encourage individuals to engage in the process.

A second contributor who works as a tutor paid by the VEC states 'I believe in a humanistic approach and try to cater to the needs of individuals in my group. I also would like to emulate Freire where I can in providing opportunities for individuals to become empowered and not to feel that they are not valued in society'. Frequently, interpretations of Freire are politically charged. One person, who works with Traveller women within the LCDP, describes learning environments as politicised spaces characterised by 'culture circles, critical consciousness, and education for liberation'. Others reject banking approaches to education in favour of politicised dialogic and a social analysis of class and gender. A Freirean approach across contributions is described as emancipatory and as about power and empowerment. It is linked to Marxism, liberation theology, community development and participatory democracy. Freire is also linked explicitly to Karl Marx, bell hooks, Margaret Wheatley and a Human Rights approach, Augusto Boal, David Kantor, John Kotter, and, from a number of sources, Hope and Timmel and the Training for Transformation movement. 


\section{Reasons for not ascribing to a philosophical discourse}

For those who reject any affiliation to philosophical underpinnings there are two reasons offered. These are a vocational responsibility to be led by the philosophies of the organisation as employer, and a rejection of the notion of being led by any philosophy at all. With reference to the later, one comments, 'I never needed other people's theories to do my job. I can read people and work on their strengths' whilst another maintains a building of her own style and approach based on over 20 years of experience. Another, who is elsewhere cited as influenced by universal approaches, distances herself from alignment with specific philosophies but does make reference to 'respect' as important.

\section{The importance of group-work in detailing philosophical leanings}

Many submissions again refer to the importance of group-work with specific reference to participatory and experiential learning. One speaks about 'listening to participants and working together - not top heavy but a partnership open to listing and learning from each other'. For another who has been catagorised as humanistic/person-centered in her approach, her work is influenced by the desire to create '... an experiential environment in which the group pre-agrees to mutual respect (and all that that encompasses) and where everyone is listened to and heard and held in an environment of growth' (brackets in original).

\subsubsection{Shared examples of practice}

One reason why I invited people to share examples of their work was because of conversations within other studies on possible differences between what people say, and what people do. Discussion on expressed attitudes and beliefs and the actions that people actually take, is commonly dated to research by Richard LaPiere undertaken in the 1930s and revisited by Dockery and Bedeian in the 1980s. Both studies contend discrepancies are not between true attitudes and actions, but between attitudes as measured in a survey questionnaire and actions (Dockery and Bedeian, 1989). This means that surveys mostly 
capture symbolic social and political orientation measuring what respondents imagine their approach to a situation ought to be, rather than how they actually behave when faced with particular situations and circumstances. In determining relationships between what is said and what is done in this instance, q20 asked participants 'can you give an example of something you were recently involved with that best illustrates your approach to community education and the ideas underpinning it?'

Categorising practice is ambiguous if interpreted as impervious to other influences and ways of working. With any educational engagement, context matters and it is worth reminding the reader of features outside of tutor philosophy such as the reasons why a group comes together, contractual parameters such as funder demands, the socio-economic circumstances of the time and the personal issues affecting people both individually and collectively.

Acknowledging permeability across classifications, the examples shared have been categorised as follows,

1. Individual support to learners and groups that enhance personal growth and development.

2. Examples of critical education underpinned with a strong analysis of inequality and social justice ambition.

3. Work that initiates the establishment of a local service or amenity.

Each answer given leant itself to one grouping over another with these categories not determined in advance, but arrived as by reviewing data generated. These are recorded across $n 151$ responses therefore with a non-response rate of $33 \%$, the highest non-response rate measured across survey questions. 


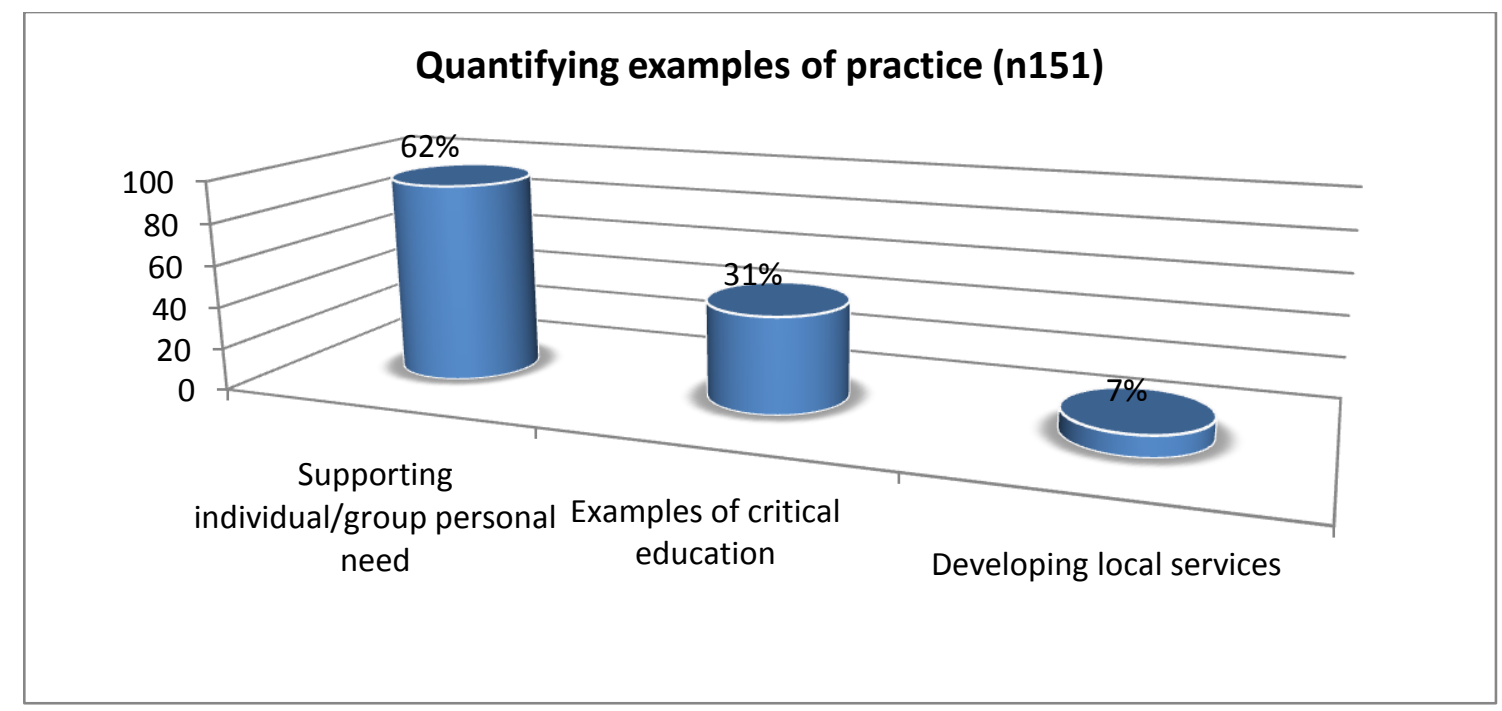

Figure 15 - Quantifying examples of practice.

Further sub-categorisation is also retrievable that extrapolates examples more specifically as presented below.

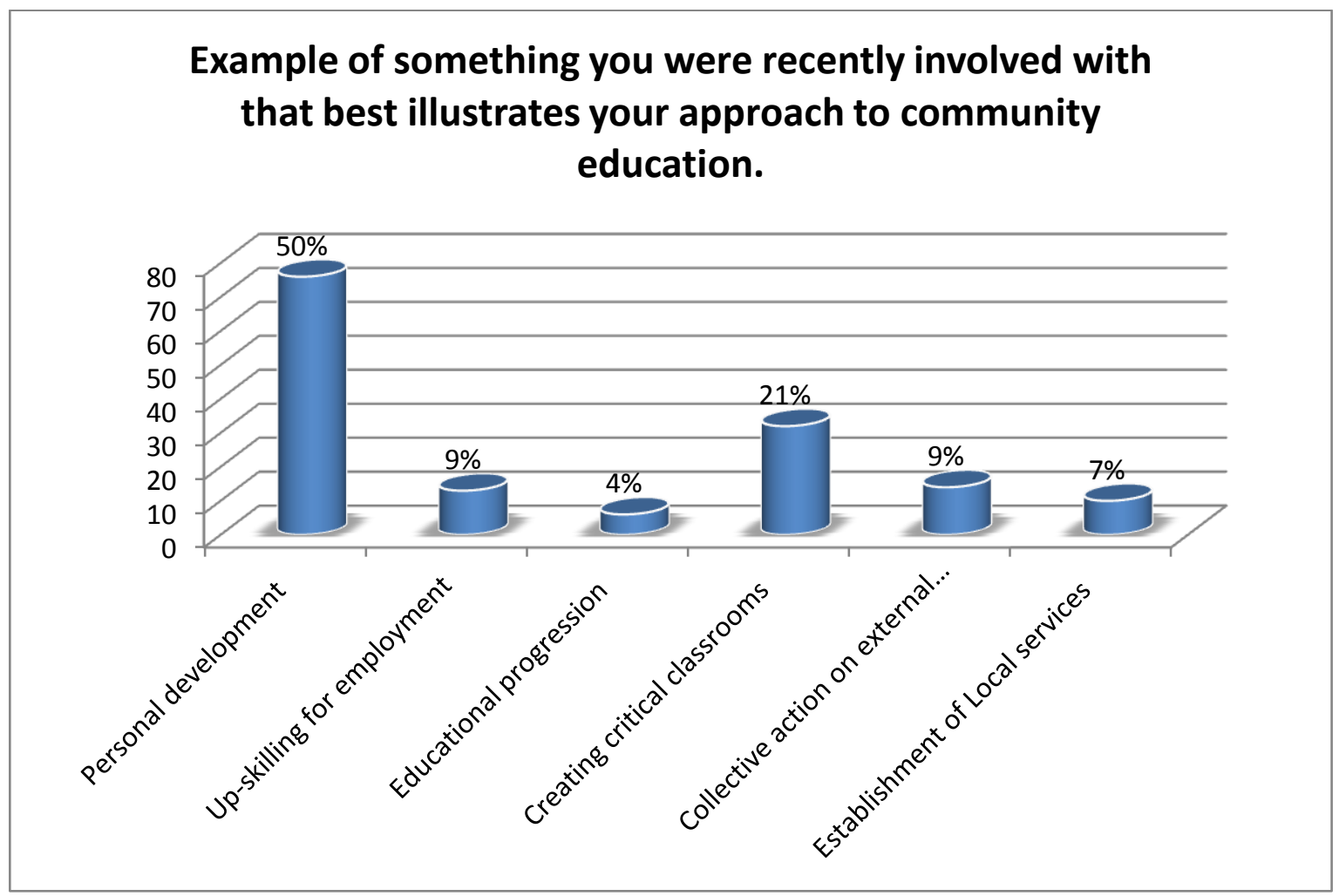

Figure 16 - Sub-catagorised quantification of examples of practice

The bulk (63\%), are stories of individualised support within person-centred approaches. This is higher than a previously measured $56 \%$ who ascribe to this approach when citing philosophical leanings. This is potentially explained through varying response rates. 
Examples of person-centered approaches can be further catagorised as supporting personal growth and development, up-skilling for employment, and support towards recognisable educational progression. A breakdown of these is offered below.

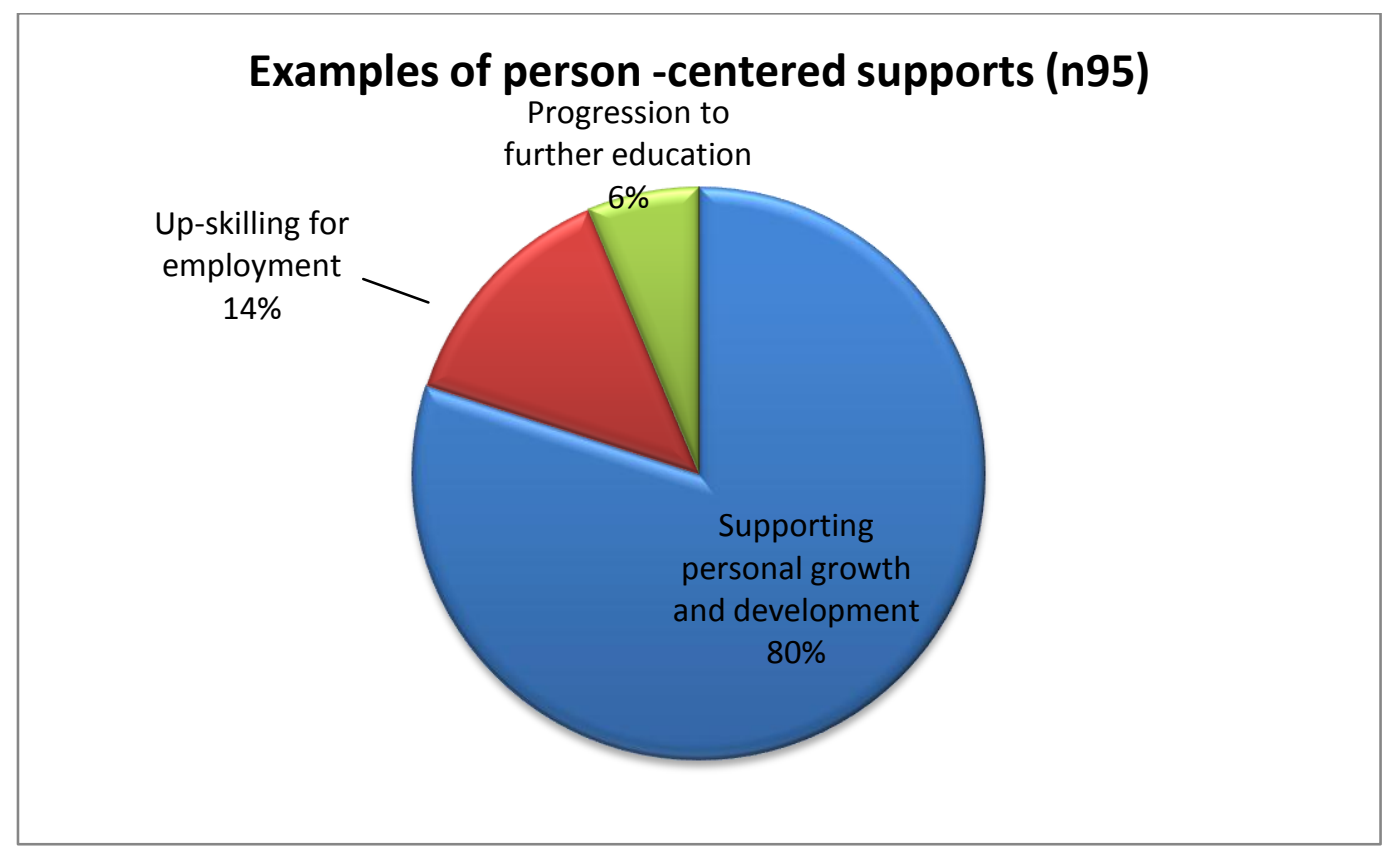

Figure 17 - Breakdown of person-centered examples of practice.

Each sub-categorisation will now be further discussed.

\section{Supporting personal growth and development}

Specific examples shared include parent support programmes, some designed to support the day-to-day challenges of parenting, others that position the parent/s as first educators and that set out to improve relationships between parents and schools. Computer classes designed to bridge a generational digital gap are also shared. One voice links these to up-skilling in email and Skype so people can better communicate with adult children who have emigrated.

Arts based programmes include music, poetry, drama and cookery programmes. One AONTAS CEN member, whose work includes bridging urban-rural divide, shares the following, 
I facilitate a women's singing group, where I teach songs and basic music theory. I have a very diverse group of women with varying degrees of disadvantage. Within that group there is tremendous solidarity. Friendships have been made that have changes the lives of participants. Some who have come from domestic violence situations, suffered from depression, racial discrimination etc. have found the strength and confidence to bridge that gap between isolation and personal development in the form of further education or self-employment.

There are also personalised literacy programmes and health and fitness programmes, some specifically targeted at men. One of these is for those with a history of problematic drug use and is offered alongside counselling services should these be required.

Stories are also shared of teaching methodologies that enable individuals and groups to take the lead in determining how to best meet their educational needs with tutors often straying from the prescribed curriculum. Examples include a group determining their own time-table, sex-education with young adults that was introduced in response to group need, suicide awareness and prevention, again in response to the issue being raised, fundraising work with a support groups to enable its survival, and a session on map-reading the context of which is explained below.

Someone said she could not read a map, that once she went beyond Newlands Cross [on the outskirts of Dublin] she did not know whether she was going north, south, east or west. So we brought in several large blank maps of Ireland, divided the class in two, and gave out two sets of cut-out car registration letters and asked the two teams to place the car reg. letters on their appropriate counties. Then we listed the counties in each province. So we adapt our sessions to the needs/suggestions of participants.

Work with immigrant communities also emerged. One describes 'basic English' programmes funded to offer vocational supports but manipulated to better meet the needs of the groups helping out with visa applications and more effective communication with public services and schools. A second example captures similar sentiment as follows,

[the class] did not just involve teaching English - many of the students had good English. They need to learn about the Irish system of education and health care. They needed to know how the tax system worked, that their husband could use their tax credits if they were not working, that they could claim child benefit and FIS [Family Income Support]. They asked about car tax, car insurance, how to get a PPS [social insurance] number - lots of basic questions that they needed help with. Those who had good English translated the questions and the answers for the others. 
There are also examples of tutors offering support they perceive as over-and-above that offered in traditional models of education. This is a strong theme with community educators encouraging cross-cultural communication, offering additional supports to those with learning disabilities, providing extra tuition time, waving fees, and uncovering literacy difficulties through individualised support. One shares how a course participant was imprisoned and, rather than defer the student, negotiations with the Prison Service were opened so they could complete their studies. This is described as an exercise that 'facilitated empowerment and greater social participation and promoted positive change'.

\section{Supporting employment and educational need}

When describing community education earlier in the study, less than 3\% (n5) directly linked it to employment related support. When giving examples of practice, 9\% (n13) can be catagorised as primarily linked to employment. Where described, these programmes include assertiveness and confidence building. One educator, herself from a background interpreted as disadvantaged, describes employment related work with early school leavers as follows,

One of my main objectives at the moment is to help the learners to consider others in whatever they are doing. I think this will improve their chances of gaining employment as well as helping them to become considerate adults. I think this is important as I believe that the learning we undertake in the class should be transferrable to real life situations outside the classroom.

She believes it is the learner-centered teaching methodologies that make this a good example of community education. Particular vocational courses are also named. These were childcare for crèche workers, and a 'building futures' programme described as 'about training long term unemployed people to use and interpret their own life experiences to become trainers, peer educators and community workers working particularly with disadvantaged groups'.

Examples of supports for education progression (named by 4\%) are through communitybased access to HE programmes, progression pathways from minor to major awards and certificate to diploma level, induction for Back to Education Initiative (BTEI) entry, and 
involvement with library based courses designed to give attendees 'a taster for third level studies'.

\section{Breakdown of examples of Critical Education}

Thirty-one percent of examples of practice that 'best illustrates' respondent's philosophical approach have been catagorised as critical education. This represents a $4 \%$ drop in those previously quantified as aligned with critical education philosophies. Examples shared can be further grouped. First is where tutors/facilitators endeavour to develop the critical capacities of participants within its classroom walls and secondly through incidences where effort is extended beyond these boundaries resulting in direct engagement with local or national issues of concern.

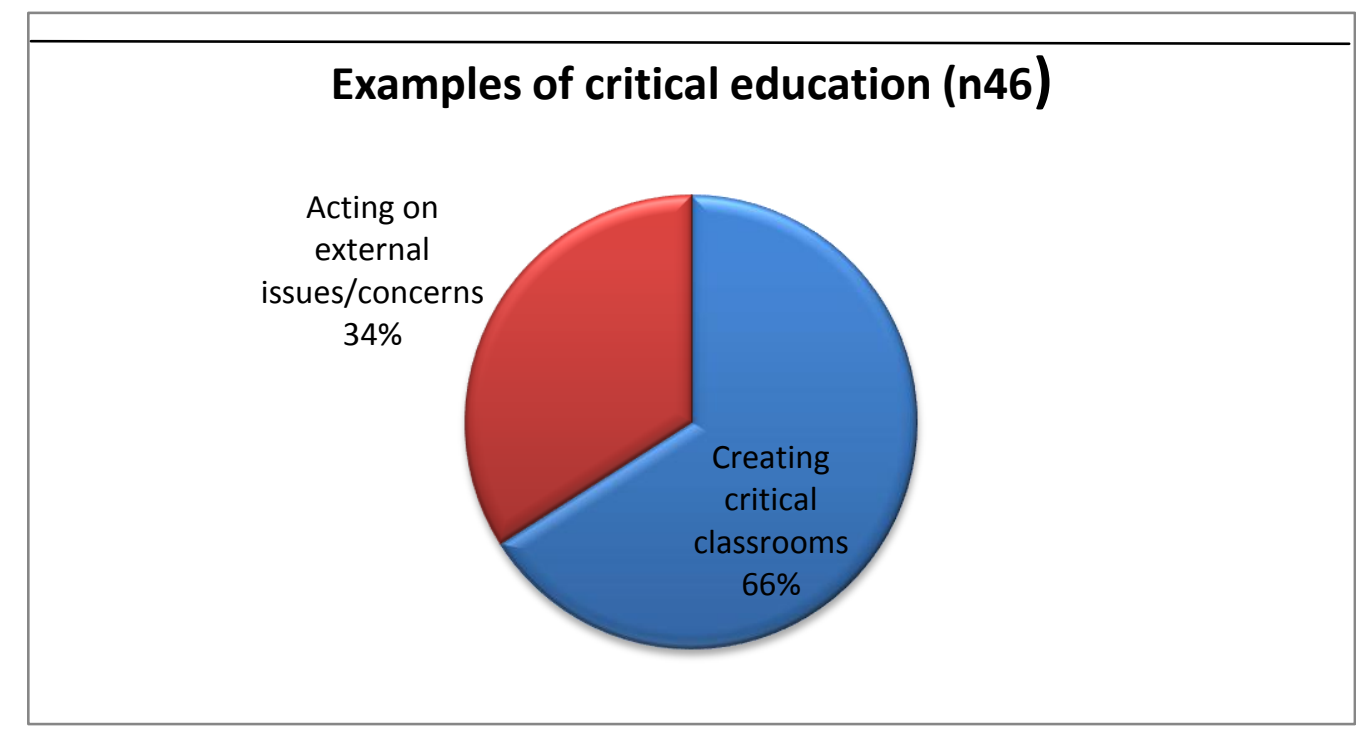

Figure 18 - Sub-catagorised examples of critical education

\section{Examples of creating critical class-rooms}

Tutor attempts to create critical classrooms represent $21 \%$ of all examples of practice shared and reference to equality, social justice, human rights, political discussion, citizenship, intercultural work and critical approaches to group-work were all commonplace. There were dialogic analyses of traditional education and stories of groups designing their own methods 
of assessment. Some cited use of Training for Transformation (TfT) materials whilst one shared design and implementation of a simulation exercise where group-members replicate a campaign on a 'rights based issue of their choice'.

There is an example of raising 'participant awareness of oppression in the workplace from a class on reflective practices and classroom conflict'. This contributor (a part-time staff member with an Independent Community Education organisation) continues, 'sometimes it just takes giving people a safe space to explore and give themselves permission to listen to their inner voice'. One woman, working with Traveller groups within the LCDP demonstrates critical reflection in uncovered contents shared as 'culture, poverty, discrimination and sexuality and I could feel those stories had a great effect in triggering their thinking about these situations and relating them to their own lives'. Within these stories, some share frustration at attempts to apply accreditation, a theme returned later in this chapter.

\section{Collective action on external issues}

Nine percent of examples that are categorised as critical education extend the focus towards external issues affecting the lives of those involved. These stories are politically charged with respondents up-front about their radical tendencies and intentions. Further subcatagorisation can be created differentiating between activism to address specific issues such as housing conditions and benefit cuts, and more generalised actions initiated to raise public awareness offering counter-hegemony to the status quo. Sharing the latter first, one women's group came together to analyse women's identities in society before recording insights through photography, publically exhibited within a prominent city centre location and in local community centres. A men's group the respondent describes as being 'fed up with being forced to participate in a course that had no real outcomes' detail dialogic approaches that enabled them to, 
Manipulate the funder's desires and to create a programme that would develop other skills such as networking with other men's groups, creating a dedicated website and the production of e-zines that would be used to explore and highlight issues affecting other men in similar situations.

There is involvement in the stage show Revolution, a theatre production that chronicles austerity where a citizen's movement begins a chain of events which cause rebellion across Ireland. Also overtly political, one relays involvement in the Book of Grievances and Hope organised by the Spectacle of Defiance and Hope as a process where 'individuals in groups wrote down their grievances as to what has been happening at a political and economic level in Ireland in recent years and within the same context also articulated their hopes for a different and radically more equal Ireland'. These books then featured in street based protest. Another contributor explains a correlation between teaching methodologies and the establishment of a campaign for the rights of lone-parents, and a Facebook campaign that coordinated a march of 15,000 people against the closure of a city hospital.

Whilst the closure of a local hospital is undoubtedly an event that affects a particular community (abet contextualised in national policy on healthcare), other stories also deal with local issues related to dissatisfaction with standards of social housing. Four of these related to community education work that was influential in shaping Dublin-based housing regeneration projects. One spoke of this being a 'slow process of people engaging in the regeneration process with community leaders creating a climate where residents could be more and more involved'. Another relays 12 years of 'hard slog trying to bring about change'. This voice also mentions involvement in the Spectacle of Defiance and Hope project. Outside of regeneration, but housing related nonetheless, one contributor speaks about a tension between residents of social housing and the charitable Housing Association they rent from. They explain how there is resistance from the housing provider to resident collective action on a local issue, with community education offering a conduit for both parties to come together in an attempt to resolve difficulties. The research participant relays, 
Effort was taken to create a confidential space whereby the group members could express their frustration to the housing provider supervisor without fear of consequences. The aim of this was to address the lack of autonomy the group felt they had, which was needed in order to progress work around issues they wanted to engage with.

Striking about this example is the way in which the process was linked to formal assessment on a certificate programme accredited by a university. Another example of action outcomes linked to formal assessment is also shared as the creation of 'wall of issues and manifesto'. This was prepared by a women's group and its conception led to a seminar with a local politician and the wider community so a follow-up plan could be agreed.

Work with identity based communities is also revealed. This includes work with members of the Traveller community to generate a critical analysis of their communities. This analysis was then shared with other Travellers through peer-education. In a separate incident, a group of drugs-workers came together to challenge contemporary concepts of addiction, the fruits of which informed their organisational strategic plan. There is also a sharing of work with community activists campaigning for the rights of older people.

\section{Developing local services/amenities}

Seven percent of all cases shared also extended beyond classroom walls but somewhat differ from the work described above. This is through its efforts to bring about change by addressing a gap in local service provision. These were stories of specific services or amenities which did not exist prior to the group coming together and were a local playgroup for children, men's groups, services for young mothers, support groups for parents, computer classes for the wider community, a creative writing group that linked to local library services, and a local training centre. A particular theme was the work of men's groups in establishing 'Men's Sheds' ${ }^{51}$. One participant explains,

\footnotetext{
${ }^{51}$ The Men's shed association supports the development of Men's Sheds described as meeting places where men come together and undertake a variety of mutually agreed activities in order to enhance or maintain the wellbeing of the participating men. Further information at www.mensshed.ie
} 
It began as a computer and personal development course over the space of year the guys became a fully-fledged working men's committee. They held the first [names area] Men's Health Day, produced a calendar for 2013 and have acquired two buildings in the town where they have open a Men's Shed project - Brilliant stuff.

Stories about community gardens were also shared. One of these was funded through a Local Authority grant and is perceived as having ongoing benefits for the community. The contributor shares,

Many of the participants return over the summer on a voluntary basis to maintain the garden with the more-able participants supporting the less-able. There is no qualification at the end of this course but each participant, no matter what their ability, is confident and happy to demonstrate what they've learnt. There's more than just learning about gardening going on here. People from different walks of life are learning about each other, they're learning to trust the class room environment and they're learning that they CAN learn, that it's exciting to learn something new and it is fun to demonstrate that learning to others.

The final section within this chapter (section 9.4) will now provide an account of attitudes to quality, accreditation, and relationships with the State. 
SECTION 9.4 Attitudes to equality, accreditation, and relationships with the State.

This third and final section predominantly reports attitudes when community educators were presented with certain pre-determined hypotheses. These relate to range of topics including disadvantage, accreditation, co-option and the need for fundamental political change. The

use of a 7-point likert scale (as opposed to the more usual 5 points) was adopted as a recommendation from survey piloting.

\subsubsection{Inequality and disadvantage}

First to be explored are responses to statements posed that relate to concepts of both inequality and disadvantage as presented in figure 19 on the following page. 


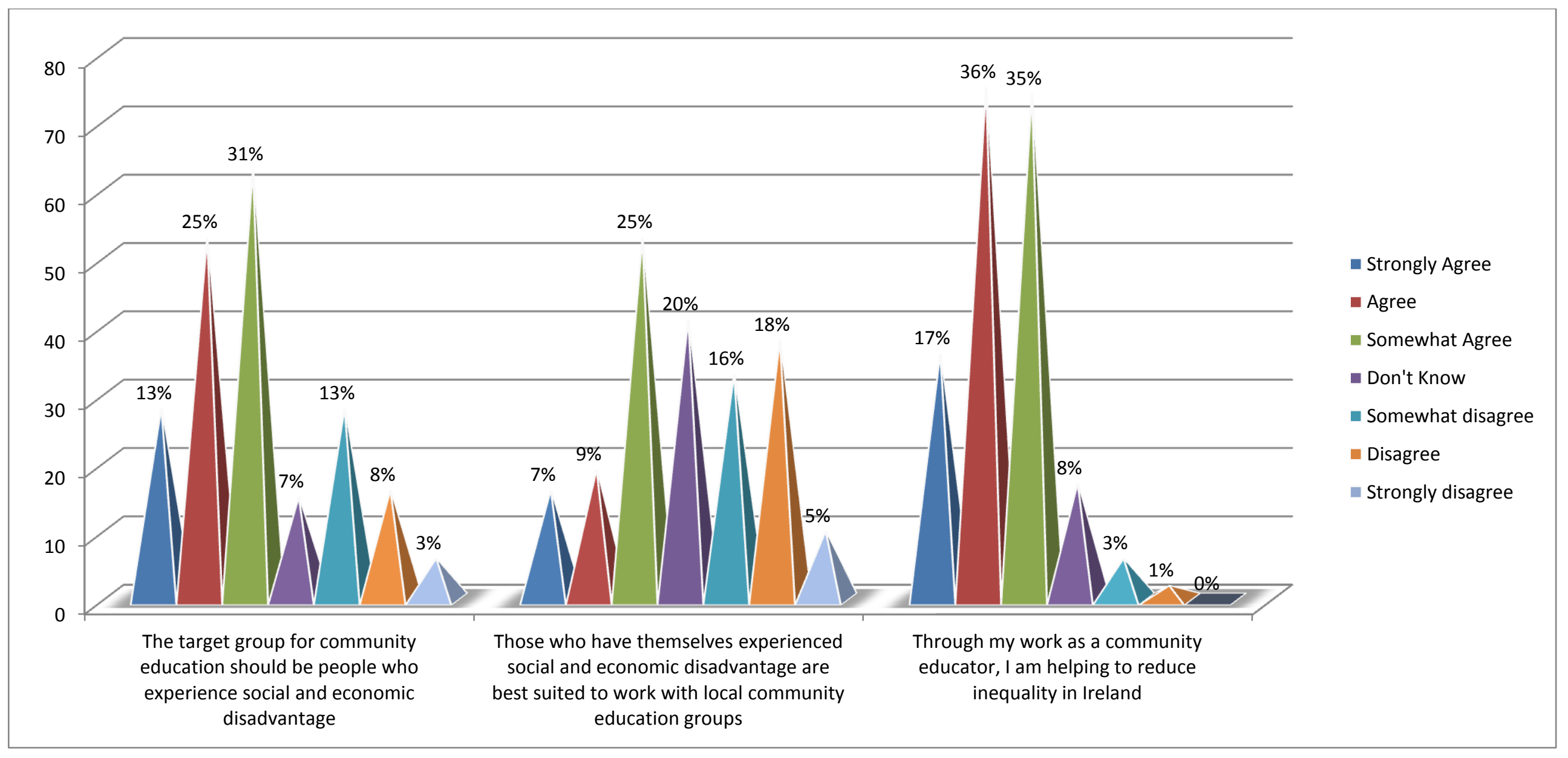

Figure 19 - Survey respondents attitudinal scales relating to inequality and disadvantage. 
The first attitudinal measurement presented relates to whether community education should specifically target those who 'experience social and economic disadvantage'. Sixty-nine percent agree with this statement with $24 \%$ disagreeing. This finding confirms strength of conviction amongst community educators towards addressing inequality. Twenty-four percent in disagreement with the statement above is a lower amount than the $37 \%$ previously ranked as preferring a universal approach raising implications for data validity. This is somewhat addressed when one considers a high level of ambiguity with $30 \%$ answering 'somewhat agree' and a further 7\% answering 'not sure' if the target groups for community education should be those who experience social and economic disadvantage. This uncertainty reminds us of the limitations of quantitative findings and the difficulties when respondents are compelled to catagorise potentially complicated responses.

People were asked if those who had themselves experienced the impacts of structural inequality through less advantaged circumstances are best positioned to work with local groups. Overall, $41 \%$ are in agreement with this assertion with $39 \%$ disagreeing. Twenty percent answer 'don't know'. Ambiguity is again present with $61 \%$ of answers ranging between 'somewhat agree' to 'somewhat disagree'. Comparing this finding with those identified as insider practitioners, we can determine that $55 \%$ of this cohort agree, compared with $33 \%$ of outsider practitioners who are also in agreement. Table 8 below numerically demonstrates this cross-tabulation.

\begin{tabular}{|ll|c|c|c|c|}
\hline \multirow{2}{*}{} & & \multicolumn{2}{|c|}{$\begin{array}{c}\text { Is your own background typically } \\
\text { described in this way? }\end{array}$} & \multirow{2}{*}{ Total } \\
\cline { 3 - 5 } & & Yes & No & Don't know & \\
\hline Those who have & strongly agree & 11 & 4 & 1 & 16 \\
themselves experienced & agree & 11 & 7 & 1 & 19 \\
social and economic & somewhat agree & 18 & 30 & 4 & 52 \\
disadvantage are best & not sure if I agree/disagree & 12 & 25 & 4 & 41 \\
suited to work with local & somewhat disagree & 11 & 20 & 2 & 33 \\
community education & disagree & 7 & 31 & 0 & 38 \\
groups & strongly disagree & 2 & 7 & 1 & 10 \\
Total & & 72 & 124 & 13 & 209 \\
\hline
\end{tabular}

Table 8 - Cross tabulation of socio-economic background and community education work. 


\section{Discussing disadvantage}

Concepts of disadvantage emerged as a theme from responses to open questions. Fifteen percent of additional contributions were about disadvantage, with most of these comments from those who disagree with the statement 'the target group for community education should be people who experience social and economic disadvantage'. One cited 'strong views that community education should not necessarily be the domain of the marginalised and socioeconomic disadvantaged'. She calls for a broader definition of community that would be more representative of rural experiences where geographically focused class division is described as 'not as embedded'. Whilst this point was raised a number of times, the majority who commented on disadvantage were those based in urban settings. One tutor paid by a VEC who is recorded as in support of a universal approach, shares 'the community is not restricted to the underprivileged, the community is everyone, the problems in the community are caused by everyone and the solutions for the community lie with everyone'. Another, working in an Independent Community Sector Organisation and strongly disagreeing with the statement that community education should target those disadvantaged shares 'education is for everyone regardless of social status'.

Some challenge the way disadvantage is determined with one urban based tutor paid by a VEC voicing,

There is a lot of hidden disadvantage e.g. self-employed people now out of work, not entitled to anything. Because you live in a certain area doesn't necessarily mean you are advantaged. The margins are getting wider, people getting lost in the middle.

Other observations are how those from outside disadvantaged communities can act as allies who can offer certain expertise, and how more advantaged participants can potentially pay thereby acting as a source of revenue through scaled fee structures. Another suggests those more advantaged can act as partners in learning with class-based cultural comparisons enriching learning environments. This is explained as follows, 
The reason I think community education should be available to all regardless of socioeconomic background is that it encourages communication and friendship between people of different backgrounds and de-stigmatises "other" (inverted commas in original).

A further point is made by an employee of an independent CDP who wonders if current approaches are perpetuating disadvantage. She remarks,

I am greatly concerned that the approach and decisions being taken in the restructuring of adult education services of the state are being undertaken without appropriate consideration for front-line delivery of community education...some of the new practices are in themselves discriminating against the communities where the education and training provisions are most needed

A university employee whose remit is community liaison also shares disagreement with the original statement commenting how 'it suggests only those who experience social and economic disadvantage can empathise and related to these issues' adding 'if this is the case, the future is indeed very bleak'.

The final question under discussion at this point relates to the directional hypothesis "Through my work as a community educator, I am helping to reduce inequality in Ireland". Just n8 disagree spread across LDCP, Independent community education organisations, and VEC employees. This statement generated contemplation for some. One VEC tutor involved in the delivery of programmes carrying university accreditation and who answers 'not sure if I agree or disagree' reflects as follows,

I find question 26 hard to answer - if the question had been 'I am contributing to the reduction of inequality in Ireland' I would have answered strongly agree. This is linked probably to a longer discussion I have with myself about where the Facilitator / Tutor stands in relation to the notion of 'helping to reduce inequality in Ireland.' This, to me, is about the idea or notion of stance rather than belief. This in turn is linked more to 'how' a tutor / facilitator works to 'reduce inequality in Ireland' rather than whether they believe in reducing inequality in Ireland. Just because someone believes in equality does make them a good community educator. There may also be question here around the distinction to be made between individual Facilitators' / tutor' methods and the methods used by their organisation.

Another tutor paid by an VEC and working just 2 years as a community educator also refers specifically to this question stating, 'answering question 26 made me think about what I do and who benefits'. She continues, 'at the moment I think that the people organising these 
community based courses benefit more than the individuals taking part in them. It seems to be jobs for the boys as such and I can't help feeling a little disheartened by it. I also feel complicit'.

Twenty-eight percent of those to 'somewhat agree' "through my work as a community educator, I am helping to reduce inequality in Ireland are previously catagorised as critical educators. This indicates uncertainty on the effectiveness of their work in achieving its equality ambitions. One adult literacy tutor illuminates this uncertainty agreeing with the statement whilst simultaneously expressing frustration at how she feels her hands are tied. She explains how her work 'can be very taken up with 'small' stuff, personal contacts, paperwork, etc. It can be difficult to look out at the bigger picture, where the real change needs to be initiated and driven'.

\subsubsection{Discussing accreditation}

As revealed earlier, over $80 \%$ of those who completed the survey have some involvement with accreditation structures with FETAC being the most likely awarding body (figure 12). Given the weight of involvement, the problems with FETAC structures that emerged in phase one, and my own researcher interest in the impact of accreditation on community education, specific directional hypotheses were posed as follows,

'The fact that most courses are now accredited is a good thing for community education', then, 'FETAC is the most suitable awarding body for community education' and 'when I am delivering accredited courses, my experience has been that this interferes with the way that I would ideally like to be as a tutor'. Responses are measured as follows. 


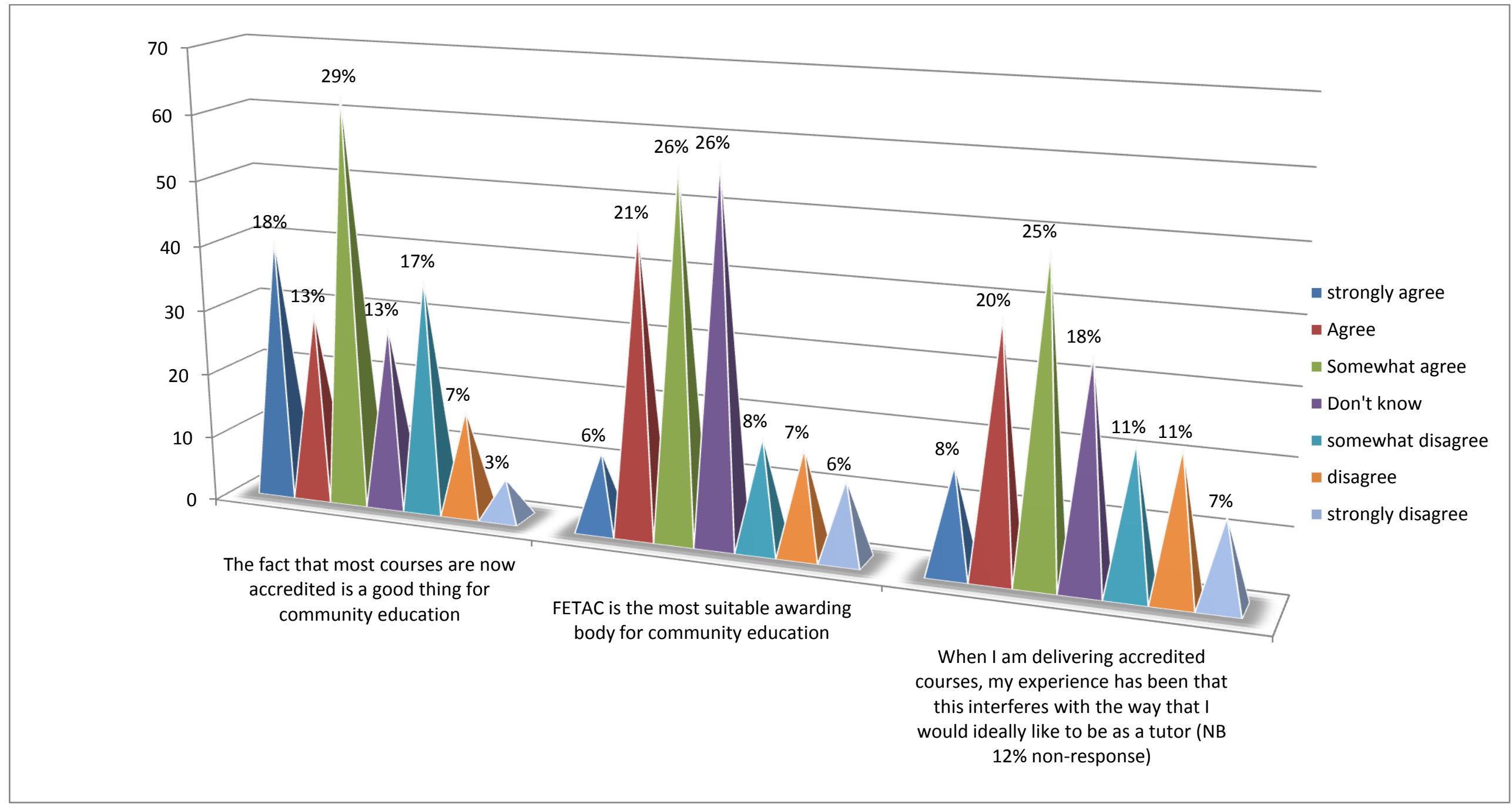

Figure 20 - Survey findings of attitudes to accreditation within community education 
Textual contributions relating to accreditation was the most common topic raised. This may be influenced by my emphasis on accreditation within the questionnaire, a point raised by a CEF who shares 'accreditation is not a core objective of community education even though many questions were offered to this section'. Demonstrating support for non-accredited work, she continues, 'CE is the only FE sector that can offer adults the opportunity to re-enter adult education without having to follow [a] certification route. It is really important to maintain this option for adults'.

When asked if accreditation is good for community education, $60 \%$ agree with $27 \%$ disagreeing with no discernible difference in likely response compared to length of time as an educator. Some qualitative contributions affirm positives. These are the power in validating learning and its importance for employment and progression within education. Wholly positive contributions were in the distinct minority with others offering support balancing this with some concerns. One participant working within the LCDP and identified as a critical educator shares 'FETAC offers an excellent model of accreditation' but tempers this with concern about financial under-resourcing of its development, something she extends to the Community Sector as a whole. Another, who believes FETAC 'somewhat interferes' with how she would ideally like to work as a tutor expresses concern about the dominance of FETAC describing it as 'the only show in town', but also asserting the potential for ingenuity believing 'it is possible to be creative with a syllabus'.

A particular hope shared by many is for the accreditation of learning to remain optional. One calls for 'equal access to non-accredited courses as there are to accredited courses' the justification being that some are 'put off' by not having a chance to initially re-enter education in non-accredited spaces. Accreditation is described by an employee of a FRC as 'important to maintain standards [but] I have a real concern that it will discourage those in the 
community who may be intimidated by the process involved'. Another, herself educated to degree level through community education programmes notes'

In community education the rise in accredited courses I believe is to be welcomed. It gives students an accessible way to climb the educational ladder and become more successful in their lives. However I strongly believe that it is the entrance courses i.e. personal development, parenting that breaks through isolation and builds confidence in people. There should be a high value put on these courses as I believe this is where the real personal growth starts to happen for people.

Another, involved in the delivery of FETAC certification and working within the LCDP delivering health-related programmes promotes the idea of accreditation but relays 'I strongly feel it should not be to the exclusion of the personal and social aspect of training' continuing,

Unfortunately this is happening more and more within community education since the introduction of FETAC and with the current changes in FÁS and the upcoming amalgamation with the VECs. Personally I foresee a situation where personal and social development will disappear, certainly in the area which I work in.

Positive attributes are outweighed by those who raise concerns, with a small number believing community education should not offer accreditation. One community educator, who works in an urban organisation that utilises FETAC, interprets accreditation as a negative development and strongly disagrees that FETAC is the appropriate awarding body. Instead she proposes, "communities should set the standards of accreditation and be the accrediting bodies (ownership) it cannot and should not be the preserve of the universities or government bodies' (brackets in original). Another expresses ideological concern about ownership and control of knowledge stating, 'the legacy of devaluing communities needs to change where the approach of education can come from communities and the knowledge stored within them is education; education is not a prescribed course'.

Another contributor whose background is from a disadvantaged community and who now working within the LCDP relays 'I feel very strongly that the most disadvantaged miss out on community education courses as the process has become more accredited focused'. She 
continues, 'If I had not had the opportunity to start at my own pace I would not have been able to progress to degree level as I had no second-level education'.

When asked if FETAC are the most appropriate awarding body a majority of $53 \%$ agree. Twenty-one percent disagree whilst a sizable $26 \%$ answer 'not sure if I agree or disagree'. Difficulties with mechanisms for accreditation are qualitatively raised with concerns about the Common Awards System (CAS) consistently aired. These are a desire for more emphasis on process, and less on results, a belief that CAS ignores the wider benefits of education, a fear it restricts the voice of learners, that it inhibits critical thinking, and that it favours individualism over collectivism. CAS is interpreted as inflexible with programmes believed to be too long. There is also concern that CAS copper-fastens the design of programmes by those outside of particular community settings, over-emphasises summative assessment and is saturated by paperwork. One contributor notes the way in which many people have gathered a number of disparate FETAC component awards that even when combined, do not result in a measurable qualification. Finally a number of responses refer to fee structures as potentially exclusionary.

The third statement presented at this juncture proposed 'when I am delivering accredited courses, my experience has been that this interferes with the way I would ideally like to be as a tutor'. A majority of $53 \%$ are in agreement, $29 \%$ disagree whilst $18 \%$ are not sure. Comparison against awarding bodies reveals $58 \%$ of those working exclusively with FETAC are in agreement whilst $49 \%$ of those accessing accreditation through universities agree. Qualitative comments include concern accreditation makes it increasingly difficult to differentiate between community education and more traditional approaches to education. One explains 'accreditation is good however it is putting pressure on our learners again. Sometimes I fear we are putting them back into a system that has already failed them. We must be careful this does not happen'. Others relay fear of alienation from those most in need 
of community education with the bureaucratised and standardised approaches within accreditation thought to potentially mirror previous negative life-experiences; a point raised a number of times. One full-time employee of a LCDP (previously within an independent $\mathrm{CDP})$ raises concern as follows,

\begin{abstract}
Although I see the value of FETAC accreditation...I am concerned about the constant and growing requirement for alignment of standards and the restrictions this puts on tutors to respond to the diverse needs of the groups involved in training. FETAC was originally envisaged as a community response to educational disadvantage. External evaluators who come from mainstream education facilities are placing increasing requirements of form filling and standardisation of training on providers.
\end{abstract}

One describes accreditation as something that can 'block the flow' of the experiential nature of much community education.

\title{
9.4.3 Thoughts on the potential involvement of the Teaching Council
}

At the time of the survey, a proviso had recently been introduced that all those working within a 'recognised school' (The Teaching Council, 2009: 17) and delivering Further Education (FE) qualifications must register with the Teaching Council of Ireland. This required all affected practitioners to hold both an under-graduate degree, and a specialist post-graduate qualification (see section 3.4.3). Uncertain as to the extent to which this would be extended beyond FE Colleges and into community contexts, a related directional statement was posed as follows. 'The need for all those delivering FETAC accredited courses to have formal qualification at degree level is desirable so we can ensure high standards'. A majority, 55\% were in agreement, with some ambiguity identifiable through the weight of response of those to 'somewhat agree'. Thirty-three percent disagree with this statement as indicated in figure 21. 


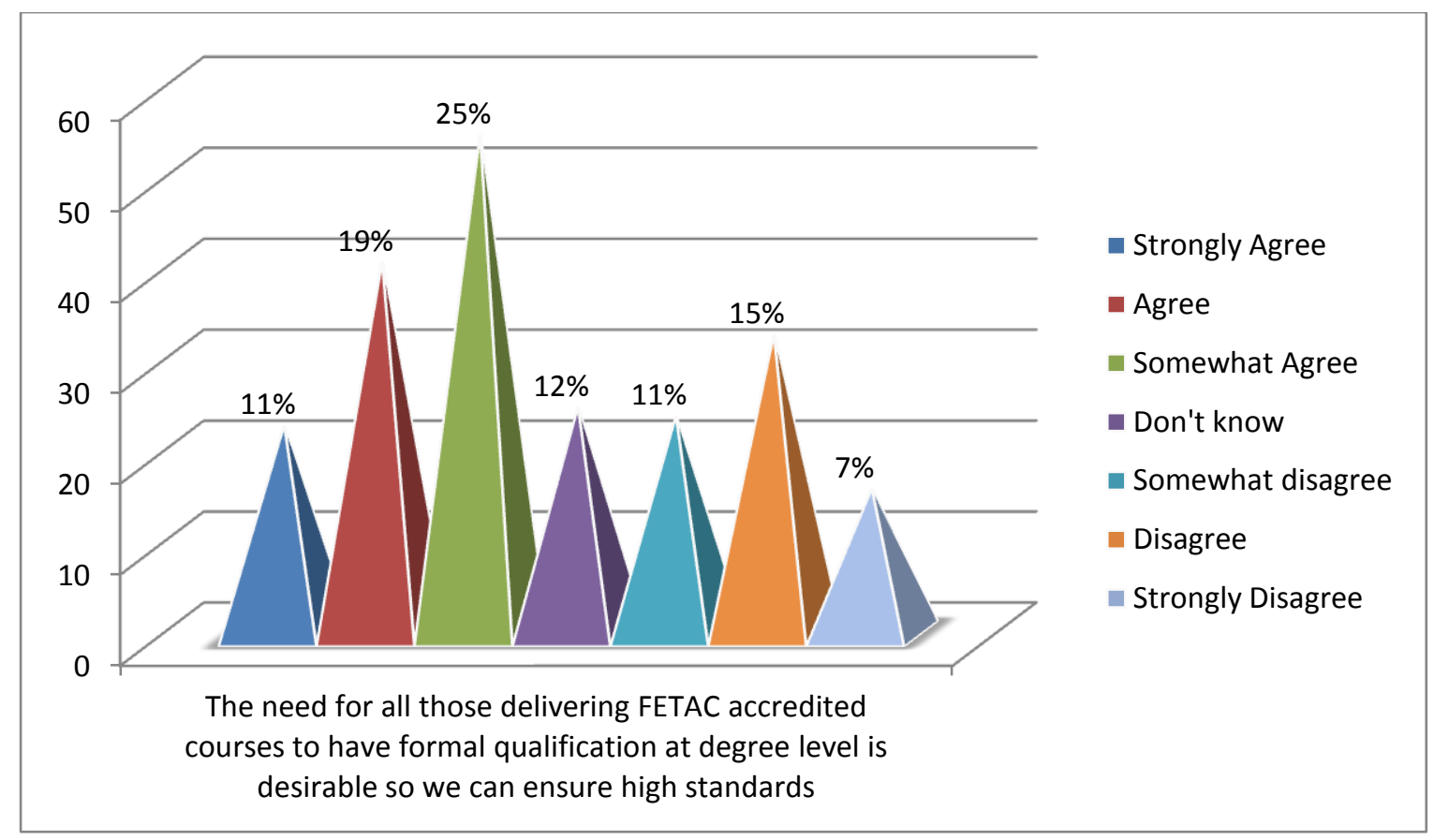

Figure 21 - Attitudinal scaling on need for community educators to hold a primary degree

For those who disagree, sentiment is often strong. Directly referencing Teaching Council enforced changes, one contributor who delivers accredited programmes within an FRC, shares 'the new regulations that all tutors in Further Ed. have to have a degree and H.Dip. will have a very negative impact on community education in my opinion'. Another fear some people express is that tutors who have developed sufficient skills through practice might be excluded from future delivery of programmes. Citing 20 years experience in the field and currently working within an NGO one shares, 'insisting tutors have degrees is both elitist in impact and disregards the ability to engage well with a group'. Aligning her own background to those traditionally described as disadvantaged, she herself is qualified to degree level. Another, a volunteer currently undertaking third level studies as a mature student shares,

I feel that by expecting tutors to have a third level qualification to deliver accredited FETAC courses now is not the right thing to do. I feel that a lot of extremely skilled tutors will be left out of the net. I also feel that this will encourage teachers into the community education sector and this I feel would be detrimental to the clients who avail of these courses as some of them have had particularly bad times in school to begin with. 
This excerpt expresses sentiment held within a number of qualitative contributions with some community educators proposing the design of a specific framework for protecting those who are working effectively without qualifications. Another offers an alternative to Teaching Council registration proposing 'as long as the umbrella organisation is satisfied that the trainers/facilitators are sufficiently trained, and have a proven record of providing satisfactory education (and all that this entails) then very successful community education can result' (brackets in original). One final contribution shares similar sentiment pointing out the importance of considering the broader skills and capacities carried by facilitators when she states,

The 'professionalisation' of the Community Sector has played a role in this as people can be hired as educators/ community workers on the grounds that they have a degree, rather than their capacities to work with others to bring about changes which are supposed to be implicit to community education and development.

\subsubsection{Thoughts on relationships with the State}

Taking its cue from a combination of my own personal opinion, influencing theoretical perspectives and inquisition from literature and policy reviews, directional hypotheses were posed designed to uncover broad based attitudes towards the State. These took the form of two potentially provocative statements the first of which read 'The only way equality and social justice can be truly achieved is through a complete overhaul of our political and economic system'. Seventy-five percent of those surveyed were in agreement with this statement, with strength of opinion strong evidenced by $34 \%$ who strongly agree. Those in agreement emerge from across all organisational types with no discernible difference in expressed socio-economic background.

Co-option is addressed through a second statement asserting 'the Irish Community Sector has been co-opted by the State and is not a force for influencing change'. A majority of $61 \%$ were in agreement with $23 \%$ disagreeing. Most likely to agree are independent practitioners, $77 \%$ of whom concur. Most likely to disagree are $28 \%$ of those working within the 
Community Sector, a further $11 \%$ of whom are not sure. Over $60 \%$ of Community Sector workers surveyed agree that their work has been co-opted and is not a force for influencing change. Sixty-six percent of those working within VEC structures and 55\% of those working within NGOs also agree. These results can be viewed within figure 22 on the following page and within appendix 5 as table D1. 


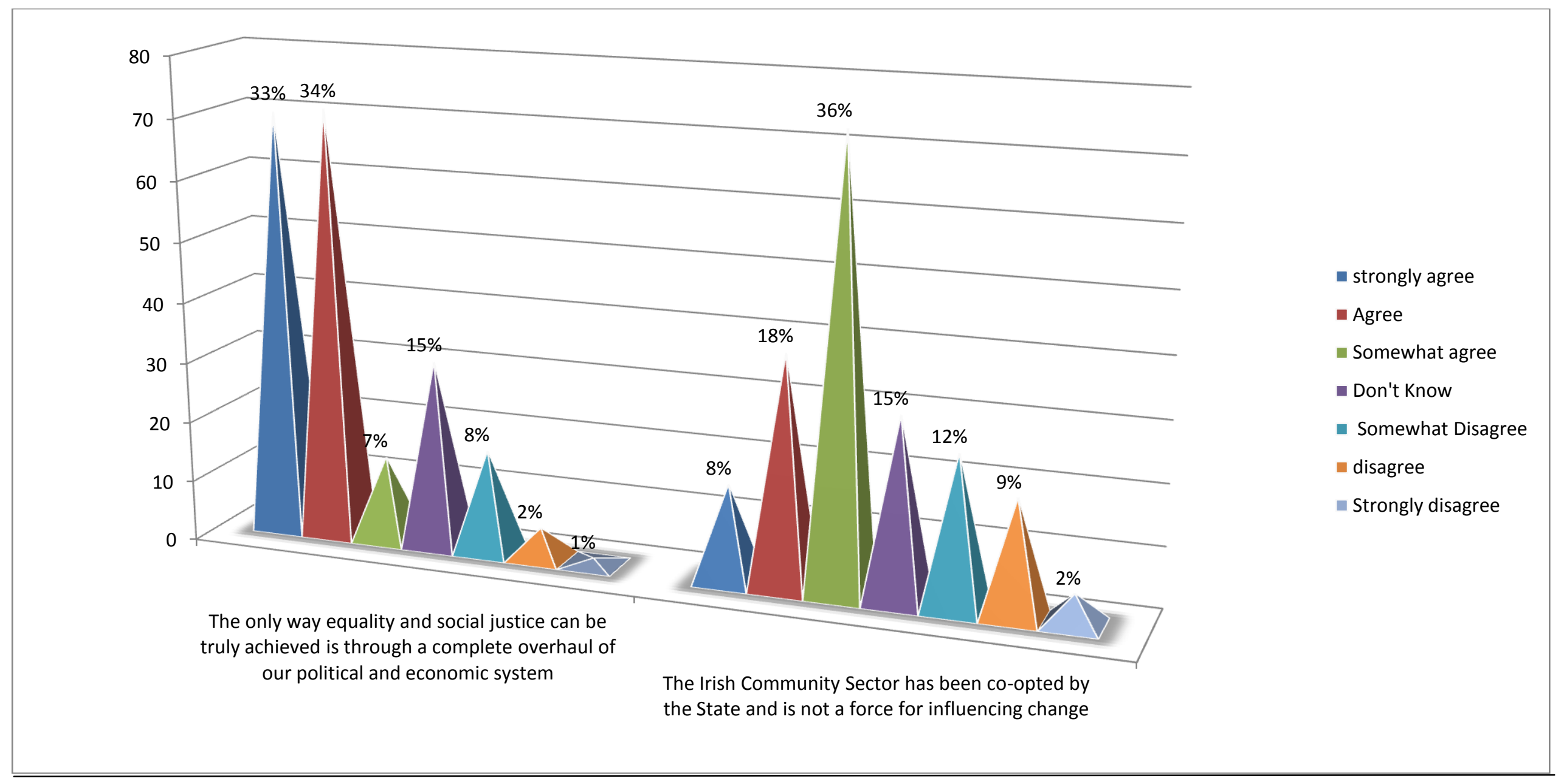

Figure 22 - Measurements on attitudes to relationships between the Community Sector and the State 
Tensions between community educators and the State were raised by over $30 \%$ of respondents who opted in to an invitation to comment further. This is the second highest topic to be raised (after accreditation). Along with concerns previously noted regarding lack of funding, other emergent strands were a prioritisation of economic over social wellbeing, and of a lack of understanding about community education. For two respondents there is direct reference to legislative changes. One expresses dissatisfaction with the Charities Bill the enactment of which it is believed will result in the sector no longer being able to lobby for change. For another, a full-time employee of an NGO the following is shared,

The value of community education as a whole is being diminished. Should the FET [Further Education and Training] bill go through as it is currently worded then both community education and adult education will fade very quickly into the past. We need to work together to ensure that this does not happen.

There were strong reactions to community education's involvement with the Department of Social Protection funded labour market activation programmes. Educators involved were unhappy with people being channelled into programmes considered inappropriate for them, and of difficulties they encounter where people have to take on assignment work they are not motivated to complete. There are also many broader comments on the employment focus of community education. One CEF relays,

The government pay lip-service to community education and local communities...the reality is this government is only interested in getting people on education and training to show they are doing something about unemployment...the only figure that matters is output in terms of bums on seats.

Another voice, who interprets community education as 'vital in shaping our society' and 'about social justice and equality', shares 'the current focus of the Government on progression for individuals into employment is extremely narrow'. A rurally based contributor working with the LCDP shares, 'the focus on jobs and training undermines the valuable work of community education.' 
One independent practitioner describing her own background as disadvantaged and who gained qualifications through community education demonstrates the depth of emotion that is sometimes present. She states,

My experience of the Community Education today is one of a dying sector, the sector has become so professionalised it is now another arm of labour activation and no longer allows for learning to occur for human growth and development. Furthermore as so many so called Community Sector groups are now driven by the funders, they have lost their autonomy. This means government departments/ funders can pull and push them around. No one wants to rock the boat as those within the sector know right well their job or the group as a whole will be gone with the stroke of a pen.

A belief that 'the State wishes community development groups to perform some social services (on the cheap) like information provision' (brackets in original) is also shared. This comment is by an NGO employee frustrated with current State framing of the work. She further shares, 'but real community development, building capacity, empowerment, equality, requires investment and community education provision, which would only serve to highlight the on-going injustices'.

Co-option was also raised by some participants choosing to comment further. Two disagree the Community Sector has been appropriated. One believes co-option is better understood as co-operation and maintains that despite State influence, the Community Sector remains 'well placed to influence change and effect transformation in Ireland'. Another believes State involvement to date has been positive, improving the administration and monitoring of funding. For those in support of concepts of co-option, community education is describes as 'totally constrained', as undermined by State actions, and of hamstrung by interference that inhibits the work. One working within an Independent Community Education Organisation that has accessed funding from the Department of Social protection shares her own internal dilemma as follows, 
Community Education has already changed and does not hold with the ethos it had formerly. It has been co-opted by the State into training. I have great difficulties reconciling this with my political beliefs as I don't really want to be training people so the multi-nationals will have good little workers until they decide to pull out. If the labour market is to benefit then I would rather it was benefited by educating people so they can create worthwhile jobs for themselves and others in their community.

Relationships with the State are also interpreted as something that has not remained static through the lifecycle of community education. One laments 'current government policies seem to be hell-bent on diminishing the gains during the boom in disadvantaged areas especially in community employment and first and second level education'. Another claims 'it appears evident they [community education and community development] are being singled out to bare the biggest burden'. Similar tensions are shared by an employee of an independent CDP, who shares,

Community education and community development have become almost wholly dependent on the State. I think that the State is becoming increasingly hostile to community development (understandably) and seem to have little interest in community education. I think that both need to seek wholly different ways of rethinking themselves in order to re-establish their independence and to survive in any meaningful form.

An additional point relates to politicking by local representatives who become involved in community work motivated by a desire to raise their electoral profiles and not to address social injustice. This carries weight when one considers Ireland's domestic political culture that incorporates an electoral system largely based on localism and clientelism (Kirby and Murphy, 2011).

\section{Other findings expressed}

Some other findings were uncovered. These were proposals for greater attention to specific population groups named as new communities, people with disabilities, and men's groups. There was concern for additional supports. These were named as childcare, affordable transport, counselling, manageable fees and hospitality, all cited as integral to community education. The need for a manageable fees structure and greater financial assistance to those outside of BTEI and VTOS frameworks is raised. One person claims many accessing 
programmes are those 'already in the system' implying a revolving door of participants with falling rates of those new to community education. There is also a worry about literacy levels in many groups, of theory-practice divisions, and of the need to more holistically promote volunteerism. In line with hegemonic notions of the important of public pedagogic spaces, one contributor speaks of a belief that the media is 'the main community educator' and is threatening practice on the ground. Another relays belief in the importance of early intervention interpreting adult education as a means to this end.

\subsubsection{Strengthening Community Education}

During completion of the survey, thoughts on strengthening community education emerged with some expressing these as hopes and proposals for the future. Amongst these are suggestions programmes be marketed more effectively, that a data-base of all providers be established, and, for two, continual alignment of practice with concepts of continuing, lifelong education. Many contributions are linked to the need for community education to offer a more overt sense of itself with some linking this to its role in connecting the personal with the political and its potential to influence social change. One part-time employee of an Independent Community Education organisation with 20 years experience expresses a need to strengthen the connection between community education and community development believing this has been weakened in recent times. Other suggestions include a greater role for FRCs, collective action through networking in order to influence policy, re-politicisation from within, and hopes there will be a decrease on dependency on State funding.

\subsection{Summary of survey findings}

Findings from this embedded survey offer much to be considered when sketching a landscape of community education in Ireland as interpreted through practitioner thoughts and experiences. It reveals a majority female practitioner presence (80\%), with $76 \%$ educated to degree level or over. Sixty-one percent are those whose personal socio-economic 
background differs from those traditionally participating in community education. These are considered outsider practitioners as distinct from 33\% catagorised as insider practitioners. Insider practitioners are more likely to have returned to Higher Education as mature students and are more likely to agree those who have similar life experiences are best suited to community education (measured at $55 \%$ where an overall agreement rating is $41 \%$ ). Amidst textual comments qualitatively reported, some express strong views there should be broader definition beyond parameters of advantage/disadvantage and that community education offers opportunity for building alliances across advantaged/disadvantaged. There is also the suggestion that current changes are re-enforcing rather than reducing educational disadvantage.

In locating practice, $49 \%$ work within Community Sector organisation whilst $30 \%$ work within VECs. Within this latter cohort, there are indications some of this work is within Community Sector organisations, most likely through allocated tutor hours. Higher Education Institutions also have a local presence measured as 5\%. Seventy-four percent are members of practitioner networks with the AONTAS CEN cited most frequently. Outside of network involvement, some report concerns of a lack of unity across practitioners.

Some discontent with working conditions are raised such as reports of pay-cuts, and expectations that people will undertake some tasks without pay. This latter finding is significant when considered within reports that over $80 \%$ work for more hours than they are paid for.

Most (83\%) of all practitioners apply accreditation to their work with FETAC responsible for up to $84 \%$ of all certification. Sixty percent agree accreditation is a good thing for community education but high numbers express discontent with over-bureaucratisation, standardisation and loss of autonomy. The bulk, 53\%, agree accreditation interferes with 
how they would ideally like to be as a tutor/facilitator, something often described through opposition to banking approaches to education that many link to school experiences. Community education is considered more participative and more person-centered with $38 \%$ believing facilitative teaching methodologies are a requisite feature of practice. Examples shared including negotiating curriculums, being led by groups and of tutor led attempts to power-share. There are concerns expressed that the potential involvement of the Teaching Council might increase the number of those working from secondary school perspectives into community education. Most (55\%) agree those delivering FETAC accredited should be qualified to degree level with those disagreeing expressing concern for insider practitioners perceived to be those most likely not to hold qualifications. This perception is not held up in this study where insider community educators are as likely to hold qualifications. However, those with qualifications are also those that are most likely to participate in research such as this (De Vaus, 2002: 59).

Sixty-nine percent believe community education should target those considered disadvantaged with $88 \%$ believing their work is helping to reduce inequality in Ireland. The most likely way this is thought to be achieved is where $45 \%$ cite individual change as the strongest requisite feature. Other requirements of community education that are named are collectivism, challenges to the status quo, being local to participants and where work is with those considered socio-economically disadvantaged. The majority philosophical tendency to be uncovered is a person-centered or humanistic approach measured at $56 \%$ (with examples of practice measured at $62 \%$ person-centered). Differences between cited philosophy and actuality in practice are not unusual with surveys generally measuring what is aspirational (Dockery and Bedeian, 1989). Recurrent humanistic tendencies are towards personaldevelopment, self-actualisation, self-directedness and a belief in individual capacities. Less than $3 \%$ believe the purpose of community education is to up-skill for employment. This is 
significant when considered against government interpretations of the purpose of community education as discussed within chapter four. Up-skilling for employment rises to $9 \%$ of examples shared. This is considerably lower than $50 \%$ of examples which relate to personal growth and development. Critical approaches to community education are also measured within $35 \%$ of stated philosophies and $31 \%$ of examples of practice. Nine percent of these have been linked to direct engagement with issues/concern outside of the classroom walls with some integrating these with accreditation.

There is unhappiness about the vocationalisation of practice and discontent with State approaches to community education more broadly. Indicative of New Public Management, there are reports of increased emphasis on outputs, greater administrative and bureaucratic demands, insufficient funding and disproportionate cuts. Dissatisfaction with the State is extended beyond community education with $75 \%$ agreeing 'a complete overhaul of our political and economic system' is required to truly achieve equality and social justice'. Sixty-one percent, believe the Community Sector has been co-opted. A desire to strengthen community education was raised by some. Particular themes were towards networking and a strengthening of relationships across providers, and a re-assertion of a more politicised vision of community education.

These key findings will be analysed further when integrated with findings from phases one and three, collectively presented as chapter 11. Findings from phase three (focus-groups and tele-interviewing) are contained within the next chapter. 


\section{Chapter ten: Delving deeper, findings from focus-group encounters}

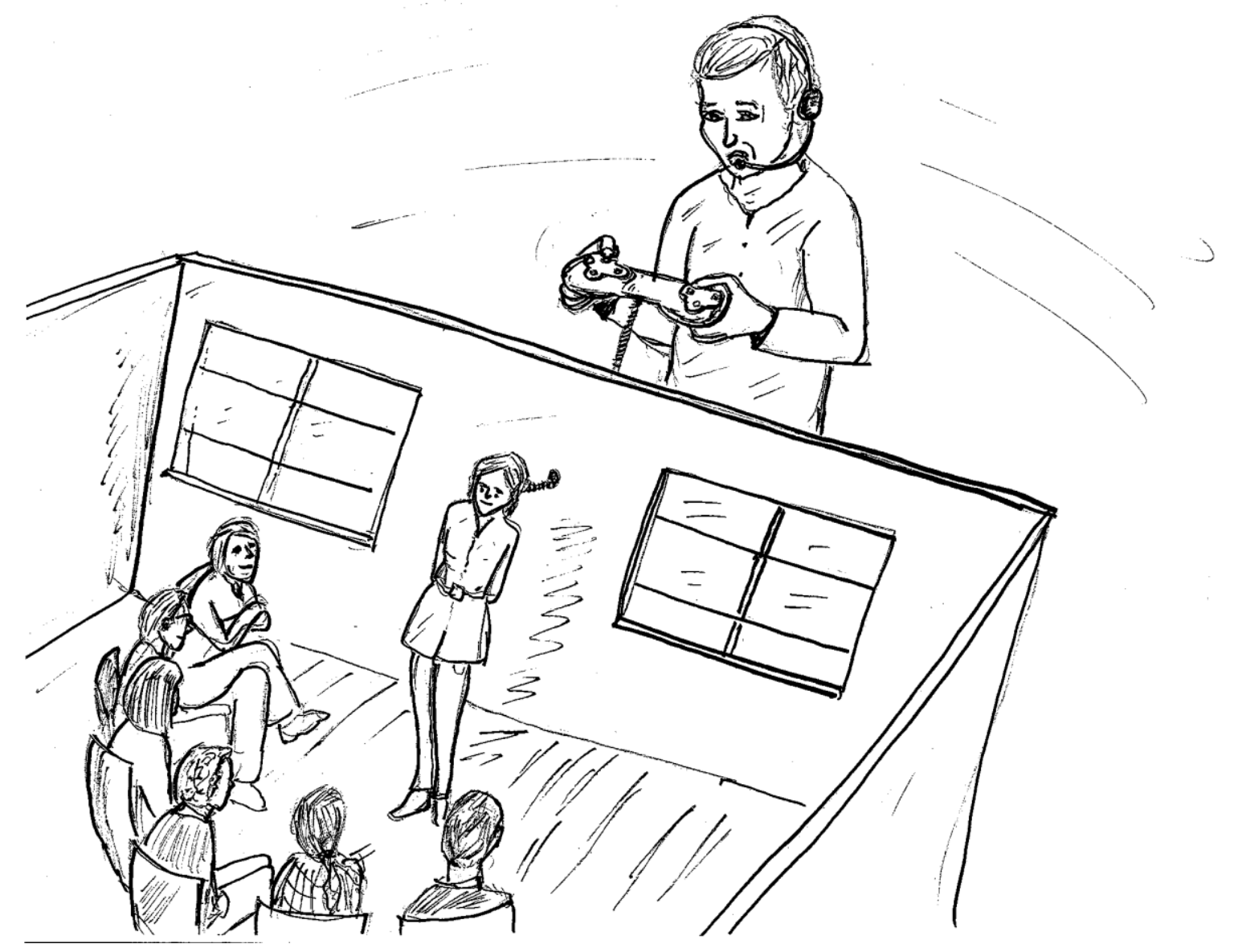

This picture depicts the code used within focus-group discussions 


\subsection{Introduction to chapter}

This chapter sets out to report on findings of eight focus-group discussions held nationwide within which 35 community educators participated. Focus-group meetings were held in Dublin (x3), Cork City, Limerick City, Naas in Co. Kildare, Waterford City and Athlone in Co. Westmeath. Each was held in familiar settings with a minimum of three and a maximum of eight attending. The chapter also reports on findings from six one-to-one telephone interviews (tele-interviews) undertaken with those unable to attend organised sessions but keen to be involved. These findings are presented within section two of this chapter. Details on recruitment and organisation can be found within chapter seven (section 7.3.3), as can attention to ethical concerns (section 7.4). Within this chapter, preparation for each group is shared, participants are introduced and findings are thematically presented.

When led by the purpose of a particular study, focus-groups can bring richness to social research. They create a more interactive encounter than one-to-one and survey methods, encourage revision and reflection of opinions spurred by inputs from others, and minimise de-contextualisation by better rooting participants in familiar surroundings (Bryman, 2004: 357-359). Focus-groups also bring additional benefit by generating a different type of qualitative data that is co-created by practitioners in collective settings. Focus-group encounters were undertaken after phases one and two and are influenced by these preceding elements of the research. In practice they allowed me to follow-up on themes after an initial analysis of findings and probe more deeply into repetitive concerns. They also offered an opportunity for participants to raise discussion not facilitated to this point.

Given their identity as educators, interacting in groups is familiar to participants. The role of facilitator is also something familiar to me, and a role I bring certain qualities to. These are particularly described through the work of John Heron (1999) as underpinned by a 
commitment to ensuring a shared understanding of process and imagined objectives, the valuing of all contributions, a dedication to consciousness-raising, and an awareness of the emotional dimensions of group-work. These factors, participant familiarity with group-work and my own experience as a facilitator, appeared to have resulted in relaxed, authentic, dialogic environments.

\subsubsection{Preparation for focus-group encounters}

Important to the Freirean influenced principles that ground each aspect of this study, the way in which I approached this phase was to treat findings from previous phases as a listening survey (Kirkwood and Kirkwood, 1989). This meant listening for the themes most prominent and that stirred the most energy and emotion. These were then re-presented to those affected through the use of a code. Codes are described by Hope and Timmel (1995: 75) as 'a concrete presentation of a familiar problem about which the group present has strong feelings'. Hope and Timmel (1995: 75) differentiate a pictorial code from an illustration and further note, 'the important thing about it is that it raises questions, it does not provide solutions...if they are demonstrations of the answer...they are not codes'.

I specifically designed a pictorial code for this process on the basis of what I believed to be a dominant theme from the survey phase. This was the weight of influence many survey participants located with forces outside the immediate learning environment for example with funders, accreditation bodies and policy makers. The code (as presented to groups) and discussions relating to it appear in section 10.1 .3 of this chapter. There were other similar features across how groups were organised. Firstly there was space for lengthy introductions, after which there was a short presentation to give a sense of the research. This included information on methods used in phases one and two, participation rates to date, hopes for the research itself, and expectations for this group-encounter. There was also a reminder to observe confidentiality and agreement that participants were free to exit the research process 
at any stage.

Each group also shared a particular structure that was introduced through planned prompts. These were introduced with a caveat that if pre-prepared elements did not resonate, they could be abandoned in favour of a preferred direction taken by the group. Following the use of a code as already outlined, the second tool was a reflective exercise designed to stimulate deeper consideration and critical thinking (appendix 7). This was completed individually and in private before inviting group discussion on insights uncovered. This reflection exercise was only used in the first two workshops. Whilst I had intended introducing it in the third (and largest) focus-group, I decided to drop this element mid-session. This was principally due to time constraints but also drawing from a sense that, as an exercise, I was unsure if it added anything to previous sessions or if it just encouraged repetition on themes already evolving. Reflecting some time later, I remain unsure if I should have introduced this tool within further focus-group meetings.

The third tool used was a diagrammatic representation of what I perceived as the main stakeholders in community education, individuals/groups, facilitators/tutors and stakeholders outside the learning environment (displayed in section 10.7). A final element was to draw participant's attention to other themes that emerged through the survey. This was done by displaying chosen quotations on walls and inviting participants to read these and, if they wished, comment in whatever way they wanted. Some statements again proved to be repetitious as organically evolving discussion had covered these themes already. These statements can be seen as appendix 8 and emergent discussion has been woven into overall findings. In some settings very little space was given to this element as we ran out of time. It is hard to know how such difficulties can be avoided in the future, or even if they should be curtailed, as each element introduced did resonate with each group. I hoped these methods would help create a critical educational space to capture experiences and responses more 
comprehensively but also encourage community educators to consider themselves as a locus for change in contemplating ways forward. Given the facilitation style adopted, some discussion was encouraged in pairs or threes (particularly in larger groups). Notes taken were gathered and drawn from as will be indicated in the text.

\subsubsection{Introducing focus-group participants}

In order to ensure identities remain anonymous, it is not possible to divulge fully the roles held by each person. To give an example, were someone employed as a Community Education Facilitator (CEF), to locate them in a particular region would reveal who they are. What is shared is if someone works within an Education and Training Board (ETB) ${ }^{52}$ (previous VEC/FÁS) structure. Another category is where someone works within a Community Sector organisation. This includes Local and Community Development Programme (LCDP), independent Community Development Projects (CDPs) and Community Education Organisations, Family Resource Centres (FRCs) and addiction projects. Further differentiation is made between those employed by Higher Education Institutions (HEIs) and non-governmental organisations (NGOs). In total eight are paid employees of an ETB and one works as an ETB based volunteer literacy tutor. An independent practitioner also details some work for ETBs alongside Community Sector work. Nineteen are drawn from the Community Sector working within Independent Community Education Organisations, the Local and Community Development Programme (LCDP), a Family Resource Centre (FRC), a project supporting those with addiction problems, and an independently funded integration and intercultural group. Two from within this Community Sector grouping are volunteers. Five work for HEIs whilst the final participant works for a Dublin based national NGO, their role being to provide locally based education and training.

\footnotetext{
${ }^{52}$ By the time focus-groups were carried out, VECs had been merged and amalgamated with FAS to form 16 nationwide Education and Training Boards (ETBS). Further information on this is contained within chapter four.
} 
Nine were men and twenty-six were women. More lengthy introductions to each participant are available as appendix 6 . Findings have been grouped thematically utilising a constant comparative method as detailed within chapter seven. It is to the reporting of these I will now turn, beginning with further explanation on the use of a code.

\subsubsection{Using a code in focus-group encounters}

When discussing how qualitative researchers interpret findings, Maykut and Morehouse (1994: 122-3) encourage the skilled researcher to weave descriptions and quotations into a narrative, whilst cognisant of their own interpretation of what is being said. Given the way in which we interpret much meaning through experience, a researcher cannot be certain of a match between what they hear and what is intended to be heard. Introducing a code adds further dimension in ensuring intentional weight of meaning is elicited and ethically reproduced by the researcher. How do I know if a code is achieving its desired function, to present in a challenging way, that which is being talked about haphazardly. Perhaps it is $m y$ dominant interpretation and therefore what I hear, rather than what others intend me to hear?

One indication Hope and Timmel (1995: 76) give is the way in which 'we recognise a generative theme has been tapped when a group suddenly comes to life'. This was the case with each group when presented with the pictorial image overleaf with strong reaction commonplace. 


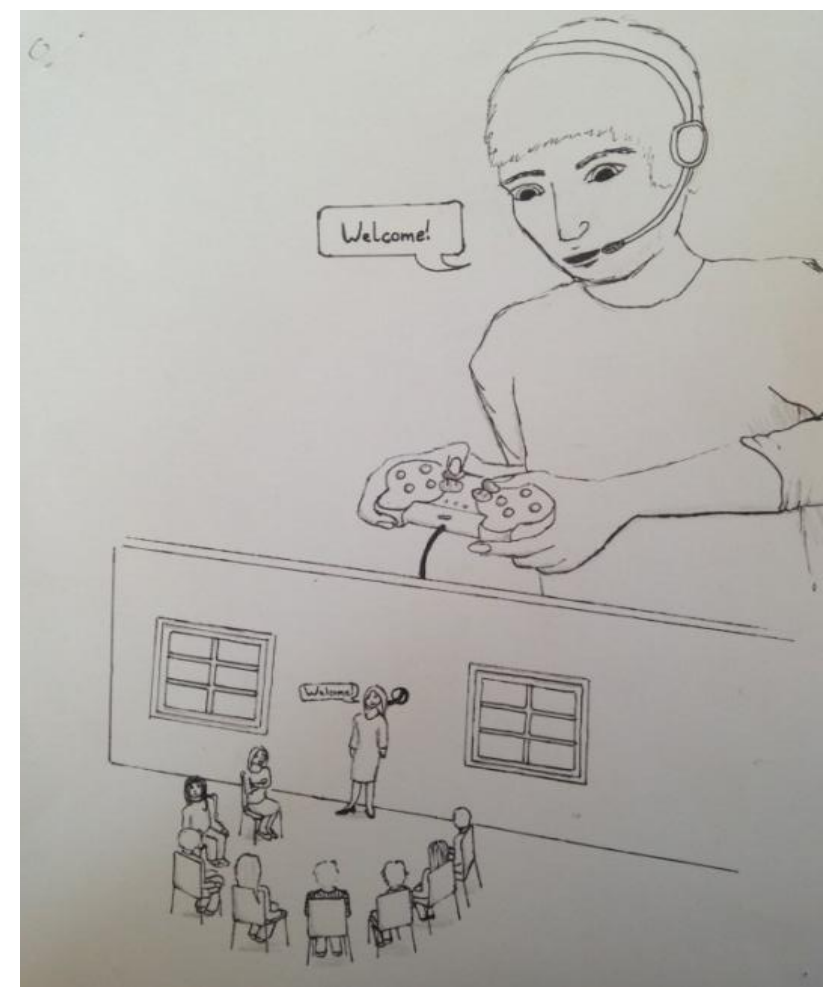

Figure 23- Illustrative code used in focus-group inquiry

De-coding was facilitated along suggested stages of what participants see, relating this to real life, first analysis and related problems and action planning (Hope and Timmel, 1995, 77-8; Sheehy, 2001: 19-20). Rather than follow these rigidly, I followed the flow of the group, whilst keeping within the boundaries of the theme under discussion (Sheehy, 2001: 20). As the sessions were just two hours long and part of a research project rather than on-going praxis oriented work, the action planning phase was one of sharing suggestions without collectively agreeing or concretising if and how these might be advanced. As the code was presented early in each focus-group discussion, the strength of the theme and its collective resonance is likely to have shaped much evolving discussion.

De-coding; what do you see?

Each group was invited to comment on what they see in the picture. Reaction overleaf resonates with many responses across groupings. 
[Laughter when the code is circulated]

What is happening in the picture? (Interviewer)

She seems to be stuck to the wall; she is not allowed to move (Waterford, participant 1).

She is the puppet (Waterford, participant 2).

There is such control (Waterford, participant 3).

And the controller is male and the facilitator is female (Waterford, participant 1).

I wouldn't say that [laughing] (Waterford, participant 3)

That is speaking as a feminist [laughing]. It looks like it is within an institution, the space, and you are just putting chairs around but it doesn't look welcoming at all even though the chairs are in a circle (Waterford, participant 1).

Yes, it looks like it should be participative but it is actually not (Waterford, participant 3).

Even the equality isn't there with the facilitator standing up (Waterford, participant 1).

So you are seeing a facilitator who is standing, a group who is sitting, but it doesn't seem to be a particularly warm space and they, the facilitator is being controlled, is that right? By either a male, or maybe not, but something that is bigger and outside of the room (Interviewer)?

The structures, even to the script being provided...the size imbalance really gives me a sense of the scale of that control (Waterford, participant 2).

Immediate reactions not uncommon in others settings included 'very good, very good', 'wow', and 'that's me'. One shares 'I really like this picture. It reminds me of when I was a kid this was how I thought the world works, we were like little ants and there was bigger people controlling what we did. It is like education is controlled by other outside forces that are much bigger' (Kildare, participant 2).

Recurring reactions were an emphasis on control, the image of puppetry, and disparity in size between the person with the controls and the facilitator/tutor in the group. One wonders if 'maybe that person at the front is not able to work from their true soul because somebody else is pulling the strings or working them' (Dublin-North, participant 3). Another shares 'it's a very rigid stance and I interpret that as a lot of stress, tension, I have certainly felt at times my back is to the wall, also if you look at the feet it sort of implies a kind of uncertainty, the stance, she is not quite sure of the ground she stands on maybe' (Dublin-Central, participant 
2). A sense that the tutor in the picture feels 'powerless', 'frustrated', 'quite exposed in some situations' with her back 'literally against the wall' is shared in the Limerick focus-group. Other discussions on the relationship between the facilitator and the person behind the wall are also shared including observation from a number of groups that the learners depicted seem unaware of the presence of an outside force as captured below.

I think there is something about being the front or the face of the organisation, like this person is the person that people see, they are the face of the organisation, they are the public face of the organisation, nobody sees the person behind and we all have a habit of being led by the person that can't be seen but also the person on the ground is the person who delivers the message but the person behind the scenes is the person who can't be seen or can't be 'got at' or 'accessed'. (Limerick, participant 2)

On two occasions people question the amount of control the tutor in the code thinks they have over participants, the suggestion being this is not as much as the picture might depict. In Dublin-South, the following exchange occurs;

The thing that comes to mind is the whole idea of banking, giving people a rota to learn. But that is not to say that the people don't disagree with what they are getting, there doesn't seem to be anything that seems passive about the group, lots of times people are quite but their brains are going at 100 miles an hour so there is always scope for that (Dublin-South, participant 3).

They strike me as, you know, like they look like they [group members] are fine. It is only we who have the perspective of what is going on behind the wall; they don't seem to be aware of that so the person who really has my sympathies is the tutor (Dublin-South, participant 8).

Concern for the larger character in the code is also voiced and how 'possibly that person [is] being controlled by somebody else outside of the room [who] may themselves be controlled by others limited in what they can do' (Kildare, participant, 2), a point raised elsewhere also.

An alternative perspective is also presented on two occasions (Dublin-North and Kildare) with the controlling force interpreted as benevolent and supportive. In response to this observation by one, another group member responds as follows, 
Well the work that I do...in fact a system like that would be a great help... It is a drop in and it is voluntary it doesn't really have an authority (Dublin-North, participant 4).

So to have this kind of support structure behind you? (interviewer)

Would be a benefit (Dublin-North, participant 4)

Ok, thank you (interviewer)

Because I am not employed (Dublin-North, participant 4).

Similarly, someone working as a freelance community educator/consultant therefore independent of organisational structures notes,

I have a funny one in that sometimes there is a great advantage when you are tapped into the system because when you do things there is a back-up, there is a status and I am often struck by the way that because I am freelance I am quite separate which apparently is very free but it is also very limiting and I am often struck by that (Kildare, participant 3 ).

Another, almost equally striking and recurring reaction is observation on relationships between the facilitator/tutor and the group. The way in which the tutor was standing whilst others in the room were sitting is repeatedly commented on, described by one as follows,

I mean I won't repeat the controlling business because that is there and it has been spoken about. I also think that the tutor is standing and they are seated so that puts, there is a distance there. The circle isn't complete, it is a semi-circle...I think that is what struck me, the distance between the tutor and the group, it looks as if it is a teaching situation as opposed to an education setting where you draw people out, and you draw them out by being with them. Now I know tutors have to stand up to write on boards, take down comments but I prefer a situation where the tutor is in the circle. (Dublin-Central, participant 4)

Other things seen in the code were a sense of resistance by group members and a perception there were more female than male participants. In Cork there was discussion on the increasingly dominant influence of technology in the social and economic world and how this can disenfranchise many of the people community educators work with.

\section{Relating it to real life}

Following descriptions of the code itself, facilitation encouraged people to re-examine the picture, this time connecting conversations more overtly to lived experiences. With varying 
degrees of intensity, people overwhelmingly felt their work in community education resonated with the image. Specifically named as those in control were voluntary boards of management who have compromised an original ethos under the constraints of funder demands, FETAC (named within each focus-group), the Department of Education and Skills, FÁS, the Department of Social Protection, the State, Pobail, 'policy drivers' both national and European and the Troika (see section 1.2.1). In reaction to group members naming government departments, one respondent shares,

The chap with the headset to me represents other people as well, for example the Troika and their influence which seems to be coming all the way down now. From my own experience, this year for example I was told that I would have to demonstrate a $50 \%$ progression rate which is completely unrealistic but I was told 'take it or leave it' basically, what do you do? (Dublin-South, participant 2)

This contributor also makes the point that even in this post-Troika time, 'they will still be controlling it indirectly because they have already embedded their agenda and the changes that are happening now are irreversible changes'. In Athlone, one locates the controlling influence within European contexts stating "when I look at this and the person holding the controls, to me it is an EU directive' (Athlone, participant 2).

As indicated earlier, the code continued to provide a backdrop for discussion within groups which will now be thematically presented.

\subsection{Uncomfortable bedfellows: relationships with the State}

Much discussion related to relationships with the State which itself will be thematically reported.

\subsubsection{State funding relationships}

Reductions in State grant aid was raised within each focus-group. Stories are shared of difficulty paying utility bills and affording sundry items such as tea and coffee, and of classes being cut short in order to cover costs. There are stories of people working significantly 
longer hours for less wages and cases of funding only being provided for accredited programmes. This included an example of a voter-education programmes being cancelled due to difficulties securing funding. A sense of excessive paperwork when drawing down funding is also shared, even where grants are small, with additional challenges identified for issue-based and identity-based groups when sourcing funding.

\section{Personal impacts of funding cuts}

Discontent with working conditions as a result of funding cuts to host organisations is also raised across focus-group settings. Issues included expectations that people would work without pay, something influenced by the volunteerism streak within the Sector, the quality of employment contracts and reports of recent wage reductions. Some also believed such conditions are being implemented with little difficulty given the hierarchy of esteem between schools/university based teachers/tutors and Community Sector teachers/tutors.

\section{Impacts for participants}

Within three settings there are examples shared of financial assistance for learners being cut thereby hugely reducing their ability to access education. In Dublin-Central, this is expressed as specifically affecting members of the Travelling community, as noted in the following comments,

Is there anything else anybody wants to say, which can be completely different to what we have been discussing (Interviewer).

I have a big concern...historically Travellers have received a payment for engaging in education and there is an expectation that that will happen. And I have read this in a number of places that people are trying to get away from this idea, that people would get a payment. But education costs money, there has to be, I can't remember the name of the guy I read but he talks about 'extrinsic motivation' and if you don't come from the background where education is valued as a long term investment and there is the money there to make that investment, I am actually very concerned that people will just not engage. I am very concerned. I don't care what brings people in once they come into the setting there is so much that can be done and that can happen. So that is one of my big concerns at the moment. (Dublin-Central, participant 2)

Where participants are receiving payment for programme attendance as part of a condition of welfare, another (in another setting) describes this as inadequate as demonstrated in the 
contribution below,

One woman said she was putting diesel into the car to get to the course, and she was in tears because she said she was under pressure at home because her husband was saying 'we haven't got this money out of our payment' but the threat was, they didn't get paid until the end of the course so they had to come up with the childcare fees, the diesel or petrol fees or whatever they needed to get through the course and they didn't get payment until the end, and the pressure, it was like a time-bomb in the homes...it was just volatile...(Athlone, participant 2)

\subsubsection{Vocationalisation and conditionality of participation}

A particular theme to emerge strongly and one which also features within survey findings related to engagement with the Department of Social Protection (DSP), something mostly believed to be problematic. Describing an interaction where this participant was invited to carry out an evaluation with a group where people attended by referral from Intero, therefore as a condition of welfare payment (see section 4.4.3), she shares the following,

I couldn't imagine how true to life this is [the code]... oh my God it was frightening. We went in to do maximum an hour, we expected to be in and out in a half an hour, you know, just get their feed-back and see what they think. Two hours later there were people in tears, there was so much going on in that room it was frightening. And we suggested that they collectively write a letter to the minister explaining their concerns and what the impact was, because the impact was emotionally, psychologically, on these people, and the detrimental things that were going on in their families as a result of them leaving their homes to come on a course, some of them had third level some of them had basic literacy, they were all on one course. (Athlone, participant 2)

This is not the only comment to emphasise the impact of this is particular policy directive with compulsory attendance eliciting much emotion for some. In Dublin, one explains the challenge faced as follows,

When you go back to mentioning the Troika, government direction, they are 'up-skilling' people who are long term unemployed and disadvantaged groups in our communities are now being forced to engage in training to get their social welfare payment. So it is kind of a contradiction, in one sense the tutor doesn't really have as much control as the students coming into the room because if the student is not happy and doesn't engage, it would affect everything, it would affect your reputation, your ability to bring that learner through, it would affect your figures, pro rata payments, and really what has happened in the last few years is the total commodification of unemployed people. They have become a commodity for the education awards. (Dublin-Central, participant 1)

Concerns were also repeatedly raised about the level of paper-work involved in maintaining 
relationships with the DSP. In one focus-group, a single participant praised the involvement of the DSP and the conditionality of welfare linked to community education programmes.

There was also apprehension about the vocationalisation of community education as a whole with all funders increasingly insisting on a measurable connection between programmes and employment based outcomes. One notes, 'the big brother is the policy drive...the policy context is absolutely around certification and labour market activation and if you can't make direct links between your work and somebody getting a job within a very short period of time, what you do?' (Limerick, participant 1). Another participant remarks on how VEC (now ETB) based community education programmes are 'under this immense pressure to be professional and to go with this agenda of labour market activation'. This point is extended to explain how 'there is so many other programmes in the VEC that lead to an accredited award and a job at the end of the course and that community education is almost being forced to tweak its approach to satisfy this agenda' (Athlone, participant 5). Elsewhere, the detrimental impact for those not seeking employment is described as follows,

It's all about numbers and bums and seats and how many people get jobs and it is moving very much into enterprise and pre-enterprise and bringing people closer to the labour market and for a lot of the people I work with, participants in our programme, their working life is over. Some of them by choice, some of them because they hit retirement age and they have had to leave work and, again, not for everybody but usually somebody in their eighties is not going to be out looking for work and that is the reality of it. And they might, and fair play, but I don't think it is a reasonable expectation to have, and that would be our area of discord. (Kildare, participant 4)

Concerns relating to the Family Support Programme were raised in both Waterford and Limerick specifically a shift from a role of support and/or emancipation, to one of monitoring and control. One frames this as follows,

suddenly you have this whole agenda of case-studies with families, we could be asked to pick up bits of this which changes everything, the way you work, the way you approach people, everything used to be voluntary now somebody might be told to take that course there, like that is all dictated outside. So suddenly you are arguing with them, 'this won't work because this is how we approach things' and, you know, they use us because we are on the ground with the communities, and we have the contacts. But like 'if you make us do it the way you do it you will destroy what we have' (Waterford, participant 3). 
Stipulations being imposed on literacy services are also shared. One explains, 'I think it is $25 \%$ of our new intake has to be long term unemployed (Cork, participant 1) a point picked up by another who adds,

And that a percentage of courses must be dealing towards getting employment. But that $25 \%$ doesn't include parents at home, it doesn't include people with disabilities, it doesn't include you know, those two particular groups or people in employment who need supports, or older people who are not going to be ever going back into the workforce. (Cork, participant 2)

\subsubsection{Perceived Reasons for tensions with the State}

Reasons for disparity between State/funder intentions and the intentions of practitioners are discussed. One shares 'I think that there is a great lack of understanding of where people are coming from, I mean most of the policies, it is a class issue as far as I am concerned most of the policies etc. are drawn up by middle-class people who just simply don't understand where people are coming from' (Dublin-Central, participant 2). She continues,

To them [policy makers] education is a long term investment, they have the money and all the supports and there is whole culture around education. For people who are marginalised, there is much more immediacy in their lives and there has to be some kind of an incentive for them to engage in education.

Changes are also linked to co-option. An example of such discussion is shared below,

I think the social change bit in what happened even before the financial crash, the suppression of dissent, the cutbacks in The Equality Authority, Combat Poverty being put into social welfare, all of those things for us really said where the State was coming from (Waterford, participant 2).

So before the recession? (Interviewer)

Oh yes,...they [the State] were so anti-community development, they represent those who wanted community development to be service delivery whereas all of the work that had been going on since 1988 and the bottom-up approach and the social change agenda, I mean just look at the way that has been picked off, bit by bit. (Waterford, participant 2)

Another in the group picks up this point framing it as resistance to collectivism specifically identifying the CDP programme expressing surprise at the ease at which, 
The whole thing was wiped out, like very deliberately, very deliberately I think. That is how I see it anyway. There is a huge agenda that you are up against, that individualisation, it is huge and deliberate' (Waterford, participant 3).

Similar sentiment was expressed in three other groups.

\subsubsection{Managing imposed changes implemented through policy}

Whilst repeated concerns about the influence of those 'outside of the room' are raised, there is evidence of defiance. The manipulation of funding is strong to emerge, often used in a way that better matches community need and therefore not as funders intend. One explains,

Now that I am a tutor and also a funding applicant I can say whatever is necessary to get that money and I will teach whatever the group want in that classroom, but I am a complete fake, you know what I mean? I will falsify everything to make that happen. (DublinCentral, participant 1)

Another shares similar tactics in commandeering available funds as follows, 'I would also be watching what funding is coming in and you are trying to match, and you are looking at, can that bit fit here, and can I make that bit fit that, something like that, or, if we twist it this way it could match' (Waterford, participant 3). There is also discussion on how philosophical tendencies can influence the direction of particular work, again funded for one function but directed another way. One example is of funded English conversational classes where one shares,

Looking on that with your Freirean lens you are going to see other kinds of things coming up and they are getting discussed and people are getting confidence...to have a critical reality of Irish life as well, to be able to hold all that so they can read the situation well and help people to be able to work out where they want to go. Not to limit it. (DublinSouth, participant 5)

Other discussion includes lobbying work, most notably that co-ordinated by AONTAS, named in five settings. Someone who took an active lead in co-ordinating collectivised consultation with QQI on changes to accreditation frameworks pessimistically notes 'does it actually make any difference or does is slightly round sharp edges but actually do nothing to the actual shape of the object'. Another, within another group setting also shares a sense that 
consultation process with QQI had not worked.

There is a sense elsewhere that efforts to shape policy can be successful. Two CEFs in different settings refer to a recent position paper on community education circulated by the Department of Education and Skills (DES). One speaks of being 'kind of flabbergasted' when proposals sent to the DES were accepted continuing "we thought "my God, they listened to us", so it is the value of having something written down that you can come back to that is supportive'.

However, a stronger theme to emerge was a sense of paralysis within groups preventing them from taking action to alter current circumstances. In contemplating why, the co-option of the Trade Union Movement, apathy, the forced closure of the CDP programme and job insecurity are all named. In response to a probing question on the implications of working in harmony with how people would ideally like to work (q2, appendix 7 ), some overtly discuss risk to their employment should they stray outside of current parameters. 'I'd lose my job' shares one (Limerick, participant 2), from another 'you wouldn't be employed [the group are laughing] (Limerick, participant 3), 'it would be very stressful (Limerick, participant 4) and 'I

just wrote stress' (Limerick, participant 1). Similar discussion evolves in Kildare', 'I know if I was to try to work in a way that I feel I should work, I am relatively new to this, I reckon I would be out the door in the morning, seriously' (Kildare, participant 1). Another adds, 'I mean just listening to what you (referring to Kildare Participant 1) said there, I thought well I'd just have to leave my job [laughing], but that is just not practical so the trade-off is the piece about, you know, we don't live in a utopia, that is the balance, the trade-off' (Kildare, participant 2). These are the only two groups where this question was directly posed.

\subsection{Relationships with accrediting and regulatory bodies}

Discussions relating to FETAC (now QQI) emerged. Some admonished relationships between educators and the accrediting body, with a particular concern relating to the 
implementation of the Common Awards System (CAS). Competing implementation models emerge in this study depending on the employer organisation. Relating conversation back to the code, a sense of control is discussed in Dublin-South as follows,

There is definitely manipulation going on and both of us [referring to participant 1] identified with this person [tutor in the code] where we are on a very short leash and you basically have to get them through the learning outcomes, all the FETAC courses are very vocational and focus on, like when they get up to level 3, level 4 they all have a work experience module, they are all designed for employability. (Dublin-South, participant 2)

Another voice concurs 'I completely agree with you because the FÁS version of FETAC is worse than others' (Dublin-South, participant 7). She distances this approach from other users of FETAC adding 'I mean it is possible to write your own modules in a way that are a little bit more holistic' but tempers this by sharing 'but it is a horrendous process and I think the new system won't improve things much'. The relationship between FETAC and FÁS is referred to by others also, specifically the way in which some ETB tutors have no room for manoeuvre forced to work from pre-set lesson plans, class based exercises and pre-designed assignment briefs detailed as a legacy issue from previous FÁS programmes. Within three groups, people spoke of how they sometimes give participants the required answers to short in-class exercises, exercises they believe hold little pedagogic value but are insisted on by ETBs. One explains how you can then, 'get on with the real learning'. There are other examples of difficulties with rigid interpretations of FETAC approved programmes shared. One notes, 'in a real class [comparing it to the code] I would apologise to the trainees for what I have to do, you know the silly little assignments' (Athlone, participant 4). Another group member concurs, adding she would explain to people that if 'you want to get your award this is what you have got to do' (Athlone, participant 1). The conversation continues, 'they [those engaging in community education] are at the bottom of the line completely now. We are trying to still include them and remember their needs and what they want but we are not allowed now because they are totally forgotten about' (Athlone, participant 4). 
Difficulties with FETAC (now QQI) itself rather than how it is interpreted by certain employers are also raised. These concern the way in which component (minor) awards are discouraged, the rigidity of programme descriptors, over-prescribed learning outcomes, excessive paperwork, the over-assessment of modules, mismatch between vocational learning and community need, and its suitability to banking approaches to education over democratic, dialogic learning. The challenge of maintaining a participatory, group-led approach is raised in each of the eight settings. One conversation goes as follows,

I feel that the pressure that is put on participants from the onset and the amount of outcomes that students must meet in order to gain any kind of accreditation, it is enormous. And if you put it beside a certificate course or your first or 2nd year in college, there is no comparison, you are strangled in FETAC (Athlone, participant 2).

It is over-assessed isn't it? (Athlone, participant 4)

It is, and the concern I would have is that most people as far as I am concerned who work in the community education sector, a lot of them are dealing with FETAC and to me most people, as I said earlier, I feel that it is more than a job, it is a vocation people have a lot of passion for it and I feel people in the sector who are tutoring are activists, they are critical educators and they are trying to do that and at the same time to conform to the strangling process that is involved with FETAC and that is the only way I can describe it. (Athlone, participant 2)

As with previous findings, there is also much support for the use of FETAC accreditation. Of benefit were the recognition of work accreditation brings, the increased opportunities it extends, and the pride in which some learners take in receiving awards often for the first time. There are also examples shared of creative approaches to FETAC modules, adapting these to the needs of a particular group and setting. One participant challenges others in a group who seek to locate FETAC as a controlling force 'outside of the room'. This contributor notes a historical bottom-up demand for certification believing difficulties are often to do with the interpretation of FETAC rather than the structure itself. She does raise concern over the way in which QQI are approaching relationships with community organisations noting,

FETAC are pretty much throwing small providers out the door by saying to a provider that anything you have done previously, for credits to be transferable you have to put it into your common awards system. Small providers can't do that so it is a kick in the face for access, transfer and progression as far as I am concerned' (Waterford, participant 2). 
This expressed concern, that smaller groups will struggle to maintain an ability to accredit themselves through their own quality assurance mechanisms, is also raised in Limerick, Cork, Dublin-North and Dublin-Central. Within one group, it is directly linked to reduced staff numbers within QQI thereby limiting QQI's own internal capacity. Significant space is also reserved in some groups for discussion on the squeezing out of non-accredited work in favour of accredited programmes.

\subsubsection{Involvement of the Teaching Council and Community Sector professionalisation}

Discussion on the need for people to have qualifications to deliver FETAC accredited programmes emerges in some of the focus-groups. Some people question whether a qualification should be sought at all, and a theme that emerges is the need for experience to be held in higher esteem than is currently the case. One way this is expressed is detailed below,

To me, I don't give a damn or not whether you are a qualified teacher, I just want you to be able to do the job. Many times it is not about qualifications, it is about what we are going to do, how we are with people. It is not the amount of learners we are able to carry that makes you a good teacher'. (Dublin-Central, participant 4)

Another personalises it to her own organisation explaining,

The whole thing of having to register with the Teaching Council, that was another block and I was the only one qualified within [names organisation] to do that, and that put a lot of pressure on me, and it meant that other people can't tutor and they don't have the piece of paper qualification. They might have 20 years experience and be absolutely fantastic but they don't have the piece of paper. (Dublin-North, participant 3)

This last comment reveals how some organisations are already working to the assumption that Teaching Council requirements will be extended beyond Further Education Colleges. This has not been confirmed at the time of writing, though a trend is emerging where new positions advertised cite Teaching Council registration as a requirement for application.

Amidst defence of Teaching Council involvement by another participant who interprets it as a way to 'increase the quality of teachers' (Dublin-North, participant 2), there is agreement that 
there should be proviso for accrediting those with experience. This is illustrated in the following comment, 'I think they took a shot-gun to people's lives, you know there is a lot of people out there who, as you say have years of experience, have no qualification'. Discussion continues with a third participant adding,

I would go further actually because I am trained as a teacher as well and then I had to retrain to do adult education and I think people who teach adult education, it is much better if they are not, if they don't have a H.Dip [secondary school]. Because you learn a certain habit and a way of teaching on a H.Dip and it does not work, I mean that is the way that most of them were put off education, by that person coming to the front and the minute you do that they nearly switch off and you don't remember anything. (DublinNorth, participant 1)

In two settings another concern is raised regarding the way in which only accredited programmes comply with The Teaching Council requirements for student-teacher placements. This in thought to undermine the worth attributed to non-accredited teaching practice.

There is just one incidence of discussion on the concept of professionalisation framed as a 'professionalising of the voluntary sector' (Cork, participant 3). The participant remarks 'I can see positives to it [professionalisation] but I also see that there are constraints and many of them [policy makers] are from a narrow focus of what community is'. He expresses concern at the lack of regard these policy makers give to academics, and others within the field of community education and community development continuing,

It is like there is an accountant somewhere who is pushing a bean that doesn't fit into that hole do you know so while there are positives to professionalising and demanding more from the sector, it is not the whole picture of what should be there, it is support that they need rather than confining us to rules and regulations' (Cork, participant 3 ).

\subsection{Criticism of community education providers from within}

Reasons for changes within community education are not only laid at the feet of the State but from within the sector itself the sentiment being that there has been an inculcation of current capitalist norms, something that is indicated within three groups. In Dublin-South there is a 
challenge to perceptions that community education is a politicising space at all, the suggestion being '...you have got to be critical of the practice itself internally, I think there are huge problems within community work as a field itself, and it is such a myth that is propagated in a way at various levels'. This contributor continues,

...for me there is a general acceptance, you know this bit about, say the question of 'why do we need community projects and stuff like that?' The reasons they are there is because massive inequalities exist within those places. But the community and youth projects generally don't really tend to push the question out there about what we really want is for the playing field to level...what we ended up with at one level is understandable, the sort of institutionalisation of the field itself, trying to hold the field in place at the expense of levelling up the playing field. That is a real problem in the sense that people don't understand and they get pissed off when you ask them about it because they are wrapped up in the face-to-face work; that they are absolutely wrapped up in the care. And there so much care going on, that the structural change is left over there [gestures distance with his arms] and it doesn't get touched. (Dublin-South, participant 3)

Comparable discussion happens in Waterford, framed within a sense that activism has been 'silenced because you are now responsible for an organisation and all that comes with it... and it is very hard to manage organisations' (Waterford, participant 2).

\subsection{1 'Insider' community educators and relating to experiences}

Within phase two, a directional hypothesis was presented asking if those who could relate to a history impacted by structural inequality are best suited to work with local community education groups, with $41 \%$ in agreement. Without prompt, discussion emerged in some focus-groups that expanded on this point. One respondent speaks of better relating to those experiencing redundancy, another of personal experience of difficulty accessing education. This respondent believes his socio-economic history makes him more suited to the work but believes this is not always recognised. He proposes shared experience brings qualities that enable you sufficiently take on the role in which 'you are a counsellor, you are a manager, you are able to bring the enthusiasm that you need to meet the [group] outcomes, those things can really get re-directed with all the outside interference' (Dublin-Central, participant 4). Another links personal motivation to her background describing how 'I sit at my desk and I 
look out the window and I look out at people hanging around at a bench, they could have addiction problems, and I grew up with those people, we have the same knowledge, grew up together, all that separates me from them is a glass window'. She continues,

I always think back to those people, 'there's whoever, and we grew up on the same street'. That motivates me to continue what I am doing because if these people can come in, whether it is the parenting course...they don't really think that they are doing a good job and they don't really believe they are and it is just fantastic when you can say to somebody, 'you are a good enough parent and you have a lovely child'...for me it is when people come in the door and they go out with a smile or when a penny drops and they realise something and believe they can do something else, even if they have left school at 12 [years old] and the biggest thing that we make them, is make them feel comfortable. At the beginning it is a cup of tea and a chat. Everyone's life is important, what everyone went through is important. (Dublin-north, participant 3)

The reverse experience is also shared for those not local to their endeavours as educators. One expresses discomfort at disparity in activism when considering the community in which he lives and the community in which he works. He explains, 'I drop into a community and I deliver a course and meet lovely people, and they think I am lovely too, but I am always drawn to the fact that I don't do anything where I live and I am not used as a resource' (Cork, participant 3). In questioning why this is the case he adds, 'something about wanting my own privacy stops me but I am probably getting to a point where there is so much lacking in my own community this stuff needs to be there too'. There is also a challenge to concepts of disadvantage from a contributor who self-identifies as an insider practitioner. This is in part prompted by the introduction of a statement from survey findings focused on disadvantage $(\text { see footnote })^{53}$. Originally from Dublin, he contextualises his contribution within the rapid housing expansion in the 2000s outside of urban areas. He explains,

\footnotetext{
53 The statement taken from a survey finding and introduced within focus-groups read "There is a lot of hidden disadvantage. Because you live in a certain area doesn't necessarily mean you are advantaged. The margins are getting wider with people getting lost in the middle".
} 
I live in a very rural area and during the Celtic Tiger years there were some massive big houses built on two and three acre sites and lots of people were getting into huge debt. But because of the façade itself, because the house becomes their mask and they don't dare use the word disadvantaged as they live in an advantaged area. I know where I live there are no water systems, no sewerage systems, local shops are miles away, local schools are miles and miles away. But because of the mask, the house, the structure itself hides this disadvantage... you can go into our estate and straight away you are making assumptions of this advantage and where I am, it is quite the opposite. You would say 'oh this is a real privileged and advantaged area' and there is a mountain of poverty.

(Kildare, participant 1)

This sentiment is raised within other focus-group encounters also.

\subsection{Relationships with the Academy}

Discussion on relationships with the academy emerged to a greater extent within focusgroups than in previous research phases. A prominent feature for those working for HEIs (two of which were universities, three were Institutes of Technology) was a contrasting experience to much of what others shared when discussing accreditation. This is summed up well by the following citation when, after listening to the experiences of others, a participant remarks,

I actually see now how fortunate we are because we are not financially bound to FÁS or the Department of Education and that allows us bigger possibilities and responsiveness...I know that this [the code] is the prevailing model at the moment in community education which I agree is just not relevant, it doesn't meet anyone's needs. (Dublin-South, participant 4)

Similar sentiment was expressed by other HEI employees at times expressed as relief the accreditation system they operate within is less confining, at other times expressed more in terms of individuals within universities structures being more sympathetic to the philosophies underpinning community education

Whilst all those working for HEIs undoubtedly report a less controlling environment, there were broader relational features raised. Some of this was positive particularly comment on successful community-university partnerships in the delivery of both accredited and nonaccredited work. In one instance this latter collaboration is described as the space where community education is most free. Some comments are not so affirmative. One contributor 
working for a HEI expresses considerable concern of about a 'cosiness' within academia, where many working in the university sector are described as completely removed from the realities within the community projects they commonly discuss and of the stark impact of poverty on the ground.

\subsubsection{Insider practitioners experiences at college}

Within phase two, insider community educators who returned to education as mature students were identified. Elements of this experience are shared, unprompted, in Waterford, DublinNorth and Kildare. Within two focus-groups there is a sense of denial of access to higher education after compulsory-schooling and within each setting, a sense of alienation when insider practitioners do attend HEIs. One refers to experiencing an 'imposter syndrome' (Kildare, participant 1) when on campus presented as a sense that university life was the preserve of a certain social strata from which he felt excluded. Another participant shares a lack of support from within her community. Discussing her position as first in her family to attend higher education she reveals,

I remember being asked at the time 'would you not mind your own children instead of pursuing this education' it just really wasn't expected that I pursued my third level education. So I had to struggle with that with my family, my peers, my husband and I understand that struggle. But if you are not brave enough, if you don't say 'you don't want to mind my kids, ok' and move on, if you are not brave enough to do that.

Sometimes I had to go to Maynooth and let them play tennis on the grounds while I was in the room getting my class or else it wouldn't have happened and it is not a given for people and it has to be fought for. (Dublin-Central, participant 1)

There is also concern about the difficulty of progressing from community education to higher education, with financial barriers identified as a particular hurdle that is increasingly difficult to overcome.

\subsubsection{Relationships between the academy and the field}

A fourth drift in discussion that connects, or more accurately disconnects, the experiences of these practitioners from the world of academia is a strong sense of separation between the academy and the field. One makes reference to a presumption within HEIs 'that theory is out 
there [in the realm of the academy] and not being generated by us' (Waterford, participant 2).

Another infers a digression along class lines, a situation that perpetuates rather than addresses inequality as many academics that advocate and sometimes negotiate for those experiencing oppression, do so from a position of privilege. This is presented as something that has led to unacceptable compromise with the State born out of a desire for harmony. This voice explains,

the whole of the academic sphere of the Community Sector is negotiating with the State about the lesser of evils if you like... as oppose to saying 'fuck them'; the things that we really fought for over the years are this, this, and this'. So much so that 5 years ago the biggest community work conference that was held in this country for a long time was 'From the margins to the mainstream' and completely missed the fact that within six months everything had just gone belly-up. So there is a kind of complacency and a satisfaction of 'job done'... For the past 25 years, all of the institutions from the unions down have pushed the pluralist model that there is something in it for everyone, but there wasn't something in it for everybody, we know that, and what is really happening is that people in the lower tiers and the echelons of the system are paying absolutely enormous prices for the bigger questions (Dublin-South, participant 3)

Within the same group, another gathers threads from discussions on relationships with HEIs. He summarises these as distance from communities experiencing oppression, the freedom of HEI staff, and the alienation of university settings for many. He proposes that those most affected by inequality are those who are most marginal from academic spheres, spaces where their lives are often under discussion. This is then related to the linear structuring of our National Framework of Qualifications (NFQ) presented as a perpetuating feature given its separation of critical thinking (the preserve of the higher rungs) and technical skills (dominant at lower rungs). His concern is articulated as follows,

It is only when you get to university and you do your masters that you are actually free to do that, to follow your energy. Otherwise you take what you are handed and you go through document, and document, and document and then when you are 'up here' [higher levels on the NFQ] you will eventually be able to become an adult and think for yourself. (Dublin-South, participant 8)

Further indication of disharmony between university and community is shared in Limerick. This is through an example is of an initiative organised by university employees embedded in the community that hoped to strengthen civil society-university relationships. This 
contributor, herself paid by a university but entrenched within the community, describes the interaction as a missed opportunity by the university sector. This is because many within the university entered into the process driven by an agenda more concerned with addressing the individual needs of their students in satisfying work placement demands, than building meaningful relationships with community education organisations. She is also unhappy that the desire to undertake social research to advance academic credentials, can also take precedence over strengthening connections with community education providers. Her intervention encourages discussion by another who shares, "not to pillory the universities but there has to be a discussion about that [relationships between the community and the academy]'. She outlines her belief practitioners are limited in what they can do to influence policy before referring to the academy and asking,

But like who is talking to the Department of Education or to the EU council or whatever because, if it's policy, that is where it is coming from, I mean you can chip away and you can work within it but we need to be trying to make a shift at policy level. (Limerick, participant 1)

The conversation continues as follows,

So let me get this right. So there are practitioners on the ground, there are policy makers at the top, but there is a space in the middle that the universities should be filling and they are not? Is that it? (Interviewer)

I mean it's, I don't know who else can do it, you can see in industry the role of universities, in science the role of universities, so in the social sciences who is doing it? (Limerick, participant 1)

It is like who is presenting the vision, and like the universities is where that vision of a society that we are aiming for is coming from...(Limerick, participant 4).

I actually think the universities have not engaged enough at policy in terms of influencing what has come down and the gap between academic and practice and policy is huge in terms of adult education and you know I think there really does because I mean a lot of community education going back, it was very much the bottom up approach where as you know, and it is policy driven and there is nobody influencing that policy outside of possibly AONTAS, NALA, I don't see the universities doing it (Limerick, participant 1).

Sometimes I think it is interesting that the ETBs don't have any formal link to universities (Interviewer).

Yes, that is very strange (Limerick, participant 2). 


\subsection{Other focus-group findings}

Other themes to emerge included the need to attend to the needs of people who are older, people with disabilities, migrants, and women. There is dissatisfaction with journalistic reporting on Community Sector cuts and related demonstrations, with another also unhappy with the media more broadly arguing it is little more than a mouthpiece for neoliberal private sector global corporations. An additional finding is a suggestion that community education should be doing more to support the agricultural sector, whilst a lack of support for volunteers is also raised (by a paid employee). Contrasting experiences emerge when discussing relationships between public community education provision and Community Sector involvement. In Dublin-North there is a disconnection relayed between locally based ETB community education, and Community Sector providers. Strong relationships between ETB and non-ETB providers are emphasised in Cork, Kildare and Limerick.

\subsubsection{Naming gender inequality}

Influenced by methodological foundations in support of feminist standpoint epistemology, a deliberate decision was made to introduce discussion on patriarchy, thereby working towards the re-authentication of knowledge to include women's experiences and perspectives. This was facilitated through the introduction of a probing statement drawn from phase one (oneto-one interviewing) of the research project that reads as follows, 'I think people are starting to look at women and their role and their place in society, there is still a lot to learn and to explore'. This statement was introduced along with other statements (in some instances displayed on the wall, in other instances laid across a table which can be viewed as appendix 8). In Limerick a story is shared of a Women's Studies course where despite a perception that it was going well 'gradually women started to depart' (Limerick, participant 3). The story teller relays reasons for a drop in participation rates within the excerpt on the next page. 
They [participating women] said when the dinner table started to include discussions on philosophy, when things had got a bit heavy, it became a little harder for them to find a babysitter, or not to be knocked, and it was easier for them to drop out, and I am just thinking of women and their role, and there is still a lot to be done, a lot to learn, to explore, sometimes when we liberate women we have to do it in quite a gentle way because otherwise they leave us. (Limerick, participant 3)

One woman also raises difficulty in working with some men from some overseas nations claiming she experiences increased levels of misogyny in these settings. Within one group, when greeted with the statement shared on the previous page, there is initial concern expressed for men by a female participant sharing 'the men in our society...the traditional role of the man, somehow that has been taken away and men have lost their direction' (Dublin-North, participant 4). This spurs disagreement from other women which evokes the following input from the only male in the group,

the problem man has always had is that we want to change things quickly, and it has suddenly gone from being the man as breadwinner the woman as house-maker which is unequal, I have no problem with that, but what I am just saying is that when you go through hundreds and hundreds of years of that being the norm, to just suddenly, from the mid-1970s to now; that is a very, very short time. The whole game has changed. And many people have opted into it, there are others who haven't. (Dublin-North, participant 2)

In Kildare, there is also concern about the challenges men face within a changing society, presented as alienating and disconcerting. One male participant shares what he believes is the appropriate response for community education where he uses a men's return to work programmes to raise gender awareness and pose questions that evoke discussion and reflection on men's role in perpetuating women's oppression (Kildare, participant 1). This point is picked up by another who argues for the need to include dimensions of gender even when groups do not specifically request this. On explaining a conscious decision to include Women's Studies within a suite of ETB offered programmes, the following dialogue unfolds, 
So why have you persisted, why has your VEC persisted with Women's Studies?

(Interviewer)

I think that we are looking at that community education continuum and looking at moving from the personal into social analysis and it more usually happens that the majority of people want the personal development kind of stuff. Initially I thought that groups would automatically, you know if they did something around the personal stuff, that they would come back the next year and they would want community development and that wasn't really happening so then I became a lot more conscious of, a bit like what you were saying, integrating all of the different parts of the continuum into everything that you do. (Kildare, participant 1)

$[\ldots]$

I think when you mentioned equality, I think it is one of the biggest lies that is being sold to us, that we are supposed to have an equal society and I really don't think so and, we kind of touched on this earlier, as men we have this power that we don't want to give up, or we don't even recognise it either, and I think again coming back to community education, encouraging people who are within our groups to start thinking about what they are learning in the home I think is a big, big step to make, particularly for young lads now, and I don't think women's studies can really fulfil itself unless it engages with men's studies as well (Kildare, participant 3)

Similar sentiment on men becoming aware of their power within society was evoked by a male participant within the Dublin-Central focus-group.

\subsection{Redirecting discussion - what can we do?}

As detailed earlier, one prompt introduced was designed to encourage a re-direction of concern away from those 'outside of the room' and towards discussion on what community educators can do to address disquiets. In helping to frame contributions, the following visual was presented to groups in distinguishing three distinct stakeholders. What I suggested was that, moving forward, all three entities would continue to be involved; individuals/groups we work with, ourselves as tutors/facilitators, and those outside of the room. 


\section{Individuals/groups/communities}

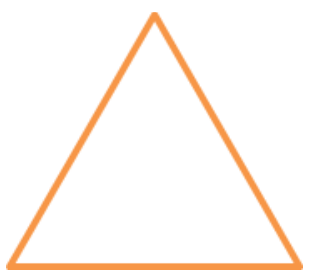

Community educators

Those outside the room

In each setting people were reminded of those they earlier named as influential forces before discussion was invited on who, of these three distinctions, was primarily authoring the work at present. This question gleaned mixed response mostly leaning towards a sense that, despite the many challenges people were facing, they were still able to influence the way in which they carried out many aspects of their work, abet with different degrees of autonomy. Most hamstrung were those working within previously FÁS structures but also those involved with the Department of Social Protection and some working with FETAC led environments. Those linked to some Independent Community Education Organisations and HEIs expressed the most freedom.

A second question posed was to look at the triad and ponder what can we, as community educators, do to address our concerns? Dependent on the size of the group, discussion was sometimes in pairs or in threes, feeding elements of discussion back to the wider group.

In Kildare there was a challenge to the rigidity of division within the diagrammatic presentation with someone sharing,

I am sure there are good people outside the room as well and we are presuming that all tutors are coming from the same place when of course they are not and the same with the group... I think you can only change your own sphere of influence and there is different ways of looking at that from each of those perspectives I think' (Kildare, participant 2).

There is also a suggestion that it is groups themselves that should be considered the catalyst for change so 'that we are not either blocking them, or filling them up with our stuff, or taking away their stuff from them' (Kildare, participant 3).

A number of strong themes do emerge. These can be named as a desire to better showcase 
our work, a desire to continue to work with the State whilst consistently centralising community need over labour market need, a strengthening of networks both national and local, the creation of our own accreditation apparatuses, greater engagement in direct action campaigning and a reinvigoration of the politicising potential of community education. These will each be discussed below.

\subsubsection{Community education and the need to showcase our work}

Consistently, there were suggestions of the need to present a more cohesive and united vision of the work of community education, and of the need for more research to emphasise this. One example of how this might be done is shared as the report Capturing the Wider Benefits of Learning (2011) prepared by the Limerick Community Education Network a collaborative approach across VEC and the Community Sector. There is also confidence expressed that relationships with universities 'could be turned around on its head a little bit' (Limerick,

participant 3) in order to organise some of this. She continues, 'even what we have been talking about, recording, documenting quality progressions, universities can certainly help, can have the money to do some research, to present the research, to have it brought to the table in education department committee meetings'.

\subsubsection{Discussion on continued relationships with the State}

Most (not all) asserted a need to continue to engage with the State as to break away would be detrimental. One explains how if you were to disengage, 'you are going to be completely marginalised and seen as not relevant, not valued... you can't buy into everything but you need to find out where the niches are within that and you need to find out how to address them' (Limerick, participant 2).

This suggestion of 'finding the niches' runs through discussion elsewhere. Another notes, 'for the future be more creative in the way we look for funding sources and engage with those outside the room - be very creative to hang on to your own style to be true to education to be 
true to what Paulo Freire talks about to be meeting people where they are at' (Dublin-Central, participant 1). These chosen excerpts reflect sentiment across each focus-group setting however, as discussed in the introduction to this chapter, consensus cannot be assumed as not every participant contributed to discussions on this topic, a point that holds across other proposals also.

\subsubsection{Proposals on network formation}

A dominant point to emerge across many discussions was a desire to strengthen networks, the result of which was hoped would deliver some tangible actions. Actions encouraged were to lobby local politicians, to advocate for change, and to formalise consultation processes. For some, the strengthening of networking is through existing structures with the AONTAS CEN named in Waterford, Cork, Limerick, Athlone, Dublin-South, Dublin-Central and DublinNorth. Praise for the AONTAS CEN was tempered with the challenge in finding time to commit to its development as follows,

I mean the CEN is great, but it can be so difficult to actually get out, to make that time because we are all so constrained by 'we all have to do so much more with less' I think we have to really try and make that effort that we come together because we will be so much stronger if we are together. Literally we can be crying in the wilderness (Dublincentral, participant 2)

Others were less sure of the suitability of the AONTAS CEN. In Dublin-South, notes gathered from small group discussion wondered if AONTAS has taken a route that promotes problematic policy initiatives around individualisation, vocationalisation and uncritical professionalisation. Other network structures are also mentioned. In Cork the Basic Education Teachers Association for literacy tutors was identified although there is concern this 'hadn't really taken off'. In Limerick there was continued reference to the need to strengthen the work of the Limerick Community Education Network, a model of collaboration between ETB and Community Sector organisations. There was also a proposal for greater involvement in the existing resistance network of The Spectacle of Defiance and Hope. 
Some proposals were for a more politicised network that could 'fight on its behalf, [be] more organised in the public domain'. There are proposals for the creation of regional networks both in urban clusters including areas of Dublin, and through regional gatherings which could better link with the national organisation proper. In response to a suggestion to network at the midlands meeting, some shared previous difficulties encountered in trying to organise this including reluctance by employers to release staff.

On more than one occasion participants made reference to these particular focus-group encounters as an example of the importance of networking. One exchange demonstrates the potential for such dialogic spaces to advance and hone opinion. The impact of the exchange of radical ideas is captured as follows, 'I hear [names participants 3 and 8] speaking and I am thinking, Christ I have forgotten that all again...I need to keep reminding myself that I am doing this [community education] in the context of this huge inequality' (Dublin-South, participant 5).

\subsubsection{Direct action? Discussions on greater involvement}

The potential for greater participation in politically motivated direct action is raised in a number of spaces. In Dublin-South this is through discussion notes from one small group and is relayed as a belief that funding will be cut regardless of whether a groups speaks out or not. The contributors encourage others to engage in direct action protest against Community Sector cuts. Referring to community education as a movement, another in the same focusgroup shares thoughts on the current lack of an identifiable counter-hegemonic entity continuing, 
Small fires are burning in different places...there is always a counter, not always but there is a counter-alternative to the dominant view as well and I absolutely stay away from the idea of accepting the analysis they are presenting us and my argument is that, that is what we need to change... we have got to distribute an alternative view across Irish society which articulates a really powerful egalitarian vision and I think that is possible, we can do it but it is a huge struggle at the moment to get it over. Those other voices are extremely powerful and have us in a neoliberal State; we live in a neoliberal State that acts on behalf of the powerful interest and the bullshit that is peddled. (Dublin-South, participant 3)

One Waterford participant, who repeatedly shared examples of involvement in direct action campaigning shares, 'I see the energy in the room with me and the excitement of people out demonstrating... I love that because it is still there, it is still there, it is to support the others, to continue to agitate' (Waterford, participant 1). The conversation continues as follows,

What would that look like, that sort of community activism? (Interviewer)

Well for me there is no course mentioned, there is no FETAC mentioned, I was taught that community education is a social movement and it is not about having to tick a box or say what you're learning is, it was more a, I mean we are seeing it here, the demonstration on the hospital, you know, that was a mass amount of people challenging that we are not accepting this...In some ways when we put people into systems, FETAC and [names HEI] you actually silence their activism, there energy to get out there.

Another participant continues,

For me that outcome is that groups then become a group entity, an organisation, not even an organisation but when the collective works they can actually work together, they are no longer individuals working for change or to better their own lives, they are doing it as a group, and I saw that so rarely throughout the years, that you actually will see that from the start of linking the personal to the political, so the feminism comes in because that to me is always the basis of community development anyway, that they go on to independently define what their needs are and take action against them, but not as individuals. I think I would like to see that coming back more and more. (Waterford, participant 2)

\subsubsection{Can we create our own accrediting capabilities?}

In Dublin-South, there is a concrete proposal that a function of an emergent collection of organisations would be to minimise reliance on FETAC (now QQI) awards by moving towards the design of our own accreditation mechanisms which could be mapped to higher, more analytically focused levels of the NFQ. Arguing for a collective over individualist perspective, one participants explains, 
People go to university; first there is the cost, secondly they tend to go as individuals so they are not part of a group anymore and they are, unless they are at the very highest levels of the academic ladder they are not following their own generative themes. So to actually try to reclaim that space, by community educators reclaiming that space so that they can do that stuff so the kind of educational processes that go on at masters level can go on in our local communities for residents living in that community around the generative issues that are in their community so that is what we thought we can do. (Dublin-South, participant 8)

Another in the group further enhances the proposal adding,

Can community educators get together and get accreditation in a holistic way for the kind of stuff that is really important for community development as you were talking about [to participant 8] it is possible in the university level why can't it be accredited at the lower level and I think that for me is huge and there is a huge resources issue (Dublin-South, participant 7).

Elsewhere the functions of a network are extended to include the development of more affective systems of recognition of prior learning.

\subsection{Re-invigorating the politicised message within}

A need for community educators influenced by a desire to encourage conscientisation to reassert the political ambitions of their work is proposed in some settings. Notes gathered in Athlone urge participants as follows, 'do not be complacent; engaging the disaffected, there are people in community education who just come to do the job and do not think about what they do and why they do it...there is a lot of passiveness'. They support this assertion with concrete proposals for 'active citizenship programmes', courses in 'women in Leadership' and in 'politics'. Another participant expresses hope in the potential this can be nurtured by sharing 'I do think there are a lot of people, tutors and organisers who are actually very committed to a critical approach.... critical is still there, so that is the hopeful bit around a lot of the VEC work (Athlone, participant 5). The continuation of an equality based agenda is also proposed in Kildare, Waterford and Limerick. 


\subsection{Summary of findings from focus-groups}

Focus-group encounters were rich, dialogic spaces that are unique within this study given their creation of conditions where practitioners could interact with each other. Within these spaces some participants expressed a feeling of empowerment and energy as a result of being involved. They were also a crucial part of this research given their ability to embody critical education, linking participants in a problem-posing environment and eliciting thoughts on ways forward. Key findings to emerge will now be summarised.

A central feature of focus-group encounters is the use of a code specifically designed on foot of survey questionnaire findings within phase two of this study. The strength of resonance with this code indicates a sense of powerlessness and control over their work by others. This was acknowledged amidst some sharing of an under-estimation of the power of groups, also capable of analysing the circumstances within which they find themselves. Most community educators to participate in focus-groups believe they are continuing to exercise control over the authoring of much of the work.

There is much emotion when discussing relationships with the State and a reporting of situations concurrent with New Public Management (NPM) practices as detailed within earlier chapters. Participants report funding cuts and restrictions to their practice that include inability to purchase sundries, curtailing of practice because of budget cuts and the personal impacts of pay-cuts and reduced working hours. There is also concern about reduced income for some participants with particular mention of members of the Travelling community. Some trace the influx of features of NPM to some time ago and not as a result of more recent recessionary times. One analogy shared is of how State-led interpretations of the Community Sector, combined with conflicting philosophical orientation within, have led to a situation where the emphasis is on 'trying to hold the field' rather than 'trying to level the field' when considering an equality agenda. The Community Sector is criticised for succumbing to many 
of the changes imposed on it, with perceptions of a united-left perspective within dismissed by some. However the challenges of speaking out are expressed, most particularly direct reference to fears of job security were people to work more authentically with their philosophy of community education.

The notion of working in the niches is named. Many report successful manipulation of funding to better suit the needs of communities they work with amidst challenging and, at times, unsupportive relationships with the State. This is a strong theme with much resistance to State interpretations of community education apparent. The way in which community education participants don't automatically move from the personal to the political is also discussed. It is suggested that such a shift requires a problem-posing approach from educators. There is also acknowledgement of the need for a feminist pedagogy and a naming of the power of patriarchy.

Those encountering community education participants attending as a conditionality of welfare, report this as being particularly challenging, both for themselves as educators, and for others in the group. There is also a sense of powerlessness on listening to the negative impacts for those obliged to attend for fear of sanction. There is concern about the vocationalisation of community education as a whole, a theme that generated considerable discussion.

There are difficulties raised concerning accreditation. Whilst people are largely supportive of the concept and welcome opportunities to validate learning, there are concerns of overprescribed programmes, excessive assessment, complex reporting relationships, and excessive bureaucracy and standardisation. Also emerging is a situation where certain umbrella organisations, particularly ETBs, foist a particular interpretation of FETAC accreditation upon locally based educators. There is also ideological challenge to the linear nature of the NFQ interpreted as contrary to the critical nature of community education. 
Also clearly emergent is distinction between HEI and FETAC accreditation, the former perceived as more free.

Much discussion emerges on relationships with the academy, something not anticipated within previous phases. The academy is viewed as distant from, and often out of touch with, community education on the ground. Specific concerns include disappointment the academy has not been more pro-active in attempts to shape policy and concerns there is a prioritisation of finding student placements and engaging in research over forging relationships with civilsociety organisations. There are also concerns of a class divide between those within the academy, and those within disadvantaged communities.

Some of those working with people experiencing the harsh end of structural disadvantage, and who have direct experience themselves, describe this as a strength they bring. Others identify their role as ally, including some challenges this can bring.

When invited to comment on what community educators might do, there are five distinct proposals put forward. The first of these is a desire to strengthen networks, named within each focus-group. For some this is through existing entities particularly the AONTAS CEN, for others through more politicised network structures. A second proposal is to continue to work with the State but to be more assertive in our dealings whilst continuing to manipulate funding where possible. Thirdly there is proposal within one group to establish independent accrediting capabilities, fourthly there is a call (within three groups) for greater engagement with oppositional movements. Finally within each group there is a desire to re-assert ourselves as a more identifiable, politicised sector. There was also some discussion on the role of universities and the sense that this could be strengthened in two directions. Firstly towards brokering policy perspectives that might be more representative of the work of community education, secondly that they might extend energies towards the field bridging a gap between the academy and practitioners on the ground, a gap some felt was significant. 


\section{Section 2 - Findings from Telephone interviewing}

This section reports on findings from six one-to-one interviews held with participants who initially expressed interest in focus-group attendance. Details on recruitment, operationalisation and ethical considerations can be found within sections 7.2.3.1 and 7.3. All but one (participant 6) demonstrated affiliation with second-chance approaches to adult and community education. Participant 6 revealed a radical approach to community education linking his practice to collective action for social change. Further introductions will be woven into findings when reported on below.

During tele-interviews, there were some lengthy conversations relating to the accreditation of learning, and, again, some difficulties shared about involvement with the Common Awards System (CAS). Background discussion on CAS and its implications for community education are discussed within chapter five (section 5.2). There is some inconsistency of language within this section as, whilst Quality and Qualifications Ireland (QQI) had been formed at this stage (see section 5.2.1), the tendency amongst research participants is to continue to refer to the Further Education and Training Awards Council (FETAC), its predecessor.

\subsection{Introductions, motivating factors, and thoughts on community education as a whole}

By way of building relationships at the beginning of interview conversations, I asked each person to share with me something that they enjoy about their work as a community educator. The first person I spoke to (participant 1) works in a Community Development Project (CDP) situated in a Gaeltacht area that has remained outside of the integration process therefore outside of the Local and Community Development Programme (LCDP). Their organisation operates within a community that is without a library and public adult education provision. It is 60 miles from the nearest large town. The CDP delivers a range of programmes, mostly 
non-accredited and all in response to community need. He describes his motivation as 'really helping people back into the idea of learning' of offering opportunities for people to begin in safe, supported environments before, where possible, progressing to more traditional educational environments.

Participant 2 is a part-time tutor within a Dublin based ETB and is involved in delivering QQI level 5 major awards mostly in community-care and childcare. She gets particular strength from when students affirm the group-work process that is central to her way of working. She also shares a motivating factor as seeing students succeed who have been away from education for many years.

The third person you will encounter (participant 3) works for a non-governmental organisation (NGO). She is involved in the delivery of QQI courses, university programmes and non-accredited work, all in local contexts. She cites particular satisfaction in supporting progression pathways, witnessing growth in confidence and self-worth, in seeing people achieve recognisable qualifications, and in enhancing employment opportunities. Many programmes she runs involve bringing paid community workers and volunteers together. She shares,

the fact that you [the paid workers] are working with people who are actually living on an estate and working on an estate, you are getting a variety of different perspectives where as if you are going to university to learn about community development, the majority of people who are learning it have either never worked in it, and they just get on without that or they have no practical experience of it. (Participant 3)

Another interviewee (participant 4) has worked in community education for over 25 years beginning as a literacy tutor in the 1980s. She now works in a range of contexts including allocated hours with an ETB, and recurring work within the LCDP. She gets strength from 'empowering people' particularly within their families something 'which hopefully will have a knock on effect on their community'. Speaking of the joy she gets from seeing individuals progress she shares 'when you are talking with someone and you can be in the moment, when 
you realise they either get what you are saying, or they say something; that something has changed in their life and you think 'fantastic' that is why I am here, because I just love it'.

The fifth to be introduced (participant 5) has previous experience of many years within the private sector and describes her relatively new occupational identity as a community educator as very different to her previous employment. She describes being motivated by offering second-chances at education for those who might not have achieved their fullest potential when at school. The population group she works with is lone-parents, mostly women.

Lastly, participant 6 works within an organisation that supports Travellers. Working with people in both one-to-one and group settings, a key part of his work is linking people to existing local services as relevant to their needs. He explains,

The overriding ambition is to have a meaningful impact on people's lives on their real life chances, their experiences. So what that means is that you would hopefully empower people to give them the skills, knowledge, tools and self-esteem to be able to directly apply tactical solutions to problems. (Participant 6)

\section{Thoughts on community education as a whole}

Each person was asked their thoughts on community education as a whole. A number of different areas for discussion emerge that included discussion on a largely co-opted sector, concerns about accreditation, perceptions of the work, working conditions, and funding. When considering the sector as a whole, one relays 'it appears to be that, bit by bit, it is becoming decimated' (participant 6). He continues, 'the Community Sector in general, and education being an integral part of that, there is all the supports being withdrawn'. Referring to the creation of SOLAS (see section 4.4.2) he adds,

It is just another example of the austerity programme where they smash things together in terms of 'they fit in neatly' so they can turn centres and make savings, and they did the same with the Traveller Senior Training Centres, so everything is really depending on costs and not seeing any of the value so it is completely undervalued.

For one, there is an alternative view expressed, that community education 'probably needs a big shake-up' (participant 5). Making reference to concern for standards of practice she continues, 'I don't know, maybe it needs a review and I am nervous about even saying this 
you know'. Another is unhappy about societal perception of community education, something she believes 'can be quite negative...that it is a lesser form of education'. This is expressed despite confidence programmes are often of high quality, are delivered in a way that is more convenient to participants and are frequently taught by those with more legitimate community connections than those within traditional educational environments (participant 3). One cites his 'biggest concern' as 'that we are losing the benefit of community based learning' continuing, 'adult learning in itself raises people's expectations, raises their sense of their own abilities, raises their own confidence, it became very focused on pieces of paper' (participant 1).

\subsubsection{Considerations on accreditation}

With three out of the six interviewed working directly with FETAC, it is unsurprising that unprompted, the accreditation of learning emerges as a strong theme. Again there is broad support with employability and validation cited as particular benefits. There are some specific concerns shared namely over-assessment and rigidity in the interpretation of course modules by certain employers. One remarks, 'I think the learning outcomes needs to be addressed, that everything needs to be measured' (participant 5). From another,

FETAC is very difficult to be honest. It is very assessment heavy for one module. I know there are people who don't feel that, but I would feel that you could nearly get a first year of a degree for what you would get of one module, for what you have to do. (Participant 3)

Another, whilst supportive of FETAC, shares disappointment at the way in which it has evolved since its inception recalling "I remember thinking "that is magic" because now we can develop a course and we can get it accredited and people can do what they are doing but they will get something at the end of it that says "this is real education"' (participant 4). However her feelings have now changed as current implementation of FETAC awards fall short of early aspirations. Her primary concern is loss of tutor/facilitator power as, similar 
to experiences reported within some focus-groups, she shares difficulty in its implementation as dictated by FÁS,

I am handed all of the assessment briefs, you know - these are the ones to deliver - now to some degree, they are actually, whoever designed them is very coped on, they are actually very good. But that is very inflexible, extremely inflexible. They do a generic approach so that it should fit most groups but you know, and there is no option in that system to do something else other than the brief that you have got so that doesn't work very well. (Participant 4)

She compares this experience to the work she does with an ETB sharing it is a slightly different system in that, and you probably know this, we develop our own [assignment] brief which is great, we can develop them to suit the group that we have, but you know that's tons of extra work, tons of it that we are literally not paid for' (participant 4). Indicative of a lack of consistency across ETBs, another, again largely supportive of FETAC, complains about a lack of control for tutors this time within an ETB where she is 'bound by the VEC module descriptors' (participant 2) instructed not to stray beyond contents she is provided with. She shares an awakening that exposed here original blaming of FETAC for these limitations as misguided. She now locates blame with her employers, the ETB telling me,

I delivered this module, it was terrible, it was so badly written it was so broad, it was all over the place, and I just thought, 'ok that is FETAC and FETAC have given this terrible module, they have written this terrible module', and then I was given work from a different organisation to write a module, to write a descriptor, and it was one that I had taught and I realised, actually FETAC, their direction was fine... it was whoever had taken that on for the VEC and who had written it, they just did not understand the subject and they just did not understand how FETAC works or how any assessment process works. The content did not match what the assessment was and everything was overcomplicated and when I actually got to write it for myself I realised how badly written they were, and I thought it was FETAC and it wasn't, it was the VEC and I realised that actually the FETAC guidelines, they were quite good. (Participant 2)

This same person also expresses discontent about her increased work-load in planning for revised modules most notably the way in which it is neither acknowledged nor financially remunerated as it fell outside of tutor contact hours. She explains 'that kind of pissed me off because that wasn't named, nobody said "thanks for everything, you have written everything and we need to acknowledge what you are doing"' (participant 2). A third is also unhappy 
with the amount of work involved in moving awards into CAS sharing, 'that was a shocker for me I have to say with the migration [to the CAS], my perception was with the migration they would have been less prescriptive but I think what they have done is they have been more prescriptive' (participant 3).

There is also a story shared that reveals the way in which FETAC can be manipulated to address community need. This is of a new communities group led by a desire to learn English so they can better integrate with their native Irish workmates. Participant 4 explains her decision to run a level 3 programme despite it being 'completely inappropriate' for the group given its mismatch with this clearly expressed group need. She chose the particular module as it was, in her opinion, the least burdensome in terms of assignment demands and shares how the assignment requirements would be addressed at the end of each session rather than being the force that leads the educational intervention. The rationale is 'because to get funding for a second term, they had to do something FETAC' (participant 4). Describing how she works to ensure the FETAC requirement had as little impact on the programme as possible she gives a flavour of how the course is run,

So for the first couple of weeks we looked at the RTE [national news broadcaster] news website, and chatted about things that were going on, the kind of things that you would talk about at [work] breaks and that and they said that their relationship with their colleagues was going great, but there was nowhere in FETAC where you could tick a box to say anything along those lines, so none of that was counted. (Participant 4)

There is also praise for the use of FETAC. Participant 2 in particular compares the use of accreditation in community contexts as interpreted in a more flexible way than she imagines is the case in Further Education (FE) Colleges. She explains how many she works with 'won't go to an FE College, or would struggle with 9am-5pm, or who need that little bit of extra support' continuing, 'I can spend another hour on this if you want me to, because it is more important that you get it'. She continues, 
I do feel that there is this pressure with all this FETAC stuff you know 'how many hours can you do, how many meetings can you do' this kind of pressure to keep this whole thing moving and I just don't want to lose sight of the fact that my students, I don't want to sound derogatory to them but this is where they are at right now, and maybe they are not ready for... I mean some of these women have 5 kids and they are worried about being 5 minutes late I am going against the policy, we have sign in sheets and stuff that are supposed to be kept. (Participant 2)

FETAC is also linked to mechanisms that assist new management systems through its processes of transparency and outputs measurements. This latter point is drawn out by one as a positive, enabling holders of FE awards clarity in communications with Higher Education Institutions where they wish to progress.

\subsubsection{Concerns about funding}

Again, and in some instances immediately, discussion revolves around funding. Though one voice supports a more streamlined approach, abet concerned funding for her own position is 'piecemeal' and therefore problematic (participant 5), the bulk express frustration. One relays significant impacts on staff morale due to 'particularly savage' funding cuts to Traveller specific programmes (participant 6) and divisive competition between ETB and Community Sector organisations. Deteriorations in personal working conditions are shared by those working within ETBs who both report increased unpaid hours, insecure contracts, work being sometimes cancelled at short notice, and a lack of space with both relaying how the physical presence of their work is evident in their homes. They also share a sense of isolation from their peers resulting in a less collaborative approach than they would ideally like.

\subsubsection{Other findings}

Another concern raised relates to lack of confidence in supporting those with literacy and language difficulties, a point raised by two interviewees. One comments, 'you have to be mindful that just because someone is sitting in a room, doesn't necessarily mean that they actually can write an essay that you are asking them to do and that was probably the biggest 
shocker for me because I wouldn't have thought someone would come to do a course when they can't write, do you know' (participant 3). As a way of managing this, she suggests greater collaboration between providers ensuing more effective referral systems to specialist literacy supports. The challenge for adult learners when working and studying at the same time is named. One expresses concern for community educators working without qualifications. She suggests enhanced systems of recognition of prior learning to support adherence with The Teaching Council of Ireland requirements which will potentially be extended to all contexts where FE awards are delivered (see section 3.4.3). There is also a proposal from one interviewee that groups should lobby for a return to three year work-plans with funding approved cyclically in accordance with this timeframe.

\subsubsection{Managing change and shaping the future}

Again, in accordance with my hope to generate thoughts on how community educators should best respond to current circumstances I asked for suggestions on ways forward. Within most conversations there is a belief that recent changes are in contravention to the desires of practitioners. Some share belief the Community Sector has been co-opted, particularly emphasised by one person unhappy with the way in which the voice of those most affected by structural inequality have been silenced by the structures of the Community Sector. He is critical of some leaders within the Community Sector noting,

So the thing about being led from the ground, a real grassroots community development project would continue to focus on the issues at hand, and it didn't take place that way because it is much easier for them if they can get one person into a room and they can do what they want in terms of that and then they get bought off effectively, that is the way co-option works... there is a myriad of ways they can do that but it gets them further and further away from actually having to deal with the issues that are affecting the communities directly. (Participant 6)

This interviewee is particularly vocal on his frustrations with the Community Sector further sharing, 
We talk about building a social movement and if community education is serious about that I would love to get all of them in a room together so we could actually trash that out because I think that that is the way that change is going to come about. It is not going to come about in anything we have seen so-far...but we are too busy filling out reports that we never actually get around to that stuff. (Participant 6)

Similarly, another expresses frustration at a silencing of workers within the sector announcing 'we don't have a voice, there is no reasons why we can't be asked by policy developers, we collectively, not a couple of people they have appointed we want everybody's voice coming through, these are the policies, lets debate them' (participant 1). Expressing a sense of stuckness, this contributor identifies universities as a potential ally 'to give us the language, to say what it is that we are doing because we don't speak to each other enough'. He is not the only one to raise relationships between practice and the academy. Participant 3 shares 'I think there are many within [names a university] who haven't a clue what is going on, the changes that there are now, they are starting to make it more and more difficult for community education to actually happen and I think that is a very negative thing'.

\section{Influencing accreditation}

When prompted to reflect on what community educators can do to influence change, just one returns to concerns with accreditation as follows,

In terms of FETAC, I don't know, maybe I am just being pessimistic but I don't know what you could actually do to change that system because it is now, you know the horse has bolted in my opinion, I don't know what you could do to change that only that you keep the struggle for representation, you know that people are trying to get on the ETB board and that kind of thing, that stronghold, that that kind of strong voice is lost, we cannot give up the ghost altogether, then FETAC have won it. (Participant 3)

\section{The role of Networks}

The possibility of expanding and strengthening networks is also raised. With reference to involvement with the AONTAS CEN one shares,

I think AONTAS are very good at lobbying, I think the changes in the legislation that they have initiated were great, it is great to have a voice for community education. I think it is great for community educators to come to a forum like that [the CEN] and actually have it explained to them in plain English what is going on. (Participant 3) 
She is one of two who spontaneously expresses support for the AONTAS CEN. A third shares an awareness of the AONTAS CEN and positivity surrounding its actions though relaying 'to my shame I am not a member'. Reasons cited are lack of time and distance to travel to attend meetings. Positives of network engagement are shared as collaboration, information sharing and collective lobbying. Others also express a desire for greater networking and collaboration though the AONTAS CEN is not seen by one as the conduit best suited for this given what they perceive as AONTAS's co-opted status.

There is also a desire for those politically motivated to re-assert this ambition more publically citing increased collaboration with egalitarian social movements, politicised research and written opinion pieces. Citing the work of Paulo Freire as influential, this contributor relays,

I think it is possible for people, if they are really serious about trying to be the change then they have to have a political analysis of what is going on in politics. They have to bring that into the learning environment. So if you want to be the change I think you have got to make the participants be a part of that change. So you have to politicise, you have to give them an analysis of what is going on in terms of how things impact on their lives directly and why they impact on their lives directly and I think that is easier now than ever to do that in the context of reading the newspaper. Every time you read the newspaper there is another story about austerity, there is another story about cuts, there is another story about how we have to 'make' this 2.5 billion or 3 billion reduction or whatever it is, and why is that happening? (Participant 6)

He suggests that to do this, there needs to be a re-assertion of 'leadership and action and political action' and 'a move away from the co-option model, that whole social partnership model which has completely failed and it means, thinking about how you can actually put pressure on people' (participant 6).

\subsection{Summary of findings from telephone interviews}

Telephone interviews were introduced in order to ensure ethical commitment to enabling maximum participation for those wishing to be involved. Whilst all interviewees originally intended to participate at focus-groups, this proved logistically impossible with reasons shared as distance to travel, childcare commitments on the day, and clashing diary 
appointments. Many of the same themes discussed within focus-groups again emerged. This was without the prompt of a code, or with pre-chosen survey statements.

Those participating in tele-interviews are motivated by a range of factors that include affirmation from participants of community education, and a sense of pride when they see people do well through education who might previously have under-achieved. One is motivated by the potential for community education to address structural inequality; though this participant is disillusioned by a sense the Community Sector itself has been a barrier rather than bridge for change.

As with focus-group and survey participation results, they too report challenges when working within State structures. Specifically named are the impacts of funding cuts and the way in which this has curbed their activities through increased restrictions. One shares an example of the personal impacts of expectations work will be completed without pay identifying this as a demoralising experience.

There is both support for, and discontent with QQI. Accreditation is seen as an important equality of opportunity mechanism but admonished for its over-assessment particularly within FE awards. An important finding to emerge strongly from within two interviews is discrepancy between organisational interpretation of QQI guidelines, and the guidelines as dictated by the accrediting body. In both instanced this is revealed because practitioners work across more than one organisation. There is also comparatives drawn between university accreditation and QQI accreditation with the former described as more flexible and better suited to community contexts within which this practitioner works. Some difficulties with the academy are also expressed with a sharing that universities are out of touch with events on the ground. Ways forward expressed are similar to those shared elsewhere in the study namely strengthening of relationships with the academy and greater networking and 
coordination across community educators. Some cite commitment to strengthening the AONTAS CEN, whilst one views AONTAS as co-opted. There is also a naming of practical difficulties in network engagement.

An important part of telephone interviewing was their methodological dimension where the notion of equality in participation was deliberately exercised. Valuable findings have been uncovered from this final phase that both re-enforce previous encounters and throw new light on experiences. These findings form part of an integrated analysis that will now be presented where the threads of chapters eight, nine and ten are collated and considered amidst theoretical and literary contributions. 
Chapter eleven: Mapping a landscape of Practice

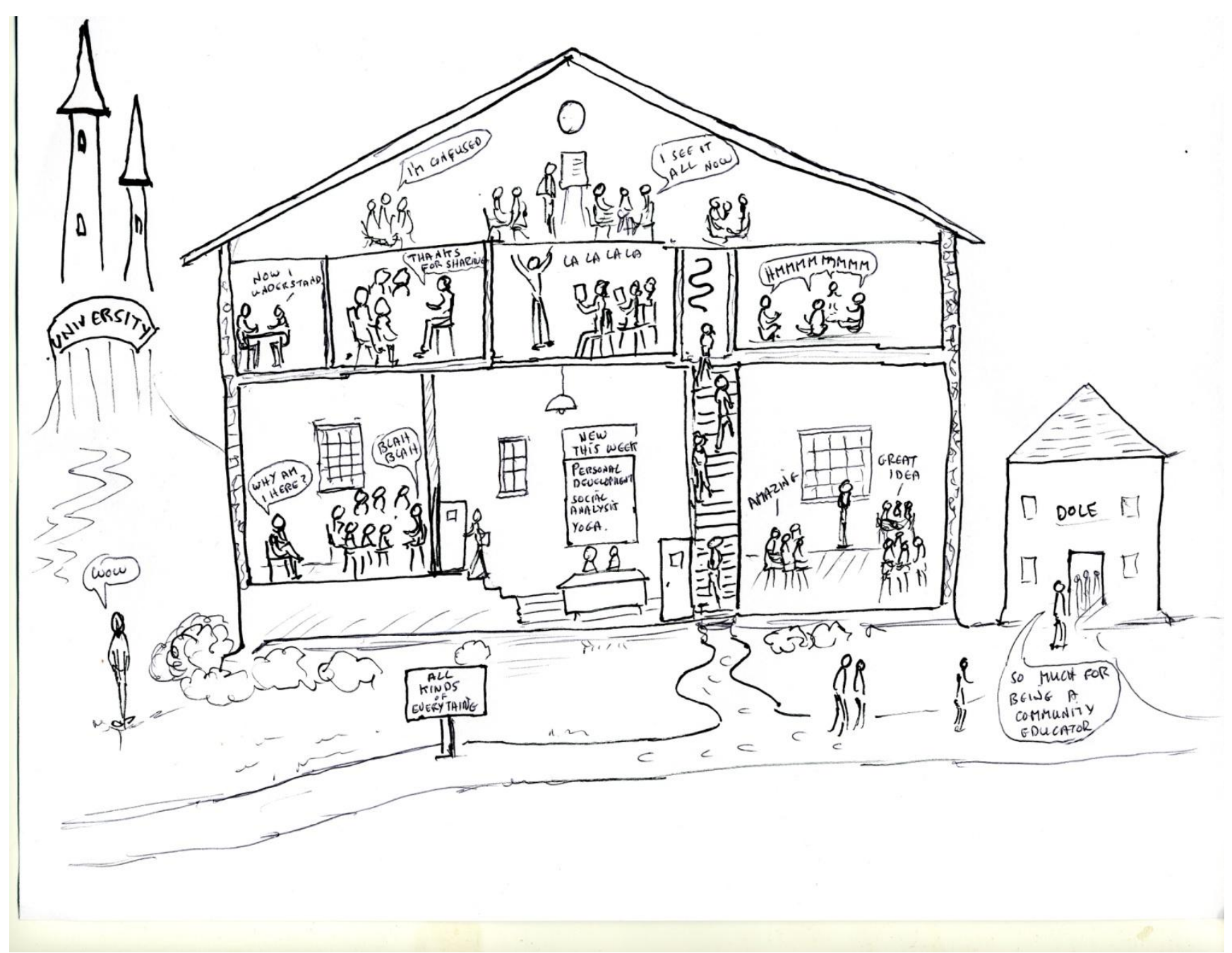




\subsection{Introduction to chapter}

At a recent conference on Further Education, a community educator addressed the keynote speaker from The Teaching Council (the council) asking him what, if any, were the council's plans for community education in Ireland. I suspect the reason for this line of inquiry was ongoing uncertainly if a legal stipulation that Further Education College based tutors must register with the council, would be extended to localised community settings. Readers will by now be aware that this potential proviso has caused some disquiet. What struck me most about this exchange was not the question posed, but the way in which the answer was framed. Though well versed in educational policy nationwide, the responder answered in a way that was blind to all community education outside of specific public provision. He could see the work of Vocational Education and Training Schemes (VTOS) and of Community Education Facilitators (CEFs), somewhat predictably interpreting these as vocationally-driven. However, his answer shared no sense of any wider interpretation of community education, either through an alternative philosophical perspective, or through the breadth of provision outside of that directly provided by the State. I found myself feeling momentarily anxious that this broader interpretation of community education might be revealed to the speaker, fearful of the changes that this might bring.

Part of the purpose of this chapter is to rectify such limited interpretations. This is attempted through an integrated analysis of findings across each of the three phases of the study's data generation: one-to-one research conversations with radical practitioners, an embedded (qualitative and quantitative) survey circulated to a purposefully selected research population, and focus-group and tele-interviewing with survey contributors who agreed to further participation.

I put a lot of thought into how to structure these last two chapters including abandoning an earlier draft where they were presented as one. What I settled on is this integrated chapter 
which satisfies the first two ambitions of the study, to sketch a previously undisclosed landscape of practice and to uncover the perceived consequences of neoliberalism through community educator experiences and insights. Findings from primary research are infused with theoretical insights and relevant contributions from other writers. This type of 'mixedmethods analysis' is encouraged by Creswell and Clarke (2011: 212) where the lead is taken from the task at hand. Complementing this, a final contribution as chapter 12 considers the third research objective most specifically; to investigate ways in which a critical approach can further inform egalitarian ambition.

\subsection{Mapping a landscape of Practitioners and Practice}

My ambition to propose ways in which critical education can inform community education practice can only be undertaken upon greater understanding of the landscape of community education, and the circumstances under which practice is undertaken. This begins with figure 24 which provides a summary of selected characteristics.

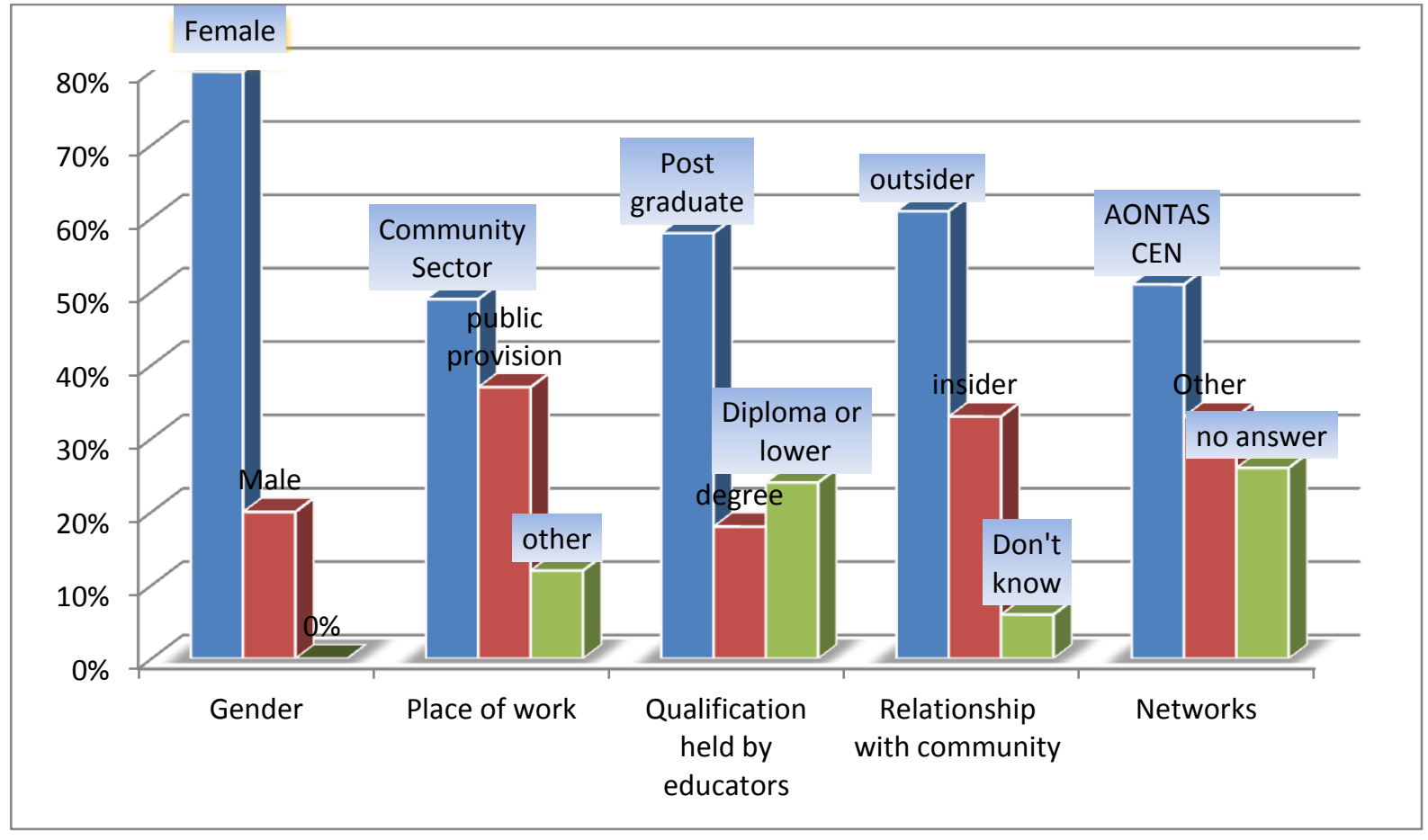

Figure 24 - summary of selected characteristics 
Community education's inauguration through local adult education initiatives, the women's movement, anti-poverty movements including anti-drugs initiatives and liberation theology, remain palpable within contemporary practice. This study confirms this by uncovering a vista of national provision where $49 \%$ of participating practitioners are situated within the Community Sector, and 30\% are located within Education and Training Boards (ETBs). The remainder are within Higher Education Institutions (5\%), other State providers (2\%), nongovernmental organisations (4\%), private provision (4\%), and, for $6 \%$, as independent practitioners. Some qualitative discussion with this latter cohort reveals previous employment within Community Sector organisations and occasional work within ETBs. Most community education described is within urban settings (90\%). Ninety-six percent is State funded.

As demonstrated throughout the study, momentous change has occurred in recent years most notably the realignment of both Community Sector and State (public) provision (as detailed within chapter four). Public provision is now organised across sixteen Education and Training Boards (ETBs) within which a network of Community Education Facilitators (CEFs) and also Adult Education Organisers (AEOs) oversee a range of activities. This is sometimes within specialist VTOS centres, other times within a range of community contexts and with a Community Sector host organisation. There is also extensive literacy provision within ETBs, much of which relies on significant voluntary effort. As will be further detailed, participants within this research share accounts of pressure to increase participant numbers with set targets at times imposed. There is discouragement of non-accredited (therefore non-measurable) learning and pressure to ensure greater employability as the end result of any learning encounter. Much of the Community Sector, originally organised through Community Development Projects (CDPs) was realigned into the Local and Community Development Programme (LCDP). The LCDP has itself been further condensed 
into the Social Inclusion and Community Development Programme (SICAP). For those working within Family Resource Centres (FRCs) and projects designed to support those with drug or alcohol problems, there are reports of limitations on their freedom to practice as they wish. One telephone interviewee describes the changes as 'just another example of the austerity programme where they smash things together in terms of "they fit neatly"...so they can make savings'.

Alongside organisational location, a philosophy of practitioner networking is uncovered, most commonly through the AONTAS Community Education Network (CEN). There is also affiliation with the Community Workers Cooperative (CWC), the practitioner network usually aligned with the Community Sector. Some research participants detail membership of both the AONTAS CEN and the CWC. Some difficulties with networking emerge. These include trouble negotiating such practicalities as getting time to attend, a Dublin-centric focus, and concerns regarding network co-option. This latter concern matches arguments elsewhere where networks are considered a site for neoliberal subterfuge (Giacinto Garcha, 2001; Bowl, 2011). Secondary research also uncovered differing network responses to State imposed change. The CWC have provided a consistent oppositional voice to the restructuring of the Community Sector, whilst, throughout a paralleling restructuring of adult education provision, AONTAS (referring to the umbrella organisation within which the CEN exists) has remained more circumspect. During focus-group and one-to-one discussions some direct criticisms towards AONTAS are aired, with their position cited as compromised due to their reliance on State funding.

\subsubsection{The precarious and demanding nature of community education}

Within this research, $80 \%$ of practitioners surveyed are female, with $20 \%$ male. Women's epistemologies and biographies are therefore particularly influential in shaping this work. This disproportionate gender weighting has implications for community education 
particularly for the working conditions likely to be present. To explain, when O'Sullivan (2012) considers women's experiences in the workplace she begins by outlining changing opinion in Ireland which, in recent years, has moved away from interpreting women as holding a traditional homemaker role. By entering the workforce, women have met some of the demands of feminism particularly flexible-work and part-time work, the latter now being the preferred societal option for women (O'Sullivan, 2102: 228). However, the ways these demands have been met have coincided with an erosion of working conditions. O'Sullivan (2012) draws from a range of domestic studies to demonstrate difficulties for women specifically low and unequal pay, work-placed segregation, gender discrimination, age dependent opportunity and a situation where women continue to do the majority of care work in the home. Further research on the feminisation of the community educational workspace and the way this shapes conditions of work would enhance our understanding of this phenomenon. This is beyond the scope of this study.

What we do know is that, in this study, $52 \%$ of community educators are employed part-time and this is at times described as precarious. Specific difficulties with working conditions are reports of redundancies, reduced hours of work, pay-cuts, expectations of voluntary commitment, the emotional burden of working with people experiencing oppression on a regular basis, and, for some, isolation within their employer organisations. Volunteerism is also strong with $11 \%$ working without financial remuneration, and a further $10 \%$ working in both paid and voluntary capacities. Eighty-one percent report working for more hours than they are paid for. Across different occupational settings contributions identify an unhelpful culture of volunteerism that erodes working conditions through pressure to work without pay. Another factor that enables this is a strong commitment to the work. This is repeatedly stressed, and illuminated by one focus-group contributor's description of community education as 'more than just a job', driven by loyalty to communities within which 
practitioners work. Some share the demoralising impact it can have when this is not recognised by funders and host organisations.

In considering occupational identity, concepts of professionalisation did not emerge as a strong theme. The possibility that professionalisation benefits practitioners (community educators) over recipients (communities) as proposed within literature (Larson, 1977; 2014; Collins, 1995; MacDonald, 1995) is not raised. Supports for professionalisation and professional standards, where present, are framed through consideration for the precarious nature of community education and through expressed hopes for a more stable employment footing. One one-to-one interviewee describes the recent cuts to the Community Sector as 'such an insult to my profession' and there is broad concern about a lack of esteem for community education when compared to other education related employment.

The conditions described are difficult for many and are likely to be amplified by an often uncertain occupational identity that is shaped by a liminal and marginal position within the wider tapestry of educational provision (O'Neill, 2014). One way in which occupational identity is expressed, quite forcefully at times, is through self-differentiation from secondary school teachers who are thought to more readily align with banking approaches to education. This belief is captured elsewhere when Cullinane (2003: 82) notes how 'successful secondary school teachers may not always make successful Community Education tutors'. Commitment to participatory and experiential teaching methodologies especially emerged within survey findings where it is cited as a requisite feature for $38 \%$ of participants. This sentiment is repeated at dialogic phases of the study also. The illustration overleaf, offers a pictorial overview of one perceived difference comparing banking approaches (on the left) to a more dialogic way of working. 


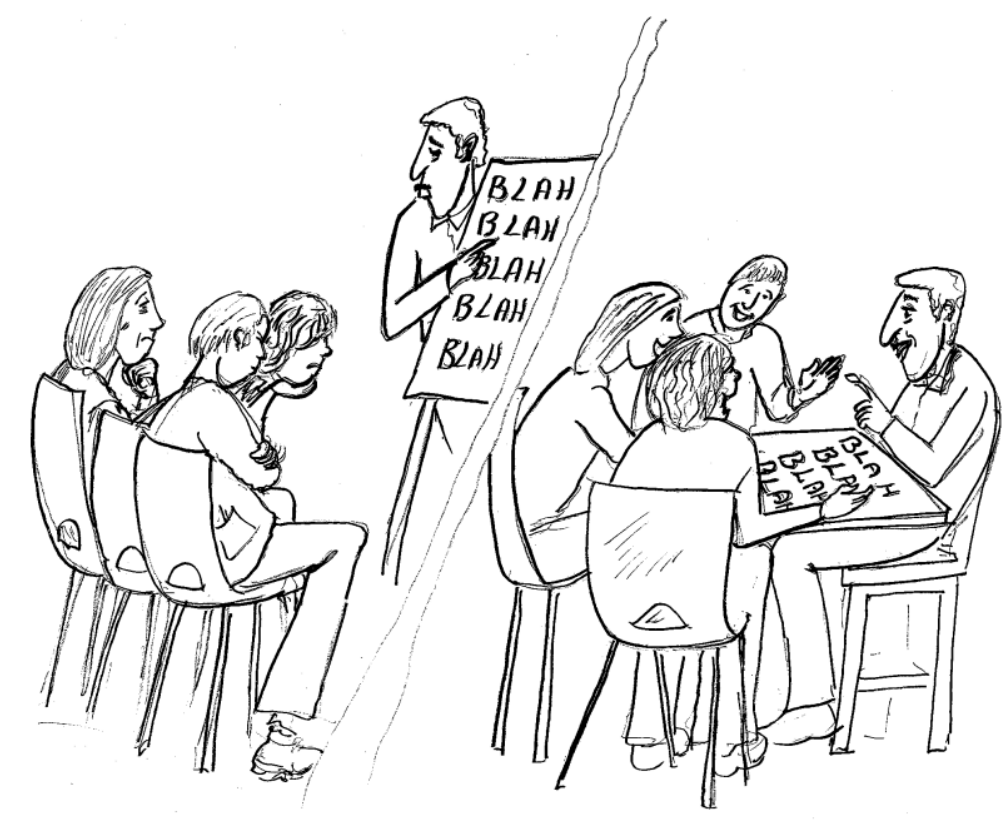

There is a conspicuous fear raised that the dialogic and participatory approaches held within community education could be undermined should traditional approaches infiltrate practice with some relating this to the potential involvement of the Teaching Council of Ireland. This perceived intrusion from an external stakeholder is, by some, seen as a disempowering development and its involvement undermines community education's ability to critique its own practice. Further research on philosophical expectations of the Teaching Council, and how these relate to established adult and community education practices would be welcome in considering how best to respond to these concerns.

A further tension expressed is that an increase of secondary school teachers into community education spaces will alienate participants of community education many of whom have had negative school encounters.

\subsubsection{The work of community education}

Amongst stories shared are examples of groups coming together for personal support and development, to deal with unemployment, to offer assistance and support relating to parenting, to sing together, to learn about computers and get other literacy supports, to gain 
access to higher education and to up-skill for employment. Some groups unite through shared interests such as community gardening, cookery, the arts, personal development, and health and fitness. Several come together to address a shared issue or concern. These include anti-racism initiatives, attempts to address inadequate and poor housing conditions, cuts to the Community Sector, the need to establish local services otherwise unavailable, and in support of leadership capacities as part of wider community development initiatives. Specific population groups are named as gender based groups, those unemployed, those with drug and alcohol problems, those with an intellectual disability, Travellers, and new migrant communities.

Eighty-three percent of those surveyed use accreditation, though just $11 \%$ share using certification for all their work. FETAC (now QQI) are the majority accreditor responsible for $84 \%$ of awards. Opportunities to accredit were welcomed by $60 \%$ of those surveyed. Accreditation was an important early ambition of community education though historically expressed with caution relating to ownership of certification mechanisms and potentially problematic influences from EU policy (Kelly, 1994). These fears have been played out with much ambiguity captured. This is within $33 \%$ of open survey contributions relating to this theme with concerns also consistently raised through research conversations. These concerns were of over-assessment, lack of curricular control, excessive administrative demands, and the appropriateness of Further Education (FE) qualifications. This latter unease is specifically relayed to their compulsory inclusion of work experience modules, their limited potential in enabling non-vocational educational spaces, and their potential to discourage critical thinking when considered against their positioning on the NFQ. This sense that FE awards are contrary to the critical educational demands of community education is also uncovered in research elsewhere (Fitzsimons and Dorman, 2013). Some believe the 
Common Awards System (CAS) was introduced with little regard for the knowledge and expertise of those educators those most directly involved.

\subsubsection{Analysing insider - outsider relationships}

Across practitioners, 33\% align their own socio-economic circumstances as from within communities experiencing the impacts of structural inequality. Applying contributions within literature, these are determined insider practitioners, set against outsiders (like me) from more advantaged neighbourhoods (Whelan, 1989; Henderson and Glen, 2006; Fitzsimons, 2011). As discussed in more detail within chapter three, when these practitioners work in a problem-posing critical way, insider practitioners can be interpreted as organic intellectuals and therefore significant in directing the ideas and objectives of the class they are originally bound to (Gramsci, 1971: 3). For those working from radical perspectives in particular, the legitimacy of community education as an entity whose vision is for structural egalitarianism through self-determinism needs the involvement of insiders as a requisite feature. Fifty-five percent of insider participants agree those who have similar life experiences are best suited to community education; a statement with an overall agreement rate of $41 \%$. Further insights from insiders include a strong sense of authenticity their experiences bring. At times there is also dissatisfaction with self-appointed leaders within the Community Sector, including those within the academy, whose limited experience of the impacts of austerity is thought to compromise their ability to effectively represent communities more directly affected. By word of caution in assuming political intent, one insider practitioner details how experiencing inequality doesn't necessarily result in antineoliberal sentiment, but often an embracement of capitalism. Hegemonic notions of the way in which to be is to have (Freire, 1972: 46) help us understand the internalisation and at times celebration of the forces of oppression. 
At each stage of the study, some outsider practitioners put forward the notion of ally including challenges this can bring. A voice shares unease about high levels of community engagement within the community where he is employed and low levels of engagement where he lives. With $61 \%$ aligning their own backgrounds to one of advantage, therefore an alternative class-experience as those engaging in community education, reflection on the cultural power this imbues is required. The privileged position from which outsider community educators perceive the social realm, and the 'othering' of working-class culture (Lawler, 2005) require reflexivity from advantaged practitioners towards awareness of the cultural power they bring when they enter into a classroom or community context. Worth noting, and a theme at times strongly expressed, is refutation of distinctions between those considered advantaged and those disadvantaged with an argument put forward in a way that strongly upholds meritocracy.

Relationships between outsider community educators and the communities they work within are complex with some theoretical contributions on their role signifying a requisite abandonment of class-allegiance if they are to truly enter into communion with those oppressed (Gramsci, 1971: 7; Freire, 1972: 30). Also put forward is a belief traditional education demands that those from working-class backgrounds 'surrender all habits and ways of being associated with this background' (hooks, 1994: 182) in order to conform. These polarisations are somewhat reductionist, falling short in explaining the complexities of classidentity. They also fail to account for neoliberal circumstances where those conventionally considered middle-class are increasingly experiencing the unequal brunt of neoliberalism (Giroux and Giroux, 2006). That said, there have been difficulties outlined elsewhere where outsiders have positioned themselves in representative positions with their lens of privilege influencing concessions made (Meade and O’Donovan, 2002; Ikeotunoye, 2002). Some agreement with these observations is shared within one focus-group discussion. 


\subsubsection{Dominant philosophical underpinnings}

A connecting feature for the vast majority of practitioners, across employer type and networks alike, is conviction that inequality disproportionately affects certain sectors of society. Eighty-eight percent believe community education goes some way in alleviating this, with some of those in disagreement referring to the limitations in fulfilling this through a co-opted sector, and not a conceptually different optic. In attending to this majority equality based agenda, community education encapsulates a gamut of approaches along a continuum from traditional charity models to anarchic and socialist perspectives alike. This is in part made possible through the way in which historically, neither State provider nor Community Sector designated a clearly identifiable, overriding mission and purpose. This has enabled heterogeneity to flourish but also creates uncomfortable spaces for practitioners. Forty-three percent cite philosophical leanings at odds with their employer and it is not unusual for seemingly incompatible approaches to be contained within the confines of the same organisation.

Three specific interpretations of community education are identified which are named as universal (or conservative), compensatory, or radical. The first of these, a universal and seemingly neutral approaches can be captured with $37 \%$ aligning themselves with a belief community education (vocational, personal and political) should be for all regardless of socioeconomic circumstance. My own fallibility as a researcher is evident when considering differences as retrospectively I am not comfortable with how this question was posed. This specifically relates to the inclusion of the word 'political' within presentations of a universal approach. The use of a test-retest approach somewhat counteracts this hesitation confirming universal tendencies elsewhere. Twenty-four percent disagree community education should deliberately target those considered 'disadvantaged', with related textual sentiment in support of universally approaches often strong. That being said, this philosophical perspective did 
not emerge within phase three of the study where more deliberative conversations were held. Thirty-five percent align themselves with compensatory approaches, an interpretation not uncommon within literature (AONTAS, 2004; Bailey et al, 2011, Field, 2011), and that which is most frequently aligned to organisational ethos, whilst $28 \%$ align themselves with a statement designed to evoke radical allegiance.

Figure 25 reminds the reader of the quantification of philosophical tendencies when shared through textual contribution, and also examples of practice as philosophically catagorised by the researcher.

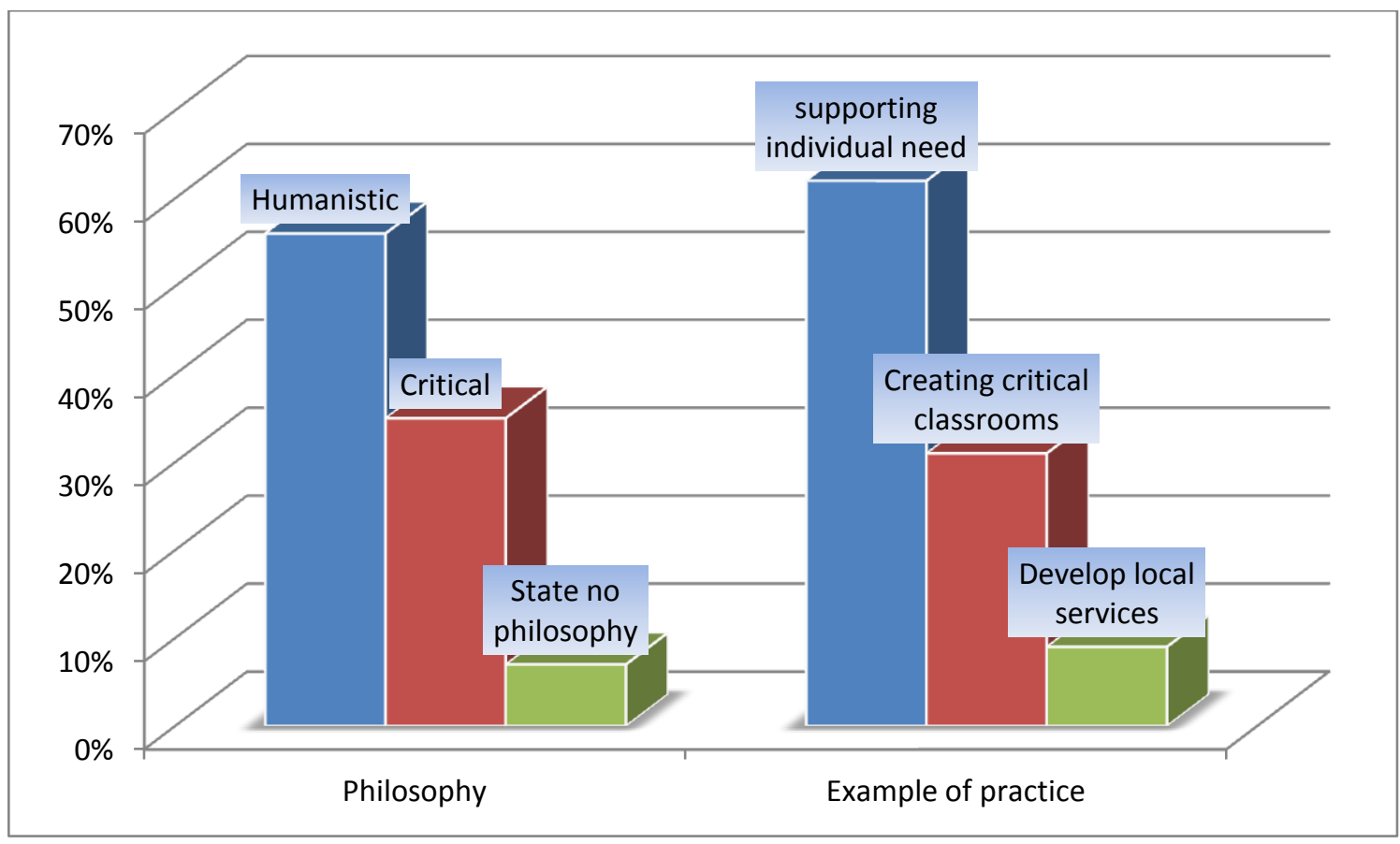

Figure 25 - Quantification of philosophies and examples of practice

This reveals how 56\% hold humanistic, person-centered inclinations rising to $62 \%$ of examples of practice shared. Discrepancy between what is said and what is done further illuminate the fallibility of human participant surveying where responses given are likely to reflect what people perceive to be the most appropriate answer (Dockery and Bedeian, 1989). Recurrent humanistic tendencies are towards personal-development, self-actualisation, selfdirectedness and a belief in individual capacities. These practitioners endeavour to provide 
supportive spaces for building the confidence and capacities of people, and for enriching lives through opportunities potentially not otherwise available to some.

A radical interpretation of community education is also uncovered with an initial $28 \%$ who align themselves with this approach. This rises to $35 \%$ when textual contributions on stated philosophy are quantified, falling to $31 \%$ of examples of practice shared. A feature of community education in Ireland is the way in which many groups to come together are recruited as individuals, often from across different communities, subsequently formed into a group with a shared identity. This can jar with some Freirean/popular educational notions of more organically emergent gatherings united by a specific and localised issue or concern. This is likely to influence the way in which most critically oriented work shared is in the creation of critical classrooms, a practice described elsewhere as limited in achieving change beyond the classroom walls (Murray, 2013). One research participant in this study reveals the possibility for delayed praxis as a result of educational engagement. Others share incidences of direct action interventions, quantified at $9 \%$ namely against community cuts including hospital closures, as part of housing action campaigning, and as wider politicising interventions. This is noticeably lower than $50 \%$ of examples which relate to personal growth and development.

Those who share radical approaches as influential often link their practice with community development which is interpreted as a way of working that supports consciousness-raising, believes in self-determination, and as intimately connected to praxis (Beck and Purcell, 2010; Ledwith, 2011; Crowther and Shaw, 2014). This study is not the first to measure radical tendencies as a minority approach amidst a more dominant humanistic/liberal perspective. This was also detected by Inglis et al (1993) when considering early community education work across both public and Community Sector provision, and within research by Powell and Geoghegan (2004: 157) whose emphasis was on those within the Community Sector. In- 
depth individual interviewing with purposefully selected practitioners gave further insight into this minority grouping. Strong ideological commitment is uncovered, with most also identifying their background as one of disadvantage. As well as the influence of community development, insights from development education are also strong, a connection that has been identified elsewhere also (Kane, 2001: 252). It is important to emphasise that not all practitioners support a radical interpretation of community education with $21 \%$ ranking the statement 'to encourage the groups that I work with to collaborate with each other and together, take action to address issues that affects their community' as least accurate in describing their role.

Across each philosophical orientation, there is evidence of community education's oppositional nature when set against current governmental interpretations of its role. The Department of Education and Skills (DOES) have recently described adult and community education as 'a range of education and training provided by various organisations aimed at up-skilling and re-skilling people who are unemployed', continuing, 'providing skills for work is a priority' (DOES, 2014) ${ }^{54}$. In this study, less than $3 \%$ describe community education as principally about up-skilling for employment, a point continually and repeatedly emphasised at each stage of the research. A second measurement further supports this quantification of textual submissions when just $\mathrm{n} 7(6 \%)$ chose the statement to up-skill individuals so they are better equipped to compete against others in getting a job', as that which mostly matches their role. The need to provide locally based education that up-skills people for employment is not dismissed; rather it is interpreted as relevant when contextualised within the expressed needs of a group or community.

\footnotetext{
${ }^{54}$ This has been taken from the Department of Education and Skills website http: // www.education.ie/en/TheEducation-System/Further-Education-Training/, accessed February, 2015, there is no date listed as to when the post was originally published.
} 


\subsubsection{Relationships with the academy}

An unanticipated finding to emerge related to relationships with the academy, an entity some express as out of touch with practice on the ground. Criticism relates to the academy's failure to take more decisive action in influencing policy towards a less vocationalised outcome, a significant gulf between practitioners and the academy, failure by the academy to advocate more vocally against the weight of change experienced on the ground, and a priority of class loyalty over alliance with communities of disadvantage. Chasms between the academy and practice are claimed elsewhere. Choules (2007) proposes a domestication of radicalism within protected university spheres, however Connolly (2006) sets Irish adult education apart from the wider academic sphere, noting dissymmetry. The academy's continued engagement within local practice is identified within this study, most notably in the first phase of this study. All but one narrative contributor within phase one emphasised the significance of their engagement with radically oriented university courses naming both Adult and Community Education and Equality Studies programmes as influential. This demonstrates the importance of these spaces in holding, and developing, radical approaches to community education in Ireland and demonstrates the translation of these ideas into community contexts.

Another concern, which is not unconnected from relationships with the academy relates to the possibility of future change led out by the Irish Teaching Council of Ireland (the council) should they extend registration requirements into community contexts. Whilst $55 \%$ in this study agree those qualified to degree level are those most suited to deliver accredited FE awards, the introduction of council regulations would directly impact a minimum of $42 \%$ of practitioners in this study qualified to degree level or lower (including 3\% without qualifications). Also likely to be impacted are many with post-graduate qualifications as 
these are most likely to be across a range of subjects and not those more recently approved by the council.

The approval of programmes carrying strong adult education philosophies is a welcome development and it lessens the likelihood of an uncritical extension of the school experience should council stipulations be imposed. In exercising this role, universities should take note of focus-group discussions that suggested the technical requirements of organising student placements in the field have at times usurped the development of relationships for change between the academy and Community Sector providers. There is an additional responsibility for the academy when considered within the neoliberalisation of the university sector and commodification of much educational opportunity. Universities and other higher education settings are facing their own challenges negotiating the terms of neoliberalism (Ball, 2012), with increases in precarious working conditions for many academics also. In negotiating its own survival mentality, the academy must make sure newfound involvement with the Teaching Council does not lead to a whole scale re-direction of energies towards developing critical capacities within the FE sector. This could result in the academy turning its back on more historical connections with community educators, weakening its own potential for praxis. Participants in this study recommend a strengthening of relationships between universities and the field of practice.

\subsection{The brunt of New Public Management}

At each phase of the study, within focus-groups, in one-to-one conversations and through textual survey contributions, much emotion is expressed when discussing relationships with the State. Thirty percent of survey contributors commented further on these relationships. One sentiment strongly expressed was of a prioritisation of economic over social wellbeing, and a corresponding lack of understanding about community education. This research uncovers much evidence of NPM. Micro-level concerns related to practitioner's ability to 
work freely and in confidence, on a day-to-day bases and of funding cuts that have restricted the ability to provide additional support outside of immediate group contact.

The introduction of measurable outputs is shared on many occasions. Sometimes this is through pressure to increase participant numbers, with the notion of 'bums on seats' as a driving force directly referred to from contributors across both Community Sector and State provider alike. Another mechanism for monitoring outputs is through certification with many sharing how only accredited programmes are considered a measurable outcome. By way of challenging this latter finding, alternative ways of measuring learning have been advanced by community educators. The AONTAS CEN propose a choice of models for measuring the outcomes of community education (2012b), whilst work by the Limerick CEN offer a framework for capturing the social value of community-based education (Neville et al, 2014). Further evidence of NPM is through emphasis on accountability and transparency, with substantial increases in administrative and reporting demands shared at every phase. An encapsulating analogy shared within one interview is of practitioners caught in a game of survival where paper-trail requirements usurp the primary purpose as the gaze of the State is firmly fixed on the scaffolding and not the building it is intended to support.

The assertion of a State led vocationalisation agenda is strong within the literature reviewed (e.g. Johnston, 2000; Borg and Mayo, 2005; Brine, 2006; Grummell, 2008; 2014; Óhidy, 2008; Hurley, 2014). This is mirrored through policy with analysis of the SOLAS Further Education and Training Strategy (2014-2019), and the Social Inclusion Community Activation Programme (SICAP). For SCIAP, this is a particular shift in direction given previous, although somewhat restrained, support for concepts of process-oriented community development. Many voices describe the experience of vocationalisation on the ground, again emulating from State and Community Sector providers alike. Participating Community Education Facilitators (CEFs) detail a shift in emphasis within their work. Where historically 
they had the freedom to work in a process-oriented fashion utilising accreditation only when appropriate to community need, there is increasing pressure to measure all learning through certification. This corroborates similar findings by McGlynn (2012) who also notes NPM incursion within State provision.

Despite reports by the Department of Social Protection (DSP) of positive relationships between the DSP and Community Sector and ETB providers (DOES, 2011: iv), concerns in negotiating relationships with labour market activation measures are expressed (at length in some instances) by those working with participants attending as a conditionality of welfare. This is perhaps the finding that most surprised me, as I was unaware of the incursion of the DSP into community education prior to undertaking this study. What was particularly striking was the strength of emotion expressed by those involved. This is through a sharing of negative impacts on practitioners, participants and the wider group. These experiences add negative practitioner experiences, to UK based findings by O'Grady (2008) who identified negative implication for adult learners attending by fear of sanction. Further research in Irish contexts with both practitioners, and those compelled to attend, would greatly enhance our understanding of this phenomenon.

Where discussion moves specifically to the Community Sector, $61 \%$ agree with the hypothesis that 'the Irish Community Sector has been co-opted by the State and is not a force for influencing change'. Further discussion during phases one and three of the study uncover contentions of a deliberate disempowerment of the Community Sector. One reason repeatedly given is of a silencing of a potentially oppositional force, something that some believe began prior to the announced sectoral realignment in 2009. Another argument put forward is of a class-based misinterpretation of the work with policy makers positioned as middle-class and participants of community education as working-class. This is thought to have resulted in decisions being made about the Community Sector by those unaffected by 
the issues the sector sets out to alleviate. Statistics generated relating to co-option of the Community Sector were gathered prior to the purloining of the previously independent Community Development Programme (abet reliant on State funding) within State structures. This appropriated assets that were built up by communities into State ownership and potentially into future private ownership through the SICAP tender process. For what remains of the Community Sector, detail of the impact of NPM that is shared include an increased monitoring over supportive role for Family Resource Centres (FRCs), and the introduction of fees for QQI legacy providers. Some experience these latter changes as coercively implemented, again cloaked in the language of cost-cutting with all accrediting provision potentially compressed into Education and Training Board (ETB) structures, regardless of a Community Sector organisation's location, mission and purpose.

Elsewhere I propose three reasons to explain the ease at which the Community Sector has been co-opted. These are a Janus-faced State that extols the virtues of community work whilst simultaneously undermining its viability, co-option through involvement in social partnership, and as a result of ideological divisions within the Community Sector (Fitzsimons, 2012). Relating specifically to ideological divisions within, differing philosophical tendencies were, at times, palpable during focus-group discussion. Each focusgroup brought together those influenced by humanistic approaches and interpreting community education through its compensatory capacity, and those espousing a minority radical perspective. Dialogue was often philosophically discursive, and, within one setting, one focus-group participant comments on the benefits in listening to those speaking from more radical perspectives. She claims that listening to such discussions can remind us of what the purpose of community education should be. Across each phase and philosophical perspective, there was a sense of despondency about the Community Sector's ability to effectively steer its own path. Co-option of the Community Sector is not only influenced by 
more recent neoliberal practices. Other factors to consider include the limitations of localism outside of connecting with wider political struggles, and the interdependence of many new social movements with nation States. This has always compromised their ability to act freely given their dependence on infrastructural supports including funding (Steyn, 2012).

\subsubsection{Negotiating neoliberalism: the malleable nature of relationships}

Despite repeated concerns about influences outside of practitioners and groups/communities, it is also clear that much community education differs to how policy direction and funder demands would appear to dictate. A number of research conversations reveal manipulation of funding to suit perceived community need, deliberate discrepancy in written accounts of practice and actualities on the ground, and of tactically matching pieces of work to particular funders. The creation of alternative spaces such as these is not always oppositional in nature but can be interpreted through Holloway's (2010: 19) explanation of people opening alternative ways of doing and being, as we navigate our way through increasingly neoliberal cultural surroundings.

There are also examples shared of successful intervention in shaping a government position paper relating to public provision of community education. A sense that social partnership engagement strengthened leadership capacity is also raised, something Larraghy (2014) also professes through the nurturing of 'policy entrepreneurs'. Whilst individualised benefits are perhaps measurable, the potential for participation to represent a form of manipulation (Arnstein, 1969) holds true when we acknowledge the subsequent co-option of the Community Sector. This ability to manipulate State funding is worth holding onto in nurturing hope for community education beyond neoliberal State interpretations. Difficulties arise when this is contextualised within an increasingly coercive closure of Community Sector spaces, often with little opposition either from those directly affected, or by the public at large. 


\subsection{Summary of chapter}

This chapter incorporated findings from three distinct research phases in a way that particularly addressed two of three research objectives: to expand knowledge on practitioners and practice and to consider the influence of neoliberalism on their work. It has sketched a broad landscape of community education, the first such undertaking in Ireland. It proposes that provision exists across State provider and Community Sector alike. Philosophical inclination across universal, compensatory and radical approaches are identified and supported through examples of practice. A process of neoliberalisation through New Public Management has been demonstrated, tempered with examples of practitioners manipulating funding in order to match group and community need. This creates some space for alternative social relations outside of many common neoliberal portrayals. A sense of powerlessness amidst community educators is however uncovered, particularly when one considers the weight of reaction to the illustrative code utilised to evoke discussion.

This chapter is incomplete without further reading within chapter 12. This is where the final research objective, to contemplate the contributions radical education can make in enhancing egalitarian potential, is particularly addressed. 


\section{Chapter twelve: Re-kindling Community Education}

Small fires are burning in different places...there is always a counter...a counter-alternative to the dominant view.... we have got to distribute an alternative view across Irish society which articulates a really powerful egalitarian vision and I think that is possible, we can do it but it is a huge struggle at the moment to get it over. Those other voices are extremely powerful and have us in a neoliberal State, we live in a neoliberal State that acts on behalf of the powerful interest and the bullshit that is peddled.

Focus-group participant 


\subsection{Introduction to chapter}

When I look back over the time I spent undertaking this research, a lot of memories surface. One of these is a recollection of thumbing through someone else's completed doctoral thesis which also concerned community education. There was resonance with my own study, the use of a code, focus-group discussions, and some similar findings such as an attempt at vocationalisation through policy. Half way through reading, I was jolted by the reflections shared by one woman who expressed a yearning for a less politicised worldview. This, she lamented, might have given her a less contentious identity as a community educator, and ultimately, an easier life. After reading these comments and being so struck by the words, I suddenly recalled my own participation in this study, a connection I hadn't immediately made when deciding to read the work. These were my words, spoken within a group-setting of peers, now re-played at an unexpected time creating, for me, a reflexive watershed.

For as long as I have been working as a community educator, my personal practice has always lain within politicised interpretations. For me community education is about creating space for discovering alternative notions of society. It is a space for challenging depictions of active citizenship as passive consumerism and docile employment, as policy documents such as the Memorandum on Lifelong Learning (European Commission, 2000) and the Further Education and Training Strategy (SOLAS, 2014), to my ears, would have us believe. These analyses could only carry weight if education actively set out to deconstruct such notions, with praxis central to credibility should it carry the worth of such greats as Freire and hooks. This was, at times, a burdensome load as I took on a responsibility to engender social activism within others as a result of an educational encounter. A consequence of this study has been a broadening of my interpretation of community education, appreciating other equality focused interpretations and reflection on my commitment to self-determination. 


\subsubsection{Re-asserting anti-neoliberalism}

Ambitiously this research set out to re-kindle community education, a starting point that implies contemporary practice needs nourishment. Central to this suggestion is an antineoliberal argument, the ubiquity of which, across left-leaning literature, sometimes results in a caricature of its sentiment. Critics can interpret supporters as blind to the many complex and complicated interplays that determine the nature of reality, and of blaming the behaviour of a tiny elite, or oppressor class, for all social ills. One misinterpretation that holds currency when discussing community education is how theoretical and empirical tendencies within the neoliberal narrative can over-emphasise the coherence of neoliberalism, whilst simultaneously ignoring alternative political projects often exercised in local contexts (Bianco et al, 2014: 3130).

It is true that at its core, an anti-neoliberal perspective relies on a class analysis. Common within such arguments is reference to ongoing statistical portrayals that determine a gap in wealth distribution, both internationally (for example Wilkinson and Pickett, 2009; OECD, 2011; Oxfam, 2014) and domestically (for example Allen, 2003; O’Connor and Staunton, 2015). For those ascribing to an anti-neoliberal argument, these circumstances are not viewed as an inevitable feature of human development, but as a consequence of the way in which our social, economic and political realm is organised. Another common feature is support of intersectionality through stratifications such as gender, ethnicity, religious belief, and perceived ability. In attending to inherent discrimination, limitations of equality of opportunity; a chance for individuals to improve their lot without challenging structural causes, are also commonly ascribed to.

A flaw that can be identified within some anti-neoliberal arguments is a conviction that a sudden change in structural circumstances can alone eliminate inequality. Not only does this offer no explanation as to how intersectionality is effectively addressed, it under-estimates 
the pervasive and entrenched logic of neoliberalism, carried within society as common sense. Turn on the radio and you will frequently hear government ministers defend cuts in public transport through business logic and not people's need to get around. Cursorily analyse advertising and you witness symmetry between wellbeing and the workplace, review policy on educational reform and, overwhelmingly, its purpose is described through an instrumentalist vision where labour market demands are uncomplicatedly met. In embedding this hegemony, the education system plays a considerable role through its reproduction of capitalist norms (Freire, 1972, Giroux, 1983).

Contemporary capitalism also features alternative ways of thinking and being though these are less pervasive given the imbuement of capitalist logic within mainstream media (Herman and Chomsky, 1994; Bagdikian, 2004; Giroux, 2013) and the dominance of approaches to education that seek to integrate people into the structures of oppression (Freire, 1972). Alternatives include epistemological confrontations that conceptualise an alternative type of social order, one that Brookfield and Holst (2011, within chapter one) articulate as a world where basic needs are met, where there is fairness and inclusion, and where people's creativities are nurtured and supported. Through an anti-neoliberal lens and sharing aspirations for an alternative society, this chapter seeks to pull the threads of inquiry into a cohesive contribution that hopes to bring sustenance to community educators.

Adopting a mixed-methods model, the research topic was undertaken amidst ongoing tension on the use of quantitative research. Burdening concerns relate to researcher subjectivity when determining hypotheses to be tested, and reductionist tensions when quantifying complex concepts that are catagorised outside the contexts within which they are they played out. My defence of its use is influenced by a belief that the fight for social justice needs quantitative research to provide a tangible entity from which to defend its position (Oakley, 
1999). The incorporation of qualitative methods addressed much of my discomfort with quantitative research, providing an opportunity for participants to offer context, to challenge hypotheses, to elaborate on responses, to introduce areas for discussion, and, importantly, to enable deeper dialogic engagement on foot of survey participation.

This final consolidating chapter is specifically concerned with the incorporation of a third realm of inquiry pertinent to the research topic, to investigate ways in which a critical approach can further inform egalitarian ambition. In determining why critical intervention is required, this segment begins by problematising contemporary practice, particularly emphasising the limitations of individualised approaches when practiced within the socioeconomic restrictions of neoliberalism. It also challenges those influenced by social movement perspectives to consider the effectiveness of efforts where these are confined to localised, State-funded work. This chapter also draws from findings across all three phases of the study as I weave participant's proposals on ways forward with my own thoughts and reflections. I will also draw from my own experiences in community contexts, something you will be familiar with encountering throughout this contribution.

\subsection{Problematising practice}

One of the core themes developed in this study is the way in which a majority of practitioners lean toward a humanistic/person-centred approach. Many community educators are undoubtedly working to support personalised symptoms of inequality, and to open windows of possibility that would otherwise be difficult to access. In attending to this, many examples of teaching methods often associated with Freirean influences are shared by participants such as high levels of interaction, deep participation, and hands on learning (also incorporated across radical approaches). Though not always interpreted through the politicised lens Freire proposes, these are nevertheless a welcome alternative to the behaviourist-oriented approaches many of us experienced in school. Although the absence of community education 
participant-voices could be construed as a considerable blind spot in this study, what becomes evident though the expressions of practitioners is a sense of respect, care and concern built on an equality based foundation.

The weight of person-centeredness is not surprising given the hegemonic dominance of neoliberal concepts of individualism, and the political doctrine's dependence on its propagation for its own survival. However, for locally based educators to effectively commit to an equality agenda, the limitation of person-centeredness outside of a more structurally equitable society raises significant difficulties. These begin with its reliance on an autonomous self with inner freedom (Rogers, 1989: 28), a restrictive perspective considering the asymmetry of power inherent within neoliberalism. Moreover, individualised practitioner responses, whilst often oppositional in their refusal to embrace vocationalised demands, can strengthen the cultural embedding of individualism and individualised wellbeing. This restricts the potential for counter-hegemonic possibilities where, through sharing and validating personal experiences, a picture is painted of collective concern, one that exposes structural inequality and enables exploration of possibilities for intervention.

It is also worth interrogating the way in which theory and practice is sometimes dichotomised. This is because this division is too simplistic a paradigm to capture the complexity of relationships between doing, thinking and being. Divisions of theory and practice can afford a hierarchy of esteem to the theoretical, often requiring legitimisation by the academy. An implication of this can be demonstrated in the anti-intellectual response captured in this study, with $7 \%$ deliberately distancing themselves from adopting a philosophical approach. This is an understandable position to take when one considers the way in which the holding of theory can be used as a form of privilege, and can sometimes appear disconnected from lived experiences (hooks, 1994). One participant also makes the point that people can experience personal negativity by aligning themselves with a radical 
perspective, despite the way in which those offering challenge would also put forward ideas that 'would be considered part of left wing ideology'.

\subsubsection{The appropriateness of Further Education Awards in Community Education}

A second consideration worthy of deeper interrogation is the use of Further Education (FE) qualifications as positioned along the National Framework of Qualifications (NFQ), as the default certification mechanism for community education. It is worth reminding the reader that when groups were presented with the illustrative code (page 327), FETAC was named as a controlling force outside the room within each group setting. This point was also raised (sometimes at length) within tele-interviews and face-to-face individualised interviews. This study enabled practitioners to express their frustrations and to have these legitimised by peers. Through some exchanges, participants were encouraged by others to trust their intuition. Some comparisons were shared of creative approaches to accredited community education and some expressed confidence in being able to navigate the system in a less prescribed manner than is often the case. Whilst concern regarding over-assessment and the over-prescribed nature of programmes was a recurring theme, proposals for change could find currency with QQI, an organisation itself faltering under the weight of its work-load (QQ1, 2013a; 3-4), and victim of the neoliberal led stripping away of State support structures through New Public Management.

Evoking Foucauldian logic in considering how within an individualised society power through discourse can be exercised at the extremities (Foucault, 1977) there is also a question mark over the extent to which practitioners are regulating themselves. This is based on perceptions of FETAC/QQI convention and an inaccurate picture of the demands of the awarding body. This assertion is cautiously made amidst recognition of findings where tutor autonomy is described as considerably curtailed within some organisations, though strengthened through conversations within telephone interviews in particular where clear 
examples are relayed of organisational interpretation as problematic as distinct from accreditor demands. Other assertions of self-regulation are also made amidst my own experiences, relayed elsewhere, of how even when FETAC awards are stretched to their limits there is an ultimate, though not overwhelming, favouring of teaching to the assignment instead of teaching to community/group need (Fitzsimons, 2014). Further research on tutor perceptions when compared to the rules of the QQI regulatory body would be a welcome addition to our current understanding of community education practice.

The infiltration of Further Education (FE) awards is understandable given their affordability for organisations and participants alike. Alongside operational proposals for change as described above, there is an ideological difficulty that cannot be ignored given the potential for FE awards to re-enforce class division through associated social, cultural and economic esteem (Brine, 2006) and epistemological weight of meaning (West, 2006). Even where community educators share clandestine development of more critically-oriented classrooms than would be anticipated through strict conformance with the NFQ, the way in which these awards entrench class-based binary oppositions should not be ignored. This limits options for recipients, financial and otherwise (Davione et al, 2008; Maltone et al, 2012), and strengthens the likelihood of community education becoming an instrument in the reproduction of dominant social and material conditions.

The notion of a survival mentality (Crowley, 2013), as sometimes expressed within this study, is also important to interrogate. This relates to a sense that, if we keep our heads down and surf the wave so to speak, things will again get better. Any re-birth of an identifiable Community Sector as existed within the 1990s and 2000s seems extremely unlikely given the nature of our current neoliberal epoch, more than the usual boom-bust cycle of capitalism but an alternative model of financial organisation. The precarious nature of funding for Community Sector organisations coupled with their at times open opposition to government 
decision making has made them especially vulnerable to the shrinkage of the State which has been shepherded in through NPM. For those Community Sector organisations that remain within the Social Inclusion and Community Activation Programme (SICAP), approaches to community education outside of measureable employment related outputs, appear increasingly unlikely.

\section{3 Being the change - practitioner suggestions for change}

The suggestion that, through our actions, community educators might perpetuate inequality is, I imagine, a difficult pill for some to swallow. Many work tirelessly, and within increasingly precarious employment circumstances, to mop up the symptoms of inequality. Practitioners also report witnessing real change for individuals. These include growth of intellectual capacities, improved self-esteem and self-worth, reduced isolation, enhanced community and social engagement, and progression into education and employment.

Somewhat contradictorily, problematising practice in this way might not surprise practitioners as, when presented with the hypothesis 'the only way equality and social justice can be truly achieved is through a complete overhaul of our political and economic system', $75 \%$ agreed, $67 \%$ of who align themselves with person-centeredness as their default approach. This requires community education to turn in on itself, challenging practitioners to reconcile this sentiment with their equality agenda. Through dialogic exchanges, awareness of this gulf would seem to emerge from the expressions of practitioners. These have been gathered into five core themes: relationships with the State, potentials for networking, stronger sectoral identity, alternative accreditation possibilities and greater engagement with oppositional social movements. Each theme will now be discussed.

\subsubsection{Relationships with the State}

The first proposal by research participants is for continued engagement with the apparatus of the State, but in a more assertive, considered manner than is currently the case. This proposal 
was at times presented with reference to the pliability of funding, but this was not the only reason, with hopes to influence change infused within. A model of strategic participation/non-participation put forward by Crowther and Shaw (2014) and introduced earlier in this study (section 4.6) provides a template for conceiving of this. This encourages intervention where to do so would strengthen the democratic efficacy of a particular space, and where institutions can be held to account. One example might be current encouragement by network organisations to support practitioners in taking up spaces on Education and Training Boards (ETBs). This has been backed up by AONTAS who are providing shared spaces where people in these roles can come together to learn from each other, to support and to strategise. A limitation of this approach is an assumption of philosophical homogeneity within any block of community educators, who we now know to be influenced by a range of ideas. Varying perspectives considering our own experiences of inequality are again also important to contemplate. A continual question for community educators is how representative are they of those accessing community education? Should it be those accessing community education that provide representation at ETB level and not practitioners? When principles of community development are evoked, we are encouraged to act in a way that builds the capacity of those most affected by structural inequality, so they can be the locus for change. This was a point emphasised within one focus-group discussion. Community educators can be an important instrument in realising this by strategically avoiding participation, extending energies instead towards strengthening democratic educational spaces outside of governance settings; spaces within which politicisation and capacity building can be nurtured.

\subsubsection{Strengthening network relationships}

A second proposal extended within each focus-group and strong at other stages too, is a desire to strengthen networking relationships. Network formations offer a potential to share 
and legitimate experiences, to learn from each other, to generate knowledge and to help us make sense of our surroundings. Networks also enable us to collectively act (and reflect) on circumstances we are unhappy about. Proposals espoused earlier in this chapter, of the potential to push open the door in negotiating some sort of change with FETAC/QQI curricular design would, for example, carry more currency if it were advanced with the support of a network. Joining forces can also minimise self-regulatory behaviours as practitioners can find allies and grow in confidence in their abilities to shape structures, or adapt to group/community need. There is also a danger of network formation being offered as an elixir for all ills. This is especially so considering participant sharing of practical difficulties in attending network meetings, and of examples where networks failed to get off the ground. There is also a sense by some, that existing networks are, perhaps unwittingly, little more than an extension of the neoliberal State. In advancing this latter point, there were proposals for more politicised network formation without dependence on State funding.

\subsubsection{Stronger sectoral identity}

A desire to present ourselves as a more identifiable sector was asserted within each focusgroup setting, through many one-to-one interviews and amidst textual contributions within the research survey questionnaire. Outside of alignment through networks as asserted above, few tangible suggestions on how this might be advanced were put forward. Heterogeneous identity is an ongoing characteristic within both community education and community development work, perhaps symptomatic of the many interpretations of community as a concept, and determination of its purpose and relationships within society. Some ground has been made within the Community Sector in forging a unifying identity. Reports such as that commissioned by the trade union SIPTU (Harvey, 2012) outlining cuts to the Community Sector, have garnered some attention within the wider Trade Union movement. Individual 
and collective efforts by some journalists ${ }^{55}$ and activists have also broken into media spaces, pushing forward an identifiable sector in public awareness. However this has not curbed the severing of funding as was its usual intention. Studies such as this can help. This research scopes community education across provider type, not only through State provision, as is increasingly the interpretation implied through policy interventions but from a more politicised vantage point. Notwithstanding these suggestions, the absence of a clearly parametered understanding for community education can be perceived as a good thing (a point I will return to) as it has enabled its heterogeneous nature to flourish providing space for innovation and difference.

\subsubsection{Extending accrediting options}

A fourth proposal to emerge within one focus-group was towards establishment of independent accrediting capabilities. This is linked to preferences for university accreditation articulated as more suited to community-based education. Reasons for this preference are the less prescriptive nature of programmes, often supportive relationships from academic staff, and a reduced emphasis on technical skills-based learning. It is also proposed as a better ideological fit for those working in community development contexts. An easy recommendation to make on these pages is a call to strengthen alignment with alternative accreditors such as the university sector, but the prohibitive cost of this relationship is revealed through one contributor's sharing of how, in one instance, university registration costs were greater than the total cost of programme delivery. This should be of concern to radically oriented academics as it can compromise their ability to forge alliances.

For practitioners who interpret their role radically and as aligned with social movements for egalitarian change, there is also a need to continually negotiate the tension between praxis,

\footnotetext{
${ }^{55}$ One example is Vincent Browne, a high profile left-leaning political journalist and current affairs host who consistently invites representatives from the Community Sector on his high rating television show. He has broadcast 'budget specials' from within communities where there is a strong Community Sector presence featuring Community Sector employees, many from the areas in question, as members of expert panels.
} 
and a situation where the end game becomes the achievement of an award. Certainly it has been demonstrated that accreditation on a subject relevant to life struggle can lay a foundation in personal confidence (Fitzsimons and Dorman, 2013). Examples of this are shared in this study with certification being awarded for activism and collective politicisation. There is also a difficulties shared of how funding is increasingly tricky to source outside of interventions beyond an accredited set learning period. This is a difficult situation to reconcile when one considers the lengthy process of engagement others have detailed when working from principles of popular education (Kirkwood and Kirkwood, 1989; Kane, 2001; Beck and Purcell; 2010).

\subsubsection{Greater engagement with social movements}

A final proposal put forward from participants is that there should be greater engagement with oppositional movements. This was raised within three focus-groups and emerged during discussion relating to interpretations of community education as part of social change movements. It seems logical to suggest that, whenever possible, community educators should ally themselves with collective mobilisations against the impacts of neoliberalism, some of which are detailed throughout this study. However not all community educators are motivated, or comfortable with the notion of participation in oppositional demonstrations and civil disobedience, and the interpretation of community education as a social movement is a minority perspective within this study.

\subsection{Oil and Water? Person-centered approaches and relationships with radicalism}

Another way to approach, or perhaps complement the suggestion of greater involvement in oppositional movements, is to interrogate dichotomisation of practice into the radical, something often conceived of as 'over there' and articulated through active demonstration, and the non-radical, or person-centered, as is the dominant categorisation in this research. 
Certainly there are ideological differences between universal, compensatory and radical approaches, yet there can be fluidity across differentiation, particularly when socio-economic and historical contexts are taken into account. One way to conceive of this is to consider with whom community educators wish to ally, with employers, policy-makers and institutions, or with individuals, groups and communities? For many, I imagine the answer is all of these as determined by contexts, and again dichotomisation can be unhelpful. However, it is worth considering is the way most focus-group conversations included a questioning of the extent to which community education participants (or learners) were aware of controlling influences and power-brokers outside of the room. This is an important question and in order to demonstrate trust with learners/groups, we must interrogate the logic of the education systems within which we work (Shor and Freire, 1987). This includes being prepared to share our sense of frustrations and limitations.

Contributions by John Heron (1999) within chapter four of The Complete Facilitator's Handbook help us conceive of how this might be achieved. Heron details how, when groups come together, they are commonly characterised by dominant oppressive societal relations such as cultural norms on race, gender and perceived ability, emotional and creative repression, and dominant approaches to teaching and learning. Prevailing educational approaches usually locate power with the tutor/facilitator. When practitioners embody this, it can manifested itself in a reluctance to reveal frustrations, the adoption of a protectionist role, and a false perception that 'professionals' should in some way remain detached. Heron (1999) suggests tutors/facilitators can deliberately disrupt such patterns, enabling groups to unlock their potential to become spaces for cultural, educational and psychological openness. Part of how this is done is through already drawn out tenets of community education; the creation of environments conducive to dialogic learning, the design of multi-strand responsive curricula, a modelling of non-hierarchical leadership, and by encouraging 
emotional and creative expression. To do this authentically, Heron (1999) proposes dominant patterns need to be interrupted by deliberately naming behaviours, dilemmas and difficulties. Evoking these tactics means practitioner repertoires should be extended towards creating open spaces for critical problem-posing. In doing this, they should allow for reflective spaces within which tutor/facilitator frustrations and difficulties with power can also be shared. This is both person-centered and radical in its essence as it empowers groups and individuals by supporting their capacity to self-analyse their circumstances, and to determine their own involvement from a more informed position. Connolly captures the centrality of this approach below when she shares,

\footnotetext{
If we can ever have such a thing as a single, essential principle, it is that the entire process begins with the participants. It begins with their experience, their fears, their hopes, and their perceptions. Nevertheless if adult educators were to stay at this point, the whole endeavour would be fruitless. That is, the process of adult and community education is to engage with the experience of the participants and enable them to reflect on the significance and implications of the experience, making it meaningful for themselves, in the light of social and cultural structures. (Connolly, 2008: 55)
}

For the participants of community education being able to 'engage with the experience...in the light of social and cultural awareness' includes being able to critically analyse the structures that shape the educational experience they are participating in. These frameworks include the restrictions being placed on community education through vocationalisation, marketisation and the need to measure outcomes. Only then can we enable a theorisation of personal development that ensures it is understood within political and structural frameworks (Ryan, 2001: 65, Connolly and Hussey, 2013).

\subsection{Light many fires: encouraging anti-neoliberalism within and beyond}

Whilst much community education evolved within feminist notions of the personal as political, a concept extended across the broader community development spectrum (Connolly, 1996), neoliberalism has in many ways sought to reverses this. Poverty, unemployment, poor-housing, unequal access to education, and precarious working 
conditions, all of which have increased under the auspices of neoliberalism, are largely considered private concerns for the affected individual to rectify. The historical emergence of the Community and Voluntary Sector, in the 1980s and 1990s offered an oppositional movement to the direction of the State (Kirby and Murphy, 2011: 35). It has since been neutered through partnership, re-organised through New Public Management, and co-opted through realignment and privatisation. As a result of these changes, the Community Sector can no longer be considered an identifiable oppositional movement. These events are quite recent, and many attracted into the sector for its social movement potential, both insiders and outsiders, remain employed within structures now aligned with the State and controlled through increasingly rigid contracts. Equally the case, many attracted to Education and Training Board (ETB) structures are also restrained in determining the freedom through which they can work in a way that better reflects their philosophical orientations. This is a difficult situation for practitioners to reconcile as most are constrained by the need to work in order to meet demands within their personal lives, also determined through the neoliberalisation detailed within chapter one.

The co-option of the Community Sector and the increasing control over public sector provision is a devastating blow for community education. It represents the appropriation of traditional spaces for both consciousness-raising and spaces for healing. As part of trying to reclaim lost ground, it is important to conceive of community education as process-led and not locationally-led. This is an important point, as although a recommendation from practitioners relates to the assertion of a more recognisable sector, there are problems with attempts to do this. This includes the way in which any attempt to ring-fence practice, can in turn limit innovation and freedom. What cannot be co-opted are the principles of democratic problem-posing, an education that is rooted in justice, and commitment to self-determination. 
Those dedicated to these principles should incorporate them into practice in whatever spaces they can.

A common response I encounter when proposing such an approach, is concern with an increasing trend toward subject-specific approaches to community education. This cannot be removed from the dominance of accredited learning and the need to attend to requirements within module descriptors. However there can be compromise between these demands that would again discourage an understanding of radical practice as something that is beyond the confines of vocational and personal educational spaces. An example from my own practice might help. When considering the development and delivery of healthcare programmes within the confines of FETAC/QQI awards, a social analysis module was deliberately included. This enables incorporation of social determinants of health, an analysis of healthcare provision introducing concepts of neoliberalism, and a critique of the dominance of the medical model. Within other aspects of programme delivery there is also incorporation of the precarious and feminised nature of healthcare work, as well as examination of our own health, contextualised within socio-political and environmental circumstances. Other possibilities could involve forming alliances with social movements/advocacy groups. Invitations can be extended to patient-rights groups, elder-rights groups, and movements against hospital closures. Bringing social movements into community educational spaces helps to create permeability between these classroom environments, peoples lived realities, and associated responses more broadly. Brookfield and Holst (2011: 129) also offer examples of where vocationally driven agendas have been delivered in a way that exposes the relationship between programmes offered to recipients, and the global corporations that benefit from a flexible, mobile, precarious workforce. Additionally Kane (2001: 253-256) details how politicised pedagogy can underpin seemingly neutral spaces for teaching modern languages. 


\subsubsection{Extending practice beyond traditional walls}

Alongside creating spaces within a largely colonised space, community educators can, where possible, extend associated principles and processes into other spaces. Examples of this are within oppositional social movements (e.g. Kane, 2001), the Trade Union Movement (e.g. Newman, 2006) and environmental movements (e.g. Ryan, 2009). Domestic social movements such as the Right 2 Water $^{56}$ anti-water charges movement and contemporary feminist movements centred on women's reproductive rights have recently emerged. These are likely to incorporate praxis within and some practitioners in this study have indicated involvement in these spaces.

This notion, of lighting many fires through alternative ways of doing and being, can be enriched by further examination of arguments and concepts made in Crack Capitalism by John Holloway (2010). Many, including myself, are likely to find points of connection with much of his writing. Concepts that reverberate include the idea that spaces created as an alternative to the dominantly expressed norms of capitalism are not always politically conceived of, and of how movements established to oppose existing phenomenon can themselves become characterised by the very features they hoped to counter. It is by conjoining the many contrasting social relations and oppositional spaces, 'an interstitial process' (Holloway, 2010: 63) from below, within, and above, can potentially unlock the route to an alternative way of being.

There are some problems with Holloway's proposals, not least his determination that some individualised actions, such as reading a book, a day in the park, or chatting to friends (Holloway, 2010: 33) represent alternative ways of being that can be linked to anti-neoliberal sentiment. Susen (2012) robustly critiques Holloway's argument at length. These include his 'apocalyptic account of capitalist society' and unrealistic outlook on society (Susen, 2012:

\footnotetext{
${ }^{56}$ This broad based movement against the water charges includes Trade Unions, NGOs, network affiliations and left-wing political parties. Fuller information is available at www.right2water.ie
} 
295), conceptual vagueness, little substantive and empirical evidence in support of claims, and an essentialist approach to gender analysis. The difficulty with these criticisms is Susen's failure to capture the sentiment of Holloway's writing, a sentiment that carries much practical and personal resonance for many community educators as they struggle in their attempts to create a better world.

Whilst upholding the necessity to interrogate theory, it is through the eloquence of hooks (1994, particularly within chapter five), that we are encouraged to interpret theory in a way that helps us to make sense of what is happening around us, and of imagining possible futures. hooks reminds us that many people practicing from rich theoretical spaces may never have conceived of these through the academic terms associated with them. She also opposes the way in which jargonistic use of theory can perpetuate intellectual elitism, becoming an entity in itself that is disconnected from the lived realities of those it analyses. This suggestion is not one of anti-intellectualism, rather quite the opposite is proposed, by means of an intellectual gathering from below. The hope is of 'new theories rooted in our attempt to understand both the nature of our contemporary predicament, and the means by which we might collectively engage in resistance that would transform our current reality' (hooks, 1994: 67).

Holloway's notion of working in the cracks is not new to community education. hooks (1994: 185) herself has described consciousness-raising as the process 'of pedagogical strategies that create ruptures in the established order, that promote modes of learning which challenge bourgeois hegemony'. Others too evoke the notion of working within the fissures of society (Thompson, 2007). Working within the cracks, or margins, is also named within two one-to-one interviews with purposefully selected popular educationalists in this study, as well as within two focus-groups. The difficulty with this approach is outlined by one interviewee (within phase one) who names the way in which cracks can be interpreted as 
spaces where radicalism can be practiced in relative harmony, and without upsetting the apple cart in any meaningful way. This concealment of radical practice is perhaps where co-option can be considered particularly effective by siphoning those with oppositional tendencies away from more overtly political organisations. I echo sentiments expressed by this research participant in phase one, that we come out of the cracks and encourage a more critical approach across the wider community of education providers extending this beyond the confines of Community Sector and public community education provision.

\subsection{Concluding remarks}

This research presents a tapestry of community education across provider type. It reveals practitioner characteristics, employment conditions and common approaches to practice. It shares details of the type of groups and communities community educators engage with and it provides information on the influences that underpins their work. It also tells us about challenges they face and their hopes for the future of community education in Ireland. I undertook this inquiry in order to address a gap in Irish research with potential to influence the international field more broadly also.

This final chapter set out to consolidate thoughts built from extensive findings and analysis on community education through the perspective of practitioners, of which I am one. Reasserting its anti-neoliberal position, it again emphasised the logic of neoliberalism and the potential for community education to create counter-hegemonic spaces for change. If we are to reclaim the practice of community education, wherever this is located, we must litmus test our actions against the needs and expressed concerns of communities within which we live, work, advocate for, and, at times purport to represent. Only through this can we encourage a practice of freedom and not domestication, of problem-posing and not instrumentalism, of caring and not cruelty. 
The study is offered as a potential tool to inform communities, community educators, organisers, academics, and other interested parties. Some dissemination and incorporation of methods developed have already been tried out particularly the use of codes and illustrations designed for this research. Each time these have evoked similar response to that which has been detailed in this contribution. This latter action in particular alludes to the way in which my work as a researcher is, as yet, unfinished. I hope there will be a further phase of active dissemination and future planning and dialogue on next steps, most likely through existing network structures.

My hope is that community educators can work in a way that supports self-determination for those experiencing structural inequality, something educators can strengthen through authentic and honest relationships with those they encounter. A further goal is that those of us occupying ally positions continue to engage in a reflexive relationship with the cultural privilege we assume. By way of bookmarking this body of work, it seems best to leave the last words to a research participant.

The levels of exploitation, corruption and inequality are simply unacceptable and the levels of suffering that people are experiencing are also unacceptable. We need to change this and community education is one of the key tools that we have for doing this. Let's continue this journey! 


\section{Bibliography}

Allen, K. (2000) The Celtic Tiger: The myth of Social Partnership. Manchester University Press

Allen, K. (2003) 'Neither Boston nor Berlin: Class polarisation and Neo-liberalism in the Irish Republic' in Coulter, C. and Coleman, S. (editors) The End of Irish History? Critical reflections on the Celtic Tiger. Manchester University Press

Allen, K. (2007) The Corporate Takeover of Ireland. Dublin: Irish Academic Press

Allen, K. and O'Boyle, B. (2013) Austerity Ireland: The Failure of Irish Capitalism. London: Pluto Press

Allias, S. (2007) 'Education service delivery: the disastrous case of outcomes-based qualifications frameworks’ Progress in Development Studies, 7(1): 65-78

Allias, S. (2011) 'The changing faces of the South African national qualifications framework' Journal of Education and Work, 24 (3): 343-358

Allman, P. (2001) Critical Education against Global Capitalism. Karl Marx and Revolutionary Critical Education. Westport CT: Bergin and Garvey publisher

AONTAS (2004) Community Education. Dublin: AONTAS

AONTAS (2010) Response to the report of the Further Education (Teacher Education Qualification Group) of the Teaching Council. Retrieved from http://www.aontas.com/download /pdf/teachcounsub10.pdf [accessed March, 2014]

AONTAS (2011) Strategic Plan 2011-2013. Dublin: AONTAS

AONTAS (2012) AONTAS submission on SOLAS consultation Process. Retrieved from, http://www.aontas.com/download/pdf/aontas_submission_on_solas_consultation_process.pdf [accessed September, 2012].

AONTAS (2012b) Measuring the Outcomes of Community Education - various models and the role of accreditation. Retrieved from http://www.aontas.com/download/pdf/meeting _16_report_final.pdf [accessed February, 2015]

AONTAS CEN (2008) Community Education Network, Developing a voice for the nonformal adult education sector. A case study of the AONTAS community Education Network. Retrieved from, http://www.aontas.com/download/pdf/aontas_community_education_ network_a_case_study.pdf [accessed November, 2014]

AONTAS CEN (2011) Summary Report on small-scale research into the funding streams accessed by members of the Community Education Network, retrieved from http://www.aontas. com/download/pdf/20100511125711.pdf [accessed March, 2015]

AONTAS CEN (2014) The QQI Re-engagement Fee and the case for a waiver for independently managed community education providers. Retrieved from,

http://www.aontas.com/download/pdf/the_qqi_reengagement_fee_the_case_for_a_waiver_fo r_independently_managed_community_education_providers.pdf [accessed July, 2014] 
Archer, M. S. (1995) Realist Social Theory: The Morphogenetic Approach. Cambridge University Press

Arensman, E., McAuliffe, C., Corcoran, P., Williamson, E., O’Shea, E. and Perry, I. (2012) First Report of the Suicide and Information System. Cork: National Suicide Research Foundation

Arnstein, S. (1969) 'A ladder of citizen participation', Journal of American Institute of Planners, 35 (1): 216-24

Aronowitz, S. (1993) 'Paulo Freire's Radical Democratic Humanism' in McLaren, P. and Leonard, P. (editors), Paulo Freire a Critical Encounter. London and New York: Routledge

Aspin, D.N. and Chapman, J.D. (2000) 'Lifelong Learning, concepts and conceptions' International Journal of Lifelong Education, 19 (1): 2-19

Azmanova, A. (2012) 'De-gendering social justice in the $21^{\text {st }}$ Century, an imminent critique of neo-liberal capitalism', European Journal of Social Theory, 15 (2): 143-156

Bagdikian, B. H. (2004) The New Media Monopoly. Boston: Beakon Press Books

Ball, S.J. (2012) 'Performativity, commodification and commitment: an i-spy guide to the neoliberal university', British Journal of Educational Studies, 60 (1): 17-28

Ball, R. and Drury, J. (2012) 'Representing the Riots: The (mis)use of statistics to sustain ideological explanation', Radical Statistics, 106. Retrieved from, http://www.radstats.org. uk/no106/ [accessed, March, 2014]

Bailey, I. (2006) 'Overview of the Adult Literacy System in Ireland and current issues in its implementation', Review of Adult Learning and Literacy, 6. US: National Centre for the study of Adult Learning and Literacy

Bailey, N., Breen, J. and Ward, M. (2010) Community Education: More than just a course. Dublin: AONTAS

Bailey, N., Ward, M. and Goodrick, M. (2011) Sowing the seeds of change, The Outcomes and Impact of a Social Action Model of Community Education, Dublin: AONTAS

Baker, J., Lynch, K., Cantillon, S. and Walsh, J. (2004) Equality, from Theory to Action, UK: Palgrave MacMillan

Barbour (2007) 'Doing Focus Groups' in The Sage Qualitative Research Kit. London: Sage publications

Barkholt, K. (2005) 'The Bologna Process and Integration Theory: Convergence and Autonomy', Higher Education in Europe, 30 (1): 303-312

Bassett, M. (2007) Background Paper to inform Combat Poverty Submission to Department of Community Rural and Gaeltacht Affairs on the development of the Community Development Programme Dublin: The Combat Poverty Agency. Retrieved from http://www.combatpoverty.ie/publications/BackgroundPaperOnCDP_2007.pdf [accessed January, 2015] 
Bassett, M., Brady, B., Ingles, T. and Fleming, T. (1989) For Adults Only - A case for Adult Education in Ireland, Dublin: AONTAS

Beck, D. and Purcell, R. (2010) Popular Education Practice for Youth and Community Development Work, Exeter: Learning Matters Limited

Beno, B. A. (2004) 'The Role of Student Learning Outcomes in Accreditation Quality Review', New Directions for Community Colleges, 126

Berner, E. and Philips, B. (2005) 'Left to their own devices. Community self help between alternative development and neo-liberalism' Community Development Journal, 40 (1): 17-29

Bethlehem, J. (2010) 'Selection Bias in Web surveys', International Statistical Review, 78 (2): $161-188$

Bhagwati, J. (2004) In Defense of globalization, Oxford University Press.

Bhaskar, R. (1998) 'General Introduction', in Archer, M., Bhaskar, R., Collier, A., Lawson, T. and Norrie, A. (editors), Critical Realism: Essential Readings, Centre for Critical Realism

Bianco, I., Griggs, S. and Sullivan, H. (2014) 'Situating the local in the neoliberalisation and transformation of urban governance', Urban Studies, 51(15): 3129-3146

Biesta, G. (2010) 'Pragmatism and the philosophical foundations of mixed-methods research' in A., Tashakkori and Teddlie, C. (editors), The Sage Handbook of Mixed-methods in social and Behavioural research USA: Sage Publications

Biesta, G. and G. J. Stams (2001) 'Critical Thinking and the Question of Critique: Some lessons from deconstruction' Studies in Philosophy of Education, 20: 57-74

Bissett, J. (2008) Regeneration public good or private profit, Dublin: Tasc at New Island Birch, K. and Mykhnenko, V. (2010) The Rise and Fall of Neoliberalism, London and New York: Zed Books

Blackburn, J. (2000) 'Understanding Paulo Freire, reflections on the origins, concepts and possible pitfalls of his educational approach', Community Development Journal, 35 (1): 3-15

Blaikie, N. (2010) Designing Social Research, $2^{\text {nd }}$ edition, Cambridge: Polity Press.

Bloom, S., Krathwohl, D. and Masia, B. (1984) Taxonomy of Educational Objectives and the classification of educational goals, University of Michigan: Longman

Boldt, S., Devine, B., MacDevitt, D. and Morgan, M. (1998) Educational disadvantage and Early School Leaving, Dublin: The Combat Poverty Agency

Borg, C. and Mayo, P. (2005) 'The EU Memorandum on lifelong learning. Old wine in new bottles?', Globalization, Societies and Education, 3 (2): 203-225

Boshier, P. (2006) Perspectives of Quality in Adult Learning, London: Continuum International Publishing.

Boud, D. (1995) 'Assessment and learning: contradictory or complementary?' in Knight, P. (editor) Assessment for Learning in Higher Education, Oxon: RoutledgeFalmer 
Boughton, B. (2013) 'Popular Education and the Party Line' Globalisation, Societies and Education, 11 (2): 239-257

Bourdieu, P. (1984) Distinction: A social Critique of the Judgment of Taste, USA: Routledge and Kegan Paul Ltd

Bowles, S. and Gintis, H. (1976) Schooling and Capitalist America. Educational Reform and the Contradictions of Economic Life, London: Routledge and Kegan Paul Ltd.

Bowl, M. (2011) 'Communities of practice, compliance or resistance? Regional networks in the adult and community education sector in Aotearoa New Zealand', Community Development Journal, 46 (suppl. 2): 83-96

Boyce, D. (1995) Nationalism in Ireland, $3^{\text {rd }}$ Edition, London: Routledge

Brady, B. (2003) 'Twenty Years A-Growing', The Adult Learner, Irish Journal of Adult and Community Education, 67-72

Brady, B. (2006) 'Developing Innovative Responses to the education of adults and young people: the Irish experience', Convergence, XXXIX, (2-3): 39-47

Brine, J. (2006) 'Lifelong Learning and the Knowledge Economy: Those That Know and Those That Do Not: The Discourse of the European Union' British Educational Research Journal, 32 (5): 649-665

Broaderick, S. (2002) 'Community Development in Ireland - A policy review' Community Development Journal, 37 (1): 101-110

Brittingham, B. (2009) 'Accreditation in the United States: How did we get to where we are?' New Directions for Higher Education, 145: 7-27

Brookfield, S. D. and Holst, J. D. (2011) Radicalizing Learning: Adult Education for a Just World, San Francisco: Jossey-Bass

Brooks, A. (2006) 'Feminist Standpoint Epistemology, building knowledge and empowerment through women's lived experience', in Nagy Hessey-Biber, S. and Leavy, P. (editors), Feminist Research Practice, A primer, USA: Sage Publications

Bryman, A. (2004) Social Research Methods, $2^{\text {nd }}$ edition, Oxford University Press Bryman, A. (2007) 'Barriers to Integrating Research' Journal of Mixed-methods Research, 1 (8): $8-22$

Burke L. and Miller M. (2001) 'Phone interviewing as a means of data collection: Lessons learned and practical recommendations' [Online journal] Forum: Qualitative Social Research. Retrieved from, http://www.qualitative-research.net/index.php/fqs/article/ view/959/2094, [accessed June, 2014]

CAN (2010) Community Development for Positive Systemic Change Strategic Plan 20102015, Dublin: CAN publications

Carr, J. (2011) 'Regulating Islamophobia: The Need for Collecting Disaggregated Data on Racism in Ireland', Journal of Muslim Minority Affairs, 31 (4): 574-593 
Carroll, D. and Patterson, V. (2011) A profile of under graduate mature new entrants. Higher Education Authority, Retrieved from, http://www.hea.ie/en/statistics/statistics-sectionpublications, [accessed December, 2013]

Carey, L. (1979) 'The History of AONTAS', A review of Adult Education. Dublin: AONTAS, 10-15

Castro, F. G., Kellison, J. G., Boyd and S. J., Kopak, A. (2010) A Methodology for Conducting Integrative Mixed-methods Research and Data Analyses', Journal of Mixedmethods Research, 4 (4): 342-360

Community Education Facilitators' Association (2011) Community education, enhancing learning, fostering empowerment, contributing to civic society: Position paper. Retrieved from, http://www.cefa.ie/uploads/1/5/8/8/15883224/cefa_ce_position_paper.pdf, [accessed March, 2015]

Central Bank (2014) Quarterly Bulletin, April, Dublin: Central Bank of Ireland. Retrieved from, http://www.centralbank.ie/publications/Documents/Quarterly\%20Bulletin\%20QB\% 202.pdf [accessed, November, 2014].

Cervero R. (1988) Effective Continuing Education for Professionals, San Francisco: JosseyBass

Chanan, G. (2009) 'In and not Wholly Against the State: Widening Standards for Community Development', Working for Change: The Irish Journal of Community Work, 52-63

Chaney, P. (2012) 'New legislative settings and the application of the participativedemocratic model of mainstreaming equality in public policy making: evidence from the UK's devolution programme' Policy Studies, 33 (5): 455-476

Chomsky, N. (1999) Profit over People: Neoliberalism and Global Order, New York: Seven Stories Press

Chomsky, N. (2006) Failed States: The Abuse of Power and the Assault on Democracy, London: Penguin books

Choules, K. (2007) 'Social Change Education, context matters' Adult Education Quarterly, 57 (2): I59-176

Citro, C. F., Ilgen, D. R. and National Research Council (2003) Protecting Participants and Facilitating Social and Behavioral Sciences Research, Washington: National Academies Press

Clancy, P. (1999) 'Education Policy' in Quin, S., Kennedy, P., O’Donnell, A. and Keily, G. (editors) Contemporary Irish Social Policy, Dublin: University College Dublin Press

Clark, D. (1996) Schools as Learning Communities. Transforming Education, London: Cassell Education

Clarke, J. (1989) 'Issues arising at the conference' in Community Work in Ireland: Trends in the 80s; Options for the 90s, Dublin: Combat Poverty Agency

Clarke, J. and Newman, J. (1997) The Managerial State. Power, Politics and Ideology in the Remaking of Social Welfare, London: Sage Publications 
Clover, D. E., Jayme, B. O., Hall, B. L. and Follen, S. (2013) The Nature of Transformation: Environmental Adult Education, Rotterdam: Sense Publishers.

Coakley, M. (2012) Ireland in the World Order: A History of Uneven Development, London: Pluto Press

Coffey, A. (2004) Reconceptualizing Social Policy, Berkshire, GBR: McGraw-Hill Education

Cohen, L., Manion, L. and Morrison, K. (2011) Research Methods in Education, $7^{\text {th }}$ Edition, London: Routledge

Collins, T. (2002) 'Community Development and State Building: A shared Project', Community Development Journal, 37(1): 91-100

Collins, M. (1993) 'Critical Commentaries on the role of the Adult Educator: From selfdirected learning to postmodernist sensibilities' in Welton, M.R. (editor) In Defense of the Life-world, New York: State University of New York Press

Collins, M. (1995) Adult Education as a Vocation, A Critical Role for the Adult Educator. London: Routledge.

Collins, K. M. T., Onwuegbuzie, A. J. and Jiao, Q. G. (2007) ‘A Mixed-methods Investigation of Mixed-methods Sampling Designs in Social and Health Science Research', Journal of Mixed-methods Research, 1: 267-294

Collins, M. L., MacMahon, B., Weld, G. and Thornton, R. (2012) 'A MINIMUM INCOME STANDARD FOR IRELAND, A consensual budget standards study examining household types across the lifecycle', Studies in Public Policy, 27, The Policy Institute, Trinity College Dublin

Combat Poverty Agency (1994) 'Overview and main recommendations' in Harvey, B.

Combating Exclusion: Lessons from the third EU poverty programme in Ireland 1989-1994.

Dublin: Combat Poverty Agency

Combat Poverty Agency (2003) Submission to the Department of Community, Rural and Gaeltacht Affairs on Local and Community Development Structures, Dublin: The Combat Poverty Agency.

Commission on Adult Education (1984) Lifelong Learning: Report on the Commission on Adult Education, Dublin: The Stationary Office

Committee on Adult Education (1973) Adult Education in Ireland, Dublin: Stationary Office

Community Educators Facilitation Association (2011) Community Education, Enhancing Learning, Fostering Empowerment and contributing to Civil Society, A position paper by the Community Education Facilitation Association, CEFA

Community Workers Cooperative (2008) Towards standards for Quality Community Work. An all-Ireland statement of values, principles, work standards, Galway, Community Workers Cooperative

Community Workers Cooperative (2013) Alignment Update \#2 The second in a series of Updates on the CWC Alignment Project, retrieved from, http://www.cwc.ie/wp-content/ uploads/2013/10/CWC-Alignment-Project-Update-23.pdf, [accessed March, 2015] 
Community Workers Cooperative (2014a) Alignment Update \#5 The fifth in a series of Updates on the Reform of Local Government Act and the implementation of SICAP Social Inclusion community Activation Programme. Retrieved from, http://www.cwc.ie/wpcontent/uploads/2014/11/SICAP-Update-draft-2.pdf [accessed, February, 2015]

Community Workers Cooperative (2014b) 'CWC alignment Project' Community Work News, the newsletter of the community workers cooperative, Spring: 2-5. Retrieved from http://www.cwc.ie/2014/03/cwc-community-work-news-spring-2014/ [accessed August, 2014]

Connolly, B. (1996) 'Community Development and Adult Education: Prospects for Change?' in Connolly, B., Fleming, T., McCormick, D. and Ryan, A. (editors) Radical Learning for Liberation, Centre for Adult and Community Education, St Patrick's College, Maynooth

Connolly, B. (1999) 'Groupwork and facilitation: a feminist evaluation of their role in transformative adult and community education' in Connolly, B. and Ryan, A.B. (editors) Women in Education in Ireland, Volume 1. Kildare: Centre for Adult and Community Education

Connolly, B (2001) Women's Community Education in Ireland, AONTAS, retrieved from http://www.aontas.com/pubsandlinks/publications/womens-community-education-in-ireland2001/ [accessed July 2012]

Connolly, B. (2003) 'Community Education: Listening to the voices', The Adult Learner, the Irish Journal of Adult and Community Education, (10): 9-19

Connolly, B. (2005) 'Learning from the Women's Community Education Movement in Ireland' in Crowther, I., Galloway, V. and Martin, J. (editors) Popular Education, engaging the Academy, International Perspectives, Leicester: NAICE

Connolly, B (2006) Adult and Community Education, a model for Higher Education? Retrieved from http://eprints.nuim.ie/1064/1/BridConnollyAdEdMPPS.pdf [accessed October, 2014]

Connolly, B. (2007) Beyond the Third Way: New Challenges for Critical Adult and Community Education in Connolly, B., Fleming, T., McCormack, D. and Ryan, A. (editors) Radical Learning for Liberation 2. Maynooth Adult and Community Education, Maynooth

Connolly, B. (2008) Adult Learning in Groups. Berkshire: Open University Press

Connolly, B. (2010) Community Education: Perspectives from the Margins. Retrieved from http://eprints.maynoothuniversity.ie/3570/1/BC_community_education.pdf, [accessed March, 2015]

Connolly, B. (2014) 'Community Education: Exploring formative influences within the maelstrom of conflicting social forces', in Murray, M., Grummell, B. and Ryan, A. (editors) Further Education and Training, history politics and practice, Kildare: MACE press publications

Connolly, B. and Hussey, P. (2013) 'The War against People: Adult education practice for critical democracy', The Adult Learner. The Irish Journal of Adult and Community Education, 75-89 
Connolly, E. (2007) The Irish Experience of Development: Local Partnership - Working Paper from research project on Engagement with Civil Society for Poverty Reduction, The advisory Board for Irish Aid. Retrieved from, http://www.dcu.ie/ cis/research/PDF/CivilSoc-Irish-Local-Partnership.pdf [accessed May, 2014]

Connolly, L. (2002) The Irish Women's Movement, from Revolution to Devolution, Basingstoke: Palgrave

Connolly, L. and Hourigan, N. (2006) Social Movements and Ireland, Manchester University Press

Conroy, P. and O' Leary, H. (2007) Community Development and policy learning in Further Education in Ireland, Dublin: Combat Poverty Agency

Coolahan, J. (1981) Irish Education: Its History and Structure, Dublin: Institute of Public Administration.

Cornelius-White, J. (2007) 'Learner-centred teacher-student relationships are effective: A Meta-Analysis' Review of Educational Research, 77 (1): 113-143

Coulter, C. (2003) 'The end of Irish history? An introduction to the book', in Coulter, C. and Coleman, S. (editors) The end of Irish history? Critical reflections on the Celtic Tiger, Manchester University Press

Council of the European Union (2008) Consolidated Versions of the Treaty on European Union and the Treaty on the Functioning of the European Union. Brussels, retrieved from https://www.consilium.europa.eu/uedocs/cmsUpload/st06655-re01.en08.pdf, [accessed March, 2015]

Council of the European Union (2011) Council Resolution on a renewed European agenda for adult learning. Retrieved from http://register.consilium.europa.eu/doc/srv?l=ENandf=ST $\% 2016743 \% 202011 \% 20 I N I T$ [accessed, May, 2015]

Craig, G., Popple K. and Shaw M. (2008) Community Development Theory and Practice, an International Reader, London: Coronet Books Inc

Crean, M. (2008) PRAXIS: Developing a popular education model in Ireland Exploring the role of ideology and popular education as part of a community-based movement for equality and social justice, retrieved from https://universityincrisis.files.wordpress.com /2011/12/praxis _working-paper_july-2008.pdf [accessed March, 2015]

Crenshaw, K. W. (1995) 'Intersectionality, identity politics and violence against women of color' in Crenshaw, K. W., Gotanda, N., Peller, G. and Thomas, K. (editors) Critical Race Theory: the key writings that formed the movement, New York: The New Press

Creswell, J. and Plano Clarke, V. (2011) Designing and Conducting Mixed-methods Research, $2^{\text {nd }}$ Edition, USA: Sage Publications.

Crickley, A. and Devlin, M. (1989) 'Community Work in the '80s - an Overview' in Community Work in Ireland: Trends in the 80s; Options for the 90s, Dublin: Combat Poverty Agency.

Crickley, A. and Mc Ardle, O. (2009) 'Community work, Community development: Reflections 2009', Working for Change: The Irish Journal of Community Work, Issue 1 
Croché, S. (2009) 'Bologna network: a new sociopolitical area in higher education', Globalization, societies and education, 7 (4): 489-503

Crowley, N. (1998) Partnership 2000: Empowerment or Co-option? in Kirby, P and David Jacobson (editors) In the Shadow of the Tiger: New Approaches to Combating Social Exclusion, Dublin: Dublin City University Press

Crowther, J., Martin, I. and Shaw, M. (1999) Popular Education and Social Movements in Scotland today, Leicester: National Institute of Adult Continuing Education

Crowley, N. (2013) 'Lost in Austerity. Rethinking the Community Sector' Community Development Journal, 48 (1): 151- 157

Crowther . J., Galloway, V. and Martin, I. (2005) Popular Education, engaging the Academy, International Perspectives, Leicester: NAICE

Crowther, J. and Shaw, M. (2014) 'Adult Education, Community Development and Democracy renegotiating the terms of engagement' Community Development Journal, 49 (3): 390-406

Cruikshank, J. (2004) 'A tale of two Ontologies: an imminent critique of critical realism' The Sociological Review, 52 (4): 567-585

CSO (2008) Statistical Yearbook of Ireland, Dublin: Central Statistics Office

CSO (2012) This is Ireland, Highlights from Census 2011, part 2, Dublin: Government Publications, The Stationary Office

CSO (2013a) Quarterly National Household Survey Effect on Households of the Economic downturn, Quarter 3 2012, retrieved from, athttp://www.cso.ie/en/media/csoie/releases publications/documents/labourmarket/2012/QNHSeconomicdownturnq32012.pdf [accessed June, 2014]

CSO (2013b) Survey on Income and Living Conditions (SILC) Thematic Report on the Elderly 2004, 2009, 2010 (revised) and 2011, retrieved from http://www.cso.ie/en/media/csoie/releases publications/documents/silc/2011/elderly040910and11.pdf, [accessed January, 2015]

Cullen, B. (1994) A programme in the Making, a review of the community development programme, Dublin: The Combat Poverty Agency

Cullen, C. (2009) 'The Museum of Irish Industry, Robert Kane and education for all in the Dublin of the 1850s and 1860s' History of Education, 38 (1): 99-113

Cullen, M. (1987) Girls Don't do Honours. Irish Women in Education in the $19^{\text {th }}$ and $20^{\text {th }}$ centuries, Dublin: Women's Educational Bureau

Cullinane, S. (2003) 'Community Education Facilitators- Salvation for Community Education?', The Adult Learner, the Irish Journal of Adult and Community Education, 79-86

Curley, H. (2007) Finding Your Way around the Community and Voluntary Sector, Dublin: The Combat Poverty Agency 
Daly S. (2007) 'Mapping civil society in the Republic of Ireland', Community Development Journal, 43 (2): 157-176

Darner, A., Baltodano, M. and Torres, R.D. (2009) The Critical Pedagogy Reader, $2^{\text {nd }}$ edition, New York and London: Routledge

Davidson, A. (1977) Antonio Gramsci, Towards and Intellectual biography. New Jersey: Merlin Press

Davione, L., Erhel, C. and Guergoat-Lariveire, M. (2008) Monitoring Quality in Work: European Employment Strategy Indicators and Beyond' International Labour Review, 147 (2-3): 163-198

Della Porta, D. and Diani, M. (2006) Social Movements: An introduction, $2^{\text {nd }}$ edition, Oxford: Blackwell publishing

Denny, K. J., Harmon, C. P. and O’Sullivan, V. (2003) Education, Earnings and Skill, a Multi-Country Comparison, London: The Institute for Fiscal Studies

Denzin N. K. and Lincoln, Y. S. (2005) The Sage Handbook of Qualitative Research, ${ }^{\text {rd }}$ Edition. USA: Sage Publications.

Department of Community, Rural and Gealteacht Affairs (2009) National Drugs Strategy (interim) 2009-2016 retrieved from http://www.drugsandalcohol.ie/12388/1/DCRGA_ Strategy_2009-2016.pdf, [accessed March, 2015]

Department of Education and Science (1997) International Adult Literacy Survey Report, results for Ireland, Ireland: Department of Education and Science

Department of Education and Science (2000) Learning for Life, White Paper on Adult Education Dublin: Government Publications

Department of Education and Science (2001) EU Memorandum of Lifelong Learning Response to the Irish Consultation Process, Dublin: Department of Education and Science

Department of Education and Science (2004) A brief Description of the Irish Education System, Communications Unit Department of Education and Science

Department of Education and Science (2005) Literacy and Numeracy in Disadvantaged Schools: Challenges for Teachers and Learners, Dublin: Government Publications

Department of Education and Skills (2011) Evaluation of the Labour Market Activation Fund (LMAF) 2010, Final Report.PA Consulting group, retrieved from, https://www.education .ie/en/Publications/Corporate-Reports/Financial-Reports-List/lmaf_report.pdf, [accessed July, 2014]

Department of the Environment, Community and Local Government (2007) Cohesion Process, retrieved from, http://comhshaol.ie/en/Community/LocalCommunity Development/ CohesionProcess/ [accessed July, 2014]

Department of Environment, Community and Local Government (2012a) Final Report of the Local Government/Local development Alignment Steering Group. Dublin: Government Publications. 
Department of Environment, Community and Local Government (2012b) Putting People First, Action Programme for Effective Local Government, Government of Ireland.

Department of Social Protection (2011) Project Plan for the Development and Implementation of the National Employment and Entitlements Service, retrieved from http://www.welfare.ie/en/downloads/nees.pdf, [accessed March, 2015]

De Vaus, D. (2002) Surveys in Social Research, $5^{\text {th }}$ Edition. London: Routledge Taylor and Francis Group

Dewey, J. (1997) Experience and Education, New York: Touchstone

Dickins, C. (2012) Hard Times, London: Harper Press

Dockery, T. M. and Bedeian, A. G. (1989) 'Attitudes versus Actions, LaPeire's classic study revisited' Social behavior and Personality, 17 (1) 6-19

Dooley, M. and Kavanagh, L. (2006) Philosophy of Derrida, Durham: Acumen

Dorgan, J. (2009) Adult Literacy Policy, A review for the National Adult Literacy Agency, Dublin: NALA

Dorman, P. (2006) Things Can be Different, The Transformation of Fatima Mansions. Dublin: CAN publications

Douthwaite, R. (1999) The Growth Illusion. How economic growth had enriched the few, impoverished the many and endangered the planet, revised edition. Devon: Green books ltd

Drudy, P.J. and Punch, M. (2005) Out of Reach. Inequalities in the Irish Housing System, Dublin: Tasc at New Island.

Duckworth, V. and Tummons, J. (2010) Contemporary Issues in Lifelong Learning, Berkshire: Open University Press.

Duggan, (1999) Locally-based Interventions to Combat Poverty and Exclusion How effective can they be? A Paper Presented at the 1999 conference of the Irish Social Policy WRC Social and Economic Consultants, retrieved from http://www.wrc.ie/publications/locallyb.pdf, [accessed September, 2014]

Duménil, G. and Lévy, D. (2004) ‘The Neoliberal (Counter) Revolution' in Saad-Filho, A. and Johnston, D. (editors) The Crisis of Neoliberalism, London: Pluto Press

Duménil, G. and Lévy, D. (2011) The Crisis of Neoliberalism, Cambridge: Harvard College publishers.

Easterly, W. (2005) 'What did structural adjustment adjust? The association of policies and growth with repeated IMF and World Bank adjustment loans', Journal of Development Economics, 76: 1- 22

Elias, J. L. and Merriam, S. B. (1995) Philosophical foundations of Adult Education, $2^{\text {nd }}$ edition, Florida: Kreiger Publishing Company

Ellison, S. (2009) 'On the poverty of philosophy: The metaphysics of McLaren's "Revolutionary critical pedagogy" Educational Theory, 59 (3): 327-351 
Eivers, E., Shiel, G. and Shortt, F. (2004) Reading literacy in disadvantaged primary schools, Dublin: Educational Research Centre

Eivers, E., Shiel, G., Perkins, R. and Cosgrove, J. (2005) Succeeding in reading? Reading standards in Irish primary schools, Dublin: Stationery Office

Eivers, E., Close, S., Shiel, G., Millar, D., Clerkin, A., Gilleece, L. and Kinriy, J. (2010) The 2009 National Assessments of mathematics and English reading, Dublin: Stationary Office.

Entwistle, N. (2005) 'Learning outcomes and ways of thinking across contrasting disciplines and settings in higher education', The curriculum Journal, 16 (1): 67-82

Eschle, C. (2001) Global Democracy, Social Movements, and Feminism, Colorado: Westview Press.

ESRI (2015) New Irish Research Shows that the Gap in Life Expectancy Between Social Groups Increased During the Boom retrieved from, www.esri.ie/newsevents/latestpress releases/new-irish-research-shows-/index.xml [accessed March, 2015]

European Commission (2001) Making a European Area of Lifelong Learning a Reality, retrieved from http://eur-lex.europa.eu/LexUriServ/LexUriServ.do?uri=COM:2001:0678 :FIN:EN:PDF [accessed March, 2015]

European Commission (2000) A memorandum for Lifelong Learning, retrieved from http://pjp-eu.coe.int/documents/1017981/1668227/COM_Sec_2000_1832.pdf/f79d0e69b8d3-48a7-9d16-1a065bfe48e5, [accessed, March 2015]

European Higher Education Area (1999) The Bologna Declaration, Retrieved from, http://www.bologna-berlin2003.de/pdf/bologna_declaration.pdf, [accessed July, 2014]

European Parliament (2014) DIRECTIVE 2014/24/EU OF THE EUROPEAN PARLIAMENT AND OF THE COUNCIL on public procurement and repealing Directive 2004/18/EC, retrieved from http://eur-lex.europa.eu/legal-content/EN/TXT/?uri=uriserv:OJ.L _.2014.094.01.0065.01.ENG, [accessed July, 2014]

Evans, L. (2008) 'Professionalism, Professionality and the Development of Education Professionals' British Journal of Educational Studies, 56 (1): 20-38

Fahey, T. (1999) Social Housing in Ireland. A study of success, failure and lessons learned, Dublin: Oak Tree Press.

Fahey, T., Russell, H. and Whelan, C. (2007) The Best of Times? The Social impact of the Celtic Tiger, Dublin: Institute of Public Administration

Fallon, J. (2005) 'Targeting disadvantage among young children in the republic of Ireland: An overview' Child Care in Practice, 11: 289-311

Feeley, M. (2007) 'Redefining Literacy from an Egalitarian Perspective' The Adult Learner: The Irish Journal of Adult and Community Education, 15-27

Feehan, P. (1979) 'Pearse College Development' A review of Adult Education, Dublin:

AONTAS, 36-38 
Fenwick, T. and Tennant, M. (2004) 'Understanding Adult Learners' in Foley, G. (editor) Dimensions of Adult Learning, Berkshire: McGraw-Hill Education.

FETAC (2010) Quality Assuring Assessment Guidelines for External Authenticators V1.0, retrieved from https://www.fetac.ie/fetac/providers/tools/authenticators.htm [accessed October, 2014]

Field, J. (1998) European Dimensions: Education, Training and the European Union, London: Jessica Kingsley Publishers

Field, J. (2011) 'Adult learning, health and wellbeing - changing lives' The Adult Learner: The Irish Journal of Adult and Community Education, 13-25

Field, J. and Leister, M. (2000) Lifelong Learning Education across the lifespan, London: RoutledgeFalmer.

Finnegan, F. (2008) 'Neo-Liberalism, Irish Society and Adult Education' The Adult Learner: The Irish Journal of Adult and Community Education, 54-76

Fishman, J. R. (2004) 'Manufacturing Desire: The Commodification of Female Sexual Dysfunction', Social Studies of Science, 34: 187-218

Fitzsimons, C. (2010) 'Professionalism in Community Work and its implications for radical community education', The Adult Learner. The Irish Journal of Adult and Community Education, 53-71

Fitzsimons, C. (2012) 'Social Change Community Education, where are we now?' The Irish Review of Community Economic Development Law and Policy, 1 (4): 26-41

Fitzsimons, C. (2014) 'Worlds Apart? The disunity of FET policy directives and Communitybased Education for social change', in Murray, M., Grummell, B. and Ryan, A. (editors) Further Education and Training, history politics and practice, Kildare: MACE press publications

Fitzsimons, C. and Dorman, P. (2013) 'Swimming in the Swamp - inquiry into accreditation, community development and social change' The Adult Learner: The Irish Journal of Adult and Community Education, 44-58

Fleming, T. (1989) 'Back to the future: Ten years of Adult Education Coordinators' The Adult Learner. Journal of Adult Education Organisers Association, 2-7

Fleming, T. (2004) 'The State of Adult Education' The Adult Learner, The Journal of Adult and Community Education in Ireland, 9-17

Flexnor, A. (2001) 'Is Social Work a Profession?' Research on Social Work Practice, 11 (2): $152-165$

Foley, G. (2004) Dimensions of Adult Learning. Adult Education and Training in a global era, Maidenhead: McGraw-Hill Education, Open University Press

Fordham, P. (1979) Learning networks in Adult Education: Non-formal education on a housing estate, UK: Routledge Education Books 
Forrest, S. (2009) 'Divided kingdom: Ireland 1630-1800 - book review' Irish Studies Review 17 (3): $377-403$

Foucault, M. (1977) Discipline and Punish: The Birth of the Prison. London: Allen Lane, Penguin.

Foucault, M. (1980) Power and Knowledge Selected Interviews and other writings. London: Harvester Wheatsheaf

Fowler (2002) Survey Research Methods. $3^{\text {rd }}$ Edition. CA: Sage Publications

Fraser, N. (2009) 'Feminism, capitalism, and the cunning of history'. New Left Review 56: $97-121$

Friedman, M. (2002) Capitalism and Freedom. Fortieth Anniversary Edition, Chicago and London: The University of Chicago Press

Freidson, E. (2004) Professionalism Reborn: Theory, Policy and Prophecy. The University of Chicago Press

Freire, P. (1970) Pedagogy of the Oppressed, Harmondsworth, Penguin

Freire, P. (1972) Pedagogy of the Oppressed, Middlesex: Penguin Education

Freire, P. (1994) Pedagogy of Hope - Reliving Pedagogy of the Oppressed, London and New York: Continuum International Publishing Group

Freire, P. (2001) Pedagogy of Freedom, Ethics Democracy and Civic Courage, Lanham USA: Rowman and Littlefield Publishers Inc

Freire, P. (2005) Teachers as Cultural Workers, Letters to those who dare Teach, expanded edition, Colorado: Westview Press

Freire, P. and Macedo, D. (1987) Literacy: Reading the word and the world, Westport:

Bergin and Garvey publishers

Freshwater, D. and Cahill, J. (2012) 'Why Write?' Journal of Mixed-methods Research, 6: $151-3$

Freshwater, D. and Cahill, J. (2013) 'Paradigms lost and Paradigms regained' Journal of Mixed-methods Research, 7 (1): 3-5

Fudge, J. (2014) 'Feminist Reflections on the Scope of Labour Law: Domestic Work, Social Reproduction, and Jurisdiction' Feminist Legal Studies, 22 (1): 1-33.

Gacitua-Mario, E., Georgieva, S. and Norton, A. (2009) New Frontiers of Social Policy: Building Equality and Opportunity Through Social Guarantees : New Approaches to Public Policy and the Realization of Rights, Herndon, VA, USA: World Bank Publications,

Garcia-Moreno, C., Jansen, H., Ellsberg, M. Heise, L. and Watts, C., (2006) 'Prevalence of intimate partner violence: findings from the WHO multi-country study on women's health and domestic violence' Lancet 368: 1260-69

Gereluk, D. (2006) Education and Community, London: Continuum International Publishing 
Giacinto Garchi, G. (2001) 'Caught in the nets: A critical examination of the use of the concept of networks in Community Development studies' Community Development Journal, 36 (1): 63-71

Giddens, A. (1998) The Third Way. The Renewal of Social Democracy, UK: Policy Press

Gilchrist, A. (2009) The Well Connected Community, A networking approach to community development, 2nd edition. London: The Polity Press

Giroux, H. A, (1983) Theory and Resistance in Education, Westport, CT: Bergin and Garvey Press

Giroux, H. A. (2004) 'Public Pedagogy, and the Responsibility of Intellectuals' Communication and Critical/Cultural Studies 1 (1): 59-79.

Giroux, H. A. (2006) America on the Edge: Henry Giroux on Politics, Culture, and Education. Gordonsville, VA, USA: Palgrave Macmillan

Giroux, H. A. (2007) 'Introduction: Democracy, Education and the Politics of Critical Pedagogy' in McLaren, and P. Kincheloe, J. L. (editors) Critical Pedagogy: Where are we now? New York: Peter Lang Publishing

Giroux, H.A. (2009) 'Critical Theory and Educational Practice' in Darner, A., Baltodano, M. and Torres, R.D. (editors) The Critical Pedagogy Reader, $2^{\text {nd }}$ edition, New York and London: Routledge

Giroux, H. A. (2013) America's Education Deficit and the War on Youth, New York: Monthly Review Press

Giroux, H. A. and Giroux, S. S. (2006) 'Challenging Neoliberalism's New World Order: The Promise of Critical Pedagogy’ Cultural Studies $\leftrightarrow$ Critical Methodologies, 6 (1): 21-32

Goldthorpe, J. (1996) 'Class analysis and the re-orientation of class theory: the case of persisting differentials in educational attainment*'. The British Journal of Sociology, 47 (3): 481-505

Goodson, I. (2003) Professional Knowledge, Professional Lives, Berkshire: McGraw-Hill Professional Publishing

Gore, J. (1993) The Struggles for Pedagogies; Critical and Feminist discourses as regimes of truth, New York: Routledge

Government of Ireland (1996) First Report of the Ministerial Task Force on the Measures to Reduce the Demand for Drugs, Dublin: Government Publications.

Government of Ireland (1998) Green Paper: Adult Education in an Era of Lifelong Learning, Dublin: Government Publications

Government of Ireland (2000) White Paper on a Framework for supporting Voluntary Activity and for Developing the Relationship between the State and the Community and Voluntary sector, Dublin: Government Publications 
Government of Ireland (2012) Pathways to Work. Government Policy Statement on Labour Market Activation, retrieved from: http://www.welfare.ie/en/downloads/pathwaystowork .pdf, [accessed July, 2014].

Gramsci, A. (1971). Selections from the Prison Notebooks, (edited by Hoare, Q. and Nowell, G.) London: Smith, Lawrence and Wishart

Gramsci, A. (1994). Pre-Prison Writings, (edited by Bellamy, R.) Cambridge University Press

Granek, L. (2013) 'Putting ourselves on the line: the epistemology of the hyphen, intersubjectivity and social responsibility in qualitative research' International Journal of Qualitative Studies in Education, 26 (2): 178-197

Greene, J. and Hall, J. (2010), 'Dialectics and pragmatism: Being of consequence', in Tashakkori, A. and C. Teddlie, C. (editors), Sage handbook of mixed-methods in social and behavioral research, $2^{\text {nd }}$ Edition, Thousand Oaks, CA: Sage

Grummell, B. (2008) 'The Second Chance Myth: equality of opportunity in Irish Adult Education policies', British Journal of Educational Studies 55 (2): 182-201

Grummell, B. (2014) 'FET: responding to Community Needs or Shaping Communities to suit a Global Marketplace in Crisis?' in Murray, M., Grummell, B. and Ryan, A. (editors) Further Education and Training, history politics and practice, Kildare: MACE press publications

Guba, E.G. and Lincoln, Y. S. (2005) 'Paradigmatic controversies, contradictions, and emerging confluences', in Denzin, N. and Lincoln, Y. S., (editors) The Sage Handbook of Qualitative Research, $3^{\text {rd }}$ Edition. Thousand Oaks, California: Sage Publications Inc.

Hadrill, R. (1995) 'The NCVQ model of assessment at higher levels' in Knight, P. (editor) Assessment for Learning in Higher Education, Oxon: Routledgefalmer

Hake, B. J. (1999) 'Lifelong Learning Policies in the European Union, developments and issues', Compare: A Journal of Comparative Education (29) 1: 53-69

Hardiman, N. (2002) 'From Conflict to Co-ordination: Economic Governance and Political Innovation in Ireland' West European Politics, 25 (4): 1-24

Harding, S. (1991) Whose Science? Whose Knowledge?: Thinking from Women's Lives, New York: Cornell University Press

Harford, J. (2005) 'The movement for the higher education of women in Ireland: gender equality or denominational rivalry?' History of Education, 34 (5): 497-516

Harvey, B. (1994) Combating Exclusion: Lessons from the third EU poverty programme in Ireland 1989-1994 Dublin: The Combat Poverty Agency

Harvey, B. (2012) Downsizing the Community Sector. Changes in employment and services in the voluntary and Community Sector in Ireland, Dublin: Irish Congress of Trade Unions, Community Sector Committee

Harvey, B. (2013) Travelling with Austerity Impacts of Cuts on Travellers, Traveller Projects and Services, Dublin: Pavee Point Traveller and Roma Centre 
Harvey, D. (2005) A brief history of neoliberalism, New York: Oxford university press.

Harvey, L. (2004) 'The Power of Accreditation: Views of Academics' Journal of Higher Education Policy and Management, 26 (2): 207-223

Haug, G. (2003) 'Quality Assurance/Accreditation in the Emerging European Higher Education Area: a possible scenario for the future. European' Journal of Education 38 (3): 229-240

Hautekeur, G. (2005) 'Community Development in Europe' Community Development Journal, 40 (4): 385-398

Hayward, K. (2009) Irish Nationalism and European Integration: The Official Redefinition of the Island of Ireland, Manchester: Manchester University Press

Hearne, R. (2014) 'Is anybody interested in the Silent destruction of our Communities' in The Journal Newspaper, March $12^{\text {th }}$

Hegland, C. (2009) 'Why the financial system collapsed' National Journal, 4 (11) 3

Heilmann, A. (2011) 'Gender and essentialism: feminist debates in the twenty-first century' Critical Quarterly, 53 (4): 78-89

Henderson, P. and Glen, A. (2006) 'From Recognition to Support, Community Workers in the United Kingdom’ Community Development Journal, 41 (3): 277-292

Hesse-Biber, S. N., (2010) Mixed-methods Research: Merging Theory with Practice, New York: Guilford Press

Herman, E. S. and Chomsky, N. (1994) Manufacturing Consent, The political economy and the Mass media, London: Vintage

Heron, J. (1999) The Complete Facilitators Handbook, London: Kogen-page

Holst, J. (2009a) 'Conceptualizing Training in the Radical Adult Education Tradition'. Adult Education Quarterly, 59 (4): 318-334

Holst, J. (2009b). 'The Revolutionary Party in Gramsci's Pre-Prison Educational and Political Theory and Practice', Educational Philosophy and Theory, 41 (6): 622-639

hooks, b. (1993) 'Bell Hooks speaking about Freire. The man, his work', in McLaren, P. and Leonard, P. (editors) Paulo Freire, A critical Encounter, London and New York: Routledge hooks, b. (1994) Teaching to Transgress, Education as the practice of freedom, London and New York: Routledge

Hope, A. and Timmel, S. (1984) Training for Transformation, A Handbook for Community Workers: Mambo Press

Hope, A. and Timmel, S. (1995) Training for Transformation, A Handbook for Community Workers Book 2: Mambo Press

Houle, C. (1980) Continuing Learning in the Professions, USA: Jossey-Bass Publishers

Holloway, J. (2010) Crack Capitalism, London: Pluto Press 
Horgan, D. (2001) Childcare in Ireland, themes and issues' Journal of Applied Social Studies. 2 (3): article 8

Horton, M. and Freire, P. (1990) We Make the Road by Walking, Conversations on Education and Social Change (Bell, B. Gaventa, J. and Peters, J. editors) Philadelphia: Temple University Press

Hug, T. (2010) 'Radical constructivism Mainstreaming: A desirable endeavor? Critical Considerations using Examples from Educational Studies and Learning theory', Constructivist Foundations, 6 (1): 58-64

Hurley, K. (2014) 'Taking Shape, Shaping up, Changing Shape: Equality and Human Capital' in Murray, M., Grummell, B. and Ryan, A. (editors) Further Education and Training, history politics and practice, Kildare: MACE press publications

Hussey, T. and Smith, P. (2002) 'The trouble with learning outcomes' Active Learning in Higher Education, 3 (3) 220-233

Hussey, T. and Smith, P. (2008) 'Learning Outcomes: a conceptual analysis' Teaching in Higher Education, 13 (1): 107-115

Irish Congress of Trade Unions (2012) The Impact of Anti-crisis measures and the social and employment situation: Ireland. European Economic and Social Committee Workers' Group. Dublin: ICTU

Ikeotuonye F.C.R.A, (2002) 'Lateral shades of social engineering: A critical exploration of 'interest representation', 'state' and development', Community Development Journal, 37 (1): 69-79

Inglis, T. (1998) Moral Monopoly. The Rise and Fall of the Catholic Church in Modern Ireland, Dublin: University College Dublin Press

Inglis, T., Bailey, K. and Murray, C. (1993) Liberating Learning: A Study of Daytime Education Groups in Ireland, Dublin: AONTAS

Jackson, S. (1997) 'Crossing boarders and changing pedagogies from Giroux and Freire to feminist theories of education' Gender and education, 9 (4): 457-468

Jarvis, P. (2004) Adult Education and Lifelong learning Theory and Practice, $3^{\text {rd }}$ edition. London: RoutledgeFalmer

Jerzack, C. T. (2014) 'The EU's Democratic Deficit and Repeated Referendums in Ireland' International Journal of Political Cultural Society, 27: 367-388

Jesuits in Ireland (2012) Irish Jesuit News, 1 (20): 1-3, retrieved from, http://jesuitcommunicationcentre.newsweaver.com/Newsletter/jh48ha8b0su?a =6andp=29430 205andt=20449655, [accessed June, 2014]

Jickling, M. (2010) Causes of the financial Crisis. Congressional Research Service report for Congress, retrieved from, http://www.fas.org/sgp/crs/misc/R40173.pdf, [accessed October, 2014] 
Johnston, R. (2000) 'Community Education and Lifelong Learning, Local spice for global fare?' in Field, J. and Leister, M. (editors) Lifelong Learning Education across the lifespan, Leicester: Taylor and Francis

Jones, I. (2012) Paulo Freire's philosophy of Education Origins, Developments, Impacts and Legacies London and New York: Continuum International Publishing Group

Kane, L. (2001) Popular Education and Social Change in Latin America, London: Latin American Bureau

Kane, L. (2010) 'Community development: learning from popular education in Latin America’ Community Development Journal, 45 (3): 276-286

Kanis, H. (2004) 'The quantitative-qualitative research dichotomy revisited' Theoretical Issues in Ergonomics Science (5): 507-516

Keily, E., Leane, M. and Meade, R. (1999) 'It's all changed from here': Women's experiences of community education' in Connolly, B and Ryan, A.B. (editors) Women and Education in Ireland, Volume 1. Maynooth: The Cardinal Press

Kelly, M. (1994) Can you Credit It? Implications for Learners and Groups in the Community Sector, Dublin: The Combat Poverty Agency

Kelly, J. and Reilly, A. (2005) 'Credit Card Debt in Ireland: Recent Trends' Central Bank and Financial Services Authority of Ireland, Quarterly Bulletin (1): 85-100

Keogh, H. (2004) 'Adult Education in Ireland: The implications of developments at European Union level' The Adult Learner, the Irish Journal of Adult and Community Education, 18-26

Keyes, D. (2004) 'Accreditation within Adult Education, reflections and views from local tutors', The Adult Learner, the Irish Journal of Adult and Community Education, 68-77

Kelleher, P. and Whelan, M. (1992) Dublin Communities in Action. Dublin: CAN/Combat Poverty Agency.

Killeavy, M. (2005) 'Practice and Procedures regarding Accreditation and Evaluation in the Irish Republic' in Schwartz, S. and Westerheijden, D. F. (editors) Accreditation and Evaluation in the European Higher education Area, The Netherlands: Kluwer Academic Publishers

Kincheloe, J. L. and McLaren, P (2005) 'Rethinking critical theory and qualitative research' in Denzin, N. and Lincoln, Y. S., (editors), The Sage Handbook of Qualitative Research, $3^{\text {rd }}$ Edition. Thousand Oaks, California: Sage Publications Inc.

Kirby, P. (2002). The Celtic tiger in distress: Growth with inequality in Ireland. Basingstoke: Palgrave Macmillan.

Kirby, P. (2010) Celtic Tiger in Collapse: Explaining the weaknesses of the Irish Model, $2^{\text {nd }}$ Edition. London: Palgrave Macmillan.

Kirby, P. and Murphy, M. P. (2011) Towards a Second Republic: Irish Politics and the Celtic Tiger. Dublin: Pluto Press. 
Kirkwood, G. and Kirkwood, C. (1989) Living Adult Education, Freire in Scotland, Milton Keynes: Open University Press.

Klein, N. (2007) The Shock Doctrine, The Rise of Disaster Capitalism, New York: Pan Books Limited

Klinger, C. (1998) 'Essentialism, Universalism, and Feminist Politics', Constellations 5 (3): 333-344

Knowles, M. S. (1980). The modern practice of adult education: From pedagogy to andragogy. Englewood, Cliffs: Prentice Hall/Cambridge

Knowles, M. S. (1984) Andragogy in Action. Applying modern principles of adult education, San Francisco: Jossey Bass

Knowles, M. S., Holton, E. F. and Swanson, A. R. (2011) The Adult Learner, the definitive Classic in Adult Education and Human Resource Development. $11^{\text {th }}$ edition, Oxford: Elsevier Inc.

Kohler, J. (2003) 'Quality Assurance, Accreditation, and Recognition of Qualifications as regulatory Mechanisms in the European Higher Education Area' Higher Education in Europe, XXVIII (3):317-330

Ladi, S. and Tsarouhas, D. (2014) 'The Politics of Austerity and Public Policy Reform in the EU’, Political Studies Review, 12 (2): 171-180

Lankshear, C. (1993) 'Functional literacy from a Freirean point of view' in McLaren, P. and Leonard, P. (editors) Paulo Freire, A Critical Encounter. Oxon: Routledge

Lapavistas, C. (2004) 'Mainstream Economics in the Neoliberal Era' in Saad-Filho, A. and Johnston, D. (editors) Neoliberalism: A Critical Reader, London: Pluto Press.

Larraghy (2006) 'Origins and Significance of the Community and Voluntary Pillar in Irish Social Partnership*'The Economic and Social Review, 37(3): 375-398

Larraghy (2014) Asymmetric Engagement, London: Palgrave Macmillan

Larson, M.S. (1977) The Rise of Professionalism: a Sociological Analysis, University of California Press

Larson, M. S. (2014) 'Looking Back and a Little Forward: Reflections on Professionalism and Teaching as a Profession'. Radical Teacher, A Socialist, Feminist and Anti-racist Journal of the theory and practice of teaching, 99: 7-17

Lawlor, S. (2005) 'Disgusted Subjects: the making of middle-class identities' The Sociological Review, 53 (3): 429-446

Lauder, H. (2011) 'Education, economic globalisation and national qualifications frameworks' Journal of Education and Work, 24 (3-4): 213-221

Ledwith, M. (2007) 'Reclaiming the radical agenda: a critical approach to community development', Concept 17 (2): 8-12, Reproduced in the encyclopaedia of informal education, retrieved from, www.infed.org/community/critical_community_development.htm, [accessed April, 2014] 
Ledwith, M. (2010) 'Antonio Gramsci and Feminism: the elusive nature of power' in Mayo, P. (editor) Gramsci and Educational thought, UK: Wiley-Blackwell.

Ledwith, M (2011) Community Development; A Critical Approach. $2^{\text {nd }}$ edition, Bristol: The Polity Press

Lee, A. (2003) 'Community Development in Ireland' Community Development Journal, 38(1): 48-58

Lee, A. (2006) Community Development, Current Issues and Challenges, Dublin: The Combat Poverty Agency

Lengermann, P. M. and Niebrugge-Brantley, J. (2003) 'Contemporary Feminist Theory' in Ritzer, G. andGoodman, D. J., Sociological Theory, $6^{\text {th }}$ edition. New York: McGraw-Hill publishers

Letherby, G. (2003) Feminist Research in Theory and Practice. Maidenhead: McGraw-Hill Professional Publishing

Lloyd, A. (2010) 'The will of the state and the resilience of the Community Sector in a time of crisis: compliance or an opportunity for renewal?' Working for Change: The Irish Journal of Community Work, Issue 2: 44-63

Lloyd, A. and Lloyd-Hughes, J. (2009) 'Building Platforms for Progression or Chasing Pie in the Sky? Reflections on Participatory Approaches to Social Change', Working for Change: The Irish Journal of Community Work. Issue 1: 28-51

Lock, G. and Lorenzo, C. (2007) 'Revisiting the university front', Studies on Philosophical Education, 26:405-418.

Lohr, S. (2009) Sampling, Design and Analysis, $2^{\text {nd }}$ edition. Boston: Brooks/Cole

Lovett, T. (1975) Adult Education, Community Development and the Working-class, London: Ward Lock Educational

Lovett, T. (1988) Radical Approaches to Adult Education: A Reader, London: Routledge.

Luke, C. and Gore, J. (1992) Feminisms and Critical Pedagogy, London: Routledge

Lynch, K. (1989) The Hidden Curriculum. Reproduction in Education and Appraisal, UK: The Falmer Press

Lynch, K. (1999) Equality in Education. London: Gill and MacMillan

Lynch, K. and Baker, J. (2006) 'Equality in education: An equality of condition perspective' Theory and Research in Education, 3 (2) 131-164

Lynch, K., Grummell, B. and Devine, D. (2012) New Managerialism in Education, commercialization, carelessness and gender, Dublin: Palgrave MacMillan

Lynch, K. and Lodge, A. (2002) Equality and Power in Schools, Dublin: RoutledgeFalmer

Lynch, R. A. (2010) 'Foucault's Theory of Power' in Taylor, D. (editor) Michael Foucault, key concepts, Durham: Acumen 
Lyotard, J. F. (1984) The Postmodern Condition: A report on Knowledge, The University of Minnesota.

MacDonald, K. (1995) The Sociology of the Professions, London, Sage.

Malpas, S. (2005) The Postmodern. New York: Routledge.

Maltone, C., Yvars, B. and Brady, H. (2012) 'Globalization and social inequalities in Europe: assessment and outlook' Eastern Journal of European Studies, 3 (1): 5-30

Manfred, B. S, and Roy, R. K. (2010) Neoliberalism: A very short introduction. Oxford University Press

Martin, I, and McCormack, C. (1999) 'Making Connections: learning through struggle' in Crowther, J., Martin, I. and Shaw, M. (editors) Popular Education and Social Movements in Scotland today. Leicester: National Institute of Adult Continuing Education

Martin, I. (1987) 'Community Education, towards a theoretical analysis' in Allen, G., Bastiani, J., Martin, I. and Richards, K. (editors) Community Education, An agenda for educational reform, Milton Keynes and Philadelphia: Open University Press

Martin, I. (1999) 'Introductory essay: popular education and social movements in Scotland today' in Crowther, J., Martin, I, and Shaw, M. (editors) Popular Education and Social Movements in Scotland today, Leicester: National Institute of Adult Continuing Education

Marx, K. (1977) Selected Writings, (edited by McLellan, D.). UK: Richard Clay (The Chaucer Press Limited)

Marx, K. (1996) The German Ideology, (edited by Arther. C.J.) London: Lawrence and Wishart

Maunsell, C., Downes, P. and McLoughlin, V (2008) National Report on Lifelong Learning in Ireland LLL2010: Sub-Project 1: Towards a Lifelong Learning Society in Europe - The Contribution of the Education System, Dublin: Educational Disadvantage Centre, retrieved from https://www.spd.dcu.ie/site/edc/documents/SP1LLL2010.pdf, [accessed, 2015]

May, T. (2001) Social Research, Issues, Methods and Process, $3^{\text {rd }}$ edition. Maidenhead: Open University Press.

Maykut, P. and Morehouse R. (1994) Beginning qualitative research. A philosophic and practical guide, London and Washington: The Falmer Press

Mayo, M. (1994) Communities and Caring: The Mixed Economy of Welfare, Basingstoke: Macmillan

Mayo, P. (1999) Gramsci, Freire and Adult Education. Possibilities for Transformative Action, London: Zed Books

Maxwell, J. A. and Mittipali, K.(2010) 'Realism as a stance for Mixed-methods Research' in Tashakori, A. and Teddlie, C. (editors) Sage Handbook of Mixed-methods in Social and Behavioural Research, $2^{\text {nd }}$ Edition. Sage Publications Inc.

Maxwell, J. A. (2012) A Realist Approach for Qualitative Research. London: Sage publications. 
McCallion, A. (2009) 'An educators Dilemma' The Adult Learner, the Irish Journal of Adult and Community Education, 60-73

McCann. M. (1991) Ballymun Youth Action Project, Ten years on, Dublin: BYAP

McCoy, S. (2011) 'Higher Education Expansion and Differentiation in the Republic of Ireland’ Higher Education, 61 (3): 243-260

McCoy, S., Smyth, E. and Banks, J. (2012) The Primary Classroom: Insights from the Growing Up in Ireland Survey, Dublin: The Economic and Social Research Institute.

McCoy, S., Smyth, E., Watson, D. Darmody, M. (2014) Leaving School in Ireland, a longitudinal study of post-school transitions, Dublin: ESRI

McGlynn, L. (2012) Community Educators and the Struggle for Recognition; theorising meaning, educator and institution in Ireland's community education field using a generative grounded theory approach. Education Doctorate, retrieved from, http://eprints.nuim.ie/3902/, [accessed December, 2012]

McGlynn, L. (2014) Community Education and the Labour Activation Challenge, A Literature Review on Community Education in a Context of Labour Market Activation, Employability and Active Citizenship in Ireland and the EU. Ireland: Community Education Facilitators' Association

McLaren, P. (2000) Che Guevara, Paulo Freire, and the Pedagogy of Revolution, Maryland: Rowman and Littlefield Publishers

McLaren, P. (2009) 'Critical Pedagogy: A look at the Major Concepts' in Darder, A., Baltodano, P. and Torres, R. D. (editors) The Critical Pedagogy Reader, $2^{\text {nd }}$ edition. London and New York: Routledge

McLaren, P. and Giroux, H. (1994) Preface to Gadotti, M. Paulo Freire, His life and Work, State University of New York Press

McNeill, H. (2005) Connecting Communities. A practical guide to Using Development Education in Community Settings, Dublin: Lourdes Youth and Community Service Ltd.

McVeigh, R. (2002) 'Between Reconciliation and Pacification: The British State and Community Relations in the north of Ireland' Community Development Journal, 37 (1): 47 59

Meade, R. (2005) 'We hate it here, please let us stay! Irish social partnership and the community/ voluntary sector's conflicted experiences of recognition', Critical Social Policy, 25 (3): $349-373$

Meade, R. (2012) 'Government and Community Development in Ireland: The Contested Subjects of Professionalism and Expertise', Antipode 44 (3): 889-910

Meade, R. and O'Donovan, O. (2002) 'Editorial introduction: Corporatism and the on-going debate about the relationship between the state and Community Development', Community Development Journal, 37:1, 1-9

Meagher, A. (2014) 'Privatising Community Work, the Genie's out of the Bottle - A declining State funding remains a concern', Changing Ireland Summer 2014 
Mealer, M. and Jones, J. (2014) 'Methodological and ethical issues related to qualitative telephone interviews on sensitive topics'. Nurse Researcher, 21(4): 32-37

Merriam, S. (2001) 'Andragogy and self-directed learning', New Directions for Adult and Continuing Education, 89: 3-13

Merriam, S. B. and Brockett, R.G. (1997) The Profession and Practice of Adult Education, An Introduction, San Francisco: Jossey-Bass

Mertens, D. (2010) 'Transformative mixed-methods Research' Qualitative inquiry, 16 (6): 469-474

Mertens, D. (2012) 'What Comes First? The Paradigm or the Approach?' Journal of Mixedmethods Research, 6 (4) 255-257

Moraes, M. (2003) 'The Path of Dissent, an interview with Peter McLaren', Journal of Transformative Education, 1 (2): 117-134

Motherway, B. (2006) The Role of Community Development in Tackling Poverty in Ireland, A literature review for the Combat Poverty Agency, Dublin: The Combat Poverty Agency

Mullins, M. (1991) 'Representations of history, Irish feminism, and the politics of difference', Feminist Studies, 17 (1): 29-43

Murphy, M. P. (2012) 'The politics of Irish labour activation: 1980 to 2010', Administration, 60 (2): 27-49

Murray, M. (2013) 'What happens in the classroom stays in the classroom - the limits to the transformative approach to education for political citizenship' The Adult Learner: The Irish Journal of Adult and Community Education, 15-28

Murray, M. (2014) 'What's in a name? Terminology, Power and Contestation', in Murray, M., Grummell, B. and Ryan, A. (editors) Further Education and Training, history politics and practice, Kildare: MACE press publications

Murtagh (2009) The Irish Education Policy Process since 1997: Some Lessons for the future, Unpublished $\mathrm{PhD}$ thesis, retrieved from, http://eprints.nuim.ie/1488/, [accessed July, 2014]

Murtagh (2014a) '1973-2-13: From membership of the EEC to the Establishment of SOLAS and the ETBS' in Murray, M., Grummell, B. and Ryan, A. (editors) Further Education and Training, history politics and practice, Kildare: MACE press publications

Murtagh (2014b) 'appendix three- timeline' (addendum to chapters one and two) in Murray, M., Grummell, B. and Ryan, A. (editors) Further Education and Training, history politics and practice, Kildare: MACE press publications

Murphy, M. (2002) 'Social partnership, is it the only game in town?' Community Development Journal, 37 (1): 80-90

National Adult Literacy Agency (2010) NALA A Living History 1980-2010, Dublin: NALA.

National Archives, (ND) Hilda Tweedy Papers, retrieved from http://www.nationalarchives.ie /topics/womens_history/Tweedy.pdf , [accessed March, 2015] 
National Framework of Qualifications (NFQ) (2003a) Policies and criteria for the establishment of the National Framework of Qualifications, Dublin: National Qualifications Authority of Ireland

National Framework of Qualifications (2003b) Qualifications Matter, a brief guide to the National Framework of Qualifications, Dublin: National Qualifications Authority of Ireland

National Framework of Qualifications (2003c) A framework for the development, recognition and award of qualifications in Ireland. Dublin: National Qualifications Authority of Ireland

National Framework of Qualifications (2006a) Verification of Compatibility of Irish National Framework of Qualifications with the Framework for Qualifications of the European Higher Education Area. Dublin: National Qualifications Authority of Ireland

National Framework of Qualifications (2006b) Principles and Operations Guidelines for the implementation of a National Approach to credit in Irish Higher Education and Training. Dublin: National Qualification Authority of Ireland.

National Framework of Qualifications (ND) Grid of indicators, retrieved from http://www.nfq.ie.webhosting.heanet.ie/nfq/en/documents/NFQLevelindicators.pdf [accessed March, 2015]

Naughton, F. (2002) Training for Transformation: Utopian Hope or Practical Reality, Unpublished MPhil thesis

Neville, P., O’Dwyer, M. and Power, M. J., (2014) 'The Social Value of community-Based Adult Education in Limerick City' The Adult Learner, the Irish Journal of Adult and Community Education, 42-56

Nexus (2002) Evaluation of the Community Development Programme, Main Report, Dublin: Department of Social, Community and Family Affairs (Government publications)

Newman, F., Couturier, L. and Scurry, J. (2004) The Future of Higher Education, Rhetoric, Reality, and the Risks of the Market. San Francisco: Jossey-Bass

Newman, M. (2006) Teaching Defiance Stories and Strategies for Activist Educators San Francisco: Jossey-Bass

Norman, U. (2008). Thoughtful Teachers, Thoughtful Learners: Helping Students Think Critically (2nd Edition). Toronto: Pippin Publishing Corporation.

Norris, M. and Redmond, D. (2007) Housing Contemporary Ireland, Policy Society and Shelter, Dublin: The Institute of Public Administration

Novick G (2008) 'Is there a bias against telephone interviews in qualitative research?' Research in Nursing and Health 31(4): 391-398

Nye, M. (2001) 'Managing the boom: Negotiating social Partnership in an expanding economy', Irish Political Studies, (16):191-199

Oakley, A. (1999) 'Paradigm wars: some thoughts on a personal and public trajectory', International Journal of Social Research methodology, 2(3): 247-254. 
O’Brien, M. (2003) Girls and Transition to Second-level Schooling in Ireland: 'moving on' and 'moving out', Gender and Education, 15 (3): 85-96

O'Brien, T. (2007) 'Is There a Way Out of this Clinic? An Adult and Community Education Perspective on Methadone and the Absence of Rehabilitation' The Adult Learner, the Irish Journal of Adult and Community Education, 40-55

O'Byrne, D. (2012) 'Investigating the De-Politicisation of Community Development: What Happened? Where do we go Now?' in Jackson, A. and O'Doherty, C. (editors) Community Development in Ireland, Theory, Policy and Practice, Dublin: Gill and MacMillan

Ó Cinnéide, S. (1998/99) 'Democracy and the Constitution’ Administration, 46(4): 41-58.

O'Connell, P., McCoy, S. and Clancey, D. (2006) 'Who Went to College? Socio-Economic Inequality in Entry to Higher Education in the Republic of Ireland in 2004', Higher Education Quarterly, 60 (4): 312-332.

O'Connor, F. (2010) 'Institutional racism in Irish adult education: fact or fiction?' The Irish Journal of Adult and Community Education, 29-52

O’Connor, N. and Staunton, C. (2015) Cherishing All Equally, Economic Inequality in Ireland. TASC, retrieved from, http://www.tasc.ie/download/pdf/tasc_cherishing_all_equally _web.pdf [accessed March, 2015]

OECD (2011) Divided we Stand, Why inequality keeps rising, retrieved from http://www. oecd.org/els/soc/49499779.pdf [accessed January, 2015]

OECD (2001) The Wellbeing of Nations: The Role of Human and Social Capital, Centre for Educational Research and Innovation, Paris: OECD.

O'Fathaigh, M. (1998) 'Universities, Partnership and the promotion of social inclusion: some issues and developments in Ireland', Journal of Education through Partnership, 2 (2):2-17

O'Grady, A. (2008) Choosing to Learn or Chosen to Learn: a qualitative case study of Skills for Life learners, $\mathrm{PhD}$ thesis, University of Nottingham, retrieved from http://eprints.nottingham.ac.uk /12070/ [accessed, March, 2015]

O'Hearn, D. (1998) Inside the Celtic Tiger. The Irish economy and the Asian Model, London. Pluto Press

Óhidy, A. (2008) Lifelong Learning: Interpretations of an Education Policy in Europe. Wiesbaden, DEU: Springer

Oleson, V. (2005) 'Early Millennial Feminist Qualitative Research, Challenges and Contours' in Denzin, N. K. and Lincoln, Y. S. (editors) The Sage Handbook of Qualitative Research, $3^{\text {rd }}$ edition, London: Sage Publications.

Olssen, M. (2004) 'Foucault and Marxism: rewriting the theory of historical materialism' Policy Futures in Education, 2(3 and 4): 454-482

Ó'Muircheartaigh, L. (2004) 'Planning for the future of the Adult Education Service: A challenge for VECs' The Adult Learner: The Irish Journal of Adult and Community Education, 42-55. 
O'Neill, J. (2014) 'In search of a clearing, the potential of narrative spaces for adult educator growth' in Murray, M., Grummell, B. and Ryan, A. (editors) Further Education and Training History, Politics, Practice. Maynooth: MACE press

O'Shea, A. and O'Brien, M. (2011) Pedagogy, Oppression, and Transformation in a 'PostCritical' Climate, the Return to Freirean Thinking, London and New York: Continuum International Publishing Group

O'Sullivan, D. (2005) Culture, Politics and Irish Education since the 1950s Policy Paradigms and Power, Dublin: The Institute of Public Administration

O’Sullivan, S. (2012) 'All Changed, Changed Utterly'? Gender role attitudes and the feminisation of the Irish labour force' Women's Studies International Forum, Journal homepage: www.elsevier.com/locate/wsif. 35: 223-232

Oxfam (2014) Working for the Few, Political Capture and Economic Inequality. UK: Oxfam.

Parr, S. (2015) 'Integrating critical realist and feminist methodologies: ethical and analytical dilemmas' International Journal of Social Research Methodology, 18 (2): 193-207

Paterson, L. (1999) 'Social movements and the politics of educational change' in Crowther, J., Martin, I. and Shaw, M. (editors) Popular Education and Social Movements in Scotland today, Leicester: National Institute of Adult Continuing Education

Paul, O. (2010) Student's Guide to Research Ethics, $2^{\text {nd }}$ Edition. Maidenhead: Open University Press.

Pearson, E. M. and Podeschi, R. L. (1999) 'Humanism and Individualism: Maslow and his Critics’ Adult Education Quarterly November 50 (3): 41-55

Philo, G., Hewitt, J. and Beharrell, P. (1995) “"And now they're out again”: Industrial news', in Glasgow Media Group Reader, Volume 2: Industry, Economy, War and Politics, London: Routledge

Pillinger, J (2011) National Collective of Community Based Women's Networks, Review and Evaluation. NWCCN

Popple, K. (1995) Analysing Community Development, it's Theory and Practice, Berkshire: Open University Press.

Powell, F. and Geoghegan, M. (2004) The Politics of Community Development, Reclaiming civil society or reinventing governance? Dublin: A and A Falmer

Powell, F. and Geoghegan, M. (2009) 'Community development and the contested politics of the late modern agora: of, alongside or against neoliberalism?', Community Development Journal, 44 (4): $430-447$.

Preston, J. and Hammond, C. (2003) 'Practitioner Views on the Wider Benefits of Further Education' Journal of Further and Higher Education, 27 (2): 211-222.

Putnam R. D. (2000) Bowling Alone, The Collapse and Revival of American Community. New York: Simon and Schuster 
Qualifications and Quality Ireland (QQI) (2013a) Green Paper on the Comprehensive Implementation of the Functions of Quality and Qualifications Ireland - for consultation, retrieved from, http://www.qqi.ie/Downloads/Consultation/Green \%20Papers/Green \%20Paper-Section\%201\%20version\%202.pdf, [accessed July, 2014]

Quality and Qualifications Ireland (2013b) Comprehensive Policy Development Programme - Submissions. Dublin: QQI

Quilty, A. (2003) 'Towards a pedagogy of Demystification' The Adult Learner, the Irish Journal of Adult and Community Education, 57-66

Radner, H., Koshy, V. And Taylor, A. (2007) 'Gifts, Talents and Meritocracy', Journal of Education Policy, 22 (3): 283-299

Ramazanoglu, C. (1989) Feminism and the Contradictions of Oppression. London: Routledge.

Rees, N., Quinn, B. and Connaughton, B. (2010) Europeanisation and New Patterns of Governance in Ireland, Manchester University Press

Ridell, S. and Tett, L. (2010) 'Gender balance in teaching debate: tensions between gender theory and equality policy' International Journal of Inclusive Education, 14 (5): 463-477

Ritzer, G. and Goodman D. (2003) Sociological Theory, $6^{\text {th }}$ edition. New York: McGrawHill.

Roberts, P. (1998) 'Extending literate Horizons: Paulo Freire and the multidimensional word' Educational Review, 50 (2): 322-349

Roberts. J. M. (1999) 'Marxism and Critical Realism: the same, similar or just plain different?' Capitalism and Class, 68: 21-49

Roberts, P. (2000) Education, Literacy, and Humanization: Exploring the Work of Paulo Freire. USA: Greenwood Press

Rogers, C. (1969) Freedom to Learn, a view of what education might become USA: C. E. Merrill Publishing Company

Rogers, C. (1989) The Carl Rogers Reader, Selections from the Lifetime work of America's Preeminent Psychologist, author of on Becoming a Person and a Way of Being (Kirshenbaum, H. and Henderson, V., editors), Boston: Houghton Mifflin Harcourt Rogers, A. (2002) Teaching Adults, $3^{\text {rd }}$ edition. Berkshire: Open University Press Rogers, A. and Horrocks, N. (2010) Teaching Adults. $4^{\text {th }}$ Edition. Maidenhead: Open University Press, McGraw-Hill publications

Rogers, J. (2007) Adults Learning 5th Edition. Buckingham: Open University Press. Rogers, A. (2002) Teaching Adults. $3^{\text {rd }}$ edition. Berkshire: Open University Press Rourke, S. (2005) Citywide, A decade of Achievement. Dublin: Citywide Rosenau, P. M. (1991) Post-Modernism and the Social Sciences: Insights, Inroads, and Intrusions, New Jersey: Princeton University press 
Ryan, A. (2014) 'Further Education and Training, the Trojan Horse' in Murray, M., Grummell, B. and Ryan, A. (editors) Further Education and Training, history politics and practice. Kildare: MACE press publications.

Ryan, A. B. (2001) Feminist ways of Knowing, Towards Theorising the Person for Radical Adult Education. Leicester: National Institute of Adult Continuing Education.

Ryan, A. B. (2009) Enough is Plenty, public and private policies for the $21^{\text {st }}$ Century. UK: O Books

Saad-Filo, A. (2004) 'From Washington to Post-Washington Consensus: Neoliberal Agendas for Economic Development' in Saad-Filho, A. and Johnston, D. (editors) Neoliberalism: A Critical Reader. London: Pluto Press

Saarinen, T. and Ala-Va"ha" la”, T. (2007) 'Accreditation, the Bologna Process and National Reactions: Accreditation as Concept and Action' Higher Education in Europe, 32 (4): 333345

Sabel, C. (1996) Local Development in Ireland, Partnership, Innovation and Social Justice. OECD

Sale, J. E. M., Lohfeld, L., H. and Brazil, K. (2002) 'Revisiting the quantitative-qualitative debate: Implications for mixed-method research’ Quality and Quantity, 36: 43-53

Sandelowski, M., Voils, C. and Knafl, G. (2009) 'On quantitizing', Journal of Mixedmethods Research, 3 (3): 208-222

Satsangi, M. (2013) 'Synthesizing Feminist and Critical Realist Approaches to Housing Studies’ Housing Theory and Society, 30 (2): 193-207

Sarantakos, S. (2005) Social Research, $3^{\text {rd }}$ Edition. Hampshire: Palgrave MacMillan

Save the Children (2014) Ending Newborn Deaths; ensuring every baby survives. London: Save the Children

Sayer, A. (2000a) Realism and Social Science, London: Sage Publications

Sayer, A. (2000b) 'System, Lifeworld and Gender: Associational versus Counterfactual thinking' Sociology, 34 (4):707-725

Sayer, J. (2008) 'Ideology, the bridge between theory and practice' in Craig, G., Popple, K, and Shaw, M. (editors) Community Development in Theory and Practice: An International Reader, Nottingham: Russell Press Limited

Scheele, K. (2004) 'Licence to kill: about accreditation issues and James Bond' Quality in Higher Education, 10 (3): 285-293

Schultz, T. W. (1961) 'Investment in Human Capital' The American Economic Review, 51(1): $1-17$

Schwartz, N. (1999) 'Self-reports: How the questions shape the answers'. American Psychologist, Vol. 54(2), 93-105 
Seltzer-Kelly, D., Westwood, S. and Peña-Guzman, D. M. (2012) 'Methodological SelfStudy of Quantitizing: Negotiating Meaning and Revealing Multiplicity' Journal of Mixedmethods Research, 6 (4): 258-274

Share, P., Tovey, H. and Corcoran, M. (2007) A Sociology of Ireland. Dublin: Gill and Macmillan

Shaw, M. (2008) 'Community development and the politics of community', Community Development Journal, 43 (1): 24-36

Shaw, M. (2009) 'Repoliticising democracy, community and the state'.Concept 1(1): 1-9

Shaw, M. and Crowther, J. (2014) 'Adult education, community development and democracy: renegotiating the terms of engagement' Community Development Journal 49 (3): $390-406$

Sheehy, M. (2001) Partners Companion to training for Transformation. Dublin: Partners Training For Transformation

Sheehy, M., Naughton, F. and, O’Regan, C. (2007) Partners Intercultural Companion to Training for Transformation. Dublin: Partners Training for Transformation.

Shor, I. (1996) When Students have Power: Negotiating Authority in a Critical Pedagogy. University of Chicago Press

Shor, I. and Freire, P. (1987) A Pedagogy for Liberation, Dialogues on Transforming Education, Westport: Bergin and Garvey Publishers

Slevin, A. (2009) 'Up here it's different: Community Education in Rural East Donegal', The Adult Learner, the Irish Journal of Adult and Community Education, 47-59

Slowey, M. (1979) ‘Aspects of Women's Participation in Adult Education' A Review of Adult Education, Dublin: AONTAS, 16-24

Smyth, E. (2009) 'Buying your way into college? Private tuition and the transition to higher education in Ireland' Oxford Review of Education, 35 (1): 1-22

Smyth, E. and Hannon, C. (2007) 'School processes and the transition to higher education' Oxford Review of Education, 33 (2): 303-327

Smyth, E. and McCoy, S. (2011) 'Higher education expansion and differentiation in the Republic of Ireland' High Education, 61:243-260

Social Justice Ireland (2014) National Social Monitor 2014. Dublin: Social Justice Ireland

Soderberg, S. (2013) 'The US Debtfare State and the Credit Card Industry: Forging Spaces of Dispossession' Antipode, 45 (2): 493-512

SOLAS (2014a) Further Education and Training Strategy, The Department of Education and Skills, Dublin: Government Publications

SOLAS (2014b) SOLAS Corporate Plan 2014-2016, retrieved from, http://www.solas.ie/docs /SOLASCorporatePlan.pdf [accessed July, 2014] 
Somers, J. and Bradford, S. (2006) 'Discourses of partnership in multi-agency working in the community and voluntary sectors in Ireland' Irish Journal of Sociology, 15 (2): 67-85

Speeden, S. (2012) 'Mainstreaming Equality into Public Management, Challenges and Opportunities' in Diamond, J. and Liddle, J. (editors) Critical Perspectives on International Public Sector Management, Volume 1: Emerging and Potential Trends in Public

Management: An Age of Austerity. Bingley, GBR: Emerald Group Publishing Ltd

Stafford, P. (2011) 'The rise and fall of social partnership: its impact on interest group lobbying in Ireland', Journal of Public Affairs, 11(2): 74-79

Stammers, N. (2009) Human Rights and Social Movements, New York: Pluto Press.

Stephen, A. (2006) The Americanisation of Europe: Culture, Diplomacy and AntiAmericanism, New York: Berghahn Books

Storey, J. (2010) Culture and Power in Cultural Studies: The Politics of Signification, Edinburgh University Press.

Steger, M. B. and Roy, R. K. (2010) Neoliberalism: A Very Short Introduction. GBR: Oxford University Press

Steyn, I. (2012) 'The State and Social Movements: Autonomy and Its Pitfalls' Politikon: South African Journal of Political Studies 39 (3): 331-351

Susen, S. (2012) “'Open Marxism' against and beyond the 'Great Enclosure'? Reflections on how (not) to crack capitalism', Journal of Classical Sociology 12 (2): 281-331

Tashakkori, A. and Creswell, J. W. (2007) 'The new era of mixed-methods' Mixed-methods Research 1: 3-7

Tashakkori, A. and Teddie, C. (2010) Sage handbook of mixed-methods in social and behavioral research. Thousand Oaks, CA: SAGE

Teague, P. and Murphy, M.C. (2004) Social partnership and local development in Ireland: The limits to deliberation, Geneva: International Labour Organization (International Institute for Labour Studies)

Teddie, C. And Yu, F. (2007) 'Mixed-methods Sampling A Typology With Examples' Journal of Mixed-methods Research 1 (1): 77-100

Tett, L. (2006) Community Education, Lifelong Learning and Social Inclusion, $2^{\text {rd }}$ edition, Edinburgh: Dunedin Academic Press

Tett, L. (2014) 'Lifelong learning policies, paradoxes and possibilities' The Adult Learner, the Irish Journal of Adult and Community Education, 15-28

Thompson, D. (2001) Radical Feminism Today, London: Sage Publications

Thompson, J. (2000) Women, Class and Education, London: Routledge

Thompson, J. (2007) 'The Road to Hell...' Radical Learning for Liberation 2. Maynooth: MACE publications 
Thornburgh, N, Lee, A. W., Assinder, N., Cooke, S. V. G., Mayer, C. and Grose, T. K. (2011) 'London's Long Burn' Time, 178 (7): 28-31

Tisdell, E. J. (2007) 'Popular Culture and Critical Media Literacy in Adult Education: Theory and Practice', New Directions for Adult and Continuing Education, 115: 5-13

Tisdell E. J. and Taylor, E., W. (2001) 'Adult Education Philosophy informs Practice' Adult Learning, bringing our Philosophies into Practice, 6-10

Tobin, D. (2010) A crisis of Ethics, Moral hazard and banking regulation in Ireland, TASC Think pieces, retrieved from, http://issuu.com/tascpublications/docs/tobin_250310, [accessed November, 2010]

Tobin, P. (1989) 'Women in Community Work' in Community Work in Ireland, Trends for the 80's options for the 90 's, Dublin: The Combat Poverty Agency

Tönnies, F. (2002) Community and Society, UK: David and Charles

Torres, C. A. (1993) 'From the Pedagogy of the Oppressed to a Luta Continua' in McLaren, P. and Leonard, P. (editors) Paulo Freire, A critical Encounter, London and New York: Routledge.

Tovey, H. and Share, P. (2000) A Sociology of Ireland, Dublin: Gill and MacMillan

The Teaching Council (2009) The Teaching Council [Registration] Regulations, retrieved from, http://www.teachingcouncil.ie/_fileupload/Registration/Overview/Registration_ Regulations_2009_90665047.pdf, [accessed September, 2012]

Turner, R. (2009) 'Workers' Educational Association tutorial classes and citizenship in Scotland, 1907-1939', History of Education, 38 (3): 367-381

Twelvetrees, A. (2008). Community Work. $4^{\text {th }}$ edition. Basingstoke: Palgrave-Macmillan.

United Nations (2014) United Nations Human Development Report: Sustaining Human Progress: Reducing Vulnerabilities and Building Resilience, United Nations Publications.

United Nations (2013) The Millennium Development Goals Report, New York: United Nations

Universities UK (2011) Review of external examining arrangements in universities and colleges in the UK Final report and recommendations, London: Universities UK.

UN-GIFT (2009) Global Report on Trafficking in Persons, United Nations office on Crimes and Drugs, retrieved from, http://www.unodc.org/documents/Global_Report_on_TIP.pdf, [accessed March, 2013]

Valsiner, J. (2000) 'Data as representations: Contextualizing qualitative and quantitative research strategies'. Social Science Information, 39: 99-113

Van Der Wende, M.C. (2000) 'The Bologna Declaration: Enhancing the Transparency and Competitiveness of European Higher Education', Higher Education in Europe, XXV (3) 305310

Walsh, J. (1996a) 'Challenge of corporate governance for community directors' Poverty Today, Dublin: Combat Poverty Agency. 
Walsh, J. (1996b) 'Review highlights need for Partnership Reforms' Poverty Today, Dublin: Combat Poverty Agency

Walsh, J., Craig, S. and McCafferty, D. (1998) Local Partnerships for Social Inclusion? Dublin: Combat Poverty Agency.

Walsh, T. (2005) 'Constructions of Childhood in Ireland in the Twentieth Century: A View from the Primary School Curriculum 1900-1999’ Child Care in Practice, 11 (2): 253- 269

Walsh, P. (2006) 'Narrowed horizons and the impoverishment of educational discourse: teaching, learning and performing under the new educational bureaucracies' Journal of Education Policy, 21(1): 95-117

Watson, D. McCoy, S. and Gorby, S (2006) The Post-Leaving Certificate Sector in Ireland: A Multivariate Analysis of Educational and Employment Outcomes, Department of Education and Science and ESRI.

Weber, J. (2014) 'Humanism within Globalisation, Adult Learning, 25(2): 66-68

Weiler (1991) 'Freire and a Feminist Pedagogy of Difference' Harvard Educational review, 61 (4) 449-474

West, J. (2006) 'Patrolling the boarders: accreditation in further and higher education in England', Journal of Further and Higher Education, 30 (1): 12-26

Westerman, W. (2009) 'Folk Schools, Popular Education, and a Pedagogy of Community Action' in Darder, A., Baltodano, P. and Torres, R. D. (editors) The Critical Pedagogy Reader, $2^{\text {nd }}$ edition. London and New York: Routledge

Whelan, M. (1989) 'Training and Professionalisation in Community Work' in Community Work in Ireland: Trends in the 80s; Options for the 90s, Dublin: Combat Poverty Agency

Whitehead, P. and Crawshaw, P. (2012) Organising Neoliberalism: Markets, Privatisation and Justice, London: Anthem Press

Wiggins, N. (2011) 'Critical pedagogy and popular education, towards a unity of theory and practice', Studies in the Education of Adults, 43 (1): 34-49

Wildemeersch, D. (2014) 'Adult and community education in complex societies: reconsidering critical perspectives', International Journal of Lifelong Education, 33 (6): 821831

Wilson, A. (1995) 'The Common Concern: Controlling the Professionalization of Adult Education' in Merriam, S. B. (editor.) Selected Writings on Philosophy and Adult Education Florida: Krieger Publishing Company

Williams, J., Greene, S., Doyle, E., Harris, E., Layte, R., McCoy, S., McCrory, C., Murray, A., Nixon, E., O’Dowd, T., O’Moore, M., Quail, A., Smyth, E., Swords, L., Thornton, M. (2009) The lives of 9-yr-olds, Growing up in Ireland, National longitudinal study of children, Dublin: Office of the Minister for Health and Children

Wilkinson, R. and Pickett, K. (2009) The Spirit Level, Why more equal societies almost always to better, London: Penguin Books 
Windebank, J. and Whitworth, A. (2014) 'Social Welfare and the Ethics ofAusterity in Europe: Justice, Ideology and Equality’ Journal of Contemporary European Studies, 22 (2): 99-103

Young, M (2007) 'National Frameworks, some conceptual issues', European Journal of Education, 42 (4): 445-457

Zachariadis, M., Scott, S. and Barrett, M.(2013) 'Methodological implications of critical realism for mixed-methods research', MIS Quarterly 37 (3): 855-879

Zappone, K (1998) 'Top-Down or Bottom-Up: The Involvement of the Community Sector in Partnerships in the Shadow of the Tiger' in Kirby, P. and Jacobson, D. (editors) New Approaches to Combating Social Exclusion. Dublin: Dublin City University Press

Zerkic, C. T. (2014) 'The EU's Democratic Deficit and Repeated Referendums in Ireland' International Journal of Politics, Culture and Society, 27(30): 276-286

Žižek, S. (2009) First as Tragedy, then as Farce. London-New York: Verso 


\section{Appendix 1 - Consent form one-to-one}

Thank you for taking time to consider participation in my research.

\section{Information about me, the researcher}

I have been working in community education since the late 1990s. My first years were within a Community Development Project (CDP) in North Dublin and since then I have spent time working within a VEC and as an independent tutor. I currently work with Respond! Voluntary Housing Association as a community educator and am an associate member of staff with the Dept. of Adult and Community Education, NUI Maynooth. I am also a Director with Partners Training for Transformation and a steering committee member with the Aontas, CEN.

\section{About the research}

Broadly speaking I hope to offer an understanding of a type of community education that is political and politicising and that encourages a praxis oriented approach to addressing systemic inequality. You have been invited to participate as someone who shares some of these thoughts. I hope that together we can uncover in more detail what it is we are talking about, what challenges this way of working carries, what impacts it has and what practitioners hope for the future.

One-to-one interview

You are invited to participate in a one-to-one interview which will take place at a time and place convenient to you. I estimate this will take around 45minutes to 1hour. Should you decide to participate, you can of course change your mind and withdraw from the process at any stage.

\section{Confidentiality}

It is really important to me that you feel comfortable and are satisfied with every stage in the process. Neither you, nor the name of your organisation will be revealed at any time during the write up or presentation of the research. What will be referred to is the type of organisation you work for (e.g. a VEC, CDP, FRC etc.). Our interview will be audio-recorded and I will send you a full transcript upon completion. You will be invited to amend or remove your contributions if you are in any way uncomfortable with them retrospectively. You will also be offered the opportunity to withdraw your transcript at any stage up to the spring of 2015. Transcripts will only be read by me, will be stored in a secure place, and will be destroyed upon completion of the research.

What is uncovered will be used in my $\mathrm{PhD}$ dissertation and possibly in academic papers and presentations. Please contact me or my supervisor at any stage if you have any queries.

Camilla Fitzsimons

Dept. of Adult and Community Education

NUI Maynooth.

Camilla.m.fitzsimons@nuim.ie

\section{Dr. Brid Connolly}

Dept. of Adult and Community Education

NUI Maynooth

brid.connolly@nuim.ie

If during your participation in this study you feel the information and guidelines that you were given have been neglected or disregarded in any way, or if you are unhappy about the process, please contact the Secretary of the National University of Ireland Maynooth Ethics Committee at research.ethics@nuim.ie or +353 (0)1 708 6019. Please be assured that your concerns will be dealt with in a sensitive manner.

Name (block capitals) Signature:

Date: 


\section{Appendix 2 - Survey - Community Education, Views from Practitioners}

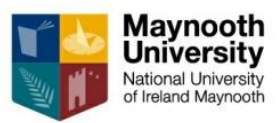

\section{Community Education views from practitioners}

\section{Welcome}

Thank you for taking the time to consider this questionnaire. It forms part of research that hopes to gather information on community education and community educators in Ireland. The research is part of a PhD I am undertaking under the supervision of the Dept. of Adult and Community Education, NUI Maynooth.

\section{If you are currently working with a group in a community setting, or have done so} in the last 2 years, you are eligible to complete this form. This means working with groups outside of Higher Education and Further Education institutions and local to participants.

The survey takes about 20 minutes to complete. Some of it is about building a profile of community educators and asks things like how long have you been working in community education, the type of organisation you work for, network membership and information on accreditation if offered. It also has a question about your own socio-economic background and any qualifications you might have. It then gathers opinions on what community education (CE) is, what ideas inform it and what thoughts you have on some of the changes affecting CE.

You don't have to give your name (unless you wish to become involved in the group stage of the research later on) and you will not be asked to name where you work. At no stage will your identity be revealed in the writing up or presentation of this research.

Completed questionnaires will be read by me alone, will be stored in a secure place, and will be destroyed upon completion of the research.

For more information contact me-Camilla Fitzsimons, Dept. of Adult and Community education, NUI, Maynooth, or at _.m.fitzsimons@nuim.ie

or my supervisor - Dr Brid Connolly Dept. Of Adult and Community

Education, NUI Maynooth or at

If during your participation in this study you feel the information and guidelines that you were given have been neglected or disregarded in any way, or if you are unhappy about the process, please contact the Secretary of the National University of Ireland Maynooth Ethics Committee at research.ethics@nuim.ie or +353 (0)1 Please be assured that your concerns will be dealt with in a sensitive manner. 
Questions 1-9 asks some details about yourself including your educational background and the organisation (if any) you work for,

1. How many years have you been working in Community Education/the

Community Sector?

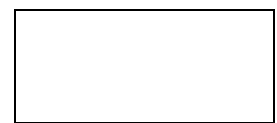

2. What is your gender?

\begin{tabular}{|l|l|l|l|l|}
\hline Female & & Male & & Transgender \\
\hline
\end{tabular}

3. Is your work usually based in,

\begin{tabular}{|l|l|l|l|l|l|}
\hline An urban setting & & A rural setting & & $\begin{array}{l}\text { Both urban and rural } \\
\text { settings }\end{array}$ \\
\hline
\end{tabular}

4. The Combat Poverty Agency describe 'educational disadvantage' as something that especially impacts "individuals from poorer socio-economic backgrounds and communities". Is your own background typically described in this way?

\begin{tabular}{|l|l|l|l|l|l|}
\hline & Yes & & No & & Don't know \\
\hline
\end{tabular}

5. Please tick the statements that describe any qualifications awarded by a recognised institution/authority that you hold

\begin{tabular}{|l|l|}
\hline & I don't have any formal qualifications \\
\hline & I have a major certificate awarded by FETAC \\
\hline & I have a certificate or diploma awarded by HETAC \\
\hline & $\begin{array}{l}\text { I have a certificate or diploma awarded by a university } \\
\text { I have a degree awarded by an Institute of technology or } \\
\text { university }\end{array}$ \\
\hline & I have a post-graduate qualification (H. Dip. or Masters) \\
\hline & I have a PhD \\
\hline & Other \\
\hline
\end{tabular}

5a If you selected other, please specify

6. If you have ticked one of the boxes above, how did you complete your initial studies (e.g. your first degree or certificate)

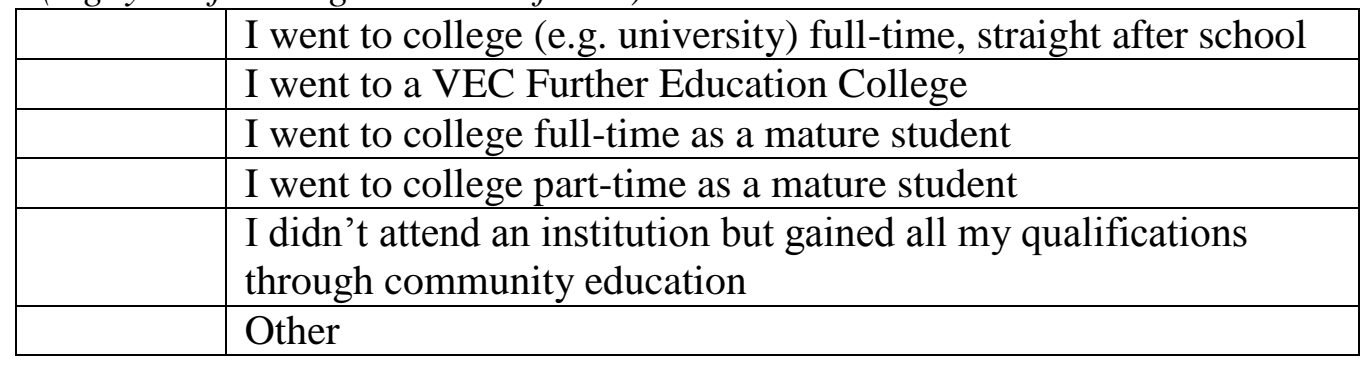


6a If you selected other, please specify

7. Is your work?

\begin{tabular}{|l|l|}
\hline & Paid \\
\hline & Voluntary \\
\hline & Part-time (less than 35 hours) \\
\hline & Full-time (more than 35 hours) \\
\hline
\end{tabular}

8. What sort of organisation (if any) do you work for?

\begin{tabular}{|l|l|}
\hline & $\begin{array}{l}\text { A community Development Project (CDP) now managed by a local } \\
\text { area partnership }\end{array}$ \\
\hline & A Family Resource Centre \\
\hline & $\begin{array}{l}\text { A project for those affected by addiction linked to a Local Drugs } \\
\text { Task Force }\end{array}$ \\
\hline & $\begin{array}{l}\text { A Vocational Educational Committee (VEC) as a Community } \\
\text { Education Facilitator (CEF) }\end{array}$ \\
\hline & A VEC as a tutor \\
\hline & A university or IT \\
\hline & I don't work for an organisation but am an independent practitioner \\
\hline & An independent Community Education Organisation \\
\hline
\end{tabular}

8b If you answered 'an independent community organisation' or 'other' who funds you?

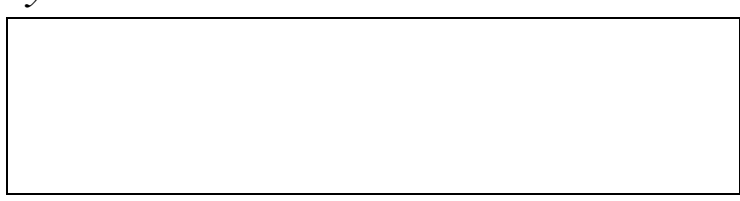

9. Are you or your organisation a member of any of the following networks

\begin{tabular}{|l|l|}
\hline & AONTAS Community Education Network (CEN) \\
\hline & Limerick CEN \\
\hline & Community Workers Cooperative \\
\hline & City-wide \\
\hline & Irish Development Education Association \\
\hline & Other \\
\hline
\end{tabular}

$9 \mathrm{~b}$ if you selected other, please specify 
Questions 10-17 ask some questions about your work as a tutor/facilitator

10. Please rank the following statements describing how you mostly interpret your role

\begin{tabular}{|l|l|l|l|l|l|}
\hline & $\begin{array}{l}\text { Most } \\
\text { accurate }\end{array}$ & $\begin{array}{l}2^{\text {nd }} \\
\text { accurate }\end{array}$ & $\begin{array}{l}3^{\text {rd }} \text { accurat } \\
\text { accur }\end{array}$ & $\begin{array}{l}4^{\text {th }} \text { most } \\
\text { accurate }\end{array}$ & $\begin{array}{l}\text { Least } \\
\text { accurate }\end{array}$ \\
\hline $\begin{array}{l}\text { To respond to the issues and } \\
\text { needs of the group regardless } \\
\text { of the course } \\
\text { module/descriptor }\end{array}$ & & & & \\
\hline $\begin{array}{l}\text { To introduce groups to } \\
\text { knowledge that I am familiar } \\
\text { with thereby sharing my } \\
\text { expertise }\end{array}$ & & & & & \\
\hline $\begin{array}{l}\text { To build the self-confidence } \\
\text { and knowledge base of } \\
\text { individuals enabling them } \\
\text { to avail of a range of } \\
\text { opportunities }\end{array}$ & & & & & \\
\hline $\begin{array}{l}\text { To encourage the groups I } \\
\text { work with to collaborate } \\
\text { with each other and to } \\
\text { together take action to } \\
\text { address issues that affect } \\
\text { their communities }\end{array}$ & & & & & \\
\hline $\begin{array}{l}\text { To up-skill individuals so } \\
\text { they are better equip to } \\
\text { compete against others in } \\
\text { getting a job }\end{array}$ & & & & & \\
\hline
\end{tabular}

11. In my job it is usual for me to work more hours than I am paid for

\begin{tabular}{|l|l|}
\hline & Yes \\
\hline & No \\
\hline & Sometimes \\
\hline
\end{tabular}


12. As a tutor/facilitator, do the courses you are involved with offer accreditation?

\begin{tabular}{|l|l|}
\hline & Never \\
\hline & Sometimes/on some courses \\
\hline & Most of the time \\
\hline & Never \\
\hline
\end{tabular}

13. If yes, who are the awarding bodies

\begin{tabular}{|l|l|}
\hline & FETAC (QQI) \\
\hline & HETAC (QQI) through an IT (e.g. IT Carlow) \\
\hline & $\begin{array}{l}\text { HETAC through an independent college or organisation } \\
\text { (e.g. a private college) }\end{array}$ \\
\hline & University (e.g. NUI Maynooth) \\
\hline & Other \\
\hline
\end{tabular}

$13 \mathrm{~b}$ if you selected other, please specify

For questions 14-17 please choose the answer that most closely matches your opinion

14. The fact that most courses are accredited is a good thing for community education

\begin{tabular}{|l|l|}
\hline & Strongly Agree \\
\hline & Agree \\
\hline & Somewhat Agree \\
\hline & Don't know if I agree or Disagree \\
\hline & Somewhat Disagree \\
\hline & Disagree \\
\hline & Strongly Disagree \\
\hline
\end{tabular}

15. FETAC is the most suitable awarding body for community education

\begin{tabular}{|l|l|}
\hline & Strongly Agree \\
\hline & Agree \\
\hline & Somewhat Agree \\
\hline & Don't know if I agree or Disagree \\
\hline & Somewhat Disagree \\
\hline & Disagree \\
\hline & Strongly Disagree \\
\hline
\end{tabular}


16. The need for all those delivering FETAC accredited courses to have formal qualification at degree level is desirable so we can ensure high standards

\begin{tabular}{|l|l|}
\hline & Strongly Agree \\
\hline & Agree \\
\hline & Somewhat Agree \\
\hline & Don't know if I agree or Disagree \\
\hline & Somewhat Disagree \\
\hline & Disagree \\
\hline & Strongly Disagree \\
\hline
\end{tabular}

17. When I am delivering accredited courses, my experience has been that this interferes with the way I would ideally like to be as a tutor.

\begin{tabular}{|l|l|}
\hline & Strongly Agree \\
\hline & Agree \\
\hline & Somewhat Agree \\
\hline & Don't know if I agree or Disagree \\
\hline & Somewhat Disagree \\
\hline & Disagree \\
\hline & Strongly Disagree \\
\hline
\end{tabular}

18. When you see community education in action, what is happening that causes you to say "now that is community education"

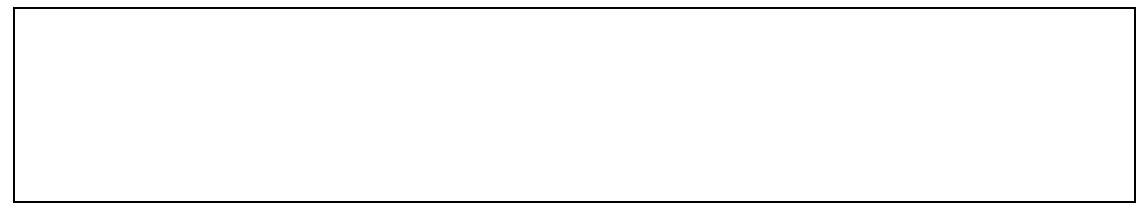

19. If there is a particular way of working that informs your approach (a certain belief system, theory, philosophy etc.) can you explain or describe it

20. Can you give an example of something you were involved with that best illustrates your approach to community education and the ideas underpinning it 
21. Books on community education sometimes talk about three overlapping approaches,

1. Where the emphasis is on offering a wide range of courses (vocational, personal, political) that are open to anyone who is interested regardless of where they live and where their background is.

2. Where there is emphasis on offering a wide range of courses (vocational, personal, political) specifically targeted at those who are considered 'educationally disadvantaged' thereby providing opportunities otherwise not readily available.

3. Where they emphasis is as a political and politicising act taking its lead from issues affecting people in communities considered disadvantaged. Its approach is collective over individual and its hope is to influence wider social change.

Ideally which one of these approaches would you most align your own practice with?

\begin{tabular}{|l|l|l|l|l|}
\hline Option 1 & & Option 2 & & Option 3 \\
\hline
\end{tabular}

21 which one of these approaches would you most align your employers with?

\begin{tabular}{|l|l|l|l|l|}
\hline Option 1 & & Option 2 & & Option 3 \\
\hline
\end{tabular}

22. The target group for community education should be people who experience social and economic disadvantage

\begin{tabular}{|l|l|}
\hline & Strongly Agree \\
\hline & Agree \\
\hline & Somewhat Agree \\
\hline & Don't know if I agree or Disagree \\
\hline & Somewhat Disagree \\
\hline & Disagree \\
\hline & Strongly Disagree \\
\hline
\end{tabular}

23. Those who have themselves experienced social and economic disadvantage are best suited to work with local community education groups

\begin{tabular}{|l|l|}
\hline & Strongly Agree \\
\hline & Agree \\
\hline & Somewhat Agree \\
\hline & Don't know if I agree or Disagree \\
\hline & Somewhat Disagree \\
\hline & Disagree \\
\hline & Strongly Disagree \\
\hline
\end{tabular}

24. The only way equality and social justice can be truly achieved is through a complete overhaul of our of our political and economic system

\begin{tabular}{|l|l|}
\hline & Strongly Agree \\
\hline & Agree \\
\hline & Somewhat Agree \\
\hline & Don't know if I agree or Disagree \\
\hline & Somewhat Disagree \\
\hline & Disagree \\
\hline & Strongly Disagree \\
\hline
\end{tabular}


25. The Irish Community Sector has been co-opted and is not a force for influencing social change.

\begin{tabular}{|l|l|}
\hline & Strongly Agree \\
\hline & Agree \\
\hline & Somewhat Agree \\
\hline & Don't know if I agree or Disagree \\
\hline & Somewhat Disagree \\
\hline & Disagree \\
\hline & Strongly Disagree \\
\hline
\end{tabular}

26. Through my work as a community educator I am helping to reduce inequality in Ireland

\begin{tabular}{|l|l|}
\hline & Strongly Agree \\
\hline & Agree \\
\hline & Somewhat Agree \\
\hline & Don't know if I agree or Disagree \\
\hline & Somewhat Disagree \\
\hline & Disagree \\
\hline & Strongly Disagree \\
\hline
\end{tabular}

27. Have you any other thoughts or views about community education that you would like to share (including any thoughts on matters already raised such as accreditation, cooption, disadvantage, working conditions etc.)

\section{Further Involvement}

I will be holding group discussions around the country where I hope we can discuss issues raised and other thoughts people have about community education. Would you like further information on these with a view to participation? Remember that by doing this you are wavering anonymity relating to your survey answers. You are only revealing your identity to me and at no time will the answers you provided in this survey be revealed to others. Your identity will at no time be disclosed in the writing up of this research.

\begin{tabular}{|l|l|l|l|}
\hline & Yes & & No \\
\hline
\end{tabular}

If you answered yes, please provide your name and contact details below

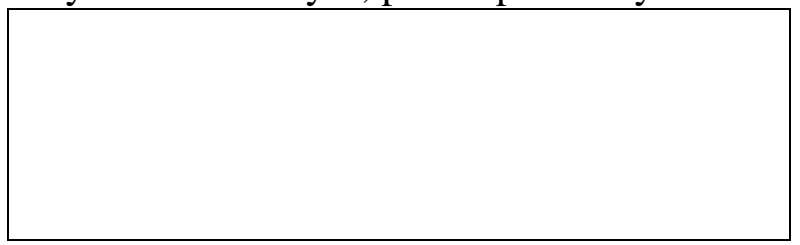

Thank you so much for taking the time to complete this questionnaire, I am hopeful your answers will assist in building a profile of the thoughts and opinions of community educators in Ireland. Please contact me if you require any further information or clarification at 


\section{Appendix 3 - Focus-group consent form}

Thank you for taking time to consider participation in my research.

\section{Information about me, the researcher}

I have been working in community education since the late 1990s. My first 8 years were within a Community Development Project (CDP) in North Dublin and since then I have spent time working within a VEC and as an independent tutor. I currently work with Respond! Voluntary Housing Association as a community educator and am an associate member of staff with the Dept. of Adult and Community Education, NUI Maynooth. I am also a Director with Partners Training for Transformation and a steering committee member with the Aontas, CEN.

\section{About the research}

Broadly speaking I hope to offer an understanding of a type of community education that is political and politicising and that encourages a praxis oriented approach to addressing systemic inequality. You have been invited to participate as someone who shares some of these thoughts. I hope that together, and with others, we can uncover in more detail what it is we are talking about, what challenges this way of working carries, what impacts it has and what practitioners hope for the future.

\section{Focus-group participation}

You are invited to participate in a group discussion with others who have also been selected from the same criteria. The focus-group will take place [place and time] and I estimate it will take around $1 \mathrm{hr}$ to $1.5 \mathrm{hrs}$. The maximum amount of people in any group will be 12 . Should you decide to participate, you can change your mind and withdraw from the process at any stage.

\section{Confidentiality}

It is really important to me that you feel comfortable and are satisfied with every stage in the process. Neither you, nor the name of your organisation will be revealed at any time during the write up or presentation of the research. What will be referred to is the type of organisation you work for (e.g. a VEC, CDP, FRC etc.). As you will be participating alongside others, a confidentiality agreement will be introduced asking those involved not to reveal the identity of others and not to share discussions with anyone outside of the group. I will be audio-recording all group discussions and will send everyone a transcript. You will be invited to amend or remove contributions you made if you are in any way uncomfortable with it retrospectively. Transcripts will only be read by me, will be stored in a secure place, and will be destroyed upon completion of the research. What is uncovered will be used in my $\mathrm{PhD}$ dissertation and possibly in academic papers and presentations. Please contact me or my supervisor at any stage if you have any queries.

Camilla Fitzsimons

Dept. of Adult and Community Education

NUI Maynooth.

Camilla.m.fitzsimons@nuim.ie

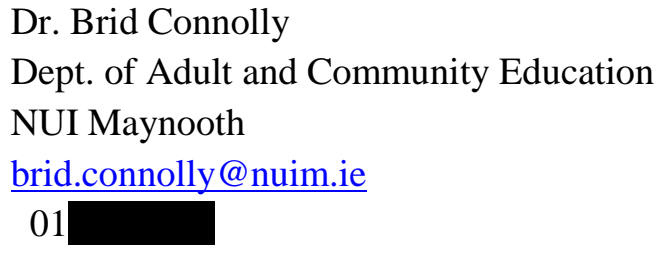

If during your participation in this study you feel the information and guidelines that you were given have been neglected or disregarded in any way, or if you are unhappy about the process, please contact the Secretary of the National University of Ireland Maynooth Ethics Committee at research.ethics@nuim.ie or +353(0)1 708 6019. Please be assured that your concerns will be dealt with in a sensitive manner.

Name:

Signature:

Date:

Survey 


\section{Appendix 4 - Telephone interviewing consent form}

\section{Research on Community Education in Ireland 'Views from Practitioners'}

\section{Information on Telephone Interview}

Thanks for agreeing to participate in a telephone interview as part of research on community education in Ireland that is interested in gathering the thoughts, experiences and issues faced by practitioners. A mixed-methods approach is being used meaning I am generating data from both quantitative and qualitative methods through a survey, one-to-one interviews, focus-groups, and telephone interviews. Over 230 practitioners are participating.

My intention is to call so we can discuss the following:

1. Tell me a little bit about the work that you do and what motivates or energises you as you do it.

2. What are your thoughts on community education in Ireland as a whole?

3. What are the biggest issues or challenges that you face within your work?

4. What do you think we, as community educators, can do to address some of the concerns that we have?

5. Is there anything else you would like to tell me about?

It is really important to me that you feel comfortable and are satisfied with every stage in the process. Neither you, nor the name of your organisation will be revealed at any time during the write up or presentation of the research. I will be audio-recording our discussion and will send you a full transcript of our conversation. You will be invited to amend or remove contributions you made if you are in any way uncomfortable retrospectively or withdraw the transcript in totality. Transcripts will only be read by me, will be stored in a secure place, and will be destroyed upon completion of the research. What is uncovered may be used in my $\mathrm{PhD}$ dissertation, academic papers and presentations. Please contact me or my supervisor at any stage if you have any queries.

Camilla Fitzsimons

Dept. of Adult and Community Education

NUI Maynooth.

Camilla.m.fitzsimons@nuim.ie
Dr. Brid Connolly

Dept. of Adult and Community Education

NUI Maynooth

brid.connolly@nuim.ie

087-

If during your participation in this study you feel the information and guidelines that you were given have been neglected or disregarded in any way, or if you are unhappy about the process, please contact the Secretary of the National University of Ireland Maynooth Ethics Committee at research.ethics@nuim.ie or +353(0)1 708 6019. Please be assured that your concerns will be dealt with in a sensitive manner.

Name: Signature:

Date: 


\section{Appendix 5 - Further detail on quantitative findings}

\begin{tabular}{|c|c|c|c|c|c|}
\hline \multirow{2}{*}{\multicolumn{2}{|c|}{$\begin{array}{l}\text { Table A - How many } \\
\text { Community Sector? }\end{array}$}} & ears have & been $y$ & in Comn & ucation/The \\
\hline & & Frequency & Percent & Valid Percent & Cumulative Percent \\
\hline \multirow{6}{*}{ Valid } & $0-5 y r s$ & 54 & 24.7 & 25.5 & 25.5 \\
\hline & 6-10yrs & 53 & 24.2 & 25.0 & 50.5 \\
\hline & 11-15yrs & 51 & 23.3 & 24.1 & 74.5 \\
\hline & 16-20yrs & 31 & 14.2 & 14.6 & 89.2 \\
\hline & over 20yrs & 23 & 10.5 & 10.8 & 100.0 \\
\hline & Total & 212 & 96.8 & 100.0 & \\
\hline Missing & 99.00 & 7 & 3.2 & & \\
\hline \multicolumn{2}{|l|}{ Total } & 219 & 100.0 & & \\
\hline
\end{tabular}

Table B - Please tick the statements that describe any qualifications awarded by a recognised education institution/authority that you hold.

\begin{tabular}{|c|c|c|c|c|c|}
\hline & Frequency & Percent & $\begin{array}{c}\text { Valid } \\
\text { Percent }\end{array}$ & $\begin{array}{c}\text { Cumulative } \\
\text { Percent }\end{array}$ \\
\hline \multirow{8}{*}{ Valid } & no qualifications & 6 & 2.7 & 2.7 & 2.7 \\
\hline & FETAC major award & 3 & 1.4 & 1.4 & 4.1 \\
\hline & Certificate or Diploma from HEI & 41 & 18.7 & 18.7 & 22.8 \\
\hline & degree from University or IT & 40 & 18.3 & 18.3 & 41.1 \\
\hline & Post-graduate qualification & 119 & 54.3 & 54.3 & 95.4 \\
\hline & PhD & 8 & 3.7 & 3.7 & 99.1 \\
\hline & JEB diploma & 2 & .9 & .9 & 100.0 \\
\hline & Total & 219 & 100.0 & 100.0 & \\
\hline
\end{tabular}

\begin{tabular}{|c|c|c|c|c|c|}
\hline & & Frequency & Percent & Valid Percent & $\begin{array}{c}\text { Cumulative } \\
\text { Percent }\end{array}$ \\
\hline \multirow{9}{*}{ Valid } & Full time after school & 89 & 40.6 & 41.4 & 41.4 \\
\hline & VEC FE college & 4 & 1.8 & 1.9 & 43.3 \\
\hline & full-time as a mature student & 27 & 12.3 & 12.6 & 55.8 \\
\hline & part-time as a mature student & 71 & 32.4 & 33.0 & 88.8 \\
\hline & community education & 12 & 5.5 & 5.6 & 94.4 \\
\hline & distance learning & 2 & .9 & .9 & 95.3 \\
\hline & Other & 4 & 1.8 & 1.9 & 97.2 \\
\hline & Not eligible to answer & 6 & 2.7 & 2.8 & 100.0 \\
\hline & Total & 215 & 98.2 & 100.0 & \\
\hline Missing & 99.00 & 4 & 1.8 & & \\
\hline \multicolumn{2}{|l|}{ Total } & 219 & 100.0 & & \\
\hline
\end{tabular}

Table D - The CPA describe 'educational disadvantage' as something that especially
impacts "individuals from poorer socio-economic backgrounds and communities". Is your
own background typically described in this way
\begin{tabular}{l|l|r|r|r|r|}
\hline \multicolumn{5}{|c|}{} \\
\hline \multirow{4}{*}{ Valid } & Frequency & Percent & Valid Percent & Cumulative Percent \\
\hline & Disadvantaged & 73 & 33.3 & 33.5 & 33.5 \\
\cline { 2 - 7 } & Advantaged & 132 & 60.3 & 60.6 & 94.0 \\
\cline { 2 - 7 } & Don't know & 13 & 5.9 & 6.0 & 100.0 \\
\cline { 2 - 7 } & Total & 218 & 99.5 & 100.0 & \\
\hline Missing & 99.00 & 1 & .5 & & \\
\hline Total & 219 & 100.0 & & \\
\hline
\end{tabular}




\begin{tabular}{|c|c|c|c|c|c|}
\hline \multicolumn{6}{|c|}{ Table E- Is your work based in Urban or Rural Settings? } \\
\hline & & Frequency & Percent & Valid Percent & Cumulative Percent \\
\hline \multirow{4}{*}{ Valid } & Urban & & 123 & 56.9 & 56.9 \\
\hline & Rural & & 22 & 10.2 & 67.1 \\
\hline & $\begin{array}{l}\text { Urban and } \\
\text { Rural }\end{array}$ & & 71 & 32.9 & 100.0 \\
\hline & Total & & 216 & & \\
\hline Missing & 99.00 & 7 & 3 & & \\
\hline \multicolumn{2}{|l|}{ Total } & 219 & 100.0 & & \\
\hline
\end{tabular}

\begin{tabular}{|c|c|c|c|c|c|}
\hline & & Frequency & Percent & Valid Percent & $\begin{array}{l}\text { Cumulative } \\
\text { Percent }\end{array}$ \\
\hline \multirow{18}{*}{ Valid } & VEC as a tutor & 39 & 17.8 & 18.0 & 18.0 \\
\hline & LCDP & 38 & 17.4 & 17.5 & 35.5 \\
\hline & Independent CE Org. & 37 & 16.9 & 17.1 & 52.5 \\
\hline & CEF & 22 & 10.0 & 10.1 & 62.7 \\
\hline & family resource centres & 16 & 7.3 & 7.4 & 70.0 \\
\hline & Independent practitioner & 13 & 5.9 & 6.0 & 76.0 \\
\hline & HEls & 11 & 5.0 & 5.1 & 81.1 \\
\hline & NGOs & 9 & 4.1 & 4.1 & 85.3 \\
\hline & Addiction projects & 7 & 3.2 & 3.2 & 88.5 \\
\hline & Other & 7 & 3.2 & 3.2 & 91.7 \\
\hline & Independent CDP & 7 & 3.2 & 3.2 & 94.9 \\
\hline & VEC as AEO & 2 & .9 & .9 & 95.9 \\
\hline & literacy tutor & 3 & 1.4 & 1.4 & 97.2 \\
\hline & for a network & 2 & .9 & .9 & 98.2 \\
\hline & FAS & 2 & .9 & .9 & 99.1 \\
\hline & private provider & 1 & .5 & .5 & 99.5 \\
\hline & HSE & 1 & .5 & .5 & 100.0 \\
\hline & Total & 217 & 99.1 & 100.0 & \\
\hline Missing & 99.00 & 2 & .9 & & \\
\hline \multicolumn{2}{|l|}{ Total } & 219 & 100.0 & & \\
\hline
\end{tabular}

\begin{tabular}{|c|c|c|c|c|c|}
\hline \multirow{2}{*}{\multicolumn{6}{|c|}{$\begin{array}{l}\text { Table G - Are you, or your organisation, a mer } \\
\text { networks (select all that apply) }\end{array}$}} \\
\hline then & & Frequency & Percent & Valid Percent & Cumulative Percent \\
\hline \multirow{13}{*}{ Valid } & Aontas CEN & 112 & 51.1 & 66.3 & 66.3 \\
\hline & Community Workers Co-op. & 13 & 5.9 & 7.7 & 74.0 \\
\hline & other & 9 & 4.1 & 5.3 & 79.3 \\
\hline & Local CE networks & 6 & 2.7 & 3.6 & 82.8 \\
\hline & CEFA & 6 & 2.7 & 3.6 & 86.4 \\
\hline & Citywide & 4 & 1.8 & 2.4 & 88.8 \\
\hline & Limerick CEN & 4 & 1.8 & 2.4 & 91.1 \\
\hline & IDEA & 3 & 1.4 & 1.8 & 92.9 \\
\hline & NALA & 2 & .9 & 1.2 & 94.1 \\
\hline & The wheel & 2 & .9 & 1.2 & 95.3 \\
\hline & Aontas & 2 & .9 & 1.2 & 96.4 \\
\hline & Don't know & 6 & 2.7 & 3.6 & 100.0 \\
\hline & Total & 169 & 77.2 & 100.0 & \\
\hline Missing & 99.00 & 50 & 22.8 & & \\
\hline \multicolumn{2}{|l|}{ Total } & 219 & 100.0 & & \\
\hline
\end{tabular}




\begin{tabular}{|l|l|r|r|r|r|}
\hline \multicolumn{2}{|l|}{ Table H - Is your work paid or voluntary } \\
\hline \multirow{3}{*}{ Valid } & Frequency & Percent & Valid Percent & $\begin{array}{c}\text { Cumulative } \\
\text { Percent }\end{array}$ \\
\cline { 2 - 6 } & Paid & 169 & 77.2 & 79.0 & 79.0 \\
\cline { 2 - 6 } & Voluntary & 24 & 11.0 & 11.2 & 90.2 \\
\cline { 2 - 7 } & Paid and voluntary & 21 & 9.6 & 9.8 & 100.0 \\
\hline \multirow{2}{*}{ Missing } & Total & 214 & 97.7 & 100.0 & \\
\hline Total & 99.00 & 5 & 2.3 & & \\
\hline
\end{tabular}

Table I - Is your work full-time, part-time

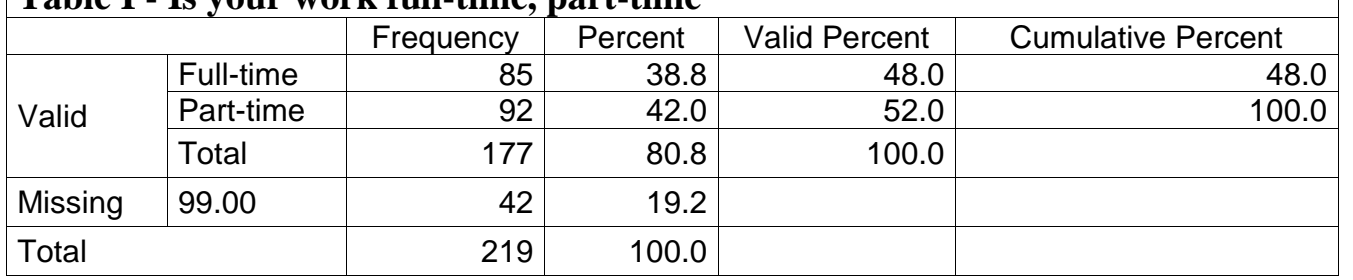

\begin{tabular}{|c|c|c|c|}
\hline Organisation & Full-time & Part-Time & Total \\
\hline Community Sector & & & \\
\hline Local and CD programme & 19 & 13 & 32 \\
\hline Independent CE Organisation & 11 & 21 & 32 \\
\hline Independent CDP & 4 & 3 & 7 \\
\hline FRCs & 11 & 4 & 15 \\
\hline Addiction Projects & 2 & 1 & 3 \\
\hline Other & 2 & 4 & 6 \\
\hline Network & 0 & 1 & 1 \\
\hline NGO & 4 & 2 & 6 \\
\hline Independent Practitioners & 1 & 9 & 10 \\
\hline Totals & 54 & 58 & 112 \\
\hline State Provider & & & \\
\hline VEC as a CEF & 18 & 2 & 20 \\
\hline VEC as a tutor & 4 & 26 & 30 \\
\hline VEC as an AEO & 2 & 0 & 2 \\
\hline Literacy tutor & 1 & 1 & 2 \\
\hline HEls & 4 & 3 & 7 \\
\hline FAS & 1 & 1 & 2 \\
\hline Totals & \multirow[t]{3}{*}{30} & \multirow[t]{3}{*}{33} & 63 \\
\hline Private Provider & & & 1 \\
\hline & & & $176^{\star}$ \\
\hline
\end{tabular}

*additional missing value as one to answer this question did not name organisation. 
Table K - In my job, it is usual for me to work more hours than those I am paid for

\begin{tabular}{|l|l|r|r|r|r|}
\hline \multicolumn{2}{|c|}{} & Frequency & Percent & Valid Percent & $\begin{array}{c}\text { Cumulative } \\
\text { Percent }\end{array}$ \\
\hline \multirow{4}{*}{ Valid } & yes & 134 & 61.2 & 61.5 & 61.5 \\
\cline { 2 - 6 } & no & 17 & 7.8 & 7.8 & 69.3 \\
\cline { 2 - 6 } & sometimes & 43 & 19.6 & 19.7 & 89.0 \\
\cline { 2 - 6 } & not eligible as volunteer & 24 & 11.0 & 11.0 & 100.0 \\
\cline { 2 - 7 } & Total & 218 & 99.5 & 100.0 & \\
\hline Missing & 99.00 & 1 & .5 & & \\
\hline Total & 219 & 100.0 & & \\
\hline
\end{tabular}

Table $L$ - As a facilitator/tutor, do the courses you are involved with offer accreditation?

\begin{tabular}{|l|l|r|r|r|r|}
\hline \multicolumn{2}{|c|}{} & Frequency & Percent & Valid Percent & \multicolumn{1}{c|}{$\begin{array}{c}\text { Cumulative } \\
\text { Percent }\end{array}$} \\
\hline \multirow{4}{*}{ Valid } & never & 36 & 16.4 & 16.6 & 16.6 \\
\cline { 2 - 6 } & sometimes on some courses & 95 & 43.4 & 43.8 & 60.4 \\
\cline { 2 - 6 } & most of the time & 62 & 28.3 & 28.6 & 88.9 \\
\cline { 2 - 6 } & always & 24 & 11.0 & 11.1 & 100.0 \\
\cline { 2 - 6 } & Total & 217 & 99.1 & 100.0 & \\
\hline Missing & 99.00 & 2 & .9 & & \\
\hline \multicolumn{1}{|l|}{ Total } & 219 & 100.0 & & \\
\hline
\end{tabular}

\begin{tabular}{|c|c|c|c|c|c|c|}
\hline \multicolumn{7}{|c|}{ Table $M$ - Cross tabulation organisational type and accreditation. } \\
\hline & & \multicolumn{4}{|c|}{ does your work offer accreditation } & \multirow[t]{2}{*}{ Total } \\
\hline & & never & $\begin{array}{l}\text { sometimes on } \\
\text { some courses }\end{array}$ & $\begin{array}{l}\text { most of the } \\
\text { time }\end{array}$ & always & \\
\hline \multirow{17}{*}{ Org. } & VEC as a tutor & 5 & 14 & 14 & 6 & 39 \\
\hline & LCDP & 8 & 16 & 12 & 2 & 38 \\
\hline & $\begin{array}{l}\text { Independent Community } \\
\text { Ed organisation }\end{array}$ & 5 & 14 & 10 & 7 & 36 \\
\hline & VEC as CEF & 1 & 18 & 3 & 0 & 22 \\
\hline & Family Resource Centre & 3 & 9 & 2 & 2 & 16 \\
\hline & Independent practitioner & 3 & 6 & 3 & 0 & 12 \\
\hline & HEls & 2 & 2 & 3 & 4 & 11 \\
\hline & NGOs & 1 & 3 & 5 & 0 & 9 \\
\hline & Addiction projects & 2 & 1 & 2 & 2 & 7 \\
\hline & Other & 2 & 2 & 3 & 0 & 7 \\
\hline & Independent CDP & 2 & 3 & 2 & 0 & 7 \\
\hline & VEC as AEO & 0 & 2 & 0 & 0 & 2 \\
\hline & literacy tutor & 0 & 2 & 1 & 0 & 3 \\
\hline & Network employee & 1 & 1 & 0 & 0 & 2 \\
\hline & FAS & 0 & 0 & 1 & 1 & 2 \\
\hline & private provider & 0 & 1 & 0 & 0 & 1 \\
\hline & HSE & 0 & 0 & 1 & 0 & 1 \\
\hline Total & & 35 & 94 & 62 & 24 & 215 \\
\hline
\end{tabular}




\begin{tabular}{|l|l|r|r|r|r|}
\hline \multicolumn{2}{|l|}{ Table N - Who are the accrediting bodies? } \\
\hline \multirow{7}{*}{ Valid } & Frequency & Percent & Valid Percent & $\begin{array}{c}\text { Cumulative } \\
\text { Percent }\end{array}$ \\
\hline & FETAC & 133 & 60.7 & 61.9 & 61.9 \\
\cline { 2 - 7 } & HEls & 21 & 9.6 & 9.8 & 71.6 \\
\cline { 2 - 7 } & FETAC and HEls & 18 & 8.2 & 8.4 & 80.0 \\
\cline { 2 - 7 } & Other & 7 & 3.2 & 3.3 & 83.3 \\
\cline { 2 - 7 } & Not eligible to answer & 36 & 16.4 & 16.7 & 100.0 \\
\hline \multirow{3}{*}{ Missing } & Total & 215 & 98.2 & 100.0 & \\
\hline Total & 99.00 & 2 & .9 & & \\
\hline
\end{tabular}

Table $\mathrm{O}$ - What is your personal approach?

\begin{tabular}{|c|c|c|c|c|c|}
\hline & & Frequency & Percent & Valid Percent & Cumulative Percent \\
\hline & universal & 73 & 33.3 & 37.2 & 37.2 \\
\hline Ylis & second-chance & 68 & 31.1 & 34.7 & 71.9 \\
\hline valiu & radical & 55 & 25.1 & 28.1 & 100.0 \\
\hline & Total & 196 & 89.5 & 100.0 & \\
\hline Missing & 99.00 & 23 & 10.5 & & \\
\hline Total & & 219 & 100.0 & & \\
\hline
\end{tabular}

Table $\mathbf{P}$ - What is the approach of your organisation

\begin{tabular}{|c|c|c|c|c|c|}
\hline & & Frequency & Percent & Valid Percent & Cumulative Percent \\
\hline \multirow{4}{*}{ Valid } & universal & 49 & 22.4 & 25.9 & 25.9 \\
\hline & second-chance & 109 & 49.8 & 57.7 & 83.6 \\
\hline & radical & 31 & 14.2 & 16.4 & 100.0 \\
\hline & Total & 189 & 86.3 & 100.0 & \\
\hline Missing & 99.00 & 30 & 13.7 & & \\
\hline \multicolumn{2}{|l|}{ Total } & 219 & 100.0 & & \\
\hline
\end{tabular}

\begin{tabular}{|c|c|c|c|c|c|}
\hline \multicolumn{6}{|c|}{$\begin{array}{l}\text { Table Q - What is your personal } \\
\text { organisation Cross-tabulation }\end{array}$} \\
\hline & & \multicolumn{3}{|c|}{ what is the approach of your organisation } & \multirow{3}{*}{$\begin{array}{l}\text { Total } \\
68 \\
\end{array}$} \\
\hline & & universal & second-chance & radical & \\
\hline \multirow{3}{*}{$\begin{array}{l}\text { What is your } \\
\text { personal approach? }\end{array}$} & universal & 35 & 26 & 7 & \\
\hline & second-chance & 5 & 52 & 6 & 63 \\
\hline & radical & 7 & 26 & 18 & 51 \\
\hline \multicolumn{2}{|l|}{ Total } & 47 & 104 & 31 & 182 \\
\hline
\end{tabular}




\begin{tabular}{|c|c|c|c|c|c|}
\hline \multicolumn{6}{|c|}{ Table R - Quantification of philosophical leanings } \\
\hline & & Frequency & Percent & Valid Percent & $\begin{array}{l}\text { Cumulative } \\
\text { Percent }\end{array}$ \\
\hline \multirow{7}{*}{ Valid } & Humanistic & 82 & 37.4 & 46.3 & 46.3 \\
\hline & Participatory & 17 & 7.8 & 9.6 & 55.9 \\
\hline & Critical -transformative & 15 & 6.8 & 8.5 & 64.4 \\
\hline & Radical/praxis & 47 & 21.5 & 26.6 & 91.0 \\
\hline & No philosophy & 13 & 5.9 & 7.3 & 98.3 \\
\hline & insufficient information provided & 3 & 1.4 & 1.7 & 100.0 \\
\hline & Total & 177 & 80.8 & 100.0 & \\
\hline Missing & 99.00 & 42 & 19.2 & & \\
\hline \multicolumn{2}{|l|}{ Total } & 219 & 100.0 & & \\
\hline
\end{tabular}

\begin{tabular}{|c|c|c|}
\hline $\begin{array}{l}\text { Table S - "Is there a particular way of working that informs your approach } \\
\text { (a certain belief system, theory, philosophy etc.) }\end{array}$ & Total & $\begin{array}{l}\text { Valid } \\
\%\end{array}$ \\
\hline $\begin{array}{l}\text { Humanistic (emphasis is on learner-centered/person-centeredness). } \\
4 \text { cite 'humanistic' with } 2 \text { of these referring to K. Rogers. } \\
5 \text { cite 'community development'. } \\
4 \text { cite Paulo Freire } \\
3 \text { cite Mazlow's hierarchy of needs. } \\
2 \text { cite Garner's concepts of multiple intelligence. } \\
\text { Cited once are 'Malcolm Knowles and andragogy' with one contributor also } \\
\text { drawing from 'Skinner and Kolb'. }\end{array}$ & 99 & $56 \%$ \\
\hline $\begin{array}{l}\text { Radical/Critical education } \\
15 \text { cite 'rights/human rights' } \\
6 \text { cite 'feminism' } \\
15 \text { cite community development } \\
27 \text { cite 'Paulo Freire' } \\
6 \text { cited 'Training For Transformation' } \\
3 \text { cite liberation theology } \\
3 \text { cite Marxism as influential } \\
3 \text { cite Jack Mezirow } \\
3 \text { Cite John Dewey } \\
4 \text { cite 'humanistic' as component to radicalism } \\
2 \text { cite David Kantor, } \\
1 \text { cite bell hooks, } \\
3 \text { cite Malcolm Knowles } \\
2 \text { cite Stephen Brookfield } \\
2 \text { cite Augusto Boal } \\
\text { Gandhi, Heron Schön are each mentioned once. } \\
12 \text { of these respondents ( } 6.5 \% \text { in total) also strongly emphasise person-centeredness) }\end{array}$ & 62 & $35 \%$ \\
\hline $\begin{array}{l}\text { State they don't have a philosophy } \\
2 \text { cite deference to their organisational philosophy without naming this. } \\
2 \text { cite a belief they did not require a philosophy but had developed their own } \\
\text { way of working. }\end{array}$ & 13 & $7 \%$ \\
\hline insufficient information provided to ascertain & 3 & $2 \%$ \\
\hline Did not answer the question & 42 & $19 \%$ \\
\hline Total & 219 & $100 \%$ \\
\hline
\end{tabular}




\begin{tabular}{|l|r|r|r|r|}
\hline Table T - Examples of practice & \multicolumn{1}{|c|}{ frequency } & \multicolumn{1}{|c|}{$\begin{array}{c}\text { Valid \% } \\
\text { Cumulative } \\
\%\end{array}$} \\
\hline Supporting individuals & 89 & 40.6 & 58.9 & 58.9 \\
\hline Creating critical classrooms & 32 & 14.6 & 21.2 & 80.1 \\
\hline Addressing external issues/concerns & 14 & 6.4 & 9.3 & 89.4 \\
\hline Developing local services/amenities & 10 & 4.6 & 6.6 & 96.0 \\
\hline Responding to group needs & 5 & 2.3 & 3.3 & 99.3 \\
\hline Insufficient information provided & 1 & .5 & .7 & 100.0 \\
\hline Total & 151 & 68.9 & 100.0 & \\
\hline Missing & 68 & 31.1 & & \\
\hline Total & 219 & 100.0 & & \\
\hline
\end{tabular}

\begin{tabular}{|c|c|c|c|c|c|c|}
\hline \multirow{2}{*}{ Table U } & \multicolumn{6}{|c|}{ examples of practice as linked to stated philosophy } \\
\hline & Humanistic & Radical & Participatory & Critical & None & Total \\
\hline \multirow{7}{*}{$\begin{array}{l}\text { Supporting individuals } \\
\text { Creating critical classrooms } \\
\text { Addressing external issues } \\
\text { Developing local services } \\
\text { Responding to group needs } \\
\text { Insufficient information }\end{array}$} & 49 & 14 & 8 & 7 & 6 & 84 \\
\hline & 9 & 14 & 6 & 2 & 0 & 31 \\
\hline & 1 & 9 & 0 & 4 & 0 & 14 \\
\hline & 4 & 2 & 1 & 1 & 1 & 9 \\
\hline & 3 & 1 & 0 & 1 & 0 & 5 \\
\hline & 0 & 0 & 1 & 0 & 0 & 1 \\
\hline & 66 & 40 & 16 & 15 & 7 & 144 \\
\hline
\end{tabular}

\section{Table V - CE should target those disadvantaged?}

\begin{tabular}{|l|l|r|r|r|r|}
\hline \multicolumn{2}{|c|}{} & Frequency & Percent & Valid Percent & $\begin{array}{c}\text { Cumulative } \\
\text { Percent }\end{array}$ \\
\hline \multirow{5}{*}{} & strongly agree & 28 & 12.8 & 13.4 & 13.4 \\
\cline { 2 - 6 } & agree & 53 & 24.2 & 25.4 & 38.8 \\
\cline { 2 - 6 } & somewhat agree & 63 & 28.8 & 30.1 & 68.9 \\
\cline { 2 - 6 } & not sure if I agree or & 15 & 6.8 & 7.2 & 76.1 \\
\cline { 2 - 6 } & disagree & 28 & 12.8 & 13.4 & 89.5 \\
\cline { 2 - 6 } & somewhat disagree & 16 & 7.3 & 7.7 & 97.1 \\
\cline { 2 - 6 } & disagree & 6 & 2.7 & 2.9 & 100.0 \\
\cline { 2 - 6 } & strongly disagree & 209 & 95.4 & 100.0 & \\
\cline { 2 - 6 } & Total & 10 & 4.6 & & \\
\hline \multirow{2}{*}{ Missing } & 99.00 & 219 & 100.0 & & \\
\hline \multirow{2}{*}{ Total } & & & & & \\
\hline
\end{tabular}




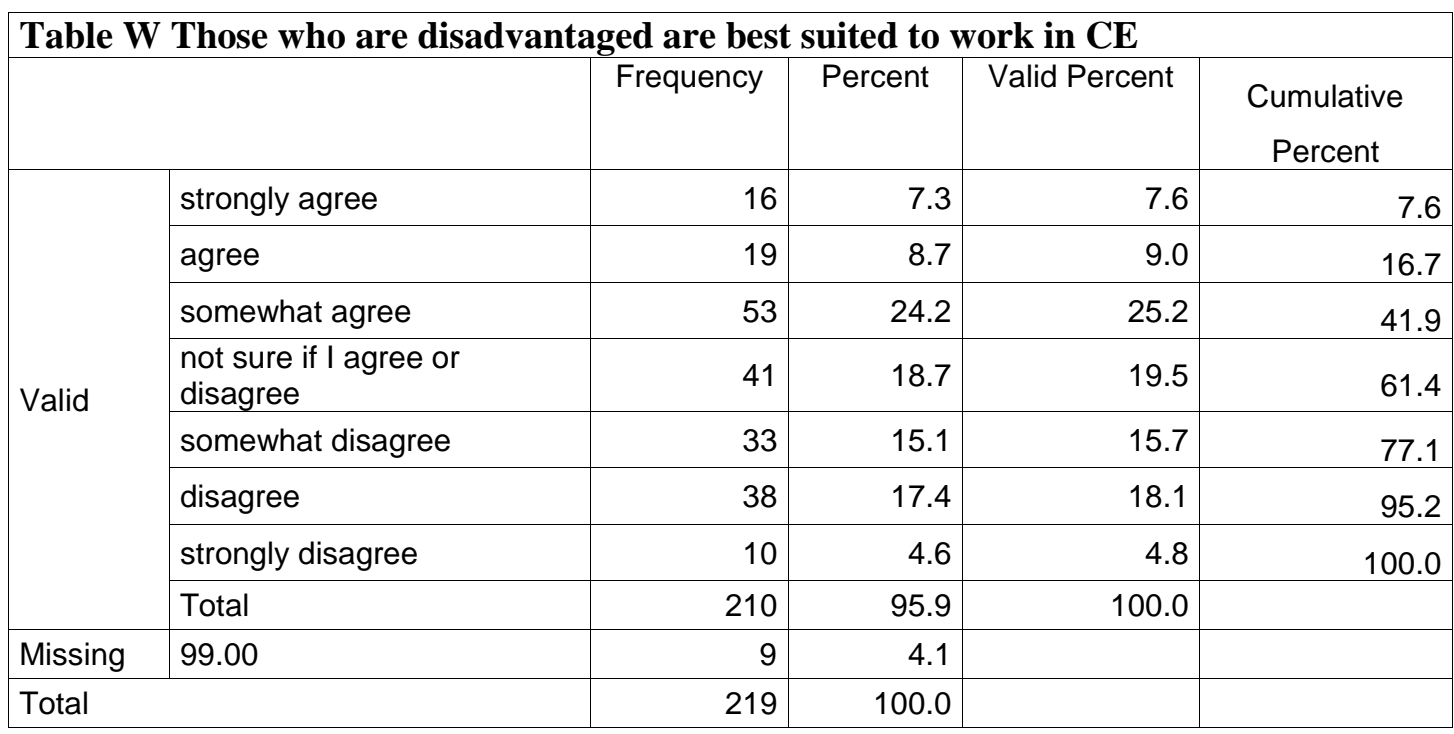

\begin{tabular}{|c|c|c|c|c|c|}
\hline \multicolumn{6}{|c|}{ Table X - in my work I am helping to reduce inequality } \\
\hline & & Frequency & Percent & Valid Percent & $\begin{array}{l}\text { Cumulative } \\
\text { Percent }\end{array}$ \\
\hline \multirow{7}{*}{ Valid } & strongly agree & 36 & 16.4 & 17.1 & 17.1 \\
\hline & agree & 75 & 34.2 & 35.7 & 52.9 \\
\hline & somewhat agree & 74 & 33.8 & 35.2 & 88.1 \\
\hline & $\begin{array}{l}\text { not sure if I agree or } \\
\text { disagree }\end{array}$ & 17 & 7.8 & 8.1 & 96.2 \\
\hline & somewhat disagree & 6 & 2.7 & 2.9 & 99.0 \\
\hline & disagree & 2 & .9 & 1.0 & 100.0 \\
\hline & Total & 210 & 95.9 & 100.0 & \\
\hline Missing & 99.00 & 9 & 4.1 & & \\
\hline \multicolumn{2}{|l|}{ Total } & 219 & 100.0 & & \\
\hline
\end{tabular}

\begin{tabular}{|c|c|c|c|c|c|}
\hline \multicolumn{6}{|c|}{ Table Y - The fact that CE is accredited is a good thing } \\
\hline & & Frequency & Percent & Valid Percent & Cumulative Percent \\
\hline \multirow{8}{*}{ Valid } & strongly agree & 40 & 18.3 & 18.3 & 18.3 \\
\hline & agree & 29 & 13.2 & 13.3 & 31.7 \\
\hline & somewhat agree & 63 & 28.8 & 28.9 & 60.6 \\
\hline & $\begin{array}{l}\text { don't know if I agree or } \\
\text { disagree }\end{array}$ & 28 & 12.8 & 12.8 & 73.4 \\
\hline & somewhat disagree & 36 & 16.4 & 16.5 & 89.9 \\
\hline & disagree & 16 & 7.3 & 7.3 & 97.2 \\
\hline & strongly disagree & 6 & 2.7 & 2.8 & 100.0 \\
\hline & Total & 218 & 99.5 & 100.0 & \\
\hline Missing & 99.00 & 1 & .5 & & \\
\hline \multicolumn{2}{|l|}{ Total } & 219 & 100.0 & & \\
\hline
\end{tabular}




\begin{tabular}{|c|c|c|c|c|c|}
\hline \multicolumn{6}{|c|}{ Table $\mathrm{Z}$ - FETAC is the appropriate accrediting body } \\
\hline & & Frequency & Percent & Valid Percent & Cumulative Percent \\
\hline \multirow{8}{*}{ Valid } & strongly agree & 12 & 5.5 & 5.6 & $x_{1}$ \\
\hline & agree & 46 & 21.0 & 21.3 & 26.9 \\
\hline & somewhat agree & 56 & 25.6 & 25.9 & 52.8 \\
\hline & $\begin{array}{l}\text { not sure if I agree or } \\
\text { disagree }\end{array}$ & 57 & 26.0 & 26.4 & 79.2 \\
\hline & somewhat disagree & 17 & 7.8 & 7.9 & 87.0 \\
\hline & disagree & 16 & 7.3 & 7.4 & 94.4 \\
\hline & strongly disagree & 12 & 5.5 & 5.6 & 100.0 \\
\hline & Total & 216 & 98.6 & 100.0 & \\
\hline Missing & 99.00 & 3 & 1.4 & & \\
\hline \multicolumn{2}{|l|}{ Total } & 219 & 100.0 & & \\
\hline
\end{tabular}

\begin{tabular}{|c|c|c|c|c|c|}
\hline \multicolumn{6}{|c|}{ Table A1 - accreditation interferes } \\
\hline & & Frequency & Percent & Valid Percent & $\begin{array}{c}\text { Cumulative } \\
\text { Percent }\end{array}$ \\
\hline \multirow{8}{*}{ Valid } & strongly agree & 16 & 7.3 & 8.3 & 8.3 \\
\hline & agree & 38 & 17.4 & 19.7 & 28.0 \\
\hline & somewhat agree & 48 & 21.9 & 24.9 & 52.8 \\
\hline & $\begin{array}{l}\text { not sure if I agree or } \\
\text { disagree }\end{array}$ & 34 & 15.5 & 17.6 & 70.5 \\
\hline & somewhat disagree & 22 & 10.0 & 11.4 & 81.9 \\
\hline & disagree & 22 & 10.0 & 11.4 & 93.3 \\
\hline & strongly disagree & 13 & 5.9 & 6.7 & 100.0 \\
\hline & Total & 193 & 88.1 & 100.0 & \\
\hline Missing & 99.00 & 26 & 11.9 & & \\
\hline \multicolumn{2}{|l|}{ Total } & 219 & 100.0 & & \\
\hline
\end{tabular}

\begin{tabular}{|c|c|c|c|c|c|}
\hline \multicolumn{6}{|c|}{ Table B1- The fact that you need a degree is a good think } \\
\hline & & Frequency & Percent & Valid Percent & Cumulative \\
\hline & & & & & Percent \\
\hline \multirow{8}{*}{ Valid } & strongly agree & 23 & 10.5 & 10.6 & 10.6 \\
\hline & agree & 41 & 18.7 & 18.9 & 29.5 \\
\hline & somewhat agree & 55 & 25.1 & 25.3 & 54.8 \\
\hline & $\begin{array}{l}\text { not sure if } i \text { agree or } \\
\text { disagree }\end{array}$ & 25 & 11.4 & 11.5 & 66.4 \\
\hline & somewhat disagree & 24 & 11.0 & 11.1 & 77.4 \\
\hline & disagree & 33 & 15.1 & 15.2 & 92.6 \\
\hline & strongly disagree & 16 & 7.3 & 7.4 & 100.0 \\
\hline & Total & 217 & 99.1 & 100.0 & \\
\hline Missing & 99.00 & 2 & .9 & & \\
\hline \multicolumn{2}{|l|}{ Total } & 219 & 100.0 & & \\
\hline
\end{tabular}




\begin{tabular}{|c|c|c|c|c|c|}
\hline \multicolumn{6}{|c|}{$\begin{array}{l}\text { Table C1- There will only be real ch } \\
\text { political system }\end{array}$} \\
\hline & & Frequency & Percent & Valid Percent & Cumulative \\
\hline \begin{tabular}{|l} 
\\
\end{tabular} & 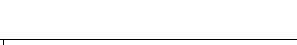 & & & & Percent \\
\hline \multirow{8}{*}{ Valid } & strongly agree & 70 & 32.0 & 33.5 & 33.5 \\
\hline & agree & 71 & 32.4 & 34.0 & 67.5 \\
\hline & somewhat agree & 14 & 6.4 & 6.7 & 74.2 \\
\hline & $\begin{array}{l}\text { not sure if I agree or } \\
\text { disagree }\end{array}$ & 31 & 14.2 & 14.8 & 89.0 \\
\hline & somewhat disagree & 17 & 7.8 & 8.1 & 97.1 \\
\hline & disagree & 5 & 2.3 & 2.4 & 99.5 \\
\hline & strongly disagree & 1 & .5 & .5 & 100.0 \\
\hline & Total & 209 & 95.4 & 100.0 & \\
\hline Missing & 99.00 & 10 & 4.6 & & \\
\hline \multicolumn{2}{|l|}{ Total } & 219 & 100.0 & & \\
\hline
\end{tabular}

Table D1- the Community Sector has been co-opted

\begin{tabular}{|c|c|c|c|c|c|}
\hline & & Frequency & Percent & Valid Percent & $\begin{array}{c}\text { Cumulative } \\
\text { Percent }\end{array}$ \\
\hline & strongly agree & 16 & 7.3 & 7.8 & 7.8 \\
\hline & agree & 38 & 17.4 & 18.4 & 26.2 \\
\hline & somewhat agree & 73 & 33.3 & 35.4 & 61.7 \\
\hline Valid & $\begin{array}{l}\text { not sure if I agree or } \\
\text { disagree }\end{array}$ & 30 & 13.7 & 14.6 & 76.2 \\
\hline & somewhat disagree & 25 & 11.4 & 12.1 & 88.3 \\
\hline & disagree & 19 & 8.7 & 9.2 & 97.6 \\
\hline & strongly disagree & 5 & 2.3 & 2.4 & 100.0 \\
\hline & Total & 206 & 94.1 & 100.0 & \\
\hline Missing & 99.00 & 13 & 5.9 & & \\
\hline Total & & 219 & 100.0 & & \\
\hline
\end{tabular}




\section{Appendix 6 - Introduction of focus-group participants}

\section{Athlone FG participant 1}

With a history of 20 years working as a community educator, this participant details her work as predominantly with Women's groups. Her current work is directly funded by FAS though the organisation she works with is also connected to a Community Sector Organisation. When asked what she enjoys about the work she relays 'I always loved teaching, I trained originally as a teacher and I get a buzz from people who learn something and as well as that too I suppose over the years I have seen so many women turn their lives around in a very positive way'.

\section{Athlone participant 2}

Describing the organisation she works for as 'an adult education organisation' funded through self-generated sources, this participant also shares a long history of voluntary involvement alongside paid employment. She shares 'a passion for creating opportunities for people to better themselves or to make their surroundings or their lives better' interpreting her role as creating a chance for people to do this.

\section{Athlone participant 3}

Describing a background in supporting local business opportunities in the community, and now involved in providing locally based training for FAS participants this participant describes her work as about endorsing 'the holistic approach and not to shove people into situations and pigeon-hole them into jobs instead of sustainable employment'

\section{Athlone participant 4}

Again funded through FAS, this participant describes her work as influenced by community development. She details how she 'tutors and coordinates programmes'. She her experience of working with groups where participants are there as a condition of welfare payments, she shares " what motivates me is that I love to see people turning around...and actually begin to enjoy learning and I love to see that, for me that is a revelation'.

\section{Athlone participant 5}

Currently employed by a HEI, this participant details a lengthy history of community education work both paid and voluntary. Historical influences are described as 'very much influenced by liberation theology and the work of Paulo Freire and adult education' with an aspect he currently enjoys being is working with people to leverage State granted financial supports for community resources. He describes the impacts of this as 'seeing people take control and getting confidence in themselves'

\section{Cork FG participant 1}

Working for an ETB, this person is motivated by progression of individuals and her work in community education has included extensive involvement with people working to improve their literacy. At the moment she is particularly concerned about the merger of VECs given the large geographical and cross county borders at play.

\section{Cork FG participant 2}

Participant 2 is also employed by an ETB and shares concerns about the merging of structures and integration of FAS within. She enjoys working with individuals in a way that encourages them to take actions, however small, outside of the instructed environment and in a way that will enhance their lives. Much of her work is non-accredited. 


\section{Cork FG participant 3}

Working as part of a tutor teams employed by an independent community education organisation with participant aligns much community education work with community development. Particularly enjoyable is the part he can play in supporting progression of those he works with. A concern he shares is towards increasing levels of technologically based inequality.

\section{Limerick participant 1}

The first member of this group-works full-time in community education and is employed through VEC structures. She too is concerned about the challenges of working to a broader geographical area. Her involvement in community education has included involvement of local policy development and evaluative work.

\section{Limerick participant 2}

Alongside being a full time student in her own right, this participant works voluntarily as a literacy tutor. She enjoys one-to-one involvement with participants and expresses concern about the precarious nature of much contemporary community education work.

\section{Limerick participant 3}

Working for a HEI but remitted to embed herself in the community, this group-member enjoys supporting people to progress from community to higher education. She relays a long history of community based education work recalling the role of extra-mural programmes and their importance in the emergence of wider community supports such as the credit union movement.

\section{Limerick participant}

Employed by the regional ETB and again specifically remitted to work in local community contexts, this participant in involved in the delivery of both accredited and non-accredited work. She shares concern about the direction of community education most notably the vocationalisation of the sector.

\section{Kildare participant 1}

Working as a tutor with a midlands based men's group, this participant is employed on a return-to-work programme within a publicly funded community organisation. He relays a personal history of unemployment as influential in his facilitation work with men's groups and demonstrates a strong interest in extending educational spaces beyond the personal and towards a politicised collective response to issues affecting those he works with. He is also a part-time mature student in the final stages of under-graduate studies.

\section{Kildare participant 2}

Employed through ETB structures, this participant shares a lengthy history of community education work relaying involvement with women's groups, with people who are unemployed, with those returning to education after long periods away. She interprets community education as multi-faceted conscious of personal, vocational and political dimensions.

\section{Kildare participant 3}

Working part-time as an independent provider employed across both State provider and Community Sector organisations, this person also relays many years working and studying within the Adult and Community education sector. He has worked with a range of groups 
including men's groups, practitioner groups, voluntary management committees, and youth groups.

\section{Kildare participant 4}

Employed through funding leveraged by a Local Partnership organisation, this participant works with a particular population group she perceives as often excluded from community education structures due to their likely motivation as not vocationally focused. Her work involves group-work and one-to-one work as, in partnership, she sets out to address the expressed needs of those she supports.

\section{Dublin- South participant 1}

Previously working for a national anti-poverty organisation before being employed within a local area partnership, this participant's experience is predominantly in supporting the development of local leadership through accredited community development programmes. Something he particularly enjoys is 'mainly the interaction with people and the surprises that come up all the time'.

\section{Dublin- South participant 2}

Employed by an urban based independent community education organisation with multiple funding streams, this participant enjoys both individual and group engagement with those returning to education. They express concern about 'the direction that adult and community education is going in' particularly the compulsory nature of aspects of his work for participants required to attend to satisfy conditions of welfare payment.

\section{Dublin-south participant 3}

Describing himself as a community worker, this participant works with a Community Sector organisation that primarily supports people with a history of problematic drug use.

Describing a history of much one-to-one work, current group involvement is described as 'around campaigning, grass-roots stuff'. Whilst allocating a value to the caring work many community workers do on a daily basis, he expresses frustration with what he describes as 'the emphasis on the practice at the expense of the bigger issues' and would like to see a more politically active community education sector emerging.

\section{Dublin South FG participant 4}

Employed by a HEI and remitted to work within a specific geographical community setting, this person describes her role as one of programme delivery, guidance and support. The core intention is to encourage progression to HEIs with those traditionally under-represented in such tertiary settings. Motivating her is the interaction with people, and witnessing the impacts on people's lives through education.

\section{Dublin South FG participant 5}

Sharing many years involvement with community education including overseas work as a missionary in Africa, this participant is particularly influenced by the Training for Transformation (TfT) movement. All of her work is in a voluntary capacity.

\section{Dublin-South participant 6}

Working with a national Traveller organisation, and sharing additional campaign work with a 'domestic workers action group' this participant links her work to community development describing both accredited and non-accredited settings. She is particularly frustrated by the limitations of FE qualifications applied to her community work, but shares creative ways in which she has been able to minimise these. 


\section{Dublin-South participant 7}

Working with a national advocacy organisation as well as sharing a recent history of facilitation of accredited courses within a Community Sector organisation, this participant describes her motivation as 'to see people doing something that they never believed that they could because you know'. She too expresses significant concern about the limitations of accreditation structures including fears for future restrictions on local community education providers within the realignment of community education work.

\section{Dublin-South participant 8}

Working with an organisation described as an independent 'community development organisation' and identifying 'Freirean methodology' as influential, this participant describes his motivation as not only about supporting individuals but about interpreting the primary function of community education as the pursuit of equality based collective outcomes for local communities

\section{Dublin-North participant 1}

Participant 1 in this workshop is employed within an independent community education organisation with multiple funding streams. Its work includes leisure courses, literacy service, and it is supported by a counselling service within. Much funding for the project comes through fundraising. She is happy with the current changes to community education welcoming funding from the Dept. of social protection and believing the merger of service providers is a positive step.

\section{Dublin-North Participant 2}

Working as an independent practitioner predominantly employed by a HEI funded community based programme, this person links the work to 'community work'. Their primary focus is on promoting access to $3^{\text {rd }}$ level education by 'taking education to community centres' rather than the other way around.

\section{Dublin-North Participant 3}

Working for an independent Community Sector over 30 yearsyears in existence, and local to the community, this participant describes her work delivering accredited and non accredited programmes. This includes significant involvement in supporting residents through an urban regeneration project describes as 'an absolutely fabulous experience'. She particularly emphasises embeddedness of her host organisation within the community and its continual capacity building for local people, many of whom are employed within the project.

\section{Dublin North Participant 4}

Working as a volunteer in a newly established intercultural centre, this participant is relatively new to community education work training as a literacy tutor following home based work as a parent and grandparent. She enjoys supporting individuals to integrate more fully into Irish society.

\section{Waterford participant 1}

Working for a HEI remitted to work in the community this contributor shares a personal history of community work for over 20 yearsyears beginning as a community education participant. that began with her own participation on a community education programme. She describes her understanding of community education as 'not about the individual coming in and getting the certificate, it is really about working as a collective, that everybody gets to achieve because everybody can, given the support'. 


\section{Waterford participant 2}

Again detailing a long history in the sector that began with work with Women's groups, this participant holds as central many of the methods that grew from that time. She shares, 'I remember back in the $70 \mathrm{~s} / 80 \mathrm{~s}$ 'no crèche no class' and we long for that, we take it for granted but it is still fundamental, we still need it'. She shares a passion for community education being open to change once underlying principles are held dear. Her current work is within a Community Sector organisation funded by the State

\section{Waterford participant 3}

Again working within a Community Sector organisation and with many years experience, this participant describes as way of working that begins by making connections through such supports as parent and toddler groups and one-to-one walk in information services, but at times culminating in both accredited and non-accredited work.

\section{Dublin-Central participant 1}

Participant 1 describes her work with a Dublin based NGO but based in Dublin. Describing 'a background in community education' her current work is about supporting people who are unemployed by addressing their education and training needs. Though she expresses considerable discontent about current policy changes and the implication for these in practice, she continues to enjoy participant interaction and supporting people towards further education.

\section{Dublin Central participant 2}

Working specifically with the Traveller population, this participant describes both accredited and non-accredited work with Traveller specific and integrated groups. She interprets her work from a social justice perspective motivated by "the inequality of our community and the idea that in some tiny, tiny way that I might help to address that for those who are marginalised".

\section{Dublin Central participant 3}

This participant chronicles a long history of community education involvement. Much of this has been as a voluntary board member with an independent community education organisation and has included group-work most notably in literacy supports. She shares, 'What motivates me is again the total injustice of poverty and our philosophy is that the path out of poverty is through education'.

\section{Dublin Central participant 4}

Working in community development with migrant communities this participant shares a pathway into community education as built on his own experiences of struggle in accessing education. 


\section{Appendix 7 - Reflection sheet - focus-group meetings}

1. In your work as a community educator/community worker, what are the things that you put most energy into?

2. In doing this, in what way is your work in harmony with structural supports (the organisation you work for, funders, government bodies, accreditors etc.)?

3. In what way (if at all) is your work in tension with these same structural supports?

3. If you were to work in complete harmony with your philosophies, what would happen?

4. Is there anything else that you would like to say? 


\section{Appendix 8 - Statements used for Focus-group meetings}

I think that the people organising community based courses benefit more than the individuals taking part in them. It seems to be jobs for the boys as such and I can't help feeling a little disheartened by it. Also I feel complicit.

I would aspire to having a Freirean Approach, but that is hard in practice when you are working in the context of accreditation.

Many VEC funded community education programmes are delivered in communities, rather than by and with communities and so lack a critical and much needed agenda for change.

I have found through my studies in Community development that the ideology and theory is what needs to be practiced.

My experience of Community Education today is one of a dying sector; so professionalised it is now another arm of Labour activation and no longer allows for learning for human growth and development.

What some consider 'co-option' in the Community Sector is often co-operation or partnership with the focus firmly on the service user.

The theories and ideas of adult and community education are fine but things can work differently in reality.

There is a lot of hidden disadvantage. Because you live in a certain area doesn't necessarily mean you are advantaged. The margins are getting wider with people getting lost in the middle.

We need to develop a much more radically political community education and to build on the strengths that already exist in the field and in communities around the country. Activism should be much more to the forefront of the work.

I think people are starting to look at women and their role and their place in society, there is still a lot to learn and to explore'

I believe FETAC should be overhauled and examined 